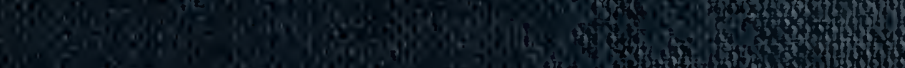
IE

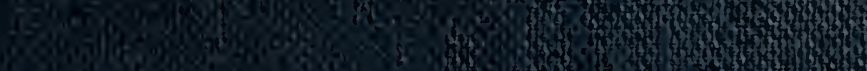
(3)

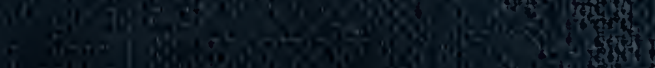








\section{ELEMENTS OF AGRICULTURE}




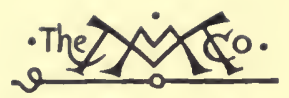

THE MACMILLAN COMPANY

NEW YORK - BOSTON - CHSCAGO

ATLANTA - SAN FRANCISCO

MACMILLAN \& CO., LIMITED

LONDON - BOMBAY - CALCUTTA

MELBOURNE

THE MACMILLAN CO. OF CANADA, LTD.

TORONTO 



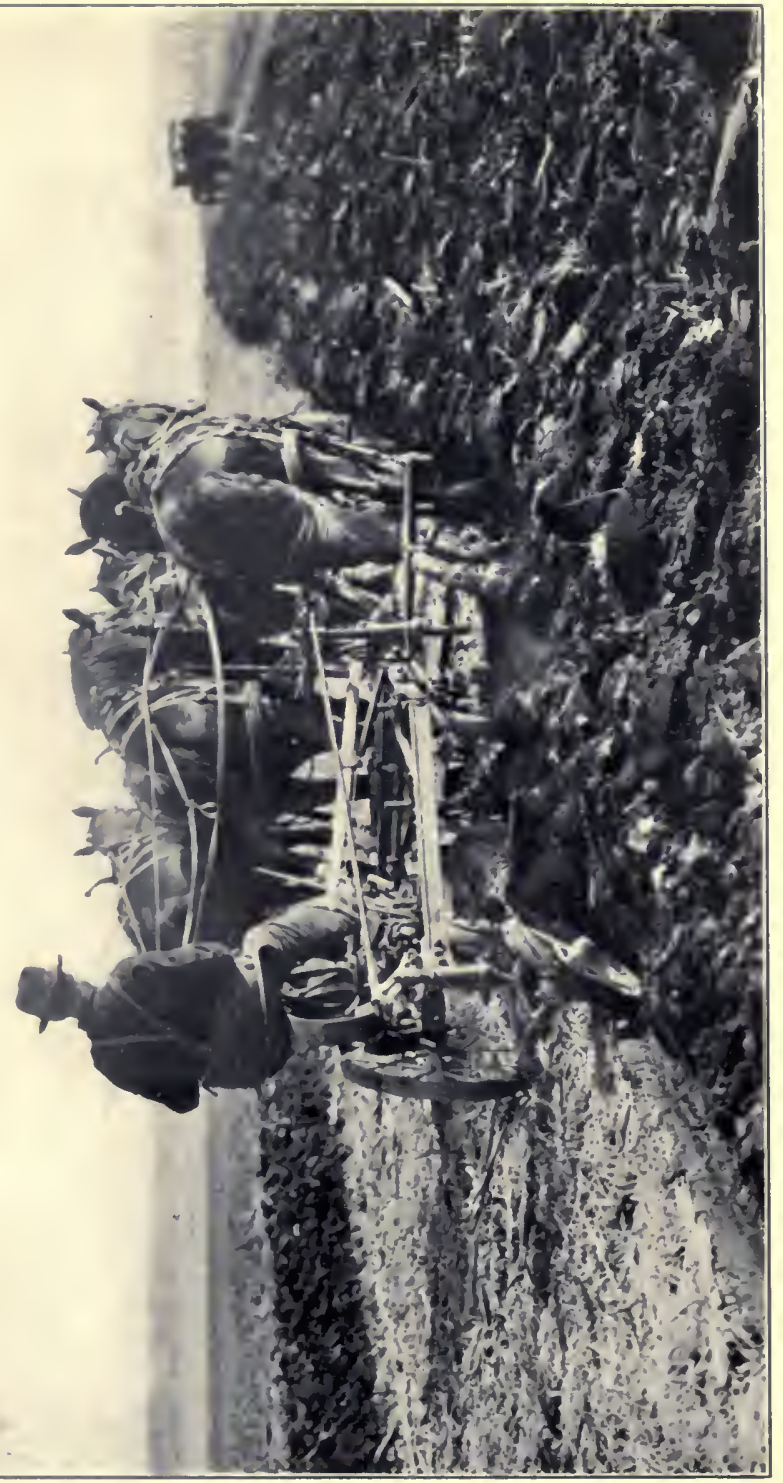

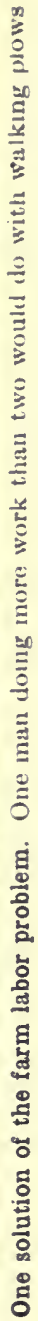




\section{ELEMENTS OF AGRICULTURE}

BY

G. F. WARREN

PROFESSOR OF FARM MANAGEMTNT AND FARM CROPS, NRW YORK STATE COLLEGE OF AORICULTURI, AT CORNELL UNIVERSITY

\section{3}

New 具ork

THE MACMILLAN COMPANY

1.0NDON: MACMILLAN \& CO., LTD.

1909

All rights reserced

18873 


\section{COPYRIGHT, 1909 \\ BY THE MACMILLAN COMPANY}

Set uy sud elertrotyped. Published, July, 1909

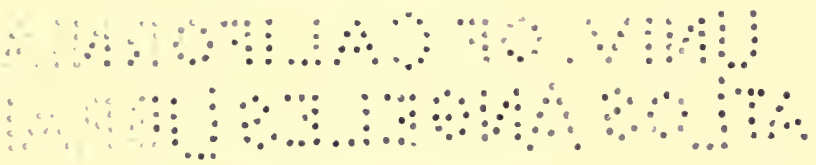




\section{5 \\ W25e}

\section{EDITOR'S PREFACE}

This book is designed for use in high-schools, academies, and normal schools, and in colleges when only a short time can be given to the subject. It is also hoped that it may be useful to the farmer or general reader who desires a brief survey of agriculture

So far as I know, this is the first text-book of agriculture appearing in North America in a generation that is distinctly of high-school grade. More than fifty textbooks of agriculture have appeared in the United States and Canada since Daniel Adams published his "Agricultural Reader" in Boston, in 1824, and J. Orville Taylor published his "Farmer's School Book" in Albany and Ithaca, N. Y., in 1837. Nearly twenty of these appeared before the founding of the colleges of agriculture, on the land-grant act of 1862. A number of these early books were distinctly scientific in treatment, and were adapted to academies and other schools of the rank of our present high-schools.

With the founding of the chain of agricultural colleges, the more full scientific treatment of the subject, so far as school texts are concerned, seems to have been reserved for these institutions, and the text-books became largely popular and elementary. This has been the epoch of the popularizing of science in the schools. The last of the extended and technical school texts appears to have been Pendleton's, in 1875. 'The large number of populal and 
practical school texts that have appeared in the last ten years gives the teacher "in the grades" a wide range of selection. Some of these texts are also adaptable to highschools.

The purpose of the present book is to make the teaching of agriculture in the existing high-schools comparable in extent and thoroughness with the teaching of physics, mathematics, history and literature. In fact, the chemistry and botany should, if possible, precede the agriculture as given in this book; and the pupil will be all the better prepared for the subject if he comes to it with considerable other high-school training, for much of the value of the work will be conditioned on the student's maturity and his experience with life. The subject is not one that can be memorized, or even acquired in the ordinary method of school study; it must relate itself to the actual work and business of the community in such a way as will develop the student's judgment of conditions and affairs.

If this type of text proves to be useful in the highschools, then another kind of book will be necessary for the grades; and this is in course of preparation.

L. H. BAILEY.

\section{THE TEACHING OF AGRICULTURE}

The interest in the teaching of agriculture is but a part of a much larger question,- the movement for teaching by means of things that have come within the student's experience. Laboratory work and all manual work are but a part of the same movement. The primary purpose of teaching agriculture is not to make farmers. It is a 
human-interest subject. The underlying reason why such teaching is desirable is because it brings the schools in touch with the home life - the daily life of the community. A large part of our teaching has had no relation whatever to our daily lives.

To those who are not familiar with the nature of agriculture teaching, it may seem like a trade subject. But it is not primarily a trade subject. Only about half of our population is engaged in agricultural work; But the interest in agriculture includes nearly all the population. A very large part of our city population, particularly of the larger cities, is coming to take the keenest interest in agricultural questions. The number of agricultural inquiries that have come to the Cornell Experiment Station from New York City within the past few years is very remarkable, but no more so than the movement for the ownership and management of farms by city men. Nearly every one is interested in growing plants and animals, and there are some fundamental principles of this growth that every boy and girl should have an opportunity to learn, if they so desire,-not that they may become farmers or farmers' wives, but for the educational training and intelligent interest in life that this knowledge brings. This training is often as desirable for those who are to live in cities as for those who are to live on farms. We can never wholly separate our interests from the soil on which we walk, and the plants and aninıals on which our life depends.

It is not desirable that a teacher try to make farmers of farmers' sons, or lawyers of lawyers' sons. The thing that distinguishes America from the Old World is the 
mobility of its society. Each man may do what he likes, and become what his energy will make him. While it is not desirable to try to make farmers, it does seem desirable to stop unmaking them. The present trend of all our education is cityward. We have been living in a citymaking epoch. The bright farm boy, as he has attended the village high-school, has been taught much that would naturally interest him in city occupations. The teacher has become interested in him, and has encouraged him to "make something of himself." This usually means that he become a lawyer, a doctor or perhaps an engineer. The nature of his books, and the advice of his friends, have led him to believe that these are the lines in which mental ability will bring the greatest returns. If he did become a farmer, he frequently felt that by doing so he lost his real opportunities. In the past, this may have been so; but today, law, medicine, and the ministry are not the only learned professions. The practice of agriculture now offers as great a field for scientific study as is offered by the practice of medicine.

The teaching of agriculture will make better farmers, who will make more money. It will lead more boys to choose farming as a profession, because it will open up a field for intellectual life whose existence they never suspected. But the great reason for this work is that it is one of the best means of training a student's mind, and it is one of the best means because it studies the things that come within his experience-the things with which and by which he lives.

In preparing this book, the author has tried to carry out, as far as possible, the recommendations of the com- 
mittee on methods of teaching agriculture of the Association of American Agricultural Colleges and Experiment Stations.

The author will be glad to correspond with teachers concerning difficulties in the work, and also to receive suggestions as to changes that they find desirable in the text.

G. F. WARREN.

ITHACA, N. Y., June 21, 1909. 



\section{CONTENTS}

\section{CHAPTER I}

What Is Agriculture, p. 1; Divisions of Agrieulture, p. 2; Forees Controlling Plant and Animal Growth, p. 2; Heredity, p. 2; Environment, p. 3.

Collateral Reading. ......................... 4

\section{CHAPTER II}

The lmprovement of Plants and Animals. . . . . . . . . .5-35

Variation in Plants and Animals ................ 5

Law of Variation, p. 5; Similar Produces Similar, p. 6.

Natural Selection.

Sports and Mutations, p. 8; The Development of Weeds

by Natural Selection, p. 8; De Candolle's Law, p. 9.

Artificial Selection. . . . . . . . . . . . . . . . . . . . 10

Reproduction in Plants ...................... 11

Seed-Produeing Organs of Plants, p. 11 ; Sexual and Asexual

Reproduction, p. 12; Artificial Crossing, p. 13.

Some Prineiples of Heredity ....................

Problems of Heredity, p. 13; Mendel's Law, p. 14; Applications of Mendel's Law, p. 19.

Steps in Breeding

Increasing Variation, p. 21 ; Selection, p. 21 ; Testing Hereditary Power, p. 22.

Improving Some Farm Crops.....................

Plant-Breeding vs. Animal-Breeding, v. 23; Comparative Inprovement of Different (rops, p. 23; Siıgar Beet, p. 24; Corn, p. 25; Cotton, p. 29; Other Cross-Fertilized Plants, 
p. 29; Oats, p. 29; Uther Self-Fertilized Plants, p. 30; Potatoes, p. 30; How (Often Do Potatoes Need to Be Grown from the Seed-Ball, p. 30; Plant-Breeding Farms, p. 31 .

Questions .31

Laboratory Exereises . . . . . . . . . . . . . . . 32

Collateral Reading. ..................... 34

\section{CHAPTER III}

Propagation of Plants $.36-59$

Methods of Propagation 36

Spores, p. 36; ('reeping Stems and Rootstocks, p. 36; Roots, p. 39; Tubers, p. 39; Cuttings, p. 41.

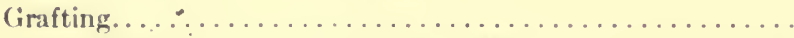

Budding, p. 43; Root-Grafting, p. 45: 'Top-C'rafting, p. 46; Relationship of Cion and Root, p. 47; Effect of Root on (ion, p. 47.

Seeds

Nature of Seeds, p. 47; Importance of Vigorous Germination, p. 48; Germination 'Tests of Seed Corn, p. 48; Seed Analysis and Valuation, p. 51; Germination Tests, p. 51; Purity and Germination Tests, p. 52; What is the Cheapest Seed, p. 52; Size and Weight of Seeds, p. 53; Seed-Testing Is Plant-Seleetion, p. 54; Storage of Seed, p. 54; Importation of Low-Grade Seed, p. 5.5 .

Questions 55

Laboratory Exercises . . . . . . . . . . . . . . . 56

Collateral Reading. .................... 59

\section{CHAPTER IV}

Plant Fool........................... 60-74

Elements Required for l'lant and Animal Growth, p. 60; Sources of Plant Food, p. 61; Water, Dry Matter and Ash, p. 62; Relative Amounts of the Different Elements in Plants, p. 62; Elements Likely to Be Deficient in Soils, p. 63; Functions of the Different Elements, p. 63. 
How the Plant Gets Its Food.

Root-Hairs, p. 64; Osmosis, p. 65; Importance of Water,

p. 67; How the Plant Gets Its Food from the Air, p. 67.

The Manufacture of Food Materials. . . . . . . . . . . . .

Carbohydrates, p. 68; Fats, p. 68; Protein, p. 69; Plants the Only Source of These Foods, p. 69.

Stored Food.

Periods in the Life of a Plant, p. 69; Effect of Time of Harvesting on Composition, p. 71 .

Questions 71

Laboratory Exercises . . . . . . . . . . . . . . . . . 72

Collateral Reading. ......................... 74

\section{CHAPTER V}

The SoIL.

What Soil Is......................... 75

Rock Particles of the Soil 76

Amounts of Mineral Matter, p. 76; How the Size of Particles Is Determined, p. 76; How Soils Are Named, p. 78; Importance of the Size of Particles, p. 79; Relation of the Size of Particles to Water, p. 79; Relation of the Size of Particles to Plant Food, p. 81; Size of Particles and Air, p. 81; Size of Particles and Temperature, p. 81; Size of Particles and Crop Adaptation, p. 82; Relation of Labor and Soil, p. 82; The Best Soils, p. 83; Flocculation, p. 83.

Soil Water.

Importance of Soil Water, p. 84; Movement of Water in the Soil, p. 85; Conservation of Moisture, p. 85; Dry Land Farming, p. 87 .

Irrigation

Areas Requiring Irrigation, p. 88; Storage Reservoirs, p. 89; Seepage from Canals, p. 90; (Over-Irrigation, p. 90; Alkali, p. 90.

Drainage

Best Amount of Water for ('rops, p. 91; Harmful Effects of Too Much Water, p. 91; All Soils Require Drainage, p. 91; Fffects of Tile Drainage During Drought, p. 92; Kinds of Drains, p. 93; Iaying Tile Drains, p. 93; Drainage as a Government Problem, p. 94. 
Soil Air .............................. 94

Importance of Soil Air, p. 94.

Organie Matter of the soil

The Uses of Humus, p. 95; Humus of Arid and Humid Soils, p. 96.

Life in the Soil.

Importance of Soil Organisms, p. 97; Soil-Bacteria, p. 97. Questions

Laboratory Exercises 101

Collateral Reading....

\section{CHAPTER VI}

Maintaining the Fertility of the Land. $109-153$

How Soils Became Productive, p. 109; How Rich Virgin Soils Become Less Productive, p. 109; Causes of Decreased Productivity, p. 111; The Limiting Faetor in Crop Growth, p. 112; The Amount of Plant Food in the Soil, p. 113; Value of Chemieal Analyses of Soils, p. 113; Materials Used as Fertilizers, p. 114.

Nitrogen

Sources of Soil Nitrogen, p. 116; Nitrogen in Rainfall, p. 116; Nitrogen Fixation by Bacteria on Legumes, p. 116; Fixation of Nitrogen without Legumes, p. 119; Importanee of Grasses, p. 120; Losses of Nitrogen from the Soil, p. 121; Forms of Nitrogenous Fertilizers, p. 122; Nitrate of Soda, p. 122; Anmonium Sulfate, p. 122; Dried Blood, Tankage and Bone Neal, p. 123.

Phosphorus

Forms of Phosphorus Fertilizers, p. 123; Phosphate Rock,

p. 123; Bone, p. 124; Thomas slag, p. 124.

Potash

Forms of Potash Fertilizers, p. 125; Kainit, Muriate of Potash and Sulfate of Potash, p. 125; Woou-Ashes, p. 125. Lime

Functions of Lime, p. 126; Relation of Crops to Lime, p. 126; How to Tell the Need of Lime, p. 127; Forms of Lime, p. 127; Applieation of Lime, p. 128. 
Complete Fertilizers

Cost, Valuation and Analyses, p. 129; Home-Mixing of Fertilizers, p. 131; How to Determine What Fertilizers to Use, p. 132.

Barnyard Manure

Importance of Manure, p. 135; Value of Manure, p. 135;

Factors Influencing the Value of Manure, p. 138; Fertilizing Value of Food and Manure, p. 138; Amount and Value of Manure Produced by Farm Animals, p. 139; Losses of Manure, p. 140; Application of Manure, p. 144.

Green Manure......................... 147

Questions and Problems..................... 148

Laboratory Exercises . . . . . . . . . . . . . . . . 151

Collateral Reading...................... 152

\section{CHAPTER VII}

Some Important Farm Crops................. . 154-243

Relative Importance of the Different Crops of the World, p. 154; Relative Rank of the Different Crops in the United States, p. 155.

Corn

Historical, p. 156; Corn Crop of the World, p. 156; Relation of Clinate to Corn-Production, p. 157; Why We Raise Corn, p. 159; Types of Corn, p. 161; Fertilizers for Corn, p. 163; Plowing for Corn, p. 163; Fitting the Land After Plowing, p. 166; Planting, p. 166; Tillage After Planting, p. 169; Harvesting Corn, p. 171; Corn Silage, p. 171; Principle of the Silo, p. 172; The Silo, p. 173; Growing Corn for the Silo, p. 174; Feeding Silage, p. 176; Uses of Corn, p. 177. Wheat

Importance of Wheat, p. 178; Types of Wheat, p. 179; (1ulture of Wheat, p. 180.

Oats 181

Meadows and Pastures 182

Cultural Methods, p. 182; Hay and Pasture Plants, p. 184; Timothy, p. 184; Kentucky Blue-(irass, p. 185; Red-Top, p. 186; Awnless Brome Grass, p. 186; Tall Meadow Fescue, 
p. 186; Orehard Grass, p. 187; Bermuda Grass, p. 187; Johnson Grass, p. 185; Alfalfa, p. 188; Value of Alfalfa, p. 188; Culture of Alfalfa, p. 189; Red Clover, p. 193; Alsike Clover, p. 194; White Clover, p. 195; Mixtures of Grasses and Clovers, p. 195; Management of Permanent Pastures, p. 197.

Cotton.

Importance of Cotton, p. 198; Historieal, p. 199; Development in the United States, p. 199; Habits of Growth, 200; Types of Cotton, 201; Breeding and Selection, 202; Relation of (limate to C'otton, p. 205; Cotton Soils, p. 206; Preparation of the Soil, p. 207; Fertilizers for Cotton, p. 208; Planting and Cultivating, p. 209; Harvesting, p. 210; Marketing, p. 211; Grades of Cotton, p. 211 ; Cotton Seed, p. 212; Fungous Diseases and Insects Affecting Cotton, p. 214.

The Wood Crop . .

Forests of the United States, p. 216; The Settler and the Forest, p. 217; The Relation of Forestry to the Nation, p. 218; Forest Poliey of the Future, p. 218; National Forests, p. 219; Forests and Climate, p. 220; Conservative Lumbering, p. 221; Forest Trees a Profitable Farm Crop, p. 222; The Farḿ Wood Lot, p. 222; What Trees to Plant, p. 226.

()rehards

Setting Trees, p. 227; Tillage of Orchards, p. 228; Spraying Orehards, p. 229; Pruning, p. 230.

Shade Trees 233

The Farm Garden. 234

Questions and Problems. 237

Laboratory Exercises 238

Collateral Reading.

\section{CHAPTER VIII}

Enemies of Farm Crops.

Weeds

What Is a Weed, p. 244; Value of Weeds, p. 244; The Control of Weeds, p. 245; The Control of Weeds in Tilled Crops, p. 245; subduing Land That Is Badly Infested with Weeds, p. 246; Spraying for WIId Mustard, p. 246; ('ontrol of Weeds in Walks, p. 247. 
Diseases of Plants

Bacterial Diseases, p. 248; An Example of a Bacterial Disease, p. 249.

Fungous Diseases, p. 250; Characteristies of Fungi, p. 250;

An Example of a Fungous Disease, p. 252; Other Fungous Diseases, p. 253.

Parasitic Flowering Plants, p. 254.

Insects

Importance of Inseets, p. 255; What an Insect Is, p. 25.5; Stages in the Life of an Inseet, p. 256; The Control of Insects, p. 258; Chewing and Sucking Insects, p. 259.

Spraying for the Control of Insects and Diseases .

Common Fungicides and Insecticides, p. 260; Spraying for Fungi, p. 261; The Preparation of Bordeaux Mixture, p. 263; Poisons, p. 264; Contact Remedies, p. 264; Combined Insecticides and Fungicides, p. 265.

Questions 266

Laboratory Exereises .................... 267

Collateral Reading.

\section{CHAPTER IX}

Systems of Cropping

$.272-280$

The Choice of Crops, p. 272; The Rotation of Crops, p. 273; CropRotation and Diversified Crops, p. 273; Advantages of Crop-Rotation, p. 274: Profits from Rotation, p. 277; CropRotation and Crop Failure, p. 277; Variation of Crop Areas, p. 278; Examples of Rotations, p. 278.

Questions . . . . . . . . . . . . . . . . . . . . . . . 280

Laboratory Exereises ........................ 280

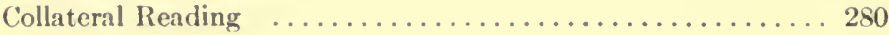

\section{CHAPTER X}

FeEd and FeEding ........................ 281-300

Importance of Animal Food and Work ............. 2\$1

Composition of liceds . . . . . . . . . . . . . . . . 282

Water, p. 282; Ash, p. 283; Protein, p. 283; Ether Extract 
or Fat, p. 283; Crude Fiber, p. 284; Nitrogen-Free Extract, p. 284; Composition of Feeds and Produets Compared, p. 284 .

Functions of the Different Food Materials.

Water, p. 285; Ash, p. 285; Protein, p. 286; lats, p. 286;

Carbohydrates, p. 286.

Digestibility of Feeds .

Feeds Differ in Digestibility, p. 287; Digestible Nutrients in Feeds, p. 288; Effeet of Time of Harvesting on Digestibility, p. 288.

Maintenance and Productive Values

Maintenance, p. 289; Extermal Work, p. 289; Production, p. 289; Energy Lost in Digestion and in Production, p. 289; Comparison of Concentrates and Roughage, p. 291.

Balaneed Rations

Food Requirements of Different Animals, p. 292: Carbohydrate Equivalent of Fat, p. 293; Nutritive Ratio, p. 293: Feeding Standards, p. 293; Computing Rations, p. 293; Another Method of Computing Rations, p. 296; Cautions in Using Balanced Rations, p. 296.

Comfort of Animals. . . . . . . . . . . . . . . . . . . 297

Relation of the Animal to Profits. . . . . . . . . . . . . 297

Condimental Foods ......................... 298

Questions and Problems.................... 298

Collateral Reading. . . . . . . . . . . . . . . . . . . . . . . . 299

\section{CHAPTER XI}

The Horse. .

$.301-321$

Substitution of Horse Power for Man Power, p. 301; Types of Horses, p. 302; Draft Horses and Horses for Speed, p. 303; Breeds of Horses, p. 307; How to Tell the Age of Horses, p. 308; Care of Horses, p. 311; Training Horses, p. 315; Rules of the Road, p. 316.

Questions

Laboratory Exercises

Collateral Reading. 


\section{CHAPTER XII}

Forms of Beef and Dairy Cattle, p. 323; Care of Beef and

Dairy Cattle, p. 324; Breeds of Cattle, p. 325; Pedigrees,

p. 330; Value of Pedigrees, p. 331; Advanced Registry, p. 332; Grading Up a Herd, p. 333.

Cattle Products

Beef, p. 333; Milk, p. 334; Composition of Milk, p. 334;

Clean Milk, p. 334; Commercial Forms of Milk, p. 335;

Babeock Milk Test, p. 336; Dairy Reeords, p. 337.

Diseases of Cattle . . . . . . . . . . . . . . . . . . 337

Tubereulosis, p. 337; Milk Fever, p. 340; Black-Leg, p. 341;

Texas Fever, p. 341.

Questions

342

Laboratory Exercises

Collateral Reading.

\section{CHAPTER XIII}

SHEEP $351-356$

Types of Sheep, p. 351; Breeds of Sheep, p. 351; Sheep Industry in America, p. 355.

Collateral Reading. . 356

\section{CHAPTER XIV}

SWINE $357-362$

Distribution of Hogs, p. 357; Breeds of Hogs, p. 358; Care of Hogs, p. 360; Hog Diseases, p. 361.

Questions 361

Collateral Reading. 361

\section{CHAPTISIR XV}

Poultry $363-371$

Importance of Poultry, p. 363; Breeds of Poultry, p. 363; Feeding Poultry, p. 365; Poultry Houses, p. 366. 


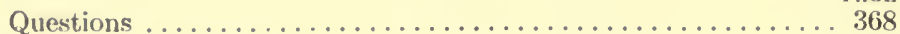

Laboratory Exereises ....................... 368

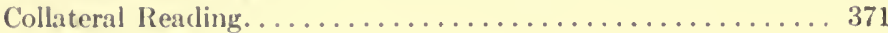

\section{CHAPTER XVI}

Farm Management

What Is Farm Management?................... 372

The Choiee of a Farm........ . . . . . . . . . . 373

Size of Farms, p. 373; Shape and Loeation of Fields, p. 374;

Topography, p. 375; Soils, p. 375; Neighloors, p. 376; Improvements, p. 377; Other Faetors Affeeting Farm Values, p. 377;

Working (apital, p. 377.

Farm Labor 377

Farm Reeords and Accounts .................. 380

Kïinds of Aceounts to Keep, p. 380; Methods of Keeping Accounts, p. 380.

Questions 384

Laboratory Exereises 385

Collateral Reading. 388

\section{CHAPTER XVII}

The Farm Home. . . . . . . . . . . . . . . . . . . . . . . . .389-395

The Farmyard, p. 389; The Farmhouse, p. 391; Modern Convenienees for the Farm Home, p. 391.

Laboratory Exercises . . . . . . . . . . . . . . . . . . . . . . . . 395

Collateral Reading. . . . . . . . . . . . . . . . . . 395

\section{CIIAPTER XVIII}

The Farm Community . . . . . . . . . . . . . . . . . . . . . . 396-399

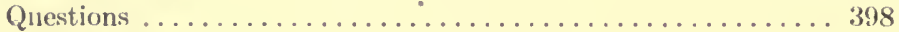

Collateral Reading........................ 399 


\section{APPENDIX}

Table 1. Apparatus and Equipment .................. 400

Table 2. Agricultural Library ..................... 401

Table 3. Addresses of the Agrieultural Colleges and Expcriment Stations, and the United States Department of Agriculture, and the Canadian Agrieultural Addresses . . . . . . . . . . . . . . . . . . . . . 403

Table 4. Length of Time Seeds Maintain Their Vitality ...... 405 Quantity of Seeds per Acre.............. 405

Table 5. Legal Weights in Pounds Per Bushel............. 406 Table 6. Fertilizing Constituents in Various Substanees ....... 408 Table 7. Feeding Standards ................... 409

Table 8. Digestible Nutrients in Various Feeding-Stuffs . . . . . 410

Table 9. Production Values of Various Feeding-Stuffs ........411

Table 10. Average Weights of Various Feeding-Stuffs ... . . . . . 412

Table 11. Values of Leading Agricultural Products .......... 413 Table 12. Agriculture Compared with Manufacturing. (Capital, Horse Power, Exports and Imports compared.) . . . 414

Table 13. Values of Agricultural Imports and Exports ........ 414 Table 14. Average Yields of Crops by Ten-Year Periods. (Acreage, Production, Value, Yields Per Acre, and Prices Per Bushel) ...................416, 417

Table 15. Farm Animals by Ten-Year Periods. (Total Number and Value, and Value Per Head) ........... 418

'Table 16. Various Statistics Showing the Progress of Agriculture. (Total Population, Number of Farms, Total Area of Farm Land, Area of Improved Land, Average Area Per Farm, Average Improved Area Per Farm, Value of All Farm Property, Value Per Farm, Value of Farm Land, Average Value Per Acre, Average Value of Farm Implements Per Farm and Per Acre, Value of Live Stock, Value of Live Stock Per Farm and Per Aere, Value of Farm Products not Fed to Live Stock, Average Value Per Farm and Per Acre, Total Expenditures for Fertilizers, Per 
Cent of Rented Farms, Number of Acres Per Male

PAGE Worker, Number of Horses Per Male Worker,

Number of Acres Per Horse) ..........418, 419

Table 17. Average Wages of Farm Labor............... 420

Table 18. Rules. (Measuring Grain, Ear Corn, Hay and Land) . 420

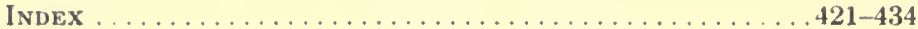




\section{PLATES}

1. PACING PAGE 1. One solution of the farm labor problem. One man doing more work than two would do with walking plows. John Deere Plow Co...................... Frontispiece

2. Sixty-five Mayweeds. No two alike. B. D. Halstead ...... 5

3. Hybrid squashes. B. D. Halstead .............. 5

4. An excellent cow who is the mother of good cows. Correct Principle in Breeding. H. A. Moyer............. 22

5. Reid's yellow dent corn. Result of fifty years of selection. A. D. Shamel .......................... 49

6. Timothy hay responds to fertilizers. J. W. Gilmore . . . . . 132

7. Timothy hay responds to barnyard manure. J. W. Gilmore. 132

8. Field of corn on which a weeder was used before cultivating.

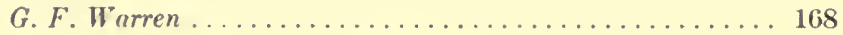

9. Field of corn on adjoining farm on which a weeder was not used. G. F. Warren ................... 168

10. Distribution of corn roots sixty days after planting. A. $M$. Ten Eyck. . . . . . . . . . . . . . . . . . . . . 171

11. A good field of wheat in New York............... 178

12. A good pasture in New York, - the Roberts pasture. Samuel Fraser ......................... 197

13. A poor pasture adjoining the Roberts pasture. Samuel Fraser.. 197 14. Destructive lumbering. Yearbook, United States Department

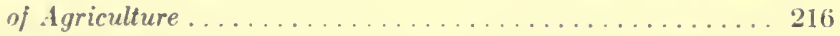

15. Conservative lumbering. Yearbook, United Stutes Department

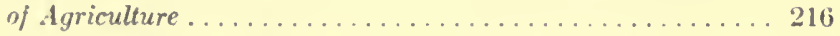

17. An ideal Baldwin apple tree for the northeastern states. $G . F$. Warren

18. A good spray $\mathrm{ng}$ for a small orchard. G. F. Warren....... 244

19. Oats sprayed for killing wild mustard. G. F. Warren....... 24t 
20. Cutting corn for the silo. Johnson Harvester Co........ 281

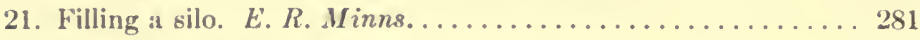
22. White Leghorn cock. . . . . . . . . . . . . . . . 363 23. White Leghorn hen . . . . . . . . . . . . . . . . 363 24. Barred Plymouth Rock cock. Win. Ellery Bright......... 363 25. Barred Plymouth Rock hen. Wm. Ellery Bright ......... 363

Figs. 16-18, 20-23, 25-27, 38-40, 44 and 45 were secured from the New York State College of Agriculture. A few figures were reproduced from the Cyclopedia of American Agriculture. All other figures were drawn for this book, unless acknowledged where published. 


\section{ELEMENTS OF AGRICULTURE}

\section{LHAPTER I 18873 INTRODUCTION}

1. What is Agriculture? Agriculture is the production of plants and animals that are useful to man.

It is the fundamental occupation on which all mining, manufacturing and commerce depend. Of course, no complex civilization could develop without these occupations. All are essential for a high civilization, but agriculture is essential for any civilization.

Agriculture is a combination of science, art and business. A good farmer needs to have executive ability, and should be a good business man. He needs to be skilful with his I hands in farm operations. The reasons for all his farm practices are based on scientific principles. He may learn to become a good farmer by imitation, in which case he applies scientific principles without knowing it. One who understands the principles involved will be able to adapt his practice to new and ever changing conditions. $\mathrm{He}$ will be resourceful.

To be able to understand the reasons for farm practices requires some knowledge of the sciences, such as botany, chemistry, physics, meteorology, bacteriology, zoölogy, geology, animal and plant diseases. In short, 
every science that deals with the factors of plant and animal growth contributes to the science of agriculture. It involves more problems than any other occupation,unless it be housekeeping. It used to be said that any one could farm. But this was merely another way of saying that farming was such a difficult study that no one knew much about it, and that all, thexefore, stood on an equal footing. Now we say that it requires as much mental alertness and education to be a good farmer as to be a lawyer, doctor, or merchant; which is another way of saying that much is now known about agriculture, so that one who does not avail himself of this knowledge is handicapped.

2. Divisions of Agriculture. Agriculture has many subdivisions. The more important ones are:

(1) Crop-growing (or crop husbandry), including graingrowing, forage-cropping, fruit-growing, forestry, floriculture, cotton-growing, vegetable-gardening, and the like.

(2) Live-stock-growing (or animal husbandry), as cattleraising, horse-raising, swine-raising, sheep-raising, poultryraising, apiculture, fish-culture, etc.

(3) Manufacture (or agricultural technology'), as buttermaking, cheese-making, cider-making, çanning, evaporating, and such other manufacturing as is done on the farms or in close association with farms.

3. Forces Controlling Plant and Animal Growth. There are two forces that control all plant and animal growth: heredity and environment. Heredity is the transmission of characters from the parent to the offspring. Environment includes all the external influences and conditions, such as heat, light, food supply, struggle for existence.

4. Heredity. A cauliflower seed looks just like a cab- 
bage seed, but, when planted in the same row, one develops into a cauliflower and the other into a cabbage. They never make a mistake and grow into the wrong plant. Evidently the seed, or embryo, had its future characteristics quite definitely fixed before it left the seed-pod. Two varieties of corn may be planted in the same field and given identical care, and yet one yield twice as much as the other. A Hereford and a Jersey calf may be raised in the same pasture, but one will develop into a heavy beef animal and one into a dairy animal. Two Jersey cows may be raised in the same herd and fed exactly alike, yet one may give twice as much milk as the other.

5. Environment. Two farmers may plant corn from the same bag, but one gets twice as large a crop as the other. Perhaps they planted at different times, stirred the soil differently, or fertilized differently. A farmer may have two cows that are giving the same amount of milk, but when one is sold to a neighbor she may produce twice as much as formerly, because of a better environment.

Nearly all farm operations that have to do with plant or animal production are performed for the purpose of modifying either the heredity or the environment.

\section{QUESTIONS}

1. Which of the four great industries, Agrieulture, Mining, Manufaeturing, or Transportation is most important in your county? In your state?

2. Give some facts showing the relative importanee of agriculture and other industries in the United States. (See Appendix, Tables 12 and 13.)

3. Which of the divisions of agrieulture is most inportant in your county? In your state? For the United States? (See Appendix, Table 11.) 
4. What are the most important farm crops, fruits and vegetables of the region?

5. What is the relative importance of horses, cattle, sheep, hogs, poultry, in the region?

6. What crops and animals are shipped out of the region?

7. What crops or animals are used in manufacturing in the region?

8. What is the etymological meaning of agriculture? Horticulture? (See dictionary.)

9. Where is your State Experiment Station located? Your Agricultural College? (See Appendix, Table 3.)

10. What kinds of work does each conduct? What work is done by the United States Department of Agriculture?

11. What publications are available from each of these organizations, and how may they be secured? (See Appendix, Tables 2 and 3.)

12. What state organizations of farmers are there in your state?

\section{COLLATERAL READING}

Principles of Agriculture, by L. H. Bailey. Pp. 1-15.

Cereals in America, by T. F. Hunt. Pp. 1-13.

Cyclopedia of American Agriculture, by L. H. Bailey. Vol. 1, pp. 7-14.

Also choose your state from pp. 29-97. 



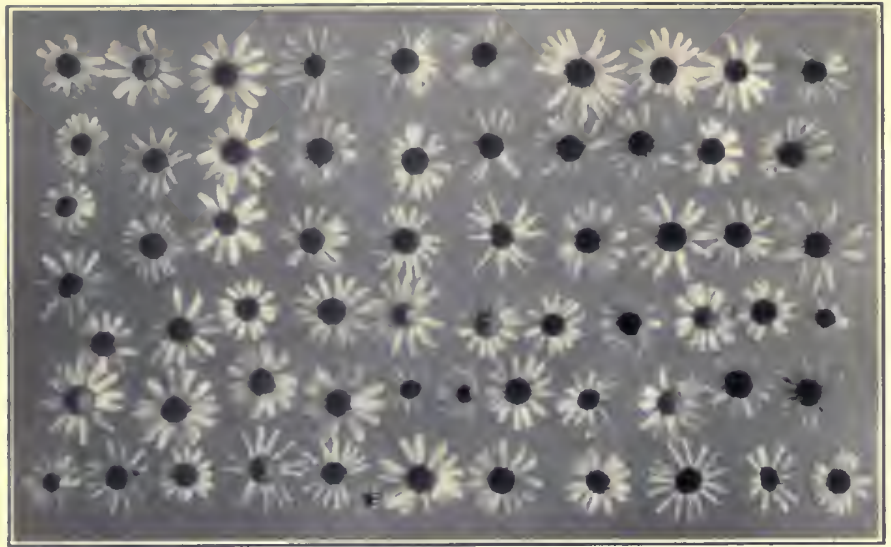

FIG. 1. Sixty-five mayweeds-no two alike

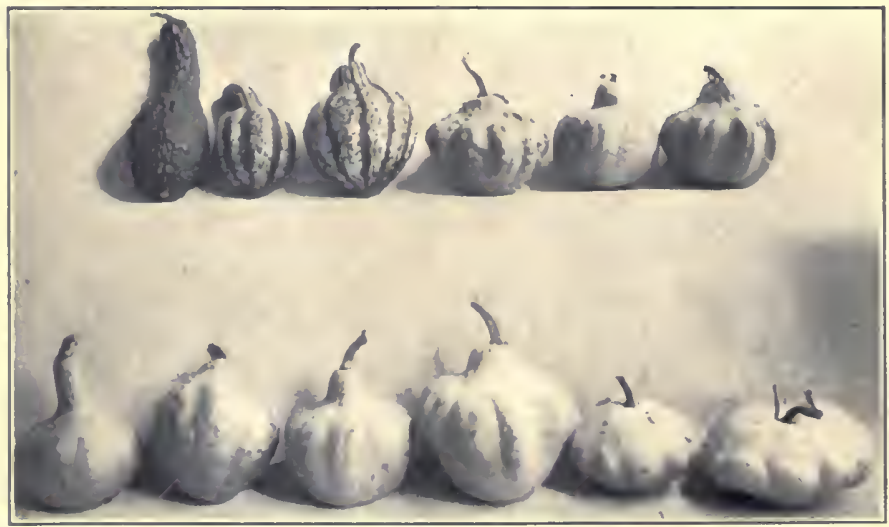

Fig. 2. Hybrid squashes. Crookneck upper row on the left, scallop lower row on right. The others are hybrids between these two 


\section{CHAPTER II}

\section{THE IMPROVEMENT OF PLANTS AND ANIMALS}

6. Variation in Plants and Animals. No two persons are alike, nor are any two living things alike, be they plants or animals. Two corn plants grown side by side are different in innumerable ways. They differ in height, in diameter, in size of leaves, amount of roots, size of ears, number of kernels, size and shape of kernels, size of embryo, chemical composition of kernels, etc. In fact, they differ in every characteristic that can be named. No two cows are alike. They differ in color, size, shape, milkproduction, disposition. Some cows produce milk with 2 per cent of fat, and others as high as 8 per cent. Some can produce three times as much butter-fat as others from the same feed. No matter on what basis we make the comparison, we shall always find differences. (See Figs. 1, 3, 11.)

7. Law of Variation. The heights of many men of the same race and country were arranged in order by Galton. Fig. 4 represents a line drawn over the heads of a thousand men when thus arranged in order of height. From this arrangement he found:

(1) That the middle man represents the average height of all the men.

(2) That the line drawn over their heads was nearly horizontal, except at the ends.

(3) That near the upper and lower ends the changes 
were rapid, that is, there are a few dwarfs and a few giants.

In other words, the great majority of the men were of nearly the same height, being from a little over five feet to six feet. But there were a few extremely short ones and a few extremely tall ones. These principles apply when we consider any character of any living thing:

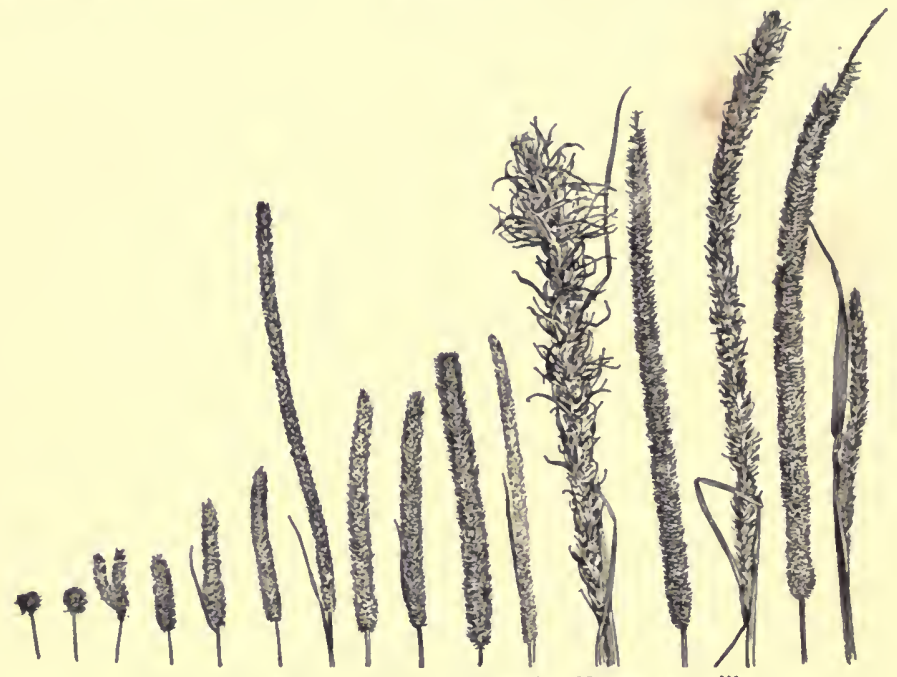

FIg. 3. Variation in timothy heads. No two are alike

Fig. 5 shows the egg-production of 65 hens for a year. The number of eggs varied from none to 170 . The number is too small to give a smooth curve, but the same general shape is indicated as that in Fig. 4.

8. Similar Produces Similar. It is often said that like produces like, but this is not strictly accurate. No two beings are alike. The members of one family are usually similar in many ways, but no two are alike. In fact, the 


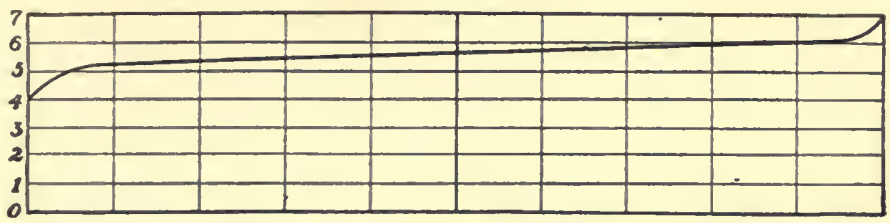

FIG. 4. Heights of a thousand men arranged in order. The great majority differ by small amounts. There are a few giants and a few dwarfs

tendency to vary may be said to be one. of the characters that is inherited.

9. Natural Selection. There is room in the world for only a small proportion of the plants and animals that begin hife. A single corn plant usually has five hundred to a thousand kernels. If all were planted and grew, the entire. world would soon be a corn-field. A morning-glory plant may produce several thousand seeds. A puff-ball produces millions of spores, each of which is ready to grow if given proper conditions. Since the total number of plants cannot greatly increase, it is evident that only a few of the hundreds or thousands of seeds produced by one plant can grow. All the others must be crowded out. If a thousand plants come up where there is room for but one, the strong will overshadow the weak

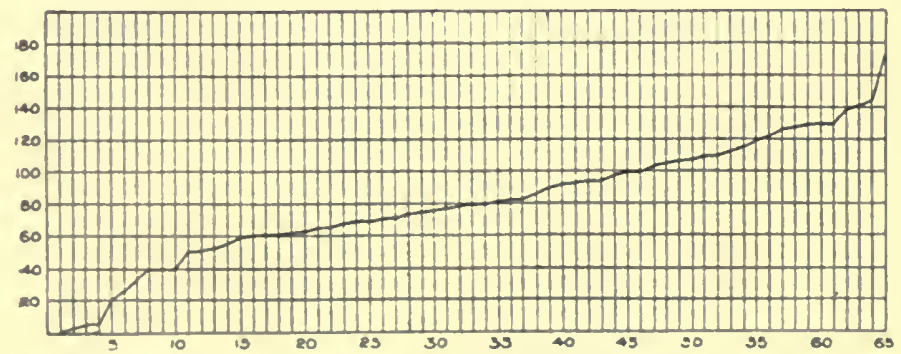

Fig. 5. Egg production of 65 hens for one year. The number varied from none to $\mathbf{1 7 0}$ 
and eventually kill them. These will in turn raise seed, and the process will be repeated. Thus, the weak, the illadapted, are always being eliminated. This constant selection of the strongest, the ones adapted to the conditions under which they are to live, may eventually result in a changed type. There are countless examples of changes that were probably brought about in this way.

10. Sports, or Mutations. Sometimes a plant appears that is quite unlike its brothers. Usually, such a one does not have the power to transmit its qualities to succeeding generations. The offspring revert to the former type. Such a new form is also likely to be poorly adapted to the environment, so that it is quickly exterminated. But, occasionally, a sport may occur that is better aclapted to the environment than the type from which it came, and that also has the power to impress its characters on its offspring. In such a case, it will crowd the old form out and give a new type in its place. Such a change might be rather rapid as compared with the ones produced by natural selection alone. The polled Shorthorn and Hereford cattle are sports. Usually such sports are lost by breeding with the common type.

\section{The Development of Weeds by Natural Selection.} Our common weeds are a good example of the adaptation of plants to particular conditions. Nearly all of our bad weeds are natives of Europe. For centuries they have been growing in the cultivated fields, until each has developed certain characteristics that have enabled it to persist in competition with the crops and in spite of man's efforts to subdue it. Only a few of the native American plants are able to persist in cultivated fields; but these foreigners, 
because of their development for just such conditions, are able to live. Possibly, in succeeding centuries we may have more of our native plants added to the list of "worst weeds."

12. De Candolle's Law. By the process of natural selection, plants have become adapted to the climate in which they live, and have thereby become ill adapted to climates farther north or south. Seed of box elder (Acer Negundo) grown at St. Louis is not hardy in northern Iowa, although no botanical differences are observable. The American plum (Prunus Americana) is hardy in Nebraska; but when these trees are taken to Texas they winter-kill, because they start too early in the spring. Red cedars (Juniperus communis) grow from North Dakota to Tennessee; but when seed from either region is taken to the other the trees produced are not hardy. De Candolle, who made a careful study of the matter, concluded that native forms are not hardy when taken one hundred miles north or south of their source.

This adaptation to climate deserves more attention than is often given to it. Northern varieties of apples, grapes, peaches, oats, and corn, are not usually adapted te southern conditions, nor are the southern varieties usually desirable in the North. The Baldwin apple, which constitutes the greater part of the New York apple orchards, is not profitable in Delaware. The Ben Davis, which is the most important apple in Missouri, is not desirable so far north as New York. Alfalfa seed from southern Europe is not hardy in northern United States, but much of this seed is sold in New York. Corn does not mature properly when seed is obtained from a hun- 
dred miles south. Much of the seed corn for northeastern United States is grown in Illinois and Iowa, but it does not always mature to the proper stage for making silage.

It is sometimes good farm management to obtain seed from a climate where more vigorous seed is produced, or where it can be grown at less cost; but for most of our farm crops it is better to have the seed grown in the region where it is to be planted. If not so grown, it is usually advisable to secure it from a region that has a similar climate.

13. Artificial Selection. For centuries, man has been saving the best plants and animals. In this way, the changes have been much more rapid than they would have been if natural selection had acted alone. Corn and wheat are so changed from the original forms that there is a question as to what the original forms were. Probably the Indians had been selecting corn for centuries before Columbus discovered America.

Artificial selection has often developed varieties that could not persist under natural conditions. We desire apples with much pulp and few seeds. Natural selection produced apples with little pulp and many seeds. In the time of Pliny, apples were so sour that he said they would turn the edge of a knife. Sour apples seem to have been best able to persist under natural conditions.

In other cases, man has aided the natural development. The corn plant that produces few kernels, or that does not mature, is discarded by the farmer. The wheat that succumbs to rust is discarded. Cattle that do not thrive on the range are eliminated by the cattleman.

Only within the last century has the improvement 
of plants been taken up in a scientific manner. The achievements of these years have been remarkable. Much of this development has been due to an increased knowledge of the laws of heredity.

\section{REPRODUCTION IN PLANTS ${ }^{1}$}

14. The Seed-Producing Organs of Plants. Fig. 6 shows the parts of a pea-blossom. The essential parts are the stamens and the pistil. The stamens are made up of two parts, the filament and the anther. Their function is to bear the pollen grains which the anther contains. The pistil has three parts, ovary, style and stigma. The ovary contains the ovules that are to be fertilized and that will then grow to be seeds. The stigma receives the pollen grains. The pollen grains start to grow when they come in contact with the stigma. This growth eventually reaches the ovules. The protoplasm of the pollen unites with the ovule, and a new plant is formed. We recognize this new plant as the embryo of a bean or kernel of

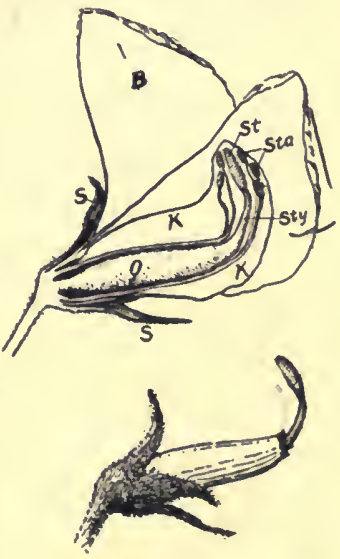

Fig. 6. Section of a pea blossom. $S$, sepal, one division of the calyx; $h, B$, divisions of the corolla; Sita, anthers of the stamens; $O$, Sty, Sit, parts of the pistil; $O$, ovary; Sty, style; St, stigma. corn. The parent plant furnishes the food for its first growth, and a supply is stored up to give the seed a start in life when it separates from the mother plant. But the embryo is a new plant as soon as the pollen grain unites

'This subject is assumed to have been studied in botany. Only a brief review is given here. 
with the ovule. Thereafter, the parent plant has no influence on it except to furnish food.

If an ovule is not fertilized, it fails to develop into an embryo. When shelling peas, we often see small traces of peas two or three times as large as a pinhead. These

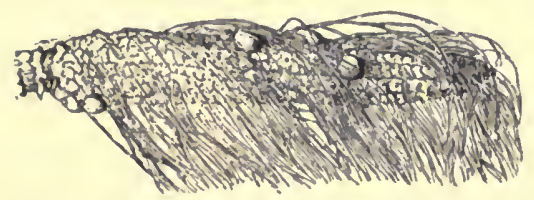

Fig. 7. Ear of corn that grew on an isolated stalk. Only a few kernels formed. Why? were ovules that were not fertilized. If an ear of corn is to fill out, every silk must receive one pollen grain. Most ears of corn have a few missing kernels because some embryos were not fertilized. The remarkable thing is that ears are so well filled. (Fig. 7.)

15. Sexual and Asexual Reproduction. When the new plant is formed by the union of two bits of protoplasm, it is called sexual reproduction. The two uniting protoplasts are called gametes. If the gametes come from diferent plants, they are said to be cross-fertilized. If both pollen and ovule are borne in the same flower, it is selffertilized.

Many plants reproduce from stems, roots or leaves. Such reproduction is without sex, or is asexual. Potatoes are reproduced by the tubers. Quack grass and Johnson grass reproduce by root-stocks, or underground stems. Sweet potatoes reproduce by roots; willows grow from cuttings; white clover stems take root; wheat, oats, and barley form large clumps by stooling. Most of the farm plants that reproduce asexually also form seeds.

The first experimental proof of sexuality in plants was made in 1691, but little application of this knowledge 
was made in the improvement of plants until within the last fifty years.

16. Artificial Crossing. It is a very easy matter to cross plants. The essential steps are:

(1) Prevent undesired pollen from reaching the stigma.

(2) Apply the desired pollen when the stigma is ready to receive it.

Suppose it is desired to cross a Ben Davis and a Winesap apple. Shortly before the blossoms open, remove the stamens from several blossoms on one tree, say the Ben Davis, and cover with paper bags. Care must be taken not to injure the pistil. The petals may be removed if they are in the way. (Fig. 6 shows a pea blossom with petals and stamens removed.) When the blossoms on the tree are in full bloom, it is ready for the application of pollen. Jar a number of blossoms on the Winesap tree over a small dish, so as to get pollen from them. This may be applied to the stigmas of the blossoms on the Ben Davis tree with a camel's-hair brush or with the finger. Cover with the paper bags to prevent other pollen entering. Remove the bags after the fruit is set. In the case of corn, the ears are covered with bags when the silks appear, and, later, pollen is applied from the desired tassel.

When two varieties or breeds of plants or animals are crossed, the new individual is called a hybrid. ${ }^{1}$

\section{SOME PRINCIPLES OF HEREDITY}

17. Problems of Heredity. If a pollen grain from a redflowered pea fertilizes an ovule from a white pea, some

1The word hybrid was formerly restrieted to crosses between different species, but it is now commonly used to designate any cross. 
plants in succeeding generations will bear red blossoms and some white blossoms. In this, as in all inheritance, two problems are involved:

(1) How the parent plant can impress its character on the gametes.

(2) How the uniting gametes impress their characters on the new individual.

How can the minute pollen grain of the pea carry the white color, the size of the vine, the shape of the pea, the earliness of the variety, and the innumerable other characters of the parent plant? How does this parent plant impress these characters on the pollen grain? These are questions about which there are many theories, but no one knows the answer.

When two gametes unite to form a new individual, how do the characters represented by each of them unite? If one represents a red and one a white blossom, the new plant cannot be both red and white,-what color will it be? To these questions we now have partial answers.

18. Mendel's Law. ${ }^{1}$ Mendel crossed a number of plants and studied the inheritance of contrasting characters in the hybrids. Only two of his experiments with peas are here mentioned. Two of the several characteristics which

${ }^{1}$ Gregor Johann Mendel was an Austrian monk, Abbot of Brunn. He was born in 1822, and died in 1884. In the garden of his cloister he conducted many experiments, particularly with peas. He published a few papers from 1853 to 1865 , but they attracted little attention and were soon forgotten. But in 1900 they were discovered. Since then his work has been the most compelling force in plant and animal improvement. Nearly every experiment station has gone to work to improve plants, and to study the principles on which this improvement depends.

His work differed from that of most students, in that he used large numbers, and so secured averages. When the laws of chance apply, no conclusions are of any value unless large numbers are used. One might draw five yellow kernels of corn in succession from a dish containing half white. His conclusions would be entirely wrong. Only when he draws a large number of times, will he be sure to have approximately equal numbers of each. 
he studied were color of flower and shape of seed. He crossed red-flowered ones with those having white flowers, and crossed those having wrinkled or angular seed with those having round peas.

Sixty blossoms were fertilized so that either the pollen or the pistil came from a pea that had the round seed, while the other gamete came from a plant that bore wrinkled seeds. When these hybrid seeds grew, they all produced round seeds. These round peas were planted, and in the next generation there were 7,324 seeds, of which 5,474 were round and 1,850 were angular, or a ratio of 2.96 to 1 . When the angular peas were planted, they produced only angular seeds, and continued so to do indefinitely. One-third of the round ones produced only round, and continued all round in later generations. The other two-thirds of the round ones, or approximately half of the whole number, produced both round and angular peas in the proportion of 3 to 1 . Of these, the angular ones remained angular when planted, and one-third of the round ones remained round, while two-thirds again broke up into round and angular.

Likewise he crossed peas with red flowers and white flowers. When the seeds were planted, all the plants bore red flowers. But in the next generation, of 929 plants 705 were red and 224 were white, a ratio of 3.15 to 1 . The white ones produced only white in the future. Onethird of the red ones produced only red, and two-thirds produced both red and white in the proportion of 3 to 1 .

From these and other experiments he drew the following conclusions:

(1) It made no difference which way the cross was 
made. When pollen from a red flower was applied to the stigma of a white flower, the succeeding generations were just the same as when pollen came from a white flower to the stigma of the red.

(2) In the first generation the characters did not blend. He did not get a half-wrinkled pea. All were round and, similarly, all had red blossoms. The character that thus appears in the hybrid is called dominant, and the character that is not apparent is called recessive.

(3) The gametes carried only one of two contrasting characters; otherwise it would not be possible to get a pure red and a pure white from hybrids. This is sometimes called the law of gametic purity.

If we represent the red color by $\mathrm{R}$ and the white by $\mathrm{W}$, a hybrid will be represented by $\mathrm{RW}$. This is what he got in the first generation, but these all appeared red, this color being dominant. When seed from these was planted, the next generation gave three-fourths red and one-fourth white. But, since two-thirds of the red ones produced both red and white in succeeding generations, it is evident that they were hybrids. The proportions may, therefore, be expressed as follows:

\section{$1 \mathrm{R}-2 \mathrm{RW}-1 \mathrm{~W}$}

One pure red, two hybrids also red, one pure white. The first three all appear alike; the only way to tell their difference being by their action in succeeding generations. A pollen grain of a hybrid is equally likely to carry the red or the white color. On the average, half of them will carry the red and half the white. Similarly, the ovules of a hybrid carry each color. When they unite, we may 
have ${ }^{1}$ : (1) Red uniting with red; (2) red with white; (3) white with red; (4) white with white, or:

$$
1 \mathrm{RR}-1 \mathrm{RW}-1 \mathrm{WR}-1 \mathrm{WW}
$$

Since $R W$ and $W R$ are alike,

$$
1 \mathrm{RR}-2 \mathrm{RW}-1 \mathrm{WW}
$$

If we suppose that each plant produces only four seeds, and that it follows the average, we should get the following results, starting with one hybrid:

First Generation

Second Generation

Third Generation

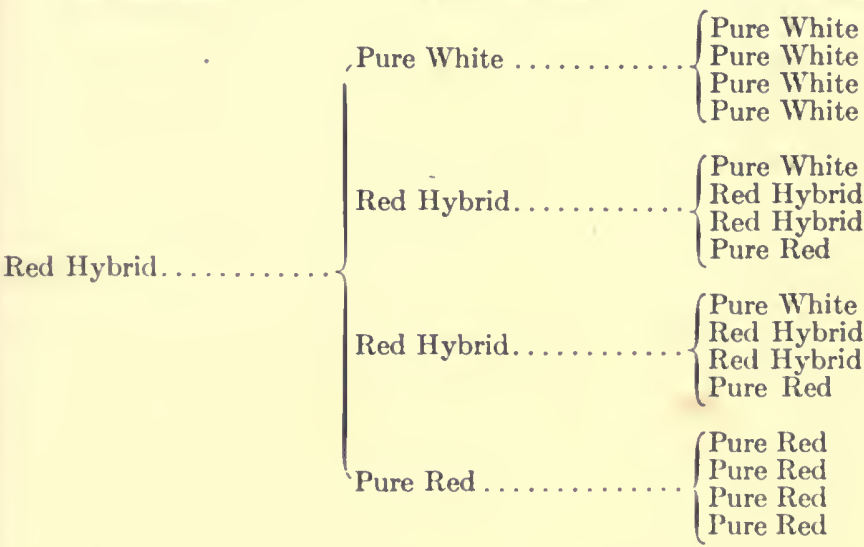

$1 \mathrm{RW}$

$1 \mathrm{RR}-2 \mathrm{RW}-1 \mathrm{~W}$

$6 \mathrm{RR}-4 \mathrm{RW}-6 \mathrm{WW}$

An interesting example of dominant and recessive characters is in eye color in man. Dark color is dominant over blue or light color. If a person has light-colored eyes, it is evident that the dark color is not present, else it would show. Those who have dark eyes may or may not

${ }^{1}$ The pea is a self-fertilized plant. With cross-fertilized plants, the mathematics is more complex. 
have the light color recessive. All children whose parents have light-colored eyes also have light eyes; but, if one or both parents have dark eyes, the children may have either color, depending on whether the dark-eyed parent has the light color recessive.

The law of chance, on which all these results depend, may be illustrated as follows:

Put equal numbers of white and yellow kernels of corn in a dish. Mix them up, then let two students each draw without looking. Mark down the result of each pair drawn. If a large enough number is used, the result will probably have a ratio very close to:

$$
\begin{array}{ll} 
& 1 \mathrm{YY}: 1 \mathrm{YW}: 1 \mathrm{WY}: 1 \mathrm{WW} \\
\text { or, } & \mathrm{YY}: 2 \mathrm{YW}: \mathrm{WW}
\end{array}
$$

When more than two characters are considered, Mendel found that each set of characters may be inherited independently of the others.

If a tall, red-blossomed, round pea is crossed with a short, white-blossomed, angular one, we shall get the following forms, besides hybrids, in each character:

$$
\begin{aligned}
& \text { Tall, white, round. } \\
& \text { Tall, red, round. } \\
& \text { Tall, white, angular. } \\
& \text { Tall, red, angular. }
\end{aligned}
$$

Short, white, round.

Short, red, round.

Short, white, angular.

Short, red, angular.

But to get any one of these kinds with each of the characters pure would be a task for a professional breeder. When we consider that each plant has very many characters, we see what a complicated matter it becomes. The great majority of the new forms will be undesirable, but occasionally one may be good. We must 
remember that our new kinds need to be better than what we now have. It is not enough that they be different.

There are cases in which Mendel's law does not seem to apply. Sometimes crosses do give blends, or intermediates. Perhaps this is because we do not know what unit characters are.

19. Application of Mendel's Law. Since the results of crossing give rise to such a miscellaneous array of forms, only a very few of which are desirable, it is evidently not a good practice for farmers to cross plants or animals of different breeds. This is a very common practice of American farmers, but certainly does not seem to be a wise one. A man will get his herd of cattle graded up to Shorthorn, then for some reason he changes to Hereford, then to Angus, then perhaps back to Hereford. The result is a mongrel herd: It is nuch better to decide on a breed and then keep breeding to pure-bred sires of that breed. One will soon have a herd that is nearly pure-bred.

Since we expect, not blends, but a recombination of characters, we shall not expect to get a plant of intermediate size by crossing a large one with a small one. Nor shall we expect moderate-sized horses because one parent is large and one small. We are much more likely to get an animal with bad proportions. We often see horses with the body of a trotter carrying the feet of a drafthorse and sometimes the head of a draft-horse. Many of the ungainly horses that are seen everywhere are the failures in attempts to get intermediates between distinct types. (See Fig. 2.)

If one wishes to produce an entirely new type or breed, it is often desirable to cross unlike forms, in the hope of 
getting desirable blends or new combinations of characters. But this is done with the knowledge that the great majority will have to be discarded. The large number of poor ones is the price paid for a possible one or two superior ones. The farmer who is not a breeder does well to decide on what breed he wants, and then stick to it.

Half-breeds are often good in the first generation; but this is what we should expect, because only the dominant characters are apparent. Mendel found that by crossing peas with stems one foot in length with those six feet in length he got hybrids six to seven and one-half feet in length-larger than either parent; but, in the next generation, short forms reappeared. The succeeding genera-

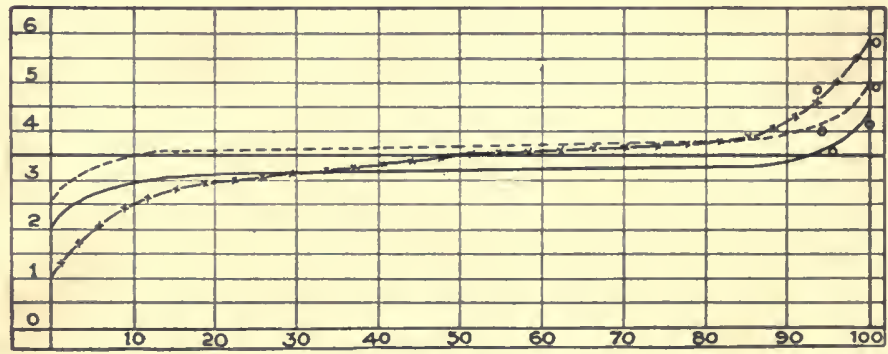

Fig. 8. Yield in grams of 100 plants of Fife and Blue-stem wheat and of a hybrid between the two. (Adapted from Hays.)

- - Yield of Blue-stem. — Yield of Fife. $x-x-x$ Yield of hybrid.

tions are the ones that are likely to bring disappointment. If the half-breeds are to be sold to the butcher, crossing may be desirable. This agrees with common experience, that it is not wise to use half-breed animals as sires even if they do appear to be good.

Fig. 8 shows the yield of one hundred plants of fife and blue-stem wheat and of a hybrid between the two. The 
hybrids do not average so good as the fife. Many of them are worse than either parent. The few good ones between $0-0$ are of interest to a professional breeder; but the discordant array is a strong argument against crossing as a general farm practice.

\section{STEPS IN BREEDING}

There are three steps in improving plants or animals:

(1) Increasing variation.

(2) Selection of desirable forms.

(3) Testing the power of the selected individuals to reproduce their desirable characters.

20. Variation may be increased by any change in environment, as a change in food supply or climate. It is greatly increased by crossing. Only those who make a business of producing new forms are likely to want to try to increase variation. For ordinary farm purposes, it is usually better to make selections from the innumerable variations that already exist.

21. Selection is the most important step in all improvement. In making selections, the primary use should always be of first consideration. It is the number of eggrs produced, and not the feathers, that determines the real worth of a hen. Unfortunately, the prizes are usually awarded on the feathers. The amount of butter that a cow produces, and not the switch of the tail, is the primary point in selecting a cow. The yield of corn, and not the peculiarities of the kernels, is the essential point. It is also necessary to remember that the individual is the unit to be considered. The hill of potatoes, and not the 
single tuber, is the unit. The melon vine, and not the single melon, should be chosen. The good melon may have been the only one that the plant produced.

Constant selection is necessary in order to keep any of our farm crops or animals up to their present standard. The breeder of pure-blood cattle who does not cull out many individuals is certain to run the average down. Our standard is the upper part of the curve of variation. If careful selection is not made, we will tend to get back to the average.

Most of our plants and animals already exhibit more variation than we desire. Uniformity is often as important as an increase in the yield. A uniform herd of cattle is a better indication of good breeding than is a variable herd that may have some better individuals. Uniformity in size, color, and general appearance is of more importance in selling vegetables and fruit than is mere size or flavor.

22. Testing Hereditary Power. Testing the power to transmit the good qualities to the next generation is really further selection. Good individuals often fail to produce good ones. The best ears of corn have been selected for many years, and great improvement has been made. Much greater improvement would doubtless have resulted if the hereditary power had been tested, as explained in the ear-row test (Fig. 12).

Dairy herds that have been carefully selected often come to be made up of the descendants of one cow; usually from a good cow, but not always from the best cow. It is not enough that a cow be a good one; she should be the mother of good cows. Fig. 9 shows a good example of such a cow. On the left is Prilly No. 40082 who produced 


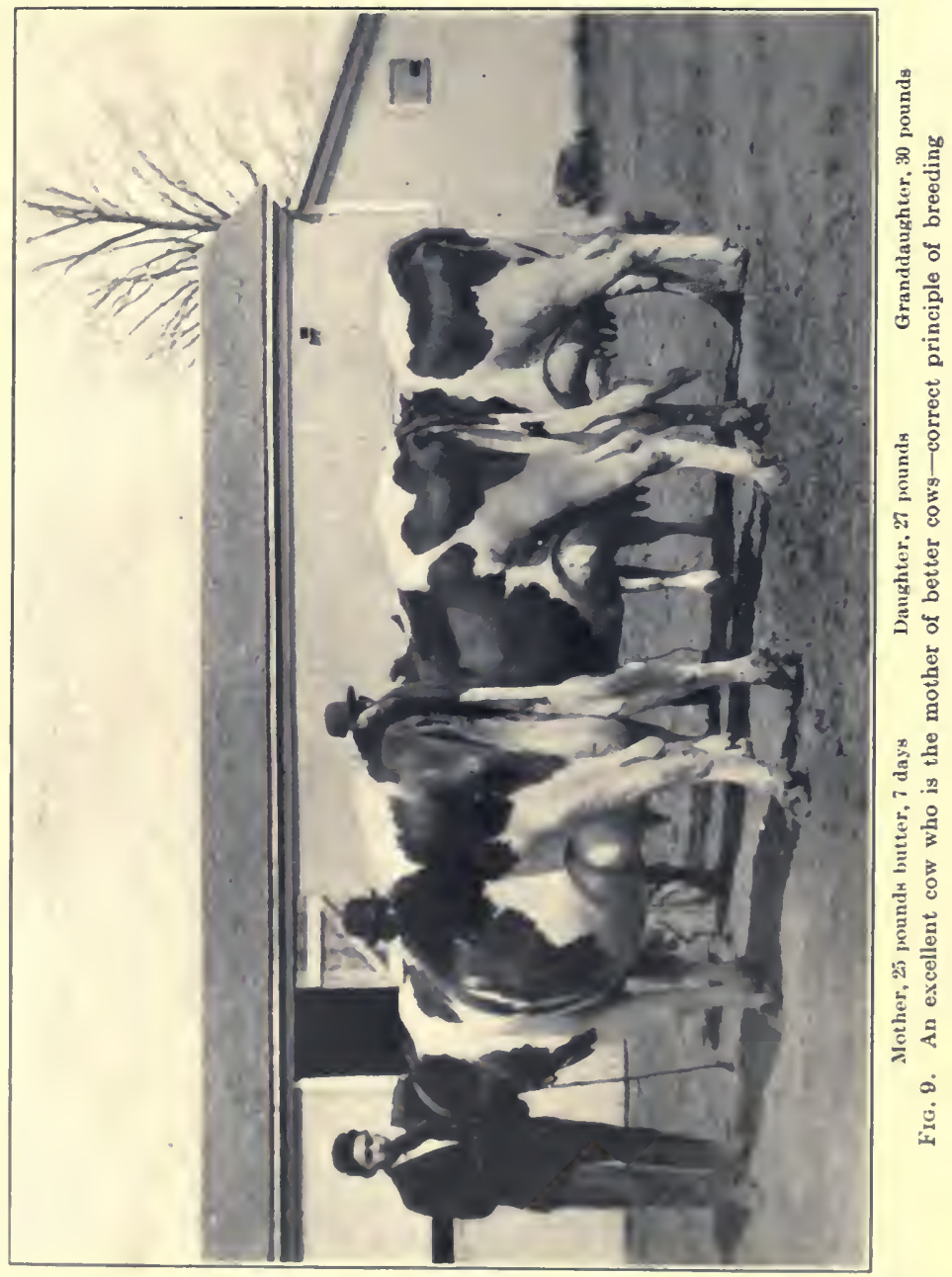


$-$ 
25.20 pounds of butter in seven days. In the center is her daughter who produced 26.90 pounds in seven days. On the right her granddaughter who produced 30.03 pounds.

The trotting horse called Messenger was not famous for his speed, but nearly every one of the best trotting horses of today has some of his blood.

Not every attractive plant or animal is desirable. Much too often an attractive young male is placed at the head of a herd, only to find that a mistake has been made. Whenever possible, it is desirable that individuals be selected because they have good offspring.

\section{IMPROVING SOME FARM CROPS}

23. Plant-Breeding vs. Animal-Breeding. The plantbreeder has several advantages over the animal-breeder:

(1) He can grow large numbers at small cost, and so have greater numbers to select from. He need save only one in thousands. The animal-breeder must work with fewer numbers, and save a larger proportion.

(2) When superior plants are obtained, they can be rapidly multiplied.

(3) Many plants can be propagated by asexual means, hence avoiding the reversion that comes from seeds. If a desirable hybrid is found, it is not given a chance to revert, but is propagated by buds, roots, or cuttings. Our varieties of apples, strawberries, and most other fruits, potatoes, and many flowers, would be lost if they had to be propagated by seeds.

24. Comparative Improvement of Different Crops. Those crops in which the individual has been handled by the 
farmer have been most rapidly improved. Each ear of corn is seen when husking, the differences have attracted

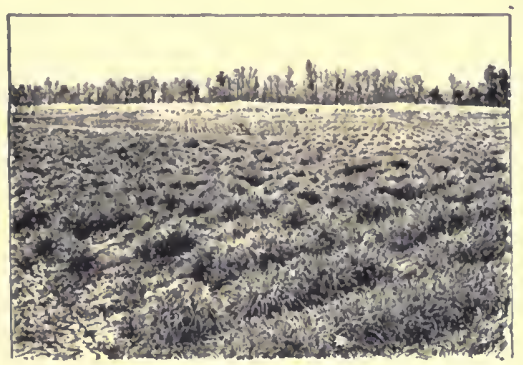

Fig. 10. Twenty thousand timothy plants. Each grown from a single seed attention. The resulting selection has given the most striking example of improvement on a large scale. Potatoes have been more rapidly improved than wheat. There are hundreds of named varieties of apples, but no varieties of timothy.

Yet the differences between timothy plants are probably as great as the differences between varieties of apples. At Cornell University, there are about twenty thousand individual timothy plants growing in rows. There are many distinct types that will make very desirable varieties (Fig. 10).

\section{Sugar-beet. The} most striking example of rapid improvement due to the application of scientific principles is the sugarbeet.

In a hundred years, the percentage of sugar has been increased from about 8 per cent to an average of 14 to 18 per cent. The average in the United

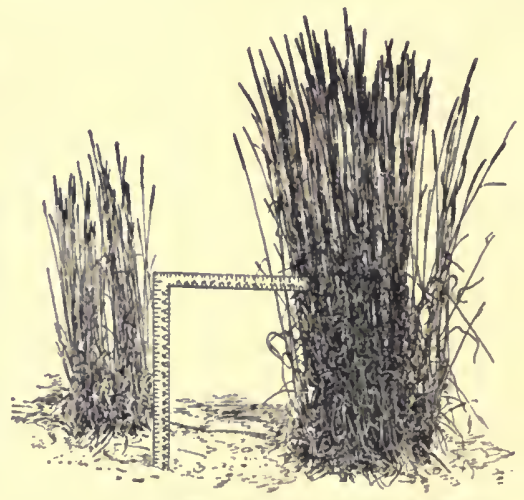

Frg. 11. Two timothy plants growing side by ride, showing difference in yield. Each one grew from a single seed. 
States was 14.9 per cent in 1907, and one field of twenty acres in Washington averaged 22 per cent sugar $^{1}$. Less than a hundred years ago (1812), the first beet-sugar was manufactured for sale; now over half the sugar supply of the world comes from beets.

Large firms have made a business of breeding beets. The method of improvement has been about as follows: When digging the beets, the workmen select the bestlooking ones of medium size (one and one-half to two pounds), smooth and uniform, and that grow below the ground. These are stored for winter testing. In the winter they are tested for sugar and per cent of solids not sugar. A sinall core is bored out for the sugar test. This does not injure the beet for planting. The solid matter other than sugar makes the extraction of sugar more difficult. Those with a high percentage of sugar and low percentage of other solids are best. The beets are graded into different classes, based on the percentage of sugar, and are planted to raise seed.

The seed produced by each of these beets is sown in separate rows, to test the reproductive power. New selections for continuing the improvement are made from the best beets of the best rows. The remaining ones are used for growing commercial seed. The seed grown from beets with a high sugar content sells higher than that grown from the poorer classes.

26. Corn Improvement. The best ears may be selected from a crib, or from the field at husking time, or one may go into the field before husking and select good ears on good stalks that grew under normal conditions. A good

${ }^{1}$ Experiment Station Record, Vol. XIX, p. 32. 
ear from a crib may have been good because the stalk grew under especially favorable conditions. It may have grown alone, when most of the plants grew in hills, or it may have grown on richer soil.

With any of these methods of selection, we know only half the parentage. The pollen to fertilize the good ear may have come from stalks with very poor ears. It is necessary, therefore, to test the yielding power.

The selected ears should be kept in a dry, moderately warm place during the winter, as freezing hurts the embryos when they are moist (page 54). In the spring, a germination test is made as a further selection (page 48). Discard all ears that do not germinate all of the six kernels tested; also discard those that produce weak sprouts.

Suppose that twenty-five of the best ears, all of perfect germination, are now taken for an ear-row test, the remaining seed being used for regular field planting. Shell each of the twenty-five ears into a paper bag bearing the number of the ear. Select a place in the regular cornfield large enough for fifty hills square. The soil should be uniform and of average fertility. Plant rows 1 and 26 from ear 1 ; rows 2 and 27 from ear 2 ; rows 3 and 28 from ear 3 , etc. This gives two trials of each ear, so that soil differences will be allowed for. Half of the seed of each ear is saved for next year's planting.

After the corn is up, it is a good practice to thin it to a uniform number of stalks per row. The corn is cultivated the same as the regular field. In the fall, husk each row separately and measure the yield.

Such a test, conducted in 1907 by Yale Deuel, a farmer living at Churchill, N. Y., gave the following yields: (The 
yields given are the averages of the two rows planted from each ear.)

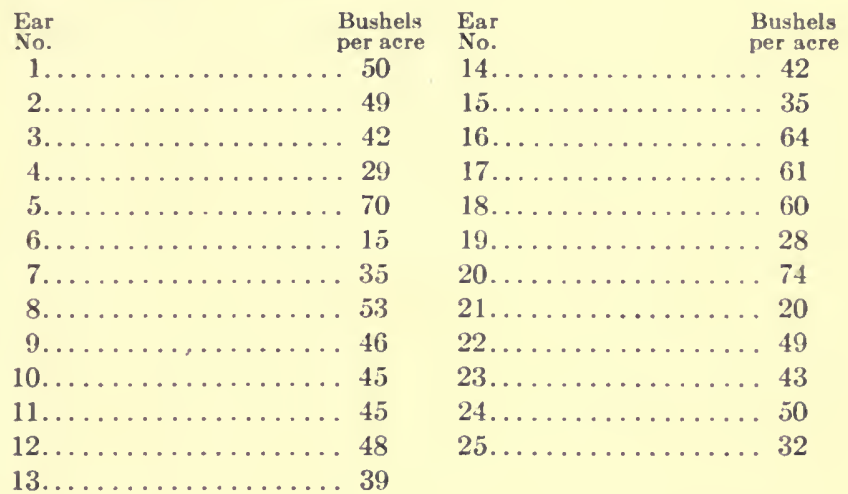

This table shows the extremely variable yielding ability of ears that are apparently all good. No one would imagine that there would be such a difference. The best four ears were $5,17,18$, and 20 . But these were all grown adjacent to poor rows. It would not do to save seed from these good rows, because they will be crossed with the adjacent poor rows. Seed from them might, however, be used in the field planting. We still have

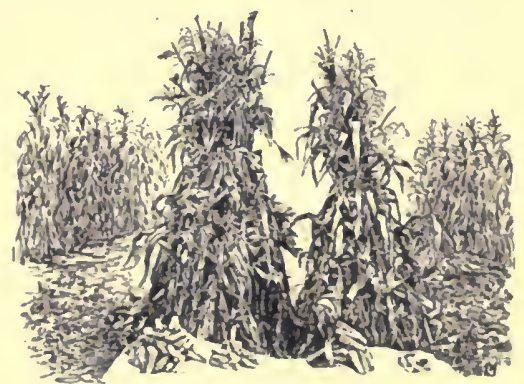

Fid. 12. Yields of adjacent rows in an earrow test, showing the difference in yielding power of two ears that looked equally good. parts of each ear saved from the spring planting. The following year, the remnants of these four ears are planted in an isolated place, where they will not mix 
with other corn. This patch will furnish seed for a small field the following year, and the third year there will be enough seed for a large area.

Each year, particularly good ears may be selected from the best rows or from the main field, and the process continued. When one carries this process out carefully, his neighbors will likely desire the extra corn for seed.

A trial conducted by the Iowa Experiment Station ${ }^{1}$ shows that variations in all characters occur. In 1905, seed from 102 of the best ears of corn was planted in an ear-row test. Records of yields, barren stalks, broken stalks, suckers, etc., were made for each row, showing the variations in the 102 ears, all of which appeared to be good.

Variation in yield:

Ear No. 75 yielded 91 bushels per acre.

Ear No. 93 yielded 36 bushels per acre.

Variation in number of broken stalks:

Ear 54 had 64 per cent of the stalks broken and yielded 68 bushels per acre.

Ear 85 had 8 per cent of the stalks broken and yielded 77 bushels per acre.

Variation in number of barren stalks:

Ear 19 produced 22 per cent barren stalks and yielded 51 bushels per acre.

Ear 83 produced 1.5 per cent barren stalks and yielded 76 bushels per acre.

Variation in number of suckers:

Ear 106 produced 21 per cent of suckers, and yielded 78 bushels per acre.

Ear 75 produced no suckers, and yielded 91 bushels per acre.

${ }^{1}$ Iowa Bulletin No. 77. 
If one does not care to select corn so carefully, he may at least select the best ears and make a germination test. If corn is husked from the field, a box may be tied on the wagon into which the best ears are put.

27. Cotton may be improved in the same manner. Seed is saved from the best plants in the field. Rows are planted from each plant, and in each case half of the seed is saved. The yield from the different rows determines which of the original plants were best able to transmit their good qualities. The remaining seed from the best original plants is then planted together, to grow seed for field use.

28. Other Cross-fertilized Plants may be improved in the same way:

(1) Select the best.

(2) Test the yielding power, saving a part of the seed from each plant.

(3) Plant the remnants of seed from the best plants. Tobacco, rye and timothy are cross-fertilized plants.

29. Oats. Oats are commonly self-fertilized, so that a poor row beside a good one will not harm it. The third step can, therefore, be omitted.

Save seed from the best plants from a field of oats, or, if the individual plants cannot be distinguished, save the best heads. The seed from each plant will need to be tested, to see whether it produces well. The plant may have been good because the soil where it grew was good.

The seed may be planted in rows six to ten inches apart, and a rod or more long. If twenty-five heads were saved, rows 1 and 26 may be planted from head 1; rows 2 and 27 from head 2 , etc. The best-yielding rows are 
saved for seed. These will have to be raised another year before there will be enough for a field. The process may be repeated for further improvement.

30. Other Self-fertilized Plants may be improved in the same manner:

(1) Select the best.

(2) Test the yielding power. The seed from those that yield most is saved for field planting.

Wheat, rice, peas, beans, are commonly self-fertilizing.

31. Potatoes are propagated by cuttings. The potato tuber is a much-enlarged underground stem. The eyes are really buds. Propagation in this way is asexual. When a good potato is secured, it is multiplied from cuttings.

The only satisfactory way to improve potatoes by selection is by hill selection. What is necessary for a good yield is good hills. If a large potato is selected from a bin of potatoes, it may have been the only good potato in the hill. If potatoes are dug by hand, the best hills may be saved while digging. If they are dug with a machine, the most promising hills may be dug by hand before digging the field. The ones that produce the largest yield of desirable potatoes are saved for seed. Enough may be saved in this way so that they will produce seed for the entire field the second year following. It is also desirable to keep each hill separate and to plant separately. In this case, the ones that yield most are kept for the breeding plot.

32. How Often Do Potatoes Need to Be Grown from the Seed-ball? Potatoes also reproduce by seeds from the seed-balls. But the number of these seeds is now small. Probably, the potato that produced fewest seeds has been 
able to grow the best tubers. The statement is often made that potatoes must be renewed from the seed-ball frequently, in order to keep up their yield. If carefully selected and well grown, the present varieties would doubtless maintain their yield indefinitely. When poor potatoes are planted and poorly cared for, they will surely deteriorate. It is probable that new varieties will continue to be formed from the seed that are better than any of the present varieties, so that even if present varieties are improved they are certain to be displaced eventually. Old varieties cannot be renewed from the seed because potatoes do not come true from seed.

33. Plant-breeding Farms. Farms whose business is the production of improved varieties of plants are now beginning to develop in different parts of this country. Several such establishments have been in operation for a number of years in Europe. In time, farmers will likely come to look to these farms for seed, as they now go to stock-farms for pure-bred stock. If improved seeds are really produced, they must be sold for an increased price. Improvement, such as can be practiced on any farm, as described in the preceding paragraphs, is not very expensive. But to produce new types of plants that are better than anything else that now exists is expensive. When once produced, they are too valuable to be grown by one man only.

\section{QUESTIONS}

1. What is protoplasm?

2. What are the worst ten weeds of the neighborhood? Look them up in the botany manual and see which were introduced from Europe. What are the charaeters of each that make it able to persist? 
3. There are about 225,000 alfalfa seeds in a pound. About fifteen to thirty pounds is sown per acre. If twenty pounds is sown, how many seeds would there be on a square foot? Some gool old fields do not have over five plants per square foot. Why is so much seed sown? If fields are available, count the number of plants on old and new seedings. Do the same prineiples apply in planting corn? To what other plants do they apply?

4. Why are the ears on a cornstalk not always filled out?

5. What part of the flower are the corn silks? Where are the other parts? To what are the silks attached?

6. What effect does wet weather at blossoming time have on an apple crop? What effect does dry weather at silking time have on the corn ears? Why is a frost at blossoming time more injurious to peaches than one later?

7. What would be the proportion of red and white peas at the end of the fifth generation from the hybrid between them?

8. Why is the ratio in which hybrids break up not exactly 3 to 1 when dealing with small numbers?

9. Why do apples, peaches and pota toes not come true from the seed?

10. Are sinall potatoes as good as large ones for planting?

11. Are the kernels of corn from the tip and butt good for planting?

12. What crops, or new varieties of crops, if any, have been recently introduced into your region?

13. What seeds of farm crops are regularly shipped into your county? Where do they come from? Is the climate of the region from which they came similar to yours?

\section{LABORATORY EXERCISES}

1. Variation in Plants.

Materials.-A number of elm leaves for each student, or leaves of some other plant, two corn-stalks or other plants for each student.

Try to find two leaves that are alike.

Make a list of all the leaf characters, and tell how the leaves differ in each character.

Make : list of all the characters of the two corn plants and state the differences: Number of leaves, height and diameter of stalk, number of parts in the tassel, number of ears, size and shape of leaves, number of ribs, length and diameter of ear, number of rows of kernels, color of kernels, color of cob, shape of kernels, size of embryo and endo- 
sperm, taste of pith and kernels. These are but a few of the many characters that may be compared.

\section{Galton's Law.}

Measure 100 or more plants of any kind, arrange the results in order and draw a curve representing the measurements. The height of 100 corn-stalks, length, weight, or circumference of 100 ears of corn, or any kind of measurements may be used.

\section{Struggle for Existence.}

Materials.-An ear of corn for each student, also a purslane plant, pigweed or other weed with many seeds. How many kernels on the ear of corn? Count one row and multiply by the number of rows.

How many seeds on the pigweed, or other plant? Count the seeds on a few branches and multiply by the number of branches.

Begin with one kernel of corn, or one pigweed seed, and suppose that each grew and developed as these have done. How many would there be in three years?

\section{Struggle for Existence.}

Field Trip. (1) Go to a weed "patch." Let each student take one square foot or more of area. Count all the plants on this area. How many are apparently not going to be able to form seeds?

(2) Examine an unpruned tree. What proportion of the branches have been killed by crowding out? Count the buds on a twig. How many can develop into branches?

(3) If a woodlot where trees grow naturally is available, visit it. Find trees that have been killed. What proportion survive? Find those that are overshadowed, but that are still alive waiting for a chance. Compare their ages with the large trees.

\section{Struggle for Existence among the Buds of a Potato.}

\section{Materials.-Potato and dish of water.}

Place a potato in a glass of water so that the stem end touches the water, and allow it to grow. How many "eyes" start? After these have grown some time, cut them out and see if the others start.

\section{The Flowers of Some Crops.}

Materials.-The flowers of such farm crops as grow in the neighborhood: Corn, oats, wheat, rye, rice, cotton, etc. Dried specimens may be used, but materials preserved in formalin are better; fresh material is the best. 
Find the stamens, anthers, pistils, stigmas, styles and ovaries of cach. Make drawings of each. Compare the abundance of pollen in a self-fertilized plant, such as wheat, rice, oats, with its abundance in the cross-fertilized plants, as corn or rye. Why this difference?

\section{Pollen Grains.}

Materinls.-Same as for No. 6, and a compound mieroseope.

Examine pollen grains of several erops with a microseope, using a one-sixth-inch objective ( $X$ about 400). Make a drawing of each kind.

8. Hybridization.

Materials.-Growing plants about to bloom.

Let each student cross-fertilize several flowers of any plants, preferably erops. If possible, have the seed from each cross saved and planted. (See p. 13.).

\section{Seed Selection.}

Materials. - A field of any erop approaching maturity. Each student to seleet ten plants for seed, giving reasons for the ehoice.

\section{The Improvement of Some Crop.}

Let each student choose some plant which he is to try to improve during the next year: An ear-row test of corn, hill-row test of potatoes, selection of earnations, or some other plant. If the school has land available, this may he done on the experimental grounds, or students may do the work at home.

\section{COLLATERAL READING}

Production of Good Seed Corn, by C. P. Hartley. Farmers' Bulletin No. 229. (Each member of the elass should have a eopy.)

A Suceessful Hog and Seed-corn Farm, by W. J. Spillman. Farmers' Bulletin No. 272, p. 12.

Corn-breeding Work at the Experiment Stations, by J. I. Shulte. Yearbook, 1906, pp. 279-294.

New Citrus and Pineapple Produetions of the Department of Agriculture, by H. J. Webber. Yearbook, 1906, pp. 329-346.

New Tobaeco Varieties, by A. D. Shamel. Yearbook, 1906, pp. $387-404$. 
Sugar-beet Seed Breeding, by J. E. W. Tracey. Yearbook, 1904, pp. 341-352.

Improvement of Cotton by Seed Selection, by Herbert J. Webber. Yearbook, 1902, pp. 363-386.

The Art of Seed Selection and Breeding, by A. D. Shamel. Yearbook, 1906, pp. 221-236.

Plant-Breeding on the Farm. Farmers' Bulletin No. 334, pp. 5 - 9.

Potato-Breeding. Farmers' Bulletin No. 342, pp. 10-14.

Cereals in America, by 'T. F. Hunt. Pp. 14-25, 63-68, 185-200.

Forage and Fiber Crops in America, by T. F. Hunt. (See Index of crops.)

Principles of Breeding, by E. Davenport.

Cyclopedia of American Agriculture, Vol. II, pp. 1-35, 53-80.

In giving references, the following abbreviations are used: "Bureau of Plant Industry," "Bureau of Animal Industry," "Forest Service," etc., refer to bureaus in the United States Department of Agriculture. "Farmers' Bulletin" and "Yearbook" also refer to publications by this department. Publications of state experiment stations are referred to by the name of the state. "Iowa Bulletin No. 75" means Bulletin No. 75 of the agricultural experiment station that is located in Iowa.

See Appendix, Tables 1, 2 and 3, for method of securing publications. 


\section{CHAPTER III}

\section{PROPAGATION OF PLANTS}

Plants may be propagated by spores, by seeds, and by division. 'The most important methods of propagation on the farm are by spores, seeds, and by several methods of division, such as creeping stems and rootstocks, tubers, euttings, buds and grafts. Nearly all economic plants are propagated by means of seeds.

34. Spores differ from seeds in that they do not contain an embryo, or young plant. They are usually onecelled, or few-celled and microscopic. Only the lower orders of plants form spores. The flowering plants form seeds. Spores may be formed sexually or asexually. The rusty margins on the underside of fern leaves contain spores. The dust of a puff-ball is composed of countless - spores. Corn smut, oat smut, oat rust, are masses of spores. This method of propagation is not of great
Fig. 13. direct importance in agriculture, because only a Fia. 13. direct importance in agriculture, because only a
Spores of

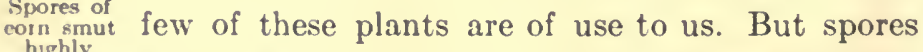
highly
magnified. are of great importance when we come to consider plant diseases, for nearly all such diseases are caused by plants that reproduce by spores.

35. Creeping Stems and Rootstocks. The branches of white clover take root, and so form new plants (Fig. 14). This enables it to persist many years in pastures where red clover is exterminated. 
Buffalo grass is able to persist in dry regions by means of the branches that take root, somewhat like strawberry runners.

The most important example of asexual reproduction is in grasses. All the perennial grasses increase by new

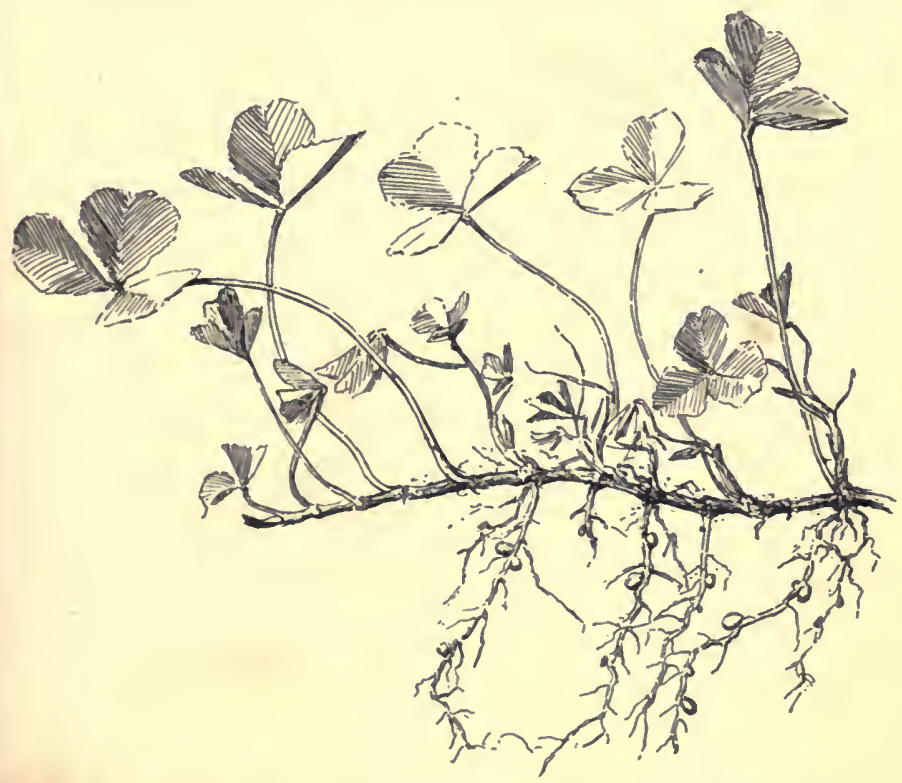

F16. 14. Branch of white clover showing the method of forming new plants stems, or culms, that arise from the nodes of the older culms. Usually the new stems come from the nodes that are near the ground, or below it. If the new stems are very short or sessile, the process is similar to the stooling in wheat and oats. More often a branch comes out more or less horizontally, either above or below ground, takes root at its nodes, and sends up one or more culms. Such a 
horizontal branch is called a stolon. The leaves of a stolon that grows below ground are reduced to colorless scales. Such a stolon is called a rootstock. The new stem is at first a branch of the old one, but it often forms its own rootsystem, becomes independent, and in turn gives rise to stolons and culms (Fig. 15). The distance of the new culm

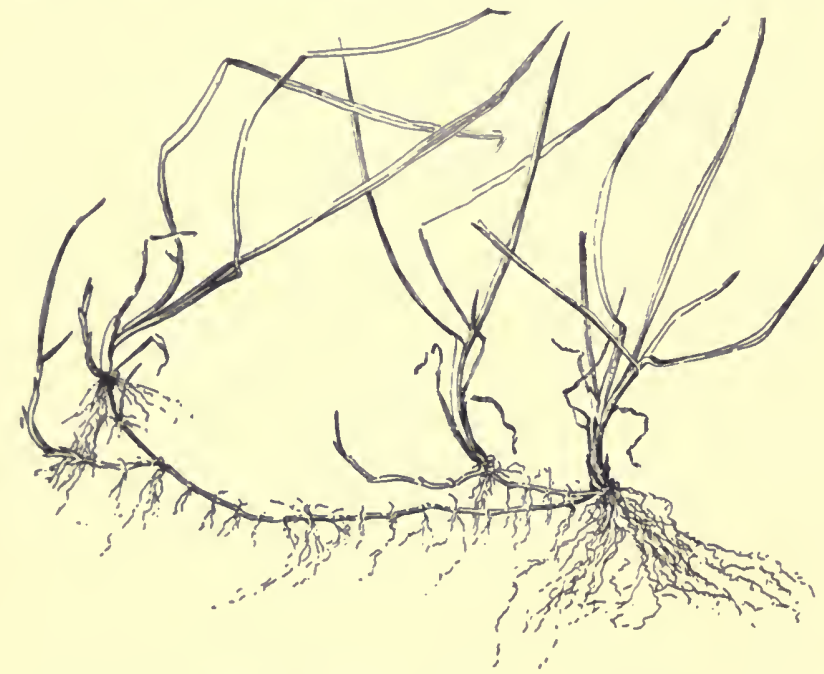

FIG. 15. Blue grass showing the method of reproduction by underground stems, or stolons

from the old one determines whether the grass is spreading, like blue grass, or tufted, like orchard grass and blue joint grass. (See Figs. 91, 92, and 95.)

It is probable that all grass plants would die after the formation of seed were it not for this means of reproduction. The plant that grows from a node apparently forms seed but once. But it may produce stolons and so continue the stand of grass. Botanists have classified 
these plants as perennials, but they are a very different kind of perennials from alfalfa and trees.

The grasses with long stolons, like blue grass, tend to form a dense sod, and are, therefore, best for pasture. The less strongly stoloniferous kinds, as timothy, are usually best for hay; probably because the dense sod developed by the strongly stoloniferous species contains so many stems that none of them can grow large enough to produce a good hay crop.

36. Roots. The edible portion of the sweet potato is an enlarged root. The potato plants are grown from these. The roots are put about an inch apart in hotbeds, with about four inches of dirt under them and two inches on top. The roots send up many sprouts from adventitious buds. When these shoots have reached the proper height, they are pulled. This permits the potato to send up more sprouts. The plants thus grown will have a good supply of roots of their own before they are pulled from the potato. Sweet potatoes are also grown from cuttings taken from the vines produced by the earlier plants. Occasionally, the potatoes are cut into pieces and planted like Irish potatoes.

37. Tubers. The field, or Irish potato, is a modified stem. The eyes send out branches, so it might be propagared in the same manner as the sweet potato, but this is not profitable.

Irish potatoes are usually cut into two or more pieces for planting. The larger pieces have given the larger yields in most experiments. Of ninety-five experiments reported from various experiment stations, seventy-six found that half-potatoes yielded more than those cut to two eyes, 
while nineteen secured greater yields from the latter. Thirty experiments considered the increased cost of seed of the half-potatoes over the two-eyed pieces. ${ }^{1}$ Twentytwo of these found a net income from the crop above the cost of seed in favor of the half-potatoes, and eight in favor of two eyes. ${ }^{2}$ The most profitable size of seed depends on the relative value of the seed and of the crop.

The number of eyes per piece above two is of little consequence. Each eye contains a number of buds. The

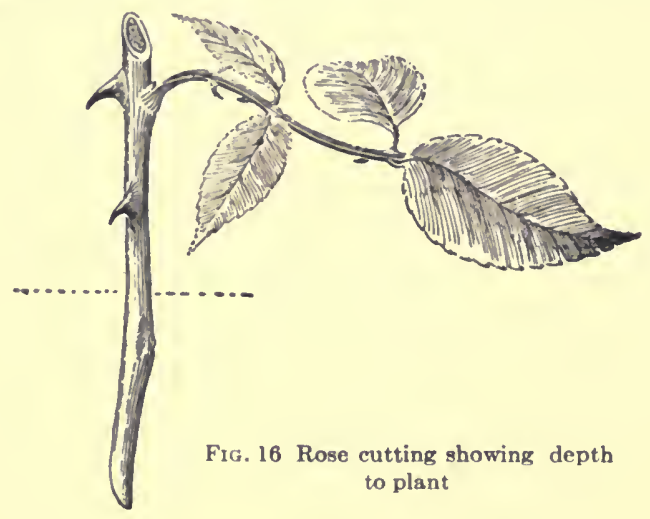

size of the piece determines the number of sprouts that it sends up. Only a small proportion of the buds sprout. Placing the potatoes in a well-lighted room some time before planting increases the yield. Sprouting in a dark room is harmful, as the sprouts produced are long and slender. If the potatoes are to be planted with a machine, the sprouts should only begin to appear before planting. For a few early potatoes, it is well to let the sprouts get

1Potato tubers are commonly called seed. They are seed in an agricultural sense, but, of course, not botanical seed.

2 Samuel Fraser, The Potato. 
an inch long, and then plant by hand. The Rhode Island station found a gain of fifty-four bushels per acre due to allowing potatoes to lie in a well-lighted room, at a temperature of 60 to 75 degrees Fahr., for four to six weeks.

The seed is best ${ }^{*}$ cut the day of planting, but may be cut on rainy days shortly before planting, to save time.

38. Cuttings. Nearly all herbaceous plants and many woody plants can be propagated from cut-

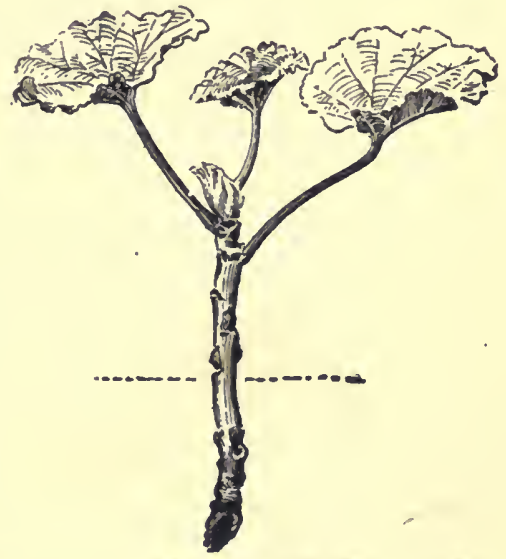

Fig. 17. Geranium cutting ready to plant tings. Alfalfa and clover plants may be so grown. Of course, this is not practical under ordinary circumstances; but alfalfa is sometimes propagated in this way by plantbreeders when they desire to multiply a desirable indi-

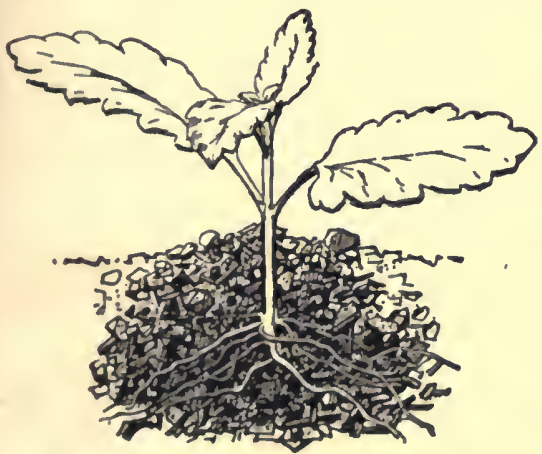

Fio. 18. Verbens cutting well rooted vidual. Most of our house-plants are propagated by cuttings. In some cases the leaves will grow, but usually stems are taken. Currants, grapes, willows, poplars, cottonwoods, are commonly propagated by cuttings.

Grape cuttings are 
made from wood of the preceding season's growth, usually with three buds on each cutting. These are planted with

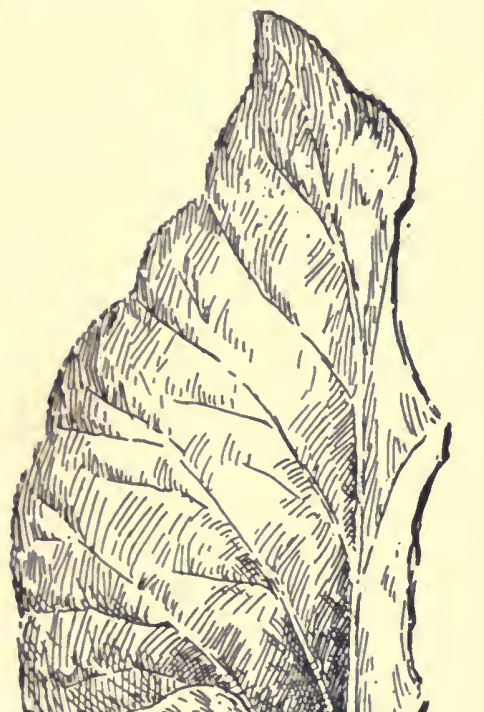

2. 1.

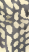

$=$

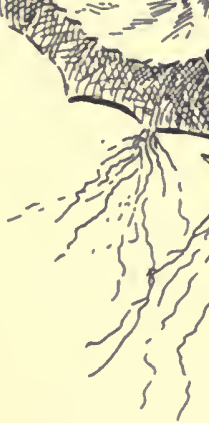

Fis; 19.

A leaf-cutting of begonia, well started two buds below the ground.

Currant cuttings are usually made about six inches long, and are set with one bud above ground.

The hardwood ${ }^{1}$ cuttings are usually made in winter, and are heeled-in out-ofdoors. They are sometimes packed in moist sand and kept in a cellar a little above freezing temperature, so that the ends become calloused over before planting.

39. Grafting.-Some plants do not readily form roots from the stems. These must be propagated from seeds, or by budding or grafting. All the tree fruits in Americaapples, pears, peaches, plums, cherries, oranges, etc. - are regularly grown from buds and grafts. Pecans and chestnuts are often grafted.

${ }^{1}$ Hardwood cuttings are those made of the mature wood, as grapes, currants, etc., as distinguished from green cuttings, as geraniums. 
Fruit trees have to be propagated in this way because they do not come true from the seed (page 23). It is also sometimes desirable to be able to take advantage of the previous growth of a tree, rather than to wait for a new one to grow. Top-grafts in an old apple tree may begin to bear the second year. In most regions it takes ten or more years for a young apple tree to reach bearing age.

The essential point in all budding and grafting is: that the cambium layers be placed together and held there until they unite. The cambium layer is the living and growing part between the wood and the bark.

40. Budding. A bud is cut as shown in Fig. 21.

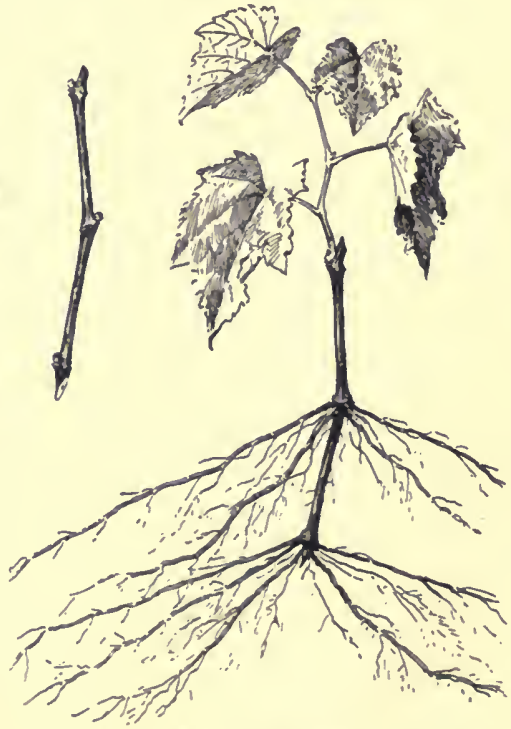

Fig. 20. A grape cutting and the same after one year's growth A T-shaped cut is then made in the plant to be budded, the bud is inserted and tied with raffia.

The life history of a peach tree before it is planted in the orchard is about as follows: The pits are stored in mbist sand or other material where they will freeze during the winter so that they will crack. These are planted in the spring. In June, or about September, the seedling tree is budded from a tree of the desired variety. The bud is inserted near the surface of the ground. After it has 
started growth, the raffia is cut, and the top cut off above the bud.

If the buds are inserted in the summer, they will grow during that season, but will not make a very large growth.

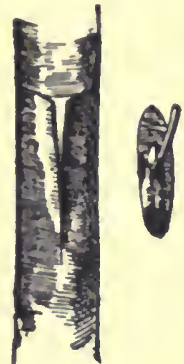

Fra. 21.
$A$ bud ready for insertion and the $\mathrm{T}$-shaped cut ready to receive it

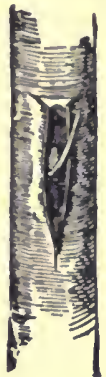

Fic. 22.

The bud inserted

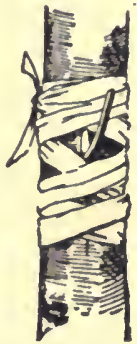

Frg. 23.

The budding completed

These trees are called "June buds." They are planted in the orchard the following spring.

If the buds are inserted in the fall, they unite with the tree but do not start growth until the following spring. Having a larger root and a long season, they make much larger trees than June buds. It takes two years to produce them, but they are in much greater demand than June buds.

Cherries and plums are propagated in the same manner as peaches.

Apple trees are usually root-grafted by the nurseryman in the Middle West, but are budded in the East. In either case, the seedling trees are usually produced by growers in the Middle West, who grow them for one year. These one-year-old seedlings are planted in the nursery and are budded the first spring. The trees are usually 
grown for two years in the nursery rowis, when they are ready for sale.

41. Root-Grafting. Seedling apples are grown for a year in a rich soil. They are dug in the fall. The root-grafts are made during the winter. After the fibers are removed from the roots, they are cut into pieces about two inches long. Smooth, one-year-old twigs of the desired variety are cut into about six-inch lengths called cions. A slanting cut is made on root and cion, and a slit is cut in each so that they will fit close together (Fig. 24). This makes three surfaces where the cambium layers meet. After being put together, they are wound with waxed cord. This holds the cambium layers so close together that they can unite. The wax on the cord holds it so that knots are unnecessary.

The root-grafts are put into bundles of about fifty, and are packed in sand in a cool cellar. By spring the cambium layers should be well calloused.

Peaches, cherries and plums are not often rootgrafted. They do not heal so readily as do apples and pears.
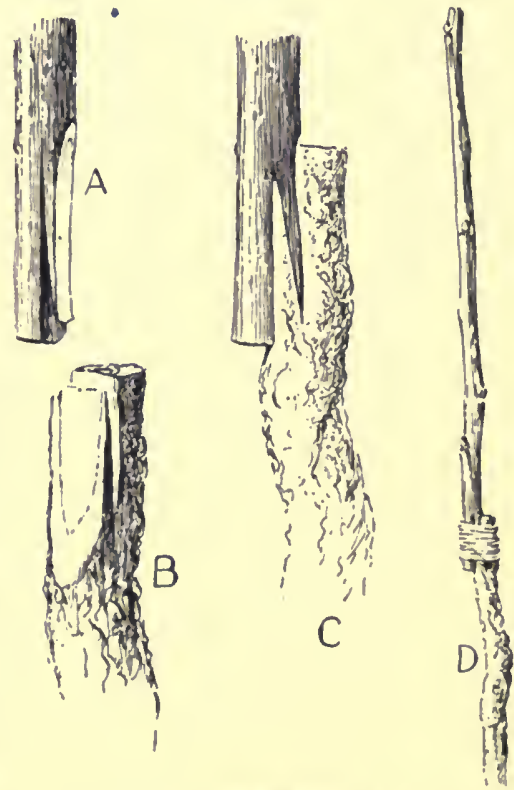

Fta. 24. Root-grafting. $A$, cion; $B$, root; $C$, Cion and root united, about natural size; $D$, Root-graft completed, much reduced in size. 
42. Top-grafting. This method is not very often used, except to work over large trees. For this purpose, limbs about one to two inches in diameter are sawed off. The cions are cut about four inches long, and are sharpened

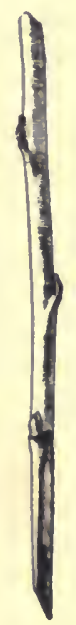

Fio. 25. Cion for a top-graft

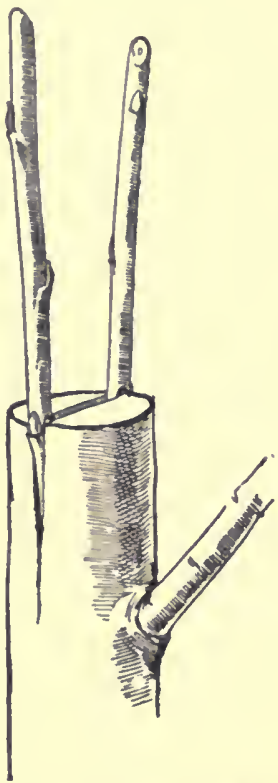

FIG, 26. Cions properly inserted for a top-graft

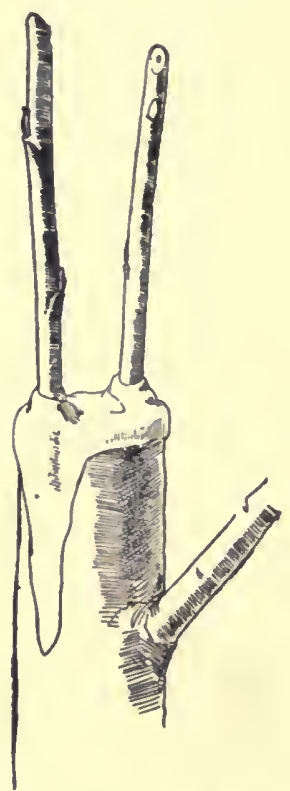

Fro. 27. A top-graft completed

on both sides wedge-shaped. One is put in at each side of the branch, care being taken to keep the cambium layers in contact. To be sure of a good contact, the cions are set at a slight angle, and may be cut thinner on the inside. The ends of the branch and the split sides are all carefully covered with grafting wax. Sometimes many varieties of apples are thus grown on one tree. 
43. Relationship of Cion and Root. Buds or grafts will seldom grow on roots of a very different kind. Apples will grow on pear roots, and pears on apple, but neither will grow on peach roots. Peaches will grow on plum roots.

44. Effect of Root on Cion. By grafting or budding, a sour apple may be grown on a root that would have produced a sweet apple. Early peaches may be grown on a root that would have grown late peaches. Many arguments have been made as to the effect of the root on the fruit. So long as the root is closely related to the cion, it has no appreciable effect on it. Fifty varieties of apples may be grown on the same tree, yet each will come true to its kind. This is what we would expect from the functions of roots. If the root furnishes the proper amount of soluble food from the soil, the top will not be affected. If the root does not furnish enough food, the tree may die or be dwarfed. Dwarf pear trees are secured by budding them on quince roots. Dwarf apple trees are produced by budding on the roots of the Doucin or Paradise apples, which are dwarfs.

\section{SEEDS}

45. Nature of Seeds. A seed consists of a young plant, or embryo, with a supply of food either in the embryo or surrounding it, all enclosed in the seed coats. The food is formed by the parent plant, and is stored up in the seed to give the young plant a start in life. Some seeds have a small amount of stored food, while others have enough to keep the young plant growing several 
weeks without having to prepare much food for itself. As the seedling develops, it gradually makes more and more of its own food, until finally the stored food is no longer needed.

\section{Importance of Vigorous Germina-} tion. The vigor of the embryo often limits the crop that is to be grown. Some kernels of corn germinate promptly and vigorously, others germinate slowly and form weak plants, others fail to germinate at all. Often a sced will have vigor

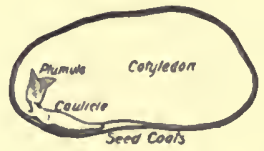

F10. 28

Section of a beanseed showing the cotyledon, plumule and cau licle which constitute the embryo. Food stored in the cotyledons. enough to start germination, but not enough to be able to establish itself in the soil. It is not enough that a seed germinate; it should germinate vigorously.

47. Germination Tests of Seed Corn. The Iowa Experiment Station examined 3,300 samples of seed corn

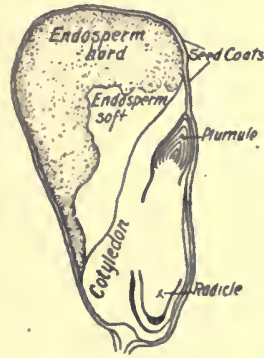

Fio. 29. Section of a kernel of corn. Food is stored in the cotyledon and in the endosperm which surrounds the embryo. for farmers in 1905. Of this number, an average of 19 per cent of the seed was entirely dead, and 21 per cent more was so weak as to be useless, leaving only 60 per cent of good seed. In the same year, counts of the number of stalks per hill were made in over one thousand corn fields. These showed an average of 66 per cent of a stand. ${ }^{1}$ This may have been an unfavorable season, but every year there is an enormous loss in yield of corn because of dead seed or weak seed.

The kernels on an ear of corn are usually about equally 



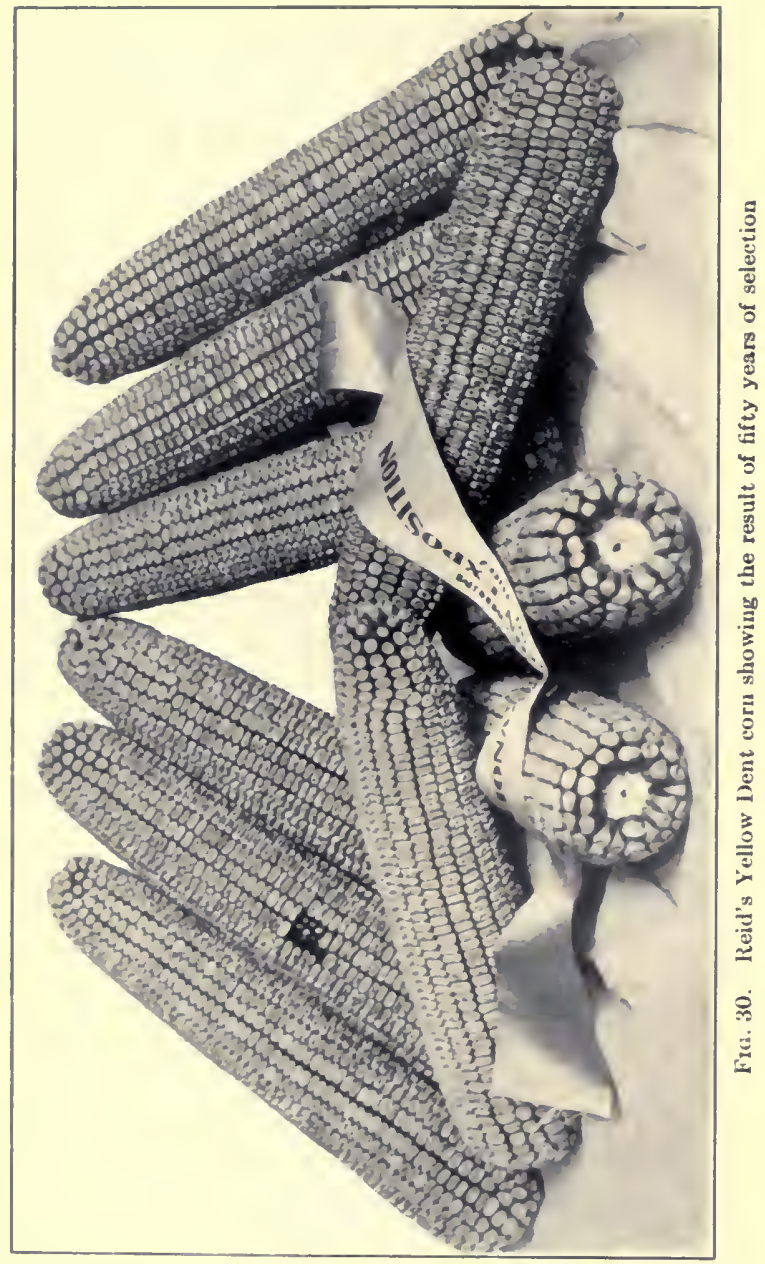


vigorous. Hence a test of a few kernels taken from different parts of the ear will give a fairly accurate idea of the ear. Since it takes only about a dozen ears to plant an acre, it is a very easy matier to test every ear. And, since one ear plants so large an area, it follows that a single ear that germinates poorly may decrease the yield of corn several bushels. One of the most important, as well as one of the easiest ways to increase the yield of corn is to test the vigor of every ear before planting, and use for seed only those that show a good germination test. The germination test should be made before the spring work begins.

Secure a box about two by three feet and six inches deep. Fill this half full of saw-dust, sand or soil. Take a white cloth a little larger than the box and rule into

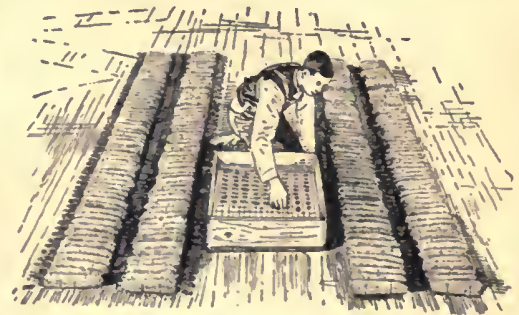

FIG. 31. Ears of corn laid out for germination test. (After Holden) squares with a lead pencil about one and one-half inches each way. Number each square. Lay this cloth over the sawdust or other material, and tack to the box in a few places. Put enough sawdust into a sack, so that it will fit into the box, and cover it an inch deep. Moisten the sawdust of the box and bag.

Lay out the ears of corn in rows on the floor or on shelves, and number them to correspond with the squares on the cloth in the box. Remove six kernels from each ear, taking them from different places on the ear. Put the kernels from ear 1 on square 1 , those from ear 2 on square 2 , etc. When all the kernels are in place, lay a 
piece of cloth over them and cover with the sack. Keep the box in a warm place and moisten it if necessary. The kernels will germinate in four to six days. Remove the cover carefully so as not to disturb the kernels, and examine.

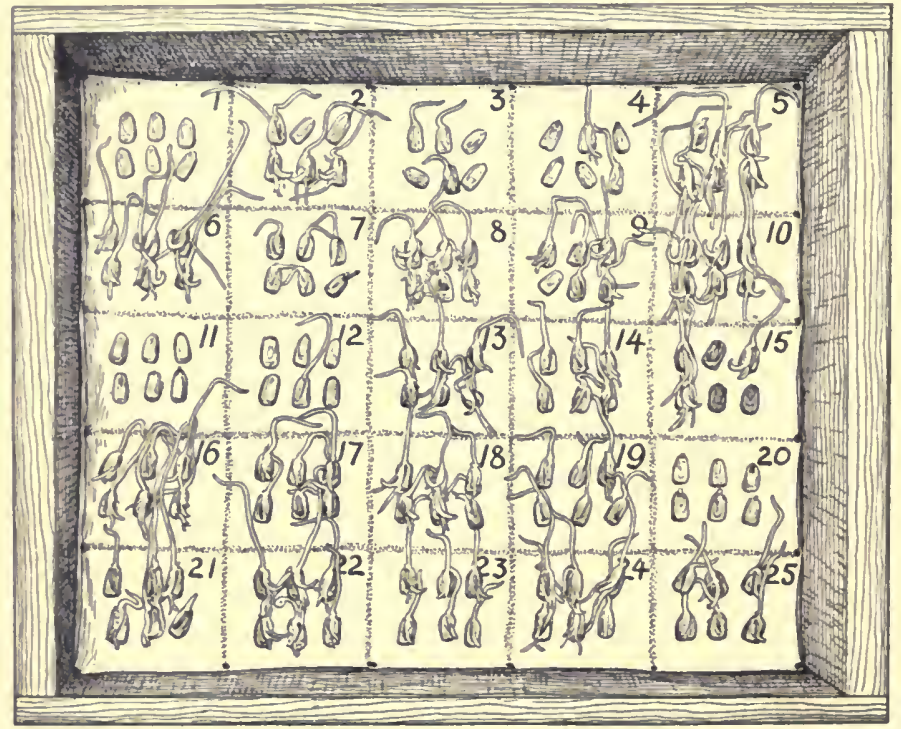

Fig. 32. Germination test of different ears of corn. Discard ears $1,2,3,4,5$, $7,9,11,12,15,20$

Fig. 32 shows the result of such a test. The kernels from ears 1, 11 and 20 all failed to grow. One or more of those from ears 2, 3, 4, 5, 9, 12 and 15 failed. The ears from which these came are all discarded. Kernels from ear 7 all germinated, but the growth is so weak that this ear is also discarcled. While making this test, the very best ears may be selected for an ear-row test. 
48. Seed Analysis and Valuation. Corn seed is always pure seed, but with other farm seeds there is another factor to consider, - the amount of weed seeds and dirt. This is more important with the small seeds, such as grass and clover, than with the larger seeds, such as wheat and oats. The small seeds are more likely to contain weeds, the weeds are more likely to escape notice, and are harder to remove from small seeds. A sample of seed may contain:

(1) Live, or viable seed.

(2) Dead seed.

(3) Seeds of other useful plants.

(4) Broken seeds, dirt, chaff, etc.

(5) Weed seeds of the kinds common in the region.

(6) Noxious weed seeds, even a few of which condemn the seed.

49. Germination Tests. Lay a moist blotter or a piece of moist cotton flannel on a plate. Count out one hundred seeds, just as they come. Put them on the blotter; cover with a piece of paper, and then with another moist blotter. Lay over this a piece of glass, or cover with an inverted

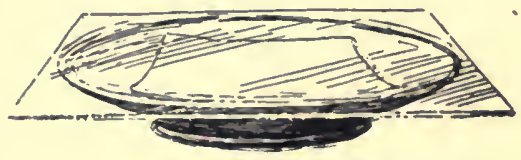
plate. Keep in a moderately warm place, and examine from time to time. Remove the sprouted seeds, and count them to get the per cent of germination. Several samples may be tested at one time on a plate (Fig. 33). 
50. Purity and Germination Test. For a more careful test, a sample is weighed. It is then separated into: (1) pure seed; (2) inert matter-dirt, broken seed, etc.; (3) weed seed. Each of these is weighed. The germinating power of the pure seed is then found. The per cent of purity multiplied by the per cent of germination gives the per cent of live or viable seed. If a sample of alfalf a seed contains 90 per cent of pure seed, and 90 per cent of this germinates, it contains 81 per cent of viable seed.

51. What is the Cheapest Seed. The cheapest seed is usually the most expensive. The following analyses show the extremes of low-grade, low-priced red clover seed, and high-grade, high-priced seed: ${ }^{1}$

Price per 100 pounds.

Weed seeds

Dirt, sticks, ete.

Red elover seed.

Red clover seed that germinated...........

Number weed seeds per pound

Actual cost of 100 pounds elover seed that

germinated

Red Clover Seed

Low Grade High Grade

$\$ 5.20$

$25.78 \%$

$26.16 \%$

$48.06 \%$

$18.26 \%$

139,727

(5)

$\$ 28.48$

$\$ 15.00$
$.09 \%$
$1.08 \%$
$98.83 \%$
$95.86 \%$
150

$\$ 15.65$

The seed that could be purchased for $\$ 5.20$ per hundred pounds was nearly twice as expensive as the seed that cost $\$ 15$ per hundred, because it contained so little live seed. The low-grade seed should not have been sown at any price, because of the weed seeds. If one sowed such seed at the usual rate of sowing, he would not only fail to get a good stand of clover, but would be sowing weeds. 
If one sample of seed contains 90 per cent of live seed and costs $\$ 9$, and another sample contains 80 per cent of viable seed and costs $\$ 8$, they would appear to be equally cheap. But the former sample is to be preferred, because, if a sample germinates poorly, we may expect

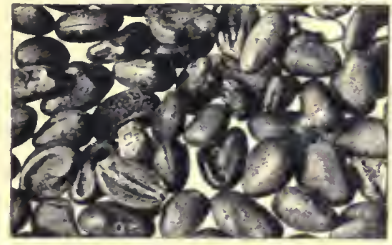

Fig. 34. Poor clover seed containing many weeds

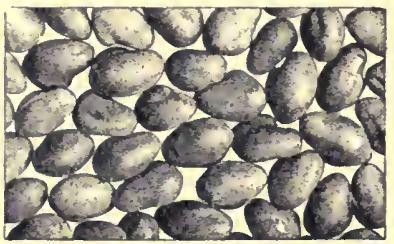

Fig. 35. Good pure clover seed

that the same causes that killed many of the seeds weakened all the others.

There is one case in which the cheaper seed might be best, and that is, if the other contained seed of some very serious weed that was not present in the cheaper kind.

52. Size and Weight of Seeds. Many experiments have been tried with large and small seeds, and with seeds of high and low specific gravity. In the majority of trials, the larger and heavier seeds have proved best. Usually the small seeds are lighter for their size, or have a less specific gravity, than the large seeds.

Heavy cotton seed separated by an air-blast was grown in comparison with unseparated seed at Lamar and Hartsville, S. C., in 1906. ${ }^{1}$ At each place, equal areas of about an acre were planted with each kind of seed. The average yields of cotton were:

Heavy seed.....................1,106 pounds

Unseparated seed ..................1,010 pounds

'Farmers' Bulletin No. 285 
At the Nebraska station, where equal weights of wheat were used for eight years, the light seeds gave practically the same yield as the heavy. Similar results were obtained in Ohio and Kansas.

An ordinary fanning-mill is of use in removing weed seeds, and to some extent in removing the lightest seeds: It does not usually remove the moderately light ones. Probably the removal of the weed seeds is the most valuable result.

53. Seed Testing Is Plant Selection. All seed selection, whether it be for germination or size and weight of seeds, is really plant selection. The seed is a plant. Its size and the vigor of its germination are some of the first evidences of its individual characteristics. Seed selection is one step in plant-breeding.

54. Storage of Seed. We must always remember that seeds are alive. It is true that they are dormant, and can stand some adverse conditions, but they are not immune from injury. One of the chief causes for the poor germination of Kentucky blue grass seed is the heating during the curing process. Any seed that smells musty needs to be tested before being accepted.

Seed corn is not hurt by freezing when it is very dry, but in many parts of the United States it will absorb enough water from the atmosphere so that freezing will damage it. Except in dry regions, the seed corn should be stored in a warm room. A good method of storing is to tie up with binder twine (Fig. 36) and hang in the attic. If there is danger of a frost before the corn is thoroughly dry in the fall, the seed corn should be husked and hung up in a dry room before freezing weather. 
Light frosts will not hurt it while it is on the stalks. Seed corn should never freeze when moist.

55. Importation of Low-Grade Seed. The United States exports large quantities of clover seed, and imports smaller quantities of low-grade seed. One reason for this is that Canada and most of the European countries have laws

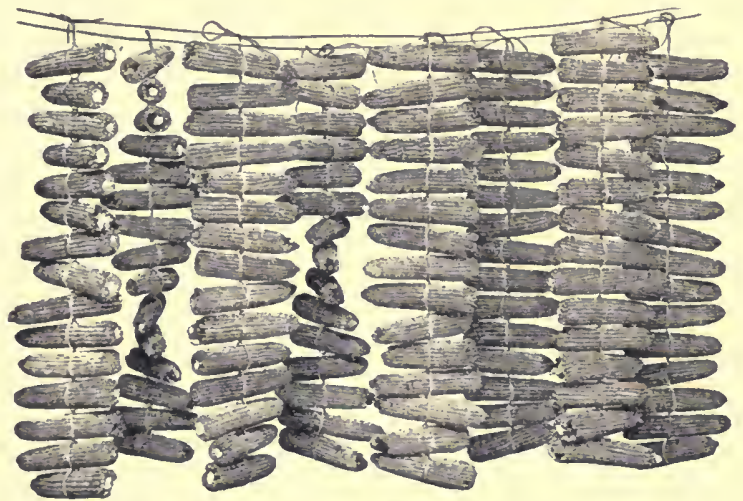

Fig. 36. Method of drying seed corn. (After Holden.)

for seed inspection. Screenings, very weedy seed, or seed of low vitality cannot be sold, but can be exported from those countries. We shall probably have laws for seed inspection in this country in the future. In the meantime, every farmer will have to examine his own seed, or send it to the State Experiment Station for examination.

\section{QUESTIONS}

1. Make a list of all the important farm plants of your region and tell how each is propagated.

2. Do you know of any fruit trees that bear two kinds of fruit?

3 . Give the life history of the apple tree from the time the seed is planted until the tree is set in the orchard. 
4. What time of year is it easiest to make willow whistles? Why?

5. What beeomes of a nail that is driven into a tree? Why?

6. Do farmers in your region grow their own fruit trees? Grapevines? Currant bushes? Would it pay them to do so?

7. What seeds are shipped out of your region for seed purpose?

8. What seeds are shipped into the region?

9. What bad weeds in your region have come with the seed?

10. How do the farmers of the region store their seed corn?

11. Is there any trouble in getting a good stand of corn? Was the stand good this year? Count the stalks in a short row and determine the per cent of a stand.

12. Which grow most rapidly at first, plants from large seeds like beans or those from small seeds like radishes?

13. Does the fanning-mill or air-blast separate seeds on the basis of weight or of specific gravity?

14. How long do some of the more important seeds of your section retain their vitality? (See Appenctix, Table 4.)

15. What are the legal weights per bushel of a few of the more important products in your section? (See Appendix, Table 5.)

\section{LABORATORY EXERCISES}

\section{Spores.}

Materials. - Compound microscope, corn smut, oat smut or spores of any other kind.

Examine the spores $(\times 500)$. Make drawings of them. How do they produce new plants?

12. Relation of Habit of Growth of a Grass to its Value for Hay or Pasture.

Field Trip.-What are the best pasture grasses in the region? Examine thein to see whether they are strongly stoloniferous. The stolon always arises from within the leaf sheath; if it remains there, its growth is intravaginal. If it breaks through the leaf sheath, it is called extravaginal. Which way do the stolons of these pasture grasses develop? What are the best hay grasses of the region? Fxamine them in the same manner.

\section{To Make Grafting-wax and Waxed String.}

Materials.-One pound resin, one-hslf pound beeswax, one-fourth pound tallow, one ball of No. 18 knitting cotton. Larger or smaller 2mounts for classes above or below ten. 
Pulverize the resin; melt all the materials together. Drop the ball of cotton into the melted wax. Remove in about five minutes, and you will have waxed string ready for making root grafts. Pour the wax into cold water. Grease the hands and pull and work the wax until it becomes of a straw color.

\section{Cambium Layer.}

Materials.-Twigs several years old taken from any tree. Make a drawing of a cross-section of the twig, and indicate: (1) The pith; (2) annual rings; (3) cambium layer; (4) bark. The cambium layer is the layer between the wood and the bark. It is this layer that breaks apart when the bark is removed. Why is the bark more easily removed in summer than in winter? How old is the twig? Why is there a ring at the close of each year's growth? Is the wood in the inner or the outer part of the ring the harder?

\section{To Make a Root Graft.}

Materials.-Waxed string prepared in No. 13. Seedling apple trees one or two years old. Smooth, one-year-old twigs from apple trees of the desired variety.

Let each student make about twenty-five or more root grafts according to directions (page 45). These may be taken home to be planted. They should be packed in sand and kept moist and cool until spring. The school can raise its own seedling apples, peaches, etc., or may get students to raise them.

\section{To Bud a Tree.}

Materials.-Raffia, knives, growing trees. If possiblc, have important trees of the region.

Cut the buds as shown in Fig. 21. Make the T-shaped cut through the bark of the tree. Lift the bark carefully and insert the bud. Tie firmly with raffia.

\section{To Top-graft a Tree.}

Materials.-Saw, knife, chisel, hammer, grafting wax, apple trees or other trees.

Perform the operation as directed (page 46). If possible, this should be done on a tree; but limbs of trees may be used in the laboratory to teach the method if outdoor work cannot be given.

\section{To Make Hard Wood Cuttings.}

Materinls.-Stems of grapes, currants, willows, or other woody plants of the region. 
Make the cuttings as described (page 42). Each student should make a number of useful ones to be planted at home.

\section{The Bean Embryo.}

Materials.-Beans soaked for a day, enough to supply each student with several.

Make a drawing of the split bean showing the cotyledons, plumule and radicle. Indicate each part. How many parts are there to a bean seed? What is the function of each part? Which parts make up the embryo? In what part is the food stored? What parts come above ground when the bean grows? Is the plant monocotyledonous or dicotyledonous?

\section{The Kernel of Corn.}

Materials.-Corn soaked for a day in cold water, or for twenty minutes in hot water.

Cut the tip from a kernel of corn and make a drawing of the cross section. Indicate the endosperm, cotyledons or scutellum, plumule (or radiele if eut very close to the top). Split a kernel of corn the narrow way and one the broad way. Make drawings of each and indicate the parts. Is the food stored in the embryo, as in the ease of the bean? What parts come above ground when the corn grows? Is the corn monocotyledonous or dicotyledonous?

\section{Germination Test of Corn.}

Materials.-Germination box and fifty or more ears of corn.

Make the test as deseribed (page 49). Compare the appearance of ears that germinated well and that germinated poorly. Are there any ways of distinguishing them? Make cross-sections of kernels from each class. Compare the appearance of the embryos, or "chits." The more vigorous kernels usually have a bright, "eheerful" appearance, are plump and full at the tips, and have a large cream-colored germ. See how well you ean determine the germination in advance by these characters.

\section{Analysis of Clover Seed.}

Materials.-Balances weighing to centigrams or milligrams, and hand-lenses. Two samples of clover seed with the prices. Alfalfa, timothy or other small seeds may be used.

Weigh out a one-gram sample of the seed. Separate it into: (1) pure seed; (2) inert matter, broken seed, dirt, etc.; (3) weed seeds. Weigh each. Make a germination test of the pure seeds as 
directed (page 51). Repeat for the second sample. Record the results in the note-book as follows:

Weight of sample

Weight of pure seed.

\begin{tabular}{c|c}
$\begin{array}{c}\text { First } \\
\text { Sample }\end{array}$ & $\begin{array}{c}\text { Second } \\
\text { Sample }\end{array}$ \\
\cline { 1 - 1 } 1 gram & 1 gram
\end{tabular}

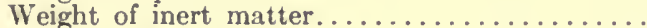

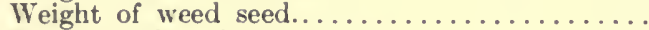

Per cent of purity.

Per cent of germination.

Per cent of pure viable seed

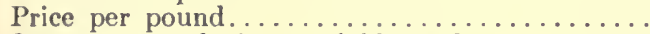

Cost per pound of pure viable seed.

If the school has a set of weed seeds, identify the kinds present and the number of seeds of each kind.

Which sample of seed would it be best to purchase? Why?

\section{Storage of Seed Corn.}

Collect a hundred ears of corn in the fall before it has been frozen. Store fifty in a dry moderately warm room. Leave the others in a corncrib. Next spring make a germination test of each sample.

\section{COLLATERAL READING}

Seed of Red Clover and Its Impurities. Farmers' Bulletin No. 260.

The Production of Good Seed Corn. Farmers' Bulletin No. 229, pp. 17-20.

The Farmer's Interest in Good Seed. Farmers' Bulletin No. 111.

Alfalfa Seed. Farmers' Bulletin No. 194.

The Advantages of Planting Heavy Cotton Seed. Farmers' Bulletin No. 286.

Office of Experiment Stations, United States Department of Agriculture, Bulletin No. 186.

The School Garden. Farmers' Bulletin No. 218.

Forage and Fiber Crops in America. Pp. 15-23.

Cereals in America. Pp. 197-201.

Cyclopedia of American Agriculture. Vol. I, pp. 131-152. 


\section{CHAPTER IV}

\section{PLANT FOOD}

"I dropped at seed into the earth. It grew, and the plant was mine. It was a wonderful thing, this plant of mine. I did not know its name, and the plant did not bloom. All I know is that I planted something apparently as lifeless as a grain of sand and that there eame forth a green and living thing, unlike the seed, unlike the soil in which it stood, unlike the air into which it grew. No one could tell me why it grew, nor how. It had seerets all its own, secrets that baffle the wisest men; yet this plant was my friend. It faded when I withheld the light, it withered when I negleeted to give it water, it flourished when I supplied its simple needs. One week I went away on a vacation, and when I returned the plant was dead; and I missed it."'

\section{Elements Required for Plant and Animal Growth. ${ }^{2}$} Of the seventy different chemical elements, only thirteen are usually found in plants and animals. These elements are:

$\begin{array}{ll}\text { Oxygen } & \text { Caleium } \\ \text { Hydrogen } & \text { Magnesium } \\ \text { Nitrogen } & \text { Iron } \\ \text { Carbon } & \text { Chlorin } \\ \text { Sulfur } & \text { Sodium } \\ \text { Phosphorus } & \text { Silicon } \\ \text { Potassium } & \end{array}$

Only the first ten of these are considered necessary for plant growth, but the last three are always found in plants, and may serve some useful purpose. Manganese and one or two other elements occur, but are not essential.

IL. H. Bailey. Junior Naturalist Monthly. February, 1903.

If the class has not studied chemistry, a few elementary lessons on this subject should precede this chapter, sce manual. 
Since all animals live on plants, either directly or indirectly, they are composed of these same elements. The salt and water that an animal uses only adds to the amount of sodium, chlorin, hydrogen, and oxygen that the plants furnish.

If any one of the first ten elements is lacking, the plant will die. Of some, very small quantities are required, but this small amount is necessary. Many experiments have been performed to test this. Plants have been grown in distilled water to which all these elements but one have been added. Fig. 51 shows such a wheat plant which had all the elements of plant food except nitrogen. The same results are obtained when any nine are furnished, but the tenth omitted. The carbon is furnished by the air, so that is not put into the water. The legumes are also able to take nitrogen from the air under certain conditions.

57. Sources of Plant Food. For a long time no one knew where the plant got its food. Some argued that its food came from the air, and others thought it came from the 'soil. Only within the last fifty years has the question been entirely answered. We now know that a plant secures its food from both the soil and the air,-the larger part coming from the air.

Oxygen and hydrogen, chemically united in the form of water, are taken up by the roots from the soil, but all water comes indirectly from the air.

The carbon is obtained from the air by the leaves in the form of carbon dioxid.

The nitrogen comes from the soil, except in the case of legumes, which are able to take nitrogen from both 
the air and the soil (page 116). However, the ultimate source of all nitrogen is from the air. The nitrogen of the soil was obtained from the air (page 116).

58. Water, Dry Matter and Ash. If a plant is heated for some time at a temperature a little above boiling, the water is driven off. By weighing before and after drying, the percentages of water and of dry matter are determined. When the dry matter is heated very hot, a part of it burns and leaves ash. The ash contains all the potassium, magnesium, calcium, iron, phosphorus, chlorin, sodium and silicon of the plant, and some of the sulfur. The ash, therefore, contains all the material that came

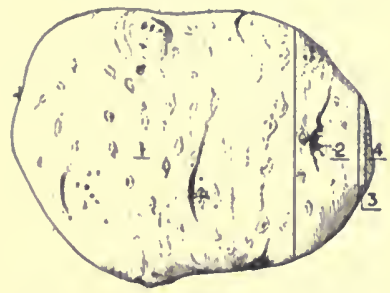

FIG. 37. Composition of the potato: 1, Water; 2, compounds of rarbon, hydrogen and oxygen, chiefly starch: 3 , nit rogen; 4 , all other elements

from the soil, except part of the sulfur, and the nitrogen.

59. Relative Amounts of the Different Elements in Plants. Oxygen and hydrogen, chemically united in the form of water, make up the largest part of all growing plants. Turnips, beets and pumpkins are about nine-tenths water. They contain a larger percentage of water than does milk. The percentage of water is much less in hay or grain, but few plant products contain less than 10 per cent of water, even when air-dry.

Hydrogen and oxygen are also contained in other compounds of the plant. In these compounds they make up about 40 per cent of the dry matter.

Carbon is next in importance. About half of the dry matter is carbon. 
Nitrogen sometimes makes as high as 4 per cent of the dry matter.

No other element occurs in nearly so large an amount, and the amount of most of them is very small indeed. It may not require over a pound of iron to grow an acre of hay, but this iron is absolutely necessary. How small a part of the plant's substance is obtained from the soil is shown by the following table. Only one pound in a hundred of turnips comes from the solid matter of the soil, and a little over 3 per cent of the grain of corn:

Proportions of Different Elements in Plants

\begin{tabular}{|c|c|c|c|c|}
\hline & $\begin{array}{l}\text { Corn } \\
\text { Grain }\end{array}$ & $\left|\begin{array}{c}\text { Green Corn } \\
\text { Fodder }\end{array}\right|$ & Turnips & $\underset{\text { Hay }}{\text { Timothy }}$ \\
\hline $\begin{array}{l}\text { Water (hydrogen and oxygen) } \\
\text { Carbon, hydrogen and oxygen }\end{array}$ & $\begin{array}{c}\text { Per cent } \\
10.6\end{array}$ & $\begin{array}{c}\text { Per cent } \\
79.3\end{array}$ & $\begin{array}{c}\text { Per cent } \\
90.5\end{array}$ & $\begin{array}{c}\text { Per cent } \\
13.2\end{array}$ \\
\hline in eompounds ............ & 86.1 & 19.2 & 8.5 & 81.4 \\
\hline Nitrogen............. & 1.6 & 0.3 & 0.2 & 0.9 \\
\hline All other elements ......... & 1.7 & 1.2 & 0.8 & 4.5 \\
\hline
\end{tabular}

60. Elements Likely to Be Deficient in Soils. Since ten elements are absolutely necessary for plant growth, if any one of these does not occur in sufficient quantities, the crop will suffer. Hydrogen and oxygen (in the form of water), nitrogen, phosphorus, potassium and sometimes calcium, are not always available in sufficient quantities for the production of good crops. The other elements are practically always present in abundance.

Water is most frequently the factor that limits the size of the crop. It is increased or conserved by irrigation, tillage and other farm operations.

61. Functions of the Different Elements. Some textbooks of botany mention iron as the element necessary 
fol formation of chlorophyll, but it is no more necessary than phosphorus and magnesium, and probably all the other elements have to do with it either directly or indirectly. A farmer interprets a light green color as indicating a lack of nitrogen,- not of iron. Plants that have an abundance of manure, or nitrogenous fertilizers, are dark green, while those that do not have enough nitrogen are light green. An abundance of nitrogen promotes growth and leafiness in plants. Too much nitrogen makes oats grow so rapidly that they are likely to fall down, hence, manure

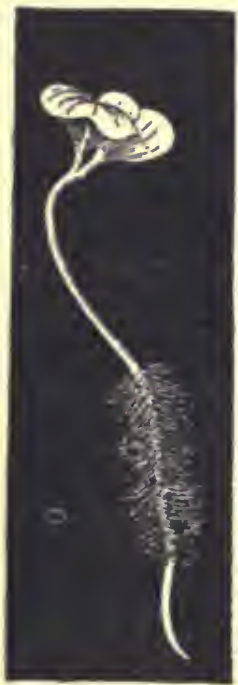

Fig. 38.

Root-hairs of a radish. These absorb most of the water for the plant. or nitrogen, in fertilizers, is not often applied on oats. A shortage of phosphorus and potassium is more likely to show in poorly filled seeds than in lack of vigor of growth. But we cannot separate out one particular element and say that it has one specific function and that one only.

\section{HOW THE PLANT GETS ITS FOOD}

62. Root-Hairs. Germinate some oats or clover seed as directed on page 51 . Examine the young roots for root-hairs. The root is fairly covered with these minute hairs, as in Fig. 38. These hairs are not young roots. They are singlecelled tubes that absorb the soil solution. Remove one of these seedlings, and see how easily these root-hairs are destroyed when handled. It would, of course, be very difficult to remove a plant 
from the soil without destroying them. The roots take some part in absorbing the soil solution, but the roothairs do most of this work.

63. Osmosis. Tie a piece of parchment or a piece of bladder over the end of a thistle tube. Fill this with a strong solution of salt. Invert in water so that the height of the water and the solution are the same. Allow this to stand for some time and observe the result. The height of the water in the tube rises above that outside the tube. This shows that the water has passed through the membrane more rapidly than the salt solution. The water passes through the membrane more readily than the denser solution.

Pare a potato and cut slices from it. Place some of these in water and some in a strong solution of salt. Examine in about an hour. The pieces in water will be found very plump and rigid. This shows that water passes into the

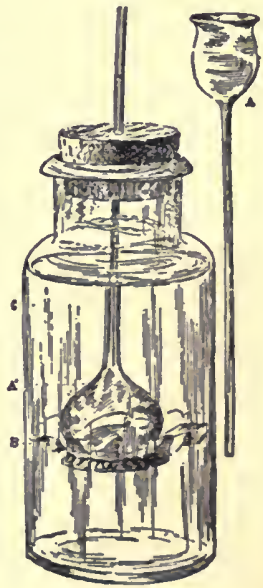

Fig. 39.

Apparatus ready for osmosis experiment to show how root-hairs take in soil-water. potato faster than the sap passes out of it. The pieces in the salt solution will be flexible or wilted. This shows that the concentrated salt solution did not pass into the potato cells so fast as the cell sap was lost. The potato "wilts" when immersed in salt solution.

The process of the interchange of fluids, either liquids or gases, through a membrane is called osmosis. Whenever a plant or animal membrane separates two solutions, there is an interchange of the two. The less dense the solution, 
the more rapidly the water passes through the membrane. The solutions in the root-hairs are more dense than the soil solutions, hence more water passes into the root than passes out into the soil. If extremely strong fertilizer is used, the soil solution may be so concentrated as to cause) more water to leave the root than enters it. In this case, the plant will wilt and may be killed. An excess of any plant food in solution may thus kill plants. The alkali soils of arid regions often contain so much soluble material as to prevent the growth of plants.

Some of the cell sap does pass from the roots to the soil. This cell-sap is slightly acid, so it helps to make more of the material in the soil soluble. The acidity of a root may be easily shown by pressing the root of a sprouting seed against blue litmus paper.

If a plant were a dead thing, the solution in the cells would eventually become of the same density as the soil solution, so that the moisture would pass out of the roots as rapidly as it passed into them. But the plant cells are alive. The leaves are constantly using such of the materials in the cell-sap as are needed for the manufacture of plant tissues. They remove the surplus water by transpiration.

The transpiration keeps the cell-sap of the leaves and upper parts of the plant densest, so that the balance of osmotic movement is always upward.

The plant foods are not taken up as elements, but in compounds. Nitrogen constitutes four-fifths of the atmosphere, but it is in the form of an element. No plant can take up nitrogen except when it is combined with other elements. It is taken up in soil solutions in the form of nitrates. No solid particles can be taken up by 
the roots. Only soluble materials can pass through membranes by osmosis.

64. Importance of Water. Water not only constitutes about nine-tenths of the growing plant, but it acts as the carrier of all the other food materials except the carbon.

The enormous amount of water that passes through a plant in bringing the food from the soil was determined in Wisconsin by King, and is shown in the following table:

Amount of Water Lost by Transpiration and Evaporation for Each Ton of Dry Matter in the Crop

Corn .............. 310 tons, equal to 2.64 inches rainfall Red clover.........453 tons, equal to 4.03 inches rainfall Barley ...............393 tons, equal to 3.43 inches rainfall Oats.............522 tons, equal to 4.76 inches rainfall Potatoes ..........423 tons, equal to 3.73 inches rainfall

In producing a ton of clover hay, which is 85 per cent dry matter, 375 tons of water are lost by transpiration and evaporation. It will be seen that oats require more water than any other crop, a fact that is observed by farmers.

65. How the Plant Gets Its Food from the Air. Over half the dry matter of a plant is carbon. The small amount of carbon di-

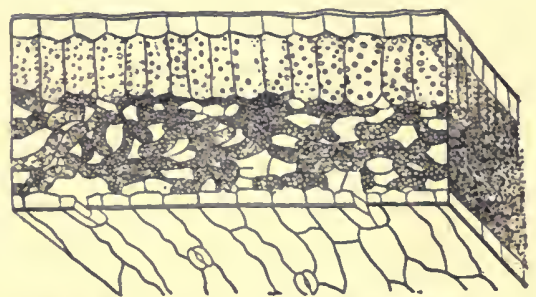

Fig. 40. Section of a leaf showing the breathing pores and intercellular spaces. The small dots are chlorophyll grains. oxid in the air, about three parts in ten thousand, furnishes all the carbon. With the air, the carbon dioxid passes into the intercellular spaces through the breathing pores, stomata, of the leaves. (Fig. 40.) When it is in 
the intercellular spaces, it is still outside the cells where the food is manufactured. It passes through the cellwalls by osmosis. Within the leaf cells the carbon is removed and united with the nutrients brought up by the roots to form starch and other plant foods. The surplus oxygen passes back into the intercellular spaces by osmosis, and thence through the breathing pores to the air.

\section{THE MANUFACTURE OF FOOD MATERIALS}

66. Carbohydrates. The most abundant food material that is built up by the plant is starch. This is a compound of carbon, hydrogen and oxygen $\left(\mathrm{C}_{6} \mathrm{H}_{10} \mathrm{O}_{5}\right)$. Starch is formed only in sunlight, and then only by green plants. The chlorophyll plays an important part in its manufacture.

Starch is insoluble, and hence cannot move through the cell walls. But the plant can readily change it to sugar and other soluble substances, so that it can be transferred. It can then be reconverted into starch. These changes are independent of light. The starch formed in potato leaves can be changed to sugar, transferred to the tubers helow ground, and there reconverted into starch. When these tubers sprout the next year, the starch is again changed to soluble compounds. All these compounds are carbohydrates. Chemically, they are distinguished from other compounds of carbon, hydrogen and oxygen, in that they contain the hydrogen and oxygen atoms in the proportion of two to one,-that is the proportion of water $\left(\mathrm{H}_{2} \mathrm{O}\right)$. This is why they are-called hydrates. Some of the other important foods that plants form are fats and protein.

67. Fats. The fats differ from starch and sugar in hav- 
ing a higher percentage of carbon. They are more concentrated than starch. When burned, one pound of fat produces about two and one-fourth times as much heat as is produced by a pound of starch or sugar. One pound of fat is equal to about two and one-fourth pounds of starch or sugar as a food for plants or animals.

68. Protein is a term used to cover a large number of different compounds. They all contain nitrogen. They may be more properly called nitrogenous compounds. They are chiefly composed of carbon, hydrogen, oxygen and nitrogen. Most of them contain phosphorus, sulfur and other elements.

69. Plants the Only'Source of These Foods. None of these compounds can be made in any way except by plants. A chemist cannot get the carbon, hydrogen and oxygen to unite, so as to form starch. Therefore, all animal life depends on plant life.

70. Stored Food. The food that is stored in a plant is nearly always in insoluble compounds, such as starch, oils, insoluble forms of protein. In this form it is less easily damaged.

71. Periods in the Life of a Plant. There are two rather distinct periods in the life of a plant: (1) The period of growth and formation of food; (2) the period of reproduction.

These stages are very marked in some plants, as turnips, that grow and store up food during one season, and that transfer the food to the seeds during the next season, and then die.

With trees the stages are less marked. It is a wellknown fact among fruit-growers that' a good growth for 
the formation and development of buds is necessary for a crop the following year. We grow much of the apple crop the year hefore we pick it. Food is stored in the twigs, so that the blossoms and fruit can have an available supply for growth in the following season.

One of the sure ways to kill any weed is to keep it cut off, so that it cannot have green leaves for starch formation. It will eventually exhaust the stored food in the roots and starve to death.

The asparagus crop is grown from food that was stored in the roots the preceding year. Many growers of asparagus fertilize the crop in the spring, thinking that it helps that year's crop. But, since the plant is not allowed to produce enough green top to prepare food, the fertilizer can bring no good results the year that it is applied. Field experiments have verified this conclusion. An asparagus bed was divided into two plots of one-half acre each. One-half was fertilized in the early spring and one-half was not. The fertilized area yielded 460 pounds, and the unfertilized $448 .^{1}$ But, when the crop of the following year was measured, the fertilizer showed a marked result. The time to fertilize the asparagus crop is when cutting ceases, unless some material is used that needs time to decay. The crop is grown and stored in the roots the year before we harvest it.

Many plants are killed or seriously weakened by the formation of seed. Rye is sometimes pastured during the first summer, and allowed to go to seed during the second year. But, if allowed to form seed the first year, it dies as the seed ripens. Red clover is much weakened by form-

${ }^{1}$ Delaware Report 1902, p. 90. 
ing seed. The stand of clover is much better maintained if the crop is cut for hay before the seed has ripened, unless the stand is kept up by the growth of new plants from seed that scatters in the field.

72. Effect of the Time of Harvesting on Composition. Annual plants take up nearly all their nitrogen and mineral matter in their early stages of growth. But the starch and other organic compounds are more largely accumulated in the later stages. This is one reason why plants require so much available food in the soil during the early stages of growth. (See Fig. 90.)

When spring wheat is half grown, it contains about 85 per cent of the total nitrogen that is required for the crop, and 75 per cent of the total mineral matter, but it contains only 40 per cent of the organic compounds.

When clover is in full bloom, it contains as much dry matter as when ripe, and more nitrogen and mineral elements. Slight amounts of these are returned to the soil in the later stages. ${ }^{1}$

Any condition that checks the growth of plants before maturity will, therefore, affect the composition of the crop. If dry weather or a lack of food supply check the growth of wheat, it will have a higher percentage of nitrogen and a lower percentage of starch than if it matured naturally.

\section{QUESTIONS}

1. Why is the soil about a tree lifted?

2. How many tons of corn, grain and stalks, is an average crop per acre in your community? Assuming the Wisconsin figures to apply, how many tons of water would be evaporated from the corn leaves on an acre?

${ }^{1}$ H. Snyder, Chemistry of Plant and Animal Life. Chapter 26. 
3. Account for the sweet taste of germinating eorn.

4. What difference in composition would you expect to find between whest of the semi-arid regions and of the humid regions? Why?

6. Which most frequently limits the size of the erop in your community, water or one of the other plant foods?

7. Which would be better for feed, the straw of oats eut when somewhat green or when ripe? Why?

8. Following a dew, a wilted plant often "freshens." Why?

9. Why should orehards be well eared for in the years when no erops are borne?

10. What allowance is made for water in buying ear corn in the early winter?

11. Why do stored potatoes shrink so much more than grain?

12. Explain the comparative effect of plants and animals on the amount of earbon dioxid in the air.

13. Of two seeds the same size, one an oily seed and one a starchy seed, which would probably grow more rapidly? Why?

\section{LABORATORY EXERCISES}

\section{The Percentages of Water, Dry Matter and Ash in Plants.}

Materials.-Balanees weighing to centigrams, erueible or other small dish that will stand heating, corn grain, potatoes, some growing plant.

Place each one in a weighed dish, heat a little above the boiling temperature for one hour or more. If the school has a drying oven, run it at $110^{\circ} \mathrm{C}$. Weigh again, then burn by heating very hot and weigh. Record the results as follows:

Weight of dish

Weight of dish and speeimen .......

Weight of specimens............

Weight of dried specimens. . . . . . .

Per eent of water...............

Per cent of dry matter

Weight of dish and ash

Weight of ash.

(n)

Per cent of ash.

\begin{tabular}{l|l} 
Corn & Potatoes \\
\hline & \\
\end{tabular}




\section{Osmosis.}

Materials.-Potato, thistle tube, parchment paper, bladder, salt. Perform the experiment described on page 65.

\section{Root-Hairs.}

Materials.-Compound microseope, roots of oats, elover or other seeds germinated between blotters. (Page 64.)

Examine the root-hairs and make drawings of them. How many celled are they? How do they differ from roots?

\section{Stored Food in Twigs.}

During the winter collect some branches of trees two or three feet long. Place them in water, change the water oecasionally. Note how much growth takes place. Where did the food material come from? What relation has this to orchard management?

\section{Tests for Proteids.}

Materials.-Nitric acid, ammonia, seeds.

All proteids (and a few other substances) are turned yellow by nitric acid. This is why one's fingers are made yellow when working with nitric acid in the laboratory. This yellow color becomes deeper when moistened with ammonia.

Cut several eross sections of corn, beans and other seeds. Make the protein tests. Which part of the kernel of eorn eontains the most protein? Do beans or corn appear to contain the larger amount?

\section{Tests for Starch.}

\section{Materials.-Iodin solution, seeds.}

Test corn, beans and other seeds for starch. Which part of the kernel of corn contains most starch?

\section{Microscopic Examination of Starch.}

Materials.-Compound mieroscope, iodin solution, eorn, potatoes, etc.

Examine sections of corn and potatnes. ( $X$ about 500.)

Make drawings of the starch grains. Compare the shapes and sizes from different plants. Notice how the grains are arranged in the cells. Add a drop of iodin solution to the different slides and note the effect. 


\section{Starch in Leaves at Different Times.}

Collect leaves of plants in early spring and in late fall, preserve in alcohol. Also collect leaves at daybreak and in the afternoon, and preserve. Test each for starch. Explain the results.

\section{COLLATERAL READING}

Chemistry of Plant and Animal Life, by Harry Snyder.

Physics of Agrieulture, by F. H. King.

Fertilizers, by E. B. Voorhees.

Elementary Exereises in Agriculture. Office of Experiment Sta tions, Bulletin No. 186, pp. 17-26.

A Secondary Course in Agronomy. Offiee of Experiment Stations, Cireular No. 77, pp. 25-26. 


\section{CHAPTER V .}

\section{THE SOIL}

"Fill a flower-pot with soft, dark earth and mold from the border of the wood, and carry it to the student of entomology and see if he can name one-half of the living forms of this little kingdom of life; or hand it to the botanist, well trained in the lower orders of plants, and see how many of the living forms which these few handfuls of dirt contain he can classify. Present this miniature farm to the chemist and the physicist, and let them puzzle over it. Call in the farmer, and ask him what plants will thrive best in it; or keep the soil warm and moist for a time, and have the gardener say of the tiny plants that appear as by magic, which are good and which are bad. Mark what all these experts have said, and call in the orchardist to tell you how to change dead, lifeless, despised earth into fruit; ask the physiologist to explain how sodden earth is transformed into nerve and brain." 1

73. What Soil Is. Many persons look upon soil as "dirt" -something to be avoided. It is almost invariably thought of as a dead thing; but it is teeming with life, and is full of activities of the most complex and interesting kinds.

The almost universal idea of soil is that it is a collection of small particles of rock that have been made fine by the process of weathering. Many books give this as the origin of soil. No crop could grow on a soil composed entirely of rock particles. An agricultural soil is made up of:

(1) Small rock particles.

(2) Soil water.

(3) Soil air.

lRoberts' "The Fertility of the Land," p. 1. 
(4) Decaying organic matter.

(5) Living organisms.

There are very few soils that are capable of producing crops that do not have all these constituents. About the only exception is the class of soils that do not contain rock fragments. Muck contains little such material. Nearly all of its solid matter is made up of organic material. It is one of the most valuable soils for growing celery, onions, and some other crops.

$A$ soil that is very deficient in water, air, living organisms, or decaying organic matter, will not produce good crops.

\section{ROCK PARTICLES}

74. Amounts of Mineral Matter. The rock particles in most soils make up 65 to 95 per cent of the weight. The organic matter usually constitutes 2 to 5 per cent. Most of the remaining weight is water. The mineral matter furnishes the solid food. It also acts as a reservoir for holding the water. In the study of geography, we have learned how the particles of rock have become so small. The size of the particles has very much to do with the value of the land.

75. How the Size of Particles is Determined. If a soil is thoroughly shaken up with water and then allowed to settle a few minutes, the larger particles will be separated out. The rily water can be poured off and allowed to settle for a longer period, when the next larger particles will have settled to the bottom. If the rily water is again

'Organic unatter is any material that is, or once was, an organism, or living thing, such as coal, wood, sugar, straw, manure, ctc. 


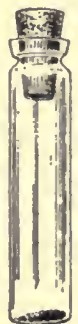

Fine

$1.3 \%$

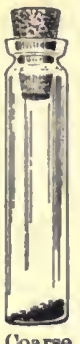

Coarse sand

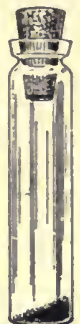

Medinm sand

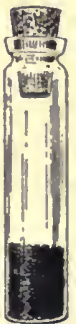

Fine sand

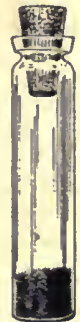

Very tine gand

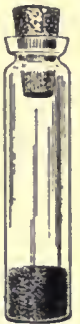

silt

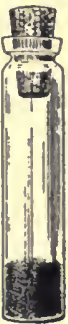

Clay

F19. 41. Composition of a fine sandy loam

poured off, we shall have the soil separated into three sizes of particles. Any number of divisions can be made in this manner. ${ }^{1}$

The finest soil particles are called clay, the next smallest silt. The larger particles are different grades of sand and gravel. The following table shows the mechanical analyses of three important soil types as separated by the Bureau of Soils:

1The common method of making the separation is to put the samples of soil in bottles of water, and shake for a day in a shaking machine. This separates the particles that are stuck together. A centrifugal machine is used to aid in making the separations, as it is more rapid than waiting for the particles to settle. The material is usually separated into three grades by means of water. The sands are further separated by means of sieves.

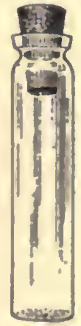

Flue uraves $0.2 \%$

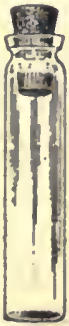

tharme kand

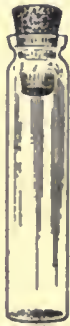

Medlum wand

$0.4 \%$

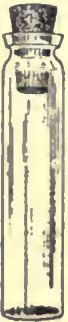

Fine rand

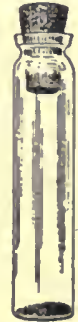

Very fiae m.1\%
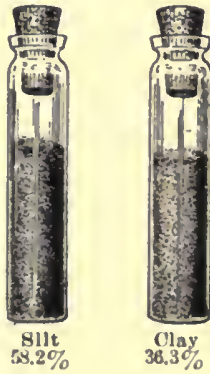

Fia. 42. Composition of a clay loam 
Mechanical Analyses of Three Important Soll Types ${ }^{2}$

\begin{tabular}{|c|c|c|c|c|c|c|c|}
\hline & \multirow{2}{*}{$\begin{array}{c}\text { Diameter of } \\
\text { Particles }\end{array}$} & \multicolumn{2}{|c|}{ Norfolk Sand } & \multicolumn{2}{|c|}{$\underset{\text { Loam }}{\text { Miami Silt }}$} & \multicolumn{2}{|c|}{ Wabash Clay } \\
\hline & & Soil & Subsoil & Soil & Subsoil & Soil & Subsoil \\
\hline Fine gravel .. & $\operatorname{mm}_{2-1}$ & $\begin{array}{r}\% \\
3\end{array}$ & $\begin{array}{c}\% \\
3\end{array}$ & $\begin{array}{r}\% \\
0\end{array}$ & $\begin{array}{r}\% \\
0\end{array}$ & $\begin{array}{c}\% \\
0\end{array}$ & $\begin{array}{r}\% \\
0\end{array}$ \\
\hline Coarse sand ... & $1-0.5$ & 15 & 16 & 1 & 1 & 1 & 0 \\
\hline Medium sand. & $0.5-0.25$ & 22 & 21 & 1 & 1 & 1 & 1 \\
\hline Fine sand..... & $0.25-0.10$ & 38 & 37 & 2 & 1 & 3 & 3 \\
\hline Very fine sand.. & $0.10-0.05$ & 10 & 9 & 8 & 7 & 7 & 18 \\
\hline Silt ......... & $0.05-0.005$ & 8 & 8 & 73 & 71 & 49 & 48 \\
\hline Clay .......... & $0.005-0$ & 4 & 5 & 15 & 19 & 37 & 40 \\
\hline
\end{tabular}

The Norfolk sand is one of the leading truck soils of the Atlantic coast. A large part of the vegetables for eastern cities are grown on this soil. The Miami silt loam is one of the leading types of soil in the "corn belt" of the Central West. The Wabash clay occurs along many of the river bottoms. It is used for corn, oats, cotton, and hay. Compare the analyses of these three soils and the crops grown.

76. How Soils Are Named. The soils that contain a large proportion of the finest particles are called clay. At the other extreme we have sands and gravels. Soils that are intermediate in texture are called loams. Those with a large proportion of silt particles, and not too much clay, are called silt-loams. These words are joined to describe intermediate types. There are gravelly loams, sandy loams, fine sandy loams, clay loams, etc. Since many soils as thus named are very different in other respects, the Bureau of Soils prefixes another name to

'Soil Survey Field Book, 1906. Burran of Soils. 
distinguish them. These names are usually names of towns near which the soils are first mapped. ${ }^{1}$

The local names used in any community are often misleading. In a region where nearly all the soils are sandy, a loam soil is usually called a clay; while, in regions where most of the soils are heavy clays, the same loam is likely to be called sandy.

Soils are also named in many other ways. Glacial soils are those that were formed as a result of glaciation, or the passage of the great ice sheet that once covered part of America. They occur in northern and eastern United States.

Arid soils are those that do not receive a sufficient amount of rainfall to produce regular crops without irrigation. They occur in the western half of the United States. Humid soils are those that receive sufficient rainfall to produce crops.

77. Importance of the Size of Soil Particles. The size of the soil particles influences the water-holding power of the soil, the amount of food that can be dissolved for plant use, the ease of movement of air and water, the growth of organisms in the soil, and the crop-producing power.

78. Relation of Size of Particles to Water. The rock particles of the soil can hold water on their surfaces only, hence the water-holding power of the soil increases when the surface area of the particles is increased.

Dip a pebble in water and a film of water will remain on it when it is removed. Wipe the pebble and the water will be gone, because no water has soaked into it. If such

'Soil maps are based largely on the size of the particles, but origin, copography, agricultural value, and other factors, are considered. 
a pebhle is hroken in two, it will have more surface area. It. can now holl more water. The finer the material is broken, the more surface there will be, and the more water it will hold.

The finest soil particles are extremely small-less than four hundred-thousandths of an inch in diameter. The total surface area in a cubic foot of such material would be very great. Such fine particles do not always act as individuals in holding water, some of the particles usually stick together. A cubic foot of soil grains having a diameter of one-thousandth of an inch (coarse silt) would have a surface area of 37,700 square feet. Four feet in depth of such a soil would have a water-holding surface of not less than 3.4 acres for each column of soil with one square foot of surface area.'

The water capacity of a soil is the amount of water that it will hold when all the free water is allowed to drain out. Some clay soils will retain about 40 per cent of water, that is, 100 pounds of soil may retain 40 pounds of water. A cubic foot of clay weighs about 80 pounds and could, therefore, hold about 32 pounds of water. Sandy soils may have a water capacity as low as 5 per cent.

Plants cammot remove all the water from a soil. They die for lack of water long before the soil is absolutely dry. They can use a larger proportion of the water from a sandy soil than from a clay. King found that in a sandy soil whose water capacity was 18 per cent, eorn was able to reduce the water to 4.17 per cent. In a clay soil whose eapacity was 26 per cent, it succeeded in using the water ${ }^{1}$ King, The Soil, p. 73. 
down to 11.79 per cent. ${ }^{2}$ In this case, the sandy soil had actually been able to furnish more water for the growth of corn than had the clay.

79. Relation of Size of Particles to Plant Food. The rock particles are very slowly soluble. Soil water can act on the surface of the particles only. Since smaller particles have more surface for a given volume of soil, they are able to furnish plant food more rapidly. The finer soils are usually more fertile, but are less easily managed.

80. Relation of the Size of Soil Particles to Air. About half the volume of a dry soil is air; that is, a cubic foot of such soil contains about half a cubic foot of air. The small particles of which a clay is composed do not pack so closely as do the larger sand particles, because they are lighter. Therefore, there is more pore space in clay than in sand. But the spaces in a sandy soil are larger, so that the air moves more freely; hence, such a soil is better aërated.

81. Size of Particles in Relation to Temperature. The temperature of the soil is influenced by its color, topography, humus content, and by several other factors But the chief factor is the water capacity.

It requires about 20 heat units to raise the temperature of 100 pounds of dry soil $1^{\circ} \mathrm{Fahr}$. To raise the temperature of the same weight of water $1^{\circ}$ Fahr. requires 100 heat units. But the effect of water is most striking when it evaporates. To evaporate 100 pounds of water requires 966.6 heat units. This explains why wet soils are always cold soils. Clay soils are cold chiefly because of the large amount of water that evaporates from them. 
King took the temperature of a well-drained, sandy loam and of a black marsh soil on five successive days, and found the sandy soil to average $7.5^{\circ}$ Fahr. warmer,-a difference sufficient to have a very decided effect on crops. It is easy to see why gardeners desire a sandy soil for early truck crops. Few crops begin growth until the soil has a temperature of $45^{\circ}$ to $50^{\circ}$ Fahr. The best growth does not usually take place until the temperature is about $70^{\circ} \mathrm{Fahr}$. Different crops differ much in the heat required. Some, like grasses, oats, onions, peas, will grow before the soil is warm enough for corn, beans, cucumbers, etc.

82. Size of Soil Particles and Crop Adaptation. The size of soil particles affects all the soil activities, and consequently must affect the crops that grow on the soils. Timothy will thrive on a heavy, clay soil on which apples, corn, and potatoes will give very poor returns. The sandy soils that are best for market-garden erops will raise very little timothy or wheat. Whitney states that a gram of soil contains two to twenty billion soil particles. He gives the following as the number of soil particles per gram of soils adapted to different erops:

Early truck. $1,955,000,000$

Truck and small fruit .............. $3,955,000,000$

Tobacco. . . . . . . . . . . . . . . . . 6,786,000,000

Wheat . . . . . . . . . . . . . . . . . 10,228,000,000

Grass and wheat................... 14,735,000,000

No person can comprehend such figures as these, but the comparison is the valuable point. The table shows how much coarser the truck soils are than the wheat soils. (See, also, page 78.)

83. Relation of Labor and Soil. Even if the clay soils would produce good truck crops, they would not be de- 
sirable for truck-growers, because they are so difficult to work. For any crop that requires so much labor, one should have a soil that is easy to work.

Sandy soils and other well-drained soils are not only easier to till, but the number of days on which they can be worked is much greater. Such soils can be tilled early in the spring and can be tilled quickly after rains. If one has a clay soil, he must spend much more time waiting for it to dry out. Hence, he cannot farm so large an area. For many kinds of farming, the ease with which soil may be tilled is of more importance than its fertility.

84. The Best Soils. The great advantages of clay soils are that they usually retain their fertility well, and will produce good grass. For general farm purposes, the medium-textured soils, sandy loams, loams and silt loams, are to be preferred. They are fairly easy to work and are adapted to a wide range of crops. For permanent pastures and meadows, the clay soils are usually preferable.

85. Flocculation. When a silt or clay soil is in good condition,

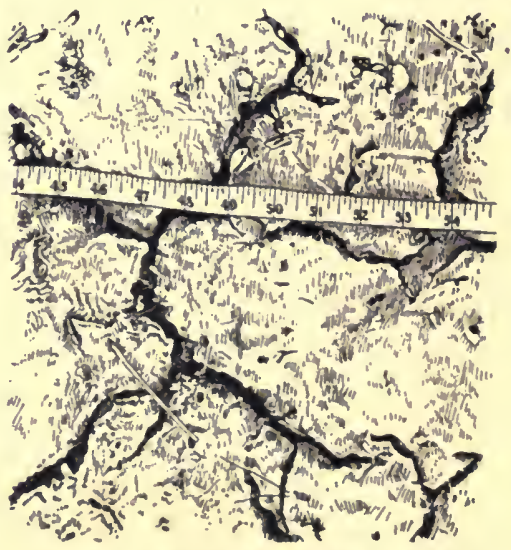

Fug. 43. A clay loam soil as it appeared in the spring after having been worked too fine in the fall. Same soil as Fig. 42.

many of the particles are united into compound, particles. Such a soil is flocculated. Good management of such a soil consists very largely in maintaining this 
granulated condition. If such a soil is worked while wet, and if it then dries, it will be greatly injured, sometimes so much ats to damage the crops for several years. Working a clay soil when wet makes "bricks" of it. The crust that is formed on the surface of soil after rains is due to the breaking down of compound particles.

If such a soil is too finely pulverized, it "runs together" and bakes because the granules have been broken up. (See Fig. 43.)

The relative fineness of the soil is called its texture, just as the word is used in speaking of the texture of cloth. If a soil is composed of very small particles that are flocculated, it may yet be of a coarse structure. Structure refers to the arrangement of soil particles. If the small particles are united, it is possible to have a soil of fine-texture and coarse structure.

\section{SOIL WATER}

86. Importance of Soil Water. In an agricultural sense, the most important use of soil is to act as a storehouse for water. The productiveness of a soil is limited by the amount of water that the soil can hold, and by the extent to which growing crops are able to remove the water. The soil water is important, not only because it is the chief plant food, but because it acts as a carrier of alt the other plant foods that come from the soil (page 66).

Soil water is very different from rain water. It contains all the plant foods in solution. The solution is very dilute, but plants use a large amount of it. Plants will 
grow in well-water or water from a tile drain, if it is renewed often enough. Such water is free soil water.

87. Movement of Water in Soil. The chief ways in which water exists in the soil are as film water and as free water. The particles can hold a certain amount of water on their surfaces, just as one's hands remain wet when removed from water. Only a limited amount can be held in this way. If too much water is present, it will drop off. If more water is present in the soil than can be held as film moisture, it will fill the pore spaces between the particles. If there is an outlet, the free water will drain away and leave the film or capillary water.

88. Conservation of Moisture. The free water moves downward by gravity. The capillary water can move in any direction, because the force of achesion between the soil particles and the water is strong enough to lift water, just as oil is lifted in a lamp-wick. After a heavy rain the soil may be filled with water. Gradually the free watel drains away and leaves capillary water only. The surface soil loses some of its water by evaporation. This leaves it drier than the soil below. Some of the water of the lower layer of soil is then drawn up by capillarity to take its place, just as more oil is drawn up in the lampwick when that at the end of the wick is removed by burning. In this way the water may be removed from the soil very rapidly, particularly when the weather is dry, warm and windy. ${ }^{1}$

If there is not an abundance of rainfall, it is desirable to stop this movement of water to the surface to be evap-

IWater also evaporates within the soil into the soil air. There is a constant movement of this air in and out of the soil, so that this aids in drying a soil. 
orated. Any loose mulch, like straw, on the surface of the soil will accomplish this purpose. The capillary water moves very slowly through dry soil, so that one of the

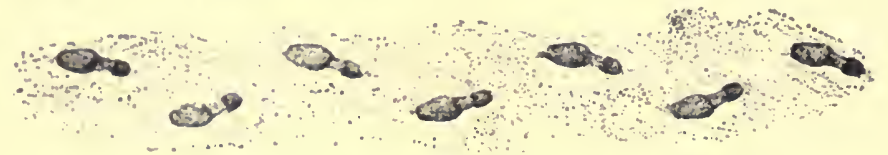

F1G. 44. Footprints kept moist and dark-colored by the rise of capillary water

best methods for preventing the evaporation is to form a dust mulch on the surface. One of the great benefits of cultivation is the formation of this dust mulch. When possible, the soil should be cultivated after every rain as soon as it is in proper condition for working. This cultivation will break up the crust, break the capillary connection, and prevent much of the evaporation. At the same time it leaves the soil in a loose condition, ready for the absorption of the next rain.

When a moist soil is stirred, evaporation will first be increased, but as the loose soil becomes dry it acts as a

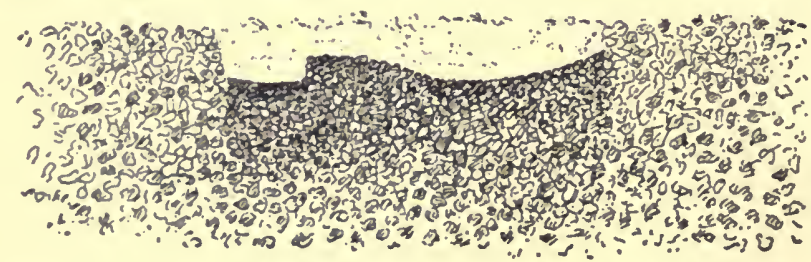

Flg. 45. A foot print. The particles are kept closer together and therefore hasten the rise of water

mulch to check evaporation. Hence, if rains are frequent, cultivation may keep the soil drier.

In most of the United States, the rainfall during the growing months is not sufficient for the production of 
maximum crops. In the northern part of the country, this is particularly true during July and August. The tillage of the soil is therefore of great importance, as a means of absorbing and retaining as much water as possible for use during the months when the demand for water is so great.

When seeds are planted, it is very often desirable to increase evaporation, so that the seeds that are near the surface will be kept moist by the water as it rises to the surface. This is accomplished by packing the ground over the seeds by rolling the field, or by packing it over the row only. as is done by a corn planter. (See Figs. 44, 45, 46.) The packing makes the pore spaces smaller so that the capillary movement of the water will be more rapid.

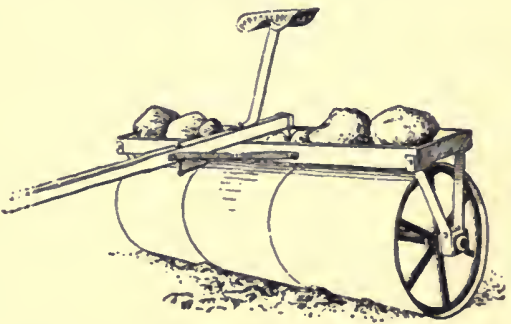

Fig.46. A roller. Crushes clods and packs the surface so as to keep the seed moist at the expense of increased evaporation.

89. Dry-Land Farming. Two-fifths of the United States is too dry to raise good crops without irrigation. (See Fig. 47.) Few crops can be grown successfully without twenty or more inches of rainfall. In the past few years, considerable attention has been given to a system of farming that attempts to save all the rainfall of one or more years for the use of a crop during the growing season. In this way, the rainfall of two years can be used for the production of one crop. Sometimes two crops are grown in three years. In this system, the land is kept tilled during the year when there is no crop, so that the rainfall may be 


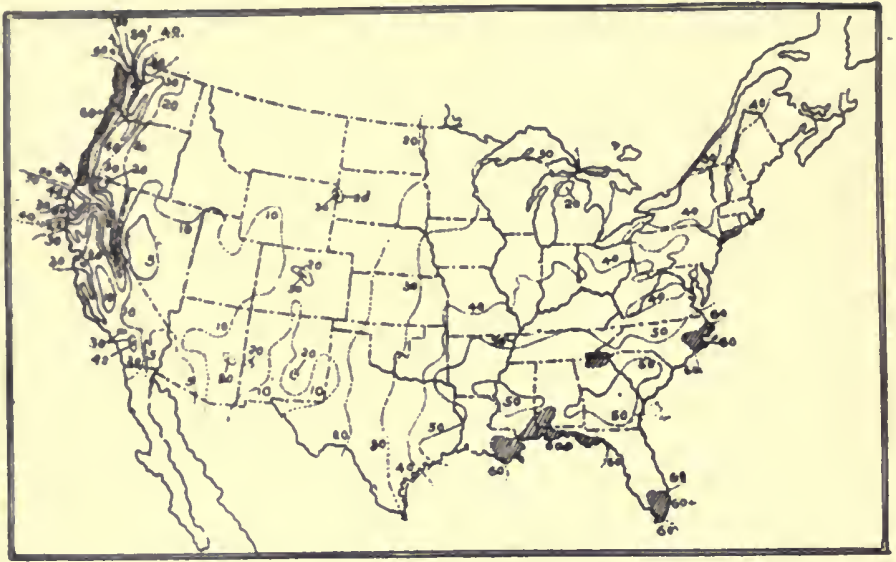

FIg. 47. Annual rainfall in the United States. Areas receiving less than twenty inches cannot be farmed by ordinary methods unless irrigated

quickly absorbed, and so that evaporation may be checked as far as is possible. Fair crops of wheat have thus been grown every other year with only twelve inches of rainfall annually.

\section{Irrigation}

90. Areas Requiring Irrigation. As stated above, twofifths of the United States is too dry to produce regular crops without irrigation. If all the water that falls in this area were used for irrigation, only about one-tenth of the land could be irrigated. The total area now irrigated is about $10,000,000$ acres. This is a little over one-thousandth of the arid area. Evidently we must ever have much arid land that is fit only for grazing, and large tracts will always be too dry for any agricultural use. The importance of saving all the water is apparent. 
The early irrigation enterprises were very wasteful of water, but more care is now coming to be exercised. There are three sources of serious loss of water: losses at seasons of the year when the water in the streams cannot all be used, seepage from canals, and over-irrigation. These losses may be decreased by building reservoirs, and by using more care in constructing canals, and in applying water.

91. Storage Reservoirs. During a part of the year, the rivers carry enough water to irrigate much more land than can be supplied through the summer months. The flow of the Nile in September is thirty-five times that of June. To hold back a part of this water, the English built the Assuan reservoir, which extends up the Nile for a hundred miles.

Forests in the mountains serve to hold back the water and so distribute it through the season. But reservoirs are also necessary. In India, 9,500,000 acres are irrigated from reservoirs, - an area equal to about five times the area of improved farm land in New Jersey.

The United States Government is now building large reservoirs for storing irrigation water. The projects now approved provide for the irrigation of 1,909,000 acres, located in fourteen states. The total cost is estimated to be $\$ 34,270,000$, or about $\$ 18$ per acre. The land thus reclaimed is sold to settlers, so that it more than pays the cost of the reservoirs and canals. The money can be used over again for irrigation of more land. After all the present reservoirs are completed, we shall have only one-fifth as large an area irrigated from them as is thus irrigated in India. 
92. Seepage from Canals. Over half the water turned into canals in the United States is lost before it reaches the fields. In India, 47 per cent is lost from many canals. ${ }^{1}$ Some of this loss is due to evaporation, but most of it is due to seepage. If the water carries considerable silt, the losses are less. Silt is one of the greatest factors in making canals water-tight. Care in canal construction will also save considerable water.

Seepage not only causes a loss of water, but it often injures large areas of land, because of the deposits of alkali by the water, or because of the rise of alkali with the evaporation of the water.

93. Over-Irrigation. This not only wastes water, but the excessive amounts are a detriment to crops. It also aids in spoiling the land by making the accumulation of alkali more rapid. It is more profitable to use moderate amounts of water and follow by tillage to prevent evaporation.

94. Alkali. In arid regions, very little of the water drains away as it does in humid regions. Nearly all the water evaporates from the soil. The water contains small amounts of salts in solution and these are left by evaporation. The process is similar to the formation of salt lakes. The best remedy is drainage. By under-draining the land and flooding it, the salts may be carried away with the water. Some soils have such good natural underdrainage that artificial drainage is not necessary. If the land is flooded without drainage, the water sinks into the soil, and, as it rises, brings with it more alkali to be left near the surface.

'Cyclopedia of American Agriculture, Vol. I, p. 422. 


\section{Drainage}

95. Best Amount of Water. Water is the most important plant-food, - the one that most frequently limits the crops of the world. It is also the plant-food that frequently causes injury by appearing in too large quantities.

For the best growth of crops, the water content of the soil should be maintained at about 50 to 60 per cent of the water capacity of the soil. (Laboratory Exercise, page 107.) If there is either much more or much less water, the growth of the plant is injured. Commonly the soil is saturated with water during the early part of the season, and later becomes too dry, so that the crop is injured by both extremes.

96. Harmful Effects of Too Much Water. The most serious result of having too much water in the soil is the exclusion of air, which is essential for plant growth and for the activities of the soil organisms (page 97 ). It also prevents plant roots from growing deeply into the soil, makes the soil cold and delays farm work. Since farm work cannot be done at the proper time, weeds are more likely to obtain a foothold. Wet land is nearly always weedy land.

97. All Soils Require Drainage. If a soil is not drained, the excess of water will prevent the growth of crops. Or, if there is no excess of water, salts and acids will accumulate to such an extent as to kill crops, as in the case of alkali and marsh soils. Fortunately a very large proportion of the farm land is underlain by porous subsoil, so that drainage takes place naturally. Whenever the 
natural drainage is not sufficient, artificial drainage has to be resorted to.

Much of the sandy land on the Atlantic coast is too well drained. The soil is so open that truck growers often say that the rain falls faster after it strikes the soil than it did in the air. This region also contains the other extreme of marshes that are useless because too wet. Most farm lands lie between these extremes. There are some farms that neel a complete system of tile drains ${ }^{1}$ placed 30 to 100 feet apart. But for each farm that needs so complete a system of dranage there are many that need partial drainage. Probably the majority of farms east of the Missouri river have one or more wet places that would be improved by tile drainage or surface ditches. The necessity for drainage depends much on the crop to be raised. Hay and pasture may do well on land that is so wet as to ruin corn and potatoes.

98. Effects of Tile Drainage During. Drought. At first thought, we should expect that tile drainage would make the land drier during a dry time, and so cause plants to suffer from drought. As a matter of fact, exactly the opposite occurs. Tile drains remove the excess of water during periods of rainfall, so that the plant roots deeply. The roots are then deep enough to endure a considerable drought. The roots will actually be in more moist soil as a result of the drains, and will have a much larger amount of soil from which to draw water. The shallow-rooted plants in undrained soil are the first to suffer from drought.

'Tiles are hollow tubes about a foot long. They are made of clav and are burned like brick. They are laid end to end about two to four feet below the surface of the ground. 
99. Kinds of Drains. The most universal kind of drains are the surface ditches. These are useful in many cases, but are not so desirable as under-drains where the latter can be used. Surface drains that are to be permanent should usually be made with sloping sides, so that they ean be driven across. Stone under-drains are often made in regions where the land is stony. They require much more time for construction than tile drains. At the present relative prices of tile and labor it is probable that tiles are cheaper than stone. Poles and many other devices have been employed.

100. Laying Tile Drains. The method of laying drains can be learned from books, or better by seeing it done, or best by doing it. There are a few points that are often neglected.

The tile should be hard-burned and should not be too small. It is doubtful whether tile smaller than three-inch should ever be used. Some manufacturers in Illinoisthe state that uses the most tile-do not make any tile smaller than four inches. Their experience is that farmers who use these sizes are so well pleased as to buy more, while those who use the smaller sizes are less likely to be satisfied. It is much more difficult to lay small tile accurately, and they are much more likely to get out of place. A slight movement is sufficient to break the eonneetion of the openings. The small tile are more likely to fill up. If possible, the lower part of the line of tile should have a steeper fall than the upper part, so as to guard against filling up with silt. For the same reason, the outlet should always he above standing water.

A map of the farm showing the location of drains should 
always be kept. This will make it easier to locate any tile that fills up. It will also make it possible to lay additional tiles in the proper places.

101. Drainage as a Government Problem. Aside from the problem of drainage on the individual farms, there are many large swamp areas that can be reclaimed by cooperative effort. Professor Shaler estimates that there are over 3,000,000 acres of reclaimable sea-coast marsh land along the Atlantic coast of the United States. The draining of such land is a problem for the United States and state governments, just as is the irrigation of arid regions. It is probable that such lands could be sold for much more than the cost of drainage. The drainage of these areas will not only add io the amount of good farm land, but it will make the coast cities much more healthful.

\section{SOIL AIR}

102. Importance of Soil Air. Most soils are about half pore space. That is, a cubic foot of dry soil would contain about half a cubic foot of air. As the water in soils increases the amount of air decreases, so that in a saturated soil there is very little air. Soil air is just as essential for the growth of farm crops as air is for animals. If water excludes all air from the soil, the crops will drown just as surely, if not so quickly, as a person drowns in water. There are some marsh plants that can grow in standing water, and rice can do so, but the usual farm crops would utterly fail under such conditions. Even rice requires some air in the soil, as do the submerged seaweeds, but in this case they are able to get air from the water. 
Aside from its direct use to crops, soil air is essential in several indirect ways. When air is excluded from the soil, the beneficial soil organisms cease to be active. It is from the air in the soil that these organisms and the leguminous plants secure free nitrogen for the use of crops. Not only does the fixation of atmospheric nitrogen cease when air is excluded from the soil, but under these conditions the organisms that break down nitrogen compounds are very active, so that the nitrogen that was fixed is lost by being returned to the air. One of the first effects of having the soil too wet is the yellowing of the leaves. This appears to be due to the lack of nitrogen.

Some soils are too well aërated, just as some are too well drained. Usually it is the same soils in each case.

\section{ORGANIC MATTER OF THE SOIL}

103. The Uses of Humus. All productive soils contain decaying roots, leaves and animal life. This partly decayed organic matter is called humus. It is the humus that gives soils their dark color. Humus is necessary for the growth of good crops. Plants may be grown in fine sand if all the plant-food elements are supplied. Under field conditions, humus is necessary if these foods are to be supplied for the successful production of crops.

Humus has many functions in soils. It increases the water-holding power, which is particularly important on sandy land. It loosens heavy soil and promotes aëration, which are of special importance on clay soils. It furnishes food for bacteria. These, acting on the humus, change nitrogen to nitric acid so that it is ready for 
plant food. As humus decays, it also liberates carbon dioxid (carbonic acid gas). This acts on the minerals of the soil, making them soluble and ready for plant use. Another extremely important function of humus is that it encourages the growth of the bacteria that fix free nitrogen from the soil air, rendering it available as a plantfood. Dark-colored soils usually contain considerable humus. Such soils are usually fertile.

The more air in the soil, the more rapidly the humus is decomposed. If a soil is saturated with water, the oxidation practically stops and organic matter accumulates. This is the way that peat and muck are formed. For crop-production, a moderate rate of decomposition is to be preferred. If too rapid, the supply is exhausted; if too slow, the plant does not receive enough food.

104. Humus of Arid and Humid Soils. In humid regions the soil is usually much darker colored than in the arid regions. The surface soil is much darker than the subsoil because of the presence of more humus. In arid regions the soils are so well aërated that the organic matter is rapidly decomposed, leaving no difference in color of soil and subsoil. The subsoils in humid regions are not very productive, but in arid regions there is not much difference between soil and subsoil. This is a great convenience, for it makes it possible to level fields for irrigation.

Some analyses have shown that, on an average, there is about four times as much humus in humid soils as in arid ones. At first thought, this would indicate a lack of nitrogen in arid regions. But the humus in arid regions is so much richer in nitrogen that the total amount present is not much less. 


\section{LIFE IN THE SOIL}

105. Importance of Soil Organisms. As we have seen, soil is not a dead thing. It is much more than a collection of rock particles. It is teeming with life. Without this life the soil would never have been able to produce farm crops. If all the living things in the soil should die, the soil would soon fail to produce crops. Keeping the soil productive is very largely a matter of keeping these organisms thrifty. The roots and stems of plants furnish food for the bacteria and molds. The waste products furnish food for other bacteria. Eventually, the food is in a form available for crops to use again. So the material is worked over and over again. Any break in the link will affect all of the chain. If the organisms do not decompose the roots and stems properly, the new crops will suffer. If there is not enough humus in the soil, the bacteria suffer and crops are immediately affected.

Earthworms serve a useful purpose in the soil by helping to break down the organic matter. They also do much good by making the soil porous. A soil that is full of earthworms is nearly always fertile.

The molds help in breaking down the organic matter, particularly the woody matter; but the most important forms of life in the soil are the microscopic organisms, yeasts and bacteria.

106. Soil-Bacteria are very minute living things, - - far too small to be seen with the naked eye. They are so small that they have to be magnified 500 to 1,000 times before they can be seen with a microscope. (See Fig. 48.) On an average, it takes about 25,000 bacteria placed end to end to meas- 
ure an inch. Of the very sinallest ones, it takes about 150,000 to measure an inch. The small size of the bacteria is more than made up by the rapidity with which they

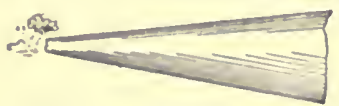

Fia. 48. The point of the finest cambric needle. A par. ticle of dust above the point and a inass of bacterin below. multiply. They reproduce by simple division, one individual divides into two. This division may take place every fifteen to thirty minutes under favorable conditions. If each divicles into two every quarter of an hour, there will be an immense number of them at the end of a day, even if there were only one in the morning. The limit of food supply and other conditions prevent this rapid multiplication from continuing.

Bacteria of many kinds are present in all soils, ranging from less than 28,000,000 per ounce of soil to many times this number. In fertile soils like gardens there are many billions per ounce. In a fertilizing experiment in New Jersey it was found that the plots that gave the greatest yields of asparagus also contained most hacteria. Often there is a relationship between the number and kind of soil-bacteria and fertility.

Bacteria may seem to be too small to be of much consequence, but they are far from unimportant. We know how many contagious diseases are caused by bacteria, so that we must recognize their power. Perhaps you have come to look upon all bacteria as harmful,- - things to be avoided. But, while certain ones ause tuberculosis, diphtheria and lock-jaw, many other kinds are useful to us. Bacteria are microscopic plants. We should look on them as we do on other plants. Some plants, as corn and rotton, are useful; others, like poison ivy, are to be 
avoided. Probably we could not live were it not for the activities of the useful bacteria and yeast plants.

"The different chemical changes produced by soilbacteria are quite numerous. Some kinds are specialized for one series of changes, others for changes of a different sort. Some will attack by preference carbohydrates like starch or sugar, some will decompose woody tissue, some will cause the decay of proteins, some of fats, etc. This division of labor allows an effective decomposition of humus. Various gases and acids are produced in the course of decay, and help to decompose the rock particles in the soil and to render the mineral plant-food contained in them available. The insoluble protein compounds in the roots and stubble are broken down and their nitrogen changed partly to ammonia. The particles of ammonia, as they are thus generated by bacteria of many kinds, are at once pounced upon by a special class of germs whose function it is-to change the ammonia into nitrate. Thanks, therefore, to the activities of many species of bacteria, the nitrogen locked up in the humus and in green manure is transformed gradually into nitrate, and is then quite suitable for the building of roots, stems, leaves and fruits."

An equally important function of soil-bacteria is the fixation of free nitrogen from the air. This subject will be treated under Nitrogen in the next chapter. 


\section{QUESTIONS}

1. How are soils formed?

2. How do the soil particles become small?

3. Do stones "grow"? Why, then, are there more large ones to be picked from stony land every few years?

4. Which fall faster in the air or water, large particles or small ones of the same material? Why? Deseribe the material in the bed of a stream in its upper, niddle and lower courses. Why this differenee? Why do raindrops fall faster than the fog?

5. What soil maps has the Bureau of Soils made in your state? From these can you identify any of the soils in your region?

6. What is the relative surface area of a one-foot eube of stone and of the same stone divided into one-inch cubes?

7. What is the name of the force that holds the film of water on a piece of glass? What liquid does not stick to glass?

8. Why does wet elay stick to one's shoes?

9. How did the Jews make brick in Egypt? Would a dry soil make brick? Apply these principles to tillage.

10. What is the difference in taste of well water and rain water? Why?

11. How of ten should house plants be waterel? How much should be applied each time?

12. Which is better, to water a flower-bed a little every day, or to give it more water less frequently? Why?

13. What crops of your region will grow best in wet seasons or on wet lands? Which ones will stand more drought?

14. What has Holland done to increase the area of farm land? How productive is this soil?

15. What human diseases would be decreased if our marshes were drained? Why?

16. What is a "dead furrow"? Why so named?

17. What is the difference in color of hillsides and bottom-land 8oils? Why?

18. If a bacterium dividert into two every fifteen minutes, how many would there be at the end of four hours? How many at the end of a day?

19. What makes bread rise?

20. Where does a fence-post rot most rapidly? Why?

21. The statement is sometimes made that "tillage is manure." Why? 
22. Account for the bubbles that come from a kettle before it begins to boil. What relation has this to water-plants? To fishes?

23. Which is heavier, sand or clay? Why do farmers call a clay soil "heavy"?

24. (For classes that have chemistry.) The red and yellow colors of soil are usually due to iron compounds. Ferric compounds cause the red colors; ferrous compounds cause the yellow colors. Why do some red soils have yellow subsoils? Explain the formation of red brick from yellow clay. What would you conclude of the aëration of a soil that has a mottled subsoil?

\section{LABORATORY EXERCISES}

\section{Origin of Soils.}

Field Lesson.-If the following points have not been studied in Physical Geography, one or more field trips should be devoted to them: Geological origin of the soils of the region. Evidences of this origin seen in the field trip. Find a rounded pebble; what rounded it? Find a "rotten" stone or a place where a rock is covered by a disintegrating rock; explain. Is the farm land rolling? Account for the low places. What part has the wind played in soil formation? Find some evidence of the work of earthworms, woodchucks, prairie dogs, or other animals in soil formation. Find evidence of the part played by plants in soil formation-decay of roots, leaves, etc. Cross a meadow or pasture. Are there any spots that are covered with weeds? Are the weeds there chiefly because they kill the grass or because the grass failed to grow? Notice that nature rarely leaves any permanently bare ground. Of what value are weeds in soil formation? If there are any steep hills in the region, notice the relative erosion on hillsides that are forested, tilled, pastured. What use is made of steep hillsides in the neighborhood? Do better crops grow on a hillside or at the foot of the hill? Why? Why are valleys generally fertile? Nearly all of these points that are adapted to the region may be answered in crossing any farm.

\section{Field Lesson.}

Materials.-Rule, spade, six fruit-jars.

Go to a nearby farm. Dig a hole about two feet deep. What is the color of the soil? Of the subsoil? Which is more compact? How deep is the soil?

Find pieces of partly decayed ronts and stems. What color are they? Which contains more of this organic matter, or humus, the soil 
or the subsoil? How does a farmer inerease the amount of humus in the soil?

Have cach pupil rub samples of soil and subsoil between his fingers so as to hecome familiar with its texture. Fill one of the jars with soil and one with subsoil and cover each. Label each with the name and date. The samples are to be kept tightly coverel for use in numbers 34 and 3 i). Similarly study and collect several different soils and subsoils. If possible, compare good and poor soils. Also compare sandy soils, loams and clays.

\section{Determination of the Per Cent of Water, Organic Matter and Mineral Matter in Soils.}

Mutriuls._- Soil simples collected under No. 33, porcelain crucibles, lallances. If the school does not have cruciloles and laboratory burners, the soil may be dried over a stove and then burned in an iron shovel in a stove.

If different members of the class take different samples, all those collected may be compared. Weigh the crucible. Put ten grams of the sample in it. Weigh before the water has time to evaporate much. Heat this a little hotter than boiling water, but do not burn it; one hour at $110^{\circ} \mathrm{C}$. or five hours at $100^{\circ} \mathrm{C}$. is about right. Weigh again. This gives the amount of water evaporated. Now heat to dull redness. After it is thoroughly burned for one hour, weigh. Compute and tabulate results as follows:

Weight of erucible (grams). .

Weight of erucible and soil (grains)

Weight of soil (grams)

Weight of both when dry (grams)........

Per cent of water

Weight of both after burning (grams)....

Weight of organic matter

Per cent of organic matter

Per cent of mineral matter.

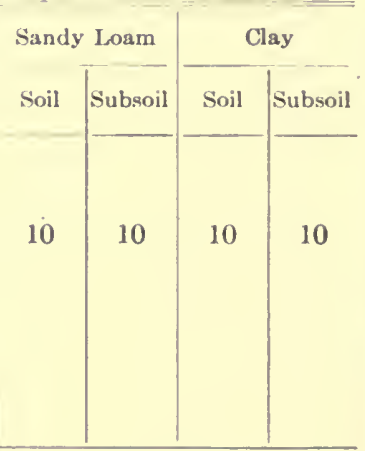

What change in color took place as the soil dried? Is the color of the soil changed by rain? What change is there in color after the soil was burned? After burning, only mineral matter remains. Compare this 
burning with burning wood. What kind of soil contained more water? More organic matter? Do the surface or the subsoils contain more organic matter?

\section{Per Cent of Air in Soils.}

Materials.-Beakers or jars, graduate, soil samples collected in No. 33.

Put a measured amount of soil into each beaker. Pour in water from a graduate containing a measured amount of water until it just rises to the surface of the soil. How much water does it take in each case? Repeat this for a very dry soil. The amount of water required is an approximate measure of the air-space. We shall then have the air space in a dry soil and in those collected under field conditions. The dryer the soil the more air-space it contains. The total space in a dry soil is the pore-space. Record results for each soil as follows:

Volume of soil .

Volume of water added

Per cent of air-space.

36. Soil Particles and Their Separation.

Materials.-Two beakers, three fruit-jars, pan, samples of soil.

(a) Put about a tablespoonful of sand in one beaker and clay in another. Shake each one and allow to settle. Which settles more rapidly? Why? Which would be deposited first when a swift stream is checked? Where in your neighborhood is there evidence of this sorting power of water? Did the glaciers thus sort soil? How could we separate the different-sized particles in a soil?

(b) The day before this lesson is given, put about four tablespoonfuls of a loam soil in a fruit-jar and nearly fill with water. Cover. Shake occasionally. After standing a day, shake thoroughly. Allow to settle one minute. Pour the rily water into another jar; allow this to stand one hour. Pour off the rily water and evaporate by setting on a stove or over a flame. When dry (which will probably be for the next lesson), examine the dry separates. The part that settled out first is sand, the second is silt, and the finest material is elay. Examine them to find differenees in texture. Which ones stick together? Would pure clay or pure sand make a good soil? Why? Save the materials for number 37 .

37. Microscopical Examination of Soil Particles.

Materials.-Compound microseope. Sand, silt and elay from No. 35.

Examine the sand particles $\left(X_{50}\right)$, i. e., use the combination of eyepieces and objectives that magnify fifty diameters. Mix the silt with 
u little water and examine a drop $(\times 100)$. Only a little of the silt is better than too much in a drop. Mix the clay with water and examine a drop of the slightly rily water $\left(X_{500}\right)$. Have each student make a drawlying of a few particles of each. Notice that the soil particles are real minute rocks and humus. Find black particles of humus and draw them. Find flocculated particles of clay, i. e., a number of particles united to form a compound particle. If such particles are not readily seen, a little clay soil moistened and a drop put under the micsrocope will show them. Do you see any reason for having the soil soak a day? Keeping a clay in good condition is largely a matter of keeping the particles thus flocculated or united into small crumbs.

\section{One Effect of Humus and of Lime and of Freezing on a Clay Soil (for Humid Regions).}

Materials-Two quarts of clay, one-fourth pound unslaked lime, leaf mold or rotted manure, bottles or beakers.

(a) An hour or inore before the class period, the lime should be nearly covered with water to slake it. Divide the clay into four equal parts. To the first two add water; to the third add water and about half its volume of humus; to the fourth add lime-milk. Make each into a ball and set aside to dry. If the weather is cold, put one of the first two where it will freeze. In a few days examine and see which is more mellow. What do you conclude as to the probable effect of working clay land when too wet? What is one value of organic matter in clay soil? What is one value of using lime on a clay soil? In what way do farmers add organic matter to their soils?

(b) Put about a tablespoonful of clay in each of the two bottles. Fill with water and shake. Add a little lime-milk to one bottle. Which one settles more rapidly? Why? Is lime used on soils in your vicinity?

\section{Soil Solutions.}

Materials._Four or more "slips" of Wandering Jew or Inch Plant (Tradescantia), two bottles, two crucibles, well water, rain water, or distilled water.

(a) Evaporate some well water in one crucible and some rain-water in another. What is left in each case? What causes the inside of a tea-kettle to become coated?

(b) Put two of these slips in each bottle, fill one with well-water anil one with rain-water. Change the water about three times a week, until the results are secured. In which do the plants grow best? Why? 


\section{Water Capacity of Soils.}

Materials.-Air-dry, sand, clay, loam, leaf-mold, or rotten manure, spring-balance, four tin cans or paint-cans with holes punched in the bottom, holes in the side, and string tied across for a bail.

(a) Weigh each can. Fill two-thirds full, one with each of the three soils, one with mixed clay and leaf-mold, one with mixed sand and leafmold. Add water until thoroughly wet. Let this drain off for about fifteen minutes. Weigh.

\begin{tabular}{|c|c|c|c|c|c|}
\hline & Sand & $\begin{array}{l}\text { Sand and } \\
\text { leaf mold }\end{array}$ & Loam & Clay & $\begin{array}{l}\text { Clay and } \\
\text { leaf mold }\end{array}$ \\
\hline 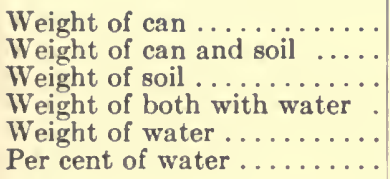 & & & & & \\
\hline
\end{tabular}

The soil should be very dry before this experiment. It will still contain some water, so that the results will all be too low. Why does sand hold less water than clay? What effect on water eapacity does the addition of organic matter have? Notice that the organic matter not only holds water on its surface, but all through it, like a piece of bread that soaks up water. Give two ways in which a farmer might increase the water-holding capacity of his soils.

\section{Capillary Rise of Water in Soils.}

Materials.-Two small glass plates, three glass tubes three feet long, one and one-half to two inches in diameter, pan of water, eloth, and sand, loam and clay. Three lamp chimncys may be used in place of the glass tubes.

(a) Fasten the two pieces of glass together by a rubber band. Put a little splint at one side and set on edge in water. Notice that the water rises between the plates and that it rises highest on the side where the plates are nearest together. Make a drawing of this.

(b) Put a piece of cloth over the end of each tube and fasten with a rubber band or tie it on. Fill each with one of the soils. Set in the pan of water. In which does the water rise most rapidly? Record the results as follows: 


\begin{tabular}{|c|c|c|c|}
\hline \multirow{2}{*}{ Time } & \multicolumn{3}{|c|}{ Height of water } \\
\hline & Sand & Loam & Clay \\
\hline 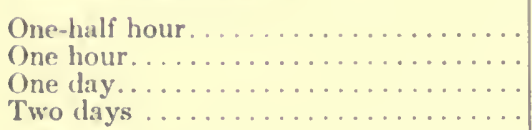 & & & \\
\hline
\end{tabular}

('ontinue for about a week. In which does the water rise highest? Why? Notice that it rises highest between the plates where they were nearest together and rises highest in the soil that has the finest spaces. (ompare with the rise of oil in a lamp-wiek, ink in a blotter, ete. What is the object of compacting the soil over seeds when planted? In what different ways is this done?

42. Evaporation from the Soil. (Special Importance in Arid Regions).

Materials.--Spring balance; three tin cans, holes punched in sides and string for a bail, the same as used in No. 39; soil, fine grass or straw.

Fill each ean nearly full of soil. Water eaeh with the same amount of water. ('over the top of one with grass. Weigh. As soon as the surface is dry enough, stir the surface on one about an ineh deep. Keep this stirred Weigh every sehool day for about two weeks.

\begin{tabular}{|c|c|c|c|c|c|c|}
\hline \multirow{2}{*}{ Date } & \multicolumn{2}{|c|}{ Bare Surface } & \multicolumn{2}{|c|}{ Cultivated } & \multicolumn{2}{|c|}{ Grass Mulch } \\
\hline & Weight & Loss & Weight & Loss & Weight & Loss \\
\hline & & & & & & \\
\hline & & & & & & \\
\hline
\end{tabular}

Which loses weight most rapidly? Why? What is one use of cultivation during a dry time? Notice that if we stir the soil when it is moist we hasten the evaporation in the part stirred. In dry weather this loose soil may aet as a dust mulch to prevent evaporation. Tillage may, therefore, first hasten and then lessen evaporation. What would its general effeet be in a wet season? In a dry season? Why is the soil under a board moist? 


\section{Drainage.}

Materials.-Two flower-pots with soil; two geraniums or other flowers growing in pots.

Set one geranium in a dish of water. Plant corn in two other pots, and stand one in a dish of water. lieep water constantly in the dishes under the two pots, and water the other two in the usual way. Notice the effect of the excess of water on the geranium and on the germination and the growth of the corn. If the corn in the wet pot grows, empty both pots and examine the roots. In which do the roots go deeper? What is the effect of flooding on field crops? On trees? Some crops will live on soils that are so wet that other crops would be killed. What ones? What kind of material underlies the soil in your neighborhood at depths of three to ten feet-sand, gravel, clay, rock? This can be answered by observing euts in the roals. Is the soil naturally well drained?

\section{Laying Tile Drain.}

If possible, practice laying a tile drain. For directions see King, Pliysics of Agriculture, pp. 256-328.

\section{Temperature of Soils.}

Materials._Four or more cigar-boxes or other sinall boxes, soil, thermometers, lime or ehalk dust.

Fill each box with soil. Water one box so as to keep it rather wet, cover the surface of one with lime, set these and a third one so that they will face the sun in a window. Set another so that it will not face the sun, that is, give it a "north slope." Take the temperature of each from time to time.

A field trip may also be taken to get the temperatures of wet and dry soil, north and south slopes, tilled and untilled land.

What effect does eolor have on temperature? Why? What effect does the water have? Why? Cut a square hole in a pieee of paper. Hold this perpendieular to the sun's rays. Hold another piece of paper back of this. Measure the area covered by the sunshine. Now incle the second piece of paper and again measure the area of sunshine. Why does the slope affeet the temperature?

\section{Absorbent Power of Soil.}

Materials. - Tin can with holes in bottom, soil and manure.

Mix water with the manure so as to get manure water. Fill the 
tin ean with soil. Pour on the water and compare the eolor of thai which is poured on with that which runs through.

47. Examination of Bacteria.

Materials.-Compound microscope, magnifying about 500 to 1,000 diameters.

Moisten some soil. Take a drop of the water and examine under the mieroscope for bacteria and other organisms.

\section{COLLATERAL READING}

Soils, by S. W. Fletcher.

Physics of Agriculture, by F. H. King.

The Soil, by F. H. King.

The Fertility of the Land, by I. P. Roberts. Pp. 34-130.

Bacteriology in Relation to Country Life, by J. G. Lipman.

Cyclopedia of American Agriculture, Vol. I, pp. 323-531.

Dry Farming. Farmers' Bulletin No. 329, pp. 10-15, and No. 262 pp. 15-18.

Reelamation of Salt Marshes. Farmers' Bulletin No. 320, pp. 9-12.

Management of Soil to Conserve Moisture. Farmers' Bulletin No. 266. 


\section{CHAPTER VI}

\section{MAINTAINING THE FERTILITY OF THE LAND}

107. How Soils Become Productive. It has required untold ages for the soils of the world to be formed and to become productive. At first the particles of rock ${ }^{\circ}$ were capable of supporting only such plants as lichens and mosses. After generations of these plants died and added their material to the soil, it became possible for other plants to grow. For thousands of years the trees and leaves of the forests have fallen and decayed to form the forest soils. On the great western plains where "corn is king," the grasses have grown for centuries and have fallen down to decay so that still larger grasses might grow. When such lands are first farmed, the crops are as large as the climate and culture will allow, for the soils are very rich.

108. How Rich Virgin Soils Become Less Productive. The first farming of a virgin soil has nearly always been grain farming. Grain is grown every year, with no provision for keeping up the humus supply, either by means of barnyard manure or by plowing under material, even the straw in the wheat-growing sections often being burned. Little barnyard manure is produced, and that which is formed is either thrown away or is allowed to lose most of its value before being put on the land. Very few farmers in any part of America have yet learned to handle manure without losing one-half of its value. The 
virgin soils are so productive that farmers nearly always make the mistake of thinking that they will always remain so. But the constant tillage exhausts the humus supply,

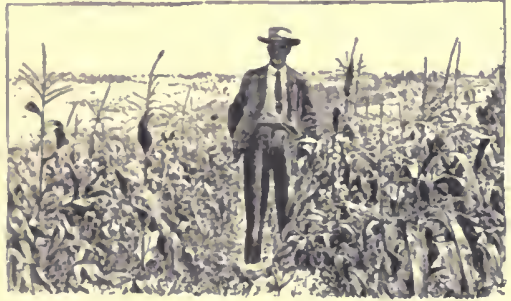

Fro.49. Corn crop on a farm that has raised - little live stock for fifty years and our virgin soils become less and less productive. The change is so gradual and is so obscured by the weather variations from year to year that the real state of affairs is often not realized until the soil is so poor that it does not pay to farm it. Sooner or later every farmer must give attention to means of maintaining the productivity of the land, no matter how rich the original soil may be. Thirty to sixty years of grain farming usually exhausts a rich virgin soil to such an extent that grain farming no longer pays. It then becomes necessary to raise stock and use manure or to plow under green-manure. Śmetimes ('ommercial feltilizers are resorted to aul these may pay for a few years, but sooner or later some provision

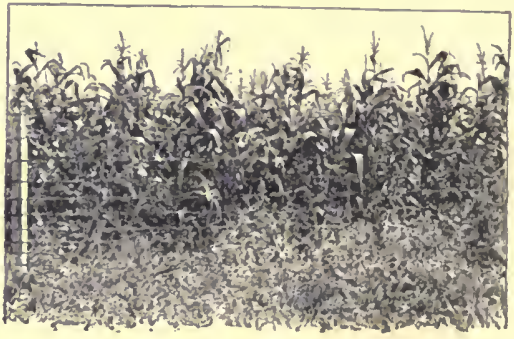

Fre. 50. Corn crop on a dairy farm near Fig. 49

for renewing the humus supply must be made, or the field must he temporarily abandoned to allow nature to renew the supply by growing weeds. Many fields in the 
older sections of the United States are thus abandoned for a few years to recuperate to such an extent that a small crop may be grown. A wiser way of farming would be to begin to raise animals for manure production before the soils become so exhausted.

\section{Causes of Decreased Productivity. (1) The fer-} tile surface soil may be carried away by erosion by wind or water. Probably more soil fertility is lost in this way than by cropping. This may be prevented by keeping the soil in sod, by keeping cover crops on it during the winter and by terracing the land as is done in the South.

(2) The soil may cease to hold the proper moisture supply. This may be remedied by drainage and tillage, and by additions of humus.

(3) The soil may cease to be favorable for the developIment of soil organisms. This may be remedied as No. 2 and by the application of lime.

(4) The nitrogen of the soil may be carried away in idrainage water or may escape to the air by denitrification. Many conditions favor the activity of soil organisms that decompose the nitrogen compounds and allow the nitrogen to escape as a gas.

(5) The constant cropping may exhaust the available supply of some plant-food. Each crop removes a certain amount of nitrogen, phosphoric acid, or potash. In time this may limit the available supply. Usually it is not a shortage of the absolute amount of such food in the soil, but a shortage of that which the plant can secure in soluble form. This may be remedied by drainage, tillage, additions of humus, lime, fertilizer and manure.

(6) The exhaustion of the humus supply is usually 
the fundamental cause for decrease in crop yields. This affects crops in many ways. It may result in an unfavorable physical condition of the soil that will limit the crop when there is no shortage of food. The soil may "bake" or it may lose its water-holding power. Since the humus furnishes the nitrogen by its decomposition and encourages the fixation of free nitrogen, the exhaustion of humus will be accompanied by a shortage of nitrogen. Or because of the lack of humus the mineral elements may not be rapidly enough dissolved, although present in abundance. In such a case the addition of phosphoric acid or potash might increase the crop, but it would usually be wiser to apply humus so as to render available the food that is already in the soil.

Many soils are losing their fertility in all of the ways mentioned above.

110. The Limiting Factor in Crop Growth. When all plant-foods are supplied in abundance, if the temperature is too low or too high, it becomes the limiting factor and determines the yield. If all other conditions are favorable, but there is not enough sunshine, the crop will be limited by this factor. A shortage of water or any other plant-food may be the limiting factor. The other plantfoods that often limit the crop are nitrogen, phosphoric acid, potash and lime. These foods are rarely needed to the same extent. If nitrogen is most deficient, the addition of nitrogen will increase the crop; but we may reach a point where a second element is necessary. Suppose that the weather and all other conditions are such as to allow a crop of 100 bushels of corn, but that the phosphoric acid supply is so short as to limit it to 70 
bushels, and that the nitrogen supply limits it to 40 bushels. The crop will then be 40 bushels. In growing such a crop, the farmer does not make use of all the favorable conditions; his crop is limited by the "weakest link." In such a case, the addition of a certain amount of nitrogen to the soil may bring the yield up to 70 bushels. Then the phosphoric acid must be added if a greater yield is to be obtained.

111. The Amount of Plant-Food in the Soil. Fortynine analyses of soils in different parts of America showed an average of 3;000 pounds of nitrogen, over 4,000 pounds of phosphoric acid and over 16,000 pounds of potash per acre.

By multiplying the average yield of crops (Appendix, Table 14) by the composition (Appendix, Table 6) we obtain the amount of foad removed by each crop. The average wheat crop of the United States for the past ten years (1899 to 1908) has been 13.8 bushels. This, together with the straw, removes about 14.5 pounds of nitrogen, 10.6 pounds of phosphoric acid and 14 pounds of potash per acre. The average surface soil would therefore contain enough nitrogen for 200 crops, phosphoric acid for 400 and potash for 1,000. But many soils do not contain so much plant-food as, this, and in the great majority of cases the food is too slowly available to produce maximum crops.

112. Value of Chemical Analyses of Soils. The chemical analysis of soils does not tell what fertilizers are needed. The almost universal opinion is that a chemist can analyze the soil and tell what it needs. The analysis may tell how much food there is in the soil, but it 
cannot tell how much of this the plant is able to get. A soil may contain enough phosphoric acid for a hundred crops, and yet the addition of phosphoric acid may be beneficial, because the plant may be unable to get this food in soluble form.

A chemical analysis is of some value. It shows the maximum limitations of a soil. It is quite clesirable to know how great a store of the plant-foods there is in a soil, in orcler to provide a permanent agriculture. If there is potash enough for a thousand years, we may still add it in the fertilizers, if it pays, but we should certainly try to find some way of unlocking that which is alrcady in the soil. But, if a soil contains potash enough for only 50 crops, we may well plan to add this food every year.

Some of the peaty soils in Illinois contain only enough potash for 41 crops of corn, each yielding 100 bushels. These soils give greatly inereased yields when potash is added. In general, muck soils are deficient in potash.

The gray silt loams of southern Illinois contain in the surface soil enough phosphoric acid for 70 such crops of corn, and enough potash for 1,900 such crops. ${ }^{1}$ Evidently one should try to draw on the supply of potash that is in the soil, and should add phosphoric acid. These soils were once so productive that southern Illinois was called "Egypt," but they are now very unproductive. By the use of lime, phosphoric acid and legumes, these soils are easily made to produce good crops once more. Most of the soils in Illinois are deficient in phosphorie acid.

113. Materials Used as Fertilizers. The oldest and best IIllinois, Bulletin No. 123 
fertilizer is barnyard manure. Growing plants have also been plowed under for many centuries. Usually these plants have been weeds, but sometimes crops are sown for the purpose of green-manuring.

The Indians taught the first settlers in America how to grow corn and to use fish as a fertilizer.

"According to the manner of the Indians, we manured our ground with herrings, or rather shads, which we have in great abundance and take with ease at our doors.

"You may see in one township a hundred acres together set with these fish, every acre taking a thousand of them, and an acre thus dressed will produce and yield as much corn as three acres without fish."

Fish are still in common use along the Atlantic coast, and dried fish and fish scraps are sold as fertilizers.

Salt $(\mathrm{NaCl})$ was sometimes applied to land, but this is not considered to be a wise practice because it does not contain the elements that are likely to be deficient. Any good effects of salt are probably due to chemical action or to the action of salt in helping to dissolve other elements in the soil. Many such substances have heen used, but they are not now used so much as formerly.

The purchased fertilizers that are most commonly used are mixtures containing nitrogen, phosphoric acid, and potash. The materials for making these fertilizers are usually obtained from slaughter-houses, or are mined from the earth.

The use of fertilizers in the United States has rapidly increased, and the area on which they are used is constantly extending westwarl. Little is yet used west of the Mississippi river. In 1879, farmers in the United situtes 
spent $\$ 29,000,000$ for fertilizers, in $1889, \$ 38,000,000$ and in $1899, \$ 55,000,000$.

\section{NITROGEN}

114. Sources of Soil Nitrogen. All soil nitrogen comes from the air. There is no nitrogen in the rocks except when these rocks contain the remains of plants and animals. The amount of nitrogen in the soil usually decreases very rapidly with the depth. The great inexhaustible source of nitrogen is the air. Nearly four-fifths of the air is nitrogen. There are about 35,000 tons of this gas over every acre of land. But no farm plants are able to take it from the air above ground. We may have sickly, yellow plants, starving to death for nitrogen while immersed in this inexhaustible supply. Since nitrogen is the most expensive of the fertilizing materials, costing about 18 cents per pound when purchased in commercial fertilizers, we may well be interested in getting the supply in the air into compounds that are available for the growth of crops. At the rate it must be paid for in commercial fertilizers, there are some ten million dollars' worth above each acre of land, -if it could be used!

115. Nitrogen in Rainfall. A small amount of nitrogenous compounds are brought down with the rain and snow. Usually this does not amount to over two or three pounds per acre per year, while about 40 pounds are required to produce a fair wheat crop..

116. Nitrogen Fixation by Bacteria on Legumes. Some of the oldest writings refer to the fact that pea-like plants have some effect on the soil that benefits following crops. Only in the last fifty years has this fact been explained. 
Until that time the Chinese explanation that "beans are good for the soil" was as good as any.

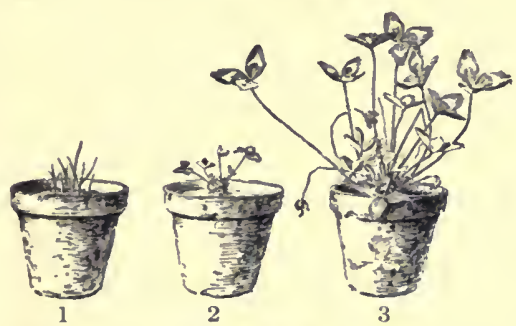

Fig. 51. (1) Wheat grown without nitrogen, all other foods supplied. (2) Clover grown without nitrogen. (3) Clover without nitrogen, but inoculated with legume bacteria.

In the last fifty years many investigators have worked on the subject, and it has been demonstrated that when legumes have certain bacteria present on their roots they are able to grow in soils that do not contain any nitrogen. The free nitrogen of the air in the soil has been proved to be the source of their supply. If the right kind of bacteria are not present, a legume cannot grow without nitrogen in the soil. No other farm plants are able to obtain nitrogen in this way (Fig. 51). Peas, beans, clover, alfalfa, peanuts and vetches are some of the legumes. Look at the roots of any of these plants and you will find small bunches on them. On clover they are a little larger than a pinhead (Fig. 14), but on beans the nodules are as large as small sweet peas. (Fig. 52). These nodules are caused by a certain kind of bacteriun ( $P$ seudomonas radi-

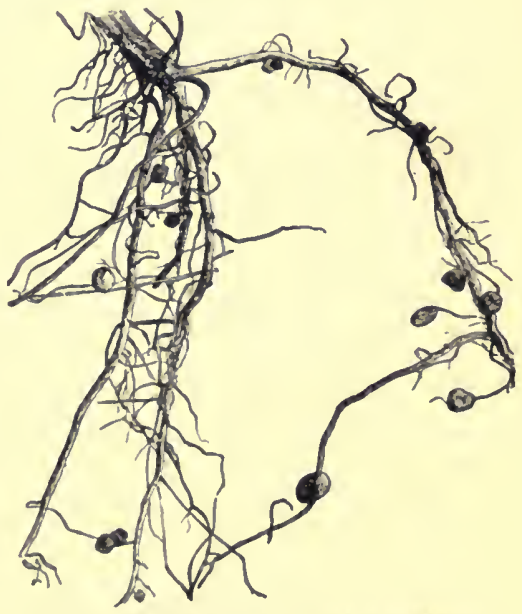

FIG. 52. Nodules in which the nitrogen-fixing bacteria live on the roots of a bean 
cicola) that enters the roots of the legume. These bacteria are able to use the free nitrogen of the soil air. After they have used the nitrogen, it is left in compounds that the plant can make use of, so that a legume can grow with no

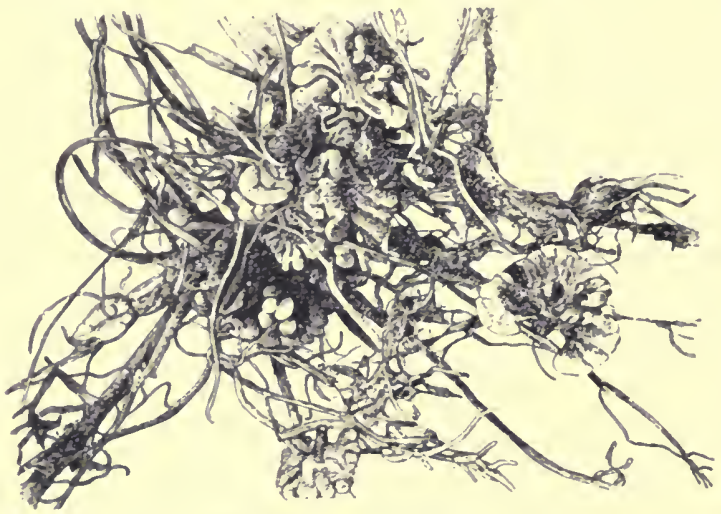

Fig. 53. Nodules on the roots of hairy vetrh

nitrogen in the soil if other conditions are favorable. The legume roots furnish a home for the bacteria and in return are supplied with nitrogen. These bacteria do not live on the roots of any other farm crops.

Iost soils contain the bacteria, so that all we need to do is to sow the legume seed; but, if the bacteria are athsent, we must sow them also. In much of the eastern part of the United States, bacteria need to be supplied for the growth of alfalfa. The best way of supplying them is to scatter a bushel or more of soil from a successful alfalfa fiekd on each acre of land that needs to be inoculated. Soy-beans, cowpeas and retches often need to be inoculated when they are grown on a soil for the first time.

Legumes are also able to take nitrogen from the soil 
compounds in the same way that other plants do. They require much more nitrogen than other plants do, and have two ways of obtuining it.

It is very hard to determine what proportion of the nitrogen in a legume comes from the air and what proportion comes from the soil. It is certain that a considerable part comes from the air under usual farm conditions. One German investigator grew twenty-eight successive crops of lupines (a legume) on the same land with no nitrogen added. But, in spite of the removal of these crops, the field gained in nitrogen. We can readily see how important it is to have some legume like alfalfa, clover, or cowpeas in a crop-rotation.

117. Fixation of Nitrogen without Legumes. During the last few years, a great deal of attention has been given to legumes as a source of nitrogen. But the fixation without legumes is probably a more important source of nitrogen. Lipman grew millet in boxes of soil that had been given different treatments. ${ }^{1}$ In all cases, the amount of nitrogen in the soil was determined at the start, and that in the soil and crop was determined at the end. A few of his results follow:

(1) No fertilizer used, no crop grown, soil kept bare, a gain of 1.02 grams of nitrogen.

(2) No fertilizer used, millet grown; slight gain of nitrogen.

(3) One gram of nitrogen added to the soil in the form of nitrate of soda, millet grown; a gain of 3.73 grams of nitrogen.

(4) One gram of nitrogen added in the form of barn¿New Jersey Experiment Station, Bulletin No. $15(1$ 
yard manure, millet grown; a gain of 10.48 grams of nitrogen.

The soil that was kept bare contained a gram more nitrogen in the fall than it did in the spring. There was a slight gain when millet was grown. When a gram of nitrogen was added in the form of nitrate of soda, the crop and soil contained 3.73 grams more nitrogen than were present in the fertilizer and soil at the beginning. But, when barnyard manure was used, there was a gain of 10.48 grams-ten times as much nitrogen as was added in the manure. These gains came from the air. The nitrogen was fixed by organisms acting independently of legumes. (Millet is not a legume.)

Certain conditions greatly favor the activities of these important organisms. The soil should be well aërated and drained, and it must contain sufficient lime and humus. The striking results with the barnyard manure are probably due to the humus that it contains, and perhaps partly due to the organisms that it brings with it. This partly explains why fertilizers alone cannot take the place of manure.

118. Importance of Grasses. Grasses do not have the power of obtaining any nitrogen from the air, but when land is left in sod there is usually a considerable gain in nitrogen. A field at Rothamsted, England, was left to grow up to weeds and grasses for twenty years. No legumes were grown on it, but there was a gain of over forty-four pounds of nitrogen per acre per year-enough to much more than grow a good crop each year. ${ }^{1}$

Every farmer knows that a field that has been in sod for a few years produces much better crops when it is ${ }^{1}$ The Book of the Rothamsted Experiments, by A. D. Hall, p. 139. 
plowed up. This is partly due to the humus added by the decaying roots, and is undoubtedly partly due to the fixation of nitrogen. Probably the humus has much to do with the nitrogen fixation.

In the regions where soils have been so farmed as to become unproductive, the fields are commonly' abandoned for one or more years, then they will produce crops again. Where the soils are not quite so far exhausted, one or two tilled crops are grown and are then followed by hay a few years, after which small crops can once more be raised. The same principle should be applied in regular farming. Under most conditions, the land should be in sod one to three years out of every five. The poorer the land, the more time it should be in sod. If legumes can be combined with this sod, so much the better. The same results may be accomplished in other ways, as by plowing under green-manure crops.

119. Losses of Nitrogen from Soils. There are other organisms in the soil which accomplish the opposite results. They act on nitrogen compounds and break them up so that the nitrogen escapes into the air as free nitrogen. This is called denitrification. When manure is left in loose piles, much of the nitrogen is lost by denitrification.

Nitrogen may also be lost by being made soluble too rapidly, in which case it may leach out of the soil. The humus in a sandy soil is likely to be burned out so rapidly that the nitrogen may be lost in this way.

Soils in Minnesota that were kept continuously in grain lost 146 pounds of nitrogen by the destruction of organic matter for each 25 pounds that was removed in 
crops.' It is evident that these soils will become unproductive if the one-crop system continues.

The better arirated the soil, the warmer the climate, and the more the lind is tilled, the more rapidly the humus will be exhausted. The ideal condition is to have the humus decompose just rapidly enough to supply the crop with nitrogen. If it burns out too rapidly, we may keep the land in sod more of the time, apply manure, or plow under (rops to keep up the humus supply.

120. Forms of Nitrogenous Fertilizers. Nitrogen is added to the soil in the form of barnyard manure, sodium nitrate, ammonium sulfate, potassium nitrate, dried blood, tankage, hoof meal, steamed bone, dried fish, linseed-oil meal, cottonseed meal, and in a number of other forms.

121. Nitrate of Soda $\left(\mathrm{NaNO}_{3}\right)$. Sodium nitrate, or Chile saltpeter, is the most common nitrogenous fertilizer. Beds of it occur along the western coast of South America, particularly in Peru and Chile. As it is taken from the earth, it contains about 50 per cent of nitrate of soda. This is purified, so that when put on the market it is usually $9(;$ per rent pure. It contains an average of about 15.6 per rent of nitrogen, and costs about $\$ 60$ per ton, or about 19 cents per pound for the nitrogen contained. This salt is very soluble and is in a form that plants can take up at once. It should be applied only where plants will soon make use of it; otherwise it may leach out of the soil.

122. Ammonium Sulfate $\left.\left(\mathrm{NH}_{4}\right)_{2} \quad \mathrm{SO}_{4}\right)$. This substance is a by-product from the manufacture of gas and coke. It contains about 20 per cent of nitrogen. The 
nitrogen in this form is a little cheaper than it is in the form of sodium nitrate. It is not so desirable as the nitrate because it tends to make the soil acid. If used continuously, lime must also be used unless the soil is rich in lime. Nitrate of soda has a slightly opposite effect.

123. Dried Blood, Tankage and Bone Meal are products from the meat-packing houses. Tankage is made up of all kinds of waste material from the slaughter-houses. The names of the others indicate their origin. They contain 5 to 15 per cent of nitrogen. Good dried blood contains about 14 per cent. These products have to be acted on by soil bacteria before the nitrogen is available for crop growth. There is less danger of loss of nitrogen than in the case of sodium nitrate. These forms are particularly desirable for fall-sown crops. Some farmers who mix their own fertilizers use about half of the nitrogen in the form of dried blood and half in the form of nitrate of soda. This seems to be a good practice.

\section{PHOSPHORUS}

124. Forms of Phosphorus Fertilizers. The chief forms of phosphorus fertilizers are barnyard manure, dissolved phosphate rock, bone meal; dissolved bone, tankage, Thomas slag.

125. Phosphate Rock. This rock is found in many parts of the United States, particularly in the Carolinas, Florida and Tennessee. It is sometimes called South Carolina rock. The deposits are remains of marine life. As the rock is mined, it is about 50 per cent tricalcium phosphate $\left(\mathrm{Ca}_{3}\left(\mathrm{PO}_{4}\right)_{2}\right)$. The rock is sometimes finely 
ground and sold as a fertilizer under the name "floats." There is an increasing amount of floats used, particularly in the central west, where the soils contain considerable amounts of olganic matter. But most of the rock is treated with sulfuric acid so as to render it soluble. The product is called acid phosphate, or dissolved rock. In this form it contains about 14 per cent of phosphoric acid," and costs about $\$ 14$ per ton in New York City. When applied to the soil, it reverts to the original insoluble form. Being soluble when it is applied, it is distributed in the soil moisture. When it reverts it is deposited on the outside of innumerable soil grains. This gives a largel area exposed to the action of soil water, so that it will dissolve and supply plants faster than it would in the finely ground form.

126. Bone. Bones are sometimes finely ground to form bone meal, or treated with sulfuric acid to form dissolved bone. They are also used as bone ash, steamed bone meal and bone black. The amount of phosphoric acid varies from 18 to 36 per cent. Good bone meal contains about 4 per cent nitrogen and 22 per cent phosphoric acid.

\section{Thomas Slag. This material is a by-product} from the manufacture of steel. It is not used to a very great extent in America at present. It is not acid in its nature and so has an advantage over acid phosphate. It is sometimes called "basic slag."

${ }^{1}$ The composition of phosphatic fertilizers is usually given in terms of phosphoric acid $\left(\mathrm{P}_{2} \mathrm{O}_{5}\right)$. Such a compound does not exist in fertilizers, but it furnishes a basis for comparison. Phosphoric acid costs about four and one-half to five cents per pound. The composition of potash fertilizers is also expressed in terms of a substance that does not occur in the fertilizers, potash $\left(\mathrm{K}_{2} \mathrm{O}\right)$. In both cases it would be much more desirable to have the composition expressed in terms of elements, phosphorus (P) and potassium $(K)$. An effort is now being made to change to this system, but it has not yet been generally adopted. 


\section{POTASH}

128. Forms of Potash Fertilizers. The chief fertilizing materials carrying potash are barnyard manure, muriate of potash ( $\mathrm{KCl})$, sulface of potash $\left(\mathrm{K}_{2} \mathrm{SO}_{4}\right)$, kainit and wood-ashes.

129. Kainit, Muriate of Potash and Sulfate of Potash. Kainit is mined in Germany in the same way as rock-salt. It was probably deposited in the same way. It was while trying to get salt that kainit was found. It contains salt and other minerals with about 12 per cent of potash $\left(\mathrm{K}_{2} \mathrm{O}\right)$. Kainit is used as a fertilizer in Germany, but is not much used in this country because it contains too many impurities on which to pay freight.

Nearly all the potash used in America is potassium chlorid, or muriate of potash $(\mathrm{KCl})$. This is manufactured from the kainit. It contains about 50 per cent of potash. It costs about $\$ 45$ per ton, or about 4.5 cents per pound of potash.

Sulfate of potash $\left(\mathrm{K}_{2} \mathrm{SO}_{4}\right)$ is also manufactured from kainit. It costs about one cent per pound more for the potash than in the form of muriate. It is used in cases where the muriate is not desirable. The muriate usually injures the quality of sugar beets and tobacco.

130. Wood-Ashes. Hardwood-ashes contain 2 to 10 per cent of potash and average 5 to 6 per cent. They also contain 1 to 2 per cent of phosphoric acid and about 34 per cent of lime $(\mathrm{CaO})$. If the ashes are leached, most of the potash is removed. Soft wood-ashes contain less potash than those from hard wood. Coal-ashes contain almost no plant-food. 


\section{LIME}

131. Functions of Lime. lime is usually spoken of as a soil amendment rather than as a plant-food, hecause its chief value when arderl to the soil does not seem to be as a plant-fool. A deficiency of lime in the soil seems to show in other ways before there is really a shortage of lime as food. Lime helps to improve the physical condition of some soils. It corrects acidity. It helps to liberate other plant-foods. Perhaps its most important effect is its influence on soil organisms. If there is not sufficient lime in the soil, the fixation of atmospheric nitrogen cannot go on properly, nor can the liberation of nitrogen from the humus. The addition of lime to the soil so favors the preparation of nitrogen food that its effect is often the same as the addition of nitrogen. If a soil is deficient in lime it is unwise to go on farming it until this deficiency has been corrected. The other fertilizers or harnyard manure cannot be used most economically if there is not sufficient lime. On the other hand lime does not take the place of these fertilizing materials.

132. Relation of Crops to Lime. There is a very decided difference in the lime requirements of different cropss. Alfalfa and clover need more lime than do any of the other common farm crops. (See Fig. 97.) These may show a henefit from the use of lime when timothy, corn and wheat are not helped. Timothy may fail for lack of lime where red-top thrives. Alfalfa, clover, lettuce, beets, cantaloupes, onions, timothy are more sensitive to acid conditions than are soy-heans, cowpeas, red-top and watermelons. 
133. How to Tell the Need of Lime. One of the most common indications of the need of lime is the failure of red clover on soils where it once grew. This is generally due to the exhaustion of lime. If red elover fails and red-top thrives we should certainly make a test of lime. Clover sometimes fails because of the root-borer, but, in this case, it does not fail until it has produced the first crop of hay. In some regions it fails because of disease (anthracnose), but, in this case, it makes a good growth until the disease attacks it. If clover and alfalfa produce good crops, lime will not be needed. An easy test for the need of lime is to lay off a plot four rods square in the field. Apply a bushel of lime on half of the plot and apply manure on half of it in the other direction. We then have lime and manure alone and together as compared with no treatment. The lime is likely to have a greater effect the second year.

134. Forms of Lime. Lime

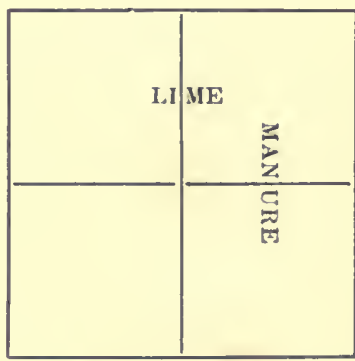

Fiv. 54. Experiment to determine whether lime is needed

occurs in the earth as limestone rock or calcium carbonate $\left(\mathrm{CaCO}_{3}\right)$. When this is burned, carbon dioxid $\left(\mathrm{CO}_{2}\right)$ is given off and we have left quicklime $(\mathrm{CaO})$. This is the lime that is used in plastering. When this lime is waterslaked to form plaster, it takes up water and we have calcium hydrate, waterslaked lime, or hydrated lime $(\mathrm{Ca}$ $\left.(\mathrm{OH})_{2}\right)^{2}$. When this is put on the walls as plaster it dries out and becomes white. As it loses water, it takes up carhon dioxid from the air and the calcium carbonate is 
again formed. When quicklime air-slakes it also takes up carbon dioxid from the air. Similar changes take place when it is used on the soil.

Quicklime, calcium oxid $(\mathrm{CaO})$ is the most common form of lime used for agricultural purposes. Usually a poorer grade is used than for plastering. When this is applied to soil, the same changes take place as in the case of plastering. The lump lime is sometimes finely ground so that it can he applied by machinery. Limestone rock is sometimes finely ground and is applied to the soil. Some firms slake the lime with water and sell the hydrated lime. This is also a powder.

Fifty-six pounds of quicklime $(\mathrm{CaO})$ are equal to 74 pounds of hydrated lime, or to 100 pounds of ground limestone or air-slaked lime.

The quicklime, or hydrated lime, should not be applied within a week of the time of planting crops, because it is sometimes so caustic as to injure young plants.

Ashes contain about one-third lime.

Gypsum or land plaster $\left(\mathrm{CaSO}_{4}\right)$ also contains lime, but it is not so good as other forms because it contains sulfuric acid. The use of it is rapidly decreasing.

135. Application of Lime. From 500 pounds to one ton (6 to 30 bushels) per acre is usually enough to apply at one time. The application may need to be repeated in a few years. Formerly much larger applications were made. There are many conflicting reports as to the benefit of lime. Many regions have taken it up, dropped it, and later come to use it once more. The explanation is that with the amounts applied there was enough to last a considerable time. 


\section{COMPLETE FERTILIZERS}

136. Cost, Valuation and Analyses. Fertilizers that are purchased by farmers are usually made up of a mixture of some of the materials previously described. Such fertilizers usually: contain nitrogen, phosphoric acid and potash. They are commonly used without much regard for the needs of crops on the particular soil.

They are subject to inspection in a number of states and must be labeled with the per cent of each plant-food that they contain. In Vermont, in 1908, the result of this inspection showed that the average selling price of mixed fertilizers was $\$ 31.24$ per ton, but the materials for mixing them could have been purchased at retail in Boston or New York for $\$ 20.75$. Evidently there is a considerable loss to farmers in purchasing complete fertilizers. Not only are the fertilizers likely to be ill adapted to their needs, but the prices are too high. The difference between $\$ 20.75$ and $\$ 31.24$ per ton covers:

(1) The cost of mixing.

(2) Cost of transportation.

(3) Storage, commission to agents, dealers, etc.

(4) Selling on credit, and bad debts.

A careful farmel should always avoid the last two expenses, so far as possible.

At the average retail prices in New York City in 1908, nitrogen cost $18 \frac{1}{2}$ cents, phosphoric acid and potash each cost $4 \frac{1}{2}$ cents per pound. The farmers have paid much more than these prices. According to the figures above they must have paid 25 cents per pound for nitrogen and 6 cents for potash and for phosphoric acid. 
A fertilizer containing 2 per cent nitrogen, 10 per cent phosphorie acid and 8 per cent potash is often spoken of as a $2,10, s$ ( $t w o$, ten, eight) fertilizer.

An approximate way to estimate the value of a fertilizer in dollars per ton is to multiply the per cent of nitrogen by four and add the per cents of phosphoric acid and potash. This estimates nitrogen at 20 cents per pound and phosphoric acid and potash at 5 cents each per pound. (Prove this rule.) These are higher than the New York prices, but lower than the farmers pay for complete fertilizers, and allow a considerable margin for freight. A $2,10,8$ fertilizer would therefore be worth approximately $4 \times 2+10+\$=\$ 26$ per ton.

The labels on fertilizer bags are often confusing, and are doubtless intended to be so. The following is a copy of such a label, and at the right are the facts reduced to their simplest terms:

\begin{tabular}{|c|c|c|}
\hline Vit & $\begin{array}{l}\text { Per cent } \\
0.82-1.64\end{array}$ & \\
\hline $\mathrm{n}$ as am & $\begin{array}{l}0.02-1.07 \\
1.00-2.00\end{array}$ & \\
\hline e phosphoric aci & $6.00-$ & \\
\hline Reverted phosphoric acid & 3.00 & Nitrogen \\
\hline $\begin{array}{l}\text { Insoluble phosphoric acid } \\
\text { Total phosphoric acid... }\end{array}$ & $\begin{array}{r}1.00-2.00 \\
10.00-1200\end{array}$ & Available phos- \\
\hline Bone phosphate of lime.. & $22.00-25.00$ & phoric acid ...8.00 \\
\hline Available bone phosphate of lime & $18.00-20.00$ & Potash. . \\
\hline Available phosphoric acid & $8.00-10.00$ & \\
\hline & .00 & \\
\hline to sulfate of & $8.00-10.00$ & \\
\hline
\end{tabular}

The higher percentages in the guarantee mean nothing. A guarantee of 4 to 5 per cent of potash is a guarantee of 4 per cent; it would be the same if it said 4 to 50 per cent. Nor do the numerous equivalents mean anything, except for comparison, as that .82 per cent of nitrogen is equivalent to 1 per cent of ammonia. 
Farmers are also likely to be misled by the names applied to the fertilizers, as potato specials, corn specials, etc. One firm in Vermont sold three kinds of fertilizer under thirty-three different names! One firm in New York sells two grass fertilizers, one analyzing 1, 7, 2, and one $9,6,6$. They must be for different kinds of grass, or more likely they are for two different kinds of farmers. The former fertilizer is cheap, thus pleasing some persons, the latter is adapted to grass, thus pleasing others.

137. Home Mixing of Fertilizers. It is not a difficult matter to mix fertilizers at home. The proper proportions may be put together on a tight barn-floor and be shoveled over a few times. If any of the ingredients are lumpy, these should be put in first and the lumps crushed. Fertilizer agents argue that the mixing is better done at the factories. This may be true, but field experiments have shown that the home-mixed ones produce as good crops and are much cheaper. Sometimes a grange purchases enough materials for a carload or more of fertilizer. The mixing is then done at the factories at little or no expense.

Suppose that it is desired to make ten tons of a $2,7,8$ fertilizer. How much nitrate of soda (15.5 per cent), acid phosphate (14 per cent) and muriate of potash (50 per cent) will be required? This will require $20,000 \times .02=$ 400 pounds of nitrogen, $20,000 \times .07=1,400$ pounds phosphoric acid and similarly 1,600 pounds of potash. To furnish these amounts will require:

$$
\begin{aligned}
400 \div 0.155 & =2,581 \text { pounds of nitrate of soda } \\
1,400+0.14 & =10,000 \text { pounds of acid phosphate } \\
1,600+0.50 & =\frac{3,200}{15,781} \text { pounds of muriate of potash }
\end{aligned}
$$


This lacks 4,219 pounds of weighing ten tons, but it has all the plant-food called for. One can put in this much dirt for filler, but it would be simpler to merely use threefourths as much per acre as was planned. If such a fertilizer were purchased ready-made, one would have to pay freight on this much useless material.

138. How to Determine What Fertilizer to Use. Grass crops and most crops whose yield depends on the total vegetative growth, are more likely to need nitrogen than are ordinary crops. On the Cornell University farms, fertilizers gave little benefit when used on oats, corn or wheat, but, when nitrate of soda was applied on timothy, it increased the yield from one and one-half to three and three-fourths tons per acre. (See Fig. 55.)

Lecruminous crops are more likely to need phosphoric acid, potash and lime than are other crops. (See Fig. 97.)

If lime is needed, phosphoric acid is also very likely to be needed, because most of the available phosphorus is in combination with lime. There may, however, be plenty of lime and not enough phosphorus, for the great storelouse of lime is limestone.

In a general way we may say that nitrogen promotes leafiness, while phosphoric acid and potash have more to do with seed-production. This may help in determining what fertilizer to try, but must not be relied upon too much.

More important than any of these points is the value of the crop. High-priced crops may be profitably fertilized when it would be folly to fertilize low-priced ones. A truck crop may be worth $\$ 200$ per arre on the same farm where a corn crop is worth $\$ 20$. If a certain fertilizer 


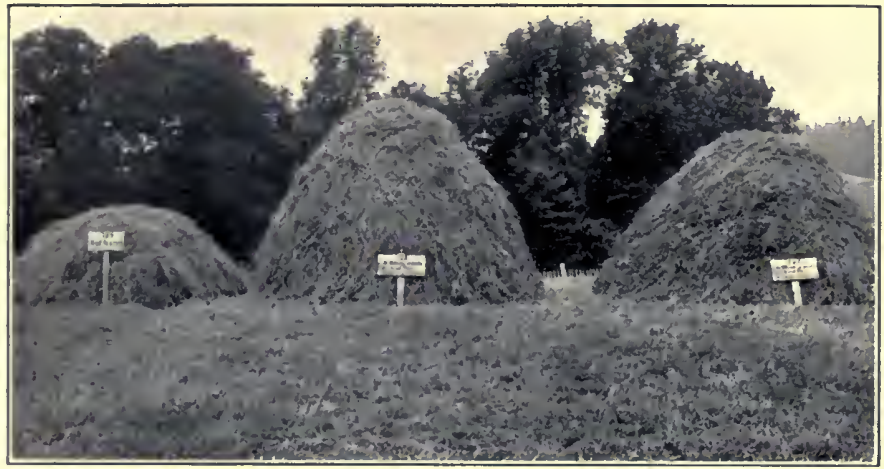

$\begin{array}{ccc}\text { Nothing } & 640 \text { lbs. nitrate sodat } & 320 \text { Jbs, nitrate soda } \\ 2.590 \text { lbs. hay per acre } & 320 \text { acid phosphate } & 320 \text { acil phosphate } \\ & \$ 0 \text { muriate potash } & \$ 0 \text { muriate potash } \\ & 7,340 \text { lbs, hay per acre } & 7,110 \text { lbs, hay per acre }\end{array}$

Fıg.55. Timothy hay responds to fertilizers, particularly nitrate of soda

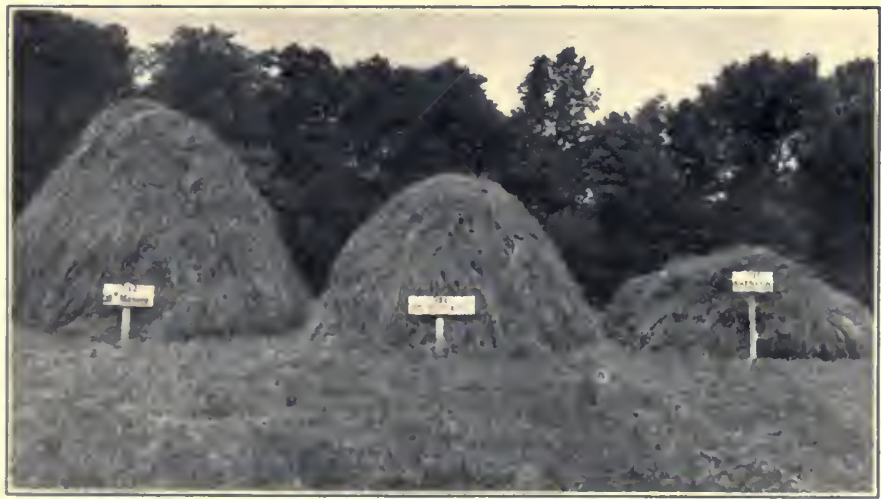

20 tons nanure

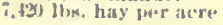

ii) tonn matnure

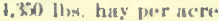

Nothink

2,230 llow, hay per acre

Fif. 56. Timothy hay responds to barnyard manure 

will increase each crop 10 per cent it will mean a gain of $\$ 2$ per acre on the corn and $\$ 20$ per acre on the truck. One might pay $\$ 10$ for such a fertilizer if he is raising truck crops, but could not afford to use it on corn.

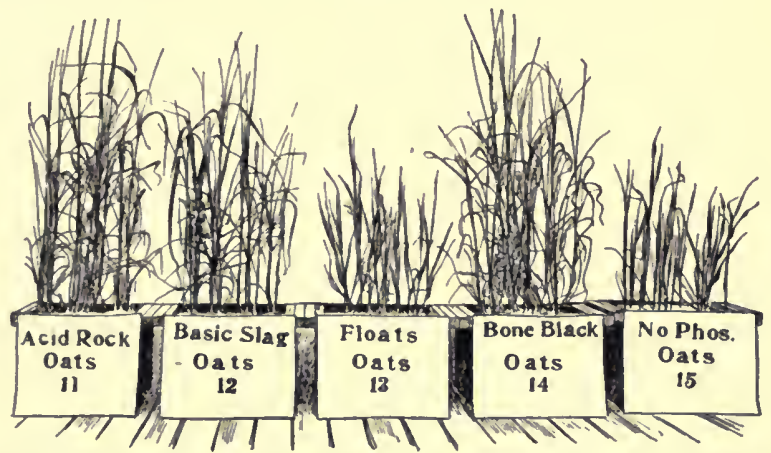

F1G. 57. The crop to be grown is as important as the soil, when deciding on a

fertilizer. Floats are of little value for oats but best for rape. (See Fig. 58)

Contrary to the common opinion, fertilizers are usually not profitable on very poor land. Such land usually needs humus, and often needs other treatment before it will pay to use fertilizers. About forty farmers in New York have reported trials of nitrate of soda for the production

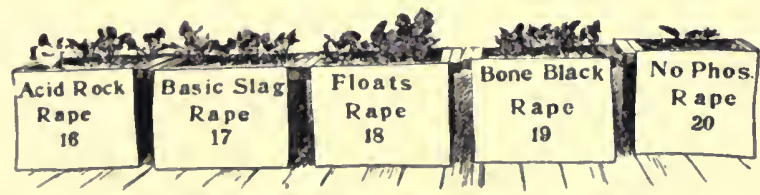

FIt: 58. Rape is best with foats. Compare with Fig. 57

of timothy hay. In very few cases has it paid if the field did not yield at least one and one-fourth tons when untreated, and in very few cases did it fail to pay when the unfertilized area yielded over one and one-fourth tons. 
It seems to be very nearly as easy to double a yield of one and one-half tons as to double a yield of one-half ton. In the former case, the gain will be three times as much as in the latter.

The profitableness of a fertilizer is very much a matter of season. In general, the best results are secured in favorable seasons. A fertilizer that pays in a good season may not pay in a season of deficient rainfall.

In deciding on a fertilizer practice to be followed, one should consult the State Experiment Station to learn whether there are any fundamental deficiencies of the soils of the region. "On practically all Ohio soils that have been for any length of time in cultivation-possibly excepting the mucks-phosphorus must be supplied before the maximum yield of any crop can be attained. The longer the land has been in cultivation the greater the need of phosphorus, but many comparatively new soils will respond to it." 1 Phosphoric acid seems to be deficient in nearly all of the soils from the Appalachian mountains to the Mississippi river.

After one has obtained all the public information concerning the region it is best to make trials of the most likely combinations on small areas of the farm. For this purpose, we should select as uniform a place in the field as possible, and one that is neither better nor poorer than the average. Even such trials must be accepted with caution. For instance, at the Ohio Station, where trials have been conducted on the same land for fourteen years, the first season was abnormal; potash gave an increase in yield of wheat and phosphoric acid decreased the yield. 
But all the later years have shown that phosphorus was most needed and potash least needed.

\section{BARNYARD MANURE}

139. Importance of Manure. Over half a century ago a French scientist declared that one of the most important lessons for the farmer to learn was how to produce good barnyard manure and to use it rationally; that the fundamental question was and would remain the manure question. The older our farm lands become, the more truth we see in his statement. In many parts of America the manure is thrown away. In regions where thousands of dollars are spent for fertilizers, a half of the value of manure is usually lost before it is applied to the land.

Figured at the price that the plant-food in manure would cost in fertilizers, the amount produced in the Uniterl States is worth $\$ 2,353,000,000^{1}$ per year. The value of the corn crop in 1908 was about two-thirds this amount, $\$ 1,601,000,000$.

140. Value of Manure. The value of manure is often figured on the basis of what the nitrogen, phosphoric acicl and potash would cost if purchased in commercial fertilizers. The plant-food in manure is less soluble than that in fertilizers; on the other hand, this method does not give any value to the humus, which is a very important part of the manure. Field trials usually show that this is a fair method of comparison with fertilizers, particularly when the lasting effects are considered. Truckgrowers in New Jersey, who buy both manure and ferti- 
lizers, pay much more for the plant-food in manure than they have to pay for it in the fertilizers. They feel that they must have the manure, even if it is more expensive. Sometimes they dispense with manure when they can plow under clover.

The price at which manure can be purchased is quite variable. In parts of the West a man is paid to haul it away to get rid of it. Farmers in New Jersey purehase it by the carload from Philadelphia and New York at about $\$ 2.50$ per ton. and there is still the expense of hauling to the farms. In many of the smaller cities of the East, it can be had for the hauling, in others, it must be paid for.

How much manure is worth on a given farm depends on how much it is needed. It may be worth more or less than the fertility in it would cost in fertilizers.

Sieventy-nine analyses of manure and bedding at the Massachusetts Experiment Station gave an average of 66 per cent water, 0.45 per cent nitrogen, 0.33 per cent phosphoric acid, 0.56 per cent potash. This is practically one-half per cent of nitrogen and potash, and one-third per cent phosphoric acid. The plant-food in a ton of such manure would eost about $\$ 2.83\left(4 \times \frac{1}{2}+\frac{1}{3}+\frac{1}{2}\right)$.

At the Cornell Experiment Station, each ton of manure gave $\$ 2.5 s$ worth of hay and oats in three years above the value from the untreated land. In one three-year rotation of wheat, clover, potatoes in Ohio, each ton of manure gave $\$ 2.96$ worth of increased crops. In each case, there will be a considerable benefit from the manure on later crops, as the good effects of manure are not all gone in three years.

Experiments at Rothamsted, England, during fifty 
years on land unmanured, manured continuously, and manured during the first twenty years only, showed a gradual decrease in the crop on the unmanured soil and a gradual increase from year to year on the manured soil. When the application was stopped there was a gradual Pounds of grain per acre

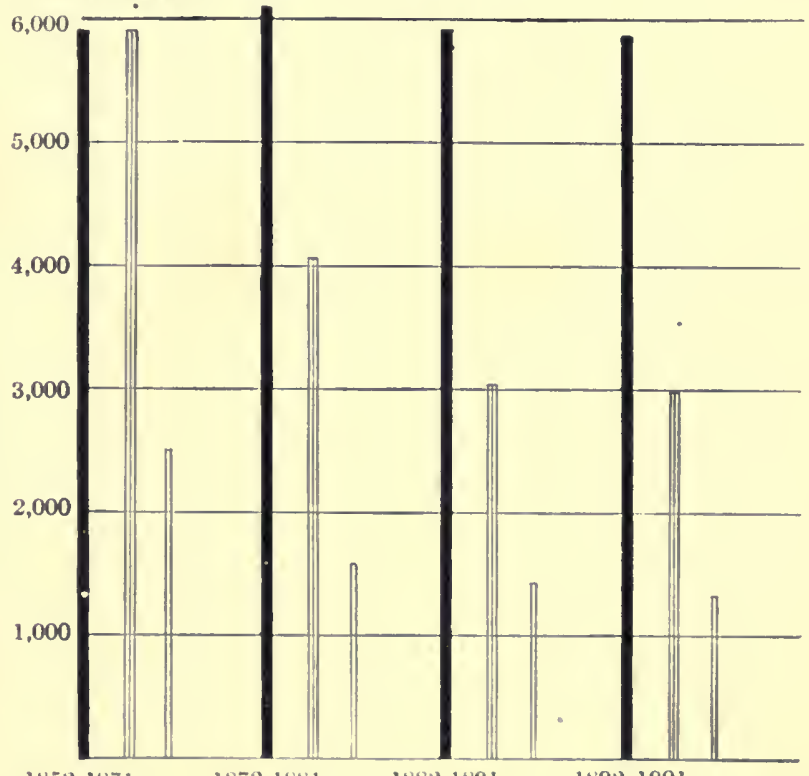

$1852-1871$

$1872-1881$

$188:-1891$

$1892-1901$

Fir. 59. Effects of barnyard manure on the yield of barlcy-ten-year averages. Manured every year.

Manured every year until 18il, but no manure since that date. No manure since 1852 .

Thirty years after the last application of manure to the second plot it still gave a ten-year average yield double that of the unmanured.

decrease, but, at the end of thirty years after the last application, the yield was still double that on the unmanured part.' (See Fig. 59.)

${ }^{1}$ The Book of the Rothamsted Experiments, by $\Lambda$. 1). Inull, p. 78 


\section{Factors Influencing the Value of Manure. Young} animals, poor animals, those producing a rich product, as milk, or those doing hard work, usually digest their food more fully, so that the manure is less valuable. If the food is rich, the manure is improved. The manure of different animals differs in value. That from poultry is most valuable. Sheep manure is more valuable than cow manure, chiefly because it is drier. The character of bedding also influences the value of manure. Sawdust and shavings are of no value, so that if they are used the manure is not so valuable as when straw is used. If the liquid portion is lost, if it ferments, or if it leaches, the manure will be less valuable.

142. Fertilizing Value of Food and of Manure. From 65 to 75 per cent of the nitrogen, phosphoric acid and potash fed to cows is recovered in the manure. In Ohio, threefourths of the nitrogen and phosphoric acid, and seveneighths of the potash in the food of steers, was recovered in the manure when they were fed on a cement floor. Two-thirds of the nitrogen, four-fifths of the phosphoric acid, and nine-tenths of the potash of the food was recovered in the manure when lambs were fed on a dirt floor. In general, it is safe to assume that three-fourths of the fertility in the feed is recovered in the manure. This, of course, assumes that the liquid portion is saved and that leaching and other losses are prevented.

This fact has an important bearing on farm management. Cottonseed meal, dried blood and tankage are used as fertilizers and as feed. The meal is fed to cattle. The dried blood and tankage are fed to hogs and poultry. It is usually more profitable to feed these to animals and 
use the manure on the land rather than purchase fertilizers. In general, it is more profitable to purchase fertility as feed for stock than to buy it in a fertilizer bag. A good many eastern farmers feed sheep and beef cattle not so much for the profit that the animals give directly as for the manure that they produce.

\section{Amount and Value of Manure Produced by Farm} Animals. A 1,200-pound horse will produce about eleven tons of excrement per year, which, together with the bedding, will make about fourteen tons of manure. A cow produces about the same amount. Steers fed at the Ohio Station averaged at the rate of nine tons per year. An equal weight of sheep produces fewer tons, but the manure is drier, so that about the same amount of plantfood is produced. A fairly safe rule for any stock except sheep, poultry and hogs is to count one ton per month for each 1,000 pounds of animals kept. To purchase an equal amount of plant-food in fertilizers would cost about $\$ 40$ per year. The following table gives results procured by Roberts:

Manure Per 1,000 Pounds of Live Weight

\begin{tabular}{|c|c|c|c|c|c|c|}
\hline & $\begin{array}{l}\text { Exerement } \\
\text { per year }\end{array}$ & $\begin{array}{l}\text { Manure } \\
\text { with } \\
\text { bedding } \\
\text { per year }\end{array}$ & $\begin{array}{l}\text { Nitrogen } \\
\text { per year }\end{array}$ & $\begin{array}{l}\text { Phosphorie } \\
\text { Acid } \\
\text { per year }\end{array}$ & $\begin{array}{l}\text { Potash } \\
\text { per year }\end{array}$ & $\begin{array}{l}\text { Value } \\
\text { per year }{ }^{2}\end{array}$ \\
\hline llorse. & $\begin{array}{c}\text { Tons } \\
8.3\end{array}$ & $\begin{array}{l}\text { Tons } \\
12.1\end{array}$ & $\begin{array}{l}\text { L.hs. } \\
153\end{array}$ & $\begin{array}{l}\text { I.bs. } \\
81\end{array}$ & $\begin{array}{l}\text { Lbs. } \\
150\end{array}$ & $\$ 42 \quad 15$ \\
\hline Cow... & 13.5 & 14.6 & 137 & 92 & 140 & 3900 \\
\hline Sheep & 6.2 & 9.6 & 175 & 88 & 133 & 4605 \\
\hline Calf ..... & 12.4 & 14.8 & 150 & 105 & 102 & 4035 \\
\hline Pig .... . & 15.3 & 18.2 & 331 & 158 & 130 & 8060 \\
\hline Fowls & 4.3 & 4.3 & 293 & 119 & 72 & $68 \quad 15$ \\
\hline
\end{tabular}

IThe nitrogen is figured at 20 cents and the other eonstituents at 5 eentr per pound. 
The amount of manure produced must be considered in planning a cropping system for a farm. If one wishes to manure one-fifth of the land every year with 10 tons per acre, there would have to be provided two tons per year for each acre of the farm. This would require about one cow or horse, or equivalent, for each six acres of land. Enough more stock would have to be kept to make up for time on the pasture, provided the pasture were not a part of the crop-rotation.

144. Losses of Manure. The great sources of loss of manure are the loss of the liquid portion, the leaching out of the fertility by rains, and fermentation.

The liquid portion of manure is much more valuable per ton than is the solid portion, as it contains over twice as much nitrogen and most of the potash. The relative composition of the solid and the liquid portions is as follows: ${ }^{1}$

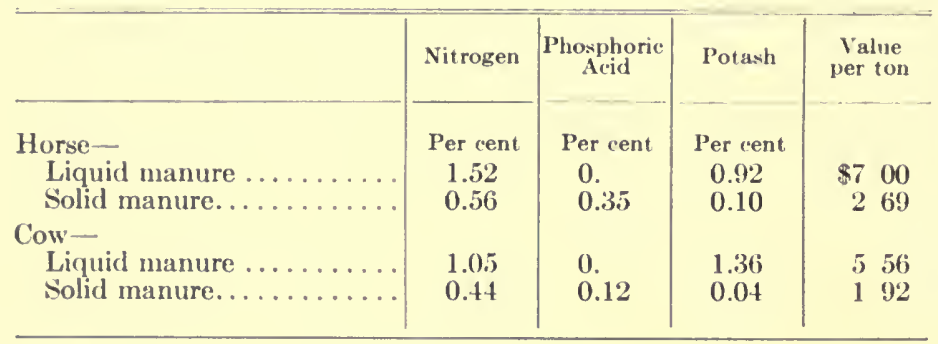

With cows, over one-fourth of the total excrement is liquid. This is worth about as much as the solid manure. Yet many farmers have arranged their barns so as to drain off the liquid portion. In this way it is easy to lose fertilizing material that would cost $\$ 10$ to $\$ 15$ per year

' Experiment Station Record V. p. 142. 
for each cow kept. Straw, or some other absorbing material, should be used so freely that none of the liquid is lost. It is also desirable to have cement gutters in cow barns.

If the manure is exposed to heavy rains, the results are still more serious, as the drainage from a manure heap is even more valuable than the liquid manure:

\begin{tabular}{|c|c|c|c|}
\hline & Nitrogen & $\begin{array}{c}\text { Phosphoric } \\
\text { Acid }\end{array}$ & Potash \\
\hline $\begin{array}{l}\text { Liquid from eow gutter } \ldots \ldots \ldots \ldots \ldots \ldots \\
\text { Drainage from manure heap } \ldots \ldots \ldots \ldots\end{array}$ & $\begin{array}{c}\text { Per cent } \\
0.98 \\
1.50\end{array}$ & $\begin{array}{c}\text { Per rent } \\
0.21 \\
0.10\end{array}$ & $\begin{array}{c}\text { Per cent } \\
0.88 \\
+.90\end{array}$ \\
\hline
\end{tabular}

Roberts ${ }^{2}$ exposed 4,000 pounds of manure from April 25 to September 22. At the end of this time there were only 1,730 pounds:

Weight

Nitrogen

Phosphoric acid...........

Potash.

Value.

\begin{tabular}{|c|} 
April 25 \\
\hline, $000.00 \mathrm{lbs}$. \\
$19.60 \mathrm{lbs}$. \\
$14.80 \mathrm{lbs}$. \\
$36.00 \mathrm{lbs}$. \\
$\$ 6.46$
\end{tabular}

\begin{tabular}{c|c} 
September 22 & Loss \\
\cline { 2 - 2 } $1,730.00 \mathrm{lbs}$. & $\% \frac{}{57}$ \\
$7.79 \mathrm{lbs}$. & 60 \\
$7.79 \mathrm{lbs}$. & 47 \\
$8.65 \mathrm{lbs}$. & 76 \\
$\$ 2.38$ & 63
\end{tabular}

Not only was there a loss of 63 per cent of the value of the plant-food, but the loss in weight was due mostly to loss of organic matter, which should have been saved to make humus. At the New Jersey Station, manure exposed for four months lost over half of its value. ${ }^{3}$

Farmers usually fail to appreciate this loss, because

1Cyclopedia of American Agriculture, Vol. 1, p. 491.

${ }^{2}$ I. P. Roberts, The lertility of the Iand, p. 192.

"Parmers' Bulletin No. 192, p. 20. 
a ton of well-rotted manure is worth more than a ton of fresh manure. The trouble is that after exposure there are so few tons. One farmer who looked over these figures remarked that he hauled 200 loads of manure to a pile beside a field in the spring, and that when he came to spread it in the fall, he had 60 loads.

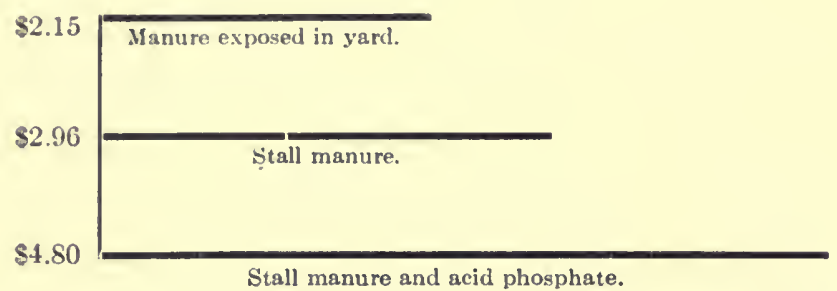

F1o. 60. Relative values of crops grown from stall manure and from an equal quantity of manure left exposed in yard and from stall manure reinforced with 23 cents' worth of acid phosphate per ton.

At the Ohio Station, manure exposed three months in an open barnyard lost one-third of its fertilizing value. This manure was used on erops and was found to be 27 per cent less effective than the same amount of manure that had not been thus exposed (Fig. 60). As manure is exposed under the eaves in barnyards, it certainly loses much more than half of its value. But merely being under cover is not a sure preventive of loss. Unless it is kept moist and compact, it will ferment, and a large part of the nitrogen will pass off into the air.

The ideal way to care for manure is to spread it on the land as fast as it is made. One ean keep a wagon or manure-spreader on which the manure is thrown each day. When a load is ready, it is hauled to the field and spread at once. This is not so difficult as at first appears. It saves the labor of handling the manure twice,--once to 
throw it out of the barn, and once to put it on the wagon. When the tilled land is all in crops, it can be spread on the pastures or meadows, so that there is nearly always a place to put it.

If manure cannot be hauled in this manner, the next best way is to have a covered barnyard or shed where all the manure is put and in which stock is kept. The stock will pack the manure and keep it moist-conditions that

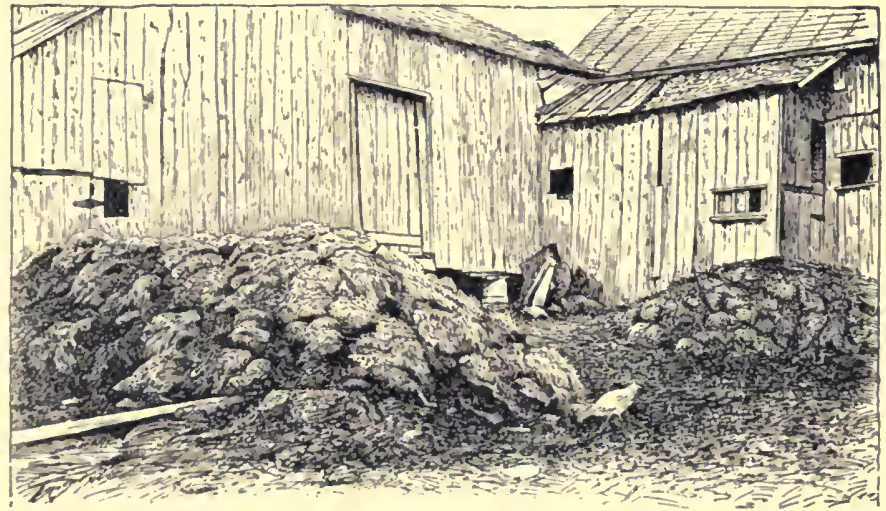

Fra. 61. Manure exposed under the eaves where it loses 30 to 60 per cent of its value

are essential for preserving it. If it is kept tramped and moist, and if the shed has a cement floor, there will be practically no loss. A cement floor under steers in Ohio was half paid for in one year by the saving of manure.

When manure is kept in this way, it should be hauled out during the winter and spring. During the summer, when the stock are at pasture, it will dry out and ferment, and much of the nitrogen will escape to the air. If it could be kept moist, this loss could be avoided. 
To prevent losses from manure, it is necessary:

(1) To use absorbents to retain all the liquid part.

(2) To spread it on the land as soon as possible.

(3) If it cannot be spread at once, keep it under cover, tramper and moist, and on a cement floor, if possible.

Various materials are used with manure to help to retain the nitrogen and to reinforce the manure at the same time. Kainit, gypsum, acid phosphate and floats are most commonly used. Of these, acid phosphate and floats are best, unless the farm is in particular need of potash. Any of these substances tend to retain the nitrogen that might escape to the air as a result of fermentation. They do not prevent much of the losses due to leaching. About 40 pounds of acid phosphate, or twice this amount of floats, may be mixed with each ton of manure as it accumulates. At the Ohio Station 40 pounds of acid phosphate, worth about 30 cents, was used with each ton of manure. This procluced a ten-year average increase in crops to the value of $\$ 4.57$ for each ton of manure above the cost of the acid phosphate. It practically doubled the benefits from each ton of manure. This is doubtless due in part to the saving of nitrogen, and in part to the need of phosphoric acid on this land.

145. Application of Manure. A good place to apply manure is preceding the corn crop. It is also desirable as a top-dressing for grass land. Unless there is some reason for not doing so, the manure should be applied on the most valuable crop that is being raised,-corn, cotton, potatoes, truck, etc. On fairly fertile land it is not best to apply it directly to the small grain crops, as oats, wheat, barley, as they are likely to make too rank a growth. 


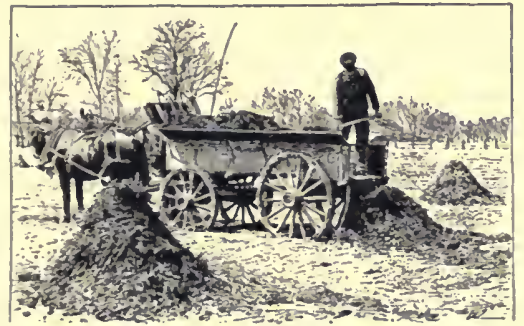

l'ic. 62. An expensive way to apply manure.

Thrown in piles and spread as in Fig. 63
On the new lands of the West, manure sometimes injures crops when it is plowed under, chiefly because it causes the land to dry out. On such lands the use of manure should not be condemned. It should be applied as thinly as possible as a top-dressing on grass lands, where it will help to retain the moisture. When it is plowed under, it will then be so well rotted as to do no halm. Sometimes it is best to let it become well rotten before applying on such land.

Small applications frequently made are much better than heavy applications less frequently. The application should, if possible, be thin enough so that the entire farm may be covered in three to five years.

Manure may be applied at any time. The sooner it is on the land the better. It is better to apply it in the fall ol winter than to store it until spring. It is much better to apply it in the spring than to

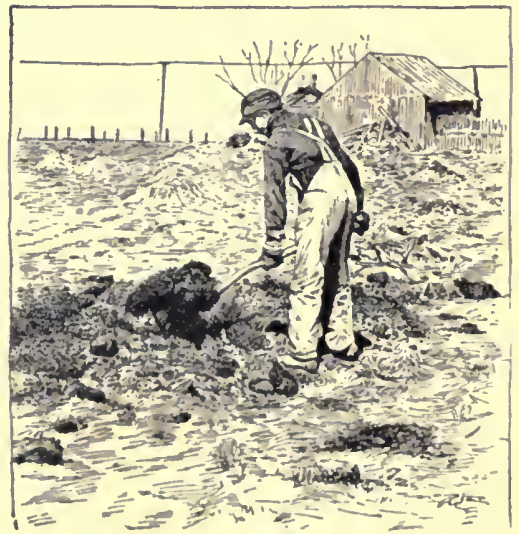

Fic. 63. An expensive way of applying manure. This manure was pitched ont of the harn onto a pile, pitched from the pile onto a wagon, pitched from the wagon to the ground. and pitched around in the field to spread it handled four times. (See Figs, 62 and 65.) 
wait till fall. It is sometimes feared that applications when the ground is frozen or when there is snow on the land may result in loss, but experiments have not shown

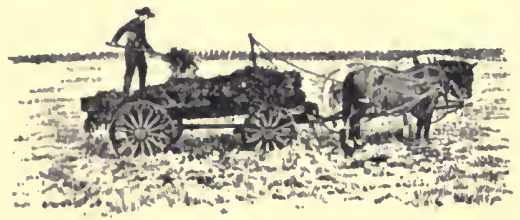

Fı, 64. Spreading manure directly from the wagon, a better method than that shown by Figs. 62 and 63. this to be serious. The smaller amount of farm work during the winter also makes this a desirable time to spread manure.

The best method of applying manure, when large amounts are to be hauled, is to use a manurespreader (Fig. 65). These are too expensive to use on very small farms. The chief advantages of a manure-spreader are that it saves labor and will distribute the same amount of manure over more land and spread it more evenly. If a spreader is not used, the manure should be spread from a wagon, and it may be desirable to go over it with a brush-harrow or spiketooth harrow to secure an even distribution. It should certainly not be thrown into small piles in the field and then spread, as this involves handling it once more than is necessary.

In conclusion, it may be said that the chief

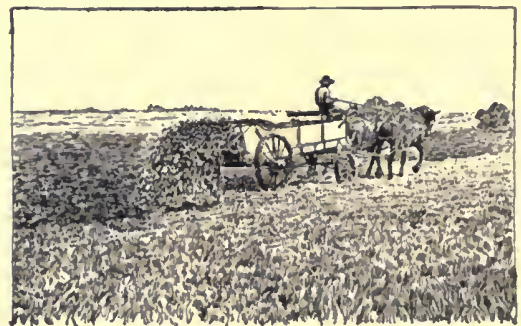

Fia. 65. Spreading manure with a manure spreader. This manure was pitched from the stable to the spreader-handled once only. (See Fig. 63.)

means of maintaining the fertility of the land are the rotation of crops, including grass and leguminous crops in 
the rotation, and the use of stable manure-which involves the keeping of stock.

\section{GREEN-MANURE}

146. Crops are sometimes grown for the purpose of plowing under as green-manure. Rye, buckwheat, cowpeas, crimson clover, are frequently grown for this purpose This is a desirable practice when the land is very deficient in humus. So far as possible, such crops should be grown without extra labor. Crimson clover or cowpeas may be sown in corn or cotton at the last cultivation with little expense except for seed. In regions too far north for these plants rye is often used. It should be plowed under in the spring before it has made enough growth to exhaust the water of the soil.

It is not often wise to make a regular practice of plowing under crops that are worth harvesting. It will be better to feed them to stock and use the manure. If one is trying to get worn-out land to produce, or under certain conditions where stock cannot profitably be kept, the practice may be followed regularly, and by many means catch crops too small to harvest, but worth plowing under, may be procured.

One is likely to be deceived as to the amount of material that is being added to the soil by the practice. Green crops are about 70 to 75 per cent water, which is likely to deceive one as to the amount of organic matter.

Some of the best potato growers plow under a clover ('rop every three years for keeping up the humus supply. The potatoes are grown on the sod and are heavily fertilized. 


\section{QUESTIONS AND PROBLEMS}

1. Are fertilizers used in your region? If so, what fertilizers produce the best results?

2. How long has the land been cropped? Are the farms as productive as formerly?

3. How do the farm practices on the most productive farms differ from those on the least productive?

4. What care is taken of the barnyard manure to prevent losses from leaching, from fermentation, and from escape of the liquid portion?

5. On what crops is manure used? Is it needed more than formerly? Will it pay to care for it better than formerly?

6. If fertilizers are used, what is their composition and cost? Would it pay to buy the separate materials and mix them at home?

i. What wild legumes are common in the region?

\$. Whe:at and oats can be grown in water cultures, yet they turn yellow when grown on wet land. Why?

4. What are the three leading erops of the region? What is an average yield of each? How much nitrogen, phosphoric acid and potash would each crop remove from an acre per year (Appendix, Table 6)?

10. (iet the present prices of dried blood, nitrate of soda, acid phosphate and muriate of potash, also the freight rate from the town where you would purchase them. If these cannot be had, use the following prices, which are f. o. b. in New York City, September, 1908. Freight rate to lthaca, less than car-lots, 18 cents per hundred.

Dried blood (10 per cent) ..............\$39 per ton

Jitrate of soda (15 per cent) ........... 52 per ton

Acid phosphate (14 per eent) ............ 12 per ton

Muriate of potash ( 50 per eent) ..........4 41 per ton

Assuming that it is desirable to apply 1,000 pounds per aere of a $3 \frac{1}{2}, 8,10$ fertilizer on eight aeres of potatoes:

(a) How much nitrate of soda, acid phosphate, and muriate of potash must be purchased?

(b) How much would it cost, including freight?

(c) How much of the mixture as made by a farmer would need to be applied per acre?

(d) On how much material is freight saved?

11. Assuming that it is desirable to apply 200 pounds per acre 
of a 2, 10, 4 fertilizer on fall-sown wheat, work problems $a, b, c, d$, as on preceding page, but use half the nitrogen in the form of dried blood.

12. In a three-year rotation of corn, wheat and clover at the Ohio Station, eight tons of manure were applied on the corn on certain plots. No manure was used on the wheat or clover. These crops got the benefits of the manure that was left in the soil. Stall manure and that from the barnyard were used, and were reinforeed with different fertilizers. The following are results on a few plots:

\begin{tabular}{|c|c|c|c|c|c|c|}
\hline \multirow{3}{*}{ Plot } & \multirow{3}{*}{ Treatment } & \multicolumn{5}{|c|}{ Average yield per acre } \\
\hline & & \multicolumn{2}{|c|}{ Corn 10 years } & \multicolumn{2}{|c|}{ Wheat 6 years } & \multirow{2}{*}{$\begin{array}{l}\text { Hay } \\
6 \text { years }\end{array}$} \\
\hline & & Grain & Stover & Grain & Straw & \\
\hline 1 & Nothing & $\begin{array}{l}\text { Bus. } \\
38.86\end{array}$ & $\begin{array}{c}\text { Lbs } \\
2,263\end{array}$ & $\begin{array}{c}\text { Bus. } \\
11.49\end{array}$ & Lbs. & Lbs. \\
\hline 2 & Yard manure and floats & 59.85 & 3,347 & 24.21 & 2,627 & 3,818 \\
\hline 3 & Stall manure and floats. & 63.08 & 3,630 & 25.82 & 2,828 & 4,525 \\
\hline 4 & Nothing .......... & 33.04 & 2,047 & 10.24 & 1,193 & 1,754 \\
\hline$\overline{5}$ & Yard manure and acid phos- & 6007 & - & ences & , & 2512 \\
\hline 6 & Stall manure and acid phos- & 00.08 & 3,288 & 7.65 & 015 & 3,513 \\
\hline & phate ......... & 64.90 & 3,534 & 25.55 & 2,800 & 4,439 \\
\hline 7 & Nothing ... & 32.50 & 2,014 & 9.44 & 1,115 & 1,672 \\
\hline 14 & Nothing. & 33.97 & 2,058 & 9.61 & 1,105 & 1,626 \\
\hline 15 & Yard manure. . . . . . . & 51.29 & 2,918 & 18.20 & 2,071 & 2,441 \\
\hline 16 & Stall manure.......... & 58.79 & 3,372 & 19.73 & 2,237 & 3,140 \\
\hline 17 & Nothing ....... & 37.84 & 2,341 & 9.93 & 1,209 & $1,97 \pi$ \\
\hline
\end{tabular}

Notice that each third plot is a check plot, to eliminate differences due to the variations in soil. It is assumed that the clange from one check plot to another is gradual. ('heek plot 1 yielded 38.86 bushels of eorn, and check plot 4 yielded $33.0+$ bushels. The difference is 5.82. We assume thet the ooil is getting poorer as we pass from plot 1 to plot 4. If in the width of three plots it has deereased 5.82, we suppose that it would decrease one-third this amount or 1.94 in one plot. If untreated it is, therefore, assumed that plot 2 would have yielded 36.92 bushels and plot 3 would have yielded 34.98 bushels. In order to check the work we may subtract the 1.94 again and we should have 33.04 . But plot 2 did yield 59.85 bushels, hence the treatment must have produced an increase of 22.93 bushels. Similarly fill out the following table. It may be easier first to make a table of probable yielde of each plot if not treated. 
Increased Yields Due to Manure and Fertilizer

\begin{tabular}{|c|c|c|c|c|c|c|}
\hline \multirow{3}{*}{ Plot } & \multirow{3}{*}{ Treatment } & \multicolumn{5}{|c|}{ Average increase per acre } \\
\hline & & \multicolumn{2}{|c|}{ Corn 10 years } & \multicolumn{2}{|c|}{ Wheat 6 years } & \multirow{2}{*}{$\begin{array}{l}\text { Hay } 6 \\
\text { years }\end{array}$} \\
\hline & & Grain & Stover & Grain & Straw & \\
\hline 2 & Yard manure and floats & $\begin{array}{l}\text { Bus. } \\
22.93\end{array}$ & & & & \\
\hline $\begin{array}{l}3 \\
5\end{array}$ & $\begin{array}{l}\text { Stall manure and floats ... } \\
\text { Yard manure and acid phos- }\end{array}$ & & & & & \\
\hline 6 & $\begin{array}{l}\text { Stall manure and aeid phos- } \\
\text { phate } \ldots \ldots \ldots \ldots \ldots \ldots\end{array}$ & & & & & \\
\hline 15 & Yard manure............. & & & & & \\
\hline 16 & Stall manure . & & & & & \\
\hline
\end{tabular}

If com is worth 40 cents per bushel, wheat 70 eents, hay $\$ 8$ per ton, stover $\$ 3$, and straw $\$ 2$, fill out the following table:

Value of Increase Due to Manure and fertilizer.

\begin{tabular}{|c|c|c|c|c|c|}
\hline \multirow{2}{*}{ Plot } & \multirow{2}{*}{ Treatment } & \multirow{2}{*}{$\begin{array}{l}\text { Total } \\
\text { value of } \\
\text { increase }\end{array}$} & \multirow{2}{*}{$\begin{array}{l}\text { Cost of } \\
\text { treatment } \\
\text { per acre }\end{array}$} & \multicolumn{2}{|c|}{ Net value of increase } \\
\hline & & & & Per acre & $\begin{array}{l}\text { Per ton of } \\
\text { manure }\end{array}$ \\
\hline 2 & Yard manure and floats & & $\$ 128$ & & \\
\hline 3 & Stall manure and floats & & 128 & & \\
\hline 5 & $\begin{array}{l}\text { Yard manure and acid } \\
\text { phosphate. }\end{array}$ & & 224 & & \\
\hline 6 & Stall manure and acid & & & & \\
\hline & phosphate . . . . . & & 224 & & \\
\hline $\begin{array}{l}15 \\
16\end{array}$ & Yard manure...$\ldots$ & & & & \\
\hline 10 & Stall Manure.... & & & & \\
\hline
\end{tabular}

\section{PROBLEMS FOR CLASSES THAT HAVE STUDIED CHEMISTRY}

13. Write the reactions when: (1) Limestone is burned; (2) quicklime is water-slaked; (3) plaster dries out; (1) when quicklime air-slakes.

14. Find the comparative amounts of lime $(\mathrm{CaO})$ in limestone, quick-linıe and water-slaked lime.

${ }^{1}$ Cost of the acid phosphate and floats per acre 
15. Complete the following reaction which takes place in the manufacture of acid phosphate:

$$
\mathrm{Ca}_{3}\left(\mathrm{PO}_{4}\right)_{2}+2 \mathrm{H}_{2} \mathrm{SO}_{4}+5 \mathrm{H}_{2} \mathrm{O}=\text { ? }
$$

The resulting mixture is acid phosphate. About what proportion of it is land plaster or gypsum?

16. A 2, 8, 10 fertilizer contains what per cent of $\mathrm{NH}_{3}$ ? Of P? Of $\mathrm{K}$ ?

17. Muriate of potash that is 80 per cent pure ( 80 per cent $\mathrm{KCl}$ ) would be stated as what per cent potash $\left(\mathrm{K}_{2} \mathrm{O}\right)$ ?

18. Nitrate of soda that is 96 per cent pure would contain what per cent of $\mathbf{N}$ ?

\section{LABORATORY EXERCISES}

\section{Examination of Fertilizers.}

Materials.-Small samples of different fertilizing materials.

Describe each. Test each with litmus paper, to see which are acid and which are alkaline.

49. Absorption of Manure by Soils. (For humid regions.)

Materials.-One quart of barnyard manure, can of soil, perforated bottom.

Let the manure soak in water for a day or two, to get manure-water. Pour this through the soil. Compare with the water that comes out at the botton.

\section{Losses of Manure.}

Materials.-Two hundred pounds or more of manure, scales.

Weigh the manure, leave it in a pile outdoors for several months; weigh again.

\section{Mixing Fertilizers.}

Materials.-Fifty pounds or more of several fertilizing materials. Mix these in the proper proportions for problem 10 or 11 .

\section{Fertilizer Trial.}

Materials.-One-fourth acre or more of farm land; separate ingredients for fertilizers.

Lay off the field into plots one-fortieth, one-twenticth, or one- 
tenth acre each, taking care to have the plots as uniform as possible. Treat the plots as follows:

Plot 1. Nothing, cheek.

Plot 2. Nitrate of soda, at the rate of 160 pounds per acre, 4 pouncls for one-fortieth acre, etc.

Plot 3. Acid phosphate, 320 pounds per acre.

Plot 4. Nothing, check.

Plot 5. Muriate of potash, 80 pounds per acre.

Plot 6. Nitrate of soda, 160 pounds; acid phosphate, 320 pounds.

Plot 7. Nothing, check.

Plot 8. Nitrate of soda, 160 pounds; muriate of potasl, 80 pounds.

Plot 9. Muriate of potash, 80 pounds; acid phosphate, 320 pounds.

Plot 10. Nothing, check.

Plot 11. Nitrate of soda, 160 pounds; acid phosphate, 320 pounds. muriate of potash, 80 pounds.

Plot 12. Barnyard manure, 10 loads or tons per acre.

Plot 13. Nothing, check.

If there is not room for so many plots, the first five may be onitted. Raise a crop of corn, cotton or potatoes according to the region. In the fall, harvest and weigh the crop, in order to see which fertilizer is most profitable.

If the school does not have land available for such an experiment, some farmer nearby will probably furnish it. Correspond with the State Experiment Station, and an experiment better adapted to the community may be arranged for.

\section{COLLATERAL READING}

Commercial Fertilizers, Farmers' Bulletin, No. 44.

Barnyard Manure, Farmers' Bulletin No. 192.

Home Mixing of Fertilizers. Farmers' Bulletin No. 222, pp. 5-9; No. 225 , pp. 7,8 .

Lime and Clover. Farmers' Bulletin No. 237, pp. 5, 6.

Use of Commercial Fertilizers. Farmers' Bulletin No. 259, pp. 56.

Leguminous Crops for Green-Manuring. Farmers' Bulletin No. 278.

Renovation of Worn-out Soils. Farmers' Bulletin No. 245.

The Conservation of Natural Resources. Farmers' Bulletin, No 327. 
Conservation of Soil Resourees. Farmers' Bulletin, No. 342, pp. 5-10.

The Maintenance of Fertility. Ohio Bulletin, No. 182.

The Maintenance of Fertility (Barnyard Manure). Ohio Bulletin No. 183.

How to Determine the Fertilizer Requirements of Ohio Soils. Ohio Cireular No. 79.

The Fertility in Illinois Soils. Illinois Bulletin No. 123.

Cyelopedia of American Agriculture. Vol. I, pp. 454-513

Soils, by S. W. Fletcher.

The Fertility of the Land, by I. P. Roberts

Soils and Fertilizers, by Harry Snyder.

Fertilizers, by E. B. Voorhees. 


\section{CHAPTER VII}

\section{SOME IMPORTANT FARM CROPS}

\section{Relative Importance of the Different Crops of}

the World. If under the one word grass we include all the hay and pasture plants, then the most important rrop of the world is grass. But this is a collection of a number of different plants.

The most valuable single plant of the world is the wheat. The potato is second in value and corn third. There are now more pounds of corn grown than of wheat, but the wheat is worth more per pound, so that its total value is still greater than that of corn.

It will be noticed that the two crops whose total yields lead all other crops are natives of the new world. The dis-

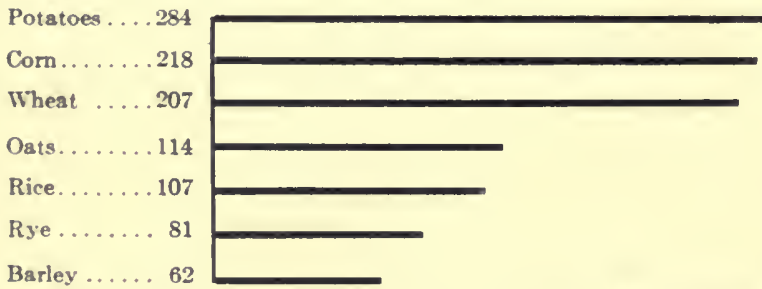

Fig. 66. The world's crop production for the year 1906 in billions of pounds."

covery of America was much more than the discovery of more land. Of these two crops, corn has attained the greatest development in America, but the potato has at-

1 Yearbook, United States Department of Agriculture, 1907. Bushels of wheat multiplied by 60 , corn by 56 , potatoes by 60 , oats by 32 , rye by 56 , barley by 48 . 
tained greater prominence in Europe than in its native land.

Of the cereal ${ }^{2}$ crops, the leading one in Europe is wheat; in Asia, rice; in South America, wheat; in North America, corn.

148. Relative Rank of the Different Crops in the United States. In 1899, the census value of corn was over onefourth of the value of all crops-all plant products-in the United States. The forest crops are second in value; then follow in order: cotton, hay, wheat, oats, potatoes, barley and tobacco. None except those listed has an annual

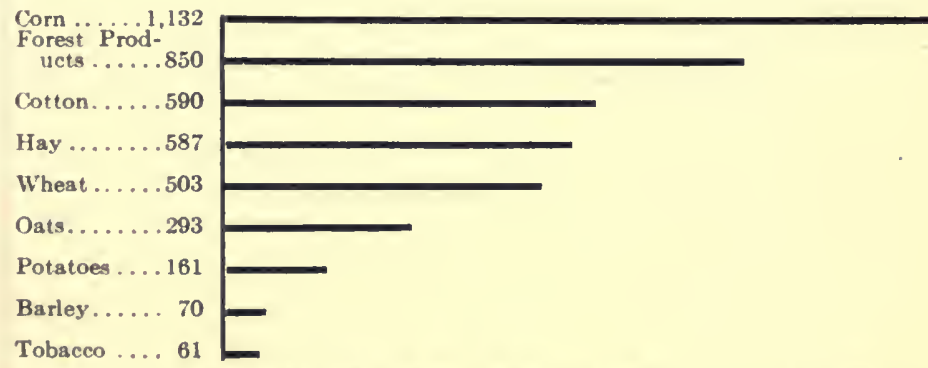

F1G. 67. Crops of the United States. Average values in millions of dollars for the five years 1903 to 1907 . Forest products for 1906 only.

value as great as $\$ 25,000,000$. The diagram shows the comparative values of these crops. The values given do not include the value of the corn-stalks or the straw of wheat and oats, or the value of the wood used as fuel. See Appendix, Table 11 for comparative values of different agricultural products. The crop yields are given in Table 14 .

'A cereal is a grass grown for its edible grain.

${ }^{2}$ Yearbook, United States Department of Agriculture, 1907, and Forest Service Bulletin No. 77. 


\section{CORN}

149. Historical. Corn is a native of the New World. It is thought to have originated in Mexico, and to have been carried north and south by the Indians. The Indians had grown it for many centuries before America was discovered. They were raising better crops of it than some farmers now raise. They taught the first settlers how to grow it. Had it not been for the corn that the Indians shared with them, the early settlers would have died of famine. Had it not been for corn, the settlement of the middle West would have been long delayed, and it is even conceivable that this region might not now belong to the United States. Had it not been for the increased wealth and population of the North, which was due to corn, it is possible that the Civil War might have ended differently. Com and cotton have had more to do with the history of America than has "taxation without representation." In fact, there would have been few people to tax at the time of the Revolution had it not been for these crops.

The botanical name of corn is Zca mays. It is often called maize, or Indian corn, in order to distinguish it from corn as the word is used in Europe. Wheat, barley, and other small grains are there spoken of as corn. The word is used much as we use the word grain. Probably most Americans think of Indian corn when the word corn is read in the Bible, but we must remember that in those days the Indians were probably the only people who knew this crop.

150. Corn Crop of the World. Over three-fourths of 
the world's corn crop is grown in the United States. Nearly half of the world's crop is grown in the seven states of Illinois, Iowa, Nebraska, Missouri, Kansas, Indiana and Ohio. These are the corn-surplus states. It is these seven states that furnish nearly all of the corn that is sold off the farms on which it grows. Corn occupies one-third of the area in crops of all kinds in the United States, other than pasture. About one-third of the farms raise wheat, but over four-fifths of them raise corn.

"If the corn crop of the United States for 1906 had been placed in wagons, 50 bushels per load, and allowed 20 feet of space for each wagon and team, the train of corn would have reached nine times around the earth at the equator."1

The United States has no rival in corn-production. Argentina ranks second, but it produces only about onefifteenth as much as the United States. Argentina still has a considerable area of undeveloped land that is adapted to corn, but it is not probable that its production will ever equal that of the United States.

151. Relation of Climate to Corn-production. As has been stated in previous chapters, climate is a much more important factor in crop-growth than is the soil. The regions that have similar climates have similar plants the world over.

In order to produce the best yields of any crop, it is necessary that the rainfall, temperature and sumshine all be adapted to that crop. For its hest growth, corn requires a high temperature during the growing season, long days of bright sunshine, and a large amount of rain during the 1Cyclopelud of American Agriculture, Vol. II, p. 403 
hottest weather. The "corn-belt" of the United States seems to be the largest area in the world where these climatic features are favorable, and where the land is level enough for economic corn-production. Even here there are probably no seasons when corn does not suffer to some extent from unfavorable weather.

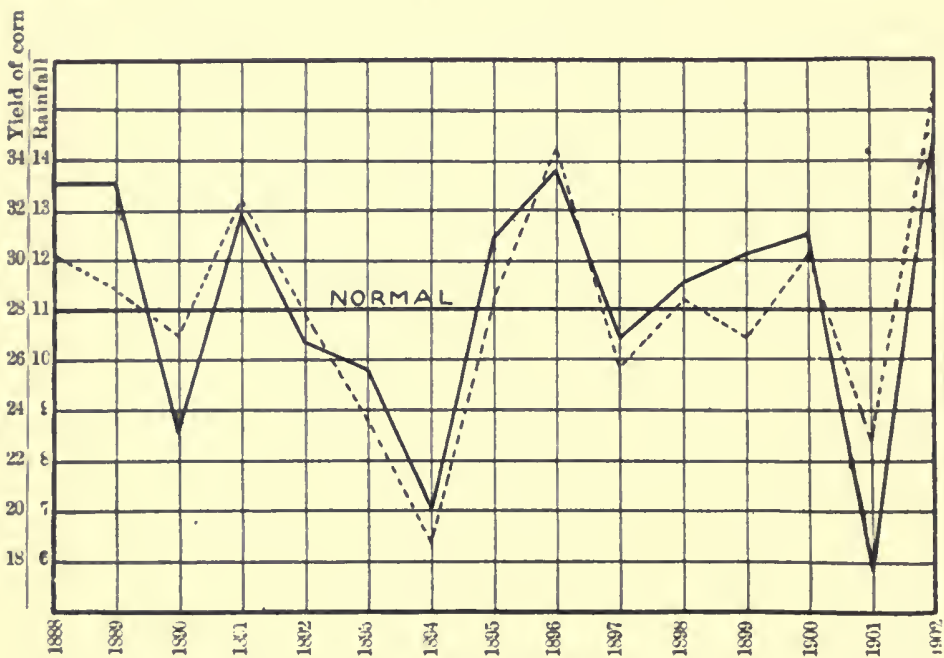

Fig. 63. Rainfall for June, July and August and yield of corn per acre. ${ }^{2}$ - Average yields of corn 1888 to 1902.

...... Average rainfall for June, July and August.

It is, of course, the temperature of the growing season rather than the temperature for the year that limits the corn crop. Nearly nine-tenths of the corn of the United States is grown in regions where the July temperature is between $70^{\circ}$ and $80^{\circ}$ Fahr. More is grown in the warmer part of this region than in the colder part.

The amount and intensity of sunshine is also important.

${ }^{1}$ Yearbook, 1903, pp. 215-224 
Few persons realize that there is much more sunshine in Illinois than in Louisiana during the summer months. Not only are there more hours of daylight, but the sunshine is much more intense. When rains come, they are usually of short duration and are followed by bright sunshine. The glaring sunlight of the middle West is one of its natural resources-worth more than gold mines.

In the corn-belt of the United States there does not seem to be any very definite. relationship between variations in temperature from year to year and the corn crop. But there is a very decided relationship between rainfall and yield. Again, it is not the rainfall of the year, but that of the growing period, that is most important. The rainfall of western England is 37 inches per year. That of Lincoln, Nebraska, is 27 inches. Yet the latter rainfall is better adapted to corn, because 16 inches of the year's supply falls in May, June, July and August, while in England only 11 inches falls during these months. The summer rainfall is deficient in most parts of Europe and Asia that might otherwise be adapted to corn. Fig. 68 expresses this relationship graphically. It will be seen that the line representing the rainfall for June, July and August is almost parallel with the line representing the yield per acre.

152. Why We Raise Corn. Where corn thrives, it produces about twice as much food per acre as is produced by any of the other grains. This, together with the limited area of land with a corn climate, makes the farms in our corn-belt very high in price. It also makes it possible to grow corn in many regions that are not best adapted to it. A half-crop of corn may produce as much food as 
a full crop of other grains. The demand for wheat as human food and for oats as horse food, makes these grains sell for higher prices per pound than corn.

Average Crops in the United States for Five Years (1903-1907).

\begin{tabular}{|c|c|c|c|c|}
\hline & $\begin{array}{c}\text { Average } \\
\text { yield }\end{array}$ & Pounds & $\begin{array}{l}\text { Total digestible } \\
\text { food per acre }\end{array}$ & $\begin{array}{c}\text { Value } \\
\text { per acre }\end{array}$ \\
\hline 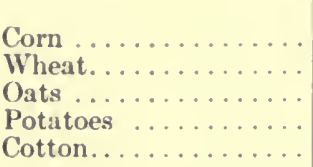 & $\begin{array}{l}\text { Bus. } \\
27.5 \\
13.9 \\
30.1 \\
95.9\end{array}$ & $\begin{array}{r}1,540 \\
8: 34 \\
96: 3 \\
5,754\end{array}$ & $\begin{array}{c}\text { Pounds } \\
1,298 \\
694 \\
636 \\
1,001\end{array}$ & $\begin{array}{rl}\$ 11 & 99 \\
10 & 80 \\
10 & 00 \\
53 & 35 \\
20 & 70\end{array}$ \\
\hline
\end{tabular}

Another reason for growing corn is that it is a tilled crop. It is very desirable to have a tilled crop in the rotation, in order to free the land of weeds and secure the other benefits that rome from tillage.

Since corn pays better than oats in most parts of the United States, why should we raise any oats? Oats are really not a competitor of corn. A farmer can raise all the corn that he can care for and raise oats besides, as the work does not come at the same time. Some persons have wondered why American farmers give so much less attentjon to potatoes and root crops than do the farmers of Europe. These crops compete with corn. They occupy the same place in the rotation as corn, and require work at the same season of the year. In Europe, the climate and cheaper labor are both favorable to these crops, so that they can drive corn out. In this country, we raise few root crops or potatoes except for human food. Our climate makes corn a cheaper stock food. A farmer should

${ }^{1}$ Total food here includes the digestible protein + carbohydrates $+2 \frac{1}{4} X$ fat. (Siee page 286.) 
grow a sufficient variety of crops so that he will be employed as much of the year as possible. He must then pick the most profitable crop for each season. In the South there are two crops that can compete with corn; they are cotton and tobacco.

153. Types of Corn. There are six types of corn: (1) Pod corn (Zea tunicata); (2) soft corn (Zea amylacea); (3) pop-corn (Zea everta); (4) sweet corn (Zea saccharata); (5) flint corn (Zea indurata); (6) dent corn (Zea indentata).

$\therefore$ The pod corn is characterized by having husks around each kernel. It is interesting, because it is thought to be the type from which the others were derived. The scales at the base of each kernel of common corn are probably the husks much reduced in size.

Soft corn is not grown in North America except as a curiosity. Its endosperm is all soft white starch.

Pop-corn is characterized by its small size, its very hard kernel and consequent habit of popping. It is the other extreme from

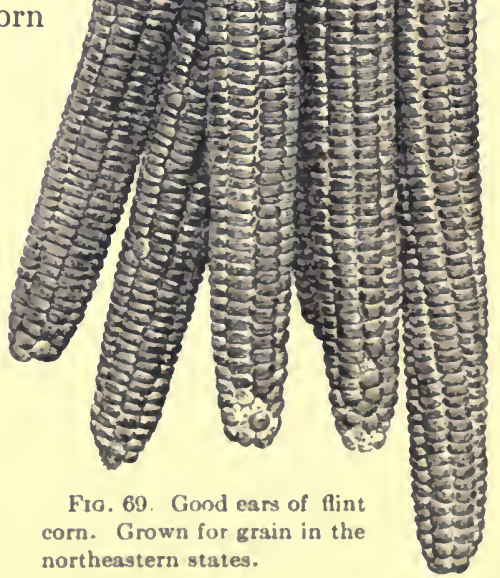


soft corn, as its endosperm is practically all hard, horny starch.

Sweet corn is grown chiefly for human food, either

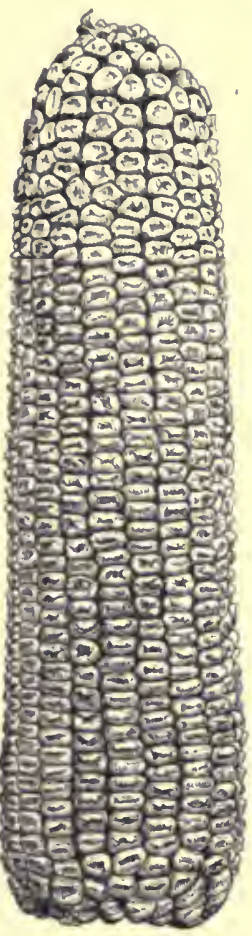

Fig. 70. A good ear of dent corn green, dried or canned. The corn-canning industry is now becoming very important.

Flint corn is characterized by having the larger part of its endosperm hard. It is still the prevailing type of field rorn in New York and New England. It is earlier than most of the dent varieties. Where the latter are successful, they will out-yield the flint. The dent types are nearly always grown for silage, and some of the earlier dent varieties are displacing the flint corn in many localities.

Dent corn has both horny and soft endosperm. It is the presence of the soft endosperm that causes the shrinking when the grain ripens and results in the "dent" at the top of the kernel. This is the type that furnishes nearly all of the world's corn crop. The flint corn is about as much of a curiosity in the corn-belt as is the pod corn. A large number of varieties have been developed. Some of the leading ones are the Leaming, Reid's Yellow Dent, and, for northern sections, Pride of the North.

There seems to be no difference in composition of the dent and the flint varieties. The difference between hard 
and soft endosperm seems to be chiefly a physical one, being the difference between ice and snow. When compacted, the endosperm is glossy, but when loose it is starchy.

154. Fertilizers for Corn. Corn is not a poor-land crop. On poor soils there are other crops, such as hay, oats, rye, buckwheat, that will give some thing of a yield when the soil is so poor that corn would produce little or no grain. Barnyard manure is nearly always applied on the corn crop. Some of the farmers in the northern states are coming to apply it with a manure-spreader on the meadows one year preceding the corn crop. This seems to be a good practice. Commercial fertilizers do not usually give so good results with corn as with hay and the small grains. This is probably because these crops are planted earlier, before the soil activities have liberated plant-food, while corn grows at the season when the food of the soil is being prepared most rapidly.

155. Plowing for Corn. There seems to be no particular difference between fall plowing and spring plowing on the average. In exceptional cases, one or the other may be best. In regions of deficient rainfall, it is desirable to plow in the summer or early fall, if possible, in order to have the land in condition to absorb and retain moisture. If the land washes badly, as in parts of the South, spring plowing is, of course, to be preferred. In most of the country, the labor question is of more importance than the soil differences. It is desirable to do as much of the plowing as possible in the fall, so as to have it out of the way of spring work.

The earlier spring plowing can be done the better; of course, it should not be done until the soil is fit to work. 
Early plowing enables the soil to take up and retain more moisture, and also increases the activity of the soil organisms, so that more plant-food is made available. The difference between early and late spring plowing is usually

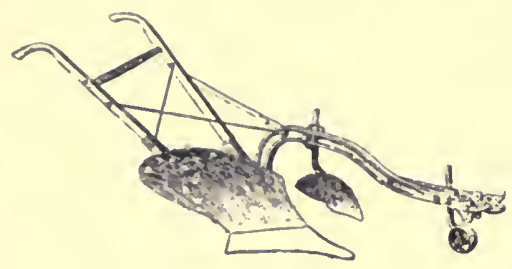

Fig. 71. A good plow more than the difference between fall and spring plowing.

Quiroga found that the surface two feet of soil on early-plowed land contained an average of 21.49 per cent of moisture for the season, while on late-plowed land the average was 20.27 per cent. The soluble nitrogen in parts per million of dry soil averaged 4.51 for the earlyplowed land and 2.83 for the late-plowed. The yields of corn were 59.6 bushels and 47.4 bushels. ${ }^{1}$ The earlyplowed land had more moisture, more soluble nitrogen, and produced more grain.

Early plowing usually requires more labor in subsequent fitting of the land. If one is turning under clover, or other green-manure crop, the early-plowed

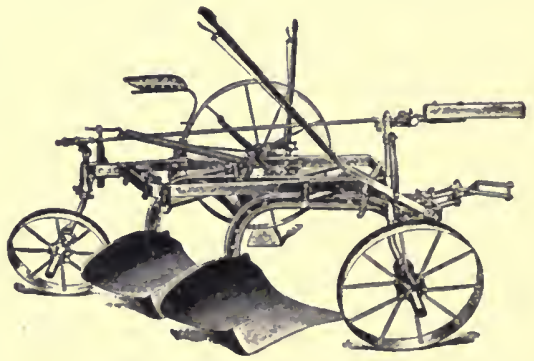

Frc. 72. A four-horse gang plow. One man can plow nearly as fast as $t$ wo men with twohorse plows.

land will also receive less additional humus.

The proper depth for plowing varies with different conditions. Experiments have not yet shown the exact 1Ohio State University Bulletin, Series 8, No. 28 
relationship to these conditions. The trials thus far conducted have given best results with depths of four to six inches. In the humid regions, deeper plowing has been more successful than in the arid regions.

Subsoiling ${ }^{1}$ is nowhere a common practice. Many trials of it have shown it to be unprofitable, with rare exceptions.

In case one wishes to deepen the soil, it should not be

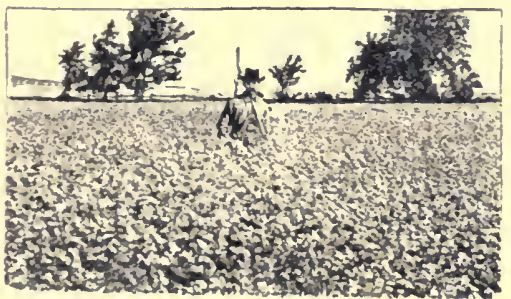

Fig. 73. Buckwheat on land that was plowed early and well fitted done all at once. If sereral inches of the raw subsoil are turned up, it will injure the first few crops. It is better to plow one inch deeper each year until the desired depth is reached. In semi-arid regions the subsoil is usually not so different from the surface soil. On many soils the depth should be varied from year to year, otherwise a hard layer may form where the plow runs.

When several teams are plowing on the same land, the plows should all be set at the same depth. If one plow runs an inch deeper than the others, it is much harder for this team than it would be if all plows ran at the same depth.

1 Subsoiling is the break ing up of the subsoil in the bottom of the furrow without hringing the aubsoil to the surface. The subsoil plow follows the regular plow in the same furrow.

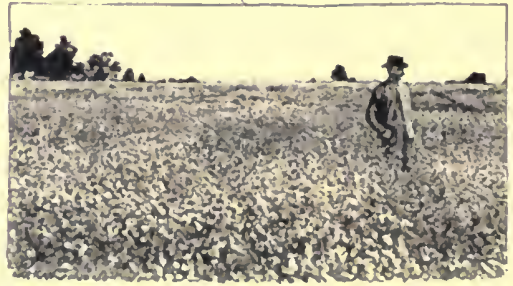

Fio. 74. Buckwhest on land that was plowed late. Farm adjoining Fig. 73 
156. Fitting the Land After Plowing. Fall-plowed land is usually left without other working until spring. If heavy soil is fall-plowed and too finely pulverized, it is likely to "run together." (See Fig. 43.)

Spring-plowed land should be dragged with a smoothing harrow or otherwise stirred before the clods become

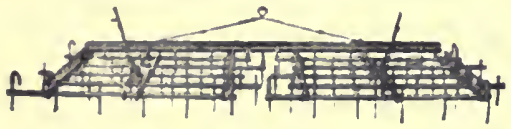

Fisi. 75. smoothing harrow. A good tool for killing weeds and fitting land too dry to crumble readily. The drier the soil the more frequently this should be done. Under usual conditions, the harrowing should be done on the day that it is plowed. If the weather is very dry, and particularly in semi-arid regions, it may he necessary to harrow within a few hours after plowing. One may stop in the middle of each half-day for this purpose. Usually the land should be harrowed with the smoothing harrow two to four times before planting. Sinmetimes it may he better to use the disk harrow. On stony land or on very hard soil the spring-tooth harrow may be used. This is really a cultivator.

If corn is to be kept clean, it should be planted in a seed-bed that is free from weeds and that has been freshly stirred in order to kill any sprouting seeds. This gives the corn a chance to start even with the weeds. It is very foolish to plant on land that has germinating weeds, thinking to kill them after planting. It is better to delay the planting long enough to kill the weeds.

157. Planting. The selection of seed and germination tests have been previously discussed (pages 25 and 48).

"The Indian method of planting maize was to plant four grains in a hill four feet each way. This method they 
taught to the colonists." Most of the corn in the cornbelt is planted 3 feet 8 inches apart each way, with two to four kernels per hill. In the more humid parts, three stalks per hill is considered best. In the semi-arid regions or on poor land, two stalks is considered best. In the South, where the season is long and the soil often poor, much thinner planting is better. The rows may be placed five feet apart and a row of cowpeas planted between for soil improvement.

Four kernels in a hill seem to give the same yield as if the same number are planted in drills, one kernel in a place. If rowed both ways, as is done by the check-row planter, the corn may be cultivated both ways and so kept clean much more easily. The check-row planters are not adapted to very uneven land or to fields that contain trees. For

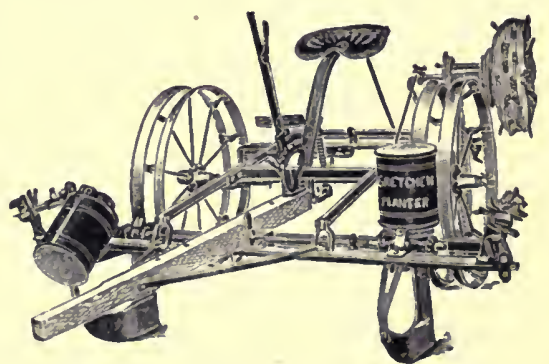

Fik. 76. A rheck-row corn-planter. Plants two rows at once and rows the corn both ways these reasons, the corn in the northeastern states is mostly drilled. The higher cost of the check-row planter is also a factor. There are, however, many level farms that might profitably use this machine.

In the semi-arid regions, a considerable part of the corn is planted with a lister. The lister is a sort of double plow that opens up a deep furrow and plants the corn in the bottom. As the corn grows, the cultivation gradually fills the ditch. Corn planted in this way in dry regions 
yields as much or more than that planted with a checkrow planter. The chief advantage seems to be in the reduction of labor. The land does not need to be plowed for listed corn. This saving in cost is of much importance when there is a possibility of a small crop.

No matter how deep corn, wheat or oats are planted, they will send out

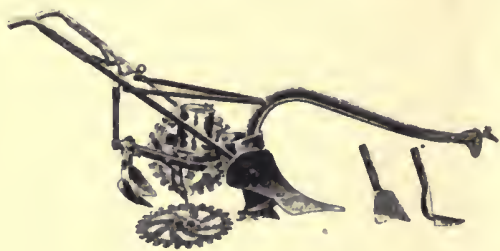

Fig. 77. A lister for planting corn in semiarid regions

their permanent roots at the depth that seems best for their growth in the particular soil. Fig. 78 shows some rye plants planted at different depths. By varying the length of the first internode, they have all started their

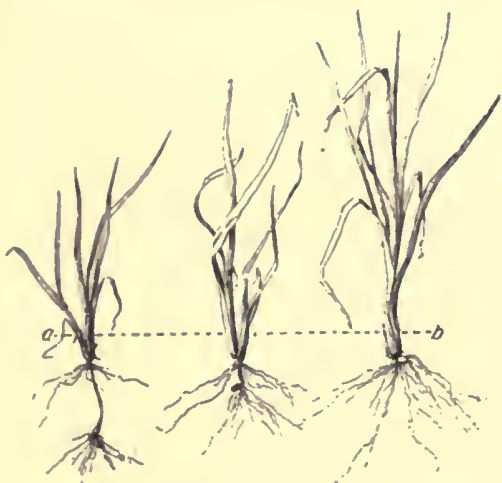

Fig. 78. Readjustment of a rye plant when planted too deep. No matter how deep the seed is planted, the permanent roots are formed at the same depth. Too deep planting weakens the plant as shown on the leit. permanent roots at the same depth,-in this case, seven-eighths of an inch below the surface. After the roots have developed from the node, the lower roots die if they have been planted too deeply. The plant can thus "transplant" itself to the proper depth.

In humid regions, one inch deep has usually given better yields of corn than deeper planting. It is usually necessary to set the planter deeper than one inch, in order to have all the grain covered. A level seed-bed will make it much easier to 


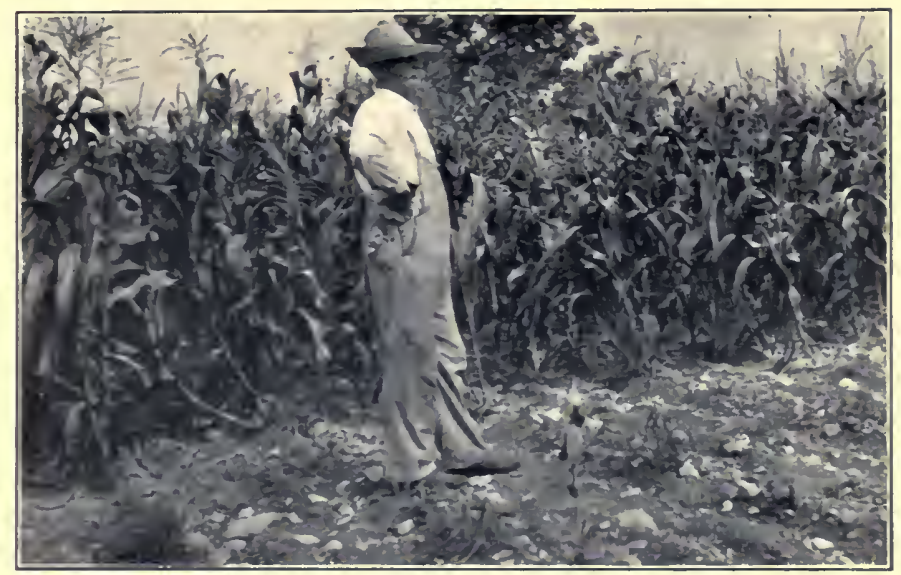

Frr. 79. Fielıl of corn on which a weeder was used before cultivating

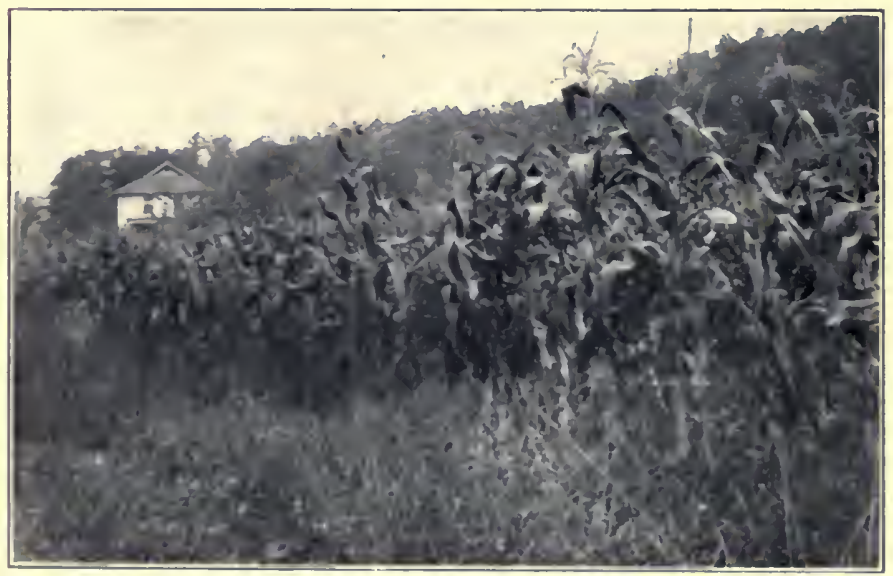

Fus. s). Field of corn on farm adjoining Fig. ig. Weeder was not userl. ()ther treatment was similar 

plant at the desired depth. The drier the region and the more sandy the soil, the deeper corn may be planted. The greatest danger of too deep planting is that a poor stand may result.

158. Tillage After Planting. After the coin is planted it should be harrowed once with a smoothing harrow, or with a

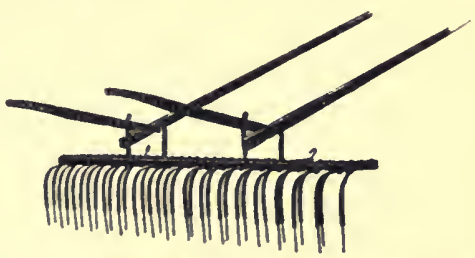

FIG. 81. A weeder. A good weed killer, better than a smoothing-harrow on stony land.

weeder, and should be gone over again after it is well up. The best time to kill weeds is when they are just coming up,- when they appear to be insignificant. When

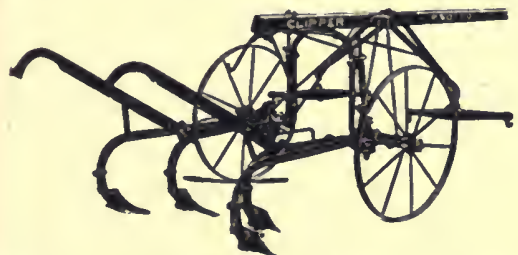

F's. 82. An undesirable cultivator. Shovels are too large and the man is required to walk they are large enough to attract attention, they are too large to be easily killed. If the land is well prepared and is harrowed just before planting, and is given these two harrowings after planting, it will be well started on its way. In large fields of mellow soil this work may be done with a four-horse smoothing harrow that will cover 16 to 20 feet, so that the work may be done very rapidly. On stony land the weeder may be used.

Corn treated this way will usually require three

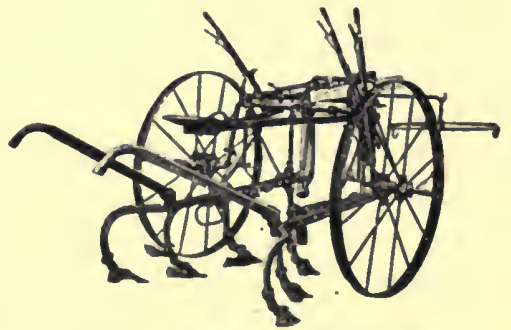

Fig. 83. A good riding cultivator 
cultivations. In some regions, as many as five may be needed. The ideal way is to stir the soil after each rain as soon as it is fit to work, and to maintain a loose, mellow surface. In the middle West, the cultivation is most commonly done with a two-horse cultivator that finishes one row at a time. Wherever possible, two-horse cultivators should be used. One-horse cultivators were all right when men worked for 50 cents a day, but they should not now be used except for small areas on small farms, or where labor is still cheap and inefficient, as in the South.

Perhaps there is no single point in the raising of corn that has been the source of greater loss than too deep cultivation. A large part of the roots of corn extenul nearly horizontally for some distance within four inches of the surface of the soil. Deep cultivation cuts these roots so much as to injure the crop. The substitution of smaller shovels in recent years has done much to encourase shallow culture. The first cultivation may be deeper than the later ones. The common practice of cultivating deep and throwing the dirt to the rows when the corn is "laid by" is very undesirable. The old shovel-plow that digs off the surface soil, exposes the roots and leaves it hard surface exposed is much worse. The only excuse for these methods is to bury weeds in the row. These weeds should have been killed at previous cultivations or by the harrowing before or after planting.

Sixty-one tests of deep cultivation at thirteen experiment stations gave an average yield of 9.8 bushels per acre less corn than shallow culture. In most cases, one to two inches has been called shallow, and four or more inches deep. 



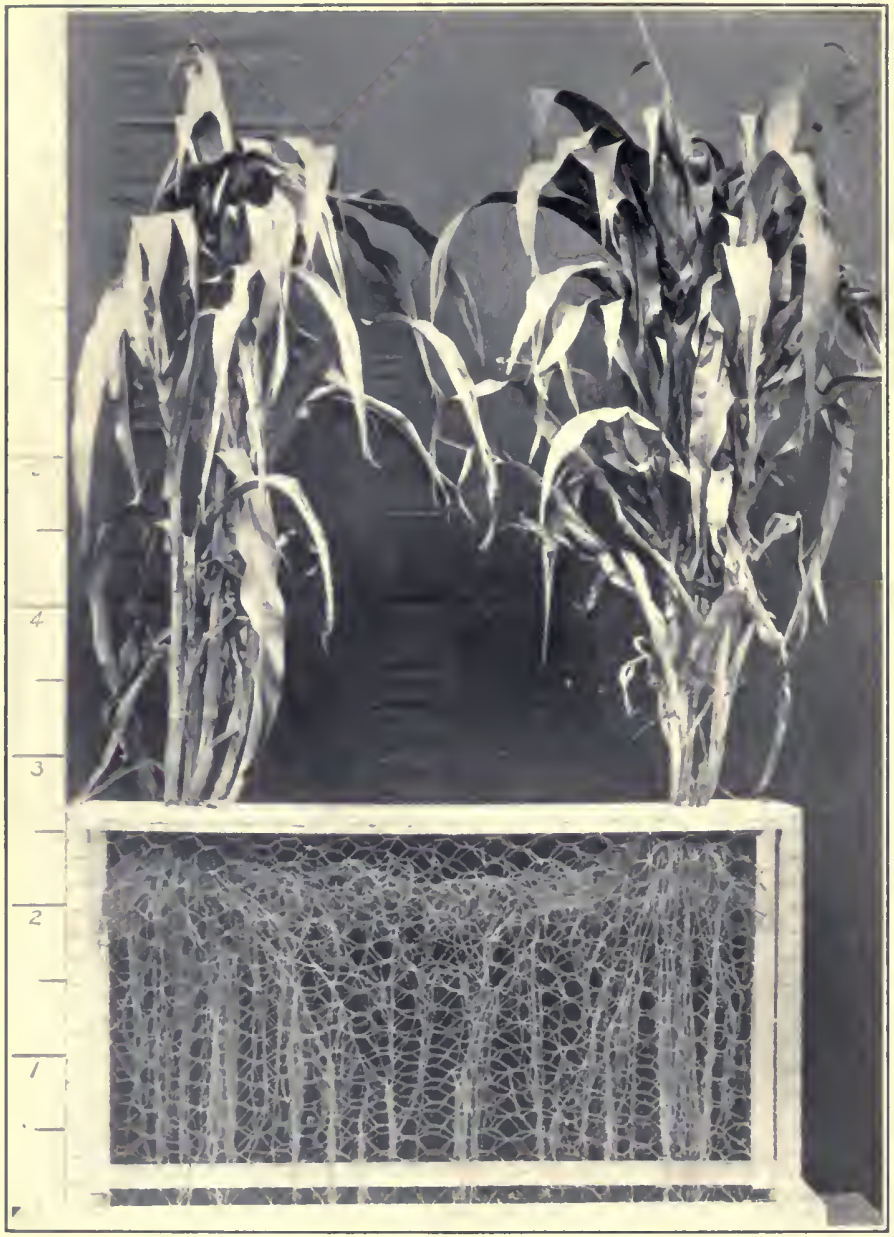

FIa. 84. Distribution of corn roots sixty days after planting. Notice the mass of roots that would be cut off by a cultivator running four inches deep 
159. Harvesting. More corn is husked from the standing stalks in the field than is. harvested in any other way. The standing stalks are then commonly pastured during the winter. This is the cheapest method of gathering the grain, but the fodder is of more value when cut. In regions where feed is less abundant, the corn is usually cut for fodder or is put in the silo.

Corn harvesters are very desirable, but are not profitable unless one has a considerable area to cut. Zintheo ${ }^{1}$ figures that the interest and depreciation on such a binder is $\$ 22.50$ per year, and that the twine and labor of cutting is worth 75 cents per acre. If one cuts only 10 acres per year, it would, therefore, cost $\$ 3$ an acre, besides the shocking or hauling to the silo. If one cuts 20 acres, the cost would be about $\$ 1.90$ per acre besides the shocking, which costs about 45 cents. It costs about $\$ 1.50$ per acre to cut and shock by hand. If one has $20 \mathrm{or}$ more acres per year to cut, it will probably pay to own a harvester, as the work can be done more rapidly and with greater independence, and the bundles are much easier to handle than the loose corn. For a less area, it will pay better to hire a neighbor who has a harvester, or do the work by hand; or a sled may be used. This seems to be the cheapest of all methods, costing about $\$ 1.20$ per acre, cut and shocked.

160. Corn Silage. One of the inost important developments in the use of corn in recent years has been the introduction of the silo. The first silo in America was built in 1879. Silos have come into general use in dairy sections during the past fifteen years. The entire corn-stalk and

$$
\text { 1Farmers' Bulletin No, } 303
$$


grain is shredded or cut into small pieces and stored in the tight silo. (See Figs. 145 and 144.)

The silo prevents much of the loss of food. It makes it easier to handle the food, and makes the manure much easier to handle than if fodder is used. In northern sections, larger varieties of corn can be grown for the silo than can be matured for fodder. Silage is more palatable than fodder, and the stock will eat more of it. The same amount of corn in the silo will produce more milk than it will if fed as fodder. The following table shows the quantity of milk produced from equal amounts of corn made into silage and fed as fodder: ${ }^{1}$

Pounds of Milk Produced

\begin{tabular}{l|c|c|c} 
& Silage & Fodder & Gain \\
\hline & & & Per cent \\
Vermont $^{2} \ldots \ldots \ldots \ldots \ldots \ldots \ldots$ & 8,525 & 7,688 & 11 \\
Wisconsin $^{3} \ldots \ldots \ldots \ldots \ldots \ldots$ & 7,496 & 7,119 & 5 \\
\hline
\end{tabular}

Any kind of green material may be preserved in the silo. Even dried corn fodder may be put in the silo, and sufficient water added to make it keep. Alfalfa, elover, soy-beans, cowpeas, are used for silage to some extent, but corn is the almost universal silage material.

\section{Methods of Preserving Food and the Principle} of the Silo. Heat and moisture are necessary for the growth of the bacteria and molds that cause decay. Hence, if a substance is sufficiently dried or is kept sufficiently cold, it will be preserved. These principles are used in

2The word fodder is used to include the stalks and grain. Stover is the stalks alone.

${ }^{2}$ Vermont Report, 1891.

3Wisconsin Report, 1891. 
preserving meat and hay by drying, and in preserving many articles by cold storage. Hay is well preserved by drying, but corn fodder retains so much water that when put in a barn or stack it will usually spoil. Certain substances prevent the action of decay organisms. These preservatives are usually harmful to men and animals, so that this is not a very desirable method of preserving. Salt is satisfactory for preserving meat and some other things, because the harmful excess of it can be washed out. A fourth method of preserving is that used in canning fruit. This is the principle employed in the silo. By heating fruit so as to kill the decay organisms and then sealing it air-tight, so that no more can get in, it may be preserved indefinitely.

In the early attempts to keep silage, it was placed in pits or tanks and sealed with earth or other material, and was cooked with steam. Later it was found to keep nearly as well when merely packed in the silo. Decay begins at once, and as a result the silage becomes very hot. This decay uses up the air in the silo and changes it to carbon dioxid. This process continues until the heat and the exhaustion of the air stop the decay. The silage will then keep indefinitely, provided no air can get into it. That on the top of the silo or near any leaks will spoil. As soon as the silo is filled, it is well to begin feeding from it. If this is not done, it may be covered with chaff and well wet down. Or the corn may be husked from the last that is put in and the silage itself act as cover; several inches on the surface will spoil. There should not be too much surface area per cow, or it will spoil while being fed.

162. The Silo. Any kind of material may be used for 
building a silo. The essential point is that it be air-tight at the sides and bottom. Cement, stone, and brick are sometimes used, but they are all more expensive than wood. There are two common methods of wond construction. In one, vertical posts are sheathed on the insicle and outside - the sheathing acting as hoops to maintain the circular position. The other type is more common. It is made of two-inch planks that are matched together and held by hoops in the form of a tank. The hoops may be tightened by means of burs. The foundation should be of cement. Wooden silos may be constructed complete for $\$ 1.50$ to $\$ 2$ per ton of capacity.

The deeper the silo, the cheaper the construction for a given capacity, and the better the silage keeps, because that in the buttom is packed harder. A silo that is 32 feet deep will hold twice as much as one that is 20 feet deep. Ordinarily, a silo should be at least 24 feet deep.

A silo is not likely to be profitable if there are not at least ten cattle to be fed. Each cow will eat about half a ton a month. The required capacity can therefore be figured from the number of cows.

163. Growing Corn for the Silo. When com is grown for the silo, it is usually planted in drills and thicker than when grown for grain. The distance at which the total yield of grain is greatest is probably best. This results in some "nubbins," but they are as desirable as large ears, provided the total yield of grain is not decreased. It is not desirable to plant so thick as to decrease the yield of grain.

Corn should be cut for the silo when fully glazed. At. this time the kernels will all be dented and a few of the 
lower leaves will be dead. The table shows that in the milk stage the corn weighs more than when glazed, but there is 60 per cent more dry matter at the later stage. The difference is water. If put in the silo in the milk stage or when ripe, the rorn does not keep so well as when glazed:

Yield of Corn When Cut at Different Stages

\begin{tabular}{|c|c|c|c|}
\hline Stage of growth & $\begin{array}{l}\text { Yield of } \\
\text { corn } \\
\text { per acre }\end{array}$ & $\begin{array}{l}\text { Water } \\
\text { per acre }\end{array}$ & $\begin{array}{c}\text { Dry } \\
\text { matter } \\
\text { per acre }\end{array}$ \\
\hline 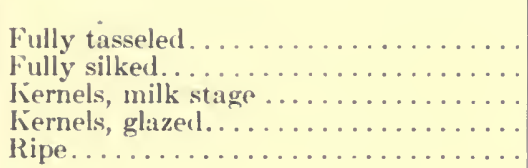 & $\begin{array}{r}\text { Tons } \\
9.0 \\
12.9 \\
16.3 \\
16.1 \\
14.2\end{array}$ & $\begin{array}{r}\text { Tons } \\
8.2 \\
11.3 \\
14.0 \\
12.5 \\
10.2\end{array}$ & $\begin{array}{c}\text { Tons } \\
0.8 \\
1.5 \\
2.3 \\
3.6 \\
4.0\end{array}$ \\
\hline
\end{tabular}

The large weight in the milk stage deceives many persons as to the best variety to grow. Farmers in the North often grow a variety that does not become glazed before frost. Such a variety may grow very large, but the yield of dry matter will not be so great as that of a variety that matures to this stage before frost. The larger the variety the better, so long as this stage is reached.

Even if the right variety is planted in northern United Sitates, there will be short.seasons when it will be in danger of frosts. If there is danger of a frost, will it pay to rut the corn, or will it be better to wait for it to mature and risk the frost? The Vermont Station tested this matter. Part of a field was cut Octoher 7, when a frost was expected. The remainder was allowed to grow until ()ctoher 23, when it was killed by a hard frost. The two 1New York State Station, Report, 18s9. 
EFfect of Frost on Corn for Silage

\begin{tabular}{|c|c|c|}
\hline & \multicolumn{2}{|c|}{ Date cut } \\
\hline & October 7 & October 23 \\
\hline 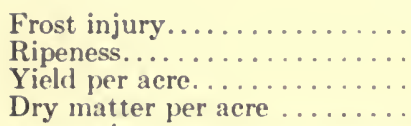 & $\begin{array}{l}\text { None } \\
\text { Late milk } \\
22,300 \text { pounds } \\
5,642 \text { pounds }\end{array}$ & $\begin{array}{l}\text { Hard frosted } \\
\text { Glazed } \\
22,750 \text { pounds } \\
6,506 \text { pounds }\end{array}$ \\
\hline
\end{tabular}

The frosted corn gave 3 per cent less milk per 100 pounds of dry matter.

The frosted corn gave 15 per cent more yield of dry matter.

The frosted corn gave 12 per cent inore milk per acre of corn.

lots were fed to cows for comparison. The frosted corn was not quite so good feed, but there was 15 per cent more dry matter, and the result was 12 per cent more milk per acre of corn. It seems that one should try to avoid a frost, but that if corn has not matured it is better to risk a frost than to cut the corn much too green.

164. Feeding Silage. Silage is not much used where hay is very cheap. It is not used extensively for fattening cattle, but experiments have shown that it is a good feed for that purpose. It is also good for sheep, but is not fed to horses. Its greatest use is as a focd for winter dairies.

There is some prejudice against milk from silage-fed cows. One of the largest milk firms in New York City refuses to buy silage milk. This prejudice does not seem to be warranted by the facts. Rotten silage or rotten hay may affect the milk, particularly if they are fed before milking, so that the odors are in the air ready to be absorbed by the milk; but, under ordinary conditions, silage does not give the milk a bad flavor. The Illinois 
Experiment Station gave silage and non-silage milk to 372 persons to be tested without knowledge of its source. Sixty per cent preferred the silage milk, 29 per cent preferred the non-silage milk, and 11 per cent had no choice.

165. Uses of Corn. The chief use of corn is as a food for farm animals. The enormous meat-producing industry of the United States is based on corn, grass and alfalfa. A large amount of corn is also used as human food, particularly in the South and in the regions where wheat is less plentiful.

Many products are also manufactured from corn. It is the chief source of alcohol and whiskey. It is the cheapest material in America for making denatured alcohol. Some of the products are malt liquors, glucose, corn starch, corn oil. Less important products are paper made from husks and stalks, explosives from the pith, packing for war vessels from the pith, corn-cob pipes. The pith has the property of expanding when wet, so that it will stop leaks in a vessel when pierced. Some counties in Missouri grow a special variety with large cobs for corncob pipes. Some of the chief by-products are gluten meal and distilled grains, which are used as stock foods.

The proportion of the corn that is fed to stock is much greater in states west of Chicago than it is in Illinois. This is because it is cheaper to ship the meat produced by a bushel of corn than it is to ship the corn. A bushel of corn will produce 10 to 11 pounds of pork. Instead of shipping five or six pounds of corn, a farmer can feed it to a hog and have only one pound to ship. (See page 357 .)

Less than 2 per cent of the corn crop of the United States is exported, while over one-third of the wheat crop is 
exported, either as grain or as flour. This has an important significance. It means that nearly all of our corn is fed in this country, so that it results in manure-production for the maintenance of the productiveness of our farms. A relatively "small amount of wheat is used fol' animals, so that wheat farms usually have too little manure to keep up the productivity.

\section{WHEAT}

166. Importance of Wheat. Long before men began to record history, they learned to raise wheat. It is the most important human food and the one that is most universally liked.

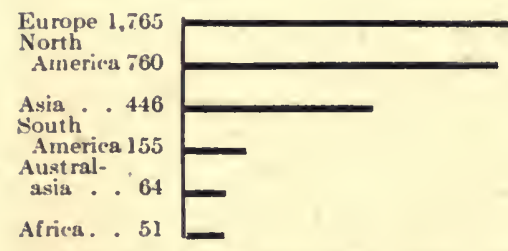

Fic. 85. Wheat rrop of the world in millions of bushels. Average for five years $(190: 3-07)$.

Nearly all of the wheat crop of the world is used as human food. This is not because it is not good for domestic animals, but because men prefer it to other grain, and hence make the price too high to allow of its general use as a stock food. The demand for it as human food is constantly increasing. As fast as men or nations become wealthy enough to afford it, they seem instinctively to demand "white bread." The peasants of Russia and of parts of Europe are compelled to eat rye, barley, millet, etc., because they are cheaper; those of Asia eat rice, 


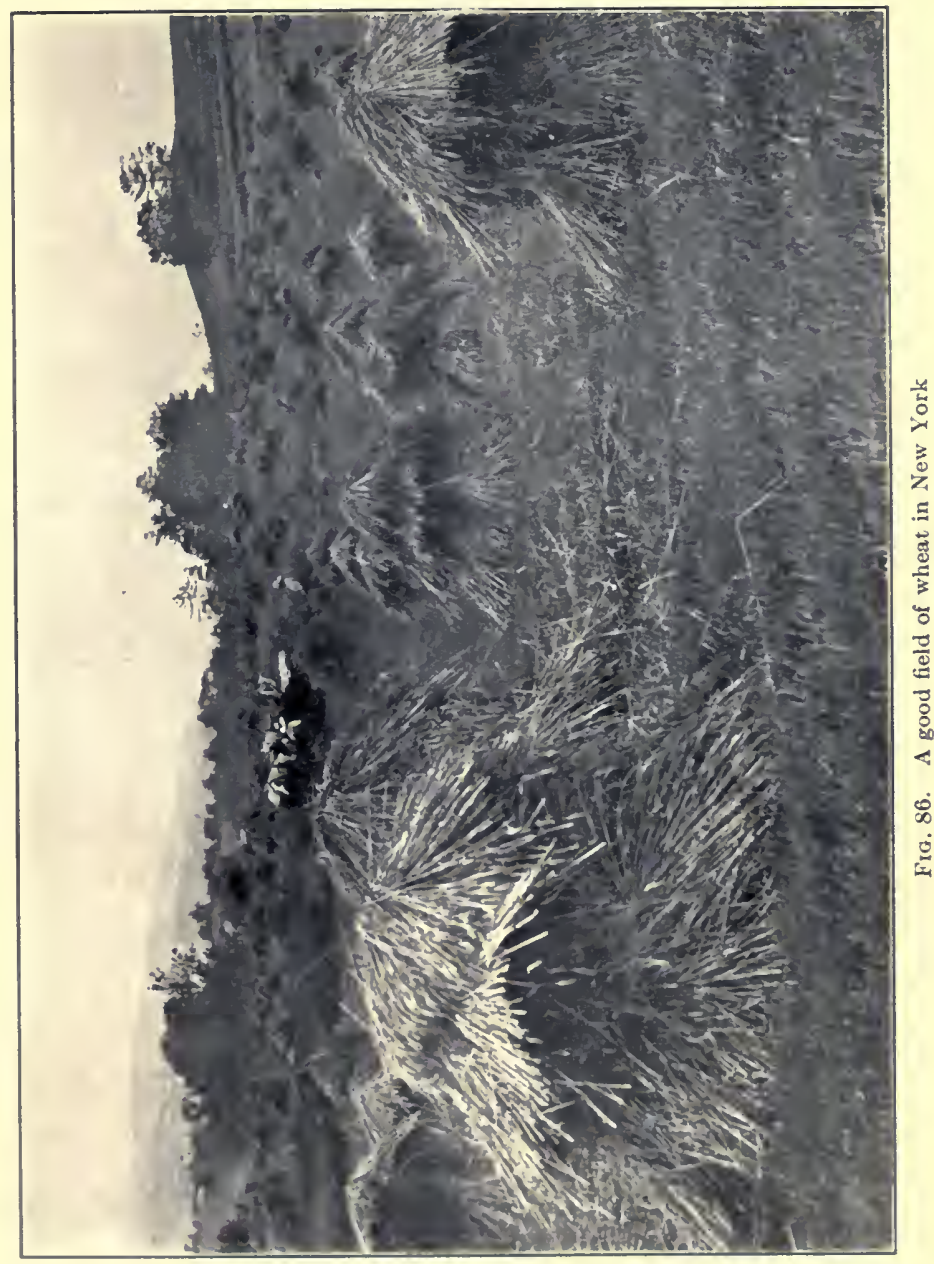



but as soon as these people become wealthy enough they demand wheat. One reason why wheat is so highly esteemed is because it makes light bread and can be cooked in so many forms. This factor depends on the gluten that it contains. Chemically, wheat does not seem to be much better than some other foods, but it is probable that it contains some substance that makes it more palatable and healthful. Some recent investigations seem to indicate that this is the case.

The wheat crop of the world is very differently distributed from the corn crop. Europe produces twice as much as North America. Europe secures about twice the yield per acre, so that it is able to compefe with America in wheat-production.

In this country, wheat is largely grown on new lands by a one-crop system. This usually ceases to be profitable after wheat has been grown 30 to 60 years, so that the wheat region continues to move westward. ('onsiderable wheat is also grown in crop-rotation in the older sections. The regions that are now being exploited by wheat-production are western Canada and Argentina.

167. Types of Wheat. There are six rather distinct types of wheat from the commercial standpoint: soft winter wheat, semi-hard winter wheat, hard winter wheat, soft spring wheat, hard spring wheat, macaroni wheat.

The wheats of the humid region are soft, those of the drier regions are hard. The hard spring wheats of the Dakotas and Canada and the hard winter wheats of Kansas and Nebraska are highly prized for flour. The hest grades of flour are made from the hard wheats or from mixtures of these with the soft varieties. Durum 
or macaroni wheat is the hardest of all. It is exported for the manufacture of macaroni and is coming to be used for flour.

The introduction of the Turkish varieties has made the production of wheat profitable in Kansas, Nebraska and other states where the soft winter varieties are not successful. Durum wheats will grow with even less rain-

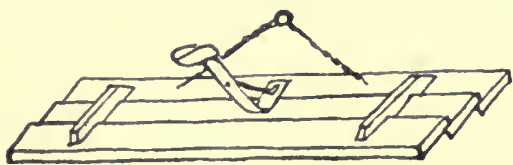

Fro. 87. A planker, for crushing clods fall. The recent introduction of this type has added thousands of acres of semi-arid land to the wheat area.

168. Culture. Wheat lends itself to machine-farming better than most crops. Nearly all the "bonanza" farms with their large machinery are wheat farms. Still, the greater part of the world's wheat crop is cut with a sickle.

Wheat is better adapted to short seasons than is corn, hence it grows farther north. It completes its growth before the severest summer droughts occur, hence it can grow in regions too dry for corn.

Some of the best wheat soils are clay loams and clays-soils that are not best for corn. In regions where the climate is suit-

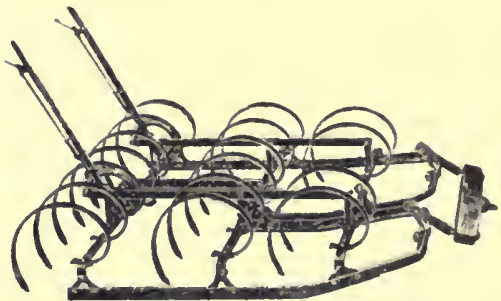

Fig. 88. A spring-tooth harrow. Particularly useful on stony land able for corn, the loamy soils are devoted to corn, not because they will not raise wheat but because corn pays better. 
Land for wheat is usually plowed, although it is sometimes disked. Early plowing for fall-sown wheat is much to be preferred, on account of the control of weeds and conservation of the rainfall. Many experimental tests of drilling and broad-cast sowing have been made. The drilled wheat has almost invariably given better yields.

The question of depth of planting, and advantages of fall and spring plowing have been discussed under corn. The same principles apply to growing spring wheat.

OATS

169. Oats thrive best in a cool, moist climate. Thëy will grow farther north than either corn or wheat. For both of these reasons, the oat crop of Europe is much greater than that of the United States. Oats will also produce something of a crop on land that is too poor to produce corn or wheat. Oats are usually given the least fertilizer of any crop in the rotation; not because they do not respond to fertilizers, but because they will grow without them. Too much nitrogen in the soil is likely to make them lodge, hence manure or nitrogenous fertilizers must be used sparingly.

Many oats are used for the manufacture of oatmeal. They are highly esteemed for horse feed. The average price of oats in New York for ten years has been 1.12 cents per pound, while the average price of corn has been .96 cents per pound. The grain of oats costs still more. About one-third of oats is hull, which has about the same value as oat straw. If we exclude the hull, the price of the grain in oats has cost about 75 per cent more 
than corn. This difference is because oats are so much preferred as horse feed. Corn seems to be as good and much more economical for farm horses. ${ }^{1}$

A large part of the oats in America are grown without plowing the land. The oats are either cultivated or disked in on corn ground. This reduces the cost of production.

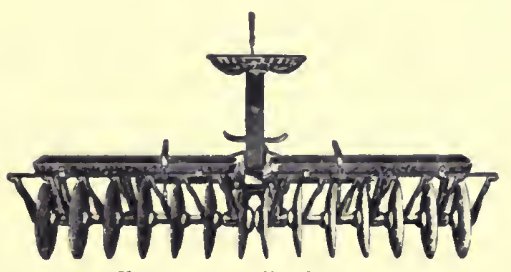

Fit. 89. A disc-harrow

These methods produce good crops in the cornbelt. Plowing is best on heavy soils.

Oats are often mixed with other crops, such ats barley and field peas. This is a common practice in New York and Canada. In these sections, the mixture gives a larger yield than any one alone. A common mixture is half oats and half barley. When peas are included, one bushel of each are often sown per acre.

\section{MEADOWS AND PASTURES}

170. Cultural Methods. The hay and pasture plants were the last to receive attention from mankind, and are yet the crops that are likely to be poorly treated. It is sometimes said that a good farmer can be told hy his pasture. This is because the pasture is the last thing to receive attention. If his pasture is cared for, everything else must be.

The grasses and clovers are usually sown with small grain. In New England they are often sown with corn. Some farmers plow the land for the grass crop and seed 1 Ohio Bulletin No. 195 
without a grain crop. In humid regions, good stands are usually secured when seeded with rye or wheat, and fairly good stands with barley, but when seeded with oats, the stand of grass is likely to be poor. This is because the oats take so much water from the soil (page $6 \overline{\mathbf{t}}$ ), because they shade the ground so much, and because they are cut later in the season. The small grass and clover plants are likely to be smothered out or to be killed by drought. The drier the year or the region, and the poorer the land, the more injury the grain crop does. Some farmers fit the land again and seed after the removal of oats. When seeded with winter wheat or rye, the grass seeds are usually sown in the fall and the clover seeds sown in the spring.

The grass plants respond to nitrogenous fertilizers. (See Figs. 55 and 56.) Nitrogen promotes vegetative growth; and it is vegetative growth, and not seed, that

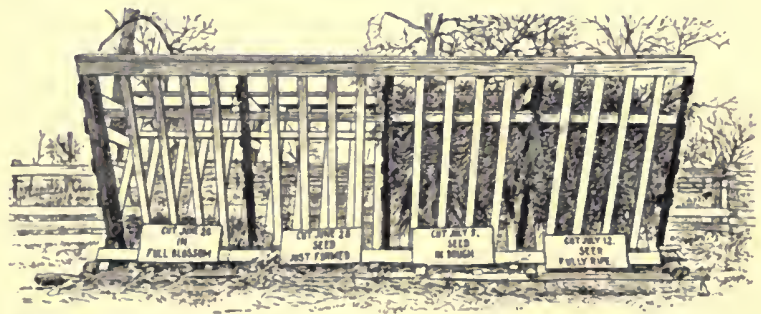

Fic. 90. Timothy hay was cut at the time indicated, rattle were allowed in eat at will. They preferred that which was cut when the seed was just formed. Missouri Experiment Station.

is wanted for hay. Another reason why the grasses respond to nitrogen is because they grow so early in the spring, before the soil organisms are sufficiently active to supply the nitrogen. Top-dressing of meadows is usually 
profitable if there is a good stand of grass and if there is sufficient rainfall. There is no use in supplying fertilizers for a four-ton crop when the climate or the stand of grass limits the crop to one ton. The price of hay is also an important factor. In the northeastern states, nitrate of soda at the rate of 100 to 200 pounds per acre may be profitably used for the production of timothy. In New York, the use of this material usually seems to be profita-

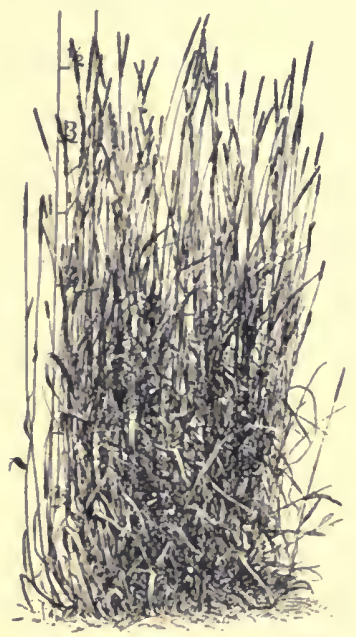

FIg. 91. Timothy plant grown from a single seedA bunch grass.

ble if the untreated land will yield a little over a ton of hay. It is applied as soon as the grass starts growth in the spring. Many farmers are now applying manure on the meadows preceding corn rather than on the corn crop. This seems to be a good practice when it can be spread thinly, $s$ is done with a manure spreader. The corn crop does not seem to be much poorer and the hay is greatly benefited. Probably the bacterial activity that is favored by the sod (page 120) and manure (page 119) prepares food for the corn crop.

171. Timothy (Phleum pratense). The most important hay plant in America is timothy. The chief timothy region is north of the city of Washington and east of the 100th meridian. Timothy has a number of desirable characters that make it popular. The seed is cheap. It grows well and produces a good yield of good hay the year after it is sown. It is easily killed by plowing. No other grass is so 
well adapted to growth in rotation with other crops. The first two crops are better than the later ones, unless the land is rich or is made so by fertilizers. It thrives best in a good soil with a good rainfall. It is primarily a hay plant, but, since the seed is cheap and since it produces a fair crop the first year, it is used in nearly all pasture mixtures. In permanent pastures it is usually displaced by other grasses in a few years. The seed weighs 45 pounds per bushel. About 10 to 15 pounds is sown per acre.

172. Kentucky Blue-Grass (Poa pratensis). The most important pasture grass in America is Kentucky bluegrass. It is of little value as a hay plant. It grows

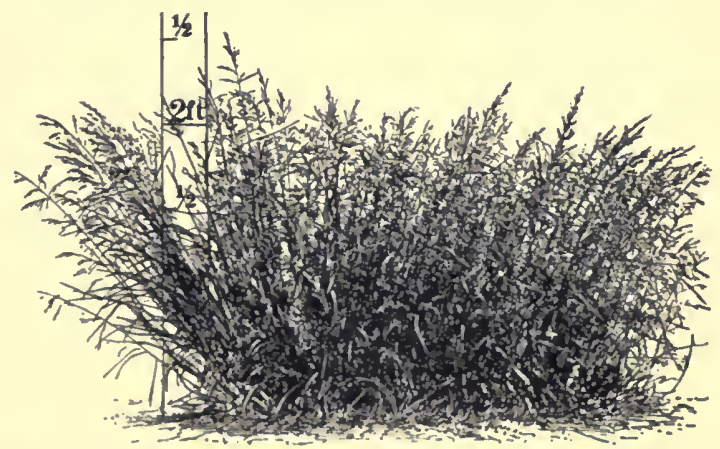

Fıg. 92. Kentucky blue-grass, grown from a single seed. Strongly stoloniferous. Compare with Fig. 91

throughout the timothy region, but reaches its best development a little south of the best timothy section. It is very strongly stoloniferous (page 38) and will run out most other plants on good soils. It takes two to three years for it to reach full development, hence it. is seldom sown alone. It is an early grass, starting growth early and heading out early. It also grows well in the fall. 
In midsummer it makes a poor growth. The seed is expensive and is often poor in quality. The method of curing the seed is such that it is often spoiled by heating.

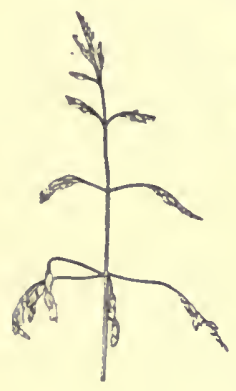

1

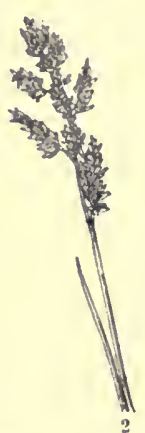

Fig. 93. (1) Kentucky bluegrass. (2) Canada blue-grass

One to ten pounds per acre are used in seeding pastures. It is sometimes adulterated with Canada blue-grass (Poa compressa), also called wire grass. The latter is a less desirable grass, except for very poor soils.

173. Red-top (Agrostis alba) is second in importance to timothy as a hay plant. It does not make as popular a hay as timothy. If much of it is mixed with timothy hay, the price is reduced. The chief value of red-top is that it will grow on soils that are too wet, too acid, or too poor for the growth of timothy. It is a shallow-rooted, strongly stoloniferous plant. It will produce hay or pasture the year after seeding. The seed is not expensive and is usually good. Recleaned seed weighs about 35 pounds per bushel. About 15 pounds is sown per acre.

174. Awnless Brome Grass (Bromus inermis) has been introduced from the plains of Russia recently. It is strongly stoloniferous and will produce one or two good crops of hay, after which the sod becomes too dense for hay and is adapted to pasture. It makes a very palatable pasture grass. It has proved its value in the semi-arid regions. In the East, it has not been thoroughly tested, but seems promising.

175. Tall Meadow Fescue (Festuca elatior) is a 
"bunch" grass, about as stoloniferous as timothy. It requires about three years to form a good sod. It is adapted to good land. The seed is not always good or pure, and is expensive. It is subject to rust, the same rust that

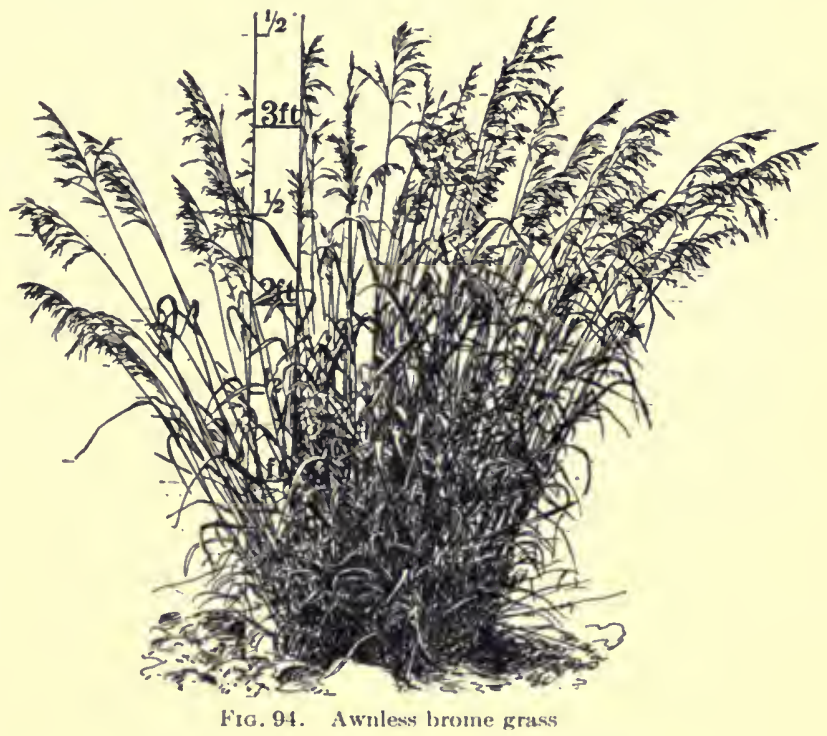

attacks oats, but it is a grood pasture grass under many conditions.

176. Orchard Grass (Dactylis glomerata.) is a tall, tufted grass. It is adapted to deep, rich soils, as it roots decply, yet it grows on poor soils to some extent. It is often desirable in a pasture mixture. The high price of seed and the seed adulteration seem to be the chief causes for its limited use.

177. Bermuda Grass (Capriola dactylon) is probably the best pasture grass for the South. It is very strongly 
stoloniferous. The seed is very scarce and high in price. It is sometimes grown from cuttings planted several feet

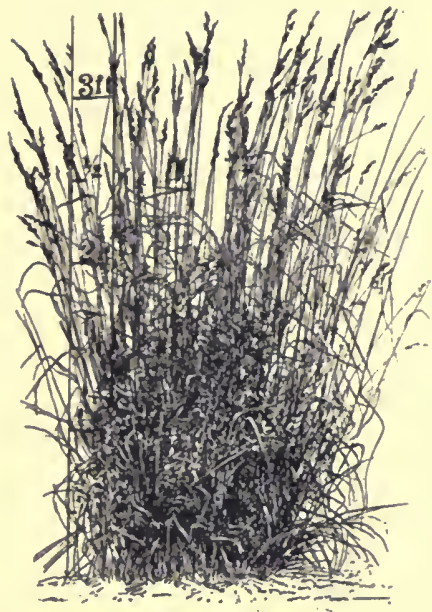

Fig. 95. Orchard grass apart.

178. Johnson Grass (Sorghum halepense) is one of the best hay grasses of the South. It has one very serious objection: it is a bad weed in cultivated land. For this reason, some of the states have laws against sowing it. It now seems that there are methods by which it can be successfully eradicated. If these methods prove practical, it will become a popular crop rather than a weed.

179. Alfalfa (Medicayo sativa). Alfalfa, or lucerne, is probably the oldest hay plant now grown. It came from Media to Greece, 490 B. C. The genus name refers to the origin in Media. How long it was grown in Media no one knows. It has been grown in New York for one-hundred years. But its effective introduction into the United States was from Chili to California, about 50 years ago. Its distribution has been particularly rapid during the past 25 years.

180. Value of Alfalfa. The table on next

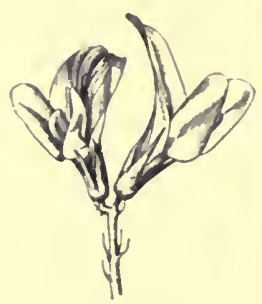

FIG. 96.

Alfalfa blossoms page shows the total number of acres of different kinds of hay and total yields, in 1899, according to the Twelfth Census: 
Comparison of Hays Grown in the United States in 1899

\begin{tabular}{|c|c|c|c|c|c|}
\hline & Acres & Yield & $\begin{array}{l}\text { Yield } \\
\text { per } \\
\text { acre }\end{array}$ & $\begin{array}{c}\text { Digestible } \\
\text { nutrients } \\
\text { per acre }\end{array}$ & $\begin{array}{l}\text { Digest- } \\
\text { ible } \\
\text { protein } \\
\text { per } \\
\text { acre }\end{array}$ \\
\hline Alfalfa & $2,094,000$ & $5,221,000$ & 2.5 & 2,673 & 609 \\
\hline Clover & $4,104,000$ & $5,167,000$ & 1.3 & 1,214 & 177 \\
\hline Cultivated grasses ${ }^{1}$ & $31,302,000$ & $35,624,000$ & 1.1 & 1,091 & 62 \\
\hline
\end{tabular}

It will be seen that from half the area alfalfa gave a little more total yield than clover. Its composition being better, it gave over the digestible nutrients per acre.

Its value is sometimes overestimated. It has almost the same composition as wheat bran. This has led to the common statement that it is as valuable as wheat bran. This is not true. It is always unsafe to compare the feeding values of grain feeds with hay on the basis of composition only. The coarser feeds are harder to digest. Feeding trials in milk-production on a commercial scale, at the New Jersey Experiment Station, showed that when bran cost $\$ 22.50$ per ton, the hay was worth $\$ 16.50$ as a substitute for it. In this case, alfalfa hay was worth a little over two-thirds as much as bran.

One-sixth of the cultivated area of Argentina is planted to alfalfa. It is said that on land where eight acres of native grasses were required per steer, one acre of alfalfa is sufficient.

181. Culture of Alfalfa. Alfalfa has a long tap-root, much longer than any other farm crop, therefore the character of the subsoil and drainage are of much im- 
portance. It is especially adapted to warm climates, is alkali-, drought- and heat-resistant. It grows throughout the warm season if there is sufficient moisture. Hence, it is possible to get two or three crops in Ontario, Canada, while in Arizona eight crops are often harvested.

Failures of alfalfa are usually due to one of the following causes: drought, lack of drainage, weeds, lack of manure, lime or inoculation. Sometimes failure is due to poor seed or to dodder.

Alfalfa is most likely to succeed on a porous, welldrained soil, but it is successful on some clay soils. It is

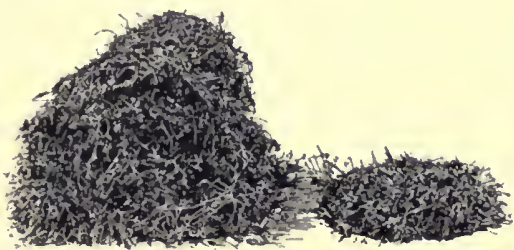

Alfalfa.-Left, limed: right, not limed

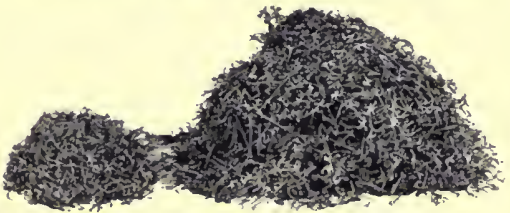

Weeds.-Left, limed: right, not llmed

Fis. 97. Influence of lime on alfalfa and weeds on a farm where lime was needed. Where limed there was no room for weeds; when not limed the weeds were able to run out the alfalfa.

not a poor-land crop. If the soil is not rich, an application of 10 to : () tons of manure should he made before sowing it.

It is more sensitive to acidity than any other farm crop. Probably half of the soils east of the Mississippi river require. lime for l)est success with alfalfa.

It is a tender plant when young, and is not likely to be successful if sown with a nurse crop unless all other conditions are very favorable. Nearly all experiments have shown that it is safest to sow it alone. If the rainfall and soil are just right, it may be successful when sown with wheat, oats, or barley, but there is much risk in sowing it this way. Fig. 98 
shows an instance where entire failure resulted from sowing with oats. When conditions are more favorable it may persist in spite of the oats. If seeded alone in the spring. the weeds are likely to injure it. It is, therefore, best to sow it in late summer or early fall. Experiments in nearly all of the states east of Colorado have shown this to be the best time. Where small grain or potatoes come

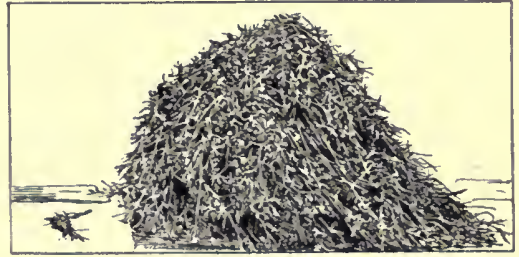

Fir: 95. Influence on alfalfa of seeding in oats when other conditions were unfavorable. On the left is the alfalfa from a square rod seeded in oats, on the right seeded alone. When other conditions are favorable the nurse crop does less damage. off the land in time, it may be sown after these crops. As far north as New York, it is usually best to summerfallow the land. It is then manured and limed in the spring when plowed, if these treatments are necessary, and is kept harrowed and free from weeds until about August 1. If this cannot be done, it may be seeded with grain in the spring and the grain cut for hay.

In order to be sure that the seed is alive, a germination test should be made (page 51). The seed is sometimes adulterated with bur clover, yellow trefoil and sweet rlover. Dodder is the worst weed in the seed. Of 399 samples examined by the United States Department of Agriculture in 1907, about half (191) contained dodder. Seed should, if possible, be purchased from regions where dodder is least prevalent. Before buying seed, a sample should be examined for dodder seed.

The beginner should sow at least 25 pounds of good seed per acre. Older growers whose soils are in condi- 
tion for alfalfa may sow 20 pounds, or less. In some sections as low as 10 pounds are sown.

Inoculation is absolutely necessary for success. Inoculation may take place naturally or may have to be applied. Soil from sweet clover will inoculate alfalfa. Most of the cases of natural inoculation appear to be due to the previous growth of sweet clover on the soil. Common clover soil does not inoculate alfalfa. West of the Mississippi river, inoculation is not so often required; but, east of it, probably half of the soils require inoculation when alfalfa is sown for the first time.

Even in fields that require inoculation for success, a few plants usually become inoculated from some source. These usually look large and dark green as contrasted with the small yellowish uninoculated ones. If such a field is planted and reseeded, it is often well inoculated. It is, therefore, often desirable to make a new trial on ground where alfalfa has thus failed.

Peas, beans, peanuts, clover, do not often require inoculation. So far as we know, alfalfa and soy-beans are the only legumes that require inocu'ation in New York. Alfalfa requires it on most soils, and we have not yet seen any soy-bean nodules where the soil was not inoculated. Many examinations have shown clover to be inoculated in all cases, even on soils where it does not grow well.

Several methods have been developed for inoculating legumes, but the best method is to take soil from a field that has grown inoculated plants of the desired kind. One or more bushels of this soil can be scattered on an acre of land. This is an easy and inexpensive method. 
Alfalfa should be cut for hay when about one-tenth of the heads are in blossom. If allowed to stand longer, the hay is poorer, and the succeeding cuttings are decreased.

182. Red Clover is the most important legume in eastern United States. There are two varieties, - the common, medium or June clover (Trifolium pratense), and the mammoth, sapling or pea-vine elover ( $T$. pratense perenne). 'The former is smaller and about a month earlier than the latter. The mammoth clover matures with timothy, which is a point of great advantage in hay-making. The two kinds cannot be distinguished

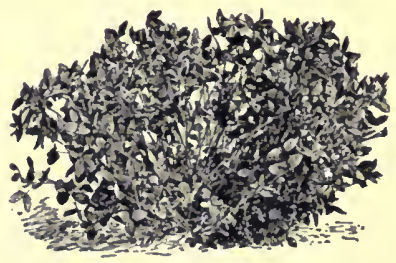

Fic. 99. A red clover plant. It does not reproduce except from seed. by their seeds, hence the difficulty in always getting the desired kind.

Red clover requires good soil. There are many farms that are now too poor to grow it. The soil should be well drained and should not be acid. The first steps in getting clover on most farms where it fails are applications of lime and manure.

The root-borer usually kills most of the clover the second year, but it does not prevent the production of the first hay crop.

Clover seed is about four times as expensive as timotlyy. Four quarts are usually sown per acre. 'The seed weighs (i0 pounds per bushel.

Clover hay usually sells for about two-thirds as much as timothy. 'Therefore, farmers usually sell timothy, and 
feed the clover and mixed hay. The chemical analysis of clover hay would seem to make it as valuable as timothy. It is better for cattle and sheep, but is not desirable for horses. This is probably the reason for the low price. Clover seems to be chiefly responsible for the disease of horses called heaves. It is said that heaves does not occur in regions where clover is not used.

183. Alsike Clover (Trifoliuin hybridum). This was formerly thought to be a hybrid between red and white clover, hence its specific name, hybridum. It is not now considered to be a hybrid.

It is smaller, earlier, and more decumbent than red elover. Its greatest use is to grow on soils where red

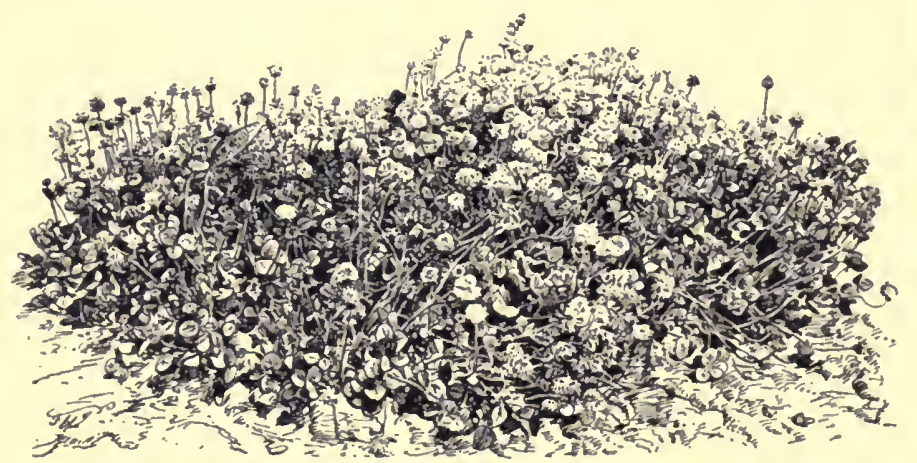

FIG. 100. A white clover plant grown from a single seed, showing spreading habit

clover fails or does poorly. It will grow on soils that are too wet or too dry for red clover. It will grow on more acid soils and on poorer soils, is less subject to disease, and is less severely injured by the root-borer. In the county where the writer lives, it is the only clover sown on the poorest and most acid soils. On the fairly good 
soils, it is mixed with red clover. On the richest soils, red clover is often sown alone.

184. White Clover (Trifolium repens). This plant is so small that it is of no value for hay purposes. But it is a very desirable pasture plant. It supplements Kentucky blue-grass for pasture, as red clover supplements timothy for hay. White clover stems spread about on the ground and take root, so that a single plant may produce many plants. (See Figs. 14 and 100.) The other clovers do not have the power to spread except from the seed. White clover will grow on poorer soils than either of the other clovers. A few pounds of it should be sown in pasture mixtures for permanent pastures.

185. Mixtures of Grasses and Clovers. Alfalfa is usually sown alone. The other grasses and clovers are commonly used in mixtures. Mixtures for hay should mature at the same time. For pastures, they should mature at different times. A plant that does not thrive alone on the soil will be of little value in a mixture.

The advantages of a mixture are that the roots of different plants do not occupy the same areas of the soil; hence the soil may be more fully used by growing deep- and shallow-rooted plants together, as red clover and timothy. Some seasons favor certain of the plants and some favor others; when red and alsike clover are sown with timothy, the clover is sometimes chiefly red and sometimes, on the same farm, chiefly alsike. In most fields there are irregularities of soil; by sowing a mixture, each soil variation will be covered with the type that thrives best on it. In pastures, a mixture will furnish grusses that grow at different seasons of the year, 
thus furnishing more uniform pasture throughout the season.

For hay production, where the meadows are left for one to three years, a good mixture to be sown per acre is: Timothy.......................15 pounds Mammoth red clover................6 6 pounds Alsike clover..................... 4 pounds

Such a seeding will usually produce hay that is half clover the first year and nearly clear timothy in later years. If the land is very poor, 10 pounds of timothy, 5 pounds of red-top and 4 pumnds of alsike may be used. On the poorest, most acid soils, red-top should be sown alone.

For pastures on good land a mixture something like the following may be used. This may be cut for hay for two years and used for pasture thereafter:

Timothy........................ 10 pounds

Mammoth red clover................. 4 pounds

Alsike clover..................... 3 pounds

White clover..................... 2 pounds

Kentucky blue-grass ................. 3 pounds

Tall meadow fescue $\ldots \ldots \ldots \ldots \ldots \ldots \ldots . \ldots . \ldots 2$ pounds

Orchard grass $\ldots \ldots \ldots \ldots \ldots \ldots \ldots \ldots, 2$ pounds

If the land will produce alfalfa, two pounds of this should be included. The blue-grass and white clover will usually be the most prominent plants after a few years.

For pasture on land that is very poor or acid, it will not pay to spend so much for seed unless fertilizers are used. Some mixture like the following may be used:

Timothy .......................5 pounds

Red-top ...................... 5 pounds

Alsike clover....................... 5 pounds

White clover...................... 2 pounds 


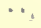

1

.... 


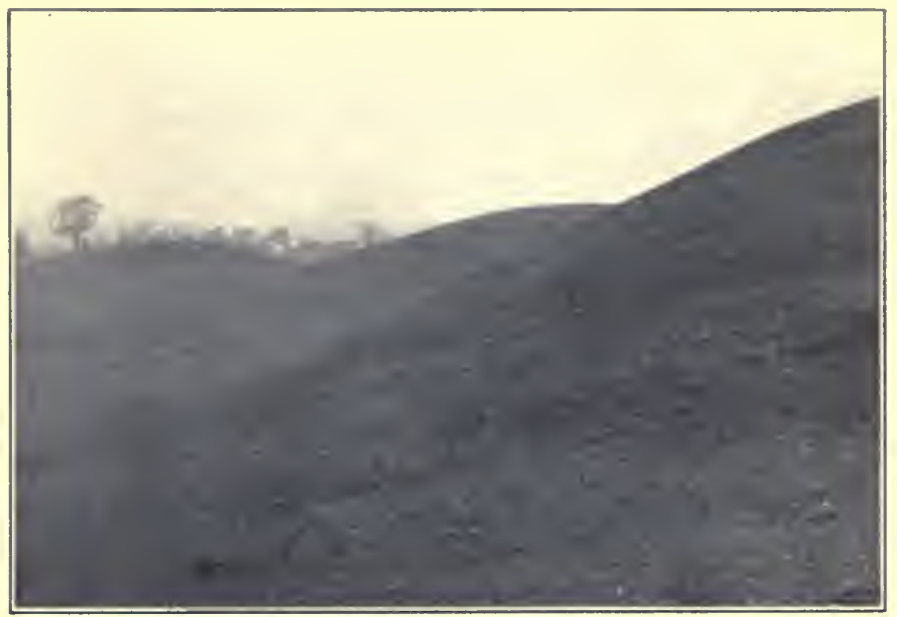

F1G. 101. A good pasture in New York, thirty years old. Cared for as suggested on page $19 \%$

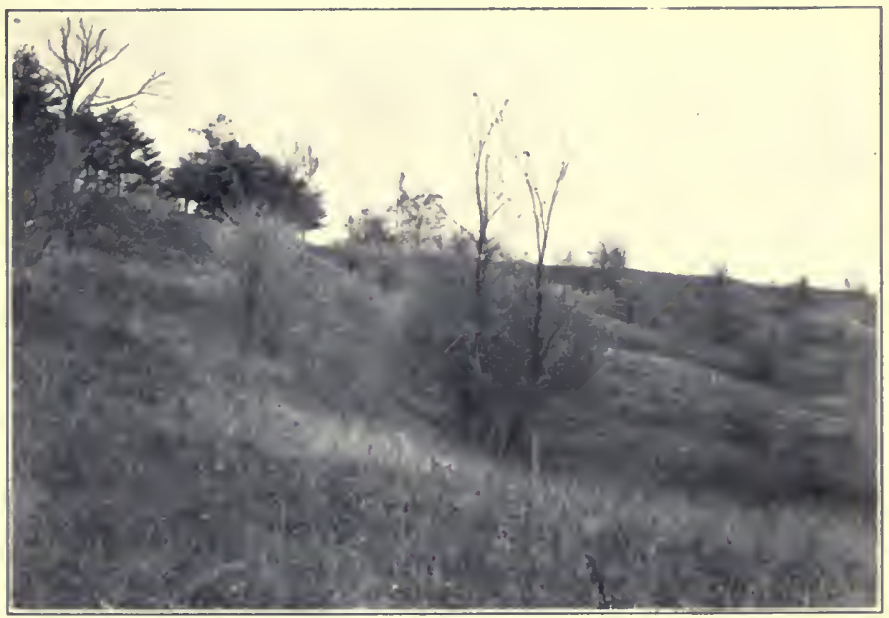

Frg 102 The opposite side of the same hill as Fig. 101 The cows have developed this pasture by exterminating the plants that they like and saving the weeds for seed. 
Any of the other plants that will grow on the land should be included. Such a pasture will soon be chiefly red-top and white clover if the land is very poor.

Professor Roberts, who developed the Roberts' pasture (Fig. 101), recommended 5 pounds of timothy, 6 pounds of red clover, 4 pounds of alsike, and $3 \frac{1}{2}$ pounds each of Kentucky blue-grass, red-top, orchard grass and tall meadow fescue.

A good mixture for a lawn is timothy, 10 pounds; red-top, 10 pounds; blue-grass, 20 pounds, and white clover, 5 pounds per acre. The timothy and red-top will make a cover while the blue-grass and white clover are becoming established. In arid regions, native buffalo grass makes a good lawn.

186. Management of Permanent Pastures. Temporary pastures are usually the second or later year's growth on land that was seeded for hay, using only timothy and clover. Too frequently a permanent pasture is made by neglecting such a field. In time, blue grass and white clover will appear, but in the meantime numerous weeds will also have become established.

As stock graze in the pasture, they select the plants that they like and allow the undesirable kinds to grow and produce seed. This is really the cultivation of pasture weeds. The results are easily seen by looking at the permanent pastures that one sees in almost any community.

If one is to maintain a good pasture, the weeds that the cow saves for seed must be cut and the desirable plants must be encouraged. The weeds should be mowed each year before they have gone to seed. This can be done at hay-making time, during rainy weather. Occasionally, 
some more seed should be scattered on the bare places. Sometimes it is well to go over the pasture in the spring with a cutaway harrow or disk. On most farms a topdressing of manure or fertilizer will be needed every three to five years. Coarse, strawy manure, or any kind of rubbish that is undesirable for the regular fields may be scattered on the bare spots in the pasture.

\section{COTTON}

By CHARLES H. ALVORD

Professor of Agriculture, Agricultural and Mechanical College of Texas

187. Importance of Cotton. Cotton is the most important fiber crop grown. It is valuable not only for the fiber or lint which it produces, but for each pound of lint there is also produced an average of two pounds of seed, which is valuable for manufacturing purposes and also as a food for live stock. Thread manufactured from cotton lint is used in manufacturing all kinds of cloth, from the coarsest ducking, used in making tents and sail-cloth, to the finest quality of "lawn." Its use is indispensable to the comfort of the human race, and there is no similar material produced in sufficient quantity to substitute for any very great percentage of it. If the farmers of America should cease growing cotton, there would be no other available material with which to clothe the people of this country. Because of its great importance to the industrial welfare of the people, this plant is familiarly called "King Cotton." The total farm value of the cotton lint and seed produced in the United States in 1907 was estimated at $\$ 675,000,000$, and of this amount $\$ 482,000,000$ worth of cotton and cotton-seed products 
were exported. ${ }^{1}$ Galveston and New Orleans are the great cotton ports of this cbuntry, the shipments from Galveston alone amounting to over $\$ 100,000,000$ worth of cotton per year.

The estimated annual production of cotton in the world in 1906 was about $21,000,000$ bales, each weighing 500 pounds. Of this vast amount, over three-fifths was produced in the United States, south of a line drawn from Norfolk, Va., to Memphis, Tenn., and ,west to Oklahoma City and El Paso, Texas. This means that the world is dependent on this section of the United States for its cotton, and indicates the great possibilities which can be attained by the farmers of the South who carefully cultivate this crop.

188. Historical. The cotton plant is of very ancient origin, antedating all recorded history. It is supposed to have originated in India, but China may have been its original home. ${ }^{2}$ It is spoken of in ancient history as tree wool. The people of India acquired great skill in the weaving of cloth from the fiber of the cotton plant. Ancient historians and travelers mention plants similar to cotton in the various countries of southern Asia and Africa, and it is also known that Columbus and other explorers who visited the western hemisphere found native cotton growing in the West Indian islands and in South America and in the territory now controlled by Mexico.

189. Development in the United States. Cotton was first cultivated in the United States in the colony of and 22 .

'Yearbook United States Department of Agriculture, 1907, pp. 15

${ }^{3} \mathrm{Cotton}$ is mentioned as a tribute from southern China to the ruler 3,000 years before Christ. Thesis in Cornell University Library, by Koliang Yih. 
Virginia in the year 1621. It has always been the chief money crop of the farmers of the southern states, and is so closely identified with the prosperity of the people that the welfare of all kinds of business depends very much upon the success of the cotton crop. For a great many years, Mississippi was the chief cotton-producing state, but within the last ten years the opening of new lands in western Texas and Oklahoma has greatly extended the area of land devoted to cotton culture. Cotton occupies the same place in the southern states that Indian corn occupies in the central states of the Mississippi valley, and both crops seem peculiarly adapted to the United States. Barley, wheat and oats are grown all over the world, but corn and cotton are not grown in other countries so extensively as they are in the United States.

190. Habits of Growth. In the tropical countries there are perennial types of cotton, some kinds growing 20 or more feet in height; but in the United States all of the varieties are annual, growing in the form of a small shrul, two to eight feet in height, depending on the variety, the amount of rainfall during the summer, and the productiveness of the soil. The plant is very tender when it first appears above the ground, but, if the weather is warm, it grows robust very rapidly. The tap-root extends deep into the soil, and the stalk above ground becomes tough and woody. There are many branches, called primary and secondary. The primary branches are longest near the ground. The flower-buds appear in the axes of the leaves on secondary branches, and are called "squares." The flowers are large in size and are short-lived, lasting only one or two days. When first opened, they are a white 
or pale yellow. The second day they turn somewhat red in color and soon drop off, leaving a small bqll which contains the seed. This boll continues to increase in size until the seeds which it contains mature. It then breaks open and the soft white lint which surrounds the seed is exposed. The boll contains three to five compartments. When it breaks open, each compartment opens separately. The seed and lint contained in each separate compartment is called a "lock." Each lock contains six to ten seeds.

191. Types of Cotton. ${ }^{1}$ Sea-island cotton is adapted to low, moist soil and a humid atmosphere. Experiment station reports indicate that certain varieties of seaisland cotton have been grown west of the coastal plain, and in irrigated sections, but, for the most part, the culture of this type is limited to regions adjacent to the coasts of Georgia, South Carolina and Florida. This cotton has a naked, black seed, and flowers that are yellow when they first open, but gradually turn purple. It does not produce so much lint per acre as the upland cotton, but, because of its greater length and fine quality, it sells for a higher price per pound.

There are two accepted types of upland cotton-G. herbaceum and $G$. hirsutum. These types include all the varieties which are commonly called short-staple cotton. The flowers are white or pale yellow when first opened, and turn to a reddish tinge. The seeds are covered with

${ }^{1}$ Cotton bolongs to the family of plants called Malvacexe and to the genus Gossypium. There are many speeies belonging to this genus among the most important of which are the upland eotton $(G$. herbaceum and hirsutum), sea-island cotton (G. Barbadense), tree cotton (G.arboreum) and India cotton $(G$. neglectum). Of these only the upland and sea-island cottons are cultivated in the United States. 
fuzz and are green in color. They are flattened somewhat and oblong in shape, and about the size of a white navy bean. Because of the fuzz or lint left on the seed, they are somewhat bulky, weighing 33 pounds to the measured bushel.

The lint which surrounds the seed is exceedingly fine in texture, and varies in length from seven-eighths of an inch in upland cotton to two and one-half inches in sea-island cotton. Some varieties of upland cotton have been selected for long fiber. When the lint produced averages over one and one-fourth inches in length of fiber, it is called "long staple." The longer fibers are much more valuable than the shorter ones,

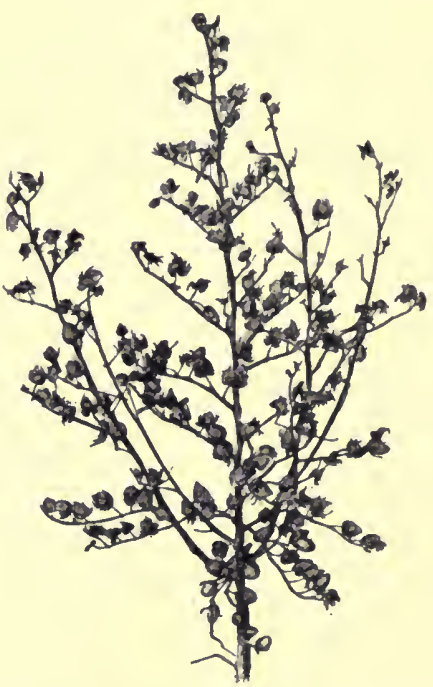

F1G. 103. An early, rapid fruiting, productive type of cotton plant, with low fruit limbs, short joints and continuous growing long fruit limbs. Leaves removed. (After Bennett.)

and "long staple" sells for a higher price in the market. Other desirable qualities of the lint in addition to length are (1) fineness, (2) strength, (3) uniformity of color.

192. Breeding and Selecting Cotton. From the foregoing paragraphs, it will be noted that the cotton plant may be greatly changed and improved by careful selection and breeding. Selection is comparatively a simple matter, but, because of cross-fertilization, which probably 
often occurs, the breeding $0^{\circ}$ cotton is more difficult. Because of the fact that the cotton stalks are a burden to the soil, exhausting its moisture and plantfood, and a bother to the farmer when it becomes neces-

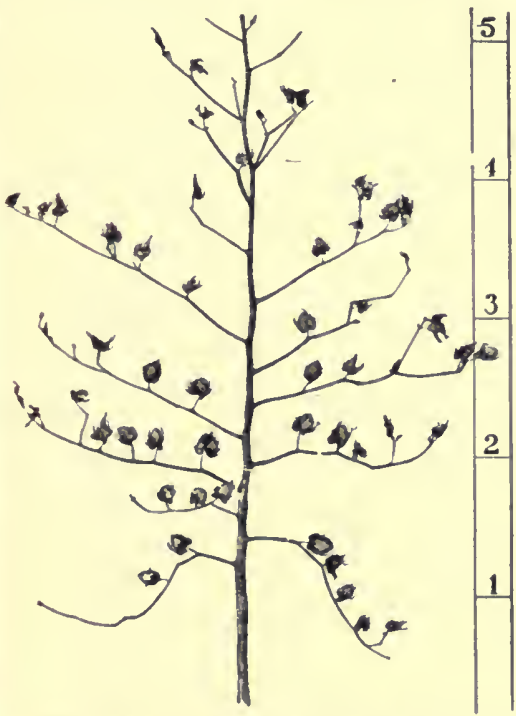

Fis. 104. A late, slow fruiting, unproductive type of cotton plant, with high fruit limbs and long joints. Leaves removed. (After Bennett.) sary to get the land in condition for the succeeding crop, it is desirable to produce the maximum number of bolls per acre on the least possible amount of stalk. Some types of cotton have the fruit branches set close tovether and the bolls close to each other on the branch. Fig. 103 shows cotton of this kind and represents a very desirable type. There are four primary limbs set close to the ground and the internodes are short. It has been determined ${ }^{1}$ that cotton of this type will blossom earlier than cotton in which the internodes are long. Early blossoming, with consequent early fruiting, is especially desirable in localities where the boll weevil attacks the cotton. A late-maturing undesirable type is shown in Fig. 104. The size of the bolls is an important factor in determining the yield of cotton. In

2Texas Experiment Station Bulletin No. 74. 
some instances, it has been stated that large bolls are always associated with late maturity, but recent experiments ${ }^{1}$ indicate that large bolls can be produced on the early-maturing, short-jointed type, and greatly increase the total yield, provided a maximum number of bolls is maintained.

The percentage of lint to seed is of importance. At present the average is about two pounds of seed to one

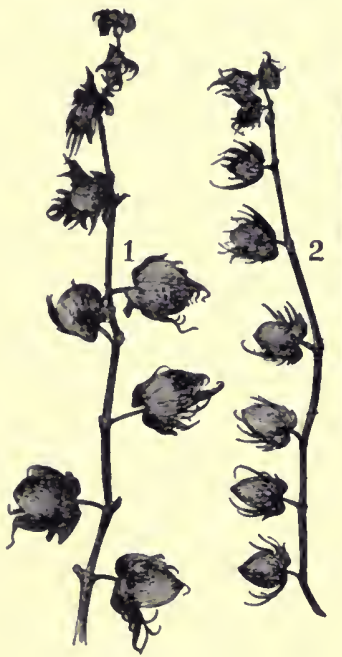

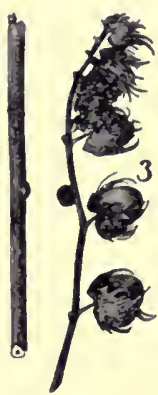
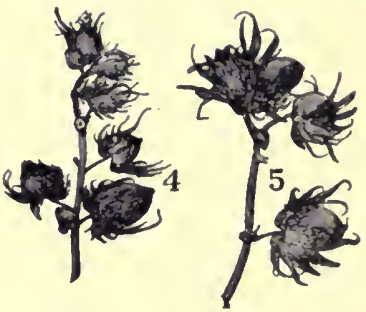

Fig. 105. (1) Big Boll. (2) Simall Boll. (3) and (4) Short fruit limbs. (5) Cluster type fruit limb. (After Bennett.)

of lint, or $33 \frac{1}{3}$ per cent of the total weight; but samples are often found in which the amount of lint will run as high as 40 per cent.

In the selecting of cotton for breeding and improvement, careful attention should be given to securing plants of early fruiting type and medium size, not over five feet high, with many bolls of large size and high per- 
centage of lint. With the seed carefully selected from individual plants, the breeding operations may be conducted in the same manner as described for corn (see päge 25).

Professor Bennett, of the Texas Experiment Station, recommends the following types of cotton:

For Early Fruiting.-The first fruit-limbs must be low-not higher than the fifth joint above the seed-leaf joint. Primary or wood limbs must be low-the first not above the fifth joint, and not exceeding four in number.

For Rapid Fruiting.-The joints on the main stem, fruit limbs and primary limbs must be short-not to exceed two or three inches is preferable. Fruit limbs should grow in succession at each joint of the main stem and primary limbs, and should be continuous in growth for continuous fruiting.

For Productiveness.-The bolls should not be less than one and one-half inches in diameter. The ratio of lint to seed cotton should not be less than $33 \frac{1}{3}$ per cent. The rate of growth is very important; and, therefore, the larger the plant of the type, the greater is its inherent rate of growth, its earliness, rapidity of fruiting and yield. Early opening of the bolls is not important in escaping the weevil. In states farther north, it is of importance in escaping the early frosts. It is not invariably a measure of the early setting of fruit.

193. Relation of Climate to Cotton. Cotton is a warmweather plant and needs a comparatively long-growing season. Its growth may be divided into two periods,the vegetative or growing period, and the fruiting period. This does not mean that the plant stops growing when it 
begins to fruit, but that it should make its most rapid growth during the first period, and attain nearly maximum size. Sea-island cotton requires 90 to 100 days for the growing period, and 80 to 90 days for the fruiting period. The early-maturing type represented in Fig. 103 should require only about 70 days for the first period. It is desirable that the vegetative period shall be short and the fruiting period as long as possible.

Warm, moist weather, with warm nights and gradually increasing heat, are desirable during the period of growth. For the fruiting period, dry weather with occasional showers is desirable. An excess of moisture in the soil at this time will cause the stalk to grow too large and retard the proper development of the bolls.

194. Cotton Soils. Cotton develops best on a clay or sandy loam soil, with a clay subsoil at a depth of about two feet. On bottom land, enriched by occasional overflows, there is a tendency for the stalks to grow very large, and they sometimes become so tough that they must be chopped down with axes before the land can be cleared and plowed for the succeeding crop.

Good cotton land should be well drained, but sufficiently retentive of moisture to insure the crop against injury by drought. To increase the water-holding capacity of the soil, there should be a higher percentage of organic matter than is usually found in cotton fields. This ean be secured by planting peanuts or some bush variety of cowpeas between the cotton rows, and plow'ng them under with the cotton stalks after the cotton has been picked. This is not yet a common practice. Bur clover grows well in the southern states in the winter, and can be used as a 
cover crop following the cotton, to be plowed under the following spring.

195. Preparation of the Soil. Early fall plowing is always advisable, especially when cotton is to follow cotton. There are three marked advantages in plowing under stalks and weeds in the fall: (1) Organic matter is added to the soil; (2) boll-weevil and boll-worm, and other insects are destroyed; (3) the seeds are destroyed which produce the volunteer cotton on which the boll-weevil feeds after the regular crop has fully matured.

Where the growth of stalk is very large, it may be necessary to clear the stalks from the land and burn them, but on soils of average productivity the stalks should be cut and turned under.

It is common practice on many cotton farms to plant cotton on land that grew cotton the previous season. The soil is prepared for planting by using a small, one-

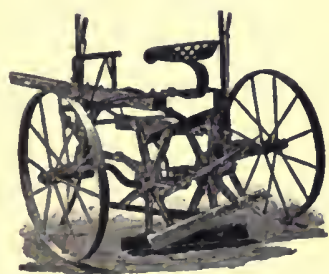

FIG. 106.

A corn and cotton stalk cutter. To cut the stalks before plowing

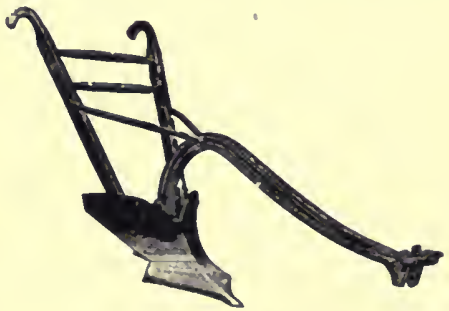

Frc. 107. A "middle-buster" for cotton fields

horse turning plow, going twice between each two rows, throwing the dirt to the center, and leaving the cotton rows which are then broken up by a plow called a middle-burster, which throws the dirt to each side. This forms the land into narrow beds, or ridges, with furrows 
between, and on these ridges the seed is planted. The chief objection to this plan is the expense of the labor. In modern systems of farming, the amount of horse power utilized per man should be increased as much as possible.

196. Fertilizers for Cotton. When the seed of the cotton plant is used on the farm for feed, and only the lint is sold, very little plant-food is removed from the farm. If manure could be saved and returned to the land, there would be little occasion to use commercial fertilizers. On farms in the South, however, the accumulation of manure is much more difficult than in the northern states, because of the fact that the cattle and work stock are not often kept in barns, but are out in the open pastures.

Experiments at various stations indicate that the nitrogen content of the soil can be maintained by the growing of cowpeas, peanuts, and clover or alfalfa, in rotation with corn and cotton. At the Texas station, no benefit was secured by the use of potash, but an application of 200 pounds per acre of acid phosphate, about two weeks before the seed was planted, produced earlier blossoms and a greater yield. At the Georgia station, it was found that when organic nitrogen, cottonseed meal or tankage was used, it should be applied about two weeks before the seed was planted; and the same recommendation was made with reference to applications of potash and phosphoric acid. It was also recommended that 16 to 20 pounds per acre of nitrate of soda should be applied with the seed.

The following suggestions may be helpful in applying fertilizer to cotton on average soil: 
(1) If the cotton is grown after cotton without rotation with a legume, more nitrogen will be needed.

(2) Potash and phosphoric acid will be needed unless liberal applications of barnyard manure are applied.

(3) Potash will make the plant hardier and more able to withstand the attacks of fungous diseases.

(4) Phosphoric acid increases the yie!d of lint and tends to produce early fruiting.

(5) When plants are small and dwarfish and not well fruited, apply complete fertilizer.

(6) When the plants are of average size, but not well fruited, apply acid phosphate.

(7) If the leaves are dropping off before the fruit is well formed, apply potash.

(8) Mix the fertilizer with the soil underneath the row or bed. Broadcasting fertilizer for cotton tends to produce late maturity.

197. Planting and Cultivating. The method of preparing the soil for planting depends largely on its texture and the drainage conditions. On wet lands, poorly drained, the best practice is to plant the seed on beds thrown up about four feet apart. On soil that is well drained and in the drier sections, level preparation of the ground is advisable. The soil should be well compacted, with just sufficient loose dirt on the surface to cover the seed. The results of various trials at different experiment stations indicate that four feet is the best average distance between the rows, and 1:2 to 18 inches is the proper distance between the plants in the row. On rich bottom-land soil this may result in crowling the plants so that the lower branches are too much shaded. If this is true, it would be 
better to select a smaller-growing type of cotton. Early planting is strongly advised in all localities, and the quantity of seed should be sufficiently large to insure absolute certainty of a stand. For early planting, not less than 30 pounds of seed per acre should be used.

As soon as the plants are well established in the soil and all danger of frost is passed, the excess number of plants should be removed by chopping out the intervening spaces with a hoe, leaving vigorous plants about 12 to 16 inches apart in the row. Following the chopping, a cultivator should be run close to the row, so as to throw some dirt toward the plants. The cultivation of the cotton should be shallow and frequent, and continued until the plants begin to mature bolls, and later, if necessary, to prevent a crust forming. If the preparation of the land was thorough and the soil has been well tilled up to this time, the crop can be laid by with an assurance that there is a sufficient quantity of moisture and available plantfood to mature the bolls.

198. Harvesting. The cotton crop is harvested by hand. Various attempts have been made, from time to time, to build a mechanical cotton-picker, and some very creditable machines have been produced, but they have not come into general use. The problem is a difficult one because of the leaves and trash that are more or less mixed with the cotton by the machine. Cotton-picking is the negro's holiday vacation, and where there is a large percentage of colored people, there is usually little difficulty in getting sufficient labor to harvest the crop. They pass rapidly through the fields, deftly picking the locks from the open bolls, and placing them in a long 
sack which they drag behind them. The cotton is usually picked by the hundred pounds. An average picker can easily pick 200 pounds of seed cotton per day.

199. Marketing. The seed cotton is carried from the field to the cotton-gin, where the lint is separated from the seed. The seed cotton is unloaded from the wagon by means of a suction tube about eight inches in diameter, the end of which is placed close to the cotton. Through this tube the cotton is carried to the "gin stand," where it passes over small, fine-toothed, circular saws, which rotate at a very high rate of speed. These saws remove the lint from the seed, which is returned by mechanical conveyors to the wagon, or carried into the house used for the storage of seed. From the "gin," the cotton comes out in great sheets of snowy whiteness, and is formed by a powerful hydraulic press into a very compact bale weighing about 500 pounds. This bale is covered with a coarse, heavy bagging, and is held together by strong iron bands. These bales are so compact that they are often left out in the rain for months without serious injury.

200. Grades of Cotton. Cotton is graded and sold acrording to the quality of lint, as shown by a sample taken from the bale. 'The variety of cotton has nothing to do with its market classification, but it depends much more on the development of the plant. The accepted standards for the grading of cotton are, from the best to the poorest: (1) Fair; (2) middling fair; (3) good middling; (4) middling; (5) low middling; (6) good ordinary; (7) ordinary. Each of these grades is divided into subdivisions which merge one grade into the other.

Middling is the accepted standard for all short-st apple 
upland cotton of good quality, and all prices are quoted on this basis. Cotton offered for sale is worth more or less per pound according to the grade as compared with middling.

201. Cotton Seed. Cotton seed, which was formerly considered worthless, is now held in high esteem as a food for live stock, and for manufacturing purposes. It is fed to cattle and sheep extensively, and, in a limited way, to horses and mules. It is not used to any extent as hogfeed, beeause of the fact that when fed in liberal quantities it is liable to kill hogs.

The oil mills use large quantities of seed in the production of cotton oil and cottonseed cake. The former, in the form of cottolene, is extensively used as a substitute for lard. A ton of cotton seed will produce approximately:

40 pounds of linter, or short fiber, which has adhered to the seed after ginning.

800 pounds of hulls.

800 pounds of cake, which is ground into meal.

280 pounds of erude oil.

80 pounds of trash and dirt.

The crude oil obtained from the cotton seed is refined and sold in different grades. The better qualities are used as substitutes for lard and olive oil, and in the manufacture of oleomargarine. Cotton oil has many valuable qualities. It has been used to some extent as an adulterant, and on this account has acquired a bad reputation; but it has merits of its own that justify its use as an article of human food, to be sold under its true name.

Cottonseed meal, hulls and linters are the by-products resulting from the extraction of the oil from the seed. 
The cotton seed, after the lint has been removed, is crushed, and the "meat" is separated from the hull. This meat is cooked at high temperature by steam, and later subjected to great pressure, which expresses the oil and leaves the residue in the form of a cake, which is ground into meal.

A different method of extracting the oil from the seed is used by a very few mills. In these the hulls are not separated from the meat, and the oil is expressed without cooking. The cake that is left by this process has more oil than that which is cooked.

Cottonseed meal mixed with hulls makes a very desirable feed for dairy cows and fattening steers. One ton of cottonseed meal contains three times the amount of digestible protein contained in one ton of wheat bran. This does not mean, however, that it is worth three times as much as wheat bran for feeding purposes, for what it gains in percentage of protein it must lose in the percentage of carbohydrates or other material. In feeding the meal to dairy cows, it is best to limit the amount fed to about two to three pounds to each cow per day. If additional grain is desired, add wheat bran, rice polish, or corn chops to the ration.

The nitrogen contained in the cottonseed meal makes it a valuable fertilizer, and it is much used for this purpose, although it would be a more protitable practice to feed the meal to dairy cows and carefully save the manure for application to the soil. If this is done, about threefourths of the fertilizing value of the meal will still be retained in the manure. It is very desirable that more livestock be kept in the South. 
The fertilizing constituents of cottonseed meal and its value per ton as a fertilizer are as follows:

\begin{tabular}{|c|c|c|}
\hline Nitrogen & $\begin{array}{c}\text { Lbs. in } \\
\text { one ion } \\
.135 .8\end{array}$ & $\begin{array}{r}\text { Value } \\
\$ 2716\end{array}$ \\
\hline Phosphoric acid & . . 57.6 & 288 \\
\hline Potash & 17.4 & 87 \\
\hline
\end{tabular}

\section{Fungous Diseases and Insects Affecting Cotton.}

Cotton is, for the most part, a robust plant; yet, where it is continuously cultivated on the same soil it becomes subject to certain parasitic and fungous diseases. These - diseases, when present in a field, develop very rapidly, and the curative measures resorted to are not very effective. When cotton is grown in rotation with corn and some legume, which occupy the soil for one or two seasons and buidd up the organic matter and nitrogen content of the soil, very little trouble is experienced with parasitic or fungous cliseases.

The two insects most troublesome in the cotton fields are the Mexican boll-weevil and the cotton-boll worm. Both of these can be retarded to some extent by early planting, and such methods of culture as will hasten the crop to maturity. (See Figs. 135 and 136.)

The boll-weevil, as its name indicates, originally came from Mexico, and in ten years' time it has spread over all of central and eastern Texas and western Louisiana, advancing at the rate of about 50 miles per year. It is estimated that the annual loss to the farmers of Texas occasioned by the boll-weevil is over $\$ 25,000,000$. Farmers' Bulletin No. 189 of the United States Department of Agriculture states that "there is not even a remote 
possibility that the boll-weevil will ever be exterminated," and also "that it will eventually be distributed over all the cotton-belt."

The weevil appears in early summer, and first attacks the buds, or squares, which are blasted by the attack and soon drop off. If any of the blossoms escape the attack of the little insect, the bolls develop unmolested during the early season; for, as long as the insects are not very numerous and the buds continue to form, it attacks them only. It is thus readily seen that the hope of the farmer, in infested districts, must rest in an endeavor to produce a crop early enough in the season to form a large percentage of bolls before the weevil appears. It is also of much importance that the fields be cleared in the fall and plowed. If cattle can be turned into the cotton field after the picking is finished, they will undoubtedly destroy a great many weevils, but the fall plowing of the land should not be neglected. Frost destroys the weevil to some extent, and its winter hibernating places should be broken up. It is also advisable to burn the grass around the borders of the fields, and to destroy all "volunteer cotton" on which the weevil might live.

The boll-worm stands second in importance as a menace to the cotton crop, but experience teaches that this insect is also beaten by an early crop. The boll-worm feeds on many other plants besides cotton, and it does not usually appear in the cotton fields until corn and other crops have so far matured as to be no longer attractive to it. If the attack of the boll-worm should be especially severe, the dusting of the plants with Paris green may be resorted to. Two.applications at intervals of ten days will be re- 
quired. In considering methods of control for any of these pests, it should be remembered, that prevention is much better than cure, and that those conditions of soil culture which tend to destroy the insect pests will at the same time produce a strong, vigorous, early crop, which will be well out of danger before the insects appear in very great numbers. These conditions unay be summarized:

(1) Plow the land deep in the fall.

(2) Select seed from early-fruiting plants.

(3) Use fertilizers that tend to produce vigorous plants and early fruit.

(4) Plant early and use plenty of seed to insure a "stand" (not less than one bushel per" acre).

(5) Cultivate the land shallow and very thoroughly during the early growth of the plant.

ᄂ

\section{THE WOOD CROP}

203. Forests of the United States. "The forests of the United States cover an area of about 699,500,000 acres, or more than 35 per cent of the surface of the country. Before so large a part of them were destroyed, they were, perhaps, the richest on the earth, and with proper care they are capable of being so again. Their power of reproduction is exceedingly good.

"In the northeastern states, and as far west as Minnesota, once stretched the great white pine forest from which, since settlement began, the greater part of our lumber has come. South of it, in a broad belt along the Atlantic and the Gulf coasts, lies the southern pine forest, whose 


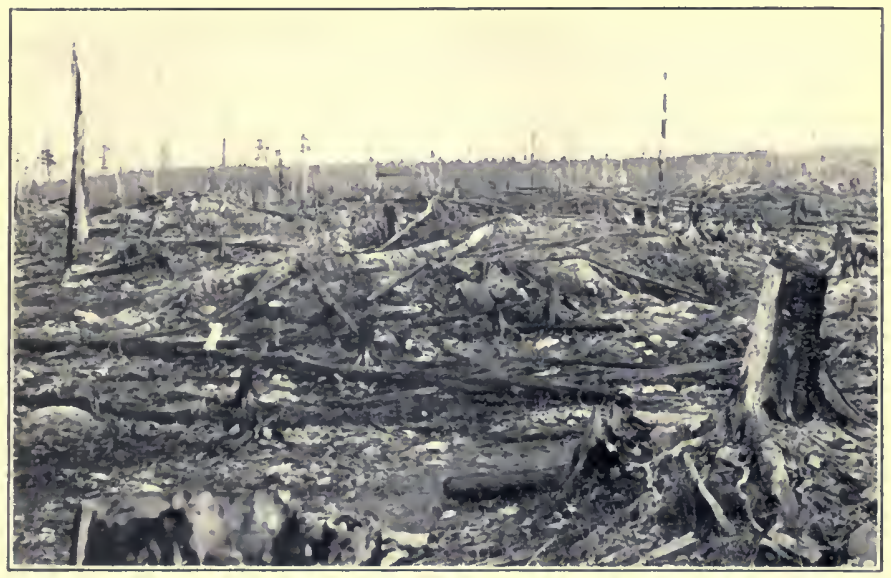

Fig. 108. Destructive lumbering. The slash enabled fire to complete the ruin

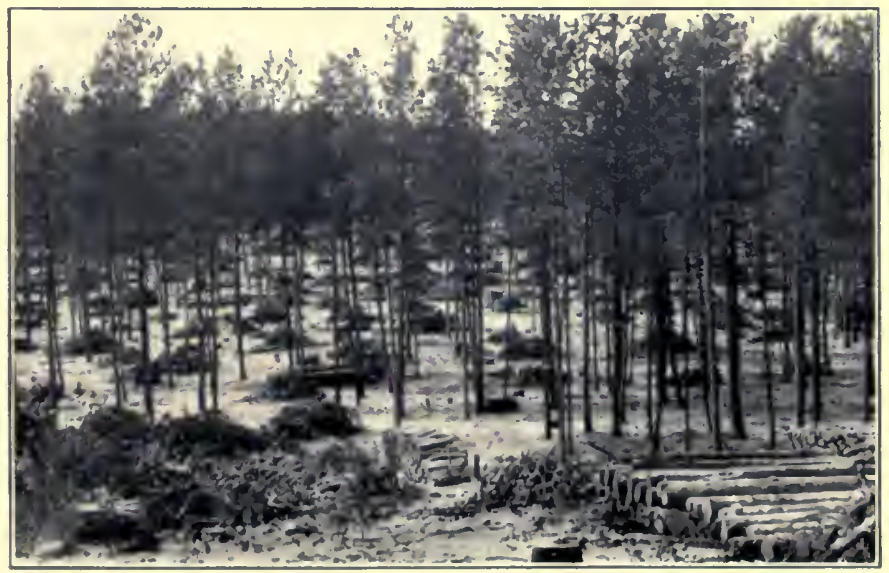

Fro. 1Uy. Conservatuve lumberng. Young growth saved, brush piled to prevenc tire 

most important tree, both for lumber and naval stores, is the southern yellow pine. In the Mississippi valley lies the interior hardwood forest of oaks, hickories, ashes, gums, and other hardwood trees. It is bordered on the west by the plains, which cover the eastern slope of the continental divide until they meet the evergreen Rocky mountain forest which clothes the slopes of this great range from the Canadian line to Mexico. Separated from the Rocky mountain forest ly the interior deserts, the Pacific coast forest covers the flanks of the Sierras, the Cascades, and the coast ranges. Its largest trees are the giant sequoia and the great coast redwood, and its most important timber is the fil.

204. The Settler and the Forest. "When the early settlers from the Old World landed on the Atlantic coast of North America they brought with them traditions of respect for the forest created by generations of forest protection at home. The country to which they came was covered, for the most part, with dense forests. There was so little open land that wround had to be cleared for the plow. It is true that the forest gave the pioneers shelter and fuel, and game for food, but it was often filled with hostile Indians, it hemmed them in on every side, and immense labor was required to win from it the soil in which to raise their necessary crops. Naturally, it seemed to them an enemy rather than a friend. Their respect for it dwindled and disappeared, and its place was taken by hate and fear.

"The feeling of hostility to the forest which grew up among the early settlers continued and increased among their descendants long after all reason for it had disap- 
peared. But even in the early days far-sighted men began to consider the safety of the forest."

205. The Relation of Forestry to the Nation. "The great industries of agriculture, transportation, mining, grazing, and, of course, lumbering, are each one of them vitally and immediately dependent upon wood, water, or grass from the forests. The manufacturing industries whether or not wood enters directly into their finished product are scarcely, if at all, less dependent upon the forest than those whose connection with it is obvious and direct. Wood is an indispensable part of the material structure upon which civilization rests; and it is to be remembered always that the immense increase of the use of iron and substitutes for wood in many structures, while it has meant a relative decrease in the amount of wood used, has been accompanied by an absolute increase in the amount of wood used. More wood is used than ever before in our history. Thus, the consumption of wood in ship-building is far larger than it was before the discovery of the art of building iron ships, because vastly more ships are built. Larger supplies of building lumber are required, directly or indirectly, for use in the construction of the brick and steel and stone structures of great modern cities than were consumed by the comparatively few and comparatively small wooden buildings in the earlier stages of these same cities. It is as sure as anything can be that we will see in the future a steadily increasing demand for wood in our manufacturing industries.

206. Forest Policy for the Future. "When wood, dead or alive, is demanded in so many ways, and when this ${ }^{1}$ Gifford Pinchot, Bulletin No. 24, Burcau Forestry, Part 2, pp. 81-83 
demand will undoubtedly increase, it is a fair question, then, whether the vast demands of the future upon our forests are likely to be met. You are mighty poor Americans if your care for the well-being of this country is limited to hoping that that well-being will last out your own generation. No man here or elsewhere is entitled to call himself a decent citizen if he does not try to do his part toward seeing that our national policies are shaped for the advantage of our children and our children's children. Our country, we have faith to believe, is only at the beginning of its growth. Unless the forests of the United States can be made ready to meet the vast demands which this growth will inevitably bring, commercial disaster, that means disaster to the whole country, is inevitable. If the present rate of forest destruction is allowed to continue, with nothing to offset it, a timber famine in the future is inevitable. Fire, wasteful and destructive forms of lumbering, and the legitimate use, taken together, are destroying our forest resources far more rapidly than they are being replaced. It is difficult to imagine what such a timber famine would mean to our resources. And the period of recovery from the injuries which a timber famine would entail would be measured by the slow growth of the trees themselves. Remember that you can prevent such a timber famine occurring, by wise action taken in time; but, once the famine occurs, there is no possible way of hurrying the growth of the trees necessary to relieve it." 1

207. National Forests. On June 30, 1908, the United States government owned 165 national forests with an

${ }^{1}$ Theodore Roosevelt, President of the United States, before the American Forest Congress. Circular No. 35, Bureau of Forestry, pp. 6, 7. 
area of $167,976,886$ acres. The establishment of these forest reserves is chiefly due to President Cleveland and President Roosevelt. The object is not to prevent trees from being cut. Forestry cuts trees and grows trees, just as farming grows crops and harvests them. The government reserves will furnish much more lumber than would be produced if the reserves were lumbered over in the usual manner, which leaves the forest practically ruined and allows fires to complete the destruction.

The chief object of the reserves is to protect the drainage basins of the streams that furnish water for irrigation. This also prevents destructive floods and furnishes a constant supply of water for water power. It also prevents the destruction of the soil that occurs when mountain sides are deforested. In such a case, it often takes but a few years to wash away the soil that it has required centuries to form. The reserves also maintain a constant supply of wood and timber. A number of states also own forest lands. Nearly every civilized government owns forests.

But the government reserves in the United States cannot go far toward furnishing our future lumber supply. The great bulk of our forest lands belong to individuals. Most of the lumber supply must be furnished by private citizens.

208. Forests and Climate. Forests do not have a very great influence on the heat of the surrounding region. They modify the wind for short distances. Contrary to popular opinion, they do not have any appreciable effect on rainfall. Their great influence is in holding back the waters that fall and so regulating the flow of streams. 
Destruction of forests results in floods and dry rivers. The severe floods of the Ohio river of recent years are due to the deforested mountain lands that it drains. The water all runs off rapidly instead of being held back. The losses caused by the floods direct and as a loss of water power would pay for reforesting the mountains.

Possibly it is the fact that forests at the source keep up the summer flow of streams that has led to the erroneous conclusion that forests increase rainfall. Or, perhaps, the error came from the observation that where forests occur there is usually a good rainfall. The rain is the cause of the forest not the result of it.

209. Conservative Lumbering. This differs from ordinary lumbering in that:

(1) The forest is treated as a crop that must produce successive and regular harvests, rather than as a mine to be exhausted once for all.

(2) Small trees are not cut when they are needed to renew the growth.

(3) Attention is given to keeping the stand neither too thick nor too thin.

(4) The tree weeds, broken and diseased trees, are removed to make room for good trees. In ordinary lumbering, the tree weeds are the ones that are left to reseed the area.

(5) Lumbering is conducted in such a way as to injure the young growth as little as possible.

(6) In some cases, seeds or young trees are planted. This is expensive and is usually not necessary if a forest is well handled.

(7) The forest is protected from fire. 


\section{Forest Trees Are Now a Profitable Farm Crop.} Neglected as they are, the farm wood-lots of many farms in northeastern United States produce $\$ 2$ to $\$ 10$ worth of wood per year from each acre.

As an example, a farm on the hill lands of southern New York consists of 100 acres, 30 acres of which is in timber. This wood-lot was cut in 1907 for the third time in 90 years. Each time it has been cut with entire disregard for the future. The third cutting on the 30 acres sold for $\$ 2,100$, standing. In spite of the present high price of lumber, no attention is given to the future in this r'utting. Young trees that are scarcely worth cutting, but that would be valuable in 10 to 20 years, are cut. Those that are too small to cut are broken down. This is the almost universal practice, in spite of the high profits that come from such a wood-lot.

After "skinning" the wood-lot, the entire farm of 100 acres, with buildings, was sold for $\$ 1,400$. This farm would not rent for $\$ 1$ an acre, as indicated by the selling price. But, in spite of the owners, it has grown $\$ 70$ worth of wood per acre since the last cutting 30 years ago. If the $\$ 1$ per acre rent were placed at compound interest it would not amount to $\$ 70$ at the end of 30 years. In other words, the wood land pays better than the farm land. If the wood land were given a very little attention in cutting, so as to maintain a stand of the best kinds of trees, the returns could easily be doubled. This instance is typical of large areas of land in northeastern United States.

211. The Farm Wood-Lot. Many farms should make a business of raising lumber, railroad ties, telephone 
poles or posts for sale. With the present prices, the woodlot is often the most profitable part of the farm, and future prices promise to be much higher.

Nearly every farm should have a wood-lot to furnish posts, fuel and repairs for home use. The majority of farms have some land that is practically useless, and this land is usually the best for trees. A little attention to planting good seeds or seedling trees, and to cutting out the poor kinds, will often transform these waste areas into very profitable woods. In the central

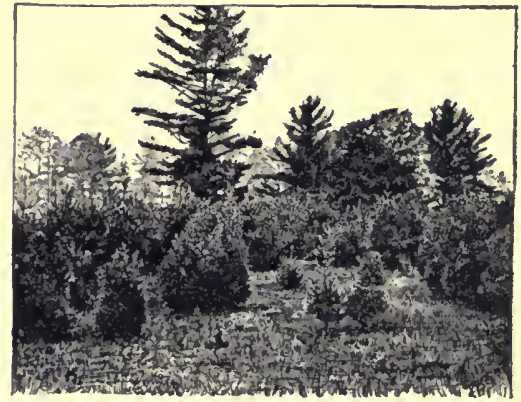

Fic. 110. White pines coming into a pasture. On this land trees pay better than the poor pasture.

West, there are many creeks and draws that are too steep or too wet or wash too much to be used for farm purposes, but that furnish an ideal place for trees. On farms where none of these conditions exist, a wood-lot may often be desirable near the buildings as a windbreak. If a small grove is planted, it will also furnish posts.

As a general thing, trees should not be planted between fields or in fields. A row may be grown along the public road, because they make the place more attractive. It is very often desirable to change the shape and size of fields. Trees along fence lines prevent this. They also sap the land for many feet. This land is usually worse than lost, for it is generally farmed each year and both seed and labor are lost. If left in sod, the loss is less. 
The writer lived for many years on a quarter-section ${ }^{1}$ of land in Nebraska that had a strip of trees all around the outside and had one row of honey locust across the farm. This row of honey locust trees one-half mile long ruined a strip about four rods wide and injured considerably

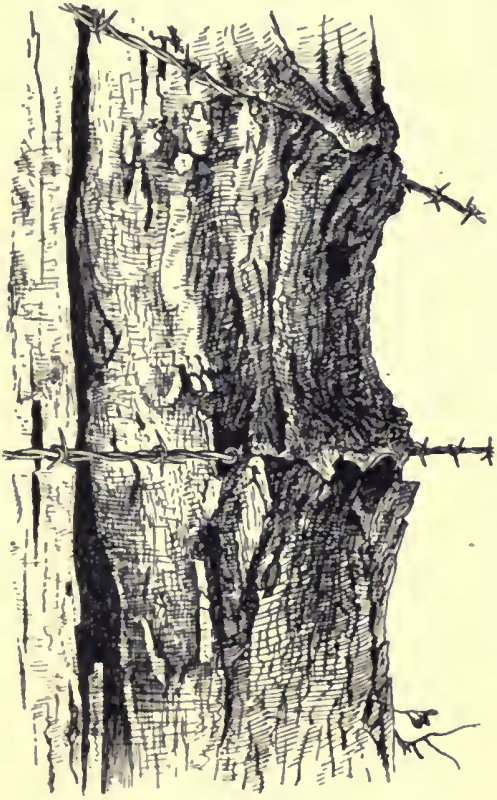

FIG. 111. An unsatisfactory fencepost. The wire spoils the tree and the tree spoils the fence. more. At the end of about 25) years they were cut for posts. They required the use of four acres of land for most of the time. If this land had been rented for cash rent at $\$ 2.50$ an acre, and the money put at compound interest at 5 per cent, it would have amounted to \$487. Probably the posts were not worth $\$ 200$. On the same farm there were groves of honey locust and catalpa, cottonwood and box elder. All these were very profitable.

Not only are the trees along a fence line a great nuisance, but this is not the place to grow good trees. Such trees branch so much as to give more brush than lumber. Trees are social beings. Many publications have-recommended such planting. A recent bulletin ${ }^{2}$ presents a plan for a model farm of 160

A section of land is one mile square; a quarter-section is one-half mile square, and contains 160 acres.

'Farmers' Bulletin No. 228. 
acres in Kansas or Nebraska that has a belt of trees around the outside of the farm and has four rows and one belt of trees running across the farm. This requires two and one-half miles of trees running across the fields, besides two miles around the outside of the farm. The rows across the fields will soon spoil four rods of land which amounts to 20 acres. The row around the outside will soon spoil two rods of land or 8 atcres. This would make 28 acres occupied by trees. If grass is grown next to the trees, a partial crop may be secured. These trees are designed as a windbreak, but it is doubtful whether the wind ever will do as much harm as the trees.

Another object of the trees along the fields is to act as fence-posts. But a tree is a most unsatisfactory post. The trees grow completely around the wire. The staples and wire in the tree make it unfit for sawing. A fence stapled to trees is nearly always distorted. The swaying of the trees, even large trees, spoils a wire fence. The sap from the trees rusts the wire so that it breaks. Even if trees are along a fence-line, it is better to set posts than to use the trees.

The wood-lot should very rarely be used as

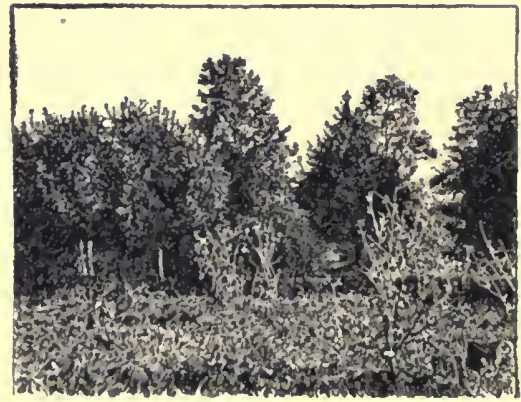

Fic. 112. Trees in a pasture. The stock prevent a good growth of timber and the trees prevent a good growth of grass. Better remove the stock or the trees.

a pasture. Stock destroy the lea mulch that is so essential for the trees. They keep down seedling trees and 
sprouts. In general, it is best not to mix trees with crops or with the pasture, except as a few trees may be desired as shade for stock, or as a windbreak.

212. What Trees to Plant. The following are some of the desirable trees for posts: Hardy catalpa (CatalpG speciosa) makes one of the best fence-posts and grows very rapidly on good land. It is adapted to rich, deep soils south of the 41 st parallel. Black locust makes a very desirable tree where it is not ruined by borers. Chestnut is one of the fastest-growing, good post trees

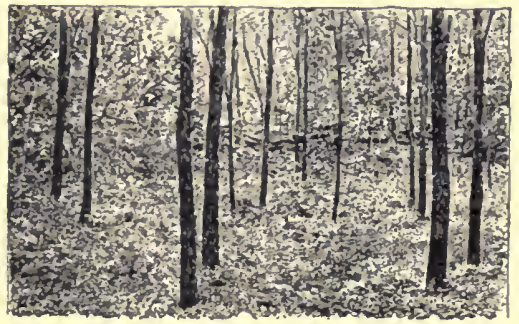

F19. 113. A black-locust grove. Contrast with the brush in the background on an adjoining farm. for northeastern United States. Osage orange is probably the best post material. It is a slowgrowing, drought-resistant tree, adapted to regions south of the 41 st parallel.

Some of the trees adapted to the semiarid regions are bur oak, hackberry, black locust, white elm, Russian mulberry, osage orange, red cedar, western yellow pine, Jack pine.

White pine, Norway spruce, chestnut, are among the best trees for planting in regions where the white pine once grew. For other regions and the numerous other trees and combinations of trees, see Bureau of Forestry Circular No. 30.

Several states are growing young forest trees and furnishing them at cost so as to encourage planting. Forest lands should not be taxed in the same manner as farm land. 



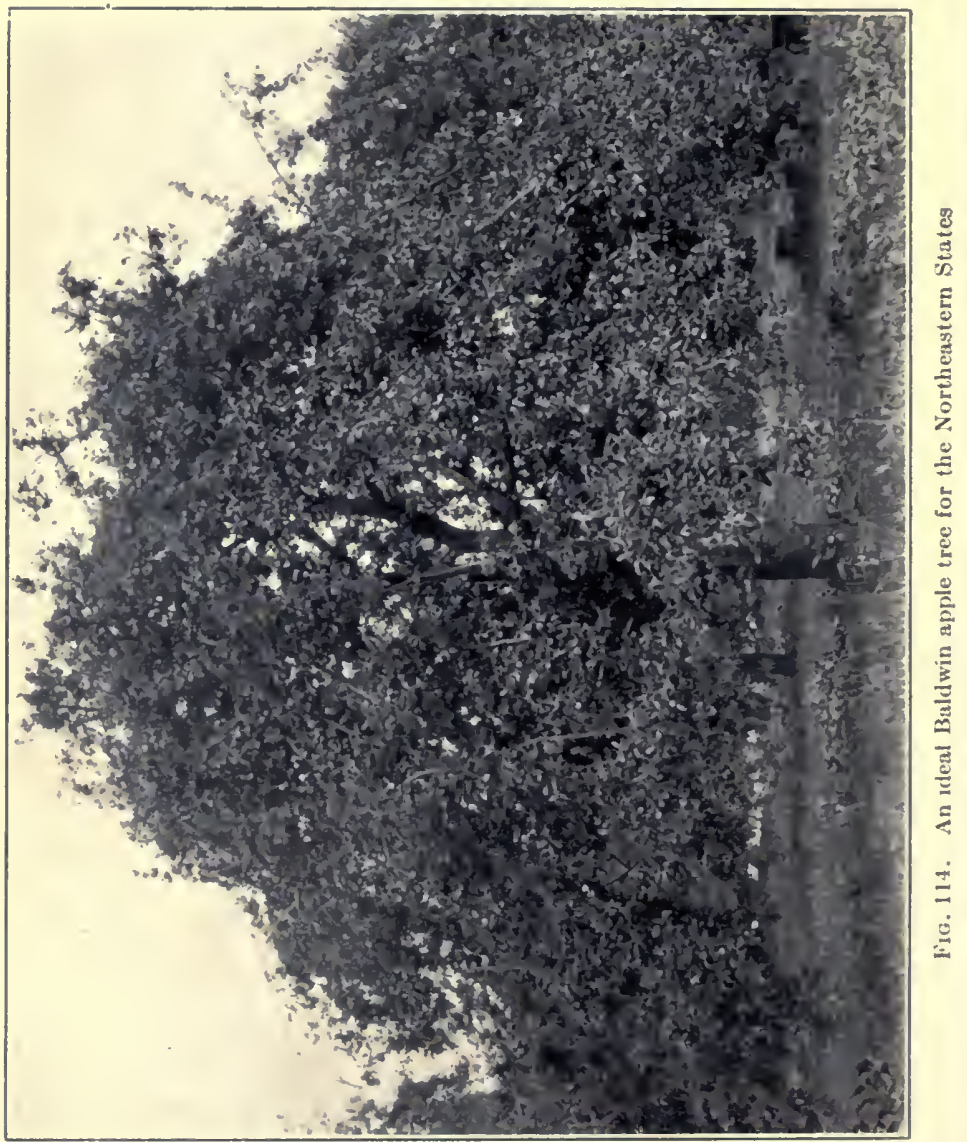




\section{ORCHARDS}

213. Setting Trees. In digging, the roots of trees are often broken and the bark at the ends is often torn off. Before planting, all such roots should be cut back, making clean wounds that will heal readily. The more roots on a tree the better. At best, a transplanted tree retains only a small fraction of its roots.

On the other hand, the branches should ordinarily be cut back or removed. The tree will soon be larger if this is done. People usually leave too much top and too little roots. It is well to remember that roots can quickly grow a top, but that a top can never take the place of roots. If too much top is left, the leaves will dry the tree to death.

Trees should not be allowed to lie around in the sun and wind before planting. The roots should

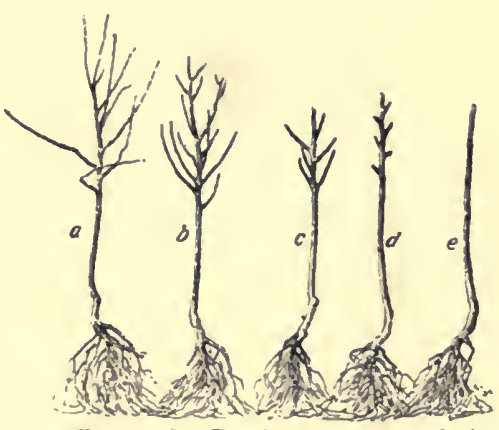

Fia. 115. Peach trees pruned for planting, $a$, unpruned; $b$, slightly pruned: $c$, four-inch stubs left; $d$, one-inch stubs; $e$, pruned to a whip. Trees that were pruned like $d$ and $e$ when set, were largest in the fall.

never be allowed to dry more than is necessary. If the roots are coated with clay, they should be dipped in water before planting.

Holes should be a little larger than the roots require, so that it will not be necessary to coil the roots into the hole. Trees should usually be planted about two inches deeper than they grew.

The most important point in planting a tree is firming 
the soil around the roots. If the soil is thrown in on top of the roots and then merely stepped on, there will be a hollow space under the center of the tree. The soil should be packed under and around the roots firmly. The upper layers of roots should be lifted up, so that they will come out in their natural direction, with the soil below them packed firmly. The last four inches of soil should be left loose to absorb the rain and act as a mulch. Commonly, trees are set in exactly the opposite mannerloose soil at the bottom and packed soil on top. It must be remembered that roots take up their water by osmosis. Only when they are in most intimate contact with the soil particles are they able to absorb the soil water.

If the region is very dry, the soil should be kept stirred or mulched, so that no weeds can grow.

214. Tillage of Orchards. Formerly, people thought that orchards were able to take care of themselves; but, with the advent of commercial orcharding, many men have come to till the orchard as regularly as they do the other crops.

Trees make nearly all of their growth before the sumner months. It is at this season of the year that they require the most food and moisture. In New Jersey, in latitude $40^{\circ} 30^{\prime}$, the writer found that nearly all the orchard trees had completed their twig growth by the last of June. In this latitude, tillage should begin as early as possible, and should stop by the middle of July. A cover crop may then be sown, or the weeds may be allowed to grow.

In tilling orchards, great care must be taken not to bark the trees. Such injuries are very serious, while the 
little grass or weeds that grow near the trunk are of no consequence. Under any ordinary circumstances, a few feet of untilled land about the base of large trees does no harm.

Apple orchards will stand more abuse than most kinds of trees, so that they are frequently grown in sod. They should ordinarily be tilled. The effects of tillage are strikingly shown in New York state. Five hundred and sixty-four orchards in Orleans county, containing 4,881 acres, were examined. The average yields and incomes from these orchards for five years are shown below: ${ }^{1}$

Yield Per Acre of Tilled and sod Apple Orchards, Five-Year Averages (1900-1904), Orleans County, N. Y.

Tilled ten years or more.

Tilled five years or more

\begin{tabular}{|c|r|}
$\begin{array}{c}\text { Average } \\
\text { yield }\end{array}$ & $\begin{array}{c}\text { Average } \\
\text { income }\end{array}$ \\
\cline { 1 - 2 } Bus. & \\
327 & $\$ 182$ \\
274 & 138 \\
22.5 & 113 \\
222 & 107 \\
204 & 108 \\
176 & 87 \\
&
\end{tabular}

The sod orchards that were used as pastures for hogs or sheep were better than the average, but not so good as the tilled ones. There are, of course. many conditions under which tillage is not desirable, such as orchards on steep hillsides.

215. Spraying Orchards. Spraying is now a regular practice of the best fruit-growers, but the majority of orchards are still unsprayed. The particular treatment varies with the kind of fruit and the region. Peaches and

1.New York (Cornell) Bulletin No. 229. 
plums are seldom sprayed unless they are infected with the San José scale. In many regions, apples are commonly sprayed three times,-once just before the blossoms open, once just as the petals fall, and again 10 to 14 days later. The mixture used is three to four pounds of copper

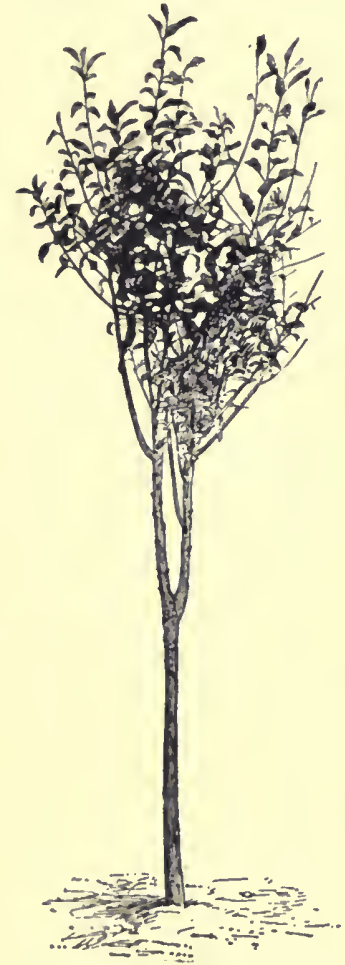

FIG. 116. A bad crotch. One of the limbs should be removed or the tree will be likely to split. sulphate, four to six pounds of lime, and one-half pound of Paris green in 50 gallons of water.

The effects of spraying apple trees in Orleans county, New York, in 1904, were as follows:

Unsprayed, \$92 average incone per acre. Sprayed once, $\$ 116$ average income per acre.

Sprayed twice, $\$ 127$ average income per acre.

Sprayed three times, \$139 average income per aere.

216. Pruning. Pruning is necessary in order to thin the top, otherwise the competition among the branches injures all of them. The main branches of a fruit tree should be so arranged as to prevent splitting.

Trees that are to stand many years should be so pruned as to preserve sound trunks. This is of less consequence with short-lived trees like the peach. Correct pruning depends on a knowledge of the cambium layer.

The living and growing part of a tree is the cambium layer. This is a tissue that lies on the outside of the wood 
and beneath the bark. From its outside it produces bark and from its inside it produces wood. It is the layer of young, tender cells that makes the bark "slip" so readily in early spring. A layer of new cells grows on the outside of a tree every year. The cells that grow in the fall are thickerwalled than those that grow in the spring. This makes the wood darker in color, so that a ring is formed at the end of each season's growth. It is these annual rings

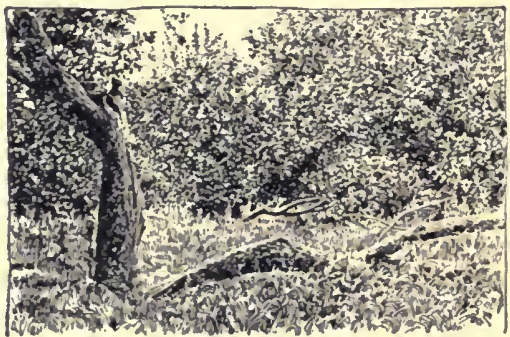
FIG. 117. Broken trees, the result of crotches

that enable us to tell the age of a tree. The sap of a tree passes up through the outer layers of wood, the sap wood, while the elaborated food is distributed through the cambium layers.

The outer bark and the inner wood of a tree are dead. This dead inner wood is protected by the cambium layer, so that fungi and bacteria cannot reach it. When a limb is cut off, or if the bark is removed, the dead cells are exposed. These cannot heal the wound. The cambium layer around the edges must grow over it. The safety of the tree depends on having it heal over before it becomes infected with molds. If the wound is large and is not treated, some decay fungus is almost certain to become established before it heals over. The tree may then heal over and look all right, but the fungi will continue to grow and will result in a decayed or hollow trunk. A hollow tree usually continues to grow all right, as the inner 
wood has no use except to support the tree; but, sooner or later, it is certain to be blown down (Fig. 118). A great majority of the trees in forests and orchards die because of rotten trunks

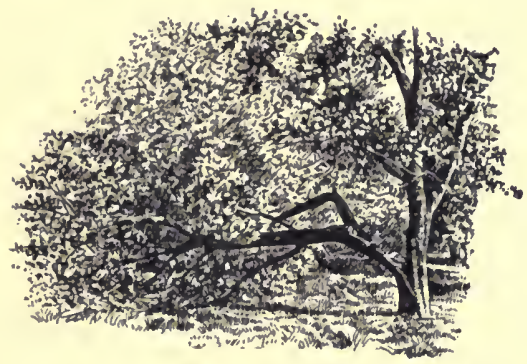

Frg. 118. Most of the apple trees in the northeastern states are killed in this way. (See Figs. 119 and 120.) that give way during a wind.

In order to prevent trunks from rotting, care should be exercised not to hurt trees with machinery or to allow them to be injured by stock. They should be pruned when young, so as to avoid the necessity of removing large limbs. If such limbs have to be removed, they should be cut in the manner that will make them heal fastest. All large wounds should be painted, so as to protect the wood until it heals over.

Wounds heal most rapidly when cut parallel with the branch, and as close to it as possible. This makes a much larger wound; but it is in line with the cambium layer and heals in less time, as proved by experiments.

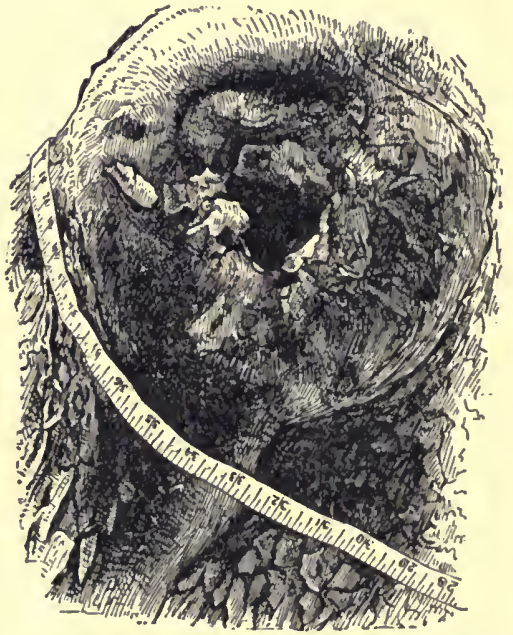

FIG. 119. The decayed hole where a limb was removed. The wood-destroying fungi caused the tree to break, Fig. 118 , 
Occasionally a sound tree starts to split, particularly if crotches were allowed to develop when the tree was young. Such a tree can often be saved by the use of bolts. A band put around a tree will girdle it, but a bolt put through it will do no appreciable damage. Sometimes it is better to put a bolt through each branch and connect them with a chain.

\section{SHADE TREES}

217. The planting and care of shade trees can be deducted from the principles of planting and pruning orchard trees as given above. The indiscriminate wounding of shade trees is the usual cause of death. Where trees are likely to be injured by horses, they should be protected by wire guards around the

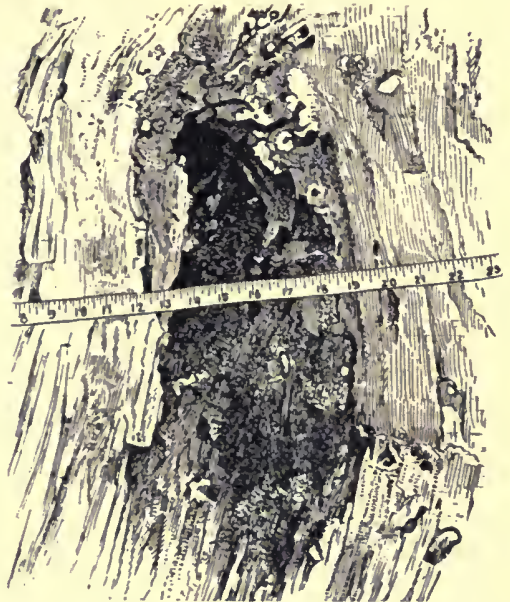

FiG. 120. Inside of the broken limb showing the decay that entered through Fig. 119. The same tree as Fig. 118.

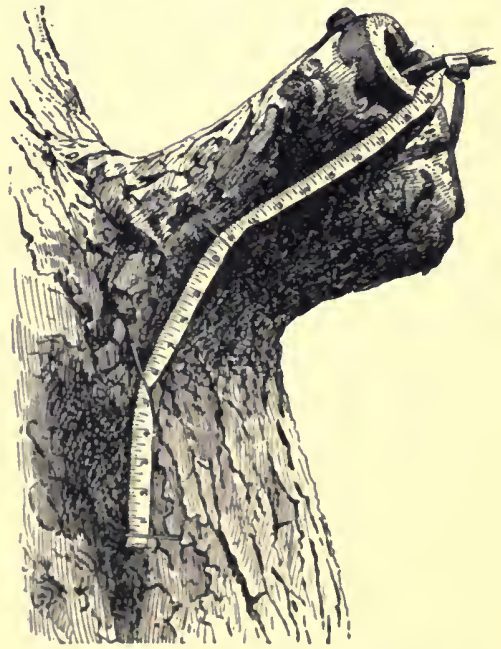

FIa. 121. A long stub left in pruning. The wound cannot heal. The tape shows how far , he trunk is hollow. The tree will soon blow over. 
trunks. Some person who knows no better is certain to hitch to the tree sooner or later, if it is handy. The indiscriminate cutting of tree-tops and the use of trees as anchors for telephone lines should not require much

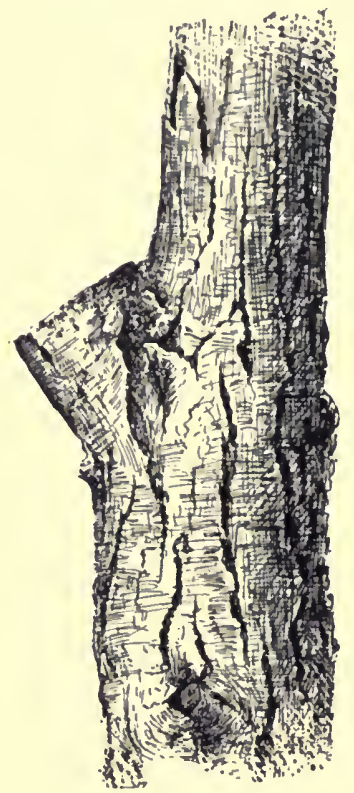

Fig. 122. The wrong way to make the cut

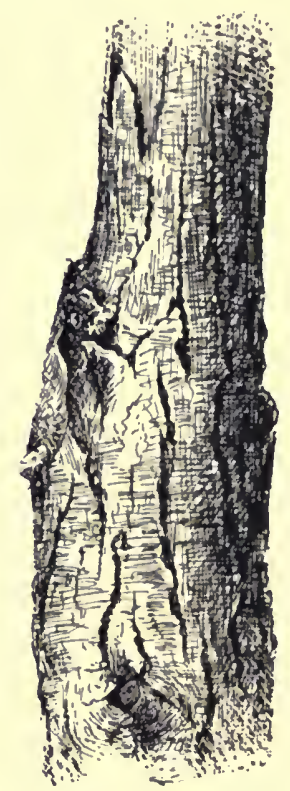

FIG. 123. The right way to make the cut

comment. The telephone is more important than the trees, but we should have both.

\section{THE FARM GARDEN}

218. The crop from a vegetable garden of one-half acre at the University of Illinois had an average value of $\$ 105$ for five years. During this time, the average ex- 
pense for seeds, insecticides and labor was \$30. ${ }^{1}$ Every farmer should have a family orchard and a garden, not only for pleasure, but for profit that results from a saving on living expenses.

The garden should be large enough to be plowed and worked with a team. All cultivation should be given with horses. This will require a little more area for the same produce, but land is cheaper than hand labor. One reason why farmers' gardens are so poor is that so much dependence is placed on hand labor which cannot be given. A half-acre to an acre next to the house should be

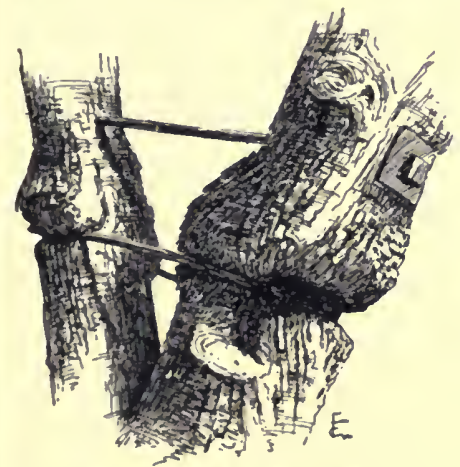

Fir. 124. The right and the wrong way to brace a crotch set aside for the garden, on most farms. If it is not all needed, it may be filled in with pumpkins, roots or corn for the stock. On most farms, the garden should be fenced with poultry-tight wire.

The grapes, rasplerries, blackberries, gooseherries, currants, winter onions, rhubarb, asparagus, strawberries, and other peremials, should be placed in full rows at one side. These rows should be six to eight feet apart. While they are young, a row of vegetables may be raised between them. When they are grown, the land may le plowed between the lows and kept tilled. Such plants as blackberries should be confined o solid rows about two feet wide. This allows for regular horse cultivation between rows. Tillage 
is necessary to produce the best fruit, particularly in dry years.

If all perennials are at one side, the remainder of the garden will be straight for plowing. The rows of vegetables should be at least two and one-half feet apart to allow for continued cultivation with a horse or team. Cultivation should be so frequent that weeds wifl never get started. In this way, little hand labor will be required.

The soil should be generously manured. It is not profitable to raise so valuable a crop on poor land. If any part of the farm is short of manure, let it he the cheapest crop.

It will pay to save seed of most of the plants, as the seed will be surer to grow and will be cheaper than buying it.

The garden and orchard should contain every kind of fruit and vegetable that will grow in the region and that the family likes. There should be enough varieties to cover the season. The season may be prolonged by bringing vegetables into the cellar. Full-grown green tomatoes may be kept for about two months by wrapping them in paper. The writer has had them in December in New York. Watermelons will keep some time. Celery may be transplanted to the cellar and kept watered. It will then grow new shoots that are of the finest quality. If one becomes interested, he will find many ways of adding to the usefulness and pleasure of the garden.

A small hotbed, perhaps four by eight feet, will grow several crops of lettuce and radishes and also plants for the garden. A hotbed is a simple affair. Old boards may be used to make a tight frame, which is about 24 inches 
deep on the north and 18 inches deep on the south. This is filled with firmly tramped horse manure that is just beginning to heat. It is covered with about six inches of good soil, and is then ready for the window-sash. Before making such a hotbed, one would do well to buy the sash and make the bed to fit it.

\section{QUESTIONS AND PROBLEMS}

1. Make a study of Appendix Tables 11, 13 and 14.

2. What are the average erop yields in your region? How do they compare with the averages for the United States?

3. What are the average yields on the best farms of the region? Why are these higher than on the average farm?

4. What erops in your county are most valuable? Which ones occupy the most area?

5. What is a low barometer area? What relation has this to storms?

6. Can rain be made by explosives or by other means?

7. What use can a farmer make of the United States weather maps?

8. How long in advance can weather eonditions be foretold?

9. Can plants or animals foretell the weather?

10. Is there a compensating cycle in the weather? Is there any truth in the statement "March comes in like a lamb and goes out like :I lion; or, if it eomes in like a lion, it goes out like a lamb?" Does a pleasant January indicate a disagreeable lebruary?

11. Does the moon affeet crops"

12. Does the climate of a region ehange in a man's lifetime? If not, why do so many persons think that it does?

13. What is the average annual rainfall in your county? What part of this falls during the growing period?

14. What is the average temperature of the year? Of the growing months"?

15. What is the average date of the last killing spring frost? Of the first killing fall frost? How many days are there between frosts?

16. At what date may each of the leading crops be safely planted in the region?

17. What is the length of a June day in Louisiana? In Illinois? In Manitoba? Of what importance is this to farmers? 
18. Is yours an important corn-growing region? Why?

19. What are the best post trees of the region? Are trees grown for lumber? If so, which are best?

20. What effect does girdling a tree have?

21 What is a knot?

22. What is quarter-sawn lumber? In what other ways is lumber sawn?

23. How can the age of a tree be determined?

24 . Will mulching the soil or tilling it affeet the time of blossoming of a tree?

25. How many bushels of ear eorn will a wagon box 2 feet deep, 3 feet wide and 11 feet 9 inches long hold? How many bushels of shelled corn will it holıl? How much will the load weigh in each ease? (See Appendix, Table 18.)

26. A man has plowed a strip $6 \frac{1}{2}$ rods wide with furrows 30 rods long. How many aeres has he plowed? How many turns has he made if the plow cuts 14 inches?

27. How many tons of hay will there probably be in a mow that is $15 \times 30$ feet and that contains 10 feet of hay that has settled all winter? (See Appendix, Table 18.)

\section{LABORATORY EXERCISES}

\section{Score Card for Dent Corn.}

Materials.-Several samples of corn, five or ten ears in a sample.

Use the score card on page 278 of "Cereals in America," or the following, deducting for imperfections in any of the points.

Yhaturity and Points

Maturity and market condition $\ldots \ldots \ldots \ldots \ldots \ldots \ldots \ldots$

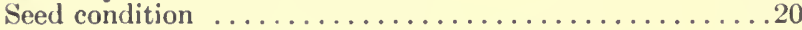

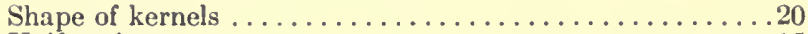

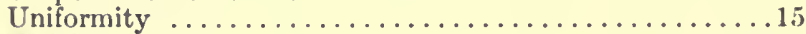

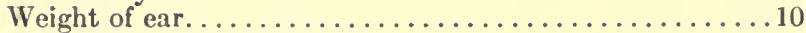

Color of grain and cob................... 5

Length of ear and proportion .............. 5

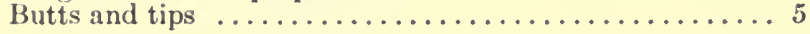

100

54. Depth to Plant Corn.

Materials.-Corn and box of soil, or a garden.

Plant ten kernels of corn at each of the following depths: one, two, four and six inches. How many days does it take for the corn to come up in each case? Which plants are most vigorous? After it 
has grown three weeks, take it up and make drawings of the roots in each case. At what depth have the permanent roots appeared? Has the depth of planting influenced this?

\section{Visit to a Flour Mill.}

Visit a flour mill, or other similar manufacturing enterprise. Learn as much as possible of the processes, and write a description of them.

\section{Good and Poor Flour.}

Materias.-High-grade flour and cheap flour. One teacupful of each for five students.

Moisten the flour just enough to make dough. Work it between the fingers, and then wash it until the starch is washed out. You will then have a sticky mass of gluten. Compare the eolor of the gluten in high-and low-grade flour. How many inches will each streteh before it breaks? Why does the high-grade flour make lighter bread? Why does corn or rye not make as light bread as wheat?

57. To Determine the Influence of Fertilizers on the Yield of Timothy Hay.

Materials.-Field of timothy, 20 pounds nitrate of soda, $7 \frac{t}{2}$ pounds acid phosphate, 37 pounds muriate of potash, 500 pounds (abolit one-fourth load) of barnyard manure, 22 stakes, tape-measure. Arrangements can probably be made to have some student conduct the experiment at home.

Lay off ten plots, side by side, each one rod by four rods.

\section{Rops}

\begin{tabular}{|c|}
\hline $\begin{array}{l}\text { Check } \\
\text { No fertilizer }\end{array}$ \\
\hline 5 pounds nitrate of soda \\
\hline $\begin{array}{l}5 \text { pounds nitrate of soda } \\
2 \frac{1}{2} \text { pounds acid phosphate }\end{array}$ \\
\hline Check \\
\hline $\begin{array}{l}5 \text { pounds nitrate of soda } \\
\text { 1t pounds muriate of potash }\end{array}$ \\
\hline $\begin{array}{l}2 \frac{1}{2} \text { pounds acid phosphate } \\
1 \frac{1}{6} \text { pounds inuriate of potash }\end{array}$ \\
\hline Check \\
\hline $\begin{array}{l}5 \text { pounds nitrate of soda } \\
2 \frac{1}{2} \text { pounds acid pliosphale } \\
1 \frac{1}{2} \text { pounds muriate of potash }\end{array}$ \\
\hline $\begin{array}{l}\text { 3-load, about } 500 \text { pounds } \\
\text { of manure }\end{array}$ \\
\hline Check \\
\hline
\end{tabular}


Apply fertilizers early in the spring, as shown in the diagram. The fertilizers for each plot are weighed out and mixed together, then sown broadeast by hand. These applications are much higher in nitrogen than those commonly used on other erops than hay. Make notes on the growth of hay throughout the season.

When the hay is ready to cut, run a binder twine from stake to stake to keep the plots separate, mow each plot with a seythe. Loop up the hay with a rope and weigh with a spring balance. Fill out the following table:

\begin{tabular}{|c|c|c|c|c|c|c|}
\hline Plot & Treatment & Yield & $\begin{array}{l}\text { Rate of } \\
\text { yield } \\
\text { per acre }\end{array}$ & $\begin{array}{c}\text { Apparent } \\
\text { increase }\end{array}$ & $\begin{array}{l}\text { Value of } \\
\text { increase }\end{array}$ & $\begin{array}{l}\text { Cost } \\
\text { of treat- } \\
\text { menl }\end{array}$ \\
\hline & & & & & & \\
\hline
\end{tabular}

For method of making calculations see page 149 .

A similar experiment is outlined for corn, cotton, or potatoes on page 152 .

58. To Determine the Best Method of Growing Alfalfa for Regions East of the Missouri River.

Materials.-Six-tenths of an acre of land, 12 stakes, 6 bushels of lime, 15 pounds (one-fourth bushel) of alfalfa seed, soil from an alfalfa

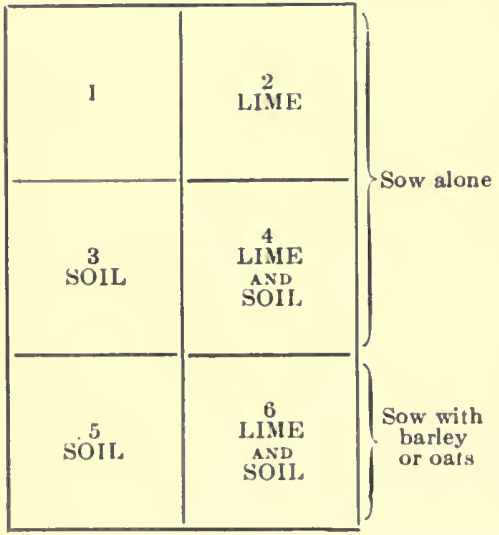
field, or from a place where sweet clover grows. Plots as sinall as one square rod may be used. In this ease, only onesixteenth as much land and materials are needed.

Unless the land selected is very rich, manure should be applied to all the plots at the rate of about ten loads per acre, or six loads for this area. Plow the land early in the spring.

Lay off a plot 8 by 12 rods and drive a stake every 4 rods, as in the figure. 
Apply six bushels of lime to plots 2, 4, and 6. This is at the rate of twenty bushels, or about 1,500 pounds per acre.

Inoculate plots $3,4,5$, and 6 with soil from an alfalfa field, or from a place where sweet clover grows, using about one or two bushels.

Sow one-third of the alfalfa seed on plots 5 and 6 , with about seven quarts of barley or oats.

Continue to harrow the other plots until all weeds are subdued, then sow the alfalfa alone, two months before the first frost is likely to come,-August 1 in the latitude of Chicago. In regions where the season is long enough, potatoes may take the place of the fallow.

The plots may, of course, be of any size. The above areas are large enough to answer the questions. If one desires to plant a larger area the following year, he will know the best method to use, and will have soil for inoculation purposes, if inoculation proves to be necessary on the farm.

\section{Field Lesson on Legumes.}

Find as many kinds of legumes as possible. Learn the common name of each. Learn to distinguish the different clovers. Red clover, by the white spot on the leaf; alsike, by the absence of this spot, smaller size, different colored blossoms; white, by still smaller size and unbranched flower-stalks. Dig up each legume carefully and find the nodules. Make a drawing of each kind of nodules. What legumes require inoculation in your region?

\section{How to Plant a Tree.}

On Arbor Day, or at some other time, plant a tree according to the directions on page 227 .

\section{Crop Production.}

Let each student select a farm crop, and learn all that is possible about the crop and its production, and write a complete discussion from the preparation of the land to marketing the crop. Other members of the class may write up the methods used in the neighborhood on some important erop, with suggestions for inprovement. 


\section{COLLATERAL READING}

Farmers' Bulletins, Nos.: (Select those that apply to the region).

233 Root Systems of Field Crops, pp. 5-11.

149. Shrinkage of Farm Products, pp. 10-15.

Corn.

81. Corn-growing for the South.

199. Corn-growing.

253. The Germination of Seed Corn.

292. The Cost of Filling Silos.

303. Corn-harvesting Machinery.

313. Harvesting and Storing Corn.

317. Increasing the Productiveness of Corn, pp. 17-22.

Shrinkage of Corn in Cribs, pp. 22-26.

Meadows and Pastures.

66. Meadows and Pastures.

72. Cattle Ranges of the Southwest.

102. Southern Forage Plants.

147. Winter Forage Crops for the South.

339. Alfalfa.

237. Lime and Clover, pp. 5-7.

260. Seed of Red Clover and Its Impurities.

323. Clover Farıning on the Sandy Jack-Pine Lands of the North.

271. Forage-crop Practices in Western Oregon and Washington 312. A Successful Southern Hay Farm.

Cotton.

36. Cotton-Seed and its Products.

48. The Manuring of Cotton.

217. Essential Steps in Securing an Early Crop of Cotton.

302. Sea-island Cotton.

314. A method of Breeding Early Cotton to Escape Bollweevil Damage.

326 Building up a Run-down Cotton Plantation. ToBacco.

60. Methods of Curing Tobacco.

82. The Culture of Tobacco.

83. Tobacco Soils.

343. The Cultivation of Tobarco in Kentucky. 
Forest Trees.

134. Tree-planting on Rural Sehool Grounds.

173. Primer of, Forestry.

262. Planting White Pine in New England, pp. 31-32.

276. Suggestions for the Management of the Farm Wood-lot, pp. 29-32.

Circulars of the Bureau of Forestry, Nos.:

30. Exhibit of Forest Planting in Wood-lots at the Louisiana Purchase Exposition.

36. The Forest Service.

97. The Timber Supply of the United States.

117. Preservative Treatment of Fence-posts.

130. Forestry in the Public Schools.

133. Suggestions to Wood-lot Owners in the Ohio Valley Region.

145. Forest Planting on the Northern Prairies.

There are publications among the Farmers' Bulletins on nearly all the other farm erops. The following are a few of the references, arranged in alphabetical order: Apples, Nos. 113, 153, 161, 208, 233, 243, 247, 283. Asparagus, Nos. 61, 233, 259. Basket Willow, No. 341. Beans, No. 289. Broom-eorn, No. 17t. Buekwheat, No. 267. Canadian Field Peas, No. 221. Celery, Nos. 133, 28:. Cowpeas, Nos. 309, 318. Citrus fruits, No. 238. Cranberries, Nos. 176, 178, 221. Cucumbers, .o. 254. Emmer, Nos. 139, 277. Flax, Nos. 27, 274. Hops, Nos. 115, 304. Kafir eorn, No. 288. Maple-sugar, No. 252. Millet, Nos. 69, 101, 168. Milo, No. 322. Onion, Nos. 39, 149. Peach, Nos. 33, 80, 208, 276. Pineapple, No. 140. Potato, Nos. 35, 149, 244, 251. Rape, Nos. 78, 164. Raspberries, No. 216. Rice, Nos. 110, 305. Sorghum, Nos. 135, 246, 238. Soy beans, Nos. 58, 309. Strawberries, No. 198. Sugar-beet, Nos. 52, 92. Siweet Potatoes, Nos. 129, 273, 324. Tomatoes, No. 220.

Many more references to these crops, and referenees to nearly all other erops, may be found in the Index to Farmers' Bulletins, Cireular No. 4, of the Division of Publications.

Cyclopedia of Ameriean Agriculture, Vol. II. Inde:.

Cereals in Ameriea, by T. F. Hunt.

Forage and Fiber Crops in Ameriea, by T. F. Hunt.

The Potato, by s. Fraser.

Corn Plants, by Sargent.

Cotton, by Burkett \& Poe. 


\section{CHAPTER VIII}

\section{ENEMIES OF FARM CROPS}

The chief enemies of farm crops are weeds, insects, and diseases caused by parasitic plants. A number of the larger animals, such as ground-squirrels, crows and gophers, tre sometimes injurious.

\section{WEEDS}

219. What Is a Weed? A weed is often described as a plant that is not wanted. The worst weed in a corn-field may be corn; that is, if corn is planted too thick, the corn plants crowd each other so that the extra ones may do more harm than is done by common weels. Johnson grass is a valuable hay plant in the South, but it is so hard to kill that it is a very bad weed.

220. Value of Weeds. Weeds are a benefit, in that they force men to till the land and often compel crop-rotation. The farmer then secures the many other benefits that come from rotation and tillage.

But many weeds are of direct value. The best plants in pastures are sometimes those that are weeds elsewhere. One of the great uses of wceds is to renew worn-out soll. In all ages some men have farmed in such a-way that the soil has become unproductive. When soil becomes too poor to grow crops, the hardy weeds will still grow on it, and as they decay will gradually build up a productive 
soil. Many fields in the older parts of the United States have been abandoned at times to recuperate under this slow process. With good farming, such a condition will never arise. But, until our farming is much improved, we may be thankful that the weeds will reclaim land after man has exhausted it.

221. The Control of Weeds. The first consideration in the great majority of cases should be to secure conditions that will favor the growth of the crop. Many crops will grow so vigorously as entirely to smother out the weeds, if conditions are favorable. But, if the conditions are not just right for the crop, the weeds may overshadow it. There is always strong competition between hay and smallgrain crops and the weeds. A very slight treatment may give the one or the other the upper hand. Fig. 97 shows how lime produced this difference with alfalfa. The application of lime on this particular soil controlled the weeds, not because it hurt the weeds, but because it caused the alfalfa to grow so vigorously as to leave no room for weeds. The orange hawkweed is very serious in some old worn-out pastures, and farmers are wondering what to put on to kill it. The real trouble is that the soil is so poor for grass that almost any more hardy plant can crowd it out. An application of barnyard manure and more grass seed is the real remedy.

222. The Control of Weeds in Tilled Crops. The time to kill weeds by tillage is before they secure a foothold. Just as the stored food in the weed seed is exhausted and before it has become well rooted, a weed is very easily killed. If we wait until it has become rooted, it my be too late. Figs. 80 and 81 show this difference. In one 
case, the corn-field was gone over with a weeder before the weeds were troublesome, just as they were coming up. In the other case, the farmer waited until the weeds were large enough to attract attention. It was then too late to kill all of them.

\section{Subduing Land That Is Badly Infested with Weeds.} Some farms are so badly infested with weeds that special treatment becomes necessary. Such land may be summerfallowed, that is, kept bare and tilled all one year. This will usually subdue any weed, but often is not profitable. as the season's crop is lost and the tillage is expensive, There are several ways of conducting a short fallow without the loss of a crop. The land may be plowed immediately after harvesting a crop of hay or small grain, and be kept stirred the remainder of the season; then grow a tilled crop the following year. Such treatment will usually clean the land fairly well. This short fallow may sometimes be reversed. The land may be plowed in the fall or spring, and be kept stirred until time to sow a crop, such as buckwheat or millet. The next year a tilled crop may be grown. The tillage will kill many weeds, and such a crop as millet will choke out weeds.

224. Spraying for Wild Mustard. Nearly any soluble chemical will kill plants if applied in strong solutions. Even plant foods, such as nitrate of soda, will kill plants if enough is applied. A solution may often be used that is strong enough to kill certain weeds, and yet not strong enough to harm certain crops.

The most important application of this principle for the control of weeds is in the case of wild mustard. This plant is easily killed by spraying with a solution of iron 
sulphate or copper sulphate. One hundred pounds of iron sulphate or 12 pounds of copper sulphate may be used in 50 gallons of water. In either case, about 50 gallons is sprayed on an acre. It is necessary to have the spray hit all the land. This is accomplished by using one of the field-spraying outfits with plenty of nozzles. (See Fig. 126.) With a properly equipped machine, 10 to 20 acres may be sprayed in a day. The spraying is best done on a bright, clear day,

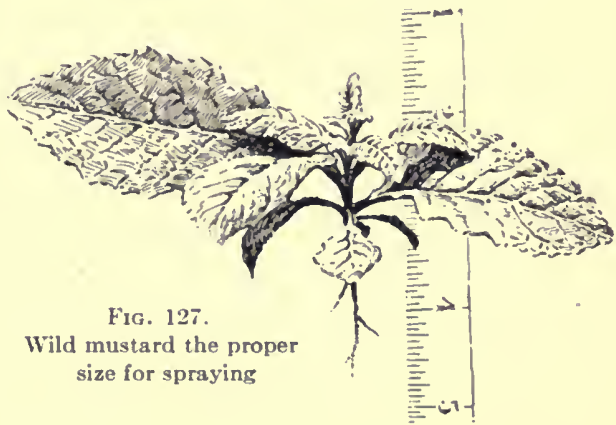
and should be done when the mustard has six to eight leaves. Mustard may then be killed in any of the cereals, or in peas, without hurting the crops. Beans, potatoes, and cabbages must not be sprayed with this mixture, as these crops would be killed.

225. Control of Weeds in Walks. In walks, tenniscourts and some other places, any plant is a weed. We can then use a treatment that kills everything. Salt may be used. Carbolic acid or sodium arsenate are more lasting in their effect. A 3 per cent solution of carbolic acid or a 2 per cent solution of sodium arsenate is about right. In either case, about eight gallons will be needed per square rod. Such treatments should not be given under trees, as the trees as well as the weeds are likely to be killed. 


\section{THE DISEASES OF PLANTS}

By H. H. WHETZEL

Professor of Plant Pathology, Cornell University

Plants, like animals, are subject to many different kinds of diseases. Most of the diseases of plants are caused by insects or by plant organisms, chiefly fungi or bacteria. Some flowering plants, as the dodder, also cause diseases in other plants.

\section{Bacterial Diseases}

226. Characteristics of Bacteria. Bacteria are the smallest of all known plants. They are to be found almost everywhere on the earth, inside and outside the human body, in milk and water, and even on the dust particles of the air. Like all plants, they grow only where food and moisture are present. Some produce diseases in animals; some cause diseases in plants. By far the most of them are harmless or beneficial.

Bacteria are among the simplest of plants. They have neither root, leaves, nor flowers, but consist of single cells made up of living protoplasm enclosed within a cell-wall. They are usually spherical, rod-shaped or. spiral in form. They are commonly slightly attached to each other in pairs, chains or clusters. Many are surrounded by a mucilaginous substance, which may aid in their distribution. Some are motile, being propelled through the liquid in which they live by long whip-like appendages (flagella). Like all plants, they take their food in solution by diffusion through.their cell-walls and protoplasm. They multiply very rapidly, reaching maturity and dividing directly into 
two, often in half an hour. Some species form spores by which they may pass through periods of dryness or other unfavorable conditions without dying. No sporeforming species is known to cause disease in plants.

227. An Example of a Bacterial Disease. The most common and destructive disease of pears, apples and quinces is a bacterial one commonly known as fire-blight or pear-blight. It occurs on other wild plants of the apple tribe, and occasionally on plum trees.

The symptom of the disease so well known to every fruit-grower is, chiefly, the sudden death of the blossoms or tips of the growing twigs. These leaves turn black and cling to the twigs after the other leaves have fallen. Sometimes, especially on pear trees, the disease runs down the limbs, often killing the entire tree. Cankers are formed on the limbs and bodies of trees about the base of blighted spurs and watersprouts. Frequently the fruit is affected, turns brown, and shrivels upon the tree.

The organism that is responsible for this disease is Bacillus amylovorus. 'The bacterium lives over winter in some of the cankers on the trunks of

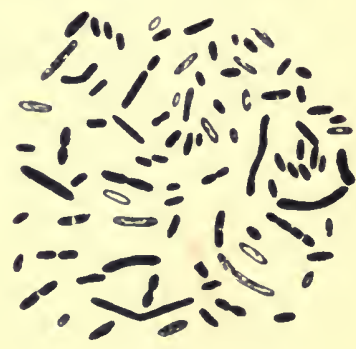

FIg. 128.

Bacteria that cause pear blight. (After Whetzel.) the trees. In the spring, sticky, milky drops, containing numbers of bacteria, ooze out from these hold-over cankers. Bees and other insects carry the bacteria from these cankers to opening flowers and tips of growing twigs. Here they are introduced into wounds made by the insects. They multiply rapidy, and in ten to fourteen days the flowers or leaves begin to show the characteristic blight. 
The control of this disease is not easily accomplished. The bacteria kill or blight the young shoots on the body or larger limbs, passing from these to the bark about their bases. Here they form the cankers in which they pass the winter. These cankers offer the most hopeful point of attack. With a sharp knife, remove the canker, cutting well back into the healthy bark. Scrape out the diseased bark, cleaning the wound thoroughly, Sponge the wound with corrosive sublimate solution. one part to 1,000 parts water. When dry, paint thoroughly with heavy lead oil-paint and keep painted until healed over. The diseased limbs and twigs in pear trees should be removed promptly whenever discovered, and frequent inspections should be made. Always disinfect cut surfaces; this is absolutely necessary for success.

Among the bacterial diseases of plants may be mentioned bacterial blight of beans, cucumber wilt, crown gall of apples, peaches, pears, etc., soft rot of turnips, black rot of cabbage, and many others.

\section{Fungous Diseases}

228. Characteristics of Fungi. Fungi are very different from bacteria, though they too are plants. Their vegetative portion consists of branching, root-like threads called mycelium (Fig. 129). Many of them are saprophytes, - that is, they live on dead or decaying plant or animal remains. Others are parasites, which means that they take their food from the tissues of living plants or animals. Fungi, as well as bacteria, differ from the plants with which we are commonly familiar, in the absence of 
the green color due to chlorophyll. Fungi take their food from the substance in or on which the mycelium is growing, by diffusion of the soluble substances through the sell-walls and protoplasmic lining of the mycelium. Many fungi secrete enzymes that dissolve cellulose and other substances, making them available for absorption; these secretions often kill the protoplasm of the host, thus compelling it to give up nutritious solutions to the parasite. Others send specialized branches of mycelium (haustoria) into the host cells. These absorb the food substances that come to these cells. Eventually, they cause the

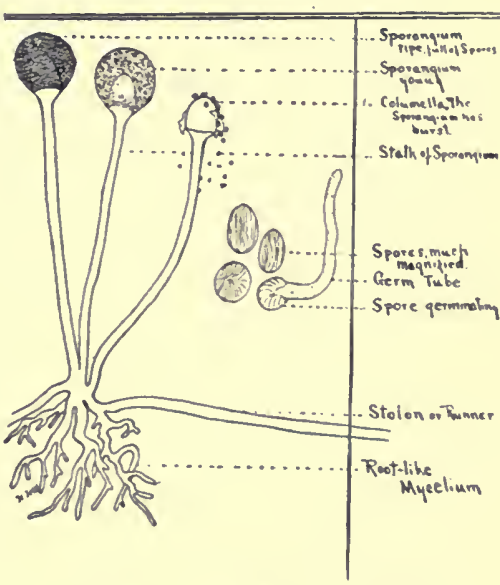

FIG. 129. The bread mold fungus.

(Whetzel)

death of the host cells. Sometimes the irritation of the parasite causes a response on the part of the host in the form of knots, swellings, etc. A good example of this is seen in the black-knot of plums and cherries.

During their vegetative stage, fungi multiply by means of various kinds of asexual spores cut off from the mycelium. This method of reproduction corresponds to the multiplication by sprouts, sets, bulbs, etc., of the higher green plants. Many fungi are also known to form sexual spores called oöspores, ascospores or basidiospores, according to the group in which they occur. These sexual spores 
correspond more nearly to the seeds of higher plants, both in method of formation and in function.

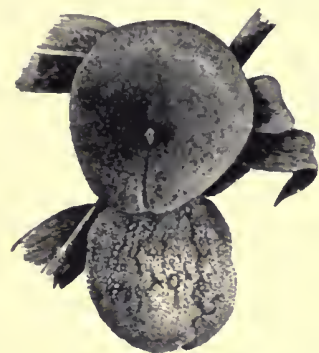

Fig. 130. Brown-rot. Healthy peach above; diseased below.

229. An Example of a Fungous Disease. One of the most common fungous diseases is the brown-rot of stone fruits, although apples, pears, etc., are also more or less subject to it. It is most destructive on peaches and plums. The chief symptom of this disease is the appearance of a blown rot in the fruit, either while it is still green, or at the time of ripening. As the disease progresses, the entire fruit becomes involved. Tiny gray pustules, or spore masses, break through the skin, and spores by the thousands are cut off in long chains to be scattered by the wind to other fruits, there to reproduce the rot. The rotted fruit soon shrivels and dries, to form the wrinkled mummies that cling to the trees through the winter, or fall to the ground beneath. With the warm spring rains, the mummies on the trees give rise to new masses of spores. These are

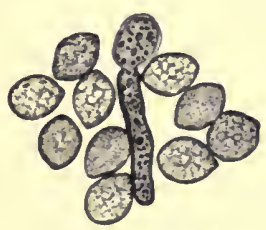

Fig. 132, Spores of brown-rot, and a germinsting spore. carried by the breeze to the blossoms and green

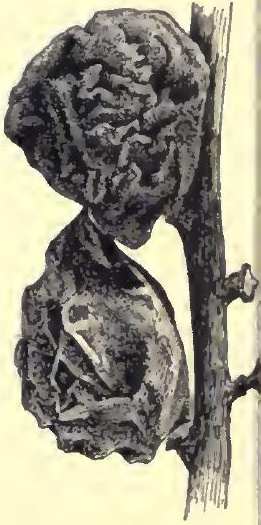

Fig. 131. Brownrot. The mummies that carry the disease over winter. fruits, and again give rise to the rot. The mummies that fall to the ground usually produce the sexual spores (ascospores) in long, slender sacs (asci), eight spores in each sac. These sacs are borne 
on the inside of a cup, several of which may grow up from each half-buried mummy. The spores are ejected from the sacs into the air, to be carried to blossoms, where they cause blight and start the summer development of the disease. Thus in two ways this parasite may continue its existence from year to year. No satisfactory method of controlling it is known. Some promise of success is given by s'cott's so-called self-boiled lime and sulfur mixture, which has recently been used as a summer spray for this disease on peaches. ${ }^{\prime}$

230. Other Fungous Diseases. The apple seab lives over winter on the fallen leaves. It ordinarily attacks the young apples and leaves at about the blossoming time. One spraying just before and one immediately after blossoming are most important for its control, but it is usually necessary to spray three times in order to secure olean fruit in regions where the scab is serious.

Potato sab is planted with the potato. It also lives over winter in the fields where seabby potatoes grew. It may be controlled by soaking the potatoes for one to two hours in a mixture of one pint of formalin to thirty gallons of water, after which they are spread out to dry and are ready to cut for planting. Thirty gallons of the solution is sufficient for treating about twenty bushels of potatoes. After treatment, the potatoes must not be placed in the old (rates or bags, as they would hecome re-infected. They should be planted on land which did not grow scabby potatoes, if possible. The treatment may be of some benefit, even if it is necessary to plant on scab-infested land.

"W. M. Scott, Self-Boiled hime and Sulfur Mixture as a Promising Fungicide. Bureau Plant Industry, (Tnited States Departunent of Agri('ulture, ("ircular No. 1. 
Oat smut is carried by the seed and may be controlled in the same manner, using one pint of formalin to fifty gallons of water. The oats are sprinkled with this solution until they are moist enough to nearly pack in the hand. Shovel into a pile, cover and leave two hours. Spread out to dry before sowing. Or they may be dipped in the solution.

Wheat smut cannot be controlled in this way, because the disease is inside the seed. Corn smut cannot be controlled, because the disease lives over winter in the fields and is blown about by the wind. The various rusts of the grain plants cannot be controlled.

The blight of potatoes may be controlled if the plants are kept coated with Bordeaux mixture, to prevent the entrance of the fungus. About five sprayings are commonly given. In rainy seasons it sometimes pays to give" more.

\section{Parasitic Flowering Plants}

Relatively few flowering plants live as parasites upon other plants. Perhaps the most common and destructive of these are the dodders, which live on many wild plants and on some of our cultivated ones, such as clover, alfalfa, etc. The dodder stems are long yellow strands with no leaves, growing in mats over their host plants. They twine about the host and send haustoria or suckers into their stems, from which they secure water and food substances.

Dodder seeds are usually small and are carried with the alfalfa and clover seeds. The best way to control the parasite is to secure seed from a field that does not contain dodder. The seeds of some species, of dodder may be separated out by sieves. 


\section{INSECTS}

231. Importance of Insects. Insects seem to be the form of life that is peculiarly adapted to this world. About 95 per cent of all kinds of animals are insects. In actual numbers of individuals they are still more in the lead. Many of these insects live at our expense, and in spite of oul efforts to subdue them. The cotton-boll weevil, chinchbug, grasshopper, San José scale, codling moth, potato beetle, and many others are well-known crop pests. It has been estimated that insects destroy about $\$ 700,000,000$ worth of crops per year in the United States. It is well worth while for the farmer to learn something of the life and habits of insects, in order that he may prevent some of this loss.

However, we must not come to think of all insects as harmful; many of them are very useful. Bees are the first of which we think. These and other insects are of use in carrying the pollen for certain crops. Other insects are useful because they live on the harmful kinds.

232. What an Insect Is. All insects have six legs in their mature stage. This feature distinguishes them from spiders, which have eight legs, and from millipedes and centipedes, which have many legs. A caterpillar appears to have more than six legs, but those at the rear end are not true legs, as will be seen by examining one. When the caterpillar changes to a butterfly or moth, only the six true legs remain.

The body of an insect is divided into three parts that are usually quite apparent: head, thorax and abdomen. A wasp shows these parts very clearly. 


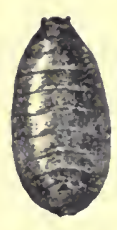

1

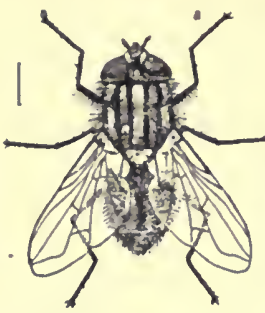

2

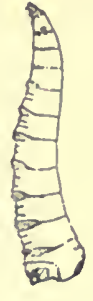

3

Fig. 133. Stages in the life of a house-fly: 3. larva; 1, pupa; 2, mature fly. (After Howard.)

233. Stages in the Life of an Insect. Many insects have four distinct periods in their life. At different stages they look so unlike that one would never suspect that they were the same individual.

Fig. 133 shows how a common house-fly looks at different ages. The first stage is the egg. From this the maggot hatches. This is called the larva stage. "When the fly maggot becomes full-grown, it changes to the pupa
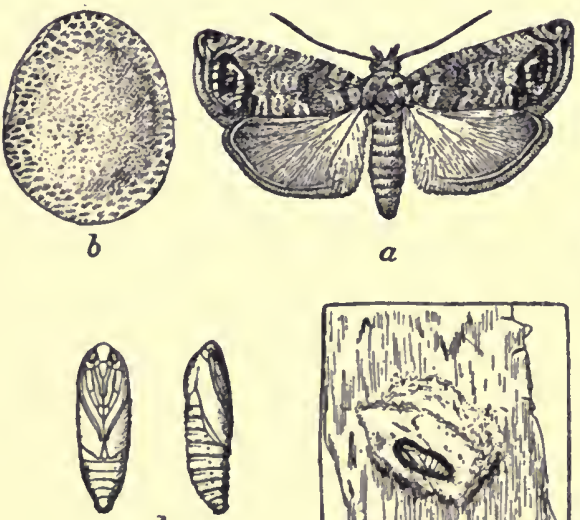

d

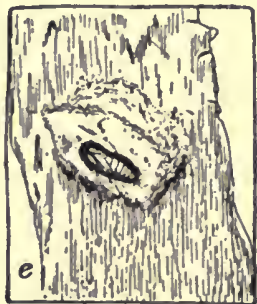

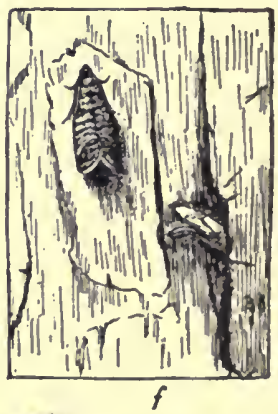

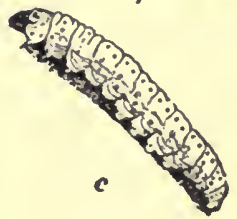

FIG. 134. Stages of the codling moth: $a$, the moth or adult insect, slightly enlarged; $b$, the egg, greatly enlarged; $c$, the full-grown larva, slightly enlarged; $d$, the pupa, slightly enlarged; $e$, the pupa in its cocoon on the inner surface of a piece of bark, reduced about one-half; $f$, moth on bark and empty pupa skin from which it emerged, about natural size. (From Simpson.) 
stage. The pupa appears to be inactive and is sometimes referred to as a resting stage, but this is far from true. Great transformations are taking place inside the pupa skin. The wings are develop-

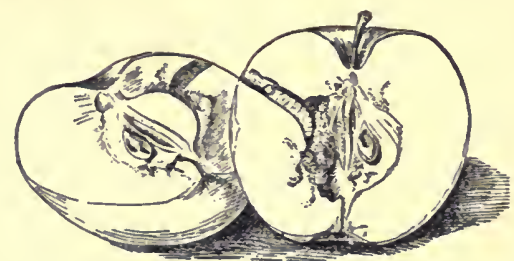

FIg. 135. Codling moth larva and its work. (Farmers' Bulletin No. 283) ing and the entire appearance of the body is changing. After these changes are complete, the fly appears in the
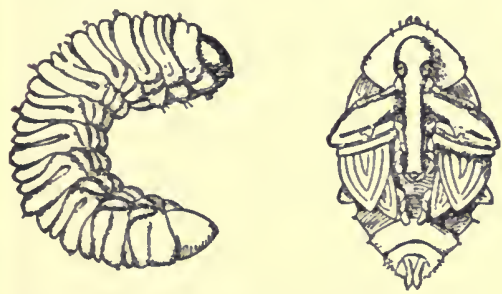

Fia. 136. Cotton-boll weevil larva at left; pupa at the right. About five times natural size. (After W. D. Hunter.) mature stage. The pupa stage lasts five to seven days, and the larva stage about as much longer, so that a new generation may be started every two weeks. A single female lays 120 to 160 eggs. It is easy to see why flies become so numerous in late summer.

Each mosquito, codling moth and cotton-boll weevil passes through these four stages. Some insects do not pass through all these stages. Grasshoppers and some other insects grow continually from the time they hatch until they are mature. Some plantlice are born alive, so that they do not pass through the different stages.
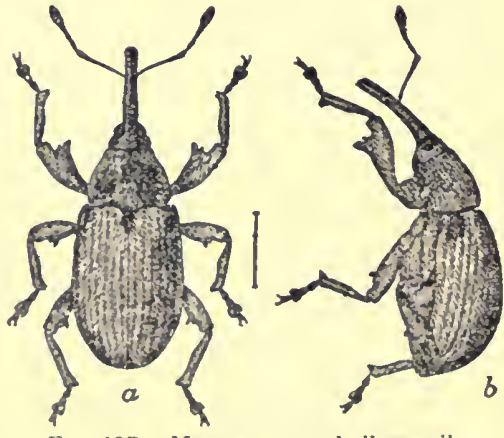

Fra. 137. Mature cotton-boll weevil. (After W. D. Hunter.) 
234. The Control of Insects. One cannot intelligently combat an insect without knowing its life history. For years we have been trying to kill mature flies. Now we are coming to know that one of the best means of limiting their numbers is to keep the horse manure hauled out, as it is in this that the flies grow.

The effective way of controlling mosquitos is not to try to kill the mature ones, but to eliminate the rainwater barrels and stagnant water, where they develop; or, if this cannot be done, place oil on the water to kill the "wrig- . glers."

The codling moth lays its egg on the apple. The time to kill it is when the Egg of codling moth young worm takes its first meal. If we on apple wait until it has entered the apple, it is too late. There

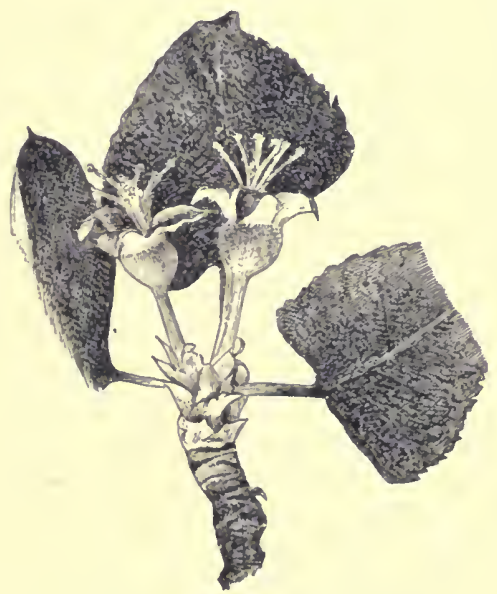

Fin. 139. Apples just right to spray for codling moth must be some poison on the apple when the worm begins to eat.

The apple maggot cannot be controlled in this way because the small fly that lays the egg punctures the skin and places the egg in the apple. The best way to control such a pest is to have the fallen apples all eaten by hogs or sheep.

The corn root-worm is very serious in some of the corn states. It does not 
live on other crops. Therefore, it may be easily controlled by rotating crops.

Few insects cause so much loss in America as the chinch bug. It is most harmful in wheat fields, but often migrates from the wheat to corn and other crops and there continues its ravages. There are no satisfactory remedies except rotation of crops.

We can never hope to exterminate any insect. The best we can hope for is to limit the numbers so that serious damage will be prevented.

\section{Chewing and Sucking Insects.} Orchards, potatoes and many vegetables are now commonly sprayed for the control of insects. There are two general classes of insects so far as spraying is concerned: those that chew their food and those that suck the juices of the plant. Potato beetles and cabbage worms eat the foliage. All that is necessary in order to kill thein is to put some poison, such as Paris green, on the leaves. The San José scale, chinch bug, and plant lice suck the juices of the plant. They cannot eat poison. To try to poison them would be like trying to poison a

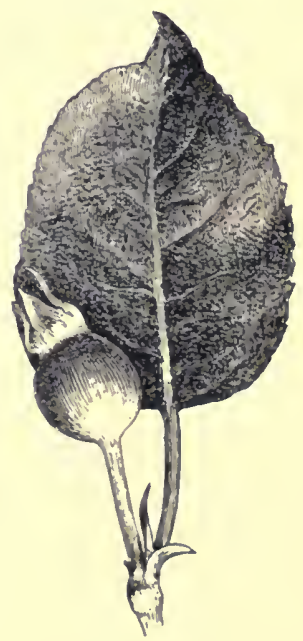

Fis: 110 .

Almost too late to spray for codling moth mosquito by placing poison on the hand. A mosquito would merely insert his bill and eat to his satisfaction without getting any of the poison. In order to kill these, it is necessary to spray with a contact insecticide-one that kills when it gets on their bodies. 


\section{SPRAYING FOR THE CONTROL OF INSECTS}

\section{AND DISEASES}

236. Common Fungicides and Insecticides. There are two general classes of enemies for which treatment is given:
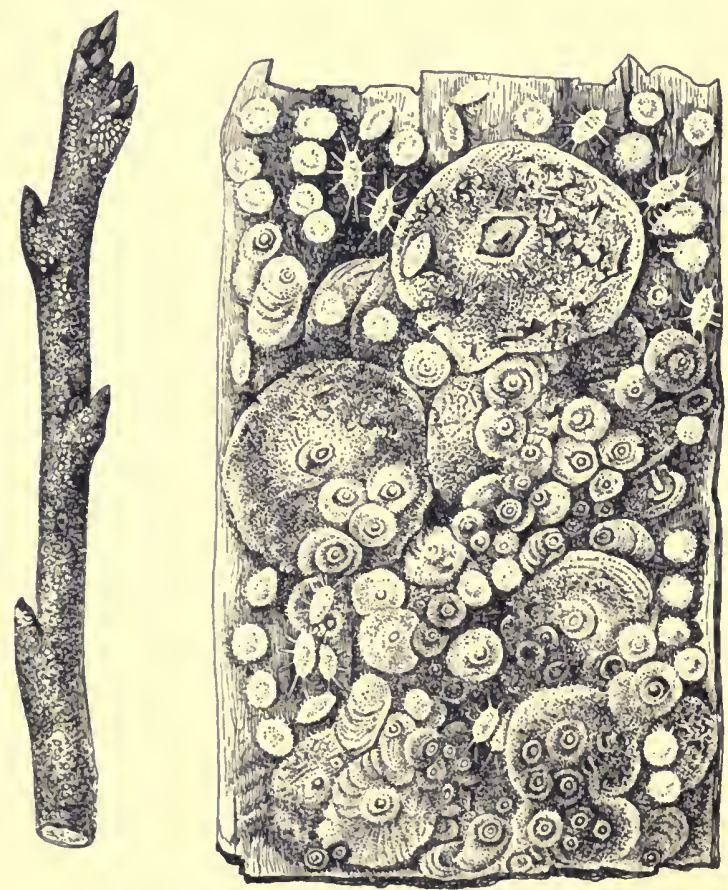

Fic, 141. San José scale. Natural size on the left; much enlarged on the right. A sucking insect. (After Howard and Morlat $t$ )

fungi and insects. Those materials that are used for destroying fungi are called fungicides; those that are used against insects are called insecticides. The following list gives some of the chief materials of each kind: 


\section{Fungicides}

Bordeaux mixture

Copper sulfate.

Ammoniacal copper carbonate.

Lime-sulfur.
Sulfur.

Potassium sulfide.

Formalin.

Corrosive sublimate

\section{INSECTICIDES}

Poisons

Paris green.

Arsenite of soda.

Arsenite of lime.

Arsenate of lead

Hellebore.
Contact Remedies

Lime-sulfur.

Sulfur.

Whale-oil soap.

Kerosene emulsion.

Crude petroleum.

Soluble oils.

Carbolic acid.

Hydrocyanic acid gas.

Carbon bisulfide.

Tobacco.

It will be seen that, in general, one material is not of much value for both insects and fungi. Lime-sulfur is a good fungicide and contact insecticide. In some other cases the same remedy does good for both insects and fungi. Bordeaux mixture repels the flea-beetle on potatoes, and the striped cucumber- and melon-beetle, so that it is of some value against these insects; and Paris green is of some value as a fungicide; but generally we nust not expect one remedy to be of value against more than one of the three classes of enemies. Many of the supposed failures in spraying are due to the use of the wrong remedy.

237. Spraying for Fungi. 'The standard remedy for fungous diseases is Bordeaux mixture. This is made of copper sulfate and lime. It is the copper sulfate that kills the fungi. But if it is used alone it will also injure the foliage. The lime prevents most of this injury. As we 
have previously learned, the fungi are small plants that live on our crops. We might say that there are two kinds of weeds that we have to control,- those that grow on the ground and those that grow on our crops. For the one kind we cultivate, for the other we spray. Fungi must be killed by a fungicide that hits them. It is just like spraying for wild mustard. We can apply a spray that is so strong as to kill the mustard, but that is not strong enough to harm the oats. If we applied it too strong, the oats would also be killed. So, in use of the Bordeaux mixture, we can use it strong enough to kill the fungi without hurting the tree or crop. Certain trees, as peaches and plums, are so tender that it is very difficult to spray without killing the leaves also.

Certain weather conditions favor the growth of fungi, just as certain kinds of weather favor the growth of corn, but weather cannot create the one any more than the other. Close, damp days, with frequent showers, are favorable for the growth of most fungi.

Another essential in spraying for fungi is that we spray before they enter the host plant. When a fungus seed (spore) grows and gets inside the plant, it is too late to spray. Spray on the outside of a leaf does not hurt a fungus that is already inside. Ordinarily it is some time after the fungus has gained entrance before the disease is apparent. We must, therefore, know the life history of the particular fungus, know when it is likely to enter the plant, and spray before that time. However, it is sometimes worth while to spray when the first plants show a disease, if we have not started earlier. In this way, some of the crop may often be saved. Spraying is insurance,-it should be 
done before the disease is apparent. Some years we may spray for a disease that does not develop seriously, but the profits on the years when diseases are bad will usually be much more than enough to pay for the apparent loss of labor. However, there are very few years when spraying does not give some benefits.

Another essential in spraying for fungi is thoroughness. If Paris green is put on a potato plant, even if only part of the leaves are hit, the potato bugs may be poisoned. If the poison is there, the bug will probably eat a poisoned leaf tomorrow if he does not get one today. But when we spray for fungi, only those leaves that are hit are protected, and the unsprayed leaves furnish a place for the disease to enter.

\section{The Preparation of Bordeaux Mixture. Several} strengths of the spray are used, as follows:

Copper sulfate- Two, three, four, five or six pounds.

Quicklime-An equal number of pounds.

Water -50 gallons.

For plants with tender foliage, two pounds of lime and two of copper sulfate are used; for apples and pears, about three to four pounds of each; for potatoes, six pounds.

The copper sulfate is dissolved and the lime slaked separately. The copper sulfate is then diluted with nearly all the water before the lime is added. If the concentrated solutions of lime and copper sulfate are put together, they form a thick, curdled mass that will not stir up readily when the water is added. The mixture is all right if either the lime or the copper sulfate is diluted before adding the other, or each may be diluted with half the water. The former method is usually most convenient. 
If much spraying is to be done, a stock solution will save time. For this, fill a barrel with water and weigh out one pound of copper sulfate for each gallon. Suspend this in a bag in the top of the barrel and it will all dissolve. Instead of weighing it for each tank of spray, we can then take out as many gallons as we desire pounds. Two pounds may be dissolved in each gallon, if desired.

The lime may also be slaked in quantities. The lime settles, and we cannot be sure when we have enough by measure, so that if we use a stock solution of lime we should also use the potassium ferrocyanide test. This is desirable, anyway. Potassium ferrocyanide makes a yellow solution. If a drop of it is added to a solution of copper sulfate, it turns a brick-red. If lime enough is first added to neutralize the copper sulfate, the drop remains yellow. About a half more lime is usually added after the copper has been neutralized.

For spraying small gardens, stock solutions may be kept in large bottles and the proportionate amounts used.

239. Poisons. Paris green and arsenate of lead are the most common poisons. Five ounces to a pound of Paris green are used in fifty gallons of spray. Or one to four pounds of arsenate of lead may be used. The arsenate of lead never hurts the foliage, so that it may be used in any strength. Paris green sometimes causes injury if used too strong, or if used without lime. Paris green is also used to dust on plants, either alone or with lime.

240. Contact Remedies. The chief use of contact remedies is to kill the San .José scale. For this purpose, the trees must be sprayed while dormant, because any spray that is strong enough to kill the scale will also kill the leaves. 
Lime-sulfur spray is most commonly used. It is usually made about as follows:

Quicklime .15 pounds

Flowers of sulfur...................

Water. 45 gallons

The sulfur and lime are boiled in a part of the water for about one hour. The remainder of the water is then added and the spray is ready for use.

The lime-sulfur spray is also a good fungicide. It will control peach-leaf curl, and will take the place of Bordeaux mixture when this is needed on dormant trees.

Numerous preparations of soluble oils are also on the market. Many of these are good. Clear oil is not often used, as it is likely to injure the trees. The soluble oils are diluted with water, so as to avoid this danger.

Kerosene emulsion is used for killing plant lice when the trees are in foliage, and is also used on dormant trees. To make it, use:

Kerosene........................ 2 gallons

Soap $\ldots \ldots \ldots \ldots \ldots \ldots \ldots \ldots \ldots \ldots \ldots \ldots$.

Water .......................... gallon

Dissolve the soap in hot water, add the kerosene and churn thoroughly until a creamy emulsion is formed. For use on dormant trees, dilute with 10 to 20 gallons of water. For killing plant lice on foliage, dilute with 40 to 60 gallons of water.

241. Combined Insecticides and Fungicides. The insecticides and fungicides may often be combined. In most cases, it pays to put Paris green or other poison with Bordeaux mixture, as in spraying apples, pears, potatoes, etc. But this combination must not be expected to kill 
plant lice or other sucking insects. There is no generally used spray that combines the three purposes-fungicide, poison, and contact remedy for sucking insects. To be successful in spraying, one must know what he is spraying for, and apply the right spray at the right time. Apples are commonly sprayed about three times, once just before blossoming, once just after the petals fall, and once about two weeks later. Bordeaux mixture and a poison are combined. Potatoes are commonly sprayed about five times, beginning when the plants are about six inches high and repeating every one to two weeks, using Bordeaux and poison. The particular treatment, of course varies in different sections, because the weather and enemies differ. For details in any section, one should apply to the State Agricultural Experiment Station.

\section{QUESTIONS}

1. What are the worst ten weels in the neighborhood? What is the eharacter that makes each one a bad weed, that is, able to live in spite of man? How may each one be most easily controlled?

2. What are the worst plant diseases in the region? How may each of these be controlled?

3. In how many ways do baeteria differ from the plants with which you are most familiar? In how many ways do fungi differ from these plants? How do bacteria differ from fungi?

4. How do spores differ from seeds?

5. In what ways may the spores of disease-produeing fungi be carried to the plants which they infect?

6. Explain how spraying the leaves of the potato with Bordeaux for late blight inereases the yield of tubers.

7. Explain why spraying pear and apple trees will not eontrol fire blight. Why is the removal and treatment of the hold-over cankers the first step to be taken in controlling this disease? 
8. What are the most serious insect pests in your county? How may each be controlled?

9. What are the most useful insects in the region? Do insects do more harm than good?

10. Complete the following reaction which takes place in preparing Bordeaux mixture:

$$
\mathrm{Cu} \mathrm{SO}_{4}+\mathrm{Cu}(\mathrm{OH})_{2}=\text { ? }
$$

11. What plants are commonly sprayed in your county? What spray is used? When is it applied? What is the cost of the sprayer? The eost of the materials? Of the labor? Does the spraying pay?

\section{LABORATORY EXERCISES}

\section{Bacteria and Molds.}

Materials.-Three test tubes, cotton, boiled potato or fruit (applesauce is good); three apples, one partly decayed.

Fill each tube about one-third full of apple-sauce or boiled potato. Plug each one with cotton. Set one aside. Put the other two into a pail of water and boil for half an hour. After boiling, set one tube aside with the cotton undisturbed. Take the cotton from the third tube and leave it out for half an hour or more, then put it in again. Leave these for a few days and see what happens. Aceount for the difference. Is it desirable to leave canned fruit open a few ininutes before covering, after cooking? Why?

Prick one of the sound apples in several places with a pin which has been sterilized by holding it in a flame. Put the pin into the rotten apple and then into the other sound apple. Repeat this in several places. set the two sound apples aside for about a week. What happens? What is one value of the skin to an apple? Why should fruit be pieked and handled with care?

\section{Bacteria.}

Materials.-Compound microscope magnifying 500 to 1,000 diameters, if the school bas such a mieroseope or can secure the use of one temporarily. Examine some stagnant water, or some water in which seeds or bread have been standing for a day or so. This will contain many forms of bacteria and other living things. Most of the bacteria are small, short rods. In many cases there are longer rods made up of two or more plants fastened end to end. Each of the plants is a single erll. They multiply by the. simple rlivision of each plant into two. 
They may reach their full growth in less than an hour. Make drawings of the different forms.

64. Bread Mold.

Materials.-A slice of stale bread, several glasses or jars, magnifying glass, compound microscope.

Moisten a piece of bread slightly and place in one of the jars or tumblers, and keep covered. In about a week the bread will probably be covered with black mold. Examine with the lens, notice the white, moldy growth-the mycelium of the fungus. The mycelium corresponds to the roots, stems and leaves of other plants. It takes its food from the bread. 'The fungus requires heat, moisture and food for its growth, but does not require light, because it is a saprophyte. Notice that the dark color is due to black specks attached to the mycelium threads; these are spore cases. Each one is called a sporangium. Some of these are white. These are the young, or unripe ones. These spores correspond to seed, while the sporangium corresponds to a pod. Make drawings of all the parts.

Mount some of the fungus in a drop of water and examine with a compound microscope. Make drawings of mycelium, sporangium and spores. (See Fig. 129.)

\section{Transformations of an Insect.}

Bring in cabbage worms, caterpillars and other insects, and place in jars in the laboratory. Feed with the proper plants and watch the transformations. Make drawings of each stage in the life of at least one insect. For this work a terrarium is very desirable. It is a box with glass sides and cover that can be conveniently opened and closed.

\section{A Study of a Grasshopper.}

Supply each student with one or two grasshoppers (or other mature insects). How many divisions in the body? How many legs does it have? What difference is there between the hind legs and the other pairs? How many wings are there? Do all insects have this number of wings? How are the wings folded? What differences between the outer and the inner pair? To what part of the body are the wings attached? The legs? Find the antennæ (feelers). Examine the jaws. Do they move in the same way that yours do? If you have a compound microscope, see whether you can find the divisions of the compound eyes. Make drawings. 


\section{Preparation of Bordeaux Mixture.}

Materials.-Half a pound of copper sulfate, half a pound of quicklime, five cents worth of potassium ferrocyanide. Two-quart fruit-jars. A measure marked in ounces.

Dissolve the potassium ferrocyanide in a two-ounce bottle of water and label "poison."

Prepare a stock solution of eopper sulfate by dissolving the halfpound in a two-quart jar of water. This will be at the rate of one pound per gallon.

Slake the lime and then dilute to two quarts.

1. Place three ounces of the stock solution of copper sulfate in one two-quart jar; fill nearly full of water, then add a little of the stock solution of lime and test by adding a drop of potassium ferrocyanide. If there is enough lime, the drop will remain yellow. If there is not enough, it will turn a brick-red. About a half more lime than the test requires should be used. This will probably take about three ounces of the stock solution of line if it is well stirred. Set aside to compare with 2,3 and 4 .

2. Put three ounces of the stock solution of lime in a second jar and fill nearly full of water; then add three ounces of copper sulfate.

3. In a third jar, put three ounces of eopper sulfate solution and fill half full of water. In a fourth, put three ounces of lime solution and fill half full of water. Pour these into another jar at the same time.

4. Put three ounces of copper sulfate solution into a jar, then add three ounces of lime solution and add water to fill the jar.

Set these four jars side by side. The material will gradually settle. Measure the height of each one and fill out the following table:

Condition when mixed

Height of column

\begin{tabular}{|c|c|c|c|c|}
\hline 2 when m & beginning & $\begin{array}{l}\text { End } 30 \\
\text { minutes }\end{array}$ & 1 hour & $1 \mathrm{day}$ \\
\hline $\begin{array}{l}\text { 1. Copper sulfate dilute . . . } \\
\text { 2. Lime dilute . . . . . . . . } \\
\text { 3. Both dilute . . . . . . . . } \\
\text { 4. Neither dilute } \ldots \ldots \ldots \ldots\end{array}$ & & & & \\
\hline
\end{tabular}

Why does the material settle more rapidly in one than in another? Which mixture would clog a spray nozzle inost? Which would be most evenly distributed by spraying? 
Shake the mixture which proves best and allow it to settle again, making note of the time required. Compare this with the time that it took the first mixture to settle. Would it be desirable to use old Bordeaux mixture?

How much of the above stock solution of copper sulfate would be required to make one gallon of a $2: 2: 50$ (2 pounds copper sulfate, 2 pounds lime, 50 gallons water) spray? Fifty gallons of a $4: 4: 50$ spray?

\section{COLLATERAL READING}

Farmers' Bulletins Nos.:

28. Weeds, and How to Kill Them.

279. A Method of Eradieating Johnson Grass.

188. Weeds Used in Medieine.

334. Vitality of Weed Seeds in Manure, p. 18.

Weed Seeds in Feeding Stuffs, pp. 18, 19.

345. Some Common Disinfectants.

243. Fungicides and Their use in Preventing Diseases of Fruits 305. Injury by Bordeaux Mixture, pp. 12, 13.

127. Important Insecticides.

227. Lime, Sulfur and Salt Wash, pp. 19-22.

281. Soluble Oils for the San José Scale, pp. 17, 18.

329. Preparation of Soluble Oils, pp. 26-28.

244. Fumigation of Nursery Stock, p. 11.

259. Disease-Resistant Crops, pp. 15, 16.

237. Apple-growing in New York, pp. 8-11.

267. Apple Bitter Rot, pp. 21-23.

283. Spraying for Apple Diseases and the Codling Moth in the Ozarks.

91. Potato Diseases and Treatment.

316. Potato Seab, pp. 11, 12.

320. Potato Spraying, pp. 22, 23.

219. Lessons from the Grain Rust Epidemic of 1904.

250. The Prevention of Wheat Smut and Loose Sinut of Oats.

132. Inseet Enemies of Growing Wheat.

231. Spraying for Cucumber and Melon Diseases.

223. Miscellaneous Cotton Inseets in Texas.

290. The Cotton Bollworm.

344. The Boll Weevil Problem.

333. Cotton Wilt. 
47. Insects Affecting the Cotton Plant.

209. Controlling the Boll Weevil in Cotton Seed and at Ginneries.

211. The Use of Paris Green in Controlling the Cotton Boll Weevil.

126. Insects Affecting Tobacco.

172. Scale Insects and Mites on Citrous Trees.

264. The Brown-tail Moth and How to Control It.

275. The Gipsy Moth and How to Control It.

155. How Insects Affect Health in Rural Districts.

221. Fungous Diseases of the Cranberry.

178. Insects Injurious to Cranberry Culture.

284. Insect and Fungous Enemies of the Grape East of the Rocky Mountains.

99. Insect Enemies of Shade Trees.

59. Bee-keeping.

54. Some Common Birds.

196. Usefulness of the American Toad.

297. Methods of Destroying Rats.

335. Harmful and Beneficial Maunmals of the Arid Interior.

The Cercals in America, and Forage and Fiber Crops in America The more important enemies of crops are discussed. See table of contents and index.

Cyclopedia of American Agriculture, Vol. II, pp. 35-53, 110-118, and index. 


\section{CHAPTER IX}

\section{SYSTEMS OF CROPPING}

One of the first farm-management questions to be considered is the kind of crops to grow and the order in which they shall be grown.

242. The Choice of Crops. The choice of crops is much more than a question of which crops will sell for the most per acre, or even which will produce the most net profit per acre. Corn may pay better than oats, yet it may be wise to continue to grow oats. One can raise all the corn that he has time to grow and raise some oats besides, because most of the work on the oat crop comes at a time when the corn crop does not require attention. Barley, oats and spring wheat require work at about the same time, so that a farmer usually chooses one from these. Rye and winter wheat are also competitors, but neither one interferes much with the work of raising spring grains.

The general principle is that a farmer should have work for the entire year. Each day he should do the kind of work that pays best on that day, although it may be much less profitable than work that he might do at some other time. The same principle applies in all occupations.

While a small number of crops is better than a single crop, yet it is not well to have too many nor to have too small areas of each. In order to grow potatoes profitably, one usually needs to have considerable special machinery, such as a planter, a digger, and a sprayer. One cannot 


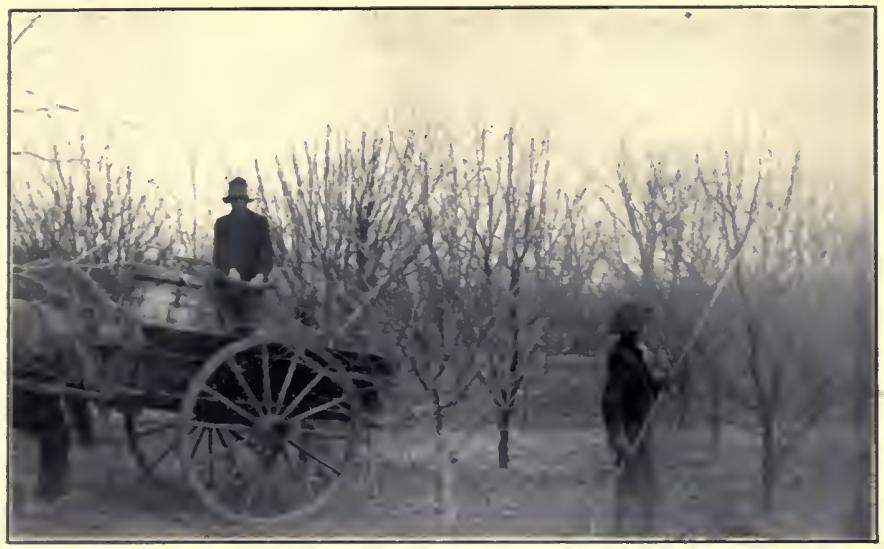

Fig. 125. A good spray rig for a small orchard

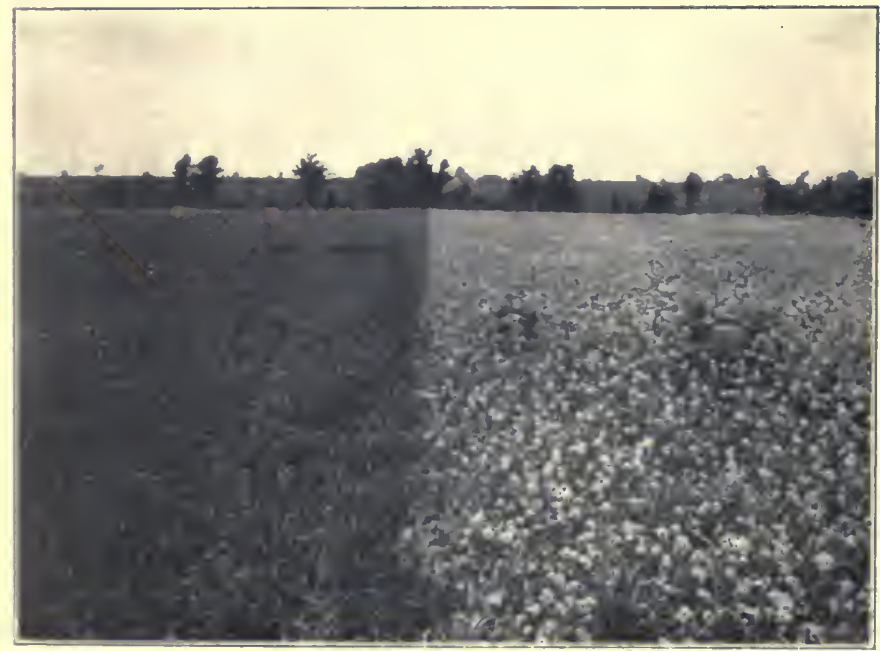

Fin 126 Oats sprayed for killing inustard on the left, unsprayed on the right 

afford to have these without a considerable area. The interest and depreciation on these machines will likely amount to $\$ 25$ to $\$ 50$ per year, an amount that is too high a tax for a small area to carry. The same may be said of special machinery for small orchards and for many other crops. These remarks do not apply to the raising of small quantities of vegetables and fruits for home use.

With the exception of some very specialized types of farming, some crops that are to be fed to animals should be grown in order to keep up the fertility of the land.

In choosing what crops to grow, it is well to follow the practice of the best farmers in the section until one gets started. Changes may then be introduced gradually.

243. The Rotation of Crops. Rotation means that the crops grown on each field are changed from time to time. Practically every farmer does change crops occasionally. Still, we have farms on which nothing but cetton has been grown for years; others, on which no crop but wheat has ever been planted. Sooner or later, all farmers will come to practice some rotation. If no other system is followed, the land will be abandoned for a time to grow weeds, which is a primitive kind of rotation. The present practices are haphazard, but some of the best farmers in all sections are coming to more or less definite systems. We do not usually speak of the haphazard changes as crop-rotation.

244. Crop-Rotation and Diversified Crops. The advantages of having a variety of crops are often confused with the advantages that come from crop-rotation. Diversification of crops keeps the laborer employed the year 
around; it provides for cash crops and crops to feed; it prevents total failure when one crop fails. All these advantages may be had when each of the several crops grows on the same field continuously.

245. Advantages of Crop-Rotation. The rotation of crops (1) helps to control weeds, insects and fungi; (2) it provides for keeping up the humus supply on each field; (3) it may provide for the growth of grass and legumes on each field; (4) it often saves labor; (5) it keeps the land occupied with plants a greater part of the time; (6) it allows the alternation of deep- and shallow-rooted crops; (7) it may provide for a balanced removal of plantfood; (8) it is possible that toxic substances may be destroyed; (9) it systematizes farming.

(1) Nearly every crop is accompanied by certain kinds of weeds that are able to grow with it. The weeds that thrive in small grain are usually quite different from those that thrive in meadows. If small grain is grown continuously, the land is likely to become very weedy. These particular weeds are likely to be easily killed by cultivation. Wild oats are a serious pest in the grain fields in Minnesota, but if crop-rotation is practiced they readily disappear. Such weeds as daisies may be bad in hay land, but are not serious in corn. The opposite is true of pigweeds.

Similarly, there are many diseases and insects that live on one crop but that are not harmful to another. The soil may become infested with potato-scab or cornroot-worm, but crop-rotation will check either.

(2) If crops are not rotated, those fields that are constantly in tilled crops will have their humus supply ex- 
hausted, and the numerous evil results that follow such exhaustion will be brought on. The control of weeds, diseases and insects and the maintenance of the humus supply are the most important reasons for rotating erops.

(3) If crops are rotated, we may have legumes and grass on all the fields occasionally. As we have previously learned, these crops are important in keeping up the productivity of the land.

(4) Labor is often saved by erop-rotation. Grasses are sown in small grain, so that the land needs but one fitting for two crops. Oats are often disked in on corn land without the land having to be plowed. In Minnesota and some other states, the disking is better than plowing, both for oats and for the grass seeding in oats. It is often convenient to be able to work land at times when it could not be done if crops were not rotated.

(5) By crop-rotation the land may be kept oceupied more of the time. Grass seeded in oats occupies the land after the oats are cut. If corn follows grass, the land may have the benefit of the grass cover until plowed for corn. Where the season is long enough, it is possible to rotate crops so as to grow more than one crop in a year. One of the best rotations for the South provides five erops in three years.

(6) Deep- and shallow-rooted crops may be alternated, thus allowing the use of different layers of soil.

(7) Formerly it was thought that the chief reason for rotation was that plants use the different plant-foods in different proportions, so that when the soil became exhausted for one crop it might contain the kind of food that the other crop required. As a matter of fact, the 


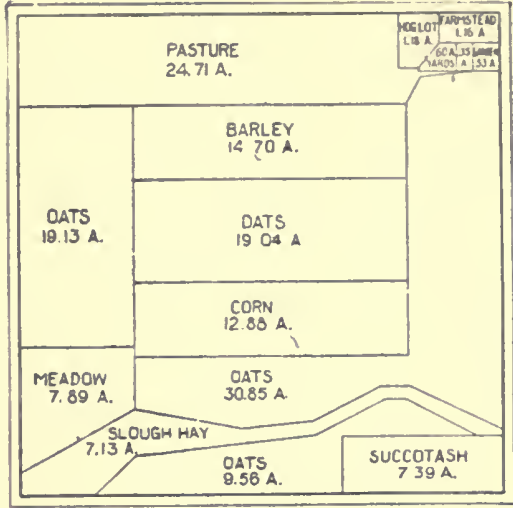

Fig. 142. Fields on a 160-acre farm in Minnesota increased yields resulting from crop-rotation will cause the removal of more of each kind of plant-food than will be taken from the field by the smaller yields that are secured if any one crop is grown continuously. However, the fact that different plants do use the plantfood in different proportions may be of some importance.

(S) It is thought by some persons that each plant gives off certain substances through its roots that are toxic, or poisonous, to that plant, but that may not be harmful to some other crop. This theory has not yet been accepted by all investigators.

(9) Crop-rotation systematizes farming. It does not make farming more complex or make more fields, as some have supposed. Thought is required in getting the system established. The farm may need to be re-

\begin{tabular}{|c|c|c|c|}
\hline \multicolumn{3}{|c|}{ 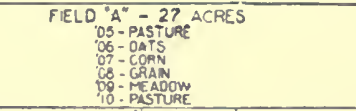 } & $\begin{array}{r}\text { FARMSTEAD } \\
8 \text { ACRES }\end{array}$ \\
\hline $\begin{array}{l}\text { FIELD " } 8 \text { " } \\
27 \text { ACRES }\end{array}$ & $\begin{array}{l}\text { FIELD "C" } \\
27 \text { ACRES }\end{array}$ & $\begin{array}{l}\text { FIELO "D" } \\
27 \text { ACRES }\end{array}$ & $\begin{array}{l}\text { FIELD "E } \\
27 \text { ACRES }\end{array}$ \\
\hline 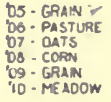 & $\begin{array}{l}\text { "OS. GRAIN } \\
\text { 06. MEADOW } \\
\text { O7. PASTURE } \\
\text { Do - OATS } \\
\text { O9. CORN } \\
\text { 10 GRAN }\end{array}$ & $\begin{array}{l}\text { DS-CORN } \\
\text { DS- ERAN } \\
\text { O7 MEADOW } \\
\text { DO PASTURE } \\
\text { O9- OATS } \\
10 \text { - CORN }\end{array}$ & $\begin{array}{l}\text { O5- CATS } \\
\text { O6- COAN } \\
07 \text { - GRAN } \\
\text { OB. MEADOW } \\
\text { O9- PASTURE } \\
10 \text { - OATS }\end{array}$ \\
\hline $\begin{array}{c}\text { PERMANENT } \\
14\end{array}$ & $\begin{array}{l}\text { MEADOW } \\
\text { AES }\end{array}$ & & \\
\hline
\end{tabular}

Fra. 143. Same farm as Fig. 142, with the fields arranged for a five-year rotation (Minnesota Bulletin No. 109.) 
arranged when the work is begun. After a systematic rotation is established, it simplifies the farming. Figs. 142 and 143 show how the re-arrangement of fields and the establishment of a rotation have simplified a farm lay-out. Formerly there were more fields, and each year the cropping scheme had to be worked out.

246. Profits from Rotation. Crops differ in necessity for rotation. At Rothamsted, England, ${ }^{1}$ where experiments have been conducted for fifty years, it has been found possible to grow good crops of roots, turnips, mangels, etc., without rotation, if the land is properly fertilized. Wheat and barley were improved by rotation. Leguminous crops failed entirely if grown continuously on the same land.

Wheat was grown in a four-year rotation for fortyeight years, giving twelve crops of wheat and thirty-six crops of other kinds. The average yields of wheat for the twelve years compared with the yields for the same years on land continuously in wheat, were as follows:

Continuous wheat, average yield, 12 crops, $12 .+$ bushels per acre. Wheat, in 4-year rotation, average yield, 12 crops, 28.6 bushels per acre.

A similar experiment with barley gave the following results:

Continuous barley, average of 12 crops, 1,735 pounds per acre. Barley in rotation, average of 12 crops, 2,960 pounds per acre.

247. Crop-Rotation and Crop-Failure. Sometimes the grass seeding may fail, or frosts or rains may spoil a crop. These emergencies can he met without interfering with the rotation. If a grass seeding in grain fails, it may be

s'The Book of the Rothamsted Fxperinents, by A. I). Hall. 
re-seeded in the fall. If a frost kills a crop, it may be re-planted, or, if too late, a catch-crop may be put in for that year and the rotation continued the next year.

248. Variation of Crop Areas. An objection to rotation is that it fixes the area of each crop each year. Some persons think that a farmer should watch the market and vary the areas of different crops to meet the market demands. Usually it is very unwise for a farmer to enter this field of speculation.

The real business practice for most men to follow is to decide on what erops pay best from year to year. Decide on the proper acreage of each. Fix the rotation, and then raise the same area each year, regardless of prices. If the original selection is wise, this practice will have everything in its favor. It will use a constant supply of labor and machinery, rather than have equipment idle every other year as the farmer oscillates, usually just in time to miss rather than meet the high prices.

249. Examples of Rotations. A five-year rotation of corn, oats, wheat, grass two years, is practiced by many of the best farmers of the northern states. This requires that the farm be divided into at least five fields. Corn, oats, wheat, each occupies one-fifth of the farm. One-fifth is in clover and timothy one year old, and one-fifth in timothy, as the clover is usually not very abundant the second year. On many farms in this section there is a permanent pasture. If there is none, one of the meadows in the rotation is used as a pasture. In this rotation, manure is usually put on the corn, and some fertilizer may be used on the oats and the wheat. The grass and elover are seeded in the wheat. With the 
present prices of hay, it will often pay to use a nitrogenous fertilizer on the grass land if there is not enough manure. Such farms usually sell dairy products, hay and wheat; and buy grain feeds.

Many variations are made in this system. One of the commonest is to allow the grass to stand for more than two years. Where potatoes are profitable, they may replace half of the corn; then oats will follow both of these crops; otherwise, the rotation is unchanged. The potatoes furnish an additional cash crop, and usually add to the profit if the soil is satisfactory for them.

The following three-year rotation is practiced in several potato sections that have light soils: Potatoes, wheat or oats, clover and timothy. This allows one-third of the farm to be in potatoes each year. The second crop of clover is plowed under and sometimes the entire hay crop. The grain and hay are usually sold. Little stock is kept and commercial fertilizers are purchased in large quantities.

A good rotation for the corn-belt is corn two years, oats, clover and timothy. Wheat may take the place of oats. The grass may be left two or more years, and may be used as a pasture if there is not a permanent one.

For regions where alfalfa is successful, this crop may be grown four years, and followed by corn two years and small grain one or two years.

For cotton farms, the most highly recommended rotation is: First year, corn with cowpeas planted between the rows or sown broadcast at the last cultivation; second year, oats, after which a crop of cowpeas is grown; third year, cotton. In starting this system, the best third of 
the farm is planted to cotton. In a few years, this rotation will produce more cotton than could be grown on the entire farm without rotation.

\section{QUESTIONS}

1. What rotations, if any, are followed in your county?

2. What rotations were formerly followed and how is the practice changing?

3. What changes should be made? Why? Ask the opinions of the best farmers; also consider what you have read on agriculture.

\section{LABORATORY EXERCISE}

68. Planning a Cropping System.

Visit a farm near the school and learn what erops were grown on each field last year and what crops the owner expects to grow next year. Make a sketch of the farm, showing the present arrangement of fields, approximate areas of each, and write in the present crops. The entire elass should go over each field to see the present conditions.

Each student should later make a map of the farm, showing the arrangement of fields that he considers best.

Give the crops for each field for five years, or long enough to get the rotation established. It will usually take two or three years to get the rotation going regularly.

\section{COLLATERAL READING}

Farmers' Bulletins Nos.:

337. Cropping Systems for New England Dairy Farms.

144. Rotation of Crops, pp. 8-11.

98. Suggestions to Southern Farmers, pp. 38-46.

The Fertility of the Land, by I. P. Roberts. Chapter XV.

Soils and Fertilizers, by H. Snyder. Pp. 111, 112, and 230-240.

Cyclopedia of American Agrieulture, Vol. II, pp. 88-109, and index.

The Cereals in America, by T. F. Hunt. Pp. 74, 209, 29.4, 329, $348,361,388,405$.

The Forage and Fiber Crops in America, by T. F. Hunt. Pp. 344346. 

.

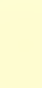

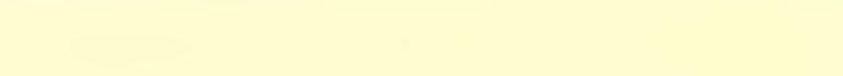




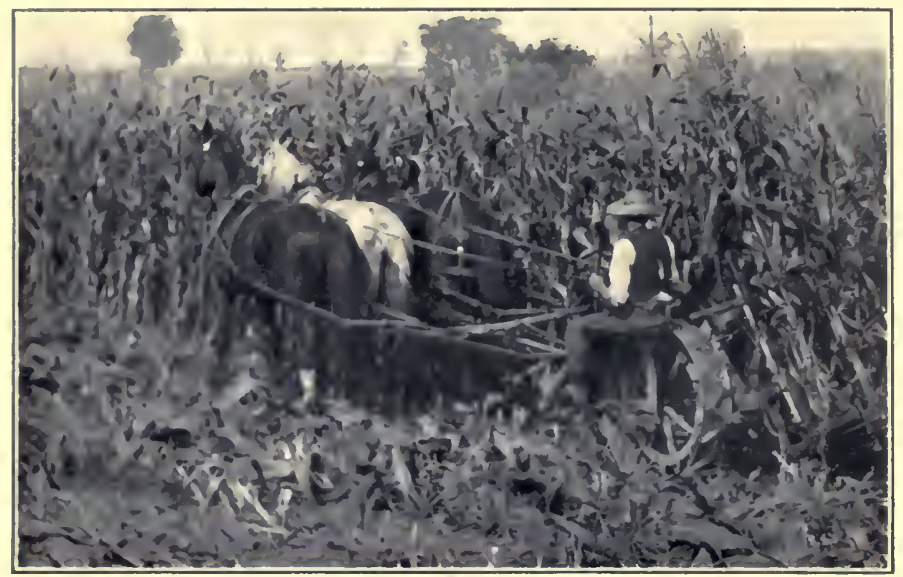

FIG. 144. Cutting corn for the silo

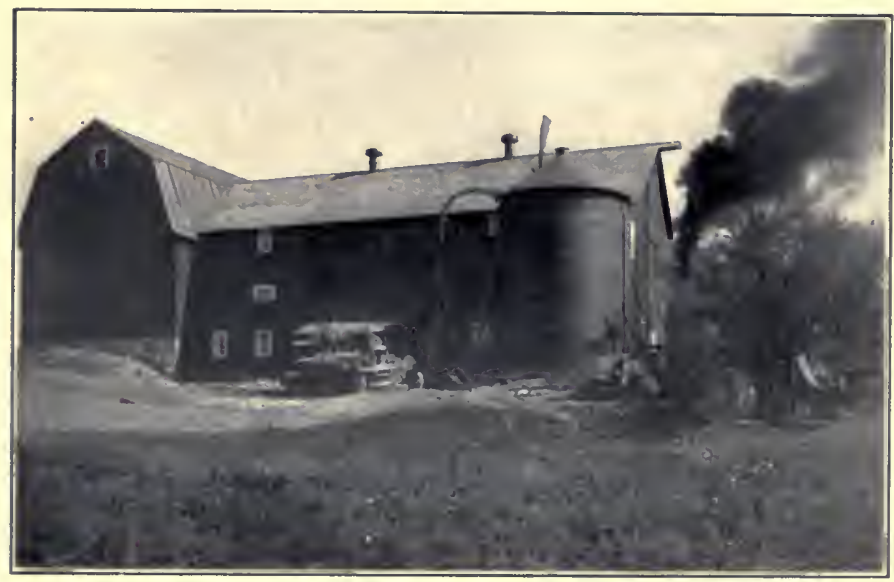

Fig. 145. Filling a silo 


\section{CHAPTER $\mathrm{X}$}

\section{FEEDS AND FEEDING}

250. Importance of Animal Food and Work. "It is estimated by competent authority that over 45 per cent of the food consumption of the better classes in the United States consists of animal products. Taking into account the relatively higher prices of these materials, it seems safe to estimate that fully half the amount spent for food by the average well-to-do family goes for the purchase of meat, eggs and dairy products. Moreover, whatever, in the light of recent discussion, may be our attitude toward vegetarianism, or our judgment as to the necessary proteid supply, it is certainly a fact, however we may explain it, that those peoples are, as a whole, most efficient which consume a reasonable proportion of animal food.

"These enormous sums spent for meat represent to a considerable extent the indirect utilization through the animal of farm products which would otherwise have no nutritive value for man. This is true on the one hand of the leaves, stems, husks, pods, etc., of our various farm crops - the so-called coarse fodders-and, on the other, of those manufacturing by-products which accumulate in the preparation of grains and other raw materials for human consumption. By feeding these products to our domestic animals, we utilize for feeding man or performing his work a portion of their stored-up 
energy, which would otherwise be practically an entire waste. Of course, surplus edible products are also utilized in stock-feeding, and, in this country, very largely so. This, however, can only be regarded as a temporary phase of our agriculture. While, on the fertile soil of the cornbelt, it is often found more profitable to convert corn into beef or pork than to market it directly, as the density of population and the demand for breadstuffs increases, the stock-feeder will be more and more constrained to the use of the cheaper by-product feeds in place of grain. From the economic point of view, then, it is highly important that that portion of our national wealth represented by these inedible products should be utilized to the best advantage, yielding a greater aggregate profit to the producer and a more liberal supply of animal food to the consumer." 1

\section{COMPOSITION OF FEEDS}

For feeding purposes, the chemist determines the composition of feed in terms of water, ash, protein, ether extract or fat, crude fiber and nitrogen-free extract, the last two together making up the carbohydrates.

251. Water. The chemist places a small quantity of the finely ground feeding-stuff in a small dish and weighs it. The sample is then placed in an oven, where it is dried at a temperature of $212^{\circ} \mathrm{Fahr}$. for several hours, or until it no longer loses weight. It is then weighed again, and the difference between the two weights is the water that the food contains. The balance on which this work is 
done is so delicate that a thimbleful of corn meal can be weighed with a smaller percentage of error than is usual when a wagon load of corn is weighed on good wagon scales.

All food materials, no matter how dry they may appear, contain a considerable amount of water. The grains usually contain about 10 per cent of water. Hay contains 10 to 20 per cent; pasture grasses about 75 per cent; green corn and silage about 80 per cent.

252. Ash. The chemist next burns the sample until the chareoal is all gone. The remainder is ash. The amount of ash in different feeds is variable. Corn contains 1.5 per cent; wheat, 1.8 per cent; wheat bran, 5.8 per cent; timothy hay, 4.4 per cent; clover hay, 6.2 per cent; alfalfa hay, 7.4 per cent.

253. Protein. The protein is not determined directly. In order to find the amount of it, the percentage of nitrogen is found and this is multiplied by 6.25 , because it has been found that the average protein substance eontains about 16 per cent of nitrogen. The method of finding the percentage of nitrogen is too complicated to be considered here. The amount of protein is highest in legumes. It is more abundant in seeds than in the stems of plants. Alfalfa hay contains 14 per cent; timothy, 6 per cent; wheat, 12. per cent; wheat-straw, 3.4 per cent; peas, 20 per cent; corn, 10 per cent.

254. Ether Extract or Fat. The dry feed is treated with ether, which dissolves out the wax, chlorophyll and fat. The largest amount of the extract, particularly in grains, is fat. It is, therefore, commonly spoken of as fat, although a more accurate term would be ether extract. 
Corn is very high in fat, containing 5 per cent; wheat contains 2 per cent.

255. Crude Fiber. The crude fiber is found by boiling the feed first in a weak acid and then in a weak alkali. These dissolve all of the softer substances and leave the insoluble crude fiber behind. It consists, for the most part, of the cell-walls or framework of the plant. The amount of crude fiber is greatest in the coarse feeds. The stalks of corn contain 20 per cent, the grain only 2.2 per cent.

256. Nitrogen-Free Extract. What is left of the organic matter of the plant after taking out the above substances is called nitrogen-free extract. It is determined by subtracting the ash, protein, crude fiber and fat from the total dry matter. It contains starch, sugar and a number of other substances. The crude fiber and the nitrogenfree extract together make up the carbohydrates.

257. Composition of Feeds and Products Compared. Notice the similarity in composition between the foods or raw materials and the animal body. It is evident that one cannot hope to secure a protein product without using a protein feed.

Raw Materials-Foods

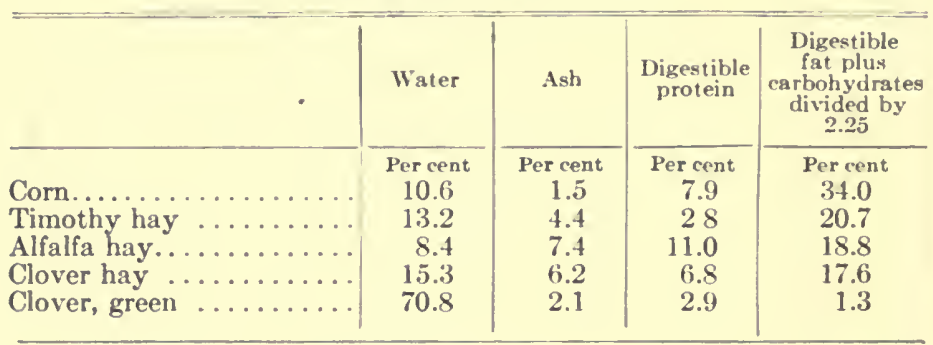


Finished Products

\begin{tabular}{|c|c|c|c|c|}
\hline & Water & Ash & Protein & Fat \\
\hline 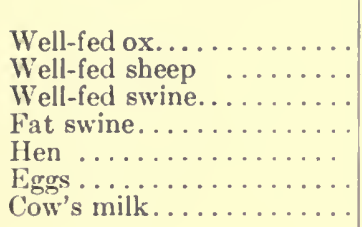 & $\begin{array}{c}\text { Percent } \\
543 \\
53.7 \\
53.9 \\
42.0 \\
55.8 \\
6.5 .7 \\
87.2\end{array}$ & $\begin{array}{c}\text { Per cent } \\
4.8 \\
3.3 \\
2.7 \\
1.8 \\
3.8 \\
12.2 \\
0.7\end{array}$ & $\begin{array}{c}\text { Per cent } \\
15.8 \\
14.8 \\
13.9 \\
11.0 \\
21.6 \\
11.4 \\
3.6\end{array}$ & $\begin{array}{c}\text { Percent } \\
7.1 \\
13.2 \\
22.5 \\
10.2 \\
17.0 \\
8.9 \\
3.7\end{array}$ \\
\hline
\end{tabular}

\section{FUNCTIONS OF THE DIFFERENT FOOD MATERIALS}

258. Water. Water in food serves the same purpose as that which the animal drinks. It is, therefore, not considered as having any value. A feed that is moist may be more palatable than a dry feed. Water is the food that all animals require in largest quantities. It not only serves as the carrier of food in the animal body, but makes up the larger part of the body itself. The great importance of an abundance of good water for all animals is not always sufficiently considered.

259. Ash. The ash is chiefly of use in the formation of bone, but it doubtless has other important functions. A mixed feed usually contains sufficient ash, so that the ash has been ignored in calculating the value of feeds. Possibly, when we learn more ahout it, we will give more attention to it.

There are several cases in which the deficiency in ash is very important. The rereals in general and Indian corn in particular are deficient in ash. The legumes rontain high percentages of ash. Hogs fed on corn alone are likely to be very weak-boned. To correct the shortage 
of ash, they may be fed lime or wood-ashes, tankage or bone meal. If fed on corn and alfalfa, the shortage of ash is made up. Hens always require more lime than is contained in their feeds. The striking reason for this is seen when we compare the composition of eggs and corn. The eggs contain 12.2 per cent ash, the corn only 1.5 per cent. Hens are, therefore, commonly fed cracked oyster shells. Possibly one reason why the Kentucky horses have such good bones and feet is the high ash content of the feed that they get in the blue-grass pastures. It is very probable that the ash food of colts in the cornbelt should be given more consideration.

260. Protein. There are a large number of compounds that are classed together as protein. The gluten of wheat, lean meat, white of egg, the curd of milk, are protein compounds. All the protein compounds contain nitrogen. They are not all of equal feeding value.

The protein compounds make the basis of the bones, muscles and other tissues. They are also used, to a limited extent, as fuel to keep the body warm, but this is not their important function.

261. Fats. The fats in food serve the same purpose to the animal as do the carbodydrates. Fat is more effective than carbohydrate. It has been found that if a pound of fat is burned it gives 2.25 times as much energy as is furnished by burning a pound of carbohydrates. We therefore say that a pound of fat is approximately equivalent to 2.25 pounds of carbohydrates as food for a seed or as food for animals.

262. Carbohydrates. The starch and sugar compounds are the most important carbohydrates. Crude fiber or 
cellulose is a less efficient one. ${ }^{1}$ The carbohydrates form only a very small proportion of the body, - less than 1 per cent. Their chief function is to furnish energy for keeping the body warm and for movement. They are also important as a source of animal fat. The animal can change the carbohydrates to fat, and the body fat can be used as a source of energy when the food does not supply enough. The fat is a reserve source of energy.

\section{DIGESTIBILITY OF FEEDS}

263. Feeds Differ in Digestibility. No feed can be entirely digested. A part of the food material is never taken up by the body. The proportion of digestible material is quite different in different food materials. The proportion also varies with the kind of animal and with the particular individual. The ruminants, or cud-chewing animals, cattle, sheep and goats, all digest their food about equally well. Horses digest 11 to 12 per cent less than ruminants.

Average Digestibility for Ruminants

\begin{tabular}{|c|c|c|c|c|}
\hline & Protein & $\begin{array}{l}\text { Crude } \\
\text { fiber }\end{array}$ & $\begin{array}{l}\text { Nitrogen- } \\
\text { free } \\
\text { extract }\end{array}$ & Fat \\
\hline 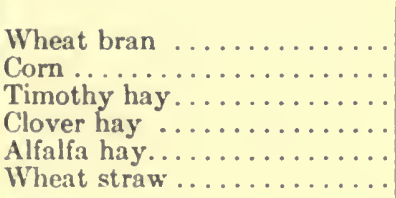 & $\begin{array}{l}\text { Percent } \\
79 \\
76 \\
48 \\
62 \\
74 \\
11\end{array}$ & $\begin{array}{l}\text { Per cent } \\
22 \\
58 \\
52 \\
49 \\
43 \\
52\end{array}$ & $\begin{array}{l}\text { Per cent } \\
69 \\
93 \\
63 \\
69 \\
66 \\
38\end{array}$ & $\begin{array}{l}\text { Per cent } \\
68 \\
86 \\
57 \\
62 \\
39 \\
31\end{array}$ \\
\hline
\end{tabular}

'The carbohydrates contain carbon, hydrogen and oxygen. The proportions of hydrogen and oxygen are the same as in water $\left(\mathrm{H}_{2} \mathrm{O}\right)$, hence the name. That is, there are two atoms of hydrogen for each atom of oxygen. There are a large nu'nber of different carbohydrate compounds. The composition of atarch is $\mathrm{C}_{6} \mathrm{H}_{12} \mathrm{O}_{4,}$, of cane sugar $\mathrm{C}_{12} \mathrm{H}_{22} \mathrm{O}_{11}$, of grape sugar or ghucose $\mathrm{C}_{6} \mathrm{H}_{12} \mathrm{O}_{6}$. 
It will be seen that 79 per cent of the protein of wheat bran is digested, while 21 per cent passes through the animal unused. But only 11 per cent of the protein in wheat straw is digested. In general, the grain feeds are much more digestible than roughage-hay, straw, etc.

264. Digestible Nutrients in Feeds. By combining the above table with the table of compositions, we can get the amount of digestible material in each food:

\begin{tabular}{|c|c|c|c|c|}
\hline & Protein & $\begin{array}{l}\text { Crude } \\
\text { fiber }\end{array}$ & $\begin{array}{l}\text { Nitrogen- } \\
\text { free } \\
\text { extract }\end{array}$ & Fat \\
\hline $\begin{array}{l}\text { Composition of corn. . . . . . } \\
\text { Digestibility of corn } \ldots \ldots \ldots\end{array}$ & $\begin{array}{c}\text { Percent } \\
10.3 \\
76.0\end{array}$ & $\begin{array}{c}\text { Per cent } \\
2.2 \\
5 S .0\end{array}$ & $\begin{array}{c}\text { Per cent } \\
70.4 \\
93.0\end{array}$ & $\begin{array}{c}\text { Percent } \\
5.0 \\
86.0\end{array}$ \\
\hline Digestible nutrients in corn... . & 7.8 & 1.2 & 65.5 & 4.3 \\
\hline
\end{tabular}

Corn contains 10.3 per cent of protein, of which 76 per cent is digestible; or it contains 7.8 per cent of digestible protein. Similarly, it contains 1.2 per cent of digestible crude fiber and 65.5 per cent of nitrogen-free extract. These are added to give the amount of digestible carbohydrates, or 66.7 per cent. This is the manner in which Appendix table 8 is calculated.

265. Effect of Time of Harvesting on Digestibility. When hay ripens, much of the food material is transferred to the seeds. These seeds are so small and hard that they are not digested by the animal, hence, hay that is cut when ripe is not very digestible. (Fig. 90.) In the case of corn, the seed is digestible, hence the total product averages higher in digestibility as the plant ripens. The total product is also much more per acre. Therefore, we cut hay plants when green and grain crops when ripe. 


\section{MAINTENANCE AND PRODUCTIVE VALUES}

The animal uses the energy of its food for three purposes: For maintenance of life, for external work, and for fattening or the production of eggs, milk, or other product.

266. Maintenance. Even while at rest, many parts of the body are active. To maintain this activity, requires a supply of energy in the feed. If feed is withheld, the animal will use the substance of its own body to keep up the life functions. When the supply in the body is no longer available, the animal will die.

267. External Work. When the demands for maintenance are met, the animal may use the extra energy for carrying loads. The energy stored in the body may also be used for this purpose, but if this is done the animal gets poor in flesh.

268. Production. An excess of food above the maintenance requirement may also be used to store up meat or fat in the body, or for the formation of wool, milk or eggs.

269. Energy Lost in Digestion and in Production. Formerly, it was considered that the maintenance values of the feeds were in proportion to the total digestible nutrients. We still compare foods on this basis in computing balanced rations, because we do not have any better means of comparison at the present time.

Armsby ${ }^{1}$ has studied a few feeds in order to determine how much of the energy is available for maintenance and for production. For these investigations he constructed 1 Pennsylvania Bulletin No. 84 
an apparatus known as the respiration calorimeter. There are only three such instruments in the world, and this is the only one used for experiments on domestic animals. The apparatus is so constructed as to enable the operator to keep an exact debit and credit account with the animal. He determines the weight, chemical composition and energy content of the feed given. He then determines the amount of matter and of energy carried off in the visible waste products, and in the gases carried off by the lungs and skin and by fermentation in the digestive tract. Finally, the apparatus is a calorimeter,-i. e., a heat measurer,-by means of which the amount of heat given off by the animal is determined. Having thus obtained a complete record of the income and outgo from the body, it is easy to compute whether the animal has stored up any of the matter and energy of the feed, or whether he has been living in part on his own tissues.

In this manner, Armsby found that the following amounts of the energy of the food were set free in the animal, or were digested:

Timothy hay 44 per cent

Corn meal 77 per cent

These figures represent the percentage of digestibility of these particular samples of feed which the particular animal used. With different lots of feed or a different animal, they might be different.

A part of this material is lost in digestion, so that it is not all available for maintenance. The percentages of the digested materials available for maintenance were:

Timothy hay $\quad \ldots \ldots \ldots \ldots \ldots \ldots \ldots \ldots$.

Corn meal .................. 78 per cent 
Or 28 per cent (44 per cent of 63 per cent) of the original energy value of timothy hay is available for maintaining the animal, and 60 per cent of the energy of corn is thus available.

When the animal stores up the energy of these feeds, there is a still further loss. The percentages of the digestible material that could be stored up were:

Timothy hay ..................... 33 per cent

Corn meal ....................... 53 per cent

Or 15 per cent of the energy of timothy was available for storing up in the body and 41 per cent of the energy of corn was thus available.

These results agree with common experience, that timothy hay is fairly good for maintaining a steer, but is very unsatisfactory for fattening. They may be summarized as follows:

Values per 100 Pounds Containing 15 Per Cent Water

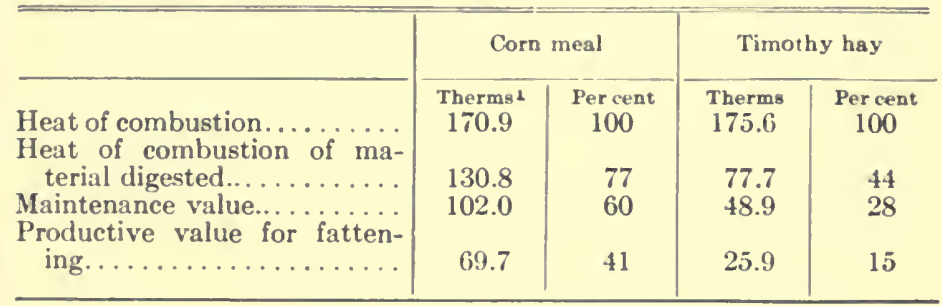

270. Comparison of Concentrates and Roughage. It will be seen, in the above comparison, that the losses in each step are much greater for timothy than for corn meal. It will not do to compare the values of these two

1 A Therm is a thousand large calories. That is the amount of heat necessary to raise the temperature of 1,000 Kilograms of water $1^{\circ} \mathrm{Cen}$ tigrade. The unit here need not be considered, as only the comparative figures or percentages are important. 
feeds on the basis of digestible material. This would make the timothy worth 58 per cent as much as the corn meal, whereas it is worth only 48 per cent as much for maintenance, and 37 per cent as much for production.

Clover hay contains about two-thirds as much digestible material as oats, but the clover is much harder to digest. Zuntz calculated that the net nutrients, after allowing for the amount used in chewing and digestion, were about one-third as much for clover hay as for oats. ${ }^{1}$ Similar results have been obtained by other investigators. (See Appendix, Table 9.)

We thus see that it is not safe to compare hay feeds with grain feeds on the basis of digestible nutrients. It is approximately correct to compare feeds of the same class on this basis. Hay may be compared with hay and one grain with another without very great errors.

\section{BALANCED RATIONS}

271. Food Requirements of Different Animals. Animals must be fed very differently for different kinds of work. The kind of feed that is adapted to producing wool, eggs, milk or muscular work is not the kind that is best adapted to fattening an animal or to maintaining it when not producing. If we expect a product that contains a high percentage of protein, as milk or eggs, we must feed a protein diet; otherwise, it will be absolutely impossible to keep up the production.

Very many experiments have been conducted in order to determine what is the best proportion of the different 'Farmers' Bulletin No. 170, p. 41. 
nutrients, and how much of each is required. These experiments have been summarized in feeding standards.

272. Carbohydrate Equivalent of Fat. As we have previously learned, the fats and carbohydrates have the same function, but fat is 2.25 times as effective as carbohydrates. One hundred pounds of corn contains 66.7 pounds of digestible carbohydrates and 4.3 pounds of digestible fat. This is equivalent to 76.4 pounds $(66.7+4.3 \times$ 2.25) of carbohydrates. This is the manner in which the carbohydrate column in Appendix, Table 8, is calculated.

273. Nutritive Ratio. One hundred pounds of corn contains 7.9 pounds of digestible protein and the equivalent of 76.4 pounds of digestible carbohydrates, or it contains one pound of digestible protein for each 9.7 pounds of carbohydrates. This is called the nutritive ratio.

274. Feeding Standards. The commonly accepted feeding standards are given in Appendix, Table 7. As an example, if we look up the standard for horses heavily worked, we will see that the standard ration is 26 pounds of dry matter, 17.6 pounds of which is digestible, containing 2.5 pounds of protein and 15.1 pounds of carbohydrates. This gives a nutritive ratio of $1: 6$. If the horse weighs over 1,000 pounds, the ration would be increased proportionately.

275. Computing Rations. " To illustrate how these tables may be used, we will examine a system of feeding cows, which is followed in some diary sections. 'Timothy hay constitutes the greater part of the coarse fodder. Oats are ahout the only grain grown. Corn is purchased and A Adapted from Cornell Bulletin . No. 154 , by J. I. Stone 
ground with the oats, in about equal weights, to make "chop," which is fed with the hay. The cows will not vary greatly from 1,000 pounds live weight. While these cows are in full flow of milk in the spring before pasture is ready, they are fed about 20 pounds of hay and 8 pounds of chop per day. Turning to the table, we find that 20 pounds of hay, 4 pounds of oats and 4 pounds of corn contain digestible nutrients as follows:

\begin{tabular}{r|c|c|c|c|c}
\hline \hline & $\begin{array}{c}\text { Dry } \\
\text { matter }\end{array}$ & Protein & $\begin{array}{c}\text { C. H. and } \\
\text { fat }\end{array}$ & Total & $\begin{array}{c}\text { Nutritive } \\
\text { ratio }\end{array}$ \\
\hline 20 pounds hay..... & 17.36 & .560 & 9.320 & 9.880 & \\
4 pounds oats ... & 3.56 & .368 & 2.272 & 2.640 & \\
4 pounds corn.... & 3.56 & .316 & 3.056 & 3.372 & \\
Total. ....... & 24.48 & $\overline{1.244}$ & $\overline{14.648}$ & 15.892 & $1: 11.8$ \\
Wolff's Standard... & 24.00 & 2.5 & 13.4 & 15.9 & $1: 5.4$ \\
\hline
\end{tabular}

Upon comparison of the nutrients furnished by this ration with Wolff's standard, as given in the table, it is discovered that, while the dry matter and total nutrients are not far out of the way, the protein is much too small, the carbohydrates and fat are somewhat too great, while the nutritive ratio is far too wide.

This result might readily have been foreseen had we paused a moment to note the nutritive ration of each of the three foods entering into the ration. They are, timothy hay, $1: 16.6$; oats $1: 6.2$; corn, $1: 9.7$. Neither of them is as narrow as the standard, and it is impossible to combine them into a ration that is approximately balanced. As corn is a purchased product, the natural suggestion is that the corn should be replaced by some food having a high proportion of protein, or, in other words, a very 
narrow nutritive ratio. Consulting the table, it is found that among such are linseed meal, cottonseed meal, gluten feed, malt sprouts, buckwheat middlings, etc. For the northeastern states, buckwheat middlings is usually reasonable in price. It is suggested to substitute it for corn in the ration. Again, taking the figures from the table, we have:

\begin{tabular}{|c|c|c|c|c|}
\hline & $\begin{array}{c}\text { Dry } \\
\text { matter }\end{array}$ & Protein & C. H. and & Total \\
\hline 20 pounds timothy hay...... & 17.36 & .560 & 9.320 & 9.880 \\
\hline 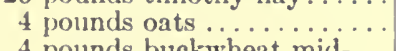 & 3.56 & .368 & 2.272 & 2.640 \\
\hline dlings $\ldots \ldots \ldots \ldots \ldots \ldots$ & 3.49 & .880 & 1.824 & 2.704 \\
\hline 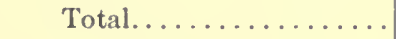 & $2+.41$ & 1.808 & 13.416 & $15.22 t$ \\
\hline
\end{tabular}

Nutritive ratio, $1: 7.4$

While this ration is much improved over the previous one and will produce a more abundant flow of milk, it is still too wide to produce the best results. If the timothy hay is reduced two pounds, and two pounds of cottonseed meal put in its place, we get:

\begin{tabular}{|c|c|c|c|c|}
\hline & $\begin{array}{l}\text { Dry } \\
\text { matter }\end{array}$ & Protein & C. H. and & Total \\
\hline 18 pounds timothy hay...... & 15.62 & .504 & 8.388 & 8.892 \\
\hline 4 pounds oats ...................... & 3.56 & .368 & 2.272 & 2.640 \\
\hline $\begin{array}{l}4 \text { pounds buckwhent mid- } \\
\text { dlings } \ldots \ldots \ldots \ldots \ldots \ldots\end{array}$ & 349 & .880 & 1.824 & 2.704 \\
\hline 2 pounds cottonseed meal... & 1.84 & .744 & .888 & 1.632 \\
\hline Total... & 24.51 & 2.496 & 13.372 & 15.868 \\
\hline
\end{tabular}

Nutritive ratio, $1: 5.4$ 
This ration corresponds very closely to the standard, and, while the purchase of the cottonseed meal will add somewhat to the expense, still it is the experience of careful feeders that the increased production will pay.

The same result may be obtained by using other feeding stuffs having a narrow nutritive ratio. The question is likely to he raised, which of the various feeding-stuffs offered in the market may be used most economically in supplementing the home-grown foods to produce a balanced ration? This question is best answered by formulating properly balanced rations containing each of the foods under consideration; and, by assigning the actual market value per pound to each of the constituents of the ration, its cost is readily ascertanied and the cheapest may be selected.

276. Another Method of Computing Rations. The total amounts of nutrients required are sometimes used instead of the above method. Cows require about 24 pounds of dry matter per day per 1,000 pounds of live weight. At least 16 pounds of this should be digestible, and 2 to 2.5 pounds should be digestible protein. This is an easier method of calculating but gives practically the same results. It will be seen that only the last one of the three calculated rations in the preceding section meets this standard.

277. Cautions in Using Balanced Rations. The nutritive ratio may vary somewhat from the standard without serious results. Cows have produced good results on feeds with a ratio as wide as $1: \mathrm{S}$, but most successful clairymen use a ration with more protein. ${ }^{1}$ One pound of proJirginia Bulletin Noo. 169. 
tein for 6 to 7 pounds of carbohydrates is usually better.

It is possible to prepare a ration that will fit the standard and yet not be satisfactory. The standards are guides but not laws. They do not do away with skill in feeding, but will help in deciding on the feeds. One might feed cows all cottonseed meal for the grain ration, but the cows would not do well. Cottonseed meal is constipating in effect. Wheat bran and oil meal are laxative. One can prepare a ration for horses including clover hay, but clover is not the best for horses. This is why it sells for less than timothy. It is better than timothy for feeding cows.

Not all cows of the same size will need the same amount of feed. Some may be harder to keep and some may be giving larger quantities of milk. It is well to balance the ration and then adapt it to the different animals by feeding larger or smaller quantities.

278. Comfort of Animals. Armsby has found that a steer produces 30 to 50 per cent more heat when standing up than when lying down. This heat, of course, comes from burning up of food. Evidently it will pay to provide comfortable quarters and a good bed for animals. This does not mean that the barn should be warm. Fattening animals produce so much heat in digestion that they are more comfortable in cool stables. All feeding experiments with steers have shown cool. dry stables to be best. Cows need warmer quarters, as they are not fattening, and are not using so much carbohydrates. Regularity in feeding is also of great importanre.

279. Relation of the Individuality of the Animal to Profits. Some animals will not produce profitable results. 
no matter how they are fed. It is necessary to have a good animal, well fed, for good returns. Either condition without the other will result in a financial loss.

280. Condimental Foods. Numerous condimental stock foods are advertised. These are guaranteed to make hens lay, cows give milk, or pigs get fat. The basis of nearly all of these is some common feed. Other ingredients are salt, fenugreek, gentian, ginger, sulfates of iron, and sola, pepper, sulfur, charcoal, etc. Substances that counteract each other are sometimes included.

Some of these substances have a tonic effect and may at times be needed, but it is rarely desirable for animals or men to take tonics all the time. If we desire to feed any of these, they can be purchased at a drug store and at a very small fraction of the cost in patent foods.

Numerous feeding experiments have failed to show the value of these feeds. If one desires to use them, he had best get a prescription from a veterinarian, or write to the State Experiment Station, and save his money for'some useful purpose.

\section{QUESTIONS AND PROBLEMS}

1. Why does a person need more clothing while sleeping than while sitting?

2. How much protein would there be in the milk of a cow that gives 30 pounds per day? What other needs would the cow have for protein? About how much would, therefore, be required per day?

3 . What would be the nutritive ratio of the following ration? (See Appendix, Table 8.)

Corn silage .................40 pounds

Clover hay ........................ pounds

Corn meal....................... 3 pounds

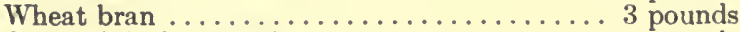

Oil meal (old process) ............ 1 pound 
How many pounds of dry matter would it contain? How many pounds of digestible material? Would it be a good ration? Will it satisfy the conditions given in paragraph 276 ?

4. A man has corn stalks, clover hay and corn. He can buy wheat bran at $\$ 22$ per ton, gluten meal at $\$ 20$, and oil meal at $\$ 30$. Which ones shall he buy in order to make a balanced ration for cows? What will the nutritive ratio of the feed be? Will this ration satisfy the conditions in paragraph 276 ?

5. Prepare a ration for fattening steers that weigh 1,200 pounds each, using alfalfa and corn.

6. Prepare a ration for a farm horse at moderate work, using timothy hay, corn and oats.

7. Prepare a similar ration for a farm horse while at rest.

8. How much of each feed will it take for a year for a team of horses each weighing 1,500 pounds, supposing that the team works half of the time?

9. What are the common feeds of your region? For what purpose are the animals fed? Prepare rations for them.

10. Find out exactly what some persons are feeding. Find the nutritive ratio, total dry matter and digestible matter in the ration, and see whether it agrees with the standards. If not, how may it be improved?

\section{COLLATERAL READING}

Farmers' Bulletins Nos.:

22. The Feeding of Farm Animals.

170. Principles of Horse-Feeding.

186. Rations for Laying Hens, pp. 23-27.

202. Home-Grown Protein for Dairy ('ows, pp. 22-24.

222. Weight Per Quart of Feeds, pp. 17, 18.

Grain Rations, pp. 18, 19.

Horse Feeding, pp. 17-24.

Silage for Cows, pp. 31, 32.

225. Mineral Matter for Chickens, pp. 26, 27.

233. Condimental Feeds, pp. 21, 22.

Methods of Feeding Skimmed Milk to ('alves, pp. 22-25.

Animal Food for Ducklings, pp. 2.5, 26.

251. Cheap Dairy Rations, pp. 26-30.

Cottonseed Meal for Hogs, pp. 30-32. 
262. Beet Molasses and Pulp, pp. 19-23.

Feed Lots, pp. 2:-25.

276. Tankage and Bone Meal for Hogs, pp. 21-24.

Grinding Corn for Hogs, p. 25.

305. Laxative Properties of Wheat Bran, pp. 16, 17.

Emmer as Feed, pp. 17-19.

Roots and Cabbages for Stock Food, Pp. 19-24.

316. Horse-Feeding Tests, pp. 22-30.

Supplements to Corn for Hogs-'Tankage for IIogs, pp. 25-30.

320. Protein Content for Forage Crops, pp. 13-17.

329. Importance of Mineral Matter in Feeds, pp. 22-26.

346. The Computations of Rations for Farm Animals by the Use of Energy Values

Human Foods.

74. Milk as Food.

85. Fish as Food.

93. Sugar as Food.

121. Legumes as Food.

128. Eggs and Their Uses as Food.

142. Principles of Nutrition and Nutritive Value of Food.

182. Poultry as Food.

249. Cereal Breakfast Foods.

298. The Food Value of Corn and Corn Products.

281. Corn as Food for Man, pp. 18-22.

Feeds and Feeding, by IV. A. Henry.

The Feeding of Animals, by W $\mathrm{H}$ Jordan.

Cyclopedia of American Agriculture, Vol. III, pp. 56-119. 


\section{CHAPTER XI}

\section{THE HORSE}

281. Substitution of Horse Power for Man Power. In 1830 , it required an average of three hours of time for each bushel of wheat grown; in 1896 it required ten minutes. In 1850 it took four and one-half hours to grow, harvest and shell a bushel of corn; in 1899, it required forty-one minutes. ${ }^{1}$ This saving of time has been due to the substitution of machinery drawn by horses for human labor. According to the last census (1900), we had twentyone million horses in the United States, or one horse to each four persons. In Great Britain there is one horse to twenty-six persons; in France, one to ten; in Germany, one to thirteen.

In America, we have gone farthest in the substitution of brute force for human energy. Human labor is the most expensive of all labor, even if the person be a slave. One horse, properly directed can do the work of ten men, while his "board and room" on the farm cost about half as much as that of one man. The farm boy who drives a good four-horse team to a gang-plow is doing as much work as if the horses were replaced by forty men. In the West, the farmer is no longer content to use a single team in his farm operations when it is possible to use larger numbers. The four-horse gang-plow and fourhorse harrow have rapidly replaced the two-horse machines.

'Yearbook United States I)partinent of Agriculture, 1897, page 600 
There are many parts of the country in which similar methods can be used. In this way one man can do the work that would require many men under European conditions. Because we make our labor count for so much, we are able to make farming an attractive business, rather than a peasant's drudgery.

We have wasted our lumber, our coal, our soil fertility; but, we have used human energy more economically than it has ever been used before. The older nations are saving of everything but human time. As a nation, we are extremely saving of time, but wasteful of everything else. Perhaps each hemisphere should learn economy from the other.

The extensive use of horses has had a great influence on our national character and history. The boy who trains a colt gets a lot of training himself. It makes a man expand as he learns to manage a spirited horse. The less intelligent races cannot manage horses well. They prefer the thick-skinned, stubborn ass.

282. Types of Horses. There are five chief purposes for which horses are raised: (1) For speed, as trotters and runners; (2) for sport or for fashion; (3) for family driving; (4) for farm purposes; (5) for draft purposes, usually in cities.

The first three classes are usually of much the same general type. They are smaller and more active than draft horses. There are no breeds of horses that are especially adapted for farm use. The best draft horses for city use are usually too heavy for general farm purposes. The horses of the other classes are usually too light.

Too little attention has been given to farm horses. 
Very often the chief reason why a horse is a farm horse is because he is not one that would bring a good price in the city. As labor becomes more expensive, we can afford to give more attention to the character of the farm horses.

283. Draft Horses and Horses for Speed. There are many contrasts between draft horses and those that are kept for speed. Many of these characters are contradictory, so that we can never hope to have horses that are best for both speed and draft purposes. The following table shows some of the contrasts:

\section{Trotter or roadster}

General appearance: high, lithe, active.

Head and neck long, graceful, thin, light, little crest.

Large nostrils.

Eyes full, bright, intelligent.

Long sloping shoulders.

Front feet near together.

Body deep up and down.

Flank high.

Legs rather long.

Hoofs smooth, polished, no creases; not too flat.

Fetlock joint not too short nor too erect.

\section{Draft Horse}

Low, massive, plump.

Short, thick, broad neck, with a crest.

Same.

Same.

More upright.

Far apart.

Round, with well-arched ribs.

Not so high; should not be "wasp-waisted."

Not so long; not over half height. Same, except flatter and larger.

May be shorter and more erect.

The hind legs of a greyhound and jack-rabbit have powerful muscles. The front legs are relatively weak. This is the case in all quadrupeds that are noted for speed. It has been said that the chief use of the trotter's front feet is to get out of the way of the hind ones. About all that they have to do is to support the front part of the body. An animal that is desired for speed needs good 
lungs, good digestive organs and organs of circulation, with powerful hind legs and other parts developed as they are necessary to support these needs. The trotter does not want to be loaded with extra head and neck, nor size of front quarters. He needs large nostrils, because

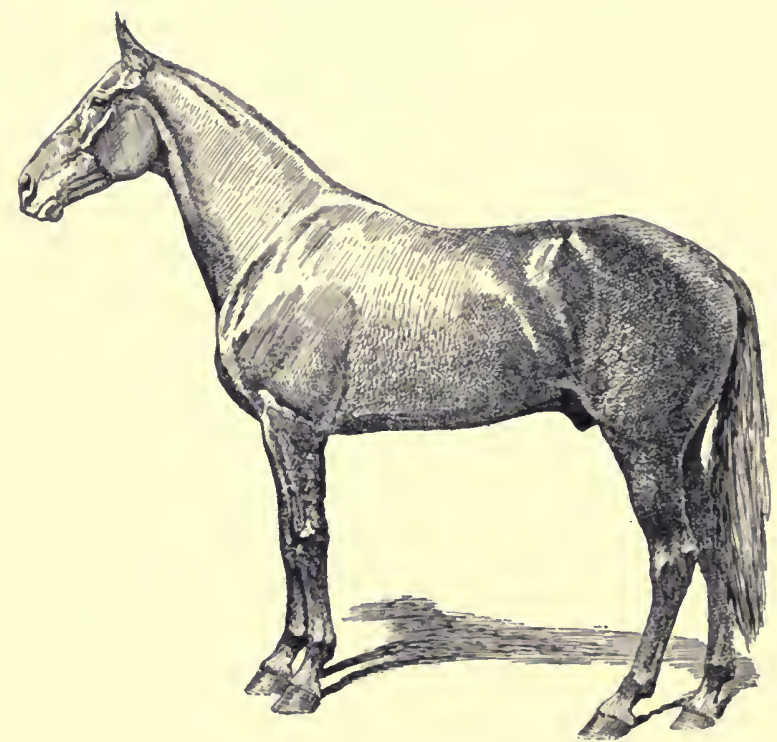

Fig. 146. The speed type. Dan Patch, 1:55t

they must allow the passage of abundant air. His shoulders need to be sloping, flank high, legs rather long, all for the same reason-to give freedom for long steps. The front feet need to be near together to correspond with the body and to be out of the way of the hind feet. The body should be deep up and down to make room for the powerful lungs. If the fetlock joint is too short and erect, the jar when the foot strikes the ground is too 
great; the longer, less erect one gives chance for more spring.

The whole conformation of the typical draft horse is heavier. The greyhound build gives way to the round

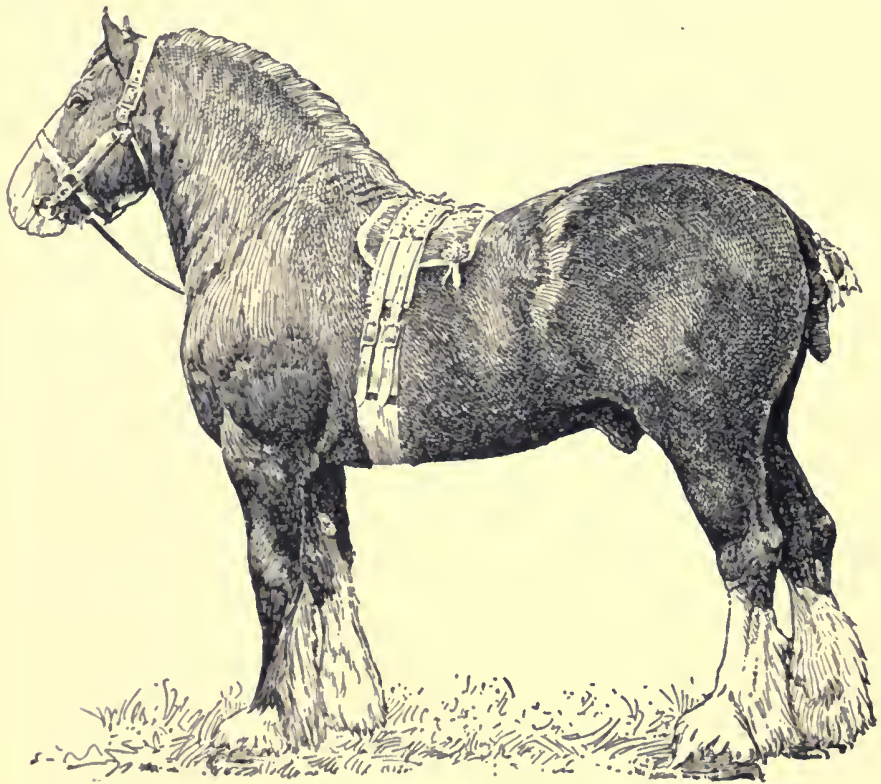

Fia. 147. The draft type. Baron's Pride, a noted Clydesdale

body, shorter legs with powerful but slower-moving muscles. He does not need a body adapted to the long steps of the trotter. While his hind legs are the stronger, yet he uses his front legs very much in pulling, therefore the entire front quarters have a good development. The broad breast puts the front feet far apart.

Horses weighing 1,500 to 1,600 pounds are classed as light draft horses. Those weighing 1,600 to 1,700 are 
medium weight. Those weighing over 1,700 pounds are heavy draft horses. The heavier horses bring the higher prices.

When a team cannot pull a load, it is the feet that give way. 'They slip because there is not friction enough to hold them. This explains why a horse can pull more when a man is on his back. It gives him more weight so that he can stick to the ground. On dirt roads, horses "dig their toes in," so as to help in getting a foothold. On pavements they cannot do this, but the sharp shoes help. This is one reason why such heavy draft horses are desired in cities. One way to make a horse heavier is to have the whiffletree low down, so that the tugs pull down on the horse's back and hold him to the ground. If the doubletree is put under the wagon tongue, the team can pull a heavier load. In his book on "The Horse," Professor Roberts tells of an experiment with a 1,500pound horse hitched to a post and pulling on a dynamometer (a large spring balance). When the whiffletree was fastened six inches from the ground, the horse pulled 2,310 pounds; when two feet from the ground, 1,980 pounds; when three feet, 1,732 pounds. This is one reason why horses draw a walking plow easier when the tugs are rather short, but here there is another reason in that the short tugs lessen the friction on the bottom of the furrow.

With a driving horse, the load is light, so the whiffletree should be high. Then, in clriving, we do not want any additional weight on the horse's feet, because rapid driving is very hard on the feet and legs. Perhaps some of you have seen hansom cabs in cities. These are two- 
wheeled and the driver sits at the back, so that the thills pull up on the horse and support part of his weight. They are awkward-looking vehicles, but they save the horse's feet very much when driving on hard pavements.

Appearance is the chief point in coach horses, and such horses are larger and plumper than roadsters. Coach horses have high knee action and travel up and down rather than reaching out, as do trotters.

284. Breeds of Horses. The leading breeds of horses in America are as follows:

\section{Draft Breeds-}

Percherons, from France.

Clydesdales, from scotland

Belgian, from Belgium. .

English Shire, from England

Suffolk Punch from England.
Carriage and Coach Horses-

Hackneys, from England.

French coach

German coach.

\section{Roadster Breeds-}

American trotter, developed in America.

American saddle horse, developed in America,-mostly in Kentucky and Virginia.

English Thoroughbred, developed in England.

Something of the relative popularity of the different breeds is indicated by the number of stallions in Wisconsin in 1908. There were 267 either pure blood or grade Percherons; 43 Clydesdales; 28 Belgians; 26 Shire; 115 Trotters; 73 of all other known breeds. ${ }^{1}$

The Percheron is seen to be the favorite draft breed. 'This breed is considered to be superior' to other draft breeds in bone and feet, and in style and finish. They are said to he more active and more intelligent than the 
other draft breeds. Their color is quite variable. Black and mottled gray seem to be the most popular.

The Clydesdales are said to lack in circumference of body and in weight. They are also said to have poorer constitutions. They have a heavy growth of hair on the fetlocks. This distinguishes them from all other breeds except the Shire. It is also one of the objections to the breed. Drivers do not like this mass of hair, which gets clogged with mud on our poor roads. The English Shires are nearly like the Clydesdales. They might be called English Clydesdales.

The Belgians and Clydesdales have not been so popular in America as the Percherons. The chief reason is probably that the latter breed is more active.

The Hackneys and coach horses are not much raised in America, although they seem to be gaining ground. Our coach horses are usually large grades that contain considerable of the trotting blood.

The American trotter and American saddler are the distinctly American productions. They are the best of their kind in the world. From selected members of these breeds, the Department of Agriculture is now trying to develop a breed of American carriage horses. The Indian pony and bronco are also distinctly American. They have many valuable characteristics, but they seem destined to extinction.

285. How to Tell the Age of a Horse. One of the first questions that is always asked when one wishes to buy a horse is the age. This is because the age is so important in determining the value. Every farmer should be able to estimate the age of a horse. 
The teeth usually furnish a fairly accurate indication of the age until a horse is ten years old. Horses have two sets of teeth, the first or temporary set and the second or permanent set, similar to the two sets in human beings. There are three pairs of nippers or front teeth on each jaw. These are the ones that indicate the age. The new teeth have deep cups or indentations in their centers. As the teeth are used, they wear down and the cups disappear. It takes about three years for a cup to disappear from the nippers of the permanent set of teeth on the lower jaw, and about twice as long on the upper jaw.

Colt.-A colt gets its center nippers at about one week of age. By the time it is a month old, it has all three pairs. The cups in these teeth gradually disappear and are usually gone at about two years. (Fig. 148.) At about two years and nine months, the center pair of permanent

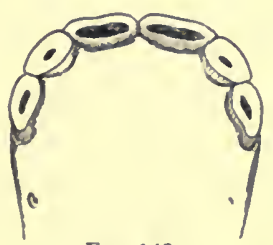

FIg. 149.

The lower nippers at

three years of age teeth appear. Up to this time, the general

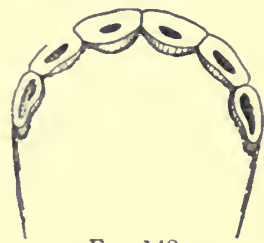

FIG. 148 .

The lower nippers of a colt two years old appearance of the colt is usually as accurate an indication of its age as are the teeth.

Three Years.-At three years, the permanent pair of center nippers will be up and ready for use. They will have deep cups, and are much larger than the temporary teeth. If the colt is a male, two small tusks will appear at about this time. Mares do not have tusks (Fig. 149).

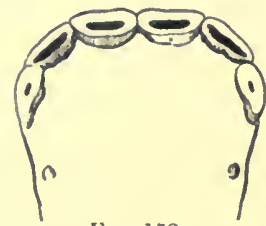

Fio. 150 .

The lower nippers at four years of age 


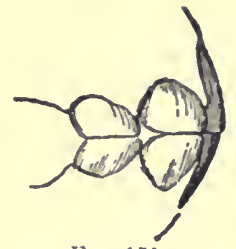

Frg. 151 .

Side view at four

years of age

Four Years.-At four years, the second pair of permanent nippers are just ready for use, and the cups in the center pair are about one-third gone. (Fig. 150.)

Five Years.-At five years, the third pair of nippers are present and just meet. The cups of the center pair are about two-thirds gone. (Fig. 152.)

Six Years.-The cups in the center pair have disappeared, or nearly so. Those in the second pair are about twothirds gone. The third pair are up and in full use.

Seven Years.-At seven years, the cups are gone from the second pair of nippers. There is then a notch in the upper tooth where it overlaps the lower one. (Fig. 156.)

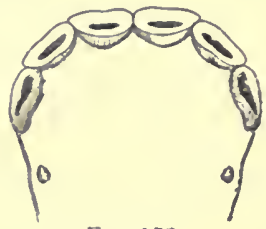

Fig. 152.

Lower nippers at five years

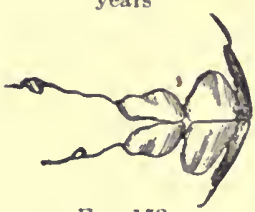

Frg. 153.

Side view at five years

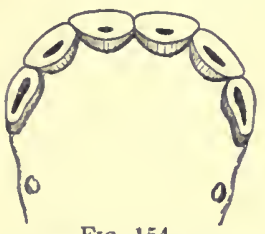

Fig. 154 .

Lower nippers at six years

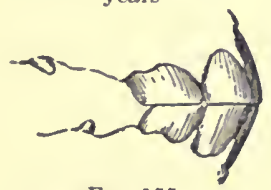

Frg. 155.

Side view at six years

Eight Years.-At eight years, the cups are gone from all the nippers of the lower jaw. We then look at the nippers of the upper jaw. The cups will then be present in the center pair, but will not be deep. (Fig. 157.)

Nine Years. - The cups in the center pair of nippers of the upper jaw have disappeared, but they are still present in the second pair, and fairly deep in the third pair.

Ten Years.-The cups are gone from 
the second pair on the upper jaw, but are still present in the third pair.

Old Horses.-The cups in the teeth usually all disappear at about eleven years. After this, the shape and direction of the teeth give some indication of age. Notice the angles at which the teeth meet in Figs. 151, 153, 156 and 159. The shapes of the end of the teeth also change. Compare Figs. 148, 154, 157, and 158. In very old horses, white hairs usually appear around the nose, eyes and elsewhere. The backbone is likely to be curved downward,

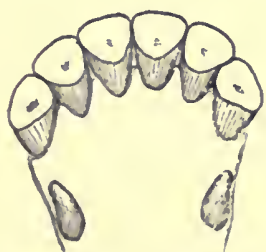

Fig. 158.

Lower nippers of an old horse

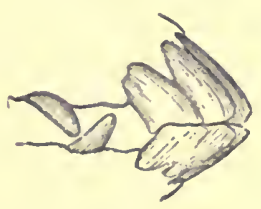

Fic. 1.59.

Side view of nippers of an old horse and the animal does

not stand squarely on its legs. The age of a

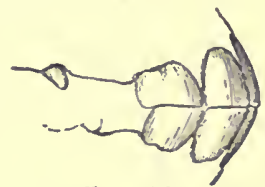

Fig. 156.

Seven years old

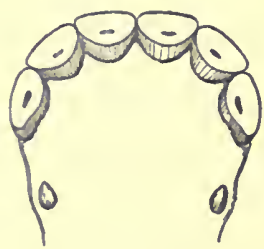

FIg. 157.

Lower nippers at

eight years horse that is over twelve is usually less important than the condition. The vigor and activity are then of more importance than the years.

Irregularities in Tecth.- Some horses do not wear their teeth as fast as others, so that they may have an irregular mouth. Horses that have dense, hard bones and hoofs sometimes appear younger than they are.

286. Care of Horses. There is space here to call attention to only a few points that may be of use on the farm. A fundamental principle that is often forgotten when feeding horses is that the horse's stomach is small, - unlike that of a 
cow or sheep. The horse cannot use as much bulky food as a cow. Farm horses are quite commonly fed too much hay, particularly if they are used on the road. The driving horse should not have so much hay as is fed to the farm team. When teams are regularly working, it is best to feed them only about one-fourth of the day's ration in the morning and one-fourth at noon, and feed half the ration at night, when they have time to eat and digest it. If a horse is not warm, it is better to water before feeding. The water then passes on to the intestines and makes room for the feed in the stomach. If a horse is very warm, it should not be watered or fed until it cools off.

Dusty Hay is one of the worst things for horses. It is the chief cause of heaves. Clover is much worse than timothy in this respect. Timothy is always to be preferred for horses, while clover is better for cows or sheep. If dusty hay must be fed, it should be sprinkled before feeding. Usually, it will pay to buy good hay for the horses and make some other use of that which is dusty.

Care of the Legs. - When a team comes in with muddy legs, they should be rubbed down or washed, particularly in cold weather. Horses, as well as men, can get rheumatism. In general, it is well to devote more time to the legs, even if the back is neglected.

Bits.-When the bits are colder than freezing, they should be warmed by putting them in water, even freezing water, or by taking them into a warm room. It is not the direct effect of cold that hurts, but the frosty bit freezes to the tongue and mouth and may tear the skin. If one doubts this, he should touch the tip of his tongue 
to $a$ piece of iron that is colder than freezing. He will probably never forget the experience.

Sore Shoulders.-Many farm horses suffer with sore shoulders. This can nearly always be prevented. The collar should fit. It should be kept clean. The shoulders should be washed in salt water at noon and evening if there is danger of sore shoulders. Sometimes a collar that fitted early in the season ceases to fit when the horse gets thinner.

There are a few points that are often discussed under the head of cruelty to animals, and that are not always understood.

Clipping.-Driving horses sometimes have their hair clipped in the winter. Clipping of horses can do no harm; in fact, it is a positive comfort, provided the horses are well blanketed. I notice the athletes who run in the winter wear only the thinnest clothing, and run with bare legs when the thermometer stands below zero. They are warm enough while running, and the moment they stop they are covered with overcoats and blankets. So with a clipped horse; he is more comfortable while going. The only danger is that he will not be well blanketed when he stops. A livery horse should not be clipped, because some of the promiscuous drivers will let him suffer; but a nice carriage horse that is always well cared for is not harmed.

Blinders that come close to the head are very objectionable, but those that stand out from the head do no harm. It is frequently desirable to have some shield that will keep the horse from watching every move of the driver.

Over-check.-The purpose of the "over-check" is to raise 
the nose of a trotter, so that in a race the air will have a straighter course from the nostrils to his lungs. When fractions of a second decide the race, this is important. We have copied this kind of check-rein from the racetrack. It is not at all suited to ordinary driving, but if not too tight it is not so serious.

Docked Tails.-Many city persons desire that their driving horses have docked tails. This practice is probably no more painful to the horse than is dehorning to a cow, but the latter practice is humane when we consider how much hooking it eliminates. The usefulness of the practice justifies it. Once in a long time, a horse is docked because it uses its tail to hold the lines while it runs away, but this is not common. Perhaps the greatest harm to a docked horse comes when it is no longer a "high stepper," and takes its place on some peddler's wagon, where it becomes a feeding-place for flies.

The important point is not this particular example, but the point of view that is back of it all. The primitive idea of beauty seems to be a distorted body. The savage paints his body, wears rings in his ears and nose, and carves out various other improvements. There was a time when men spent much time in training trees into odd shapes, or trimmed them into grotesque forms. A remnant of the same idea of beauty leads men to trim dogs' ears to the desired shape, and to the docking of horses' tails. Some day we will come to appreciate the beauty of a tree that grows in its natural shape, the beauty and symmetry of a whole horse, with its full, flowing mane and tail. It is a hopeful sign that few men who drive their own horses think the bobtail is beautiful. 
It is admired mostly by those who deal with horses secondhand.

287. Training Horses. Because of the high esteem in which the horse is held, we are likely to over-estimate his intelligence. When we consider the matter without sentiment, we must admit that the horse is a rather stupid animal. The horse appears to have little affection for men or other animals, and cares little for our admiration. The dog will do almost anything to please his master, and is always keenly appreciative of a word of commendation. These emotions are of the greatest importance in training dogs. but we must not expect them to have much value in training horses.

The horse seems to have very limited reason,-much more limited than that of a dog. On the other hand, the horse has a remarkable memory. If a horse is conquered by ropes or straps, he does not seem to understand that he could run away when these are removed. If he is tripped with a rope at the same time that he feels the pull on the bit, he seems to remember the fall ever after and to associate it with a pull on the bit.

Since a horse has such a good memory and so little reason, we should use extreme care in training him so that each step will go all right. A single runaway may be remembered forever, and spoil the horse. We should, therefore, take no chances, and should trust the horse as little as possible.

A horse should be trained to stand still while being harnessed and hitched up, and until the word to start is given. If this training is not given when the colt is first used, it will be very hard to acquire later. 
Very few words or signals should be used, and these should always be used to mean exactly the same thing, and the command should be carried out. Whoa should always mean to stop; it should not mean to go slowly or to get ready to stop. Steady is the word to use if we wish to go more slowly. Back should always mean to move backwards. Many drivers use it to mean to stop. A horse should never be allowed to start without the spoken word. If getting into the wagon is the signal for starting, we should not blame the horse if he starts before we are all ready. $\mathrm{He}$ is obeying our command if he starts as soon as he hears the step on the wagon. If we wiggle the lines to make him start, we must not blame him for starting when we pick up the lines. Such words as whoa-back are impossible commands. While I was writing one of these chapters, a man who was cultivating in the garden under my window, gave the following command: Come here! Where are you going! Whoa-back! Get up there! Whoa! Whoa! The horse merely stepped around on a few more vegetables.

The word should precede any severe pull on the lines, as the command should precede the punishment for disobedience. Some persons pull on the lines when they want a horse to go faster. The team that ran away and ran harder the more it was held in, but that stopped when the pulling ceased, was trained in this manner.

288. Rules of the Road. When two vehicles meet, each one should turn to the right, and give more than half of the road. If one of the vehicles has a heavy load and cannot readily turn out, the lighter one should go around. The heavy load should stop if the passing is difficult. 
If one desires to pass a vehicle going in the same direction, he should turn to the left. Courtesy demands that the slower-moving vehicle turn to the right to aid in passing; however, the law does not require this in most states.

When crossing streets in cities, one should turn corners as indicated in Fig. 160. That is, one remains close to the curb if this keeps him on the right side of the street $(b)$. But, when making a turn as in $a$, the street is crossed before the turn is made. This avoids collisions.

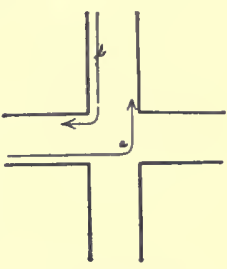

Fig. 160.

Correct method of turning street corners when driving in a city.

\section{QUESTIONS}

1. How long since horse-power began to be used generally in seeding grain? In corn-planting? In harvesting and mowing? In binding grain? In carrying bundles? In raking? In cutting corn? In lifting hay from wagons to stacks? (Ask some of the older farmers.)

2. Are there any farm operations in your county in which more horses per man are now used than were formerly used? In what other operations can the number of horses per man be profitably increased?

3. How has the number of horses per man changed during the past thirty years? (See Appendix, Table 16.)

4. What breeds of horses are kept in your county? Which breeds are most numerous?

5. How many commands or other words does a well-trained dog understand? How many does a cat understand? A horse?

6. Which will a horse obey more quickly, a word or a touch? Will he move quieker if told to "get over," or if slapped?

7. Where is a horse's knee joint? Which way does it bend? Where is the hock joint? Which way does it bend?

8. Can a horse sleep when standing?

9. What does it indicate if a horse rests one of his front feet? One of his hind feet?

10. How are the legs plaeed when a horse lies down? How does a horse get up? How does a cow get up? 
11. When a horse starts after standing, what foot does he put forward first? What foot moves next? When he trots, do the feet on the same side move together, or do lefts and rights go together? What is the order in paeing?

12. What is meant by "forging" or "over-reaching"?

13. What does it mean to say that a horse is $\mathbf{1 6}$ hands?

14. Why do low-wheeled wagons pull harder than high-wheeled ones? Under what conditions are low wheels desirable? When are high wheels preferable?

15. Why does a plow draw easier when the tugs are short?

\section{LABORATORY EXERCISES}

69. Age of Horses.

Practice telling the age of horses by their teeth, page 308 .

\section{Proportions of the Horse.}

Materials.-Two or more horses. Measure, prepared as follows: A piece of board 18 inches long and two inches wide is nailed at right angles to a similar piece four feet long. Mark off the long piece in one-inch lengths, beginning at the inside. Strap an ordinary carpenter's square so that it moves freely on the stick. (Fig. 161.)

Take the following measurements of two or more horses (see Fig. 162 for method of measuring):

1. Length of head, from tip of lips to top of poll $(a-b) \ldots \ldots \ldots \ldots \ldots \ldots \ldots \ldots \ldots \ldots \ldots \ldots \ldots \ldots \ldots$

2. Length of the neek, from top of withers to poll $(a-c) \ldots \ldots \ldots \ldots \ldots \ldots \ldots \ldots \ldots \ldots \ldots \ldots \ldots \ldots \ldots$

3. Height of the shoulder, from the top of the withers to the point of the elbow $(c-d) \ldots$

4. Depth of the boxly, from the middle of the abdomen to the middle of the back $(f-g)$.

5. Width of the bolly, from one side to the other. .

6. Length of the body, from point of elbow to buttock $(d-k) \ldots \ldots \ldots \ldots \ldots \ldots \ldots \ldots$

7. Height at withers ( $c$ to ground)..........

8. Height at rump ( $h$ to ground) $\ldots \ldots \ldots \ldots \ldots$

9. "Daylight" under body ( $m$ to ground) 
If the horse has good proportions, measurements $1,2,3,4$ and 5 will be nearly the same. Measurements 6,7 , and 8 will be nearly equal, and will each be two and one-half times the length of the head. If

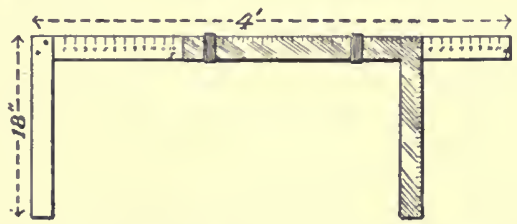

FIG. 161. Instrument for measuring horses. Four feet long and eighteen inches wide. (II. W. Harper.)

the horse is a draft horse, the "daylight" under the body (measurement 9) should not be over half the height. If a roadster, it should be over half the height.

71. Score Card for Horses. (Adapted from M. W. Harper.)

Materials.-One or more horses. Each student to fill out the score eard for one or more horses.

The object of a seore card is to aid one in making a systematic ex-

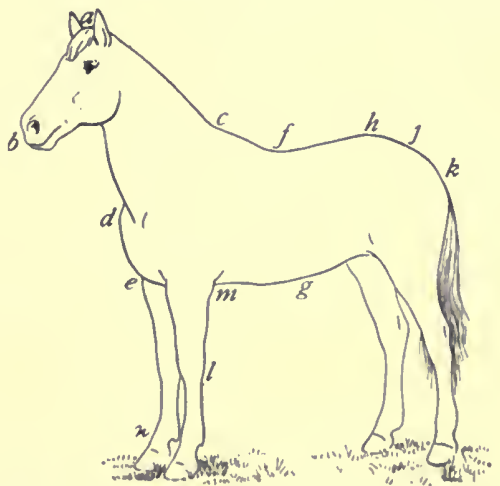

Fro. 162 A well-proportioned horse: $a$, poll; $b$, lips; $c$, withers or shoulder tops: $d$, point of elbow; $e$, chest; $f$, back: $g$, abdomen; $h$, hips; $j$, rump; $k$, buttock; $l$, knee; $n$, fetlock joint.

amination. There are so many points to be considered in judging any animal that one who has not had many years of experience will omit some if he does not have a list of them. 
Score Card for Horses

Scale of points

General Appearance: Draft 45; Driving 47.

Age.-Estimated ..... years........

Actual. ........... years.

Height.—Estimated ........hands......

Actual ................

Weight.-Estimated . . . . . pounds....

Actual ............ pounds....

Form.-For draft, low, massive, symmetrical; for driving, high, lithe, indicative of extreme activity

Quality.-Skin and hair fine...........

Color.-According to breed............

Action.-Step, sinooth, quick, long: trot, rapid, straight, regular..............

Attitude.-Members vertical ............

Temperament.-Lively, pleasant

Head and Neck: Draft 5, Driving 6 .......

Head.-Lean; length, two-fifths height of withers; width of forehead, more than one-third length of head. For driving, smaller, earried higher and more hori-

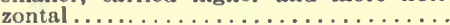

Muzzle.-Fine; nostrils large; lips thin;

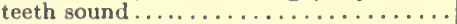

Eyes.-Full, bright and intelligent........

Ears.-Short, clean, fine, directed forward;

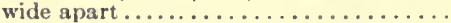

Neck.-Pyranidal, muscled; throat clean, fine; windpipe large. For draft, neck shorter, thicker, more horizontal .......

Forequarters: Draft, 19; driving, 19.

Shoulders.-Long; point of shoulder to point of withers equals length of head. For draft, shorter and more upright...

Knees.-Clean cut, wide, deep, strongly supported.....................

Canons.- Vertical, 9 to 10 inches long. lean, wide; tendons well attached. For

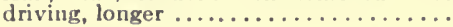

Fetlocks.-Wide, thick, clean, free from

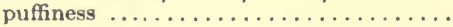

Pasterns.-Angle $45^{\circ}$, fetlock to ground, 7 to 8 inches. For driving, long, sloping. For draft, short, more upright........

Feet.-Round, even size, horn dark-colored, dense; sole concave; bars strong; frog large, elastic; heel vertical, one-half length of toe.....................

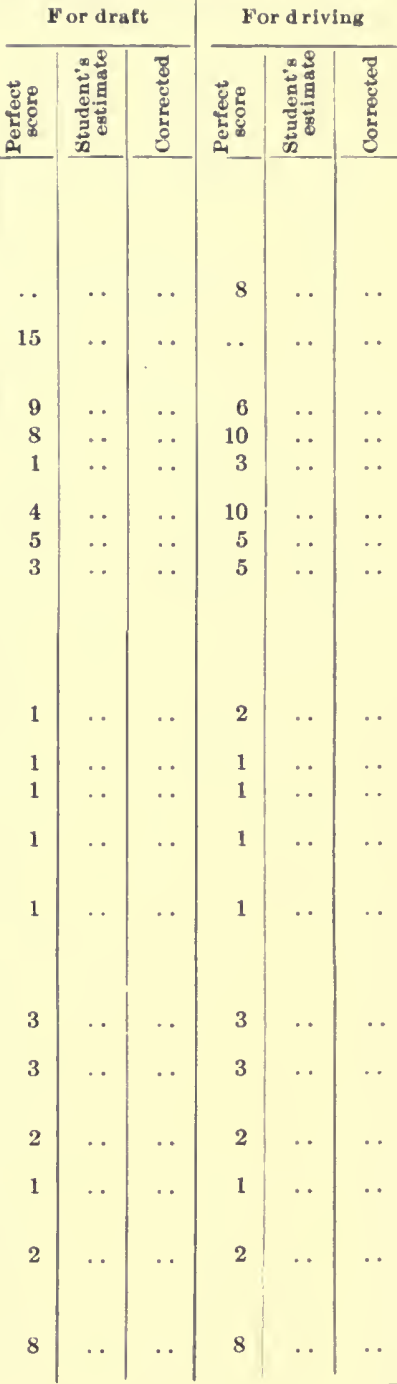


Score Card for Horses, continued

\begin{tabular}{|c|c|c|c|c|c|c|}
\hline \multirow[b]{2}{*}{ Scale of points } & \multicolumn{3}{|c|}{ For draft } & \multicolumn{3}{|c|}{ For driving } \\
\hline & 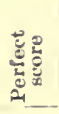 & 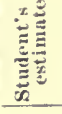 & 苞 & 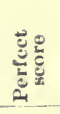 & 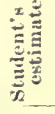 & $\frac{0}{0}$ \\
\hline \\
\hline $\begin{array}{l}\text { Chest in general.-Figh, long. For draft, } \\
\text { wide, half height of horse. For driving, } \\
\text { higher } \ldots \ldots \ldots \ldots \ldots \ldots \ldots \ldots \ldots \ldots \ldots \ldots \ldots\end{array}$ & 3 & $\cdots$ & $\cdots$ & 3 & $\cdots$ & - \\
\hline Withers.-Clearly defined for driving .... & 0 & $\cdots$ & . & 1 & . & . \\
\hline $\begin{array}{l}\text { Breast, - For driving, high, projecting. For } \\
\text { draft, broad and muscular............. }\end{array}$ & 1 & $\cdots$ & $\cdots$ & 1 & $\cdots$ & $\cdots$ \\
\hline Ribs.- - Long, round curvature, ......... & 2 & . & $\cdots$ & 1 & . & $\cdots$ \\
\hline 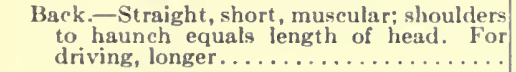 & 2 & . & . & 1 & $\ldots$ & \\
\hline Loin -Wide, short, thick, strongly joined & & & & & $\theta$ & \\
\hline 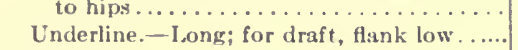 & 1 & $\cdots$ & $\cdots$ & 1 & $\cdots$ & $\cdots$ \\
\hline \multirow{3}{*}{\multicolumn{7}{|c|}{ 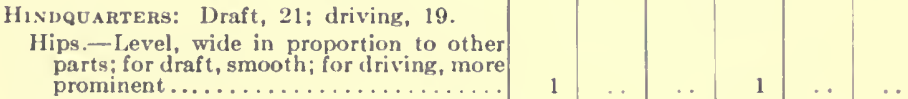 }} \\
\hline & & & & & & \\
\hline & & & & & & \\
\hline Tail.-Set and carried high: long, full, fine. & 1 & $\cdots$ & $\cdots$ & 1 & . & - \\
\hline $\begin{array}{l}\text { Thighs.-For driving, long. For draft, } \\
\text { shorter, more horizontal, muscular... }\end{array}$ & 3 & $\cdots$ & . & 3 & $\cdots$ & $\cdots$ \\
\hline 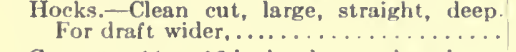 & 6 & .. & . & 4 & $\cdots$ & . \\
\hline $\begin{array}{l}\text { Canons, }-11 \text { to } 12 \text { inches long, otherwise as } \\
\text { for front legs } \ldots \ldots \ldots \ldots \ldots \ldots \ldots \ldots \ldots\end{array}$ & 2 & $\cdots$ & $\cdots$ & 2 & $\cdots$ & $\cdots$ \\
\hline Fetlocks, - As above ............. & 1 & $\cdots$ & . & 1 & . & . \\
\hline Pasterns. - As above; angle, $60^{\circ} \ldots \ldots \ldots$. & 2 & $\cdots$ & . & 2 & $\cdots$ & . \\
\hline $\begin{array}{l}\text { Feet.-Compared with above, more oval, } \\
\text { more concave; heels higher, more sep- } \\
\text { arated; walls more vertieal } \ldots \ldots \ldots \ldots \text {. }\end{array}$ & 5 & $\because$ & $\because$ & 5 & $\cdots$ & $\because$ \\
\hline Total & 100 & $\ldots$ & . & 100 & .. & . \\
\hline
\end{tabular}

\section{COLLATERAL READING}

Market Classes of Horses, Bureau of Auimal Industry, Bulletin No 37. 'The P'reservation of Our Native 'Types of Horses, Bureau of Animal Industry, Circular No. 137.

The Horse, by I. P. Roberts.

'Types and Breeds of Farm Animals, by C. S. Plumb, pp. 1-166. Cyclopedia of Ameriean Agrieulture, Vol. III, pp. 415-510.

For references on feeding, see page 299. 


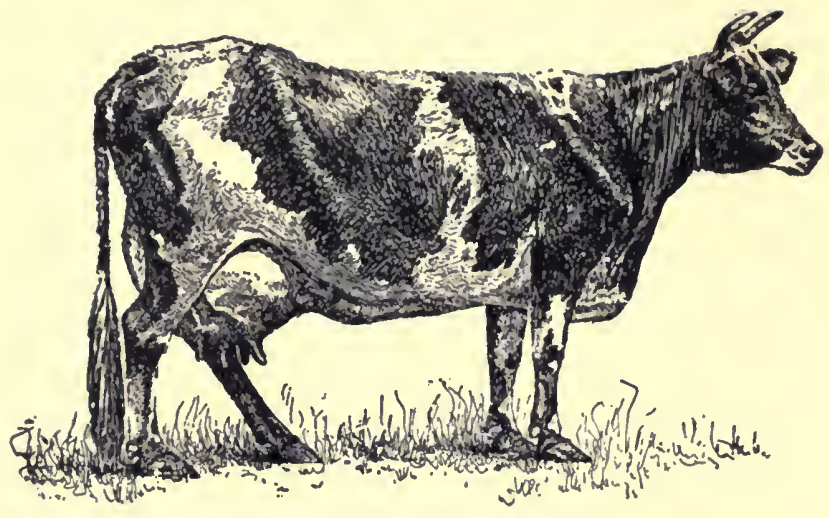

Fig. 163. The dairy type. A Holstein cow

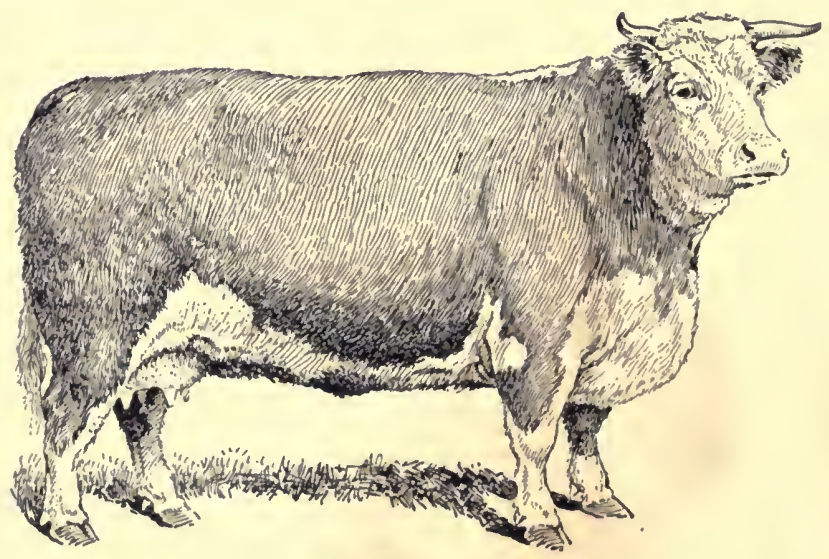

FIg. 164. The beef type. A Hereford cow 


\section{CHAPTER XII}

\section{CATTLE}

289. Forms of Beef and Dairy Cattle. Just as there are two distinct types of horses, the roadster and the draft horse, so there are two distinct types of cattle,the dairy and the beef breeds. In both cases, there are many common animals that do not belong to either class. As a horse cannot be best for both speed and draft purposes, so a cow cannot excel for both meat and milk. A few cattle are bred for both purposes. These are called dual-purpose breeds, but none of these breeds is extensively raised, as they cannot compete with either the dairy or the beef breeds. The effort to develop a great dual-purpose breed must always fail. The following table gives some of the contrasts between the beef and the dairy form:

Form............Wedge-shaped.

Beef

Head................ Small, long, narrow.

Eyes Bright, prominent.

Muzzle Mouth and nostrils large.

Neck ............ Fine, medium length, thin.

Shoulders.........Thin, lean, bony.

Baek .............. Crooked.

Ioin (back) ......... Not fleshy.

Flank ............... High.

Thighs.............. Thin.

Udder and milk veins. Large, prominent. Skin and hair....... Soft, pliable.

Rectangular.

Small, but thicker.

Same.

Same.

Short, thick.

Heavy, well-fleshed, wide between front legs, wide on top just behind shoulders.

Straight

Broad, thick, fleshy.

Low.

Full, heavy.

Not prominent.

Same. 
Both types of animals need good digestion, good lungs and good circulation. These are indicated by large abdomen, well-developed chest, soft, pliable skin, and general vigorous appearance.

The dairy animal is wedge-shaped. In Fig. 163 the top and bottom lines approach each other in the forepart of the body. If viewed from above, the side lines also approach. The beef animal has a much better development of the fore-quarters. The top and bottom lines are parallel. The animal is shaped like a brick set on edge. The neck, shoulders and thighs of a dairy cow are thin and lean. Her loin is also lean. Her hip and tail bones are prominent. If she used her food in developing these parts, it would be at the expense of milk-production. But all these parts need to be well developed in a beef animal. The highest-priced cuts of meat come from the loin. The back should, therefore, be broad and full. The thighs and shoulders should be full and heavy. The dairy animal needs a large udder and large milk-veins that extend from the udder about half way along the abdomen and there enter it. If these veins are large, they indicate a large flow of blood from the udder. This is necessary if much milk is to be produced.

290. Care of Beef and Dairy Cattle. Beef and dairy rattle require very different care, so much so that men in dairy regions rarely know how to handle beef cattle, and the few dairymen in beef-producing regions usually do not know how to eare for dairy animals. Dairy animals need to be warmly housed in well-ventilated barns, and need much attention. Beef animals require much less attention. Careful experiments by Armsby and the 
experience of feeders indicate that fattening steers do better in dry, open sheds, that are well bedded, than in warm barns. In general, fat animals do not need so warm quarters as do lean ones. The feed requirements are also quite different. (See Appendix, Table 7.)

291. Breeds of Cattle. The leading breeds of cattle in America are:

Beef Breeds-

Shorthorn, or Durham, from England.

Hereford, from England.

Polled Hereford, developed in the United States.

Aberdeen-Angus, from Scotland.

Galloways, from scotland.

Polled Durham, developed in the United States.

Dual-purpose Breeds-

Shorthorns (milking strains).

Devon, from England.

Red Polled, from England.

Dairy Breeds-

Holstein-Friesian, from Holland.

Jersey, from the Island of Jersey.

Guernsey, from the Island of Guernsey.

Ayrshire, from Scotland.

Dutch Belted, from Holland.

Brown Swiss, from Switzerland.

Shorthorns were one of the first breeds to be widely introduced into the United states. They are more widely distributed than any other breed of cattle. The early introductions were mostly of a dual-purpose type, but there has been a constant development toward better beef qualities and a loss of milking qualities. At the present time there are relatively few dual-purpose Shorthorns. 
Still, the breed ranks above the other beef breeds in milk-production. The desirability of having hornless cattle led to the development of the Polled Durham breed in the United States. Some of these were secured by collecting and breeding hornless Shorthorns that

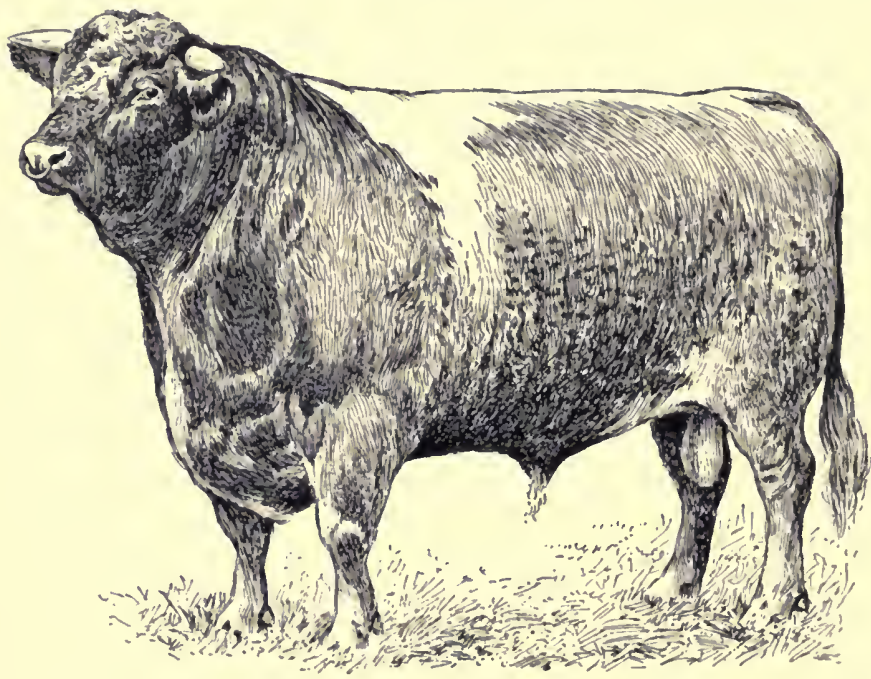

Fig. 165 The beef type. A famous Shorthorn bull

appeared from time' to time as sports. Those that were developed in this way are called "double standarl," because they are eligible to record in both the Shorthorn and the Polled Durham herdbooks. Other's were developed by crossing Shorthorns with native polled cattle. These are single standard, not being eligible to record in the Shorthorn herdbook. Shorthorn cattle are more variable in color than any other breed. They may be pure red, pure white, mixed red and white, or roan. 
Herefords were not much known in the United States until about 1880. They gained their first popularity on the ranges, where they stood the hardship well, and proved to be able to transmit their good qualities to half-breed offspring. Later, they have gained favor because of their early development. Mature animals weigh about the same as Shorthorns, but the calves and yearlings are heavier

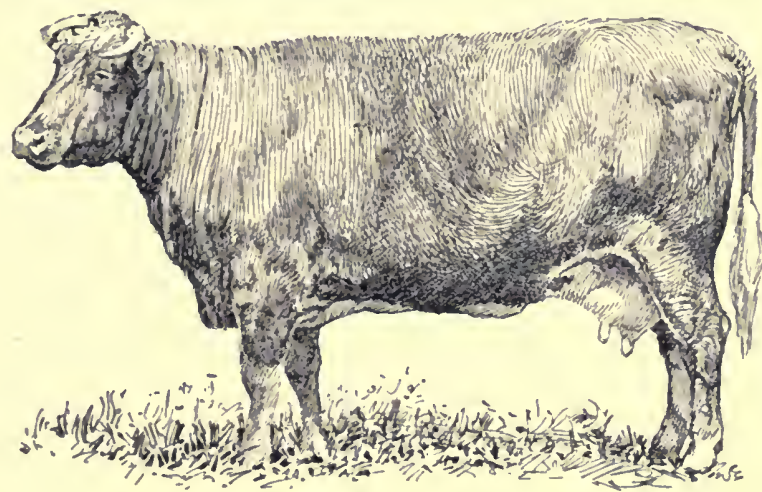

FIg. 166. A typical dual-purpose Shorthorn cow

than Shorthorns. The Herefords are very uniform in color, with white heads and red bodies with white markings.

Aberdeen-Angus cattle attracted little attention in this country until about 1885 . Since that time they have 'ome to be one of the important breeds. They are hornless, and about 95 per cent of the calves are hornless when they are crossed with horned cattle. 'The breed is black and has a smooth coat.

Galloways are another breed of black hornless cattle. They can usually be told from the Angus by their longer hair and coarser bones. During the winter, their long, shaggy coats give a high value to the hides for robes. 
They are good grazing, hardy cattle, a little slower to mature than are the Angus.

There are a considerable number of Red-Polled cattle in the United States, and some Devons and a few Brown Swiss, but none of these breeds has gained the prominent place that is occupied by the preceding ones. The American demand seems to be for either dairy or beef breeds, and not for dual-purpose animals.

Holstein-Friesian cattle are spotted black and white in color, which distinguishes them from most other breeds. They are probably the most widely distributed dairy breed, and are the leading dairy breed in northern Europe and in America. They are larger than the other dairy breeds, and can consume more lough feed. They are the most popular breed for supplying milk for our large cities, because they give more milk than any other breed of cattle. The milk is light in color, and contains a lower percentage of fat than that of some other breeds. But some individuals in the breed give rich milk. The milk is high in per cent of solids not fat. The large size of the Holsteins makes them of more value for beef than are the other dairy breeds. They cannot compete with the regular beef breeds, but their veal calves make a valuable by-product.

The New York Agricultural Experiment Station tested the milk from a large number of animals with the following result:

l'er cent of fat

Holstein-Friesian . . . . . . . . . . . . . . . . 3.4

Ayrshire. . . . . . . . . . . . . . . . . . . . 3.6

Shorthorn ....................... 4.4

Devon $\ldots \ldots \ldots \ldots \ldots \ldots \ldots \ldots \ldots \ldots . . \ldots \ldots$

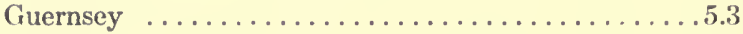

Jersey. . . . . . . . . . . . . . . . . . . . 5.6 
Jersey cattle are usually gray or fawn-colored. They can be distinguished from Guernseys by their black noses. They developed in the little island of Jersey, that is only

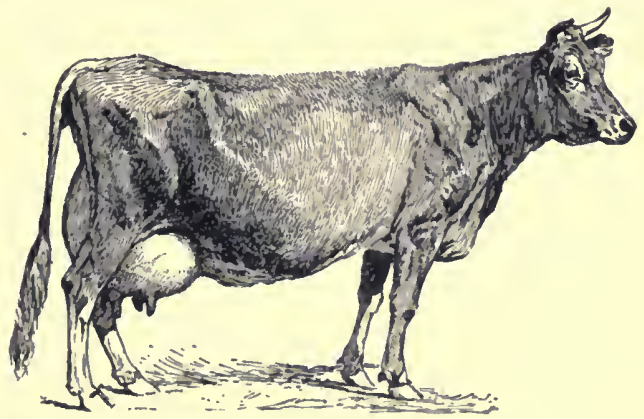

FIG. 167. Jersey cow

eleven miles long and six wide. They are held in high esteem for the richness of their milk. They do not stand exposure and other adverse conditions quite so well as do the Holsteins, and have not been able to compete

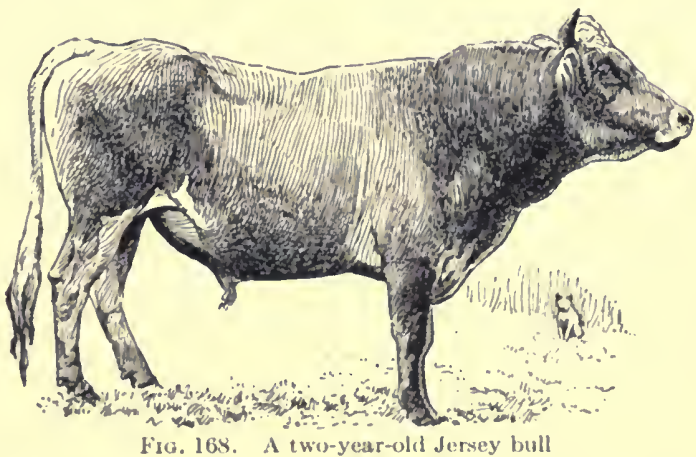

with this breed in milk-production. But they have been able to hold their own where butter is made or where cream is sold. It is the most popular dairy breed in America 
except in the neighborhood of large cities, where the Holsteins outnumber the Jerseys.

Guernsey cattle are similar to the Jerseys in many respects. Like the Jerseys, they have been handicapped by the limited numbers in their original home, so that importations could not be so rapid as has been desired. They are usually yellow or orange in color, with white spots. The nose is flesh-colored, which distinguishes them from the Jerseys. They are slightly larger than the Jerseys. Their friends claim that they give more milk. They are gaining in popularity in America.

Ayrshires developed under more severe climatic conditions, and are very active and hardy. They are not well known in America outside of New York and New England.

292. Pedigrees. The breeders of each breed of purebred stock have organizations for keeping the records of breeding of the individuals and for advertising purposes. Each animal that is born is eligible to recoid in the herdbook, provided both its parents are recorded, and unless disqualified for some defect. A record of an individual, showing the parents, grandparents, etc., as far back as the record has been kept, is called a pedigree. Americans have been foremost in keeping up these books, because we attach so much importance to pedigrees. No herdbooks were kept in Holland until our desire for pedigrees made them necessary. Both Jersey and Holstein herdbooks were first established in the United States.

We have always given more attention to pedigrees than is given in Europe. In this country, no animal is eligible to record unless both parents are recorded. In 
England, an animal that is fifteen-sixteenths Shorthorn is eligible to record. It is very doubtful whether any harm comes of this practice; but it is rather absurd for us to import such animals, when we refuse to record our own high grades with an equal amount of Shorthorn blood.

Any animal that is eligible to record in a herdbook is called a pure-blood or thoroughbred. The latter word used to be applied to a particular type of running horses, but it is now commonly used to mean any pure-bred animal. A cross between a pure-bred animal and common stock is called a grade. If an animal is three-quarters or more of one breed, it is called a high-grade. An animal that is a cross between two pure-bred animals of different breeds is called a cross-bred animal.

293. Value of Pedigrees. Pure-bred animals are valuable, because when bred with common mixed stock they are usually able to impress their characters on the offspring, - they are prepotent. They have been bred to a single type so long that their characters are more firmly fixed, and they are usually able to overcome the less stable characters of common stock. Many grade animals are as good as pure-bred ones except that they are not so likely to transmit their good qualities. (See Mendel's law, page 19.)

Not every animal with a pedigree is worth keeping. The individual should be a good one and should have good ancestors for two or three generations. Previous ancestors are of much less consequence. Too often we have paid high prices for animals simply because they carried a pedigree. A pedigree in itself is merely a recorl of 
parentage. The mere fact that the record is written does not prove that the individual is good.

294. Advanced Registry. One of the most hopeful developments of the system of registry is the taking of performance records. It is not the mere list of ancestors, but their records and the record of the individual, that are of most value. The Holstein-Friesian Association has been most active in this work. Cows are milked for a week or more under the supervision of an official representative of an agricultural experiment station, and the milk is tested for butter-fat. In order to be admitted to advanced registry, a mature cow must give 12 pounds of butter-fat-equivalent to 14 pounds of hutter-per week. A graduated scale is provided for young cows. Provision is also made for yearly records. This system has been of great service in improving and advertising the hreed. One can now look up the advanced registry records of the parents and offspring of an animal. (See Fig. 9.) The highest record thus far is 28 pounds 3 ounces of butter-fat, or nearly 33 pounds of butter, ${ }^{1}$ in one week, made by Colantha 4ths Johanna 1849. 'This is the world's butter record at the present time." Another Holstein cow produced over 15 tons of milk in a year.

The Jersey and Guernsey Associations also have systems of advanced registry.

The principle of performance records should be introduced with other pure-bred stock as rapidly as possible.

1The Holstein-Friesian Association calculates 0.8 of a pound of butterfat as equivalent to a pound of butter. Good butter will not carry 20 per cent of water. The factor 0.857 pounds is nearer correct. That is, add onesixth to the butter-fat to get the butter that it will make. This is the method used above.

${ }^{2}$ The Holstein-Friesian Yearbook, Vol. VIII, p. 320. 
295. Grading Up a Herd. When one begins raising any kind of stock, he can soon develop a good herd from common stock by using a good pure-bred sire of the desired kind. One will soon have high grades that are nearly as productive as pure-bred animals. The use of pure-bred sires should be continued, in order to prevent reversion.

If one has money enough, he may begin with purebred animals. If he has not plenty of capital, it is wiser to begin in the above manner, and then change to purebreds if desired.

\section{CATTLE PRODLCTS}

The most important cattle products are milk, meat, and leather. The by-products are almost innumerable, including fertilizers, combs, hair for plastering, brush handles, buttons, glue, etc.

Chicago is now the greatest beef market in the world. A large number of the beef cattle are raised on the ranges and shipped to the cornbelt to be fattened. But an increasing number are being fattened on the ranges. The art of feeding ('attle so as to secure the best meat-production, and, at the same time,

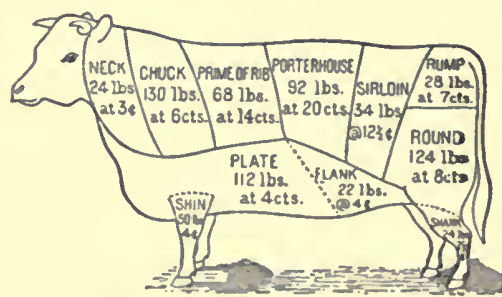

FIG. 169. Comparative prices of the different cuts of beef. Chicago retail dealer's method of cutting. (Farmers Bulletin $\approx 1$.) make a profit, is a highly developed business. The different cuts of beef and their relative values are indicated in Fig. 169. From this we ran see the importance of the shape of the heef type. 
The total value of milk and its products is even more than the value of the beef produced in the United States.

\section{Milk}

296. Composition of Milk. Milk contains much more nutriment than is commonly supposed. A quart of milk contains about the same amount of nutriment as threequarters of a pound of beef. A quart of skimmed milk contains as much nutriment as two-fifths of a pound of beef. Milk is not only a good food, but it is a cheap food as compared with meat and eggs. One hundred pounds of good milk contains about:

87 pounds of water.

4 pounds of fat.

5 pounds of milk sugar.

3.3 pounds of casein and albumen.

0.7 pounds of mineral matter.

297. Clean Milk. Milk is an excellent breeding place for germs of all kinds. It also absorbs odors from the air.

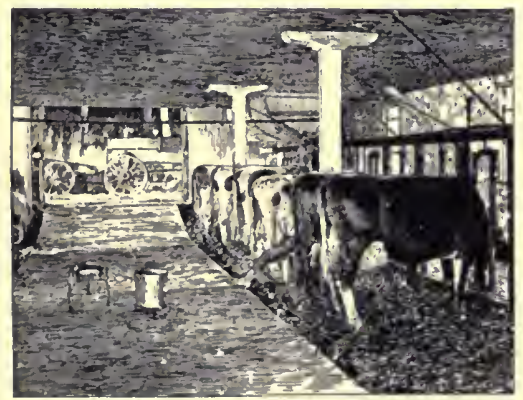

FIG. 170. A clean dairy barn. Note cement floor, tight ceiling, deep gutter, and driveway for hauling out manure.
These facts make it an extremely perishable product. As the demand for milk increases, there is a constantly increasing demand that the milk shall be clean. There are a number of conditions that are essential if milk is to keep sweet and clean: 
The cows must be healthy.

The feed must be good.

The barn must be clean and light, with plenty of windows, smooth walls and ceilings.

The feeding must be done after milking, and operations that stir up dust should not be performed near milking time.

The cows must be clean.

The milker must be a healthy person.

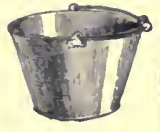

Fig. 171 . Milk pails. Compare the chances for clirt to drop into the different pails.
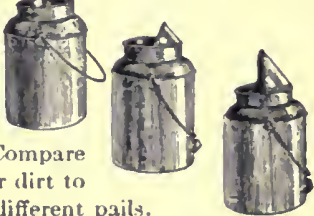

The water-supply must be good. Typhoid fever is often carried from infected wells.

The utensils must all be sterilized with scalding water.

A small-top, hooded milk pail should be used.

As soon as the milk is drawn, it should be cooled so as to check the growth of the bacteria that make it sour.

The milk should be kept sealed and cool until it is used. It may be spoiled after it reaches the consumer just as easily as before. If exposed uncovered in cities, it is more likely to take up disease germs than in the country, because the city dust contains so many germs.

298. Commercial Forms of Milk. In order to kill a large proportion of the bacteria in milk it is often pasteurized, or heated ten to thirty minutes at temperatures of $180^{\circ}$ to $150^{\circ}$ Fahr.; and then quickly cooled. Such milk will keep sweet longer than if not treated, and is safer to drink. It is very much better to have the milk so clean that it will keep until used and he safe without being pasteurized. 
Certified Milk is produced to supply the demand for the highest grade of clean, safe milk. It is produced by special agreement under strict regulations prescribed by milk commissioners. Veterinarians, bacteriologists, and physicians are usually called upon for inspection of the milk and its production and handling.

Standardized Milk is that which has been so mixed as to give a required percentage of fat.

Condensed Milk is formed by evaporating a considerable part of the water. This may be sweetened with cane sugar or be unsweetened; in either case, it is put up in sealed cans, in which it will keep for years if properly put up.

Milk Powder or Milk Flour.-There are several methods of evaporating milk to a powder that is so dry that it will keep; a part of the fat is removed before evaporation. This powder can be shipped in flour barrels, or in other convenient packages. There are now several firms producing this powder. It may be dissolved in water to form a fair quality of milk.

299. Babcock Milk Test. This is one of the best methods of determining the amount of fat in milk. ${ }^{1}$ It is one of the greatest aids. to the development of dairying. It enables the dairyman to determine which are his best cows. It enables the creamery to pay its patrons justly. It has greatly facilitated advanced registry systems. The method of making the test is described in the laboratory exercises.

${ }^{1}$ The Babcock milk test was invented by Dr. S. M. Babcock, of the Wisconsin Agricultural Experiment Station. Dr. Babcock lad it patented, but, in order that it may be furnished at the least possible cost, he receives no royalty from its manfacture. 
300. Dairy Records. Every dairyman should keep records of milk-production of the different cows, in order that he may know which ones pay. Many cows do not pay their board. These are often obscured by the profits that come from the good cows. The opinion of the farmer as to the relative merits of the cows is usually not correct. A spring balance, weighing pounds and tenths of pounds, with a sheet of paper beside it, will enable one to weigh the milk quickly. It may be weighed at every milking, but, if this is too much work, the following method will give a fairly accurate comparison: Weigh the milk for three days at the beginning of each month. The sum of the weights, multiplied by ten will give the

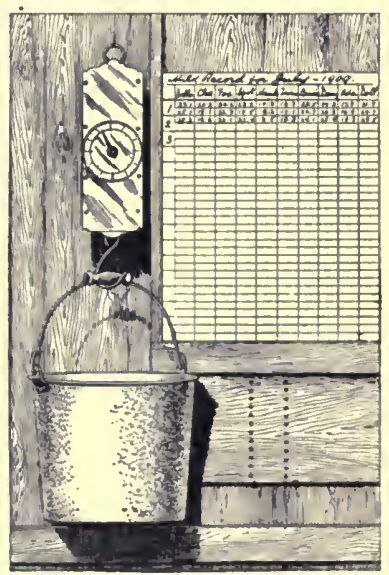

Frg. 172. Weighing the milk to find which cows pay year's production. Take samples from each cow for the Babcock test in the second, fourth and seventh months after the cow freshened. Each time take samples for two days. The average of the three tests will give the approximate per cent of fat.

\section{SOME DISEASES OF CATTISE}

301. Tuberculosis is one of the most serious diseases of cattle. It not only causes great loss in cattle, but is even more serious with hogs that are fed on the milk 
from tuberculous cows. Such milk is dangerous for human food. It is believed that people, especially children, are often infected in this way. Sixty-nine per cent of the cattle that were condemned by government meat-inspectors at slaughter-houses in the United States in 1907, were condemned because of tuberculosis. Of the 105,879 hogs that were condemned, 65,618 were for tuberculosis. Of the 436,161 parts of hog carcasses that were condemned, 364,559 were for tuberculosis. ${ }^{1}$ All these losses are borne by the farmer. The packers have to pay enough less for the live animals, so as to make good the loss of the condemned ones. A far greater loss is caused by the low production and slow growth of diseased animals on the farm.

When tubercle bacteria live in different animals, they become somewhat changed. The bovine and the human forms of tubercle bacteria are slightly different, but they are now believed to be the same species of organism. Cattle inoculated with the human form have been given tuberculosis. Apes, inoculated from cattle, contract the disease as readily as when inoculated with germs from men. ${ }^{2}$ The opinion now generally accepted is that little of the pulmonary tuberculosis in man is due to infection from milk, but that about half of the glandular cases are of the bovine type. By glandular cases is meant the cases of tuberculosis of intestines, bones or other organs, aside from lungs. It is evidently not safe to use cows' milk that contains the germs. The danger is much greater for children than for grown persons. Even though

${ }^{1}$ Report of the Bureau of Animal Industry, 1907, p. 20

${ }^{2}$ Experiment Station Record, Vol. 18, J. 478 
the chances may be small, human life is too valuable to be risked unnecessarily.

The old opinion was that tuberculosis in man or animals was inherited. We now know that it is an infectious disease that is rarely inherited. It is also sometimes attributed to dark, dirty stables, but these are not the cause. A filthy stable can no more produce tuberculosis if the germs are not present, than can a fertile field produce a corn crop if no corn is planted. The disease will spread more rapidly in dark, unsanitary barns, just as corn will yield more on good land. Ten per cent of the cattle that come from the ranges of Nevada, and that never were in barns, are tuberculous. We must distinguish between the germ which is the cause, and the surroundings which favor its growth.

One of the chief sources of the spread of the disease is the creamery. Milk from many herds, some of which are diseased, is mixed at the creamery, and the skimmed milk is returned to the farm for feeding calves or hogs. And these animals are infected. To prevent this loss, the milk must be pasteurized, as is now done in the creameries of Denmark.

The other important source of infection is the purchase of diseased animals. To guard against this, one who has a sound herd should not add animals that are not tuberculin-tested. Even tested animals are not safe if they come from badly diseased herds. One should always buy from a sound herd.

Animals usually do not show signs of the disease until they are in the last stages. Fortunately a method has been found by means of which diseased animals may be 
discovered. This is by the tuberculin test. The temperature of the animal is taken at intervals for a day. Tuberculin is then injected under the skin. If the animal has tuberculosis, the temperature will rise a few degrees during the following day. A number of cautions have to be observed in making the test and interpreting results. The work should be done by a good veterinarian, or by an exceedingly careful and well-trained farmer.

Some persons have feared that tuberculin would produce the disease. It is prepared by allowing tubercle bacteria to grow in a liquid usually containing beef extract. Before it is used, it is twice heated and twice filtered, any one of the four operations being sufficient to remove or kill all germs. No injury comes from its intelligent use.

It is sometimes desirable to keep diseased animals for breeding purposes. The calves are removed as soon as born and all milk is pasteurized before being fed. In this way a healthy herd has often been developed from a diseased one. The two herds must be kept separate at all times. If a large part of a herd is diseased, the animals that do not react are not removed, as they are likely to develop the disease later. This method of developing a sound herd is named the Bang method, after its originator.

302. Milk Fever. One of the serious diseases of dairy cows is milk fever. It attacks the best animals. Formerly, it was the great obstacle in the way of developing superior cows. It has been found that the disease can be easily cured if air is pumped into the teats so as to distend the udder. After each quarter is filled, the teat is tied so as to hold the air in it. The only danger is that bacteria may be introduced into the udder. The apparatus must 
be carefully sterilized. Farmers' Bulletin, No. 206, gives details of the method.

303. Black-Leg. This is a very serious infectious disease caused by a certain bacillus. It is not transmitted by direct contact, but comes from infected soil. Animals that die from it should be burned. The losses from this disease have been very serious and widespread. Vaccination will prevent most of the loss. A vaccine for this purpose is furnished by the United States Department of Agriculture.

304. Texas Fever. One of the most serious obstacles to the development of the live-stock industry in the South is the Texas fever. The direct cause of the disease is a microscopic animal parasite (protozoan) that lives in the blood. But it is not transmitted directly from one animal to another. It lives a part of its life in the body of the cattle tick. Cattle contract it from the ticks and in no other way. The parasite passes a part of its life in the cow and a part in the tick. This is similar to the method in which malaria and yellow fever are transmitted to people by means of mosquitos.

Cattle that are born in the South usually become immune to the disease by infection when calves. When northern cattle are taken South, they almost invariably die with the disease. When southern cattle are driven North, they mark their passage by killing the northern animals with the disease. For many years the southern states have been quarantined for this reason.

Northern cattle, taken South, are sometimes inoculated, so as to produce mild cases and cause immunity. Another method that is now being tried is to eliminate the ticks. 
These spend a part of their life on the ground. By rotating pastures, they may be eliminated. To make this method effective, it must be taken up by states or counties, and these sections would have to establish a quarantine against the surrounding infected area. Details of this subject are given in Farmers' Bulletin No. 258.

\section{QUESTIONS}

1. What are the leading breeds of dairy cattle in your county? What breeds are gaining in numbers? Why are they preferred?

2. What effect does better feed have on the per cent of fat in the milk? Farmers' Bulletin No. 225, p. 18.

3. Do thunderstorms make milk sour? Why does milk sour?

4. If there are creameries or milk stations in the county, on what basis do they pay their patrons? What effect does this have on the breed of cows kept and on the quality of the milk?

5. About how much is the average yield in pounds or quarts per year of the cows of the region? (Obtain opinions of farmers.) How much do some of the best cows produce? How much profit is there on an average cow? On a poor cow? On a superior cow?

6. If beef cattle are raised, what are the leading breeds? Why are they preferred?

7. Are the beef cattle of the section raised in the region or shipped into it for fattening? Why?

8. At what age are the beef cattle usually marketed? Are they marketed at the same age as formerly? If not, why?

9. What are the chief feeds of beef and dairy cattle of the section?

10. Who in your county are raising pure-bred animals of any kind?

\section{LABORATORY EXERCISES}

\section{Score Card for Dairy Cows.}

Materials.-One or more cows. Each student to fill out the score card. The form here given is a slight modification of that used at Cornell University. 


\section{Score Card for Dairy Cows}

Scale of points

\section{Geveral Appearance:}

Weight.-Estimated ..... pounds; actual ..... pounds.. Form.-Wedge-shaped, as viewed from front, side and top..

Form.-Spare, as indicated by prominent joints and clean bone and lack of muscular development along ribs and loins....

Quality.-Hair fine, soft; skin mellow, loose, medium thickness

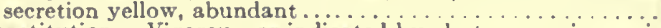

Constitution.-Vigorous, as indicated by alert expression, evidently active vital functions, and general healthy appearance

HEAD AND NECK:

Muzzle-Clean cut; mouth large; nostrils large ........

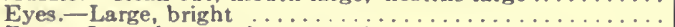

Face.-Lean, long; quiet expression . . . . . . . .

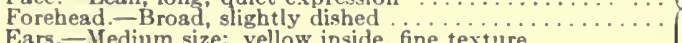

Ears.-.Medium size; yellow inside, fine texture ..............

Neck.-Fine, medium length; throat clean; light dewlap ...)

Fore AND HiNdQuarters:

Withers,-Lean, thin. Shoulders.-Angular, not fleshy......

Hips.-Far apart; not lower than spine....

Rump.-Eong, wide, level ..............

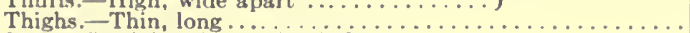

Legs. - Straight, short; shank fine

\section{Bony:}

Chest.-Deep, low; with large girth and broad, well-sprung ribs

Abdomen.-Large, well supported, with moderately high flank

Back.-Lean, straight, chine open. Tail.-Long, slim, with fine

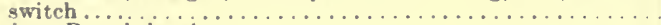

Ioin.-Broad, level.

Mile-Secreting Organs:

Udder.-Large, long, attached high and full behind; extending

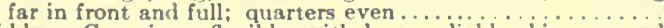

Udder.-Capacious, flexible, with loose, pliable skin, covered

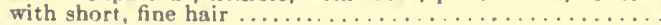

Teats.-Convenient size, evenly placed

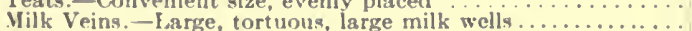

Tolal .......
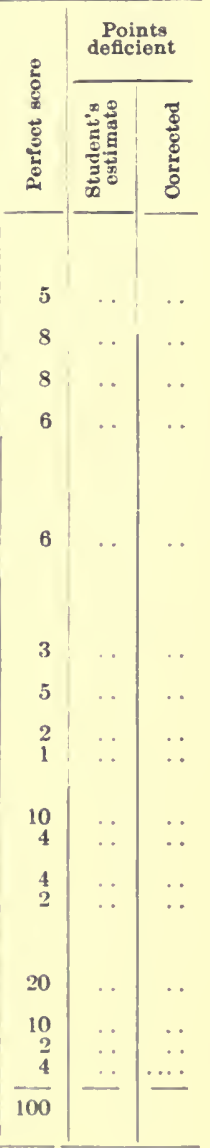

\section{Scoring Beef Cattle.}

If beef cattle are very important in the neighborhood, use the following score card in judging two or moro animals. Or a score card may be obtained from the State College of Agriculture. The following seore card is used at the University of Illinois for judging beef cattle 
that are kept for breeding purposes; a different card is used for fat cattle.

Score Card for Beef Cattle

Standard of excellence

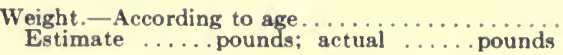

Form.-Straight top and underline; deep, broad, low set, compact, symmetrical. .............

Quality.-Hair fine; bone fine but strong; skin pliable; mellow, even covering of firm flesh, free from rolls; features refined, but not delicate; stylish. .

Constitution.-Chest capacious; brisket well developed; flanks deep; bone strong..............

Condition.-Thrifty, well fleshed, but not excessively fat; deep covering of firm flesh ..........

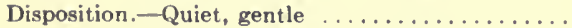

Color and markings. - According to breed ........

Muzzle.-Mouth and nostrils large; lips thin ......

Eyes.-Large, clear, placid

Face.-Short, quiet, expressive ............

Forehead.-Broad, full .................

Ears.-Medium size, fine texture.............

Neck.-Thick, short; throat clean, according to

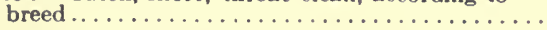

Shoulder vein.-Full . . . . . . . . . . . . .

Shoulder.-Covered with flesh; compact ........

Brisket.-Well developed; breast wide..........

Dewlap.-Skin not too loose and drooping . . . . . . .

Legs.-Straight, short, set well apart; arm full; bones smooth, strong, being neither too coarse nor

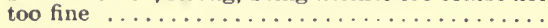

Ribs.-Long, arched, thickly fleshed.........

Back.-Broad, straight, thickly and evenly fleshed.

Loin.-Thick, broad.

Flank.-Full, even with underline

Hips.-Smoothly covered; width in proportion with other parts........................

Rump.-Long, level, wide and even in width; tail head smooth, not patchy ................

Pin bones.-Not prominent, width in proportion

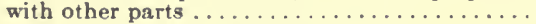

Thighs.-Full, fleshed well down to hock........

Twist.-Deep, plump, indicating fleshiness .......

Legs.-Straight, short, set well apart; bones smooth, being neither coarse nor too fine ............

Total....................

\begin{tabular}{|c|c|c|c|c|}
\hline \multirow[t]{2}{*}{$\begin{array}{l}\text { Per- } \\
\text { fert } \\
\text { score }\end{array}$} & \multicolumn{2}{|c|}{$\begin{array}{c}\text { Student's } \\
\text { score }\end{array}$} & \multicolumn{2}{|c|}{$\begin{array}{l}\text { Corrected } \\
\text { senre }\end{array}$} \\
\hline & No. 1 & No. 2 & No. 1 & No. 2 \\
\hline 6 & $\cdots$ & . & .. & $\cdots$ \\
\hline 10 & . & . & .. & . \\
\hline 10 & $\ldots$ & . & . & . \\
\hline 10 & . & . & . & . \\
\hline 6 & . & . & . & . \\
\hline 3 & . & .. & $\cdots$ & $\cdots$ \\
\hline 1 & . & . & . & . \\
\hline 1 & $\ldots$ & . & . & $\ldots$ \\
\hline 1 & . & $\cdots$ & . & $\cdots$ \\
\hline 1 & $\cdots$ & $\cdots$ & $\cdots$ & . \\
\hline 1 & . & $\cdots$ & $\cdots$ & . \\
\hline 1 & $\cdots$ & $\cdots$ & . & . \\
\hline 2 & .. & .. & . & . \\
\hline 1 & . & . & . & . \\
\hline 2 & . & . & .. & .. \\
\hline 1 & . & . & . & .. \\
\hline 1 & $\cdots$ & . & $\cdots$ & $\cdots$ \\
\hline 2 & . & . & . & .. \\
\hline 8 & . & . & $\cdots$ & . \\
\hline 8 & . & $\cdots$ & . & $\cdots$ \\
\hline 8 & . & . & $\cdots$ & . \\
\hline 2 & . & . & $\cdots$ & . \\
\hline 2 & . & $\cdots$ & $\cdots$ & $\ldots$ \\
\hline 2 & $\cdots$ & $\cdots$ & $\cdots$ & . \\
\hline 1 & . & . & . & .. \\
\hline 3 & . & . & . & . \\
\hline 4 & . & $\cdots$ & $\cdots$ & $\cdots$ \\
\hline 2 & $\cdots$ & $\cdots$ & $\cdots$ & $\therefore$ \\
\hline 100 & & & & \\
\hline
\end{tabular}




\section{The Babcock Test for Butter-Fat in Milk. ${ }^{1}$}

By R. A. Pearson, formerly Professor of Dairy Industry, Cornell University

Materials.-A hand-power centrifugal tester, at least two milk test-bottles (Fig. 173), one pipette to measure the milk (Fig. 174), one acid measure (Fig. 175), about one pint of sulfuric acid with specific gravity between 1.82 and 1.83 , a few

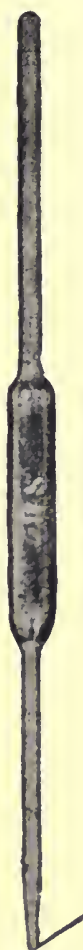

Fig. 174.

Pipette or milk measure. ounces of milk, and some hot water. All the necessary apparatus and acid can be purchased for about $\$ 5$ from any dairy supply company. They can be ordered through a hardware dealer. Sulfuric acid is sold also at drug stores.

Sampling the Milk. - The milk to be tested should be thoroughly mixed just before the sample is taken, to make sure that the fat or cream is evenly distributed. This can be best done by gently pouring back and forth between two vessels several times. The milk should be neither very cold nor hot.

Place the small end of the pipette at the center of the milk and suck the milk up above

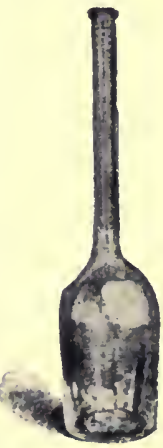

Fig. 173.

rest bottle the 17.6 cc. mark. Quickly put the index finger over the upper end of the pipette, and by releasing the pressure allow the milk to run out until its upper surface is even with 17.6 ce. mark when the pipette is held straight up and down.

Place the point of the pipette a short distance into the test-bottle neck, holding it against the glass, and with both pipette and bottle at an angle (Fig. 176). Remove the finger to allow the milk to flow into the bottle. Be sure to get every drop of the milk, taking care to drain the pipette and to blow the last drop into the bottle. A little practice should make any one proficient with the pipette.

It is best always to make this test in duplicate; hence, two bottles are neerled for each lot of milk.

Using the Acid.-The acid is very strong and must be handled with great care. If any gets on the hands, face or clothing, it should be washed off quickly, and water should always be rearly for this purpose. Do not leave the acid where young children can get it.

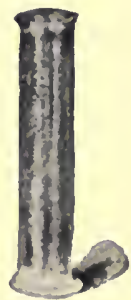

Fig. 175 . Acid measure. 
After all the samples of milk to be tested have been. measured, the acid should be added. Fill the acid measure to the $17.5 \mathrm{cc}$. mark with acid that is neither very cold nor hot. Pour this into the bottle with the milk, holding the bottle in a

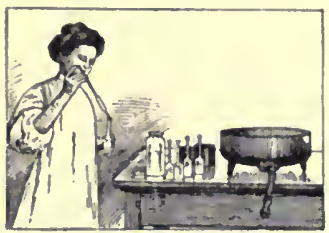

Frg. 176. Putting the milk into the test bottle. The pipette is held at an angle with the test bottle and its point against the inside of the neck. slanting position. The acid will then carry down any milk left in the neck and follow the glass surface to the bottom of the bottle and form a layer under the milk.

Hold the bottle by the neck and give it a circular motion for a few minutes, mixing the milk and acid until no milk or clear acid is visible (Fig. 177). By this time, the contents will be dark-colored and hot. This change is due to the acid dissolving all

the solid constituents of the milk except the fat, which it does not affect.

Whirling the Bottles. - The bottles are whirled to separate the fat so that it can be measured. They should be hot when whirled. If necessary, they may be heated by standing in hot water before being put into the machine. A steam machine is easily kept hot when in use. Other kinds should have

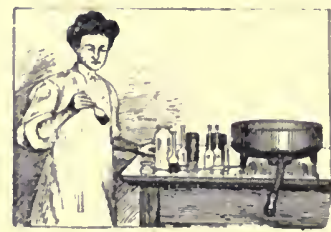

FIG. 177. Mixing milk and acid. A rotary motion with the bottle not pointed toward the face.

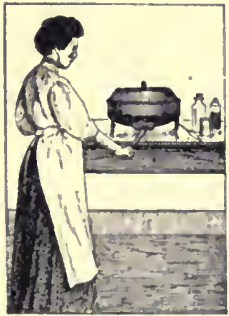

FIg. 178. boiling hot water placed in them.

Place the bottles in the machine so that each one will have another directly opposite, to keep the machine in balance. Whirl the bottles five minutes at the proper speed for the machine in use (Fig. 178). Then stop it, and, with the pipette or other convenient means, add hot water to each bottle until the contents come up to the bottom of the neck. Whirl two mintues. Add hot water enough to bring the top of the fat nearly to the top of the graduations on the neck of the bottles. Whirl one minute. The fat should then form a clear column in the neck of the bottle.

Reading the Percentage. - Keep the fat warm so that it will be in a fluid condition. Hold the bottle by the upper end of the neck, letting 
it hang in a perpendicular position, on the level with the eye. Read the mark or graduations at the extreme top and bottom of the fat column. The difference between these is the percentage of fat in the milk. Most test-bottles are made to read as high as 10 per cent. Each percentage has its number marked on the glass and there are five small spaces, each representing .2 per cent between these principal marks. Thus, if the top of the fat column is even with the third short mark above the 7 mark, the top reading would be 7.6 ; and if the bottom is half way between the first and second short marks above the 3 mark, the bottom reading would be 3.3 ; the difference is 4.3 , which is the percentage of fat or number of pounds of fat in 100 pounds of the milk tested.

Notes. -One cc. means one cubic centimeter, or about twenty drops.

If the fat column is clouded with white specks, probably the acid was not strong enough, or not enough was used, or the heat was not high enough.

If the fat column is clouded with dark specks, probably the acid was too strong, or too much was used, or the heat was too great.

Always keep the acid bottle closed when not in use or the acid will lose strength. Remember that it is a poison and corrosive.

Points to be Especially Noted in Making the Babcock Test. ${ }^{1-}$ (1) Be sure to mix the sample of milk thoroughly before drawing it out with the pipette.

(2) When measuring a sample of milk with the pipette, keep the index finger dry.

(3) When measuring a sample of milk, keep the mark on the pipette on a level with the eye. The same precaution should be observed when reading the per cent of fat after the test is completed.

(4) Do not try to measure a sample of milk by trying to draw the milk just to the mark on the pipette. Draw the milk above the mark, as rlirected.

(5) When adding milk or acid to the test-bottle, slant the bottle. The liquid will then run down the lower inside of the neck of the bottle, and will not be forced out by outcoming air.

(6) Do not hold the bottle so that its mouth points toward yourself or any one else. The action of the acid upon the milk produces great heat. This heat often caluses the contents of the bottle to spurt out violently.

${ }^{1}$ H. F. Ross in Cornell Rural School I,enflet 
(i) After adding the acid to the milk, shake the bottle thoroughly until the contents become quite dark in eolor.

(S) After using the pipette, wash it thoroughly, preferably in hot water. This will tend to prevent the transmission of disease germs from the mouth of one person to another, should any such germs be present.

(9) The tester shoukl be firmly fastened to a solid bench or table.

(10) The person operating the machine should give his or her whole attention to it, and not allow his fingers or clothing to get in the path of the bottle cups.

(11) Remove all objects from the vicinity of the testor. This will prevent their being hit by the bottle eups when the machine is in motion.

(12) If acid is spilled upon anything, pour on plenty of water, and then add some alkali, such as lime or baking soda, to neutralize the acid.

(13) Do not bave the acid bottle uncorked.

(14) Keep all glassware perfectly elean.

(15) After washing the glassware, rinse it thoroughly in elean water to remove soap powder. The soap powder and the acid form a violent ehemical reaction.

\section{To Determine the Amount of Solids in Milk.}

Weigh a sample of milk. Evaporate to dryness and weigh again. Determine the per cent of dry matter. Fill out the following table:

Weight of dish.

Weight of dish and milk

Weight of dish and evaporated milk

Weight of dry matter.

Per cent of dry matter in milk.

Per cent of solids not fat (per cent of dry matter minus per

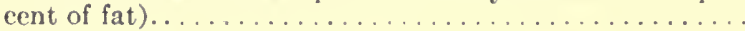

\section{Comparison of Methods of Cream Separation.}

Materials.-Milk-testing outfit as for No. 74, but with special hottles for skimmed nilk; skimmed milk from a cream separator; skimmed milk that stood in shallow pans, and some that stood in long cans.

Determine the per eent of fat left in the skimmed milk in each case. If a cow produces 6,000 pounds of milk in a year, and if butter-fat is 
worth 25 cents per pound, how many dollars worth of fat would be lost per year in each case?

77. Methods of Churning.

Materinls.-Milk-testing outfit as for No. 76. Buttermilk from different homes or factories, with a record of how the churning was done. Determine the per cent of fat lost in the buttermilk in each case.

78. To Determine the Effect of Prompt Cooling on the Souring of Milk.

Divide a sample of new milk into two parts. Cool one by setting in ice water or very cold water, or with an aërator and cooler. After it is cooled, place both samples under the same conditions. Whick. sours first?

\section{COLLATERAL READING}

Farıners' Bulletins Noos.:

71. Essentials in Beef-Production.

233. Beef vs. Dairy Types for Beef, p. 22.

251. Indoor vs, Outdoor Feerling of Steers, pp. 22-25.

106. Breeds of Dairy ('attle.

5.5. The Dairy Herd: Its Formation and Management.

124. Bcef and Dairy Types as Related to Bcef-Production, pp. 28-30.

149. Effect of Exposure on Milk-Production, pp. 28-31.

Profitable and Enprofitable ("ows. Bulletin No. 114, pp. 21-26; No. 190, p. 14; No. 162, p. 24.

151. Dairying in the south.

349. The Dairy Industry in the south.

183. Meat on the Farm; Butchering, ('uring and Keeping.

184. Marketing live stock.

201. The ('ream separator on Western Farms.

29. Souring of Milk and Other ('hanges in Milk Products.

42. Hacts Alout Milk.

63. ('are of Blilk on the liarm.

74. Milk as food.

('lean Milk. Bulletin No. 22\%, pp. 24-28; No. 27:3, pp. 23-30: No. 210, pp. 26, 27: No. 7:3, 1p. 3, 4: No. 296, p. 5; No. 169, pp. $5,6$.

166. Cheese-making on the Furm, 
241. Butter-making on the Farm.

350. The Dehorning of Cattle.

258. Texas, or Tick Fever, and Its Prevention.

206. Milk Fever.

351. The Tuberculin Test of Cattle for Tuberculosis.

Types and Breeds of Farm Animals, by C. S. Plumb. Pp. 175-332. Cyelopedia of Ainerican Agriculture, Vol. III, pp. 4-44, 122-162, $175-272,301-382$. 


\section{CHAPTER XIII}

\section{SHEEP}

305. Types of Sheep. There are two more or less antagonistic uses for sheep, just as there are for cattle or horses. We raise sheep for wool or for mutton. The type of sheep that produces the most valuable wool (Fig. 180) has a conformation much like that of a dairy cow. The type that produces the best mutton (Fig. 182) has much the same form as the beef animal. It is very difficult to improve either the wool or the mutton qualities without lowering the other. Our common breeds are classified as follows:

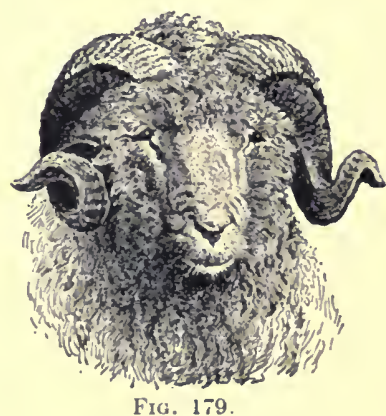

The head of the herd

1. Fine wooled...$\ldots \ldots\left\{\begin{array}{l}\text { American Merino } \\ \text { Rambouillet or French Merino } \\ \text { Delaine Merino }\end{array}\right.$

II. Middle wooled ........ $\left\{\begin{array}{l}\text { Southdown } \\ \text { Shropshire } \\ \text { Hampshire Down } \\ \text { Oxford Down } \\ \text { Dorset Horn }\end{array}\right.$

III. Long wooled......... $\left\{\begin{array}{l}\text { Cheriot } \\ \text { Cotswold } \\ \text { Leicester } \\ \text { Lincoln }\end{array}\right.$

306. Breeds of Sheep. Merinos are probably the most widely distributed breed of sheep. They are the best 


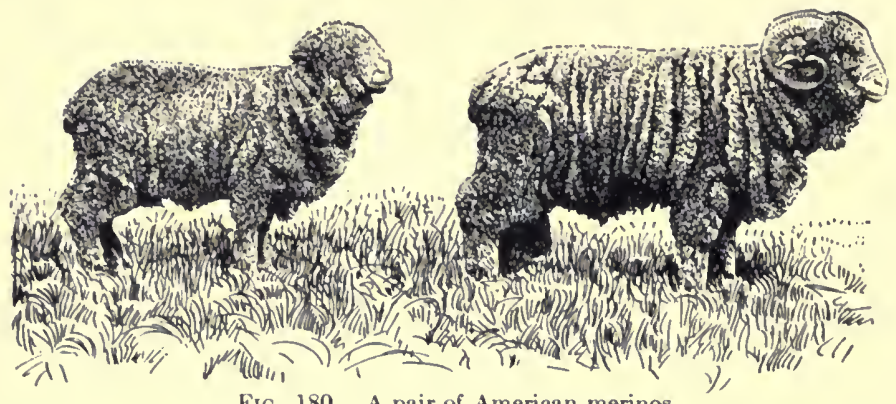

FIG. 180. A pair of American merinos

wool-producers. They yield heavy fleeces of very fine, short wool, that is used for the finest and most expensive woolen goods. The breed is small in size and lacks the fullness that is requisite for the best mutton production. They are hardy and are good grazers, and will thrive in larger flocks than will some of the other breeds. The Merinos originated in Spain, but most of their improvement has been accomplished in other countries. Many different types have been developed in different countries. The leading types are the American Merino, Delaine Merino, and Rambouillet.

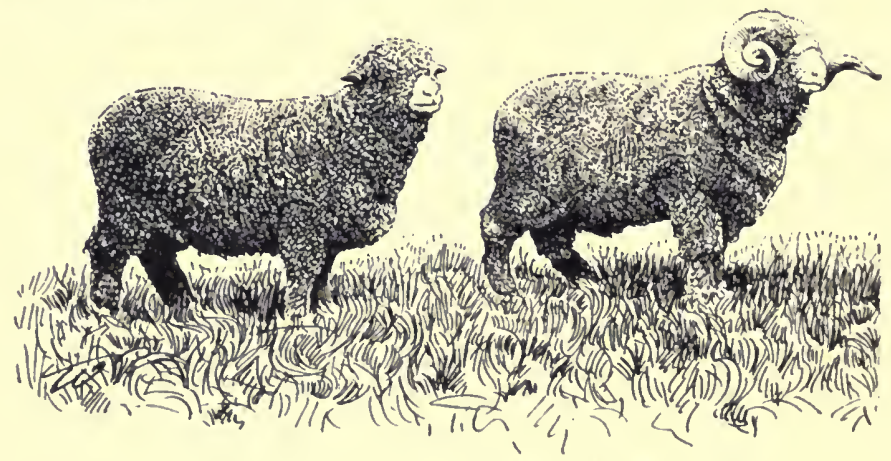

Fra. 181. A pair of Delaine merinos 
Nearly 12,000 ewes in England in a year raised an average of 168 lambs for each hundred ewes. They are especially adapted to good lands and good pastures, and are very popular in the East and Middle West. On the range they are not so hardy as the Merino breeds. Next to the Merinos, they are the most numerous breed in America.

Southdowns are another popular mutton breed. They have gray-

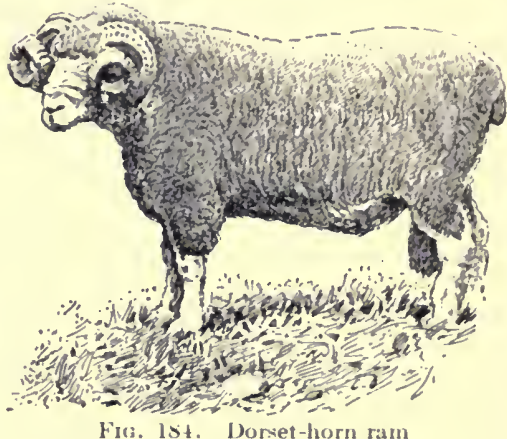
ish brown or reddish brown legs and faces and are smaller than the Shropshires. Their wool is finer and more valuable, but they arc less prolific. Other breeds

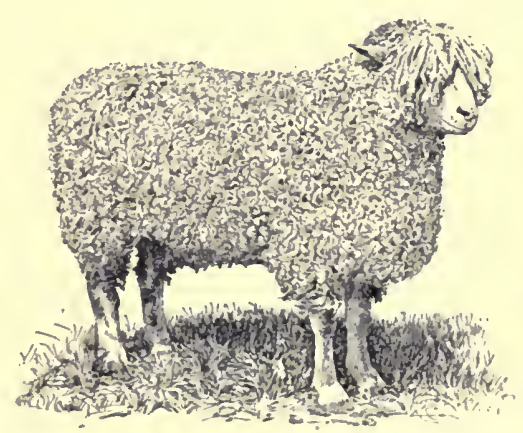

Fig. 185. Cotswold ewe of the same general class that are raised in America are the Oxford Down and the Hampshire Down.

The Horned Dorset has attracted considerable attention in sections where winter lambs are produced, as it is claimed that a large proportion of its lambs will be early enough for the winter market. The wool is not of the best quality.

Cotswold is the only coarse-wooled breed that has 
attained much prominence in America. About twentyfive years ago, it was prominent, but the Shropshires are now most numerous in the sections to which it is adapted.

307. Sheep Industry in America. Sheep-glowing first developed in eastern United States. Large numbers of Merino sheep were kept for wool-production. As the number of sheep on the ranges of North and South America and Australia increased, and as the cotton-production increased, the price of wool became so low that there was little profit in the sheep industry, even on the ranges. Most farmers in the eastern states went out of the sheep business. Later, the demand for mutton increased, and we now have an increasing number of sheep in the East and Middle West.

Two of the obstacles that have stood in the way of the sheep industry are fencing and dogs. Many farmers, who might otherwise keep sheep, do not do so because their farms are fenced for cattle. Others fear the dog nuisance, not only for the actual loss of sheep, but because of the annoyance that such troubles cause. The present prices of fencing materials make it possible to fence the sheep in and the dogs out, so that there is little danger.

There are many farms in the eastern states that are naturally adapted to sheep-production. These farms promise to be the center of a large sheep industry in the future. There are many hill farms in these sections that are now being little used, and that can be made profitable sheep farms as soon as the westem ranges are unable to supply the demand for sheep. One of the obstacles in the way is the small size of the farms. It will usually require 
several of the present farms to make one that is large enough for sheep-production.

\section{COLLATERAL READING}

Farmers' Bulletins Nos.:

96. Raising Sheep for Mutton.

119. Establishing a Flock of Mutton Sheep, pp. 23, 24.

159. Scab in Sheep.

Cyclopedia of American Agriculture, Vol. III, pp. 592-633.

Types and Breeds of Farm Animals, by C. S. Plumb. Pp. 333-4.5 


\section{CHAPTER XIV}

\section{SWINE}

Hogs rank second in total number and third in total value of farm animals in the United States, being exceeded in number by cattle, and in value by horses and cattle. The totals in 1908 were as follows: ${ }^{1}$

\begin{tabular}{|c|c|c|}
\hline & Number & Value \\
\hline 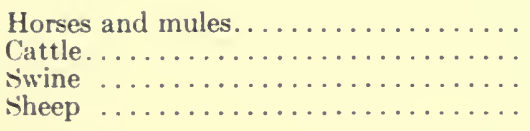 & $\begin{array}{l}23,816,000 \\
71,267,000 \\
56,084,000 \\
54,631,000\end{array}$ & $\begin{array}{r}\$ 2,284,469,000 \\
1,495,995,000 \\
339,030,000 \\
211,736,000\end{array}$ \\
\hline
\end{tabular}

308. Distribution of Hogs. Hogs are almost universally distributed as scavengers to eat the waste material from the farm and the kitchen. The commercial production is centered in dairy sections and in the corn-belt. In dairy sections that produce cheese or butter, the hogs are a by-product, being fed on the whey and skimmed milk. In the corn-belt, they are a by-product of fattening steers. Here they eat the corn that is wasted by the steers and that which the steers do not digest. Large numbers are also grown in the corn-belt independently of other stock.

It is cheaper to ship hogs than to ship the corn that is required to grow the hogs. About five to six pounds of corn are required to grow a pound of hog. The weight to be shipped is, therefore, much less if the corn is fed. If alfalfa

L'nited States Department of Agriculture Yearbook, 19(0) 
or other coarse forage is fed, the difference in the cost of shipment of the feed and of the animal is still greater. The same principle applies in the production of beef, but does not apply to milk, because the latter product is perishable. The farther corn has to be shipped, the more important this matter becomes. We expect to see a city's milk-supply produced near the city, but expect to see the meat-supply produced where feed is cheapest. The following table shows that this is what occurs:

\begin{tabular}{l|c|c|c|c} 
& $\begin{array}{c}\text { Bushels of } \\
\text { corn, 1908 }\end{array}$ & $\begin{array}{c}\text { Value per bushel } \\
\text { on the farm }\end{array}$ & $\begin{array}{c}\text { Number of } \\
\text { catte other than } \\
\text { milch cows }\end{array}$ & $\begin{array}{c}\text { Number of } \\
\text { swine }\end{array}$ \\
\hline Illinois ... & $298,620,000$ & 5057 & $2,056,000$ & $4,438,000$ \\
Iowa .... & $287,456,000$ & 52 & $3,8+2,000$ & $7,908,000$ \\
Nebraska & $205,767,000$ & 51 & $3,200,000$ & $3,904,000$ \\
\hline
\end{tabular}

Nebraska produces about two-thirds as much corn as Illinois, but produces nearly as many hogs and a half more beef cattle. Iowa has less corn than Illinois, but has about twice as many hogs and beef cattle. This shows that meat-production is most important where com is cheapest.

309. Breeds of Hogs. The most important breeds in the United States are Poland-China, Berkshire, DurocJersey and Chester-White. Breeds of less importance are the Cheshire, Large Yorkshire, Tamworth, Victoria, Small Yorkshire, Hampshire, Essex and Suffolk.

Nearly all of our important breeds of cattle and horses come from Europe, but all of the more important breeds of swine, except Berkshire, originated in this country. The Poland-China were developed in Ohio; Duroc-Jersey in New York and New Jersey; Chester-White in Pennsyl- 


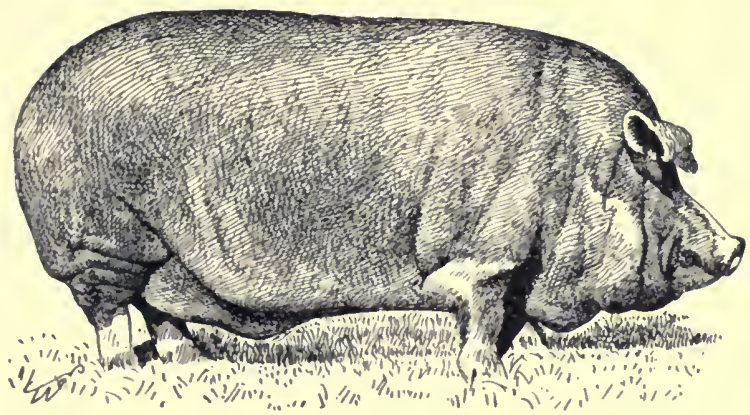

FIG. 186. The lard type. A Poland-Chinit

vania; Cheshire in New York; Victoria in Indiana; Hampshire probably in Kentucky. All of the other breeds mentioned were developed in England.

One of the chief reasons for the development of our own breeds of swine is that the English breeds are not the

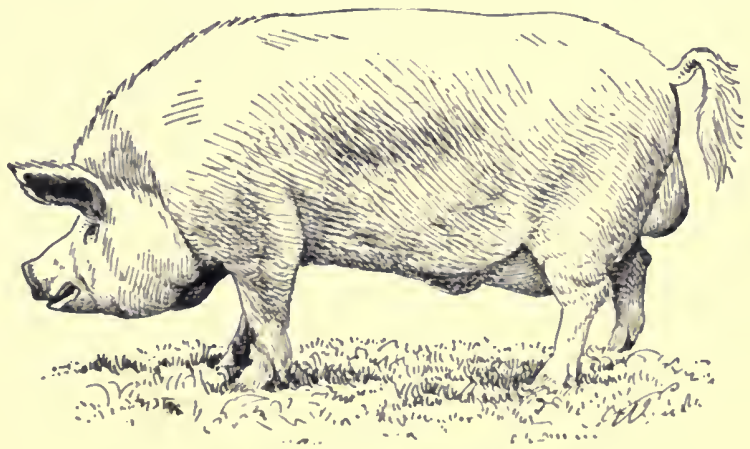

Fin. 187. The Lacon type. A large Yurkshire

best for feeding on corn. Corn is relatively rich in oil and starch, and deficient in protein. This leads to the production of fat hogs - the lard type. In England, a leaner type is more profitable-the bacon type. Their mixed foods, 
containing a greater proportion of protein, make the production of the bacon type profitable. This type is also much grown in Canada, where the Large Yorkshire is one of the most important breeds. Relatively few of the bacon type of hogs are grown in the United States.

The following points will aid in distinguishing the breeds: The Poland-China are black with white markings, and have drooping ears. The Berkshire are about the same color, but have erect ears. The Essex are black, with erect ears, but have no white markings. The Hampshire are black with a belt of white around the body. The Large Yorkshire, Small Yorkshire, Cheshire and Suffolk are all white, with erect ears. The Chester-White are white, with drooping ears. The Duroc-Jersey are cherry-red, chestnut or yellowish red, with drooping ears.

The white breeds are more prominent in the northeastern states and Canada. They are said to be less desirable in the intense sunshine of the corn-belt. Poland-China are the most numerous breed in the corn-belt. The chief complaint against them is that they are so fine-boned as to lack in vigor, and that they do not raise large enough litters of pigs. The Duroc-.Jersey have been increasing in numbers, and are said to be more prolific and more vigorous than the Poland-China. Both of these breeds and the Berkshire are popular.

310. Care of Hogs. Not many years ago, the common practice was to keep hogs in small pens that of necessity became muddy. This practice is still common in many sections of the country. But, where hogs are grown in large numbers, the importance of pastures is now recognized. For cheap production of pork, as well as for the health 
of the hogs, there should be plenty of pasture. When corn is the only grain feed, the pasture is also of value in furnishing the mineral matter that the corn lacks. The more succulent plants are better than the drier grasses. Alfalfa is the most popular pasture for hogs. Alfalfa hay is also fed in winter.

311. Hog Diseases. Hog cholera is the most serious obstacle in the way of hog-production. It is particularly serious in the corn-belt. Entire herds of hogs are often lost with it in a few weeks. Recent experiments have given promise of prevention by means of vaccination. ${ }^{1}$

Tuberculosis is also a serious disease. It is often contracted from infected milk. (For a discussion of the extent of this disease and its prevention, see page 337. )

'Twenty-fourth Annual Report of the Bureau of Animal Industry, p. 50

\section{QUESTIONS}

1. What are the most numerous breeds of hogs in your county? Which breeds are increasing in numbers?

2. What are the common feeds for hogs in your community? About how much of each is fed per day for each 1,000 pounds of live weight? Find the nutritive ratio of this ration and conpare with that given in Appendix, Table 7. For the production of the lard type of hog, the ration does not need to eontain so much protein as the standard.

3. What is the price of corn and of hogs? Find the comparative price per pound of each. Will it pay better to feed the eorn or to sell it?

\section{COLLATERAL READING}

Farmers' Bulletins Nos.:

100. Hog-Raising in the South.

272. A successful Ilog and Seed Corn Farnı.

133. P'rofitable Crops for Pigs, pp. 27-29.

296. Grinding Corn for Ilogs, p. 2.5. 
329. Hogging Off Corn, pp. 21, 22.

315. Supplements to Corn in Hog Feeding, pp. 25-29.

Forage Crops for Hogs.-Bulletins: No. 56, pp. 6, 7; No. 84 , pp. 18,19 ; No. 97 , pp. 15,16 ; No. 124 , pp. 25-27; No. 305, pp. 24, 25; No. 331, pp. 1-24; No. 334 , pp. 20-22.

Tankage and Bone Meal for Hogs.-Bulletins: No. 169, pp. 29, 30; No. 296, pp. 21-24; No. 315, pp. 28-30. Feeding.-Bulletins: No. 22; No. 92, pp. 20, 21; No. 97, pp. 13-15; No. 133 , pp. 26,27 ; No. 144, pp. 24, 25: No. 210 , pp. 30,31 ; No. 251 , pp. $30-32$; No. 305 . pp. 25-28.

Hog ('ots.-Bulletins: No. 273, pp. 11-14; No. 296. pp. 27-29; No. 334, pp. 31, 32.

87. Fecundity of Swine, pp. 23, 24.

222. Market Classes and Grades of Swine, pp. 24-3:2.

Types and Breeds of Farm Animals, by C. S. Plumb. Pp. 467-554 Cyclopedia of American Agriculture, Vol. III, pp. 644-681, and Index 


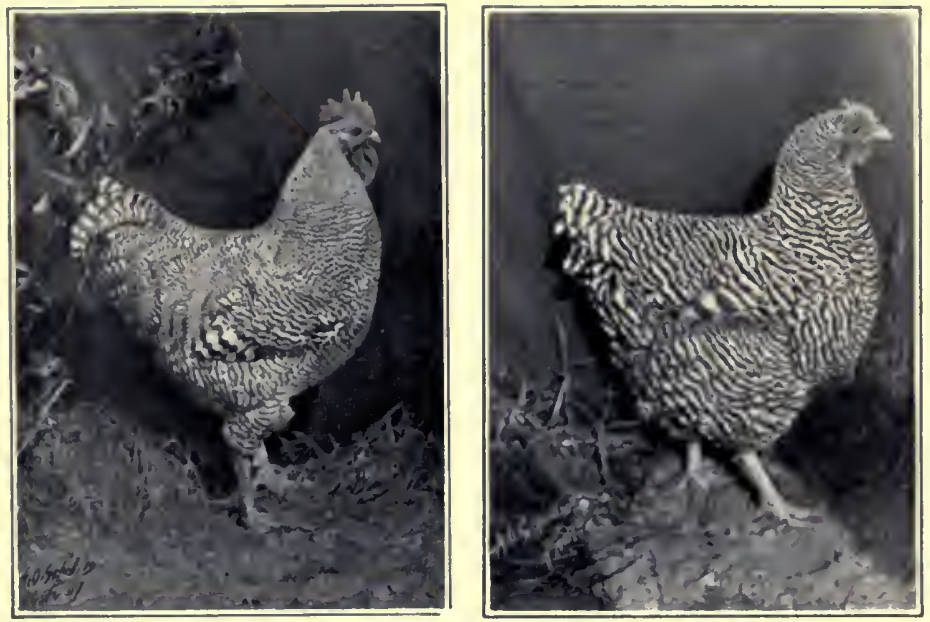

Figs. 188, 189. Barred Plymouth Rocks,-a general-purpose breed.
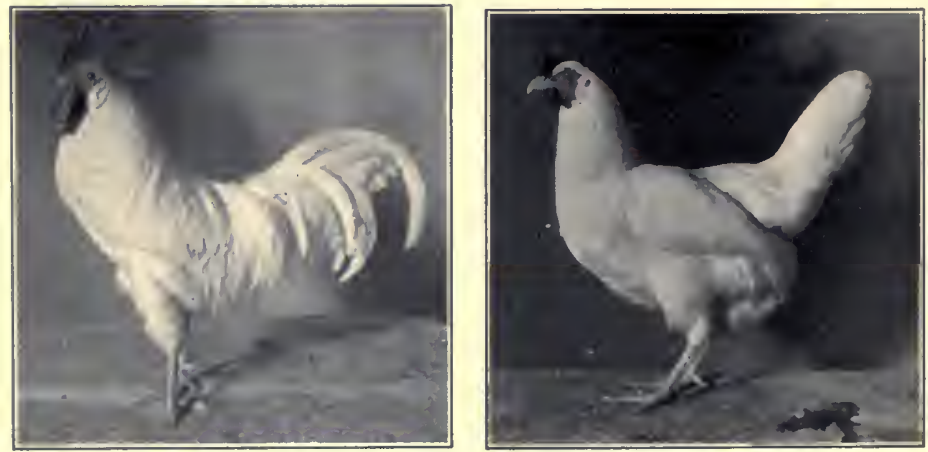

Figs. 190, 191. Single-comb White Leghorns, - an egg breed. 


\section{CHAPTER XV}

\section{POULTRY}

312. Importance of Poultry. Poultry-raising is often looked upon as a small business. But we are likely to underestimate the value of farm products because they are scattered over so wide a territory and the proceeds alre distributed among so many people. A much smaller industry that is concentrated gives the impression of being larger. The total value of all poultry raised in the United States in 1899 was $\$ 137,000,000$ and the value of the eggs produced was $\$ 144,000,000$. The total value of these products was nearly equal to the combined value of all the iron, coal, gold and silver that were mined in that year. ' Yet the value of the poultry products is only sixth among the agricultural products, being exceeded by corn, beef cattle, dairy products, cotton, wheat and swine.

313. Breeds of Poultry. Turkeys, geese, ducks, pigeons and squabs are of considerable value, but are of small importance when compared with chickens. The varieties of chickens are almost innumerable. There are four general classes:

(1) The meat breeds, or Asiatic class-Brahma, Cochin and Langshan.

1'Twelfth Census of the United Stutes: Cosl, $\$ 160,(0),(K 0)$; gold, \$33,(OON),(K) ; silver, $\$ 66,(\%) 0,0(0)$; iron nre, $\$ 33,000,0(0)$. A large umount of poultry profluets consumed on farms is omittel from the census reports, as is the value of such produets promlueed in villages. 
(2) The general-purpose breeds, or American classPlymouth Rock, Wyandotte. Rhode Island Red, etc.

(3) The egg breeds, or Mediterranean class-Leghorn, Minorca, Black Spanish.

(4) The ornamental breeds-Polish, Game, Bantam, etc. The meat breeds correspond to the beef breeds of cattle. The egg breeds are smaller and more active, and correspond to the milk breeds of cattle. The meat breeds originated in Asia. They are very superior for meat-production, but are such poor layers that they have never become very popular in America.

There are a number of varieties of Plymouth Rocks, Barred, Buff, White, etc. Of the Wyandottes, the chief varieties are White, Silver and Buff. All of these originated in America and all lay brown eggs.

The Barred Plymouth Rock is the most widely distributed and most popular variety in the United States. It is large enough for fair meat-production and is very good for egg-production, nearly equal to the Leghorn. it is a quiet breed and so causes little trouble on the farm. The hens will incubate their own eggs, which is an essential consideration where incubators are not used.

The White variety is the most numerous of the Wyandottes. It is much like the Plymouth Rock in form and utility.

The White Leghorns are the most popular of the egg breeds. They are medium-sized, active birds. They lay white eggs, and large numbers of them. They are a nonsetting breed, and are more difficult to control, so that they are not so popular as the Plymouth Rocks or Wyandottes on farms where only a few hens are kept. They 
are most numerous in the territory surrounding New York City, where white eggs sell for more than brown ones. In Boston, the brown eggs are more in demand.

314. Feeding of Poultry. There are a number of points in which the poultry ration should differ from that of other farm animals. Chickens require over twice as much feed as is required for the same weight of cattle, and this food must be largely grain. This makes the requirement of net nutrients much more than twice that of cattle. The nutritive ratio should also be very narrow, as the high protein product requires a feed high in protein. Laying hens require one pound of protein for about 4.8 pounds of carbohydrates. (See Appendix, Table 7.)

About one-third of the grain ration should be ground and fed dry in a hopper, the whole grain being scattered in straw, so that the birds will have to exercise in getting it. The ground feed should be at hand during the afternoon, so that the forls can eat as much of it as they care to after they have eaten the whole grain which is scattered in the litter. If fed in this way, they will not overeat on dry ground feed. The exact mixtures will vary with the section of the country.

It is essential for good results that chickens have some animal food. This may consist of the insects that they catch, of meat scrap, or skimmed milk. About 10 to 15 per cent of the ration should be animal food.

Egg-production requires large amounts of lime, so that this must be supplied in some form. Cracked oystershells are commonly used. Since the hen has no teeth, grit must be available for grinding the food. Usually the oyster-shells do not furnish as much grit as is desirable. 
An abundant supply of fresh water is essential for hens, as it is for all other farm animals.

A combination that has proved satisfactory at the. Maine Experiment Station for laying hens, is: Four quarts of corn, two quarts of wheat, two quarts of oats for the whole grain per day for 100 Plymouth Rock hens. The dry mash was made of a mixture of 200 pounds of wheat bran and 100 pounds each of corn meal, wheat middlings, gluten meal, linseed meal, and meat scrap. This is fed in the hopper as mentioned above.

The following mixtures are used at the New York State College of Agriculture at Cornell University:

Young chickens from three weeks old to maturity.Grain mixture: 200 pounds of finely cracked corn, 300 pounds of eracked wheat. Ground feed: 400 pounds corn meal, 400 pounds wheat bran, 400 pounds wheat middlings, 400 pounds meat scrap, 100 pounds oil meal, 25 pounds bone flour.

Pullets and laying hens.-Grain ration: 200 pounds cracked corn, 200 pounds wheat, 100 pounds oats (for pullets use 300 pounds of wheat). Ground feed: 600 pounds corn meal, 600 pounds wheat middlings, 300 pounds wheat bran, 500 pounds meat scrap, 100 pounds oil meal, 100 pounds alfalfa meal.

Fattening ration: All ground feed, 100 pounds corn meal, 100 pounds wheat middlings, 100 pounds oat flour, 30 pounds meat serap.

315. Poultry Houses. The details of construction are given in some of the references at the end of this chapter. There are a few general principles that apply in all regions. Sunlight should reach every part of the house, if pos- 
sible. If the south side is nearly all made up of windows and open front, this purpose will be accomplished. The windows should be high, so that the light can reach the back part of the house. The house shown in Fig. 192 has an

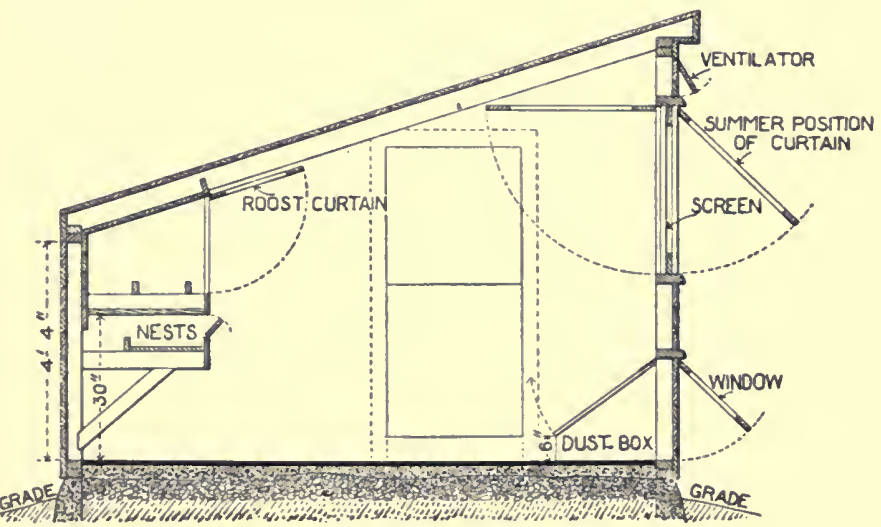

FIG. 192. Cross-section of a hen-house

open front that admits sunlight and air. It can be closed by lowering the curtain. In summer, the same curtain serves as an awning. The window admits light at the few times when the curtain is closed.

The floor should always be dry. This is best acromplished, as shown in Fig. 192, by using an elevated floor underdaid by gravel or rinders. ('ement floor's do not need to be over two inches thick for hen-houses, as there is lit tle weight to support. Surh a floor is usually not expensive. bach hen should have

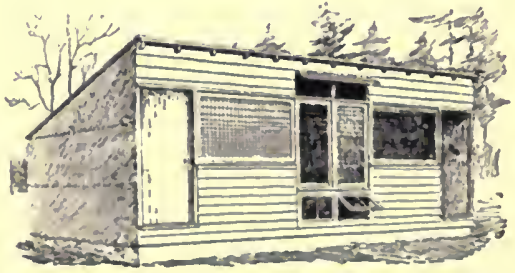

Fra. 193. Front view of hen-huuse. ('russsection shown in Fig. 192 
about five square feet of floor space. The height does not need to be great. The only reasons for having a house more than a few feet high are so that the sunlight can enter, and so that persons can walk through the houses.

Hens need plenty of fresh air. If the house is tight, so that the wind will not blow through it, and with the platform under the roosts, as shown in Fig. 192, the cloth curtain will not often need to be closed. For very cold weather there is a second cloth curtain that comes down in front of the roosts.

All interior parts, as roosts, nests, etc., should be portable, so that they may be quickly removed for disinfecting the house.

\section{QUESTIONS}

1. Make a sketch of a hen house adapted to your region.

2. What diseases of poultry are most common in the section? What is done to control them?

3. From feeds used in the region, prepare a ration for 100 laying hens, each averaging 3.5 pounds in weight. (See Appendix, Tables 7 and 8.)

4. How are eggs sometimes tested by egg-dealers?

\section{LABORATORY EXERCISES}

\section{The Parts of an Egg.1}

Materials.-One lens, and facilities for boiling eggs. Each pupil should be supplied with two eggs, if possible; have one with a light shell, the other with a dark shell, two saucers; one drawing pencil; one box of colored lead-pencils, and a knife.

An egg-tester can be made by placing a lamp in a box with a hole, slightly smaller than the egg, cut through the side. Or, the egg may be held up to a similar hole in the curtain of a darkened room. In either case, look through the egg toward the light.

${ }^{1}$ Adapted from J. E. Rice, in the Cornell Rural School Leaflet, Vol. 1, No. 2. 
(1) Strength of the egg shell. - Let each student hold a hardshelled egg between the clasped hands, the ends of the egg in the hollow of the hand, and try to break it.

Observe the great strength of the egg, due to the arrangement of the particles of the shell in an arch similar to the stones or bricks in the arch of a bridge.

(2) The contents of an uncooked egg.-(a) Break a fresh, uncooked egg in a saucer by separating the shell in the middle.

Observe the "germinal disc," which appears as a light-colored spot usually to be found on the upper surface of the yolk.

The germinal disc contains the life principle of the egg. Being on the upper surface, it remains in close contact with the source of heat during natural incubation.

(b) Note the "chalaza," or the whitish cords of denser albumen on the sides of the yolk toward either end of the egg. These cords of denser albumen serve to keep the yolk properly suspended within the albumen. Thus the chick which develops on the upper surface of the yolk is protected from injury, if, through rough handling, it should eome in contact with the shell.

(c) Note the transparent, watery appearance of the albumen (white of the egrg).

The albumen supplies the food by which the chick grows within the shell, in liquid form.

(d) Examine the shell and note the air-space usually found near the large end. Observe the two tough membranes, best seen at the air-space where the membranes separate.

The air-space furnishes a readily available supply of fresh air to the embryo chick. The two membranes prevent the too rapid evaporation of moisture through the pores of the shell, but allow oxygen to enter the egg and earbon dioxid to pass out.

(e) By placing a section of the shell under the lens, indentations or pores in the shell may be observed.

These thinner parts permit the gases to pass through the shell more readily. If the pores of the shell are closed by oil, varnish, dirt or broken egg, the chick will be smothered.

(f) Note the pigment of the shell, which gives to each egg its eharacteristic color.

Observe how the first egrgs laid for a brood are more pronounced in color, and how the color pigment decreases with each egg that is laid, due to exhaustion of the supply. 
(3) The structure of a boiled egg. - Crack the large end of a hard-boiled egg earefully. Remove the shell, piece by piece, to avoid tearing the shell membrane.

(a) Observe the air-space and the two membranes, which are separated with difficulty. Note that the outer membrane is the thicker and tougher.

(b) ('ut the egg lengthwise through the middle. Observe the lighter-colored, flask-shaped center of the yolk, and the darker yolk arranged around it in eoncentric layers. Note the "germinal vesicle," or "germinal dise," at the upper part of the light yolk. Observe that the yolk is at one side and not in the center of the white of the egg. Note also that the germinal dise is on the upper side of the yolk. This is beeause the yolk is lighter in weight than the albumen, and hence floats. The germinal dise on the surface of the white yolk is lighter than the dark yolk.

Snyder gives the ehemical composition of the dry sulstance of the inside of the egg as:

Albumen (white of the egg).........88.92

Protein Fat

Yolk. . . . . . . . . . . . . . . . . 20.62

It will be seen that there is a large amount of fat in the yolk and almost no fat in the albumen. Fat is lighter than albumen, hence rises to the surface. This may be observed in practice by holling a fresh

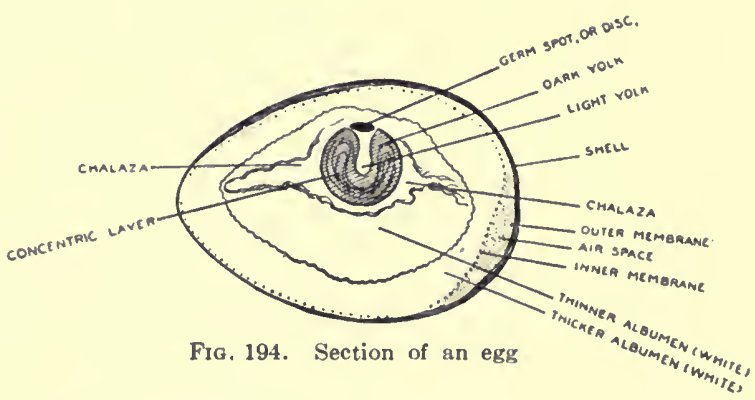

egg in front of an egg-tester and noting the tendency of the yolk to float upward.

This tendency of the yolk to float to the surface makes it necessary to turn eggs frequently when they are kept for hatching, otherwise the 
yolk will rise until the germinal dise comes in contact with the shell membrane. It will then become dry by evaporation and adhere to the membrane. If the egg is then turned the germ will be killed.

(4) Make a drawing of the longitudinal section of the egg, showing: (a) The shell and its pores. (b) The two shell membranes turned back from the shell. (c) The air-space. (d) The three layers of albumen. (e) The vitelline membrane surrounding the yolk. ( $f$ ) The vitellus contained within the vitelline nembrane. $(g)$ The white yolk and the dark yolk, showing its concentric layers. ( $h$ ) The germinal disc. (i) The chalaza ("hammoek cords").

\section{COLLATERAL READING}

Farmers' Bulletins Nos.:

287. Poultry Management.

51. Standard Varieties of Chickens.

64. Geese and Dueks.

182. Poultry as Food.

200. Turkeys.

225. Turkeys, pp. 21-25.

236. Ineubation and Ineubators.

281. Incubation, pp. $2+28$.

309. Incubation, pp. 24-26.

128. Eggs and Their l"se as Food.

Poultry-House ('onstruetion.-Bulletins: No 225, pp. 27-31; No. 227, pp. 25-32.

Poultry Appliances.-Bulletins: No. 244, pp. 25-29; No. 316, pp. 30-32; No. 317, pp. 28-32.

Feeding.-Bulletins: No. 84, pp. 19, 20; No. 97, pp. 16,

17; No. 122,pp. 25, 26; No. 225, pp. 26, 27; No. 305, 1). 28.

122. Weight of Eggs of Different Breeds, pp. 2t, $2 \pi$.

114. Floor space Necessary per Hen, pp. 18, 19.

Preserving Eggs-No. 103, pp. 17, 18; No. 273, pp. 17-19; No. 296 , pp. 29) -31.

Cyelopedia of Ameriean Agrieulture, Vol. III, pp. 525-587, and Index. 


\section{CHAPTER XVI \\ FARM MANAGEMENT}

316. What is Farm Management. It is not sufficient that a farmer raise large crops or fine animals, or that his farm appear attractive. He must so organize his business into a single unit that it will pay as a whole. He must see that his personal and household expenses do not exceed his net income. He must have a sufficient knowledge of business dealings so that he can conduct his transactions in a business-like way. The study of this class of questions is called farm management. Some of the details that each prospective farmer must consider are:

With my capital and personal qualifications, where shall I locate?

What type of farming shall I take up?

Shall I buy or rent?

To what extent may I safely borrow?

What farm shall I choose?

How shall I arrange the fields, buildings and fences?

What system of farming shall I follow?

What stock and equipment shall I buy, and how much will they cost?

How shall I secure labor and how manage it?

What records and accounts shall I keep?

What shall I sell and where and how shall I sell it? What income may I expect?

How will this compare with other occupations? 
These and many more similar questions must be answered by the successful farmer. He may not formulate the questions, but he considers them, nevertheless.

It is manifestly impossible to consider all these questions in a book of this size. Only the choice of a farm, the farm labor question and farm accounts will be considered, and these but briefly.

\section{THE CHOICE OF A FARM}

The most important business transaction that a farmer makes is the purchase of a farm. The score card on page 385 gives some of the points that need to be considered hefore purchasing. There are so many points that one is likely to forget some unless he has a list of them. While discussing these points, some other questions may be considered, as the arrangement of fields.

317. Size of Farms. If one has sufficient capital, he should not buy too small a farm. The exact size will vary with the type of farming. Investigations in New York have shown that for general farms and dairy farms those farmers who have about 200 acres make much more than those with smaller areas. The most profitable apple farms also average larger than the smaller ones, 109 acres being the average size of a number of profitable ones, and 89) acres the average size of less profitable ones.

There are a number of reasons why the man with a fair-sized farm has an advantage. There are many farm operations that require two or more men for economical work. The small farm needs as much machinery as at large one. Either it must be under-equipped or else the 
machinery will not be used to good advantage. Idle machinery means lost money. A small farm also necessitates too small fields, and these require much more time for tilling and more fencing, for the area. The larger farm gives a chance to make a profit from the labor of more men, if their labor is well directed.

These remarks do not apply when we are considering the very large farm. In this case, there must be a manager who does not do field work, and his salary must be paid. With such establishments, the interest of the men is usually not kept up, and this alone is usually sufficient to cause a loss. The most efficient and most profitable farm is usually one where the owner works with the men, and has as many men working as he is able to manage without having to stop work himself. By working with the men, the amount accomplished is often doubled.

318. Shape and Location of Fields. The shape of fields has an important bearing on the time required to till them. Odd-shaped fields are very undesirable. Narrow fields or small fields require more labor and more fencing. A ten-acre field, $40 \times 40$ rods, requires 40 rods less fence than a field that is $20 \times 80$ rods. If this fence is kept up permanently, it will probably cost at least five to ten cents per rod per year for depreciation and repairs, depending on the kind of fence; in addition there is interest on the extrat money invested. At five cents per rod, the difference would be two dollars per year. But this is a fair rate of interest (5 per cent) on $\$ 40$. The square field is, therefore, worth $\$ 40$ more, or is worth $\$ 4$ more per acre. ${ }^{1}$

1The value of a farm is determined by its earning power. It should carn a reasonable rate of interest, here asiumed to be 5 per ent on the value. If a farm earns $\$ 2$ more, or if a change in it reduces expenses by $\$ 2$, the value of the land is $\$ 40$ more. 
The distance of the fields from the barn is also of very great importance in determining the value of the land. All the time that is lost in passing back and forth from distant fields must be charged against the earning power of the land. If it costs $\$ 1$ per acre in lost time to go to a field, and if the interest rate is 5 per cent, then a field near the barn is worth $\$ 20$ per acre more.

319. Topography is usually most important in its effects on the ease of cultivation and on the use of farm machinery. If the land is too steep, it interferes with or may prevent the use of harvesters, manure spreaders and gang plows. In some sections, the most serious results of steep hillsides is the erosion. In all sections there is some loss of the productive surface soil. In many cases the direction of the slope is important. The four-year average yield of apples in a township in western New York was 43 bushels greater on easterly than on westerly slopes. ${ }^{1}$ The difference is mostly due to the strong west winds.

320. Soils. The physical properties of soils are even more important than the fertility. The expense of labor is very much more on some soils than on others, not only because of the ease of tillage, but because of the number of day's of possible labor. If one can begin spring work a few days earlier and can go out after it rains a little more promptly, it may make a number of acres difference in the area that can be farmed. The physical properties also affect the possible kinds of crops and the danger of loss of soil fertility.

The natural fertility is more important than the temporary condition, that is, it is better to buy a soil that is 
naturally rich, but that is a little out of condition, than it is to buy one that is naturally poor, but that has been so fertilized that it is temporarily rich.

The drainage and freedom from stumps, stones, weeds and waste land must also be considered. In general, one can buy a farm that is in good condition cheaper than he can improve one that is not in good condition. Cleared fields do not often sell for enough more to pay for the cost of clearing. Fertile fields do not cost as much more than poor ones as it would take to bring up the poor land.

321. Neighbors. The neighbors are much more than a social question. With them one must "change work." They furnish a market for surplus stock. They may furnish inspiration that results in profits. They decidedly affect the selling value of a place.

It is usually of great importance to have the neighbors in the same kind of business. Good apples raised out of an apple region do not sell for what they are worth. A breeder of Jersey cows will find marketing difficult if his neighbors all raise Holsteins. Buyers will then come to the neighborhood for Holsteins, not for Jerseys. Such a man had better move, or change his breed. Purchasers always want to go to a neighborhood that is full of the desired article. The same principle applies in manufacturing. Some towns become centers for one article, others for another. Both buyers and skilled laborers are thus easier to secure. Each individual contributes to advertising the community, and in turn receives the benefit of all the other advertising. If one develops special markets for his products, these points may not apply; but they apply to most farmers. 
322. Improvements. It is nearly always cheaper to buy a farm with improvements than it is to improve one, provided one can secure the buildings and other improvements that are satisfactory. One exception is in the case of paint. A coat of paint nearly always increases the selling price more than it costs.

323. Other Factors Affecting Farm Values. There are a large number of other items of great importance that can only be mentioned here. Climate, healthfulness, distance to market, roadways, markets, shipping facilities, mail delivery, telephone, churches, schools, granges, water supply, taxes, and many more factors, affect the value of the farm and the profits that can be made from it.

324. Working Capital. Finally, it must be said that one should, if possible, have a fair-sized farm, and, at the same time, have sufficient capital to equip it. For most types of farming, the equipment and supplies will call for half as much money as is invested in the farm and improvements. For some kinds of farming, as truckgrowing, more working capital is needed, and for some, as grain-farming, less is necessary. One of the common causes of failure in city or country is the investment of too much of the capital in fixed forms.

\section{FARM LABOR}

If mankind consumed all that it produced, there would be no wealth. If a country is wealthy, it indicates that human energy is used effectively. The more effectively labor is used, the higher-priced it becomes. The more efficient farmers become, the fewer we need. If one man 
produces more than formerly, an increased city population can be supported. At the same time, the farmers' wants will become greater, and more men will be needed to make his machinery, pianos and furniture. Cities are, therefore, a necessary result of good farming.

The average farmer just about makes farm wages besides interest on his capital. His labor is his chief income. He is, therefore, as much interested in having farm labor high as are his hired men. Whether farm labor is high or low makes little difference with the farm-labor problem. The real problem is to use help to a better advantage than it is used by the average person, otherwise there is little or no profit in employing men. If labor is cheap, farm products will also be cheap, and the problem of making money by hiring remains exactly the same. The man who does not use labor effectively will lose money by employing help whether wages are high or low.

One of the most important points in efficient direction of labor is in so managing it that there is work at all times. To do this, one must plan ahead, and it is usually necessary to keep lists of work for rainy days, lists of things to be brought from town, etc., so that there will be as little lost time as possible. Machinery repairs and much work about the buildings that is often clone in good weather could just as well have been done long before during bad weather had it been thought of.

Hired men in the North are usually looking forward to farm ownership. It is often possible to interest such men in the plans of the farm by discussing plans with them. In dealing with all human beings, it is well to remember that, as a general rule, judicious commendation is better 
than criticism. At times, criticism is necessary, but it should not be constant or it will destroy interest. The hired man is no exception to the rule.

Some men are worth twice as much as others, but wages are fairly uniform. By paying 20 per cent more one may often secure a man who is worth nearly twice ats much.

One of the means that has accomplished most in the past few year's is in the use of larger machines and more horses per man. (See Appendix, Table 16.)

On the average, the value of staple products is measured by the cost to produce them. The world price of wheat is probably very close to the cost of production and transportation. One community may produce it at a loss and another make more than wages. If this law is true, an individual may make more than wages by working harder; by locating where the cost is below the average; choosing a farm that will produce out of proportion to the cost; locating near a market, and thereby gaining on transportation; increasing the production out of proportion to the cost; decreasing labor or other cost without a proportionate decrease in crop; foreseeing future conditions and preparing to meet them; locating where the standard of living is higher than his own.

Many foreinners succeed in America more by their lower standard of living than by any other means. Studies in New York seem to show that the most profitable farms spend more than the less profitable, but that they spend so efficiently as to get a greater return for each dollar spent. This is the way in which many of our most successful American farmers have succeeded-not by decreasing expenses, but by spending wisely. 


\section{FARM RECORDS AND ACCOUNTS}

One of the most important questions of farm management is that of records and accounts. It is by studying the results of well-kept records that one is able to extend or retrench on the different parts of the business, so as to make more money in the future.

325. Kinds of Accounts to Keep. Records of different cows for the dairyman have been discussed under cattle. The farm map, showing drainage lines, maps showing varieties of trees in an orchard, etc., are necessary on many farms. If all business is not done on a cash basis, it becomes necessary to keep records of accounts that are owed or that are due. It is also very clesirable to keep a record of the cost and receipts from at least the leading factors in the farm business. An account may be kept with cows, potatoes, poultry, horses, etc., showing on which we are making or losing money.

326. Methods of Keeping Accounts. One may merely make a list of his property at the end of each year, with values. Such a list is called an inventory. The difference between the inventories at the beginning and the end of the year is the gain or loss. This is the most important single record to keep. It does not show what caused the gain or loss, but shows the net result. A loss may have been due to large personal expenses, or to cows or potatoes, while all other sections of the business may show a profit.

In order to show where the gains and losses occurred, we must keep a work report and a ledger. It is not necessary to keep any other books.

A convenient form of work report is shown on page 381 . 


\begin{tabular}{|c|c|c|c|}
\hline & & $\begin{array}{l}\text { Man, } \\
\text { hours }\end{array}$ & $\begin{array}{l}\text { Horse, } \\
\text { hours }\end{array}$ \\
\hline April 1... & Hauled manure to corn field. & 18 & 36 \\
\hline April 2... & Hauled manure to corn field (Smith).. & 8 & 16 \\
\hline April 2... & Hauled wood for household (self) ..... & 7 & 14 \\
\hline April 3... & Plowed for corn (Smitlı) ......... & 8 & 24 \\
\hline April 3... & Hauled wood for household (self). & 8.5 & 17 \\
\hline
\end{tabular}

1909

\begin{tabular}{|c|c|c|c|c|c|c|c|c|}
\hline \multirow[b]{2}{*}{$\begin{array}{l}\text { April } 1 \\
\text { April } 2 \\
\text { April } 3\end{array}$} & \multicolumn{2}{|c|}{ IIorses } & \multicolumn{2}{|c|}{ Cows } & \multicolumn{2}{|c|}{ Poultry } & \multicolumn{2}{|c|}{ Household } \\
\hline & $\begin{array}{c}\text { Hrs. } \\
1 \\
1 \\
3\end{array}$ & $\begin{array}{c}\text { Min. } \\
25 \\
20 \\
30\end{array}$ & $\begin{array}{c}\mathrm{Hrs} . \\
3 \\
2 \\
4\end{array}$ & $\begin{array}{l}\text { Min. } \\
30 \\
30 \\
1.5\end{array}$ & $\begin{array}{c}\text { Hrs. } \\
1\end{array}$ & $\begin{array}{c}\text { Min. } \\
15 \\
15 \\
15\end{array}$ & $\begin{array}{c}\text { Hrs. } \\
2\end{array}$ & $\begin{array}{l}\text { Min. } \\
30\end{array}$ \\
\hline
\end{tabular}

It combines a work report and diary of farm work. A second page in the same book may be used for a record of the time spent in doing chores. At the end of the month, the total time is charged in the ledger to each of the accounts. This requires very little time to keep, and little time for posting the results. If one does not care for the diary, the entire report may be kept in the second form, adding such headings as corn field, orchard, oat field. potatoes, etc.

Two accounts from a ledger are given on pages 382 and 383. A few entries are made to show the method. Ledger accounts kept in this way are complete, so that no daybook or journal is necessary. For explanation of the principles of accounting, see the Farmer's Business Handbook. or the Cyclopedia of American Agriculture. The systems there given use a daybook-journal, which the writer does not keep and does not consider to be essential. 
April 1 Amount on hand. .

\begin{tabular}{|c|c|c|}
\hline 1909 & Cows & Dr. \\
\hline April 1 & Inventory $\ldots \ldots \ldots \ldots \ldots \ldots \ldots$ & $\$ 48000$ \\
\hline April 1 & 1 calf, Bessie ${ }_{*}^{74983}$ - pure-bred $\underset{*}{*} \underset{*}{*}$ & 3700 \\
\hline April 30 & 150 hours labor, April, @15 cents........ & 2250 \\
\hline April 30 & 40 hours horse labor @ 10 cents.......... & 400 \\
\hline April 30 & Hauling milk & 240 \\
\hline April 30 & 3 tons hay, from hay field. ${ }_{*}$ & $2+00$ \\
\hline March :31 & 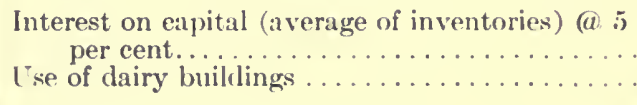 & $\begin{array}{ll}25 & 50 \\
50 & 00\end{array}$ \\
\hline & Balance-gain (red ink).. & $\mid \begin{array}{rr}\$ 1,524 & 30 \\
206 & 16\end{array}$ \\
\hline & & $\$ 1,73046$ \\
\hline $\begin{array}{l}1910 \\
\text { April } 1\end{array}$ & Inventory. . & $\$ 5.3000$ \\
\hline
\end{tabular}


$\mathrm{Cr}$.

April $7 \quad 1$ calf $(\$ 35$; express, $\$ 2) \ldots \ldots \ldots \ldots \ldots \ldots \ldots \ldots$

April 8 Household supplies .................. 300

April 8 Horses shod......................... 120

April $8 \quad 70$ pounds clover seed.......................... 1200

April 30 Hauling milk (paid Johnson)............ 240

Cr.

April 101 ealf, Della's, seven-eighths Jersey, to John Doe,

April 15

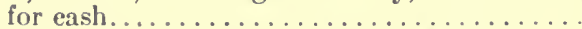

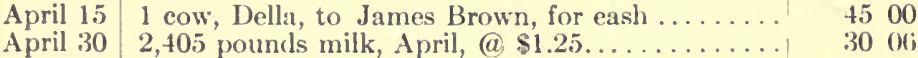

1910

April 1

$*$
Estimated value of manure for year $\ldots \ldots \ldots \ldots$

$30 \mathrm{OH}$

April 1

Inventorv (written in red ink)

12000

5.3000

$\$ 1,7: 30+6$ 


\section{QUESTIONS AND PROBLEMS}

1. If there is both sandy and clay land in your community, how soon after a rain can each be tilled? How many days difference is there in the spring?

2. To what extent does topography of farms in the community affect erosion, winds, the use of machinery?

3. How much more time will it take to raise ten acres of corn on a field one-half mile from the buildings than to raise an equal area adjacent to the buildings? How much more would the nearer land be worth per acre?

4. What area will a six-foot binder cut during a harvest period of twelve days, working twelve hours a day? (Obtain estimates from farmers.)

5. When must one begin plowing a 40 -acre field with a 14 -inch plow in order to have it completed by October 1? (Obtain estimates from farmers.)

6. How many farmers in your community keep accounts to show the gain or loss on different erops, or on the farm business as a whole?

In answering the following questions, study Appendix Tables 14-17.

7. Which has increased more rapidly, the population or the area of farm land?

8. Has there been any decided change in the area of improved land per farm during the past fifty years?

9. What changes in the total value of farm property and in the value per farm? In the value per acre of farm land?

10. What changes in the value of farm implements per farm and per aere? Compare with question No. 13.

11. Is the value of live stock per farm increasing or decreasing?

12. Are the values of farm products per farm and per acre inereasing or decreasing?

13. How are the number of acres and number of horses per male worker changing?

14. Is the per cent of rented farms increasing or decressing? Is it increasing in your community? Why?

15. How do farm wages compare with those formerly paid? Are the wages in your community higher than in 1900? Are the farmers more or less prosperous than at that time?

16. How are the farm erop yields per acre and values per bushel changing? 
17. Which crop shows the most rapid increase in total production? 18. How do the present prices of farm animals compare with those formerly paid? Which kind of animals are increasing in total number most rapidly?

\section{LABORATORY EXERCISES}

\section{Choice of a Farm.}

Fill ont a score card like the following, for one or more farms:

$$
\text { Score Card-Economic Value of Farms }
$$

Size-

1. Adapted to kind of farming

\begin{tabular}{|c|c|c|}
\hline $\begin{array}{l}\text { Stand- } \\
\text { ard for } \\
\text { a gene. }\end{array}$ & \multicolumn{2}{|c|}{ Points deficient } \\
\hline 20 & $\ldots$ & $\ldots$ \\
\hline $\begin{array}{l}30 \\
30\end{array}$ & $\cdots$ & $\therefore$ \\
\hline $\begin{array}{l}30 \\
10 \\
20\end{array}$ & $\begin{array}{l}\ldots \\
\cdots\end{array}$ & $\begin{array}{l}\cdots \\
\cdots\end{array}$ \\
\hline $\begin{array}{l}80 \\
40\end{array}$ & $\ldots$ & $\therefore$ \\
\hline 90 & $\ldots$ & . \\
\hline $\begin{array}{l}10 \\
20\end{array}$ & 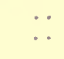 & $\therefore$ \\
\hline 50 & . & . \\
\hline 50 & $\cdots$ & . \\
\hline 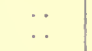 & $\because$ & $\because$ \\
\hline 40 & . & . \\
\hline $\begin{array}{l}40 \\
50 \\
30 \\
20 \\
40 \\
10 \\
30 \\
30\end{array}$ & $\begin{array}{c}\ldots \\
\cdots \\
\cdots \\
\cdots \\
\cdots\end{array}$ & $\begin{array}{l}\cdots \\
\therefore \\
\therefore \\
\cdots \\
\therefore \\
\therefore\end{array}$ \\
\hline 10 & $\cdots$ & $\cdots$ \\
\hline
\end{tabular}


Score Card-Economic Value of Farms, Continued

\begin{tabular}{|c|c|c|c|}
\hline \multirow[b]{2}{*}{$\begin{array}{l}\text { WatER SUPPLY - } \\
\text { 28. Running wa }\end{array}$} & \multirow{2}{*}{$\begin{array}{l}\text { Stand. } \\
\text { ard for } \\
\text { a gene. } \\
\text { ral farm } \\
\\
40\end{array}$} & \multicolumn{2}{|c|}{ Points defient } \\
\hline & & & \\
\hline 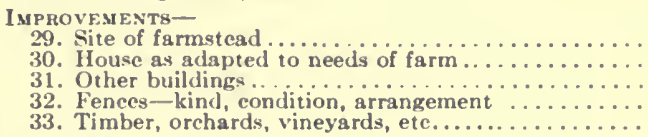 & $\begin{array}{l}10 \\
60 \\
60 \\
30 \\
20\end{array}$ & $\begin{array}{l}\cdots \\
\cdots \\
\cdots\end{array}$ & $\begin{array}{l}\cdots \\
\therefore \\
\cdots\end{array}$ \\
\hline 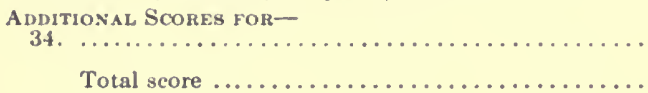 & $\frac{\cdots}{\cdots}$ & $\frac{\cdots}{\cdots}$ & $\frac{\ldots}{\ldots}$ \\
\hline
\end{tabular}

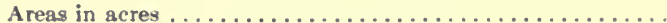

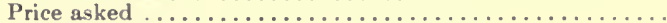

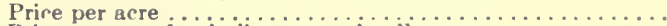

Price per acre lexcluding waste land] ..............

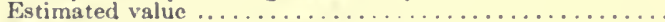

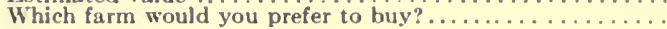

Name

Date

\section{DIRECTIONS}

If the points are not properly distributed for the kind of farming to be followed. assign what you consider to be correct. The total need not be exactly 1,000.

No points are assigned for climate. This should be considered when judging farms in different regions or at different altitudes, or when topography or proximity to water make a difference in the climate of the farms that are being compared.

The number of points assigned to each subject is not the limit but is suggestive. Deduct more than the total number when it seems advisable. For instance, distance to market may absolutely disqualify a farm if one wishes to sell milk, while it is much less important for a grain, hay or sheep farm. Similarly, there are conditions that may call for higher deductions on any of the points. Credits for exceptional values, such as superior fences, lange orchards, probability of increase in value, etc., may be added under number 34 .

\section{Farm Inventory.}

Make an inventory of all the property on a farm, not including household articles. What per cent of the capital is in real estate? In machinery? In each of the other Important items?

\section{Farm Accounts.}

Enter a set of farm accounts for a part of a year, and balance the books. (See The Farmers' Business Hand Book, pp. 1-115, or Cyclopedia of American Agriculture, Vol. IV, pp. 216-232.)

\section{Farm Accounts.}

Keep an account with chickens, horses, garden, or some crop, and determine the profit or loss. 


\section{A Farm Problem.}

A farm problem involves the application of all the principles learned in the study and practice of agriculture to the management of a particular farm. It corresponds to the plans and specifications and financial estimates that an architect makes for a building. Such a plan will require a considerable amount of time and thought, but it is well worth while. Such a problem may be written up by the following outline:

(1) Description of the farm,--location, areas, fields, soils, previous crops, buildings, fences, roads, markets, etc.

(2) Inventory of property on the farm. (May be replaced by a list of things necessary.)

(3) Proposed system of management. The chief features of the plan outlined for at least five years.

(4) Crops (for given year):

(a) Crop, field, area, estimated yield per acre; total yield. To be filled out for each field.

(b) Cash crops.

(c) Crops for feed, concentrates-roughage-bedding.

(d) Crops saved for seed.

(5) Food for stock:

(a) Cows, horses, hens, ete., esch itemized per animal, and total.

(b) Total food required.

(c) Food to be purchased.

(6) Animal products:

(a) Products of wool, nilk, lamb, colts, etc.

(b) Products sold.

(7) Receipts itemized.

(8) Expenses itemized.

(9) luventory at end of year, allowing for depreciation, increases in value, etc. (The depreciation and losses of horses and cows is usually about 15 per cent; of chickens, 40 per cent; of tools, 12 to 15 per cent.)

(10) Financial results:

Balance equals receipts, less expenses.

Farm incone equals balance, plus or minus change in inventory.

labor ineome equals farm income, minus interest on capital, or 5 per cent on average of two inventories.

If a tenant farm, labor income of tenant.

Pereentage on investment male by landlord.

In a similar way, estimate may be male for a series of years. 


\section{Plans for a Farmstead.}

Make a plan, showing the arrangements of farm buildings as you think they should be arranged on some farm. (For exercise on arrangement of fields, sce page 280.)

\section{Plans and Estimates for Farm Buildings.}

Make a plan for a small farm building, a bill of lumber and other materials required to make it, and estimate the cost.

87. Business Forms.

Make out an order for goods, a contract with a hired man, a lease, a note, a receipt.

\section{COLLATERAL READING}

Forest Service, Circular No. 159. The Future I'se of Land in the United States.

Farmers' Bulletins Nos.:

242. An Example of Model Farming.

245. The Renovation of Worn-Out soils.

272. A successful Hog and Seed ('orn Farm.

280. A Profitable Tenant Dairy Farm.

299. Diversified Farming under the Plantation System.

310. A Successful Alabana Diversified Farm.

312. A Successful Southern Hay Farm.

325. Small Farms in the Corn-Belt.

326. Building Up a Run-Down Cotton Plantation.

337. ('ropping Systems for New England Dairy Farms.

355. A successful Poultry and Dairy Farm.

347. The Repair of Farm Equipment.

62. Marketing Farm Produce.

126. Practical Suggestions for Farm Buildings.

Cyclopedia of American Agriculture, Vol. I, pp. 133-322; Vol. IV, pp. 215-239, and Index of all volumes.

The Farmers' Business Hand-Book, by I. P. Rolserts.

How to (hoose a Farm, by T. F. Hunt.

Farm Management, by F. IV. Card.

The Farmstead, by I. P. Roberts. 


\section{CHAPTER XVII}

\section{THE FARM HOME}

Farming is one of the few occupations in which the business and the home are united. So close is this union that the distinction between the business and the personal and household matters is not often thought of. Of the many things that have to do with the making of a comfortable farm home, we shall here consider only three points, - the arrangement of the grounds, the type of buillings, and the modern conveniences.

327. The Farmyard. The first essential for an attractive farmyard is neatness. After this, a little attention to planting will accomplish the rest. Nothing is more attractive than a good lawn, add to this a few trees and shrubs and flowers, and nearly any farmyard will be attractive, The shrubs should be planted in groups in the corners, around the house, and to serve as screens to shut off undesirable views. Scattered, aimless planting is not effective. Flower beds should also be placed at the sides and in corners, so as to keep the center of the lawn open. Such an arrangement is not only attractive, but it also makes the (are of the lawn much easier. Compare Figs. 196 and 197 in this respect. At the same time, over-planting should be avoided. The farmyard should not be a pattern of city properties, unless it is the country home of some city man who is able to hire a gardener to take care of it. The farm home should be attractive. but not ostentatious. 


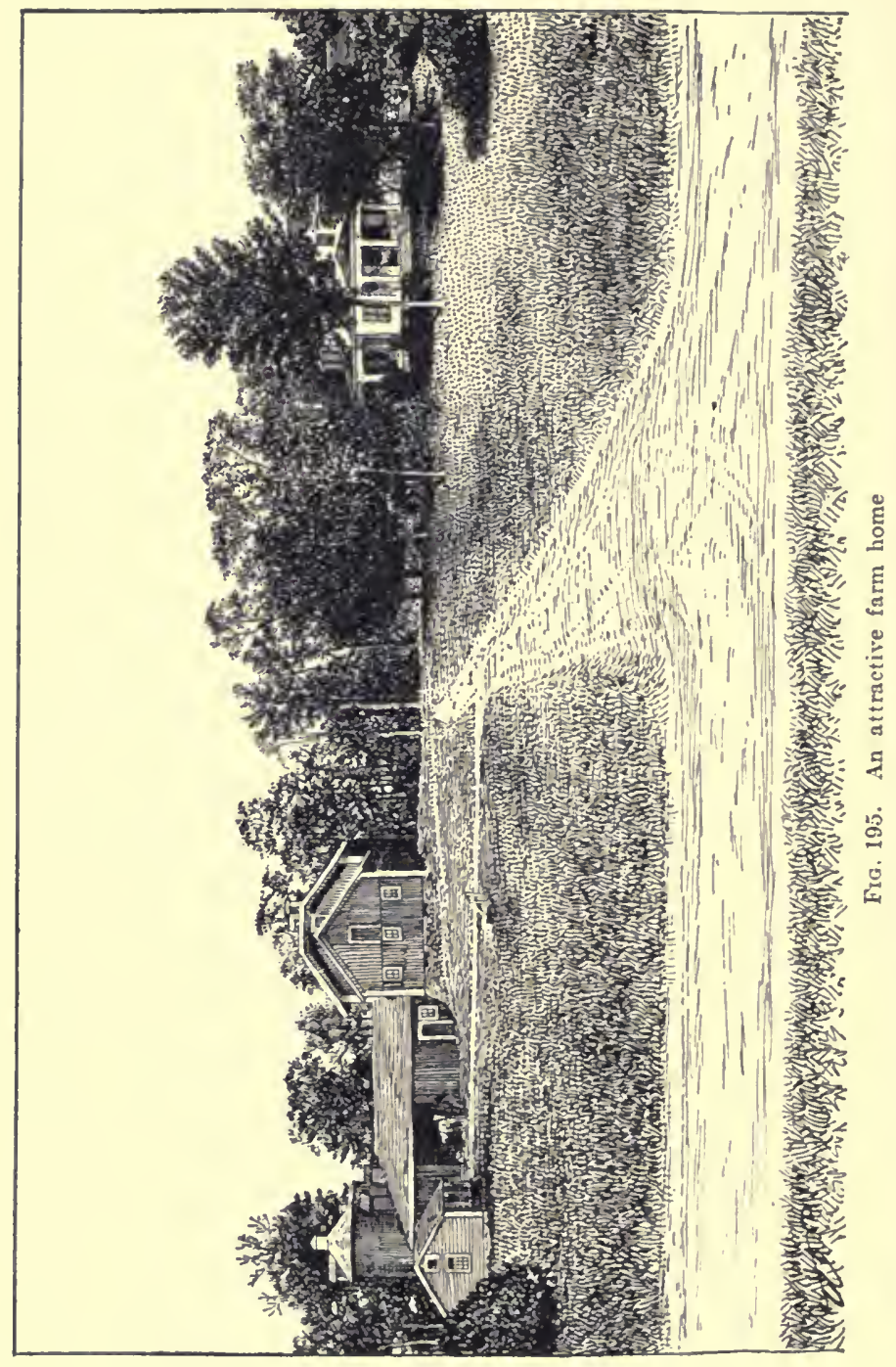


328. The Farmhouse. The type of house that is suited to the city is wholly out of place in the country. The superabundance of gables and striking shapes may not be conspicuous in a city, but in the country they give an appearance of lack of dignity. A house that is to stand alone must have strong lines.

City houses are almost always too tall to look well if standing alone. When fanked by equally tall neighbors, they may look better than low buildings, but when set off by themselves, the appearance is

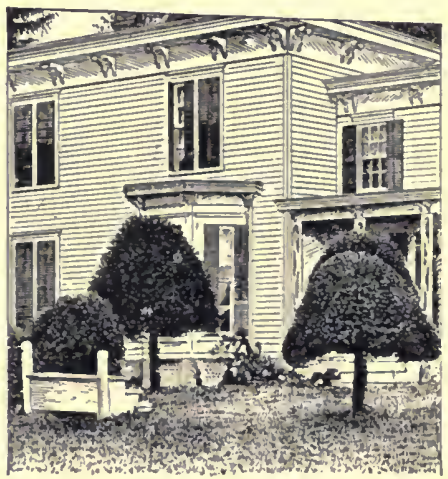

Frg. 196. Scattered planting of trees pruned in artificial shapes. An open lawn would present a better appearance. entirely changed. It is much like a forest tree that appears well when surrounded by tall trees, but that looks like an exclamation point when standing by itself.

329. Modern Conveniences for the Farm Home. As soon as a farmer becomes able, he should have water piped into the house to supply the kitchen and bathroom. This not only saves hours of labor for the farm women, but it adds to the comfort and health of the family. In many sections of the country an elevated tank and a windmill will supply the water. In other cases, water from a spring may be piped into the house, or a reservoir may be established on a hillside, or a hydraulic ram may pump up the water.

The obstacle that usually deters farmers from installing 
a water system is the supposed difficulty of disposing of the drainage water. This is usually not a difficult problem. The bathroom fixtures and plumbing should ordinarily

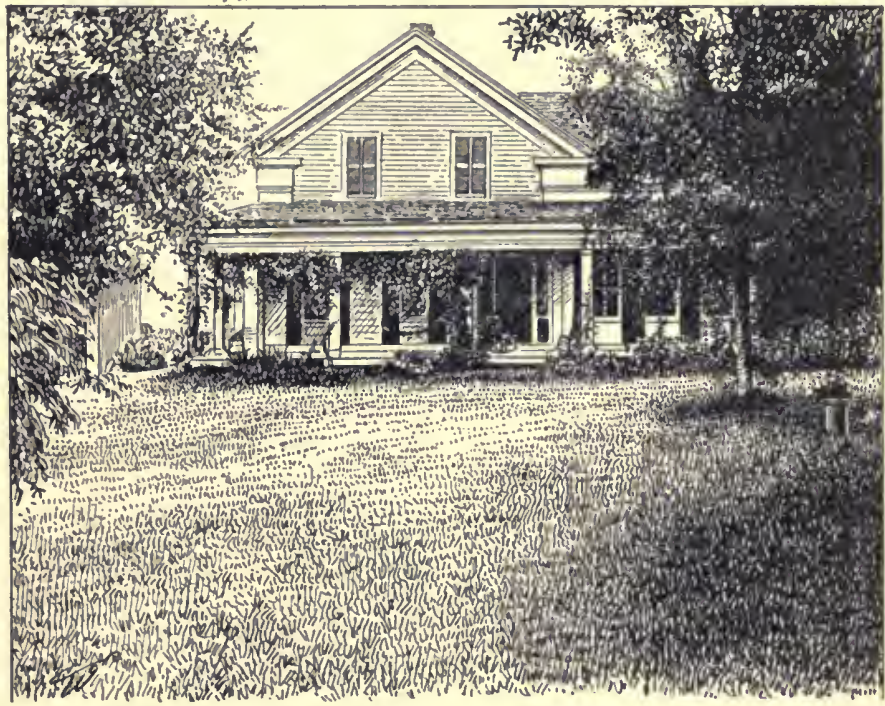

Fig. 197. Well-planted farm-yard. Trees at the sides, flowers in the corners and about the house, open lawn. Contrast with Fig. 196

be installed by a plumber. All the outsicle work may be done with farm labor. The drain-pipe should extend twenty to one hundred feet from the house, and should be made of four-inch tile with all joints closed by cement. This pipe may discharge into a cesspool that is merely a hole in the ground and that is walled with stone laid without mortar. Such an arrangement is satisfactory if the ground is very porous, and if no wells are within any possible range of contamination. The sewage should not be emptied directly into streams or ponds, 
If the land is not porous, or if there is any danger of contamination of wells, a cement collecting tank, or septic tank, should be provided. A tank $3 \times 6$ feet and 3 feet deep is large enough for a family of six persons. While the sewage remains in this tank, the bacteria decompose the solids contained in it, so that it may be distributed by underground irrigation in a lawn or field. The inlet pipe should have a bend at the end so as to direct the water lownward. The outlet pipe should slope upward so as not to allow the scum to run off, as this scum is filled with the bacteria that are essential in destroying the sewage. The outlet pipe will need to be four to eight feet long for

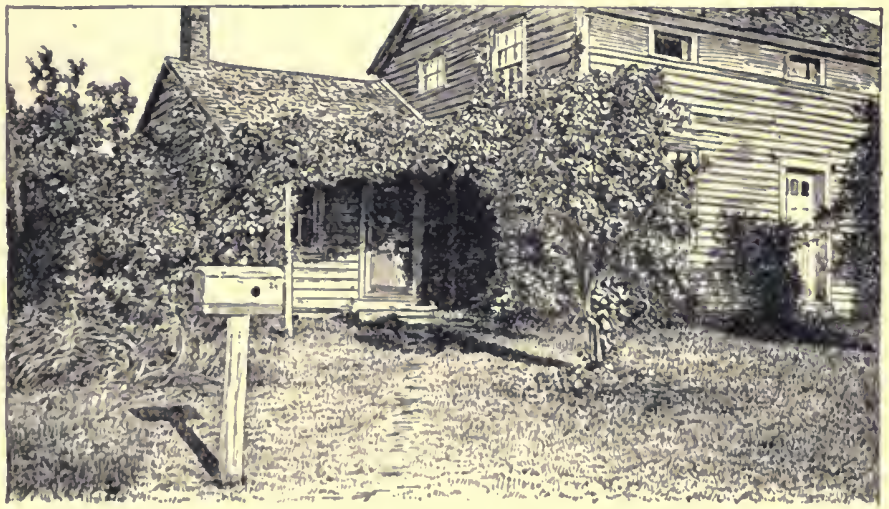

FIG. 198. A dilapidated farmhouse made attractive by vines and flowers

each person, depending on the soil. It is made of tile drainpipe laid with a fall of one inch in sixteen feet. This prevents the water running to the lower end so rapidly as to cause a wet place there. The water seeps out the entire length of the drain. 
If the farm is tile-drained, the septic tank may be connected with the drainage system. The entire cost of such modern improvements, aside from the well or

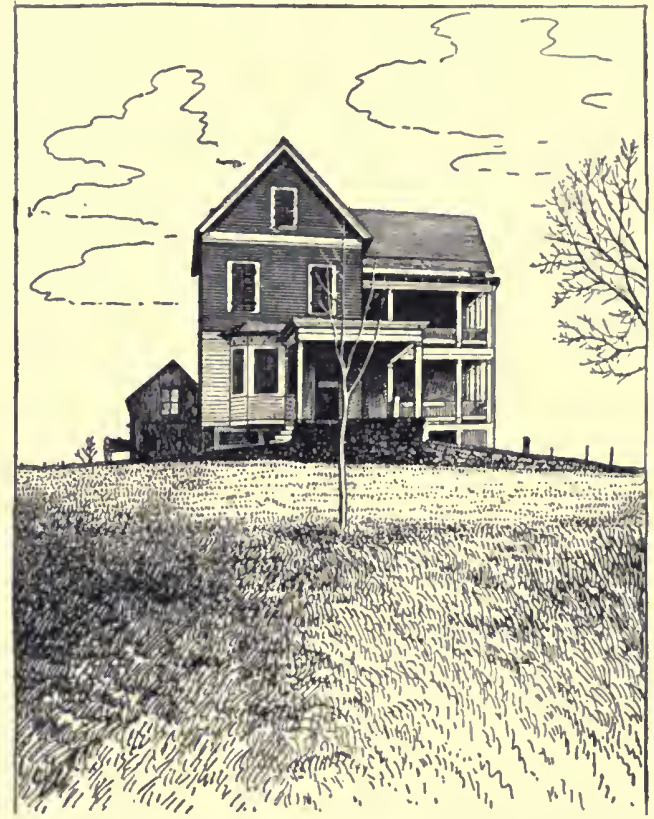

FIc. 199. The city house in the country. A tall house standing alone on a hill,- conditions that demand a low house. Trees planted at the sides would help the appearance. Contrast with Fig. 195.

other water-supply, need not exceed $\$ 150$ to $\$ 300$. The writer knows of one system with an elevated tank in the barn; sink in the kitchen, bathtub, eloset and wash-bowl in the bathroom, and a system of sewage disposal, complete that was put in for less than $\$ 250$. Nothing of equal cost will add more to the comfort of a farm home. Other con- veniences may be added as the means permit. 


\section{LABORATORY EXERCISES}

\section{Water System for a Farmhouse.}

Make a plan for a water-supply, and sewage disposal, for some farm in the neighborhood. Obtain estimates of the cost of installing the system, including bathroom fixtures and kitchen sink.

\section{COLLATERAL READING}

F'armers' Bulletins Nos.:

126. Practical Suggestions for Farm Buildings.

134. Tree-Planting in Rural School Grounds.

185. Beautifying the Home Grounds (applies to city homes mostly).

270. Modern Conveniences for the Farm Home.

317. Convenienees for the Farm Home, pp. 5-10.

342. A Model Kitchen, pp. 30-32.

155. How Insects Affect Health in Rural Districts.

Cyclopedia of American Agriculture, Vol. I, Pp. 231-245; 278-323. The Farmstead, by I. P. Roberts.

Farm Buildings, Sanders Publishing Company, Chicago.

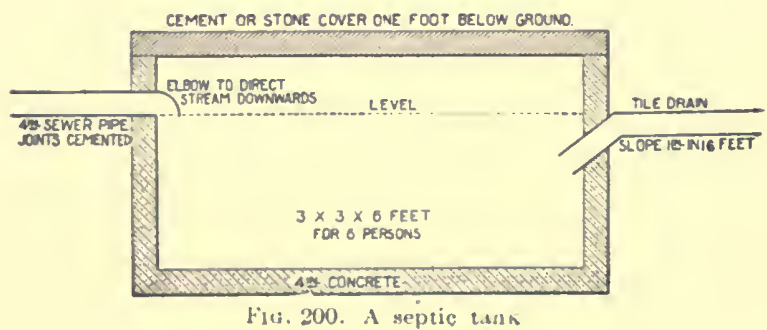




\section{CHAPTER XVIII}

\section{THE FARM COMMUNITY}

We commonly attribute success to the individual because our observations are usually confined to one neighborhood. If we compare different communities, we shall at once see that the success of an individuai is as much dependent on the community as it is on himself. If the community secures a reputation for good products of any kind, every man shares in the rewards. If it becomes noted for poor products, even the good products will not sell well, because they come from a locality that has it bad reputation. A certain county fruit-growers' society subscribed funds to spray the neglected orchards of the county, because they could not afford to have any poor apples go out from that county. (See, also, page 376.)

If one wishes to sell his farm, some of the first questions asked are about the schools, churches, roads, and the moral standards of the people. Not long ago, the writer visited two sections of the same river valley. The soils, crops and railroads were equally grood; but, in one neighborhood land was worth $\$ 30$ per acre, and in the other, $\$ 50$. The difference was wholly due to the moral standard of the community. One was composed of self-respecting farmers, in the other the chief interest of the young men was said to be in fast horses and whiskey.

The prospective buyer is also influenced by the general appearance of the community. If the buildings are un- 
painted, the barns covered with patent-medicine advertisements, the roadsides full of weeds, the fences down, it indicates that the community is not prosperous. No matter how well some one man's place may look, a buyer will be afraid that there is some fundamental trouble with the region. He will ask himself whether the farms are so poor that their small returns have to be supplemented with an income from signboards. He will fear that the land is so poor that it takes all the farmer's energy to make a living so that he has no time to clean up.

The community affects one's happiness as well as his profits. At the present time, the ideal in many farming sections is to make enough money so that one can move to town to live. One of the arguments that was presented in the central West to the Commission on Country Life, to show that farming was all right, was that the farmers were so prosperous that they were selling or renting their farms and moving to town. If the farm home and the farm community are all right, then the farm will be a place to live and die on, not merely a place to run away from. It is interesting to note the increasing number of city men who are retiring to farms at the same time that farmers are retiring to the towns.

It is the duty of every loyal citizen to take an active part in improving his community. The best place to begin such an improvement is by cleaning up the roadsides and fence-rows, and keeping the farmyard neat and attractive.

But the interest should not stop here. The obligations to the grange, the school, the church, are as positive as are the obligations to keep the corn-field clean. It makes 
no difference whether one belongs to all these organizations or not. They affect the community, and a loyal citizen is interested in everything that affects the community. Coöperative organizations of many kinds are needed, if farmers are to be able to deal successfully with the city organizations.

A reasonable amount of time spent on these civic duties will not detract from the farm profits. If one does some of this public work, he is likely to be more alert, and because of the recreation that it gives, he will be better able to conduct his farm. If one does nothing but work, his senses will eventually become dulled, his interest in life lost, his step will become slower and his smiles less frequent because he misses the diversion of community life that all humanity requires. Occasionally, a man neglects his farm because of these interests, but this is not necessary. In fact, his influence in the community is usually lost if his farm is neglected. The ideal citizen is one who works quietly, doing those things that lie first at hand; one who keeps his own place neat and prosperous, and who is ever ready to assist a public enterprise without becoming officious.

\section{QUESTIONS}

(See Appendix, Tables 11, 12 and 13.)

1. What are the most important agricultural products in the United States?

2. Which agricultural products show the greatest net exports? Imports? Which class of articles are more discussed in framing tariff laws?

3. Of the imported products, which ones might our government encourage American farmers to produce?

4. Which kind of exports are more desirable for a nation, - animals, meat and butter, or grain and cottonseed? Why? 
5. What agricultural societies or organizations are there in your region? What work is each doing?

6. What social, religious and educational organizations are there? What kind of work does each do?

7. Are the farms looked upon as permanent homes, or do the farmers desire to move to town as soon as possible?

\section{COLLATERAL READING}

Cyclopedia of American Agriculture, Vol. IV. The State and the Farmer, by L. H. Bailey.

Chapters in Rural Progress, by Kenyon L. Butterfield.

Farmers' Bulletins Nos.:

327. The Conservation of Natural Resources.

340. Declaration of Governors for Conservation of Natural Resources. 


\section{APPENDIX}

\section{TABLE 1}

\section{Apparatus and Equipment}

Good work in agriculture may be done with very little equipment. It is desirable that the school be equipped for regular laboratory work in botany, chemistry and physics. Ordinarily, the same microscopes and balances that are used for botany and physics may be used in agriculture, so as to avoid the expense of duplication. The Babcock milk-testing outfit furnishes an apparatus to demonstrate centrifugal force to a class in physics. Such of the following equipment as is not already on hand is desirable for a class of ten:

Two compound microscopes, magnifying to 500 diameters, to cost $\$ 18$ to $\$ 25$ each.

Two balances, weighing to centigrams.

One spring balance.

Ten lenses or small magnifying glasses. (Students should own these.)

One Babcock milk-testing outfit complete, with special bottles for testing skim-milk. May be purchased of the Creamery Package Manufacturing Co., ('hicago, Ill.

One saw, square, hammer, etc.

One graduate, $100 \mathrm{cc}$.

Three thermometers.

Three tall lamp chimneys, or large glass tubes.

One dozen pint fruit-jars.

One dozen quart fruit-jars.

One-half dozen beakers (drinking-glasses may be substituted).

One dozen four-inch flower-pots, with saucers, and one dozen six-inch.

Four dozen test tubes.

Six porcelain crucibles (iron spoons may be used).

One gasoline burner or laboratory burner (a stove may be used).

Ten tape measures.

One set of samples of fertilizing materials. 
Fertilizing materials for exercises 52 and 57 , if these are given. Six bushels of lime and 15 pounds of alfalfa seed, if exercise No. 58 is given.

One pound of lime.

One-half pound copper sulfate.

One pound resin.

One-fourth pound tallow.

One ball No. 18 knitting cotton.

Land,-any amount from one-fourth acre to a farm.

If the school does not have chemical supplies, apparatus and chemicals for preparing nitrogen, oxygen, carbon-dioxid and hydrogen will be needed. (See a text book of chemistry.)

Bottles, tin cans and other supplies may be brought from the homes by the students as needed.

\section{TABLE 2}

\section{Agricultural Library}

Fortunately, there are so many good bulletins on agriculture that a good library may be secured at little expense.

The school should secure a complete set of the Farmers' Bulletins of the United States Department of Agriculture. These may be obtained from the Congressman of the district or by writing to the Secretary of Agriculture, Washington, D. C. These bulletins should be bound or should be punched and tied into volumes, with manila covers. Regular binding, which will cost $\$ 6$ to $\$ 12$, is to be preferred.

The teacher or members of the class may write for additional copies of such Farmers' Julletins as are nuch used for collateral reading, so that each student may have his own copies of the important numbers.

Ask the Seeretary of Agriculture, Washington, D. C., to place the sehool on the maling list, to receive the monthly list of publications, and to receive the following:

One copy of ('ircular No. 4, Division of Publication; Farmers' Bulletin Subject Index; one copy of the List of Publications for free distribution; one copy of the list of Publications for sale. Bulletins in the former list will be sent free to any address; those in the latter list may be purchased, or some of them may be secured from Congressmen.

Write to your Congressman for such copies of the Yearbook of the 
Department of Agrieulture as he may have for distribution, stating that they are for the sehool library.

Write to your State Experiment Station (see page 403) for copies of available bulletins and reports, and ask to be placed on the mailing list.

Write to the State Board of Agriculture, asking whether it has publications for distribution.

Copies of a few good farm papers and country-life magazines are desirable for the reading-table.

\section{REFERENCE BOOKS}

The following books are referred to for collateral reading. As many of these as possible should be secured. If the school can spend only $\$ 20$ for reference books, the writer would recommend the Cyclopedia of American Agriculture as containing the largest amount of information for the price. Most of the other books in the list should be purehased as soon as possible. Many other books are desirable if they ean be afforded, particularly those that treat of important specialized agrieultural interests of the state. The exact order of purchase will depend on the type of farming in the region.

1. Cyclopedia of American Agriculture, four volumes, by L. H.

Bailey..........................\$20 00

2. The Prineiples of Breeding, by E. Davenport ........ 250

3. Chemistry of Plant and Animal Life, by Harry snyder.... 125

4. Physies of Agriculture, by F. H. King ........... 175

5. The Soil, by F. H. King . . . . . . . . . . . . 50

6. Soils, by S. W. Fletcher. (Not so difficult as No. 5) .... 200

7. Soils and Fertilizers, by Harry Snyder............. 125

8. Fertilizers, by E. B. Voorhees ............... 125

9. The Fertility of the Land, by I. P. Roberts ......... 150

10. Bacteria in Relation to Country Life, by J. G. Lipman... 150

11. The Cereals in America, by T. F. Hunt.......... 175

12. The Forage and Fiber Crops in Ameriea, by T. F. Hunt... 175

13. The Principles of Vegetable-Gardening, by L. H. Bailey . . . 125

14. The Principles of Fruit-growing, by L. H. Bailey...... 150

15. The American Apple Orchard, by F. A. Waugh ........ 100

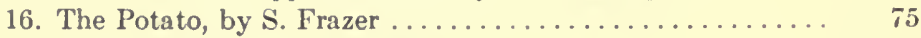

17. Corn Plants, by Leroy Sargent ................ 75

18. Feeds and Feeding, by W. A. Henry ........... 200 
19. The Feeding of Animals, by W. H. Jordan. (More diffieult than

List price No. 18.) .......................... \$1 50

20. Types and Breeds of Farm Animals, by C. S. Plumb.... 200

21. The Horse, by I. P. Roberts .............. 125

22. The Farmstead, by I. P. Roberts .............. 150

23. The Farmers' Business Hand-Book, by I. P. Roberts..... 125

24. How' to Choose a Farm, by T. F. Hunt .......... 175

25. Farm Management, by F. W. Card ............. 200

The publishers are as follows: Nos. 1, 3, 5, 7, 8, 9, 10, 13, 14, 19, $21,22,23,24$, The Macmillan Co., 64-66 Fifth Avenue, New York. Nos. 2, 20, Ginn \& Co., Boston and Chicago. No. 4, F. H. King, Madison, Wis. Nos. 6, 25, Doubleday, Page \& Co., New York City. Nos. $11,12,15,16$, Orange Judd Co., New York City. No. 17, Houghton, Mifflin \& Co., New York City. No. 18, W. A. Henry, Madison, Wis.

\section{TABLE 3}

Addresses of Agricultural Colleges and Experment Stations and the United States Department of Agriculture

When not otherwise indicated, the college and experiment station are at the same place. Any letter addressed to the "Agrieultural College" or "Experiment Station," with proper post-office address, will reach the institution.

\section{AlabaMa -}

College of Agriculture and Experiment Station, Auburn.

('anebrake Station, Uniontown.

Tuskegee Station, Tuskegee.

AlaskA-Sitka.

Arizona-Tucson.

Arkansas-Fayetteville.

California-Berkeley.

Colorado-Fort Collins.

CoNxecticut-

state Station, New Haven.

Agricultural College and Storrs

Experiment Station-Storrs.

DELAWARE-Newark.
FLorid - Gainesville.

Georgia-Experiment.

HAWAII-

Federal station-Honolulu.

Sugar Planters' Station-Honolulu.

IDAHO-Moseow.

IlliNoIS-Uribana.

INDLANA - Lafayette.

Iowa-Ames.

KAvsas-Manhattan.

KеNтUсKY-lexington.

Louisiana-Baton Rouge.

MAINE-Orona.

Maryland-College Park. 
Massaciuveetrs-Amherst.

Michigan-Fast Lansing.

Minnesota-St. Anthony Park, St. Paul.

Mississippi-Agricultural College.

Missouri-

College Station-Columbia.

Fruit Station-Mountain Grove

Montana-Bozeman.

Nebraska - Lincoln.

Nevado-Reno.

New Hampshre-Durham.

New Jersey-New Brunswick.

New Mexico-Agricultural College.

New York-

State Station-Geneva.

College of Agrieulture and Cor-

nell Experiment StationIthaca.

Nortu Carolina-

College Station-West Raleigh. State Station-Raleigh.
Nortu Dakota-Agricultural College.

Онго一

Experiment Station-Wooster. College of Agriculture-Columbus.

OKLAномa-Stillwater.

Oregon-Corvallis.

Pennsyluania - State College.

Porto Rico-Nayaguez.

RHODE IsLAND-Kingston.

Soutu (arolina ('lemson College.

South DAK()TA-Brookings.

Tennessee-Knoxville,

TExas-College station.

UTAH-Logan.

Veruont-Burlington.

Virginia-Blacksburg.

Wasungton-Pullman.

West ViRciNiA-Morgantown.

Wisconsin . Madison.

Wroming-Laramie.

The United States Department of Agriculture is located at Washington, D. (. One may address the Seeretary of Agriculture, or write to one of the Divisions of the Department. The most important ones are as follows:

Weather Burean.

Bureau of Animal Industry. Bureau of Plant Industry. Forest Service. Bureau of Chemistry. Bureau of Soils.
Bureau of Entomology.

Bureau of Biological Survey.

Division of Publications.

Burcau of Statistics.

Office of Experiment Stations.

Office of Publie Roaids.

The most important addresses in Canada are:

Dominion Department of Agriculture, Ottawa.

Ontario Agricultural ('ollege, Guelph.
Agricultural ('ollege, St. Anne de Bellevue.

Agrieultural ('ollege, Winnipeg. 
TABLE 4

Length of Time seeds Maintain Their Vitality

Average years

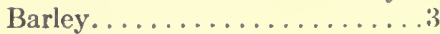

Average years

Bean ................... 3

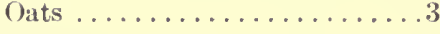

Beet ................ 6

Buckwheat...............2

Cabbage ................

Carrot ...............

Celery ................ 8

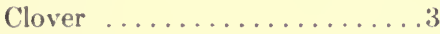

Corn .................. 2

Cucumber, common . . . . . . . 6 6

Eggplant .............6

Flax ...............2

Hор. . . . . . . . . . . . 2

Iettuce, common . . . . . . . .5

Millet .................2

Muskmelon................5

Mustard ................

Onion ...................

Orchard grass ............

Parsnip.................

Peanut ...................

Peas ...................

Pumpkin .............. 5

Radish ..............

Rape ...............

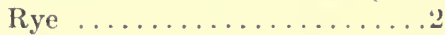

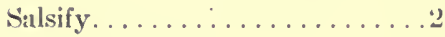

Soy-bein . . . . . . . . . 2

Squash $\ldots \ldots \ldots \ldots \ldots \ldots$

Timothy ..............2

Turnip ...............

Watermelon. ...........6

Wheat. . . . . . . . . . . .

\section{TABLE $4 \iota$}

\section{Quantity of Seed Per Acke}

Alfalfa (brosulcast) ..... 20-30 lbs. Alfalfa (drilled) ....... 15-20 [bs. Batrley ............. s-10 pks.

Beans (field)........ 2-6 pks. I3lue-grass (sown alone)... $2511 .$. Brome grass (sown alol.c) 12-20 lbs. Buckwheat 3-5 pks. Cabbage.

Carrot (for stock) ..... +4-6) llks. Clover (alsike alone) . . . . 8-15 lbs. Clover (recl alone) . . . . 10-18 lbs. Corn. 6-8 ipts. Corn (for silage)....... 9-11 qts. Cotton 1-2 bus. Cowpea $1-1 \frac{1}{2}$ bus.

Flax

Mangels.

$2-4$ pkis. i) -8 lbs. Millet. 1-3 pks.
Oats. 2-3 bus. Potato. (j-20) bus. Potuto (recommended) . 15-18 bus. Pumpkin. $4 \mathrm{lbs}$. Rape............. 2-8 lbs, Red-Top (reeleaned). . . 12-15 lbs. Rice............... 1-3 bus. Rve ........... 3-8 pks. Sugar Beets.......... 15-20 lbs. sweet Potato ....... $1 \frac{1}{2}-4$ bus. 'Timotlyy ........... 10-20 lbs. Timothy and CloverTimothy ..........10-15 llss. Clover ........... 4 4-10 lbs. Turnip, (broadenst) .... . 2-4 lbs. Vetch (huiry), 1 bus. +1 bus. smull grain.

Wheat ........... $6-9$ pks. 
วве4.11

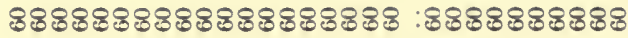

ง

รวоานบับ.

\begin{tabular}{|c|c|}
\hline ๑.кY & 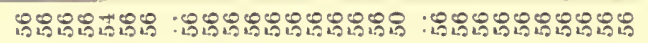 \\
\hline & $: 97$ \\
\hline
\end{tabular}

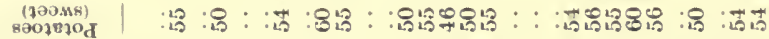

भәониन |

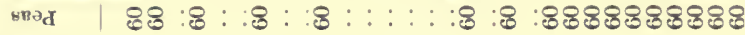

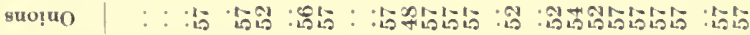

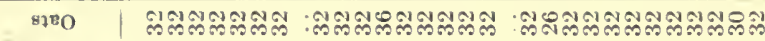

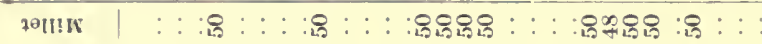

өய!T ! : : : :

(pəasuाf)

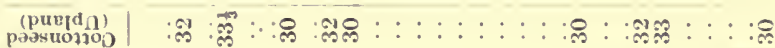

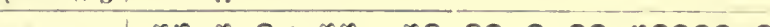

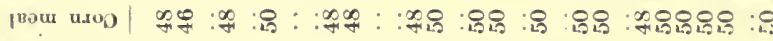
|

uxop

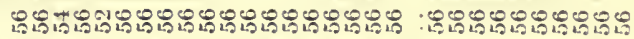

$$
1800
$$
$\varnothing:$

$: \infty 8:$

$: \infty:$

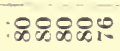
$: 8000000$

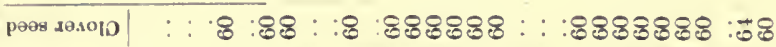

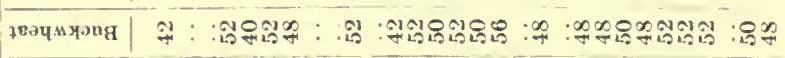

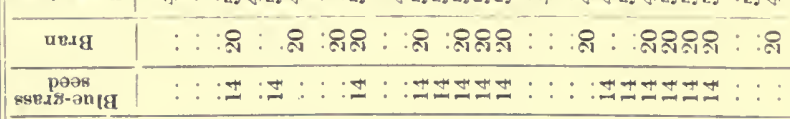

\begin{tabular}{|c|c|}
\hline винәg & 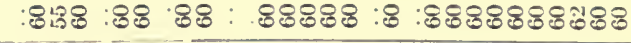 \\
\hline 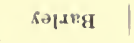 & 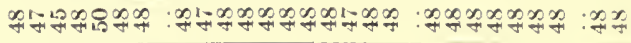 \\
\hline вaldd poil. & 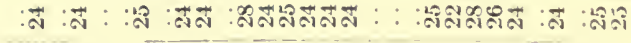 \\
\hline NojddV & 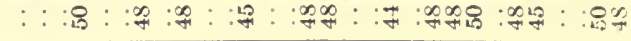 \\
\hline & 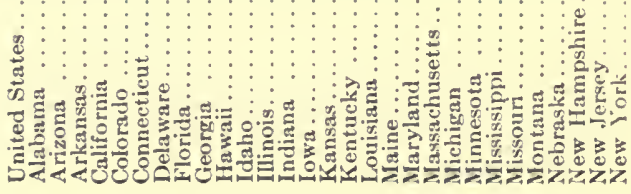 \\
\hline
\end{tabular}




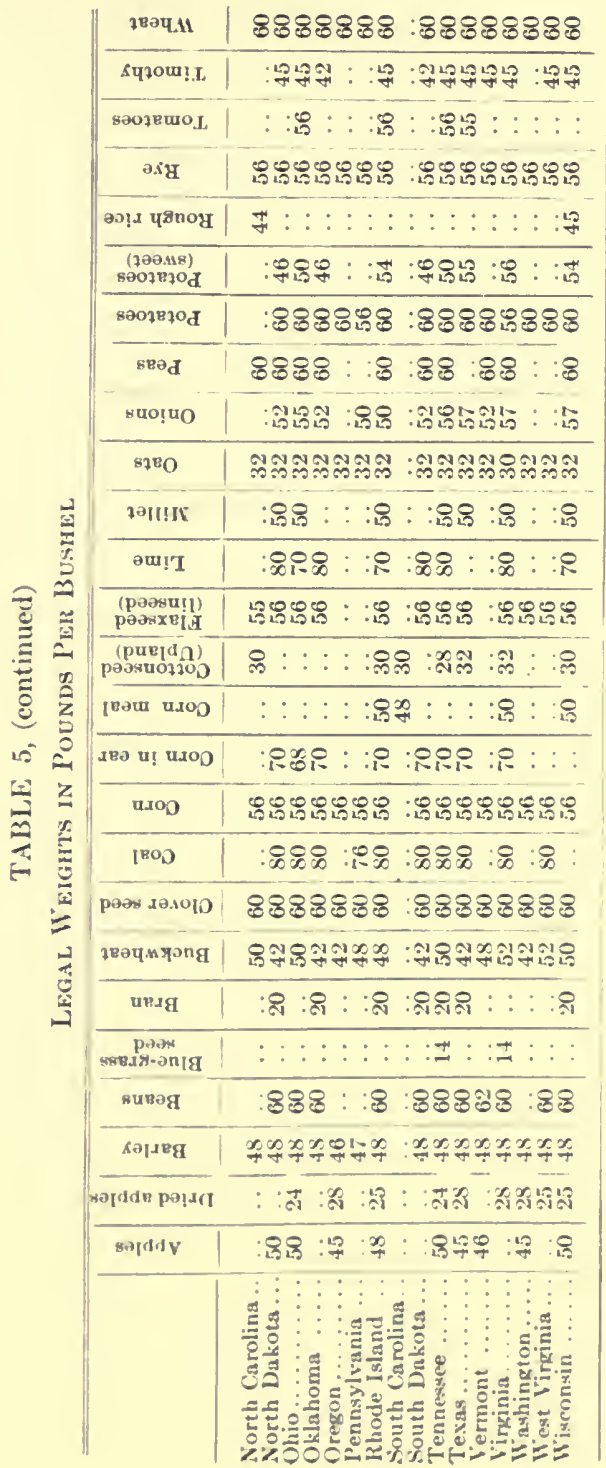


TABLE 6

Fertilizing Constituents in 100 Pounds of Various Substances

Acid phosphate $\ldots . \ldots \ldots \ldots \ldots$. . .

Alfalfa, green

Alfalia, hay ................

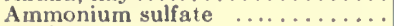

Apples....................

Apple pomace................

Ashes, average. . . . . . . . . . . . . . . . .

Ash of hardwood trees ............

Ashes, leached ..............

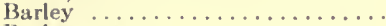

Barley straw ................

Beans..................

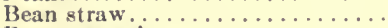

Beet, mangel ................

Beet, sugar . . . . . . . . . . .

Bone meal ..................

Brewers' grains, dry ...........

Brewers' grains, wet ..........

Buckwheat ..............

Buckwheat bran $\ldots \ldots \ldots \ldots \ldots \ldots \ldots$

Cabbage ..................

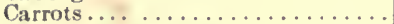

Clover (red), green ............

Clover hay .................

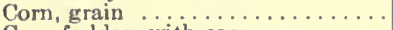

Corn fodder, with ears ...........

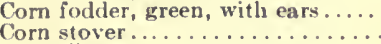

Corn silage ...............

Corn cobs .................

Cotton, lint ................

Cotton, seed ..............

Cottonsced meal ..............

Gluten meal $\ldots . . \ldots \ldots \ldots \ldots \ldots$

Guano, Peruvian .............

Hominy feed ................

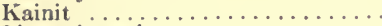

Linseed meal ................

Malt sprouts ..............

Milk, cows' ..............

Milk, skimmed...............

Mixed hay ..................

Nitrate of potash .............

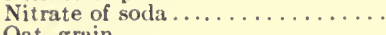

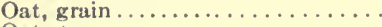

Oat straw ...............

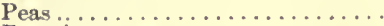

Pea-vine straw ..............

Potatoes ................. 80 per cent Potassium, sulfate of, 90 per cent .

Pumpkin

Rice

Rice hulls

\begin{tabular}{|c|c|c|c|}
\hline Water & Nitrogen (N) & $\begin{array}{l}\text { Phosphorik } \\
\text { acid }\left(\mathrm{P}_{2} \mathrm{O}_{5}\right)\end{array}$ & $\begin{array}{l}\text { Potash } \\
\left(\mathbf{K}_{2} \mathrm{O}\right)\end{array}$ \\
\hline 12.0 & & 15.20 & \\
\hline 76.0 & .62 & .15 & 35 \\
\hline 15.3 & 1.76 & .61 & 1.79 \\
\hline 4.0 & 20.50 & . ․ & $\ldots$ \\
\hline 84.7 & .05 & .02 & .11 \\
\hline 74.0 & .17 & .01 & .03 \\
\hline$\cdots$ & $\cdots$ & 1.53 & 5.13 \\
\hline 5.0 & $\ldots$ & 2.50 & 6.00 \\
\hline 5.0 & $\ldots$ & 3.50 & 10.00 \\
\hline 30.2 & $\ldots$ & 1.51 & 1.27 \\
\hline 14.3 & 1.39 & .79 & .48 \\
\hline 14.2 & 1.31 & $\ddot{0} .3$ & 2.09 \\
\hline 14.5 & 4.08 & 1.21 & 1.29 \\
\hline 5.3 & 1.14 & .21 & 1.84 \\
\hline 91.9 & .19 & .09 & .38 \\
\hline 82.0 & .17 & .08 & .37 \\
\hline 8.5 & 13.50 & 1.35 & .77 \\
\hline 13.0 & 2.30 & 17.60 & .01 \\
\hline 9.5 & 2.51 & 1.61 & .20 \\
\hline 76.2 & .62 & .42 & .05 \\
\hline 14.1 & 1.23 & .69 & .30 \\
\hline 15.6 & 1.18 & .42 & 1.27 \\
\hline 12.0 & 3.52 & 1.23 & 1.14 \\
\hline 85.6 & .28 & .22 & .52 \\
\hline 87.0 & .12 & .09 & .26 \\
\hline 79.0 & .46 & .15 & .48 \\
\hline 17.0 & 1.08 & .55 & 1.87 \\
\hline 13.0 & 1.26 & .57 & .37 \\
\hline 42.2 & .40 & 29 & 1.40 \\
\hline 82.8 & .16 & .11 & 39 \\
\hline 40.5 & .27 & .38 & 1.64 \\
\hline 77.9 & .14 & .11 & .37 \\
\hline 10.7 & .37 & .04 & .43 \\
\hline & .28 & .07 & .64 \\
\hline 10.3 & 3.07 & $1.0^{\circ} 2$ & 1.16 \\
\hline 8.8 & $5.9 \overline{5}$ & 3.04 & 1.58 \\
\hline 8.6 & 4.12 & .33 & .05 \\
\hline 15.0 & 7.00 & 14.00 & 3.30 \\
\hline 8.9 & 1.20 & .98 & .49 \\
\hline 12.7 & $\ldots$ & $\ldots$ & 12.80 \\
\hline 8.9 & 4.68 & 1.66 & 1.37 \\
\hline 12.0 & 2.97 & 1.74 & 1.99 \\
\hline 87.2 & .53 & .19 & .18 \\
\hline 90.4 & .56 & .20 & .19 \\
\hline 13.7 & .99 & .41 & 1.32 \\
\hline 1.9 & 13.09 & $\ldots$ & 45.19 \\
\hline 1.4 & 15.7 & $\ldots$ & $\ldots$ \\
\hline 13.3 & 1.47 & .69 & .48 \\
\hline 14.5 & .19 & .28 & 1.77 \\
\hline 14.0 & 2.68 & .84 & 1.01 \\
\hline 13.6 & .68 & .35 & 1.02 \\
\hline 75.0 & .14 & .16 & .57 \\
\hline 1.1 & $\ldots$ & $\ldots$ & 52.70 \\
\hline 2.2 & $\ldots$ & $\ldots$ & 49.90 \\
\hline 92.3 & .11 & .16 & .09 \\
\hline 12.4 & 1.08 & .18 & .09 \\
\hline 8.2 & .58 & .17 & .14 \\
\hline
\end{tabular}


TABLE 6 , continued

\begin{tabular}{|c|c|c|c|c|}
\hline & Water & Nit rogen $(\mathrm{N})$ & $\begin{array}{l}\text { Phosphoric } \\
\text { acid }\left(\mathrm{P}_{2} \mathrm{O}_{5}\right)\end{array}$ & $\begin{array}{l}\text { Potash } \\
\left(\mathrm{K}_{2} \mathrm{O}\right)\end{array}$ \\
\hline Rice bran .................. & 9.7 & .71 & .29 & .24 \\
\hline Rice polish $\ldots \ldots \ldots \ldots \ldots \ldots$ & 10.0 & 1.97 & $2.6 \bar{T}$ & .71 \\
\hline Rye $\ldots \ldots \ldots \ldots \ldots \ldots \ldots$ & 13.4 & 1.58 & .86 & .58 \\
\hline 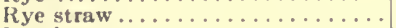 & 7.1 & .46 & .28 & .79 \\
\hline 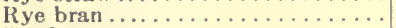 & 12.5 & 1.84 & 2.28 & 1.40 \\
\hline Soy-bean .................. & 11.8 & 5.30 & 1.87 & 1.90 \\
\hline 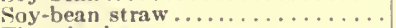 & 14.1 & 1.41 & .33 & .77 \\
\hline 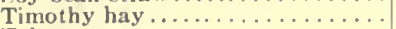 & $1+.3$ & .4 & .50 & 1.41 \\
\hline Tobacco stems . . . . . . . & 18.0 & 1.64 & .92 & 2.82 \\
\hline 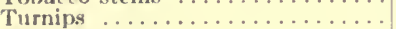 & 90.5 & .18 & .10 & .39 \\
\hline Wheat $\ldots \ldots \ldots \ldots \ldots \ldots \ldots \ldots$ & 13.4 & 1.63 & .87 & .55 \\
\hline 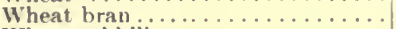 & 13.2 & 1.95 & 2.69 & 1.52 \\
\hline Wheat middlings. . . . . . $\ldots \ldots$ & 12.6 & 2.04 & 1.35 & .74 \\
\hline Wheat straw ............. & 13.6 & .06 & .22 & .63 \\
\hline
\end{tabular}

TABLE 7

Feeving Standards Per Day Per 1,000 Pounds live Weight

Iorses lightly worked.........

Horses moderately worked .....

Horses heavily worked ........

Mileh cows, Wolff's standard...

Milch cows, when yielding daily. 11 pounds milk ........... 16.6 pounds milk ........ 22.0 pounds nuilk 27.5 pounds inilk

()xen at rest in the stall .........

Oxen moderately worked .....

Oxen heavily worked ...........

Fattening cattle, preliminary period...

Fattening cattle, main periorl.

Fattening cattle, finishing period

Breediug ewes, with lambs.

Wool sheep, coarser breeds.....

IV ool sheep, finer hreeds.

Futtening sheep, preliminary

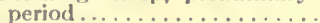

Fattening sheep, main period...

Brood yow:

Fattening swine, preliminary period...

Jattening swine, main period.

lattening swine, fuishing period Poultry, growing rhickans ${ }^{2}$

Poultry, for egg-production ${ }^{*}$..

Poultry, for fattening ${ }^{2}$

\begin{tabular}{|c|c|c|c|c|}
\hline \multirow{2}{*}{ 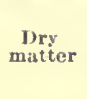 } & \multicolumn{3}{|c|}{ Digestible } & \multirow{2}{*}{$\begin{array}{l}\text { Nut ritive } \\
\text { ratio }\end{array}$} \\
\hline & Protein & $\begin{array}{l}\text { Curbohy- } \\
\text { drates anit } \\
\text { fat }(\times 2.25)\end{array}$ & Total & \\
\hline $\begin{array}{c}\text { Pounds } \\
20 \\
24 \\
26 \\
24\end{array}$ & $\begin{array}{c}\text { Pounds } \\
1.5 \\
2.0 \\
2.5 \\
2.5\end{array}$ & $\begin{array}{c}\text { Pounds } \\
10.4 \\
12.4 \\
15.1 \\
13.4\end{array}$ & $\begin{array}{c}\text { Pounds } \\
11.9 \\
14.4 \\
17.6 \\
15.9\end{array}$ & $\begin{array}{l}1: 6.9 \\
1: 6.2 \\
1: 6.0 \\
1: 5.4\end{array}$ \\
\hline $\begin{array}{l}25 \\
27 \\
29 \\
32 \\
18 \\
25 \\
28\end{array}$ & $\begin{array}{l}1.6 \\
2.0 \\
2.5 \\
3.3 \\
0.7 \\
2.0 \\
2.8\end{array}$ & $\begin{array}{r}10.7 \\
11.9 \\
14.1 \\
14.8 \\
8.2 \\
12.6 \\
14.8\end{array}$ & $\begin{array}{r}12.3 \\
13.9 \\
16.6 \\
18.1 \\
8.9 \\
14.6 \\
17.6\end{array}$ & $\begin{array}{l}1: 6.7 \\
1: 6.0 \\
1: 5.6 \\
1: 4.5 \\
1: 11.7 \\
1: 6.3 \\
1: 5.3\end{array}$ \\
\hline $\begin{array}{l}30 \\
30 \\
26 \\
25 \\
20 \\
23\end{array}$ & $\begin{array}{l}2.5 \\
3.0 \\
2.7 \\
2.9 \\
1.2 \\
1.5\end{array}$ & $\begin{array}{l}16.1 \\
16.1 \\
16.6 \\
16.1 \\
11.0 \\
12.7\end{array}$ & $\begin{array}{l}18.6 \\
19.1 \\
19.3 \\
19.0 \\
12.2 \\
14.2\end{array}$ & $\begin{array}{l}1: 6.4 \\
1: 5.4 \\
1: 6.1 \\
1: 5.6 \\
1: 9.2 \\
1: 8.5\end{array}$ \\
\hline $\begin{array}{l}30 \\
28 \\
22\end{array}$ & $\begin{array}{l}3.0 \\
3.5 \\
2.5\end{array}$ & $\begin{array}{l}16.1 \\
15.9 \\
16.4\end{array}$ & $\begin{array}{l}19.1 \\
19.4 \\
18.9\end{array}$ & $\begin{array}{l}1: 5.4 \\
1: 4.5 \\
1: 6.6\end{array}$ \\
\hline $\begin{array}{l}36 \\
32 \\
25\end{array}$ & $\begin{array}{l}4.5 \\
4.0 \\
2.7\end{array}$ & $\begin{array}{l}26.6 \\
25.1 \\
15.9\end{array}$ & $\begin{array}{l}31.1 \\
29.1 \\
21.6\end{array}$ & $\begin{array}{l}1: 5.9 \\
1: 6.3 \\
1: 7.0\end{array}$ \\
\hline $\begin{array}{l}535 \\
\ldots\end{array}$ & $\begin{array}{l}\ddot{8} .2 \\
\ldots\end{array}$ & 39.4 & 47.6 & $1: 4.8$ \\
\hline
\end{tabular}

2 For discumsion of these tahles, see Ilenry's Feeds and lieeding, page 635.

From data furnished by J. L. Rice. 
TABLE 8

Digestible Nutrients in 100 Pounds of Various Feeding-Stuffs ${ }^{1}$

\begin{tabular}{|c|c|c|c|c|c|}
\hline \multirow[b]{2}{*}{ Kind of feed } & \multirow[b]{2}{*}{$\begin{array}{c}\text { Total dry } \\
\text { matter }\end{array}$} & \multicolumn{3}{|c|}{ Pounds of digestible nut rients } & \multirow[b]{2}{*}{$\begin{array}{l}\text { Nutritive } \\
\text { ratio }\end{array}$} \\
\hline & & Protein & $\mid \begin{array}{l}\text { Carbohy- } \\
\text { drates }+ \\
\text { (fat } \times 2.25)\end{array}$ & Total & \\
\hline Alfalfa, green .............. & 28.2 & 3.9 & 13.8 & 17.7 & 1: 3.5 \\
\hline Alfalfa hay ................ & 91.6 & 11.0 & 42.3 & 53.3 & $1: 3.8$ \\
\hline Apples ................. & 19.0 & .7 & 18.8 & 19.5 & $1: 26.8$ \\
\hline Apple pomace. & 23.3 & 1.1 & 16.4 & 17.5 & $1: 14.9$ \\
\hline Barley, grain... & 89.1 & 8.7 & 69.1 & 77.8 & $1: 7.9$ \\
\hline Bean straw & 95.0 & 3.6 & 39.7 & 43.3 & $1: 11.0$ \\
\hline Beet, mangel & 9.1 & 1.1 & 5.6 & 6.7 & $1: 5.1$ \\
\hline Beet, sugar. & 13.5 & 1.1 & 10.4 & 11.5 & $1: 9.4$ \\
\hline Blood, dried & 91.5 & 52.3 & 5.6 & 57.9 & 1: 0.1 \\
\hline Brewers' grains, dry ........... & 91.8 & 15.7 & 47.8 & 63.5 & $1: 3.0$ \\
\hline Brewers' grains, wet........ & $2 \nmid .3$ & 3.9 & 12.5 & 16.4 & 1: 3.2 \\
\hline 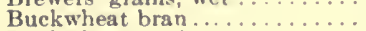 & 89.5 & 7.4 & 34.7 & 42.1 & $1: 4.7$ \\
\hline Buckwheat, grain ........... & 87.4 & 7.7 & 53.3 & 61.0 & $1: 6.9$ \\
\hline Buckwheat middlings ........ & 87.3 & 22.0 & 45.6 & 67.6 & 1: 2.1 \\
\hline Cabbage............... & $1 \breve{3} .3$ & 1.8 & 9.1 & 10.9 & 1: 5.1 \\
\hline$\ldots \ldots \ldots \ldots$ & 11.4 & 8 & 8.3 & 9.1 & $1: 10.4$ \\
\hline Clover (red), green .......... & 29.2 & 2.9 & 16.4 & 19.3 & $1: 5.7$ \\
\hline Clover (red), hay & 84.7 & 6.8 & 39.6 & 46.4 & $1: 5.8$ \\
\hline Corn-and-cob meal ........... & 81.9 & 4.4 & 66.5 & 70.9 & $1: 15.1$ \\
\hline 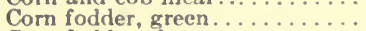 & 20.7 & 1.0 & 12.5 & 13.5 & $1: 12.5$ \\
\hline Corn fodder, dry $\ldots \ldots \ldots \ldots \ldots$ & 57.8 & $2 . \overline{5}$ & 37.3 & 39.8 & $1: 14.9$ \\
\hline 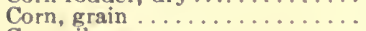 & 89.1 & 7.9 & 76.4 & 843 & $1: 9.7$ \\
\hline Corn silage $\ldots \ldots \ldots \ldots \ldots \ldots$ & 20.9 & .9 & 12.9 & 13.8 & $1: 14.3$ \\
\hline Corn stover & 59.5 & 1.7 & 34.0 & 35.7 & $1: 20.0$ \\
\hline Cottonseed meal ........... & 91.8 & 37.2 & 44.4 & 81.6 & 1: 1.2 \\
\hline Cowpeas........ & $8 \mathbf{j} .2$ & 18.3 & 56.7 & 75.0 & 1: 3.1 \\
\hline Gluten meal .............. & 91.8 & 25.8 & 68.1 & 93.9 & $1: 2.6$ \\
\hline Hominy chops & 88.9 & 7.5 & 70.5 & 78.0 & 1: 9.4 \\
\hline Hungarian hay ............ & 92.3 & 4.5 & 54.6 & 59.1 & $1: 12.1$ \\
\hline Linseed meal (new process) ... & 89.9 & 28.2 & 46.4 & 74.6 & $1: 1.6$ \\
\hline Linseed meal (old process) ... & 90.8 & 29.3 & 45.5 & $7-8$ & $1: 1.7$ \\
\hline Malt sprouts $\ldots \ldots \ldots \ldots$ & 89.5 & 15.6 & 40.9 & 59.5 & $1: 2.2$ \\
\hline Meat $\operatorname{scrap}, \ldots \ldots \ldots \ldots \ldots \ldots$ & 89.3 & 66.2 & 31.1 & 97.3 & 1: 0.5 \\
\hline Milk, cows' & 12.8 & 3.6 & 13.2 & 16.8 & 1: 3.7 \\
\hline Skim-milk, cer & 9.4 & 2.9 & 5.9 & 8.8 & 1: 2.0 \\
\hline nilk, grav & 9.6 & 3.1 & 6.5 & 9.6 & 1: 2.1 \\
\hline Butter milk. & 9.9 & 3.9 & 6.5 & 10.4 & $1: 1.7$ \\
\hline Whey. & 6.6 & 0.8 & 5.4 & 6.2 & $1: 6.8$ \\
\hline Hay of mixed grasses & 87.1 & 5.9 & 43.6 & 49.5 & $1: 7.4$ \\
\hline Oat straw.. & 90.8 & 1.2 & 40.4 & 41.6 & $1: 33.7$ \\
\hline Oats, grain. & 89.0 & 9.2 & 56.8 & 66.0 & $1: 6.2$ \\
\hline Peas, grain & 89.5 & 16.8 & 53.4 & $\div 0.2$ & $1: 3.2$ \\
\hline Peas-and-barley, green ... & 16.0 & 1.7 & 7.7 & 9.4 & $1: 4.5$ \\
\hline Peas-and-oats, green ......... & 16.0 & 1.8 & 7.6 & 9.1 & $1: 4.2$ \\
\hline Pea-vine straw ........... & 86.4 & 4.3 & 34.1 & 38.4 & $1: \div .9$ \\
\hline Pea-vine silage...$\ldots \ldots \ldots \ldots$ & 27.0 & 2.5 & 14.1 & 16.6 & 1: 5.6 \\
\hline Potatoes . . . $\ldots \ldots \ldots \ldots \ldots$ & 21.1 & .9 & 16.5 & 17.4 & $1: 18.3$ \\
\hline Pumpkin, field. & 19.1 & 1.4 & 6.5 & 7.9 & $1: 4.6$ \\
\hline Rye, grain..... & 88.4 & 9.9 & 70.1 & 80.0 & $1: 7.1$ \\
\hline Rye bran.. & 88.4 & 11.5 & 54.8 & 66.3 & $1: 4.8$ \\
\hline Rye straw & 92.9 & .6 & 41.5 & 42.1 & $1: 69.2$ \\
\hline Soy-bean .. & 89.2 & 29.6 & 54.7 & 84.3 & $1: 1.8$ \\
\hline Sugar-beet leaves. . . . . . . . & 12.0 & 1.7 & 5.1 & 6.8 & $1: 3.0$ \\
\hline Sugar-beet molasses . & 79.2 & 9.1 & 59.5 & 68.6 & $1: 6.5$ \\
\hline
\end{tabular}

${ }^{1}$ Adapted from Henry's Feeds and Feeding. 
TABLE 8 , continued

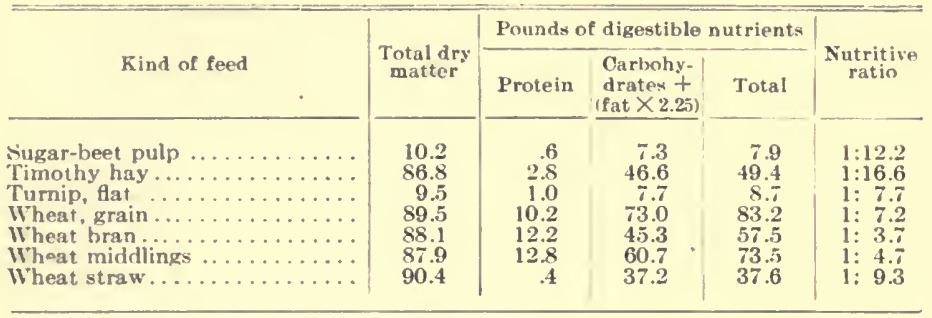

\section{TABLE 9}

\section{Production Values Per 100 Pounds of Various Feeding Stuffs}

The following table is computed according to Kellner (Pennsylvania Bulletin No. 8t, Farmers' Bulletin No. 346). The figures in the last column give approximate comparative values of different feeds for producing gains in mature fattening cattle. A pound of timothy hay produces $\frac{36}{8} \frac{3}{8}$ as inuch gain as a pound of corn. Clover hay is $\frac{33}{6} \frac{3}{6}$ as effective as oats. While these figures are for fattening cattle, it seems probable that they represent the relative values of these feeding stufis for sheep and, probably, for horses, and for growth and milk-production as well as for fattening. They are unquestionably the best approximation that we have to the comparative values of these feeds. (See page 289.)

\begin{tabular}{|c|c|c|c|c|c|c|}
\hline \multirow[b]{2}{*}{ Feeding stuff } & \multirow{2}{*}{$\begin{array}{l}\text { Total dry } \\
\text { matter }\end{array}$} & \multirow{2}{*}{$\begin{array}{c}\text { Total } \\
\text { crude fiber }\end{array}$} & \multicolumn{3}{|c|}{ Digestible } & \multirow{2}{*}{$\begin{array}{l}\text { Produc. } \\
\text { tion value }\end{array}$} \\
\hline & & & Proteids & $\begin{array}{l}\text { Carbohy- } \\
\text { drates }\end{array}$ & Fat & \\
\hline Green fodder and silage: & Pounds & Pounds & Pounds & Pounds & Pounds & Therms \\
\hline $\begin{array}{l}\text { Alfalfa } \ldots \text {. } \ldots \ldots \ldots \\
\text { Clover }(\text { red) } \ldots \ldots \ldots \\
\text { Corn fodder } \ldots \ldots \ldots \\
\text { Corn silage } \ldots \ldots \ldots \\
\text { Hungarian grasa } \\
\text { Rye } \ldots \ldots \\
\text { Timothy.............. }\end{array}$ & $\begin{array}{l}28.2 \\
29.2 \\
20.7 \\
25.6 \\
25.9 \\
.23 .4 \\
38.4\end{array}$ & $\begin{array}{r}7.4 \\
8.1 \\
5.0 \\
5.8 \\
9.2 \\
11.6 \\
11.8\end{array}$ & $\begin{array}{l}2.50 \\
2.21 \\
.41 \\
1.21 \\
1.33 \\
1.44 \\
1.01\end{array}$ & $\begin{array}{l}11.20 \\
14.82 \\
12.08 \\
14.56 \\
15.63 \\
14.11 \\
21.22\end{array}$ & $\begin{array}{l}0.41 \\
.69 \\
.37 \\
.85 \\
.36 \\
.44 \\
.64\end{array}$ & $\begin{array}{l}10.80 \\
14.52 \\
11.02 \\
14.26 \\
13.14 \\
10.31 \\
17.80\end{array}$ \\
\hline \multicolumn{7}{|l|}{$\begin{array}{l}\text { Hay and dry coarse } \\
\text { fodders: }\end{array}$} \\
\hline $\begin{array}{l}\text { Alfalfa hay } \\
\text { Clover hay (red) ... } \\
\text { Corn fodder tieli-: }\end{array}$ & $\begin{array}{l}91.6 \\
84.7\end{array}$ & $\begin{array}{l}25.0 \\
24.8\end{array}$ & $\begin{array}{l}6.93 \\
5.41\end{array}$ & $\begin{array}{l}37.33 \\
38.15\end{array}$ & $\begin{array}{l}1.38 \\
1.81\end{array}$ & $\begin{array}{l}34.41 \\
34.74\end{array}$ \\
\hline 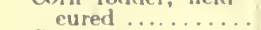 & 57.8 & 14.3 & 2.13 & $32,3 \cdot 1$ & 1.1 .5 & $30.5: 3$ \\
\hline Corn stover....... & 59.5 & 19.7 & 1.80 & 33.16 & .57 & 26.53 \\
\hline Cowpea hay ...... & 89.3 & 20.1 & 8.57 & 38.40 & 1.51 & 42.76 \\
\hline Hungurian hay .... & 92.3 & 27.7 & 3.00 & 51.67 & 1.34 & 44.03 \\
\hline Oat hay & 84.0 & 27.2 & 2.59 & 33.35 & 1.67 & 36.97 \\
\hline Soybean hay... & \$8.7 & 22.3 & 7.65 & 38.72 & 1.51 & $3 \times .65$ \\
\hline Timothy hay.... & 56.5 & 29.6 & 2.05 & 43.72 & 1.43 & 33.56 \\
\hline
\end{tabular}


TABle 9 , continued

\begin{tabular}{|c|c|c|c|c|c|c|}
\hline \multirow[b]{2}{*}{ Feeding stuff } & \multirow{2}{*}{$\begin{array}{c}\text { Total dry } \\
\text { matter }\end{array}$} & \multirow{2}{*}{$\begin{array}{c}\text { Total } \\
\text { crudefiber }\end{array}$} & \multicolumn{3}{|c|}{ Digestlble } & \multirow{2}{*}{$\begin{array}{l}\text { Produc- } \\
\text { tion value }\end{array}$} \\
\hline & & & Proteids & $\begin{array}{c}\text { Oarlohy - } \\
\text { drates }\end{array}$ & Fat & \\
\hline Straws: & Pounds & Pounds & Pounds & Pounds & Pounds & Therms \\
\hline 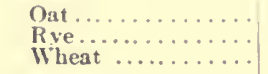 & $\begin{array}{l}90.8 \\
92.9 \\
90.4\end{array}$ & $\begin{array}{l}37.0 \\
38.9 \\
38.1\end{array}$ & $\begin{array}{r}1.09 \\
.63 \\
.37\end{array}$ & $\begin{array}{l}38.64 \\
40.58 \\
36.30\end{array}$ & $\begin{array}{l}.76 \\
.38 \\
.40\end{array}$ & $\begin{array}{l}21.21 \\
20.87 \\
16.56\end{array}$ \\
\hline \multicolumn{7}{|l|}{ Roots, etc.: } \\
\hline 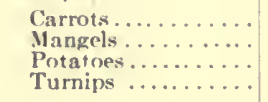 & $\begin{array}{r}11.4 \\
9.1 \\
21.1 \\
9.5\end{array}$ & $\begin{array}{r}1.3 \\
.8 \\
.6 \\
1.2\end{array}$ & $\begin{array}{l}.37 \\
.14 \\
.45 \\
.22\end{array}$ & $\begin{array}{r}7.83 \\
5.65 \\
16.43 \\
6.46\end{array}$ & $\begin{array}{l}.22 \\
.11 \\
.11\end{array}$ & $\begin{array}{r}7.82 \\
4.62 \\
18.05 \\
5.74\end{array}$ \\
\hline \multicolumn{7}{|l|}{ Grains: } \\
\hline $\begin{array}{l}\text { Barley } \ldots \ldots \ldots \ldots \\
\text { Corn } \ldots \ldots \\
\text { Corn-and-cob meal } \\
\text { Oats......... } \\
\text { Rve } \ldots \ldots \ldots \ldots \ldots \\
\text { Wheat } \ldots \ldots \ldots \ldots \ldots\end{array}$ & $\begin{array}{l}89.1 \\
89.1 \\
84.9 \\
89.0 \\
88.4 \\
89.5\end{array}$ & $\begin{array}{l}2.7 \\
2.1 \\
6.6 \\
9.5 \\
1.7 \\
1.8\end{array}$ & $\begin{array}{l}8.37 \\
6.79 \\
4.53 \\
8.36 \\
8.12 \\
8.90\end{array}$ & $\begin{array}{l}64.83 \\
661.2 \\
60.06 \\
48.34 \\
69.73 \\
69.21\end{array}$ & $\begin{array}{l}1.60 \\
4.97 \\
2.94 \\
4.18 \\
1.36 \\
1.68\end{array}$ & $\begin{array}{l}80.75 \\
88.81 \\
72.05 \\
66.27 \\
81.72 \\
82.63\end{array}$ \\
\hline \multicolumn{7}{|l|}{ Bu-products: } \\
\hline $\begin{array}{l}\text { Brewers' graius, wet. } \\
\text { Cottonseed meal .... } \\
\text { Gluten feed, dry } \\
\text { Gluten meal. Buffalo } \\
\text { linseed meal }\end{array}$ & $\begin{array}{l}24.3 \\
91.8 \\
91.9 \\
91.8\end{array}$ & $\begin{array}{l}3.8 \\
5.6 \\
6.4 \\
6.1\end{array}$ & $\begin{array}{r}3.81 \\
3.15 \\
19.95 \\
21.56\end{array}$ & $\begin{array}{r}9.37 \\
16.52 \\
54.22 \\
43.02\end{array}$ & $\begin{array}{r}1.38 \\
12.58 \\
5.35 \\
11.87\end{array}$ & $\begin{array}{l}14.82 \\
81.20 \\
79.32 \\
85.46\end{array}$ \\
\hline 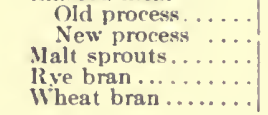 & $\begin{array}{l}90.8 \\
90.1 \\
89.8 \\
88.2 \\
88.5\end{array}$ & $\begin{array}{r}8.9 \\
8.8 \\
10.7 \\
3.3 \\
9.0\end{array}$ & $\begin{array}{l}27.54 \\
29.26 \\
12.36 \\
11.35 \\
10.21\end{array}$ & $\begin{array}{l}32.81 \\
38.72 \\
43.50 \\
52.40 \\
41.23\end{array}$ & $\begin{array}{l}7.06 \\
2.90 \\
1.16 \\
1.79 \\
2.87\end{array}$ & $\begin{array}{l}78.92 \\
74.67 \\
46.33 \\
56.65 \\
48.23\end{array}$ \\
\hline
\end{tabular}

TABLE 10

Average Weights of Different Feeding-Śtuffs ${ }^{2}$

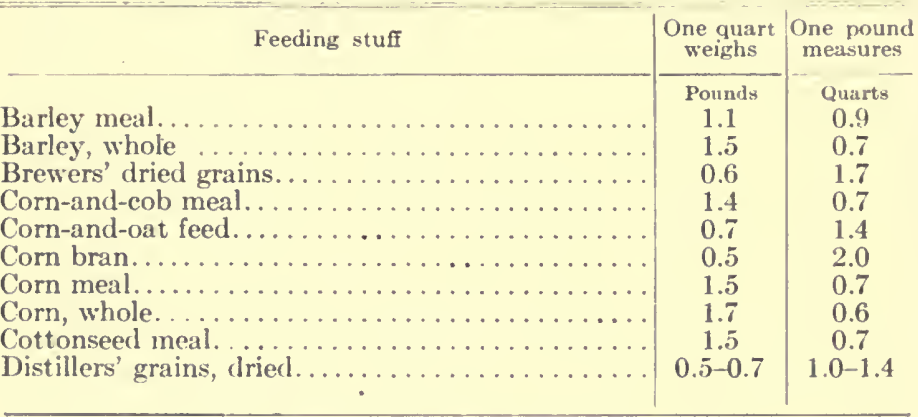


TABLE 10 , continued

\begin{tabular}{|c|c|c|}
\hline Feeding stuff & $\begin{array}{l}\text { One quart } \\
\text { weighs }\end{array}$ & $\begin{array}{l}\text { One pound } \\
\text { measures }\end{array}$ \\
\hline 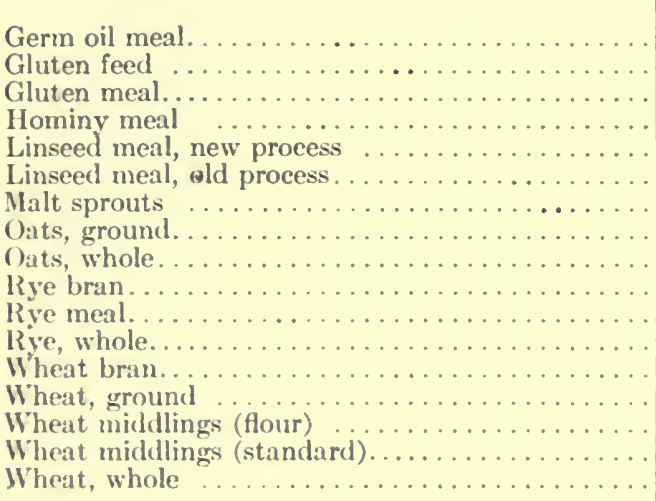 & $\begin{array}{l}\text { Pounds } \\
1.4 \\
1.3 \\
1.7 \\
1.1 \\
0.9 \\
1.1 \\
0.6 \\
0.7 \\
1.0 \\
0.6 \\
1.5 \\
1.7 \\
0.5 \\
1.7 \\
1.2 \\
0.8 \\
2.0\end{array}$ & $\begin{array}{l}\text { Quarts } \\
0.7 \\
0.8 \\
0.6 \\
0.9 \\
1.1 \\
0.9 \\
1.7 \\
1.4 \\
1.0 \\
1.8 \\
0.7 \\
0.6 \\
2.0 \\
0.6 \\
0.8 \\
1.3 \\
0.5\end{array}$ \\
\hline
\end{tabular}

TABLE 11

Values of Leading Agricultural Products in the Iinited States FOK THE YEAR 1899

Corn. . . . . . . . . . . . . . . . . . . . . . . . . . . . . . . $\$ \$ 28,000,000$

Animals sold. . . . . . . . . . . . . . . . . . . . . . . . 723,000,000

Hlay and forage ..................... $484,000,000$

Milk, butter and cheese . . . . . . . . . . . . . . . . \$72,000,000

('otton and cottonseed . . . . . . . . . . . . . . . 371,000,000

Whoat ............................... $370,000,000$

Poultry and eggs. . . . . . . . . . . . . . . . . . . . . . . 281,000,000

Oats. ................................ 217,000,000

Animals slaughtered . . . . . . . . . . . . . . . . . . . $190,000,000$

Miscellaneous vegetibles. . . . . . . . . . . . . 114,000,000

Forest products (i. (-., by-products of the farm, not including the lumber industry) . . . . . . . . . . 110,000,000

Potatoes ......................... 9\$,000,000

Orehard products . . . . . . . . . . . . . . . $\$ 4,000,000$

Tolaceo .......................... $57,000,000$

Wool ................................ $46,000,000$

Barley ................................ $42,000,000$

Small fruits . . . . . . . . . . . . . . . . . . . . . 25,000,000

Sugar-cane and products. . . . . . . . . . . . . . . . . $21,000,000$

Sweet pritatoes. . . . . . . . . . . . . . . . . . . . . 2 $20,000,000$

Flax seed . . . . . . . . . . . . . . . . . . . . 20,000,000 


\section{TABLE 12 \\ Agriculture Compared witi Manufacturing}

Total capital invested in manufacturing, $1899 \ldots \ldots . \$ 9,874,664,087$ Total value of all farm property, $1899 \ldots \ldots \ldots \ldots 20,514,001,838$

Total horse power employed in factories, $1899 \ldots \ldots \ldots \quad 11,300,081$

. Total number of horses and mules on farms, 1S99.... $18,276,5.51$

\section{Value of IMPorts and Exports for the Year ENdiNg} JUNE 30,1907

All agrieultural exports $\ldots \ldots \ldots \ldots \ldots \ldots \ldots \ldots 1,147,354,121$

All agricultural imports................ $749,257,584$

Balance of trade. . . . . . . . . . . . . \$3998,096,5:37

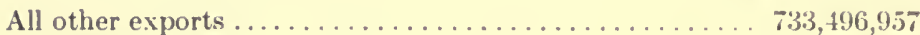
All other imports . . . . . . . . . . . . . . . . . $655,163,841$

Balance of trade . . . . . . . . . . . . \$48,333,116

TABLE 13

Values of Agricultural Imports and Exports for Year Ending JUNE 30,1907

Cattle, live

All other live animals.

Dairy products

Beef.

Hides and skins other than furs

Lard

Pork

All other packing-house products Wool, and hair of the eamel, goat, etc. Silk

All other animal matter.

Corn and corn meal

Wheat and wheat flour

All other grain and grain produets

Flaxseed, linseed oil and oil cake Alcoholic liquors .

Amount earried forward

\begin{tabular}{|r|r}
\hline \multicolumn{1}{|c|}{ Imports } & \multicolumn{1}{|c}{ Exports } \\
\hline$\$ 565,122$ & $\$ 34,577,392$ \\
$3,779,160$ & $6,625,688$ \\
$5,832,035$ & $6,633,226$ \\
$83,206,545$ & $31,831,263$ \\
$\ldots \ldots \ldots$ & $1,760,032$ \\
$12,768,326$ & $57,497,980$ \\
$41,534,028$ & $45,567,583,278$ \\
$71,411,899$ & 48,820 \\
$5,370,181$ & 37,709 \\
8,337 & $3,419,358$ \\
396,095 & $46,576,226$ \\
$4,060,371$ & $122,389,785$ \\
129,836 & $15,433,139$ \\
$22,104,235$ & $16,869,972$ \\
$3,314,578$ \\
$\$ 251,166,170$ & $\$ 459,382,029$ \\
\hline
\end{tabular}


Table 13, eontinued

\begin{tabular}{|c|c|c|}
\hline & Imports & Exports \\
\hline Amount brought forward & $\$ 251.166,170$ & $\$ 459382029$ \\
\hline 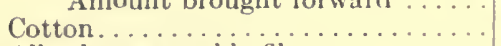 & $19,930,985$ & $481,277,797$ \\
\hline All other vegetable fibers ...... & $41,239,538$ & \\
\hline Cottonseed, çottonseed oil and oil cake & & $24,346,490$ \\
\hline 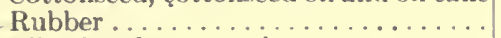 & $60,536,072$ & \\
\hline All other forest products . . . . . . . . & $61,884,704$ & $92,948,705$ \\
\hline Nuts $\ldots \ldots \ldots \ldots \ldots$ & $9,742,883$ & 382,165 \\
\hline Sugar & $92,806,253$ & 831,162 \\
\hline$\ldots \ldots \ldots \ldots$ & $11,883,168$ & \\
\hline $\begin{array}{l}\text { All other fruits, dried, preserved or } \\
\text { fresh }\end{array}$ & $14.2+1.109$ & 17206267 \\
\hline ('ocoa and chocolate ............. & $14,578,980$ & 376,467 \\
\hline Coffee ............ & $78,231,902$ & $4,989,417$ \\
\hline Tea .... & $13,915,544$ & \\
\hline Tobaceo & $26,059,985$ & $33,377,398$ \\
\hline All other vegetable matter. & $53,040,288$ & $32,236,224$ \\
\hline 'Total & $\$ 749,257,584$ & $\$ 1,147,354,121$ \\
\hline
\end{tabular}


TABLE 14

Crop Statistics for Continental United States 1

\begin{tabular}{|c|c|c|c|c|c|}
\hline & Corn & Wheat & Oats & Barley & Rye \\
\hline \multicolumn{6}{|l|}{$\begin{array}{l}\text { Average num- } \\
\text { ber of aeres }\end{array}$} \\
\hline $\begin{array}{l}1867-1876 \ldots \\
1877-1856 \ldots \\
1857-1.596 \ldots \\
1897-1906 \ldots\end{array}$ & $\begin{array}{l}38,658,449 \\
63,405,900 \\
74,290,879 \\
87,971,235\end{array}$ & $\begin{array}{l}21,690,478 \\
35,062,189 \\
36,583,809 \\
45,510,593\end{array}$ & $\begin{array}{l}10,195,566 \\
17,826,840 \\
26.919 .954 \\
27,659,458\end{array}$ & $\begin{array}{l}1,323,839 \\
2,153,883 \\
3,161,899 \\
4,158,986\end{array}$ & $\begin{array}{l}1,338,763 \\
1,936,360 \\
2,07,653 \\
1,799,512\end{array}$ \\
\hline $\begin{array}{c}\text { Average p ro - } \\
\text { duction }-\end{array}$ & Bushels & Bushels & Bushels & Bushels & Bushels \\
\hline $\begin{array}{l}1867-1876 \ldots \\
1877-1886 \ldots \\
1887-1896 \ldots \\
1897-1906 \ldots\end{array}$ & $\begin{array}{l}1,011,535,800 \\
1,575,626,651 \\
1,800,271,093 \\
2,240,363,473\end{array}$ & $\begin{array}{l}258,407,900 \\
436,726,976 \\
464,093,443 \\
631,181,626\end{array}$ & $\begin{array}{l}278,267,071 \\
491,482,427 \\
656,859,971 \\
835,644,006\end{array}$ & $\begin{array}{r}29,73,5,169 \\
48,137,782 \\
72,117,116 \\
108,644,958\end{array}$ & $\begin{array}{l}18,217,420 \\
24,580.175 \\
26,784,385 \\
25,3+11,965\end{array}$ \\
\hline $\begin{array}{c}\text { Average yield } \\
\text { per acre- }\end{array}$ & Bushels & Bushels & Bushels & Bushely & Bushels \\
\hline $\begin{array}{l}1867-1876 \ldots \\
1877-1856 \ldots \\
1887-1896 \ldots \\
1897-1906 \ldots\end{array}$ & $\begin{array}{l}26.2 \\
25.1 \\
24.0 \\
25.4\end{array}$ & $\begin{array}{l}12.0 \\
12.5 \\
12.7 \\
13.8\end{array}$ & $\begin{array}{l}27.5 \\
27.8 \\
25.5 \\
30.1\end{array}$ & $\begin{array}{l}22.8 \\
22.4 \\
22.7 \\
25.5\end{array}$ & $\begin{array}{l}13.6 \\
13.0 \\
12.9 \\
15.7\end{array}$ \\
\hline \multicolumn{6}{|l|}{$\begin{array}{c}\text { Average total } \\
\text { value - }\end{array}$} \\
\hline $\begin{array}{l}1867-1876 \ldots \\
1877-1586 \ldots \\
1857-1896 \ldots \\
1897-1906 \ldots\end{array}$ & $\begin{array}{r}\$ 457,000,523 \\
625,623,878 \\
633,694,378 \\
\$ 69,575,310\end{array}$ & $\begin{array}{r}\$ 262,245,463 \\
385,867,601 \\
319,632,591 \\
131,717,233\end{array}$ & $\begin{array}{r}\$ 103,401,326 \\
157,859,103 \\
193,005,251 \\
246,936,311\end{array}$ & $\begin{array}{r}823,030,837 \\
24,842,694 \\
333,305,476 \\
46,158,110\end{array}$ & $\begin{array}{r}\$ 14,094,508 \\
15,45-1,005 \\
14,487.116 \\
15,444,26-1\end{array}$ \\
\hline $\begin{array}{c}\text { Average value } \\
1867-1876 \ldots \\
1877-1856 \ldots \\
1887-1896 \ldots \\
1897-1906 \ldots\end{array}$ & $\begin{array}{c}\text { Per bushel. } \\
\text { (Cents } \\
46.5 \\
40.3 \\
36.6 \\
39.0\end{array}$ & $\begin{array}{c}\text { l'er busliel. } \\
\text { Cents } \\
103.0 \\
89.5 \\
68.7 \\
68.8\end{array}$ & $\begin{array}{c}\text { Per bushel. } \\
\text { Cents } \\
37.5 \\
32.5 \\
23.7 \\
29.4\end{array}$ & $\begin{array}{c}\text { Per bushel. } \\
\text { Cents } \\
78.3 \\
60.9 \\
46.6 \\
42.1\end{array}$ & $\begin{array}{c}\text { Per bushel. } \\
\text { Cents } \\
76.0 \\
62.8 \\
53.6 \\
54.3\end{array}$ \\
\hline
\end{tabular}

'Calculated from Yearbook United States Department of Agriculture. 'l'he average vields per acre and value per bushel as here calculated are the averages of the ten yearly averages. 


\section{TABLE 14}

Crop Statistics for Continental United States

\begin{tabular}{|c|c|c|c|c|}
\hline & Hay & Potatoes & Buckwheat & Cotton \\
\hline $\begin{array}{l}\text { Average number } \\
\text { of acres } \\
1867-1876 \ldots \ldots \\
1877-1886 \ldots \ldots \\
1887-1896 \ldots \ldots \\
1897-1906 \ldots \ldots\end{array}$ & $\begin{array}{l}21,188,781 \\
31,931,516 \\
46,7,21,489 \\
40,66.5,523\end{array}$ & $\begin{array}{l}1,328,050 \\
2,052,491 \\
2,651,848 \\
2,805,707\end{array}$ & $\begin{array}{l}691,863 \\
803,071 \\
833,871 \\
746,764\end{array}$ & \\
\hline $\begin{array}{l}\text { Average pro- } \\
\text { duction } \\
\begin{array}{r}1867-1876 \\
1877-1886\end{array} \ldots \\
1887-1896 \ldots \\
1897-1906 \ldots \ldots\end{array}$ & $\begin{array}{c}\text { Tons } \\
25,837,580 \\
39,379,146 \\
56,276,752 \\
58,393,644\end{array}$ & $\begin{array}{c}\text { Bushels } \\
119,028,570 \\
157,550,905 \\
200, \pm 01,101 \\
241,700,116\end{array}$ & $\begin{array}{c}\text { Bushels } \\
12,056,270 \\
11,396,686 \\
12,656,297 \\
13,551,552\end{array}$ & $\begin{array}{l}\text { Pounds of lint } \\
1,592,672,300 \\
2,711,651,000 \\
3,768,380,100 \\
5,242,555,500\end{array}$ \\
\hline $\begin{array}{l}\text { Average yield per } \\
\text { acre- } \\
1867-1976 \ldots \ldots \\
1877-1956 \ldots \ldots \\
1887-1896 \ldots \ldots \\
1897-1906 \ldots \ldots\end{array}$ & $\begin{array}{l}\text { Tons } \\
1.22 \\
1.24 \\
1.20 \\
1.43\end{array}$ & $\begin{array}{l}\text { Bushels } \\
\begin{array}{l}90.0 \\
81.4 \\
75.0 \\
85.5\end{array}\end{array}$ & $\begin{array}{c}\text { Bushels } \\
17.6 \\
14.5 \\
15.3 \\
18.1\end{array}$ & \\
\hline 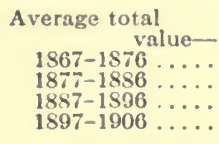 & $\begin{array}{r}\$ 292,436,319 \\
356,197,702 \\
457,121,860 \\
489,912,823\end{array}$ & $\begin{array}{r}\$ 65,413,492 \\
82,197,677 \\
89,880,929 \\
124,812,869\end{array}$ & $\begin{array}{r}88,837,488 \\
7,240,815 \\
6,713,616 \\
7,556,820\end{array}$ & $\begin{array}{r}\$ 232,360,987 \\
252,972,074 \\
279,492,962 \\
468,843.688\end{array}$ \\
\hline $\begin{array}{l}\text { Average value } \\
1867-1876 \ldots \ldots \\
1877-1886 \ldots \ldots \\
1857-1896 \ldots . \\
1897-1906 \ldots \ldots\end{array}$ & $\begin{array}{ll}\text { Per ton. } \\
\text { \$1 } 1 & 44 \\
9 & 15 \\
8 & 21 \\
8 & 45\end{array}$ & $\begin{array}{c}\text { Per bushel. } \\
\text { Cents } \\
56.4 \\
51.4 \\
49.0 \\
52.2\end{array}$ & $\begin{array}{c}\text { Per bushel. } \\
\text { Cents } \\
72.4 \\
65.0 \\
53.5 \\
55.6\end{array}$ & $\begin{array}{c}\text { Per pound. } \\
\text { Cents } \\
13.9 \\
9.3 \\
7.5 \\
8.7\end{array}$ \\
\hline
\end{tabular}

\begin{tabular}{|c|c|c|}
\hline & Cane sugar & Beet sugar \\
\hline 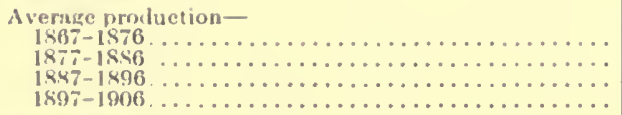 & $\begin{array}{l}\text { Pommis } \\
134,036,928 \\
241 \text { iN6,016 } \\
491,266,018 \\
633,712,352\end{array}$ & $\begin{array}{r}\text { Pounds } \\
784000 \\
1,318.912 \\
29,556,800 \\
386,280,832\end{array}$ \\
\hline
\end{tabular}




\section{TABLE 15}

Numbers and Values of Farm Animals in Continental UNITED STATES

\begin{tabular}{|c|c|c|c|}
\hline & $\begin{array}{c}\text { Average } \\
\text { Total number }\end{array}$ & $\begin{array}{c}\text { Average } \\
\text { Total value }\end{array}$ & $\begin{array}{l}\text { Average } \\
\text { Value } \\
\text { per head }\end{array}$ \\
\hline \multicolumn{4}{|l|}{ Horses- } \\
\hline 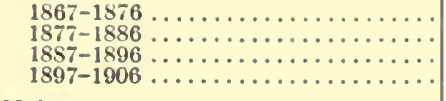 & $\begin{array}{r}8,122,847 \\
11,022,680 \\
14,640,702 \\
15,787,407\end{array}$ & $\begin{array}{r}\$ 516,776,357 \\
693,368,517 \\
859,623,091 \\
877,903,759\end{array}$ & $\begin{array}{rl}863 & 19 \\
62 & 67 \\
59 & 51 \\
54 & 05\end{array}$ \\
\hline \multicolumn{4}{|l|}{ Mules- } \\
\hline $\begin{array}{l}1867-1876 \ldots \ldots \ldots \ldots \ldots \ldots \ldots \ldots \ldots \ldots \\
1877-1886 \ldots \ldots \ldots \ldots \ldots \ldots \ldots \ldots \\
1887-1896 \ldots \ldots \ldots \ldots \ldots \ldots \\
1897-19 n 6 \ldots \ldots \ldots\end{array}$ & $\begin{array}{l}1,175,543 \\
1,788,987 \\
2,280,411 \\
2,602,73\end{array}$ & $\begin{array}{r}92,287,376 \\
128,281,822 \\
158,260,797 \\
176,754,293\end{array}$ & $\begin{array}{ll}77 & 66 \\
71 & 02 \\
69 & 55 \\
65 & 25\end{array}$ \\
\hline \multicolumn{4}{|l|}{ Milch cows- } \\
\hline 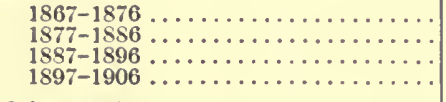 & $\begin{array}{r}9,998,355 \\
12,616,159 \\
15,861,965 \\
16,948,692\end{array}$ & $\begin{array}{l}283,515,175 \\
336,001,308 \\
360,505,202 \\
487,693,745\end{array}$ & $\begin{array}{ll}28 & 42 \\
26 & 47 \\
22 & 79 \\
28 & 74\end{array}$ \\
\hline \multicolumn{4}{|l|}{ Other cattle- } \\
\hline 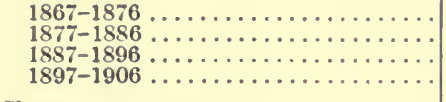 & $\begin{array}{l}14,957,992 \\
24,227,144 \\
35,331,043 \\
38,463,070\end{array}$ & $\begin{array}{l}265,992,932 \\
475,656,436 \\
562,422,695 \\
713,738,958\end{array}$ & $\begin{array}{ll}17 & 69 \\
19 & 12 \\
15 & 96 \\
18 & 98\end{array}$ \\
\hline \multicolumn{4}{|l|}{ Sheep- } \\
\hline 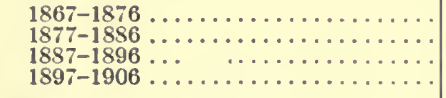 & $\begin{array}{l}35,714,435 \\
43,756,701 \\
43,652,314 \\
48,866,599\end{array}$ & $\begin{array}{r}80,586,544 \\
97,979,426 \\
94,192,051 \\
134,085,793\end{array}$ & $\begin{array}{ll}2 & 27 \\
2 & 23 \\
2 & 15 \\
2 & 72\end{array}$ \\
\hline \multicolumn{4}{|l|}{ Swine- } \\
\hline 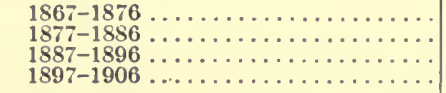 & $\begin{array}{l}27,761,442 \\
38,821,536 \\
47,219,664 \\
45,512,764\end{array}$ & $\begin{array}{l}126,707,584 \\
196,704,251 \\
237,864,737 \\
265,059,503\end{array}$ & $\begin{array}{ll}4 & 58 \\
5 & 02 \\
5 & 04 \\
5 & 72\end{array}$ \\
\hline
\end{tabular}

\section{TABLE 16}

Various Statistics Showing the Progress of Agriculture in the United States. (Fron Census Reports.)

\begin{tabular}{|c|c|c|c|c|c|c|}
\hline \multirow{3}{*}{ Year } & \multirow{3}{*}{$\begin{array}{c}\text { Total } \\
\text { population }\end{array}$} & \multirow{3}{*}{$\begin{array}{l}\text { Number } \\
\text { of farms }\end{array}$} & \multicolumn{4}{|c|}{ Acres of farm land } \\
\hline & & & \multirow{2}{*}{ Total } & \multirow{2}{*}{ Improved } & \multicolumn{2}{|c|}{$\begin{array}{l}\text { Average per } \\
\text { farm }\end{array}$} \\
\hline & & & & & Total & $\begin{array}{l}\text { Im- } \\
\text { proved }\end{array}$ \\
\hline $\begin{array}{l}1850 \ldots \ldots \\
1860 \ldots \ldots \\
1870 \ldots \ldots \\
1880 \ldots \ldots \\
1890 \ldots \ldots \\
1900 \ldots \ldots\end{array}$ & $\begin{array}{l}23,191,876 \\
31,443,321 \\
38,558,371 \\
50,155,783 \\
62,622,250 \\
75,994,575\end{array}$ & $\begin{array}{l}1,449,073 \\
2,044,077 \\
2,659,985 \\
4,008,907 \\
4,564,641 \\
5,739,657\end{array}$ & $\begin{array}{l}293,560,614 \\
407,212,538 \\
407,735,041 \\
536,081,835 \\
623,218,619 \\
841,201,546\end{array}$ & $\begin{array}{l}113,032,614 \\
163,110,720 \\
188,921,099 \\
284,771,042 \\
357,616,755 \\
414,793,191\end{array}$ & $\begin{array}{l}202.6 \\
199.2 \\
153.3 \\
133.7 \\
136.5 \\
146.6\end{array}$ & $\begin{array}{l}78.0 \\
79.8 \\
71.0 \\
71.0 \\
78.3 \\
72.3\end{array}$ \\
\hline
\end{tabular}


TABle 16 , continued

\begin{tabular}{|c|c|c|c|c|c|c|}
\hline \multirow{2}{*}{ Year } & \multicolumn{2}{|c|}{$\begin{array}{l}\text { Value of all farm } \\
\text { property }\end{array}$} & \multicolumn{2}{|c|}{$\begin{array}{l}\text { Value of farm land with } \\
\text { improvements, } \\
\text { including buildings }\end{array}$} & \multicolumn{2}{|c|}{$\begin{array}{c}\text { Average value } \\
\text { of farm } \\
\text { implements }\end{array}$} \\
\hline & Total & $\begin{array}{l}\text { Value per } \\
\text { farm }\end{array}$ & Total & $\begin{array}{l}\text { Average } \\
\text { per acre }\end{array}$ & $\begin{array}{l}\text { Per } \\
\text { farm }\end{array}$ & $\begin{array}{l}\text { Per } \\
\text { acre }\end{array}$ \\
\hline $\begin{array}{l}1850 \ldots \\
1860 \\
1870 \ldots \\
1880 \ldots \\
1890 \ldots \\
1900 \ldots\end{array}$ & $\begin{array}{r}\$ 3,967,343,580 \\
7,980,493,063 \\
8,944,857,749 \\
12,180,501,538 \\
16,082,267,689 \\
20,514,001,838\end{array}$ & $\begin{array}{r}\$ 2,738 \\
3,904 \\
3,363 \\
3,038 \\
3,523 \\
3,574\end{array}$ & $\begin{array}{r}\$ 3,271,575,426 \\
6,645,045,007 \\
7,444,054,462 \\
10,197,096,776 \\
13,279,252,649 \\
16,674,690,247\end{array}$ & $\begin{array}{rl}\$ 11 & 14 \\
16 & 32 \\
18 & 26 \\
19 & 02 \\
21 & 31 \\
19 & 82\end{array}$ & $\begin{array}{l}\$ 105 \\
120 \\
102 \\
101 \\
108 \\
133\end{array}$ & $\begin{array}{l}\text { so } 52 \\
60 \\
66 \\
76 \\
79 \\
90\end{array}$ \\
\hline
\end{tabular}

\begin{tabular}{|c|c|c|c|c|c|c|}
\hline \multirow{3}{*}{ Year } & \multicolumn{3}{|c|}{ Value of live stock } & \multicolumn{3}{|c|}{$\begin{array}{l}\text { Value of farm products } \\
\text { not fed to live stock }\end{array}$} \\
\hline & \multirow[b]{2}{*}{ Total } & \multicolumn{2}{|c|}{ Average } & \multirow[b]{2}{*}{ Total } & \multicolumn{2}{|c|}{ Average } \\
\hline & & $\underset{\text { farm }}{\text { Per }}$ & $\begin{array}{l}\text { Per } \\
\text { acre }\end{array}$ & & $\underset{\text { farm }}{\text { Per }}$ & $\begin{array}{l}\text { Per } \\
\text { acre }\end{array}$ \\
\hline $\begin{array}{l}\ldots \ldots \ldots \\
\ldots \ldots \ldots \\
\ldots \ldots \ldots \\
\ldots \ldots \ldots \\
\ldots \ldots \ldots \\
\ldots \ldots \ldots \\
\ldots \ldots\end{array}$ & $\begin{array}{r}\$ 544,180,516 \\
1,089,329,915 \\
1,229,889,610 \\
1,576,884,707 \\
2,308,767,573 \\
3,078,050,041\end{array}$ & $\begin{array}{r}8376 \\
533 \\
462 \\
393 \\
506 \\
536\end{array}$ & $\begin{array}{rl}\$ 1 & 85 \\
2 & 68 \\
3 & 02 \\
2 & 94 \\
3 & 70 \\
3 & 66\end{array}$ & $\begin{array}{r}\$ 1,958,030,927 \\
2,212,5 \cdot 10,927 \\
2,460,107,454 \\
4,739,118,752\end{array}$ & $\begin{array}{r}\$ 737 \\
552 \\
538 \\
826\end{array}$ & $\begin{array}{rl}\$ 4 & 80 \\
4 & 12 \\
3 & 95 \\
5 & 63\end{array}$ \\
\hline
\end{tabular}

\begin{tabular}{|c|c|c|c|c|c|}
\hline Year & $\begin{array}{l}\text { Total } \\
\text { expenditures } \\
\text { for fertilizers }\end{array}$ & $\begin{array}{c}\text { Per cent } \\
\text { of } \\
\text { rented farms }\end{array}$ & $\begin{array}{l}\text { Number of } \\
\text { acres per } \\
\text { male worker }\end{array}$ & $\begin{array}{l}\text { Number of } \\
\text { horses }{ }^{2} \text { per } \\
\text { male worker }\end{array}$ & $\begin{array}{l}\text { Number of } \\
\text { acres per } \\
\text { horse }\end{array}$ \\
\hline $\begin{array}{l}1880 \ldots . \\
i \times 90 \\
1900 \ldots\end{array}$ & $\begin{array}{r}\$ 28,586,397 \\
38,469,508 \\
54,783.757\end{array}$ & $\begin{array}{l}25.5 \\
28.4 \\
35.3\end{array}$ & $\begin{array}{l}23.3 \\
27.5 \\
31.0\end{array}$ & $\begin{array}{l}1.7 \\
2.2 \\
2.3\end{array}$ & $\begin{array}{l}13.5 \\
12.4 \\
13.5\end{array}$ \\
\hline
\end{tabular}

'Includes number of horses, mules and asses on farms. 
TABLE 17

Average Wages of Farm Labor ${ }^{2}$

\begin{tabular}{|c|c|c|c|c|c|c|c|}
\hline \multirow{2}{*}{ Year } & \multicolumn{2}{|c|}{ Per month } & \multicolumn{2}{|c|}{ Per day } & \multicolumn{2}{|c|}{$\begin{array}{c}\text { Per day } \\
\text { during harvest }\end{array}$} & \multirow{2}{*}{$\begin{array}{c}\text { Difference } \\
\text { per day } \\
\text { with and } \\
\text { without } \\
\text { board }\end{array}$} \\
\hline & $\begin{array}{l}\text { With } \\
\text { board }\end{array}$ & $\begin{array}{c}\text { Without } \\
\text { board }\end{array}$ & $\begin{array}{l}\text { With } \\
\text { board }\end{array}$ & $\begin{array}{l}\text { Without } \\
\text { board }\end{array}$ & $\begin{array}{l}\text { With } \\
\text { board }\end{array}$ & $\begin{array}{l}\text { Without } \\
\text { board }\end{array}$ & \\
\hline 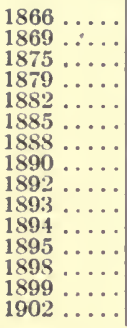 & $\begin{array}{rl}\$ 17 & 45 \\
16 & 55 \\
12 & 72 \\
10 & 43 \\
12 & 41 \\
12 & 34 \\
12 & 36 \\
12 & 45 \\
12 & 54 \\
13 & 29 \\
12 & 16 \\
12 & 02 \\
13 & 43 \\
14 & 07 \\
16 & 40\end{array}$ & $\begin{array}{rr}\$ 26 & 87 \\
25 & 92 \\
19 & 87 \\
16 & 42 \\
18 & 94 \\
17 & 97 \\
18 & 24 \\
18 & 33 \\
18 & 60 \\
19 & 10 \\
17 & 74 \\
17 & 69 \\
19 & 38 \\
20 & 23 \\
22 & 14\end{array}$ & $\begin{array}{rl}\$ 1 & 08 \\
1 & 02 \\
78 \\
59 \\
67 \\
67 \\
67 \\
68 \\
67 \\
69 \\
63 \\
62 \\
72 \\
77 \\
89\end{array}$ & $\begin{array}{rr}\$ 1 & 49 \\
1 & 41 \\
1 & 08 \\
& 81 \\
& 93 \\
& 91 \\
& 92 \\
& 92 \\
& 92 \\
& 89 \\
& 81 \\
& 81 \\
& 96 \\
1 & 01 \\
1 & 13\end{array}$ & $\begin{array}{ll}\$ 1 & 74 \\
1 & 74 \\
1 & 35 \\
1 & 00 \\
1 & 15 \\
1 & 10 \\
1 & 02 \\
1 & 02 \\
1 & 02 \\
1 & 03 \\
& 93 \\
& 92 \\
1 & 05 \\
1 & 12 \\
1 & 34\end{array}$ & $\begin{array}{rr}\$ 2 & 20 \\
2 & 20 \\
1 & 70 \\
1 & 30 \\
1 & 48 \\
1 & 40 \\
1 & 31 \\
1 & 30 \\
1 & 30 \\
1 & 24 \\
1 & 13 \\
1 & 14 \\
1 & 30 \\
1 & 37 \\
1 & 53\end{array}$ & $\begin{array}{c}\$ 046 \\
46 \\
35 \\
30 \\
33 \\
30 \\
29 \\
28 \\
24 \\
21 \\
20 \\
22 \\
25 \\
25 \\
19\end{array}$ \\
\hline
\end{tabular}

${ }^{1}$ Bureau of Statistics Bulletin No. 26.

\section{TABLE 18}

\section{RULES}

Measuring Grain.-A bushel of grain contains approximately $\frac{5}{4}$ cubic feet. To determine the capacity of a bin, find the number of cubic feet and multiply by $\frac{4}{5}$, or multiply by 8 and divide by 10 .

Measuring Ear Corn.-It requires about two bushels of ear corn to make one bushel shelled. To find the capacity of a crib, find the number of cubic feet and multiply by $\frac{2}{5}$ or $\frac{4}{10}$.

Measuring Hay.-The quantity of hay in a mow is very hard to estimate accurately. The deeper the day is, the harder it will be packed. Some kinds of hay are heavier than others, the longer it stands the more compaet it becomes. Settled hay will usually weigh about five pounds per cubic foot. Or, 400 cubic feet will weigh one ton.

Measuring Land.- The easiest way to calculate land measurements is to figure 160 square rods as one acre. A strip one rod wide and 160 rods long, therefore, equals an aere, as does a strip four rods wide and 40 rods long, or eight rods wide and 20 rods long, etc.

A surveyor's chain is four rods long. It is divided into 100 links, so that all ealeulations are in deeimals. Ten square chains equal one acre.

\section{Square Measure Equivalents}

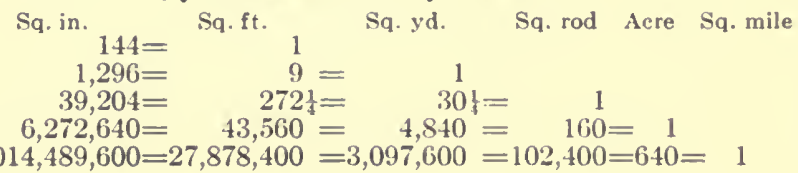




\section{INDEX}

Abbreviations, 35.

Areounts, importance of, 380; kind to keep, 380; ledger, 382; methods of keeping, 380; milk record, 337; references, 38s; work report, 381 ;

Arid phosphate, 123; fertility in, 40s. Addresses of colleges and experiment stations. 403.

Age of horses, how told, 30 s.

Agricultural colleges, addresses of, 403.

Agricultural exports, 414 .

Agricultural imports, 414 .

Agricultural technology, defined, 2 .

Agriculture, compared with manufacturing, 414; defined, 1; divisions of, 2.

Alfalfa, discussion of, 188; composition of, 284; culture, 189; digestibility of. 287; digestible food per acre, 410 ; digestible nutrients in, 410 ; fertility in, 40s; for hogs, 360; history, 1S8; inoculation, 118, 192; lime for, 126; 190: produrtion value as foot, 411; references, 242; rotations with, 279; seed, number per pound, 32; seed, source and hardiness, 9 ; seeding rate, $32,191,405$; seed references, 59; soils for, 190; value per ton, 189.

Alkali, 90; result of eanal seepage, 90 . Ammonium sulfate, 122; fertility in, 408. Animal food, importance of, 281.

Animal products. 254.

Animals, composition of, 60 .

Angus rattle, 325, 327.

Anther, defined, 11.

Apparatus, 40().

Apple, alaptation of varicties, 9 ; care of when not boaring, 70 ; rrown gall, 250: digestible nutrients in, 410; dwarf, 4\%: fertility in, 408; maggot, 258: otiginal form, 10: Pa radiae stork for lwarling. 17: propagation of 12, 14, 45; rcierences, 213, 270; scab, 253 ; spraying. 265.
Apple pomace, digestible nutrients in, 410; fertility in, 408.

Apple worm. See Codling moth. Apples, weight per bushel, 406.

Arsenate of lead, 264.

Asexual reproduction, defined, 12.

Ash, amount in feeds, 283; function of, in feeds, 285; how determined. $2 \times 3$.

Ashes, lime in, 12S; fertility in, 125, 408 .

Asparagus, references, 243 ; time to fertilize, 70 .

Ayrshire cattle, 225, 230; fat in milk, 328.

Babcock milk test, 335; method of making, 345.

Bacteria, described, $9 \vec{\imath}, 245$; importance in soil, 97; relation to agriculture, 1.

Balanced rations, discussion of, 292; eautions in using. 296.

Bananas, exports and imports, $\mathbf{4 1 5}$.

Barley, amount of water required, 67 ; as a nurse rop, 1\$3; averages for ten-year periods in the United States, acreage, proluction, yield per acre, total valuc, value per acre, value per bushel. 416; crop of the world, 154; digestible nutrients in, 410 ; fertility in, 40s; manure for, 137; oats and peas, 152; proluetion value as feed, 412; rotations with, 275; sced vitality, 405; seeding rate, 105; value of Cnited states crop, $155,413,416$; weight per buslsel, 406; weiglit per quart, 412.

Barley meal, weight per quart, $\mathbf{4 1 2}$.

Bartey straw, fertility in, 40s.

Barnyarl inanure. Siec llanure.

Buxic slag, 124.

Batlıroom, 391 . 
Bean, blight of, 250; fertility in, 40s; inoculation, 192; references, 243; seed vitality, 405; seeding rate. 405; weight per bushel, 406 .

Bean straw, digestible nutrients in, 410 ; fertility in, 40 s.

Bedding, effect on manure, 138.

Beef, production, 333; exports and imports, 414; references, 349 .

Bee-keeping, reference, 271 .

Beet, lime requirement, 126; seed vitality, 405. See Sugar beet and Nangel.

Begonia, propagation of, 42 .

Belgian horses, 307, 308.

Berkshire hogs, 358,360 .

Bermuda grass, 187.

Birds, reference, 271 .

Bits, 312.

Black-leg, 341.

Black-knot, 251.

Blight, fire, 249; potato, 254.

Blinders, 313 .

Blood, dried, as a fertilizer, 123; digestible nut rients $1 n, 410$; fertility in, 408 .

Blossom, parts of, 11 .

Blue-grass, 185; reproduction of, 38; seed, cause of poor, 54; seeding, rate, 186, 196, 197, 405; weight per bushel, 406.

Boll-weevil. See Cotton boll-weevil.

Book-keeping. See Accounts.

Bone meal, as a fertilizer, 123, 124; fertility in, 408; for hogs, 286.

Bordeaux mixture, 261; preparation of, 263, 269.

Botany, relation to agriculture, 1.

Bran, weight per bushel, 406 .

Bread mold, 251.

Breathing pores, 67 .

Breeding, chapter on, 5; cattle, 19, 21 , 22, 23; farms, 31; horses, 19, 23; plant vs. animal, 23; references, 34, 35; steps in, 21. See Corn, Cotton, etc.

Brewers' gmins, digestible nutrients in, 410; fertility in, 408; production value as feed, 412; weight per quart, 412.

Brome grass, 186; seeding rate, 405.

Broom-corn, references, 243.

Brown-rot, 252.
Brown-Swiss cattle, 325, 328.

Brown-tail moth, references, $2: 1$.

Buckwheat, averages for ten-year periods in the United States, acreage, production, yield per acre, total value, value per acre, value per bushel, 417; digestible nutrients in, 410; effect of time of plowing on, 165 ; fertility in, 408; for green-manure, 147; references, 243 ; sced vitality, 405; seeding rute, 405; weight per bushel, 406.

Buckwheat bran, digestible nutrients in, 410 .

Buckwheat middlings, digestible nutrients in, 410 ; fertility in, 40 S.

Budding, 43.

Buffalo grass, 37 .

Buildings, farm houses, 391; poultry, 366 ; references, $349,362,371,38 \%$, 395.

Bur-clover, 206.

Butter, references, 350; value of, 413; world's-record cow, 332 .

Buttermilk, digestible nutrients in, 410 .

Cabbage, black-rot, 250; digestible nutrients in, 410 ; fertility in, 405 ; seed vitality, 405; seeding rate, 405; worm, 259.

Calcium carbonate, 12\%.

Calcium, food for plants and animals, 60,62 .

Calves. See Cattle.

Cambium layer, 43, 231.

Canada blue-grass, 186.

Canada field peas. See Peas.

Cantaloupe, lime requirement, 126.

Capillary movement of water in soils, S.j.

Capital, importance of, 377; investments in agriculture and manufacturing compared, 414.

Carbohydrates, fat equivalent of, 284; function of in feeds, 286; in feeds, 254; manufacture of, hy plants, 68 .

Carbon, amount in plants, 63; food for plants and animals, $60,61,67$.

Carbonate of lime, 127.

Carbonic acid gas. See Carbon. 
Carrot, digestible nutrients in, 410; fertility in, 408; production value as feed, 412; seed vitality, 405; seeding rate, 405 .

Cattle, chapter on, 323; averages for ten-year periods in the United States, total number, total value, value per head, 418; beef and dairy contrasted, 323; breeding, 19, 21, 22, 23, 333, 337; breeds of, 322; care of 297,324 ; composition of, 285; computing rations for, 293; cottonseed for, 212; diseases, 337; exports and iraports, 414; feeding references, 299; feeding standards, 292, 296, 409; fertility of food recovered in manure, 138; grading up a herd, 333, 337; manure, composition and value of, 138, 139, 140; manure, feed recovered in, 138; milk of different breeds compared, 328; numbers of, $35 \%, 418$; origin of polled, 8 ; products, 333; rate of depreciation, 387; references, 299,349 ; score cards, 342,343 ; stables for, 297 ; types of, 323 ; value of, 357,418 ; value of $\mathrm{ma}$ nure, $138,140$.

Celery, references, 243; seed vitality, 405.

Cement floor, for poultry houses, 36r; manure saved by, 143.

Certified milk, 336.

Cesspool, 392.

Cheese, references, 349; value of, 413 .

Chemistry, relation to agriculture, 1 .

Cherries, black-knot of, 251; brown-rot of, 252; propagation of, 42, 44, 45 .

Cheshire hogs, 350, 359 .

Chester White hogs, 358, 360 .

Chestnut, grafting, 42.

('heviot sheep, 35 .

('hickens. See Poultry.

(hinch-bug, control of, 259.

Chlorin, food for plants and animals, 60,62 .

Chocolate, exports and imports, 415 .

Choice of a farm, 372 .

Citrus fruits, references, 243,271 .

Climate, effect of forests on, 220; for alfalfa, 100; for corn, 157; for cotton, 199, 205; for oat., 181; for potatoss and roots, 160; for wheat, 180; questions on, 237.

Clover, alsike, 194; soils for alsike, 194; bur-, 206; composition of, 284; digestible food per acre, 189; digestible nutrients in, 410; digestibility of 287; fertility in, 408; for horses, 312; green-manure, 147; inoculation, 192; lime requirement, 126 ; method of reproduction, 12; production value, as feed, 292, 411; red, 193; references, $59,152,242$; reproduction of, 36 ; seed, good and poor, 52; seed mixtures with grass, 195; seed vitality. 405; seed weight per bushel, 406; seeding rate, 193, 195, 196, 197, 405; time to cut, 70,71 ; varieties adapted to pasture, 36; water requirement, 67; white, 195.

Cion, effect of root on stock, 47 .

Clydesdale horses, 30 $7,308$.

Coal, weight per bushel, 406.

Cocoa, exports and imports, 415.

Codling-moth, life history and control of, $257,258$.

Coffee, exports and imports, 415.

Collateral readings, $3,34,59,74,108$, $152,242,270,280,299,321,349$, $356,361,371,383,395,399,401,403$; how to secure bulletins, 401 ; list of books, 402 .

Colleges, addresses of, 403 .

Concentrates compared with roughage, $189,291,411$.

Condensed milk, 336.

Condimental feeds, 298 .

Corn, chapter on, 156: averages for tenyear periods in the United States, acreage, production, yield, per acre total value, value per ncre, value per bushel, 416; barren stalks, 2S1; breeding, 21, 25; broken stalks, 28; ' climate for, 157; composition of, 63. 254: composition at different stages of growth, 175; composition of dent and flint, 162; cost compared with oats, 182; cultivation, depth for, 1\%0; dent, 162; digestible food per acre, 160 ; digestible nutrients in, 410digestibility of, 25\%, 290, 291; dis- 
tribution of, 156; ears, ideal, 49; earrow test, 26; exports and imports, 177,414 ; fertility in, 40s; fertibzers for, 132, 163; fitting the land for, 166; flint, 162; germination tests, 4S; greenmanure crops seeded with, 147; harvesting methols and costs, 171; history, 156; lime requircment, 126; method of measuring in cribs, 420 ; method of testing germination, 48 ; method of storing sced, 26, 54; nativity of, 154; original form of, 10; planting depth, 167 168; planting methods 167; planting rate, 166, 174, 405; plowing for, 163; pollination of, 12; pod, 161; pop, 161; production value as feed, 411 ; reasons for growing, 159; references, $34,59,242,300$. 362 ; roots, 171 ; root-worm, 254 ; rotations with, 278, 279; score eard, 23s; stands, poor, 4S; seed, storing, 26; seed testing, 54; seed vitality, 405; smut, 36, 254; soft, 161; suckers, 25; sweet, 162; time required to grow one bushel, 301; types, of 161; uses of, 177; value of the crop, $155,413,416$; varieties, 162; varieties, composition of, 162; varieties for the silo, 17j; water required, 67 ; weight per bushel, 406; weight per quart, 412 .

Corn-and-cob meal, digestible nutrients in, 410; production value as feed, 412; weight per quart, 412.

Corn bran, weight per quart, 412 .

Corn cobs, fertility in, 408.

Corn fodder, defined, 172; digestible nutrients in, 410; fertility in, 405 ; production value as feed, 411 .

Corn, kafir.

Corn meal, maintenance value, 290, 291; production value, 291 ; weiglut per bushel, 406; weight per quart, 412.

Corn silage, discussion of, 171; digestible nutrients in, 410; effect of frost on, 175; effect on milk, 176; feeding, 176; fertility in, 40s; production value as feed, 411; tine to cut for, 174; vs. fodder, 172.

Corn stover, defined, 192; digestible nutrients in, 410 ; fertility in, 408 ; production value as feed, 411 .

Cotswold sheep, 351, 354.

Cottolene, 212.

Cotton, chapter on, 195: averages for ten-year periods in the United States, production, total value, value per pound, 417; bale, size of, 211; breeding, 29, 202; climate for, 199, 205; crop value and yields, $155,198,199$, 201, 413; cultivating, 209; diseases and insects, 214; exports and inports, 198, 415; fertility in lint, meal and seed, 408; fertilizers for, 208; grades, 211; green-manure crops with, 147; habits of growth, 200; harvesting, 210; history, 199; lint, per cent of. 202; marketing, 211; planting, 209; plowing for, $20 \vec{\imath}$; rotations with, 279 ; references, $35,242,270$; seed, heavy vs. light, 53; seeding rate, 210, 405; soils for, 206.

Cotton boll-weevil, 214, 25\%.

Cotton boll-worm, 215.

Cottonseed, products, 212; weight per bushel, 406.

Cottonseed meal, 212; composition, 214; production value as feed, 412 ; weight per quart, 412.

Cottonwood, propagation of, 41 .

Cows. See Cattle.

Cowpea, as green-manure, 147, 206; inoculation, 118; digestible nutrients in, 410 ; lime requirement of, 126; production value as feed, 411 ; references, 243; rotations with, 279; seeding rate, 405 .

Cranberries, reference, 243, 271.

Cream separator, references, 349.

Cropping, clapter on systems of, 272. Crops, choice of, 272; diversified, 273; relative importance of, 154, 155 . Crop rotations. See Rotation of crops. Cross-fertilization, 12.

Crossing plants, methods of, 13; when desirable, 19.

Crown-gall, 250.

Crude fiber, 284.

Cucumber, beetle, 261; references, 243 , 270 ; seed vitality, 405 ; wilt, 250 . 
Culm, defined, $3 \vec{\imath}$.

Cultivator, 169.

Currants, propagation of, 41 .

Cuttings, 41 .

Dairying. See Cattle and Milk.

De Candolle's law, 9.

De-horning cattle, references, 350 .

Delaine merino sheep, 351, 352.

Deron cattle, 325. 328.

Digestibility, effect of time of harvest ing on, 2ss.

Digestible nutrients in feeds, 410; method of finding, 2ss.

Diseases. See Plant diseases, Cattle, etc.

Disinfectants, references, 270.

Disk-harrow, 166.

Distillers' grains, weight per quart, 412.

Dodder, 191, 254.

Dog, fencing to protect sheep, 355; intelligence of, 315 .

Dominant eharacter, defined, 16.

Dorset horn sheep, 351, 354 .

Double-tree, effect of height on draft, 306.

Drainage, by the government, 94 ; effect during drought, 92; effect on temperature, 82; for removal of alkali, 90; kinds of, 93; laying tile, 03 ; necessity for, 91: references, 108.

Dried blood. See Blood.

Diry-land farming, 85, 87.

Dry matter, how determined, 72 .

Ducks, reference, 371 .

Durbam. See Shorthorn.

Duroc-Jersey hogs, 358, 360 .

Dust mulch, 85.

Dutch belted cattle, 325 .

Earthworms, 97.

Eggs, as foorl, reference, 300; composition of, 285; parts of, 368; value of, 363.

Eggplant, seed vitality, 405.

Embryo, lefined, 11,47.

Emmer, reference, 300.

English sture borse, 30\%, 30s

Envimnment, defined, 2, 3 .

Equipment, 400.

Essex hogs, 358, 360.
Ether extract. See Fat.

Evaporation of soil-water, 85 .

Experiment stations, addresses of, 403 . Exports, 414.

Fanning-mill, value of, 54 .

Farm, best size of, 373; how to ehoose, 372; score card, 385; topography, 375 .

Farms, averages for ten-year periods in the United States, number of farms, total acreage, average size, average improved area, value of all farm property, value per farm, value of land, value per acre, average size of farms, average improved acreage, value of live-stock, average per farm, average per acre, value of products, value per farm, value per acre, per cent of rented farms, number of acres per male worker, number of acres per horse, average wages of labor, $418,419,420$.

Farm accounts. See Accounts.

Farm buildings. See Buildings.

Farm community, chapter on, 396 .

Farm home, chapter on, 389 ; references, 395.

Farm house, modern improvements for, 391; type of building, 391 .

Farm income defined, 387.

Farm labor. See Labor.

Farm management, ehapter on, 372; references, $3 s s$.

Farm products, total value, value per farm and per acre, 419 .

Farm property, compared with that in manufacturing, 414; value of, 414, 419; value per farm, 419 .

Farm records. See Accounts.

Farmyard, 359 .

Fat, defined, 283; cabohydrate equivalent of, 2s6, 293; compared with carbohydrates, 65; composition of, 68; function of, 256; how determined, 2\$3; in feeds, $2 \times 3$.

Feeding, etapter on, 281; horses, 311; poultry, 365; mtandards, 293, 409; references, 299,349 . .

Feeds, chapter on, 281; balanced rations 292; cautions in using balanced ration, 
296; composition of, 282; computing rations, 293; condimental, 298; digestibility of, 287; effect of time of harvesting on, 71, 183; fertility of, recovered in manurc, 138; functions of, 285; maintenance values of, 289; nutritive ratio, 293; production values of, 259, 411; references, 299; relative values of concentrates and roughage, 189, 291, 411; weed seeds in, reference, $2 \% 0$.

Fences, for sheep, 355; trees for posts in, 225.

Fertility of the land, chapter on, 109. See Soil fertility.

Fertilization of blossoms, 12.

Fertilizers, amount spent for, 116, 419; analyses, 129; cost, 129; effect of too strong, 66; estimating value, 130: for alfalfa, 190; for corn, 132, 163; for cotton, 208; grass, 132, 183; legumes, 132; oats, 132, 181; wheat, 132, 180; home-mixing, 131; materials used as, 114; references, 152, 153; valuation, 129; when and what to use, 111, 114, 132, 163, 181, 183, 184, 205. See Nitrogen, Phosphorus, Potassium, Lime, Manure, Greenmanure.

Fertilizing constituents in various substances, 408 ,

Fiber, crude, 284.

Fjelds, arrangement of, 223, 276; shape and location, 374 .

Filament, defined, 11.

Fire-blight, 249.

Fish as food, reference, 300 .

Flax, seeding rate, 405; seed vitality, 405.

Flax-seed, exports and imports, 414; value of crop, 413 ; weights per bushel, 406.

Flea-beetle, control of, 261.

Floats, 124; as reinforcement for manure, $144,149$.

Flocculation, 83.

Flowers, 389.

Fly, life history of, 256.

Fodder, See Corn.

Food, stored in seeds, $4 \pi$.
Forest, discussion of, 216; area in United States, 216; conservative management of, 221; destruction of, 217; effect on climate, 220; importance of to irrigation, 89,220 ; profits from wood lots, 222; references, 243; relation of the government to, 218; reserves, 219; trees to plant, 226; wood-lot management, 222.

Forest products, exports and imports, 415 ; value of, $155,413$.

Fowls. Sce Poultry.

French coach borses, 307.

Fumigation of nursery stock, references, $2 \% 0$.

Fungi, attacking tree trunks, 231: description and control of, 250, 261 .

Fungicides, 260; references, 270.

Fur, exports and imports of, 414.

Galloway cattle, 325,327 .

Galton's law, 5 .

Gametes, defined, 12; See Mendel's law, 14.

Garden, management of, 235; profits from, 234; school, references, 371 .

Geese, references, 371.

Geology, relation to agriculture, 1 .

Geranium, propagation of, 41 .

German coach horses, 307.

Germination, importance of vigorous, 48; method of testing, 48,51 .

Germ oil meal, weight per quart, 413. Gipsy moth, references, $2 \pi 1$.

Gluten meal, digestible nutrients in, 410; fertility in, 408; from corn, 17\%; production value as feed, 412 ; weight per quart, 413.

Grafting, discussion of, 42; root, 45 ; top, 46.

Grafting-wax, rule for making, 56 .

Grain, method of measuring in bins, 420.

Grapes, propagation of, 41 ; references, 271.

Grasses, discussion of, 182 .

Grass, and clover mixtures, 195; effect on soil fertility, 120; fertilizers for, 132,183 ; reproduction of, 37 ; soils for, 82 See Meadows, Timothy, tetc 
Grasshoppers, life history, 257.

Green-manure, discussion of, 147, 206; crops for, reference, 152 .

Guano, fertility in, 408.

Guernsey cattle, $325,330,332$; fat in milk of, 328 .

Gypsum, 128; reinforcement for $\mathrm{ma}$ nure, $144,149$.

Hackney horses, 307, 308.

Hampshiredown sheep, 351, 354 .

Hampshire hogs, $358,359,360$.

Harrow, 166.

Haustoria, defined, 251.

IIay, averages for ten-year periods in the United States, acreage, production, yield per acre, total value, value per acre, value per ton, 417 ; method of measuring, 420; value of the crop, $155,413,416$.

Heaves, 194, 312.

Hens, composition of, 285. Siee Poultry. Hereditary power, testing, 22.

Heredity, defined, 2; problems of, 13. Ilereford cattle, 325,327 ; origin of polled, 8 .

Hides, exports and imports, 414.

Hogs, chapter on, 357; ash for, 285; averages for ten-year periods in the United States, total number, total value, value per head, 418 ; breeds of, 358 ; care of, 360 ; composition of, 285 ; rots, reference, 362; cottonseed for, 212; diseases, 337,361 ; dist ribution of, 357 ; feeding standards, 409 ; feeding references, 299, 362; manure, amount and value per year, 139; numbers of, 357, 418; references, 299. 361; regions adapted to, 177; values of, 357,418 .

Holstein rattle, 325, 329, 332; fat in milk of, $32 \mathrm{~s}$.

Home. See Farm honse.

Hominy feed, digestible nutrients in, 110; fertility in, 408; weight per quart, 413 .

Hops, vitality of seed, 405, references, 243.

Horses, chapter on, 301; averages for ten-year periods in the United States, total number, total value, value per head, 418; age, how told, 308; amount pulled by, 306; ash for, 2S6; breeding of, 19, 23, 307; docking, 314; care of, 311 ; elasses of draft, 305 ; clipping, 313; conformation for draft and speed, 303; corn for, 182; cottonseed for, 212; draft and speed compared, 303; driving, rules of road, 316; effect of clover on, 194; effect of low double-tree on power, 306; feeding, 311; feeding references, 299; feeding standards, 293, 409; good proportions for, 318; heaves, 312; intelligence of, 315; importance of, 301; manure composition, amount, value, 139, 140; numbers of, 357,418 ; number of acres per horse, $\mathbf{4 1 9}$; number per man, 301, 419; on farms vs. horse-power in factories, 414; over-cheek, 313; rate of depreciation, 387 ; references, 299, 321; score card for, 319 ; silage for, 176; sore shoulders, 313 ; training, 315 ; types, of 302 ; values of, 357,418 ; weight for draft and speed, 305 .

Hot-bed, 236.

House-fly, 256, 258.

Humus. See Soil humus.

Hungarian grass, digestible nutrients in, 410; production value as feed, 411.

Hyhrid, defined, 13.

Iydrogen, food for plants and animals, 60,61 .

\section{Imports, 414.}

Inprovement of plants and animals, 5 . Indian corn. See Corn.

Insecticides, 260; references, 270.

Insects, discussion of, 255: beneficial, 255; control of, 258; damages caused by, 255; defined, 255: stages in life of, 256.

Iron, amount in plants, 63; food for plants and animals, 60, 62.

Irrigation, area irrigated, 88; areas requiring, SS; canuls, reepage íroun, 90; dangers of, 90; in Egypt, 89; in India, 89 ; rescrvoirs, $\mathbf{8 9}$. 
Jersey cattle, 325, 329, 332; fat in milk of, 328 .

Johnson grass, 188; control of, reference, 270.

Kafir corn, references, 243.

Kainit, 125; fertility in, 408; reinforeement for manure, 144, 149.

Kentucky blue-grass. See Blue-grass. Kerosene emulsion, preparation of, 265.

Labor, diseussion of, 377; average wages, 420; saving, $82,144,160,167$, $170,272,275,301,373,374,375,37 \overline{\text {, }}$ 378; supply, 376 .

Labor reports. Sce Accounts.

Laboratory equipment, 400 .

Laboratory exercises, 32, 56, 72, 101, $151,238,267,250,318,342,368$, 385,395 .

Land, method of measuring, 420 .

Land plaster, 128; reinforcement for manure, 144, 149.

Lambs. See Sheep.

Larva, defined, 256.

Ledger, $3 \$ 2$.

Legal weights per bushel, 406.

Leghorn hens, 364 .

Legumes, as food, reference, 300; fertilizer requirements, 132 ; inoculation of, 11s, 192; nitrogen fixation by, 116; nodules on the roots of, 117 .

Leicester sheep, 351 .

Lemons, references, 243, 271.

Lettuce, lime requirement, 126; seed vitality, 405 .

Library, 401.

Lineoln sheep, 351.

Linseed meal, digestible nutrients in, 410; fertility in, 408; production value as feed, 412; weight per quart, 413.

Lime, applieation of, 128; forms of, 127; for alfalfa, 190; how to tell the need of, 127; references, 152; weight per bushel, 406 .

Lime-sulfur spray, preparation of, 265.

Limestone, 127.

Listing corn, 167.

Live-stock, importance of in maintain- ing fertility, 110; total value, value per farm and per aere, 419.

Machinery, rate of depreciation, 387; value per farm and per aere, 419 .

Magnesium, food for plants and animals, 60,62 .

Maintenance values of feeds, 289, 411 .

Maize. Sice Corn.

Malt sprouts, digestible nutrients in, 410; fertility in, 408; production value as feed, 412 ; weight per quart, 413.

Mangels, digestible nutrients in, 410 ; fertility in, 405; production value as feed, 412; seeding rate, 405.

Manure, discussion of, 135; amount produecd per year, 139; application of, 142,144, 184; composition of, 140; factors affecting value of, 138 ; fertility of food recovered in, 135; grcen crops for, 147 ; importance of, 135 ; lasting effects of, 136; liquid composition and value, 140 ; losses of, 140; preservation of, 143 ; references, 152 ; reinforement of, 142, 144, 149, spreader, 144; value in the United States, 135; value per ton, 136, 140; value per year, different animals, 139 .

Maple sugar, references, 243.

Meadows, discussion of, 182; method of seeding, 182; references, 242; rotations with, 278,279 ; seeding mixtures, 196.

Meadow-feseue, 186; seeding rate, 196, 197.

Meat on the farm, reference, 349 .

Meat-scrap, digestible nutrients, in 410 .

Melon beetle, 261.

Mendel, biographical notes, 14.

Mendel's law, 14; summary of, 15; applications of, 19.

Merino sheep, 351.

Meteorology, relation to agriculture, 1. See Climate.

Milk, discussion of, 334; as food, 62, 334; as fool, reference, 300; Babcock test of, 336, 345; clean, 334; certified, 336: composition of, 255, 334; condensed, 336; digestible, nutrients in 
410; effect of silage on, 176; fertility in, 408; flour, 336; of different breeds, 325; pails, 335 ; pasteurized, 335 ; powder, 336; records, 337; references, 300,349 ; standardized, 336; test, 336,345 ; value of, 413 .

Milk-fever, 340 .

Millet, references, 243; seed vitality, 405 . seeding rate, 405; weight per bushel, 406.

Milo, reference, 243 .

Modern conveniences for the home, 391.

Mold, bread, 251.

Mosquito, control of, 94, 258; life history of, $25 \%$.

Mules, arerages for ten-year periods in the United states, total number, total value, value per head, 418 .

Muriate of potash, 125.

Muskmelon, sced vitality, 405.

Mustard, spraying for, 246 ; seed vitality, 405.

Mutations, 8.

Mutton, references, 356 .

Mycelium, defined, 250.

Natural selection, 7; development of weeds by, 8 .

Neiglibors, $376,396$.

Nitrate of soda, 122; composition of, 40s; effect on timothy, 132, 133.

Nitrate of potash, composition of, 408 .

Nitrogen, amount in air, 116; amount in plants, 63; nmount in rainfall, 116; anount in soils, 113; effert of time of plowing on, 161; effect on color of plants, 61; fixation witl legumes, 116. 20x: fixation without legumes, 119; food for plants and animals, 60, 61; forns of in fertilizers, 122; in manure, 136. 139, 140, 111; losses of, 121; losses from manure, 141; of fool recovered in inanure, 138; per cent of in protein, 2\$3; relation to soil organiams, 97; sourres of, 116.

Nitrogen-free extrart, 2sil.

Nutrients, amount of in various feeds, 410.

Nutritive ratio, defined, 293.

Nuts, exports and imports, 415 .
Oats, 181; as a nurse crop, 183, 190; averages for ten-year periods in the United States, acreage, production, yield per acre, total value, value per acre, value per bushel, 416 ; breeding, 29; climate for, 181; cost compared with corn, 182; digestible food per acre, 160; digestible nutrients in, 410; fertility in, 408; fertilizers for, 131. 133, 151; ground, weight per quart, 413; planting depth, 168; production value as feed, 292, 412; references, 270; rotations with, 270; soils for, 181; uses of, 181; value of the United States crop, 155, 413 ; seed vitality, 405; seeding rate, 405; water requirements, 67 ; weight per bushel, 106; weight per quart, 413 ; world's crop of, 154.

Oats-barley-and-peas, 182.

Oat hay, production value as feed, +11 .

Oat rust, 36.

Oat smut, 36; control of, 254.

Oat straw, fertility in, 408; digestible nutrients in, 410; production value as feed, 412 .

Onions, lime required, 126; references, 243 ; seed vitality, 405; weight per bushel, 408.

Oranges, propagation of, 42 ; references, $34,271,243$.

Orchards, discussion of, 227; planting, 227; pruning, 230; spraying, 229, 266; tillage of, 228; value of products, 413 .

Orchard grass, 187; reproduction of, 38; seeding rate, 196, 197; seed vitality, 405 .

Osmosis, definition and experiment, 65. Ovary, defined, 11.

Oxford-klown sheep, 351, 354.

Oxygen, as food for plants and animals, 60,61 .

Paris green, 261

Parsuip, sced vitality, 40 s.

Pasteurized milk, 335.

!asture, discussion of, 182; adaptation of elover and grass varieties, 36, 39; management of 197 ; references, $24 \%$; seed mixtures for, 196. 
Peaches, brown-rot of, 252; danger in spraying, 262; propagation of, 42, 43, 45; references, 243.

Peanut, inoculation, 192; seed vitality, 405.

Pears, how dwarfed, 47; propagation of, 42, 45; references, 243 .

Pear-blight, 249.

Peas, fertility in, 408; inoculation of, 192 ; seed vitality, 405; weight per bushel, 406 .

Peas-and-barley, digestible nutrients in, 410.

Peas-and-oats, digestible nutrients in, 410.

Peas-barley-and-oats, 182.

Pea-vine silage, digestible nutrients in, $\$ 10$.

Pea-vine straw, digestible nutrients in, 410; fertility in, 408.

Pecan, grafting, 42.

Pedigreees, 330; advanced registry, 3333; value of, 331 .

Percheron horses, popularity of, 307 .

l'erennial, defined, 38 .

Phosphoric acid. See Phosphorus.

Phosphorus, amount in soils, 113, 114; comparative effects of different forms, 133; deficiency in soils, 134; effect on seed formation, 64; food for plants and animals, 60,62 ; forms of in fertilizers, 123; in manure, 136, 139, 140, 141; losses fronı manure, 141; of food recovered in manure, 138; reinforeement for manure, 142, 144, 149; relation to lime, 132.

Physics, relation to agriculture, 1.

Pigs. See Hogs.

l'ineapple, references, 34, 243.

Pistil, defined, 11.

Plants, composition of, 60 ; periods in the life of, 69; storage of food in, 69; the only source of starch, 69 .

l'lant-breeding forms, 31 .

Plant diseases, diseussion of, 248 control of, 214.

Plant-food, chapter on, 60; amount of, in soils, 113; deficiency in soils, 63; elements required, 60; how taken up, $64,66,67$; sources of, 61 .
Plant lice, life history of, 257; contro of, 265.

Plowing, depth, 164; spring is. fall, 163; sub-soiling, 165.

Plums, black kuot of, 251; brown-rot of, 252; danger in spraying, 262; propagation of, $42,44,45$.

Plymouth Rock hens, 36.

Poland-China hogs, 358, 359, 360.

Polled Durham eattle, 325.

Poplars, propagation of, 41 .

Population of the United States, 418.

Potash. See Potassium.

Potassium, amount in soils, 113, 114; defined, 11; effect on seed formation. 64; ferro cyanide, 264; food for plants and animals, 60, 62; forms of in fertilizers, 125; in manure, 136, 139. 140, 141; losses from manure, 141; muriate of, fertility in, 408; of food recovered in manure, 138.

Potassium chlorid, 125.

Potassium nitrate, fertility in, 408.

Potassium sulfate, 125; fertility in, 408. Potato, area necessary for profit, 272; averages for ten-year periods in the United States, acreage, production, yield per acre, total valuc, value per acre, value per bushel, 417; breediug. 21, 30; composition of, 62 ; digestible food per acre, 160; digestible nutrients in, 410; flea-beetle, 261; fertility in, 408; stuethod of reproduction, 12; nativity of, 154; planting, preparation for, 40 ; planting rate, 405; propugation of, 39 ; production value as feed, 412; references, $35,243,270$; rotations with, 147,274 ; seed, size to cut, 39; seed, storage, 40; seed, time to cut, 41 ; spraying, 266; value of, $155,413,417$; water requirement, 67 ; weight per bushel, 406; world's crop, 154.

Potato-beetle, control of, 259.

Potato-blight, control of, 254.

Potato seab, control of, 253.

Potato, sweet, See Sweet potato.

Poultry, chapter on, 363; as food, reference, 300 ; ash for, 286; breeds of, 363; feeding, 365 ; feeding stan- 
dards, 409; houses, 366; importance of, 363 ; manure, amount and value per year, 139: products, value of, 363,413 ; rate of depreciation, 387 ; referenees, 299, 371; yearly egg-production, 6,7 .

Preserving food, methods of, 172 .

Production value of feeds, 259, 411.

Propagation of plants, chapter on, 36 . See, also, Cuttings, Seeds, Grafting. Protein, composition of, 69; definer, 283; function of, in feeds, 286; how determined, 283; in feeds, 283; test for, 73.

Pruning, 227, 230.

Pupa, defined, 256.

Pumpkin, digestible nutrients in, 410; fertility in, 408; seed vitality, 405; seeding rate, 405 .

Quince roots for dwarf pears, 47 .

Questions, 3, 31, 55, 71, 100, 148, 237, $266,280,298,317,342,361,368,348$, 398.

Radish, vitality of seeds, 405 .

IRambouillet sheep, 351, 352.

Rape, fertilizer requirements, 133; rate of seeding, 405 ; references, 243; vitality of seeds, 405 .

Raspberries, references, 243 .

Rations, balanced, 292.

Rats, methods of destroying, reference, 271.

Recessive character, defined, 16.

Reeords. See Accounts.

Red-Polled, 325, 328.

Red clover. See Clover.

Red-top, 186: low lime requirements, 126; seeding rate, 186, 197, 405.

References, list of, 401. See Collateral reading.

Registry, 330; advanced, 332.

Riee, fertility in, 405; references, 243; seeding rate, 405; weight per bushel, 406; world's crop of, 154 .

Rice bran, fertility in, 409.

Riee polish, fertility in, 409.

Road, rules of, 316.

Root-borer, rlover, 193, 194.
Root-crops, why not more grown, 160. Root-grafting, 45.

Koot-hairs, 64.

Roots, acidity of, 66; references, 242. Root-stocks, 36, 38 .

Rotation of crops, chapter on, 272; and manure supply, 140; advantages of, 274; defined, 273; examples of, 278; for control of insects, 258; references, 280; vs. crop diversification, 273.

Roughage compared with concentrates, 189, 292, 411.

Rubber, exports and imports, 415.

Rusts, 254.

Rye, as a nurse crop, 183; averages for ten-year periods in United States, acreage, production, yield per acre, total value, value per bushel, $\$ 16$; digestible nutrients in, 410; fertility in, 409 ; green-manure, 147 ; planting depth, 163; production value as feed, 412; seed vitality, 405; seeding rate, 405; weight per bushel, 406; weight per quart, 413; worlds" crop of, 154.

Rye-bran, digestible nutrients in, 410; fertility in, 409; produetion value as feed, 412 ; weight per quart, 413 .

Rye-meal, weight per quart, 413.

Rye straw, digestible nutrients in, 410; fertility in, 409; production value as feed, 412 .

Saddler, 307, 308 .

Salsify, seed vitality, 405 .

Salt as a fertilizer, 115.

Saw-dust as bedding, 138 .

San José scale, control of, 259, 264.

ícore eard for cat tle, 242, 243; corn, 238;

farms, 385; horses, 319.

Secl, adaptation to climate, 9 ; ehange of, 9; analysis, 51; effect of size and weight on crop, 53; germination tests, 49, 51; importation of low grade, 55; low vs. high grade, 52; nuture of, 47 ; purity tests, 52; storage of, 54 ; vitality, table of, 405.

Seedthig, rates per aere, 405.

Selection, urtificial, 10; characters to consider, 21; importance of, 21; natural, 7 . 
Self-fertilization, 12.

Septic tank, 393.

Sessile, defined, 37.

Sewer system for farm, 391.

Sexual reproduction, 12.

Shade trees, 138.

Shavings as bedding, 138 .

Sheep, chapter on, 351; averages for ten-year periods in the United States, total number, total value, value per head, 418; breeds of, 351; composition of, 285; cottonseed for, 212; feeding standards, 409; fertilizing value of feed recovered in manure, 138; manure, amount and value per year, 138, 139; numbers of, 357, 418; opportunities in raising, 355; references, 299, 356; silage for, 176; types of, 351 ; values of, 357,418 .

Shorthorn cattle, 325 ; fat in milk, of 328; origin of polled, 8 .

Shoulders, care of sore, 313 .

Shrinkage of products, reference, 242.

Shropshire sheep, 351, 353.

Shrubs, 389.

Silage, materials for, 172. See Corn silage.

Silicon as food for plants and animals, 60,62 .

Silk, exports and imports, 414.

Silo, 171, 173; cost of filling, reference, 242 ; principle of, 172 .

Snut, control of, 254 .

Sodium, food for plants and animals, $60,62$.

Sodium nitrate. See Nitrate of soda.

Soils, chapter on, 75 ; analysis, physical, 76; analysis, value of chemical, 113; best kinds of, 83,375 ; composition of soils, 76; defined, 75 ;- for alfalfa, 190 ; clover, 193-195; corn, 78, 163; cotton, 78, 206; grass, 78, 82, 183-188; oxts, 78,181 ; tobacco, 82 ; vegetables, 78 , 82; wheat, 82, 180; wood lot, 223; how formed, 109; how named, 78; management of clay, 83; plant food in, 113, 114; references, 108,152 ; rock particles of, 76; size of particles and crop adaptation, 78,82 ; size of particles and water capacity, 79,80 ; warm and cold, 81; water capacity, determination of, 105; water capacity of clay and sand, 80. See, also, Irrigation and Drainage.

Soil air, importance of, 94; determination of the amount of, 103.

Soil-bacteria. See Soil organisms.

Soil fertility, chapter on, 109; amount in soils, 113; causes of loss of, 111; how developed, 104; how lost, 109; importance of grass, 120; importanies of legumes, 116.

Soil humus, amount in soils, 96; illportance of, 95.

Soil organisms, 116-122.

Soil particles, effect on labor, 82; florculation of, 83 ; importance of size of, 79-84; relation to crop adaptation, 78,82 ; relation to water capacily, 79,80 ; separation of, 76 ; size of and temperature, 81; surface area per cubic foot, 80 .

Soil water, best amount of, 91; composition of, 84 ; conserved by early plowing, 164; comservation of, 85; low amount is determined, 72 ; importance of, 84 ; movement of, 85 . Sorghum, references, 243 .

South Carolina rock, 123.

Southdown sheep, 351,354 .

Soy-bean, digestible nutrients in, 410; fertility in, 409; inoculation, 118, 192; lime requirement, 126; references, 243 ; seed vitality, 405.

Soy-bean hay, productive value as feel, 411.

Soy-bean straw, fertility in, 409.

Spores, 36, 251.

Sports, 8.

Spraying, for insects and disenses, 258; for mustard, 246; profits, from 229; references, $2 \% 0$.

Squash, seed vitality, 405 .

Stamen, defined, 11.

Standardized milk, 336.

Starch as food, 256; composition of, 68; how formed, 68; translocation of, 68 .

Stigma, defined, 11.

Stolon, defined, 38 .

Stomata, 67. 
Stooling, 12.

Storage reservoirs, 89.

Stover. See Corn.

Strawberries, references, 243.

Style, defined, 11.

Subsoiling, 165.

Suffolk hogs, 358,360 .

Suffolk Punch horses, 307 .

Sugar, as food, 2S6; exports and imports, 415; references, 300 .

Sugar-beet, breeding, 24; breeding references, 35 ; digestible nutrients in, 410; fertility in, 40s; per eent of sugar, 24; total production, 417; references, 243; seeding rate, 405.

Sugar-beet leaves, digestible nutrients in, 410 .

Sugar-beet molasses, digestible nutrients in, 410 .

Sugar-beet pulp, digestible nutrients in, 411 .

Sugar-cane, total produetion, 417; value of crop, 413 .

Sugar maple, references, 243.

Sulfate of ammonia. See Ammoniun sulfate.

Sulfate of potash, 125.

Sulfur, food for plants and animals, 60,62 .

Sweet potatoes, method of reproduetion, 12; propagation of, 39 ; references, 243; planting rate, 405 ; value of crop, 413; weight per bushel, 406 .

Swine. See Hogs.

Tamworth hogs, 358, 360 .

Tankage, as a fertilizer, 123; for hogs, 286.

Tea, exports and imports, 415.

Temperature of soils, 81, 82 .

Texas fever, 341.

Therm, defined, 291.

Thomas slag, 124.

Thoroughbred, $30 \%$.

Tile drains. See Drainage.

Tillage of orchards, 228

Timothy, 154: breeding, 24; composition of, 63, 284: digestibility of, 257; 290. 291: digestible food per acre, 1s9; digestible nutrients in. 411: fertility in, 409; fertilizer requirements, 132;

for horses, 312 ; lime requirement, 126; maintenance value, 290,291 ; production value as feed, 291, 411; seed vitality, 405; seeding rate, $185 ; 196$, 197,405 ; time to cut, 71,183 ; variation in, 24; weight per bushel, 406 .

Toad, usefulness of, reference, 271 .

Tobacco, exports and imports, 415; references, 34, 242, 2\%1; soils for, 82 ; value of crop, $155,413$.

Tobacco stems, fertility in, 409 .

Tomatoes, weight per bushel, 406; references, 243.

Top-grafting, 46 .

Toxic substanees, $2 \pi 6$.

Trees, how to plant, 227; shade, 233; treatment of wounds, 231.

Trotting horse, 307,308 .

Tuber, defined, 39 .

Tuberculin, 340 .

Tuberculosis, 337 .

Turkeys, reference, 371 .

Turnips, composition of, 63; digestible nutrients in, 411; fertility in, 409; production value as feed, 412; seed vitality, 405; seeding rate, 405; soft rot of, 250 .

Variation, 5; how inereased, 21; law of, 5 .

Vegetables, farm garden, 234 ; soils for 82 .

Verbena, propagation of, 41 .

Vetch, seeding rate, 405 .

Vietoria hogs, $358,359,360$.

Vitality of seeds, table of, 40 s.

Wialks, control of weeds in, 24T.

Water, anount in plants, 62,63 ; as a plant fond, 61 ; fusetion in feeds, 285 ; in feeds, 2s2; in feeds, how determined, 282; requirement of different crops, 67. Sce, also, Soil water.

Watermelon, lime requirement, 126: vitality of seeds, $10 \mathrm{i}$.

Water supply, 391.

Wieder, 169.

Wieels, control of, $70,169,245,274$; rontrolled by fertilizers. 190: definerl. 
244 ; in pastures, 197 ; in walks, 217; reference, 270; spraying for, 246; value of, 244 .

Weights per bushel, 406.

Wheat, diseussion of, 178; amount exported, 177; as a nurse crop, 183; averages for ten-year periols in the United States, acreage, production, yield per acre, total value, value per aere, value per bushel, 416; climate for, 180; composition of, 179; culture, 180; digestible food per aere, 160; digestible nutrients, in 411; Durum, 179; effeet of continuous culture, 110, 121, 170; effect of rotation on, 2\% ; exports and imports, 414; fertility in, 409 ; fertility requirements, 132, 134; fertility removed by, 113; ground, weight per quart, 413; original form of. 10; planting depth, 168; production value as feed, 412; references, $2 \% 0$; rotations with 278,279 ; seed vitality, 405; seeding, 181; seeding rate, 405; soil for, 82, 180; time to grow one bushel, 301; Turkish IRed, 179; types and varieties, 179 ; uses of, 178 ; value of erop, 413; value of United States crop, 155,416 ; weight per bushel, 406; weight per quart, 413; world's crop,
154,$178 ;$ yields with heavy and light seeds, 54.

Wheat bran, digestihility of, 287; digestible nutrients in, 411 ; fertility in, 409; laxative properties, reference, 300 ; production value as feed, 412 ; weight per quart, 413 .

Wheat middlings, digestible nutrients in, 411 ; fertility in, 409 ; weight per quart, 413 .

Whent straw, digestihility of, 287; digestible nutrients in, 411; fertility in, 409; production value as feed, 412 . Whey, digestible nutrients in, 410 .

Willow, basket, references, 243; propagation of, 41 .

Wood, increasing need of, 218 .

Wood-ashes, 125.

Wood erop, 216.

Wood-lots, management of, 222; profits from, 222; what to plant, 226; where to plant, 224.

Wool, 351, 353; exports and imports, 414.; value of, 413

Work report. See Accounts.

Wyandotte chickens, 364 .

Yorkshire hogs, 358,360 .

Zoölogy, relation to agriculture, 1. 


\title{
CYCLOPEDIA OF AMERICAN AGRICULTURE
}

\author{
Edited by L. H. BAILEY
}

Of Cornell University, Editor of "Cyclopedia of American Horticulture," Author of "Plant Breeding," "Principles of Agriculture," etc.

WITH 100 FULL-PAGE PLATES AND MORE THAN 2,000 ILLUS-

TRATIONS IN THE TEXT-FOUR VOLUMES-THE SET:

CLOTH, \$20 NET-HALF-MOROCCO, \$32 NET-CARRIAGE EXTRA

\section{Volume I-Farms}

The Agricultural Regions-The Projecting of a Farm-The Soil Environment-The Atmosphere Environment.

\section{Volume II-Crops}

The Plant and Its Relations-The Manufacture of Crop ProductsNorth American Field Crops.

\section{Volume III-Animals}

The Animal and Its Relations-The Manufacture of Anlmal Prod. ucts - North American Farm Animals.

\section{Volume IV-The Farm and the Community}

Economics-Social Questions-Organizations-History - Liter ture, etc.

"Indispensable to public and reference libraries . . readily comprehen. sible to any person of uvernge education."-The Nation.

"The completest existing thesaurus of up-to-dute facts and oplnions on modern agricultural methods. It is safe to say 1 hat muny years must pass before it can be surpassed in couprehensiveness, accuracy, practical value, and mechanical excelleure. It ought to be in every library in the country." - Kecord Herald. Chleago.

Published by

\section{THE MACMILLAN COMPANY}




\section{BOOKS ON AGRICULTURE}

On Selection of Land, etc.

Thomas F. Hunt's How to Choose a Farm ....\$1 75 net

E. W. Hilgard's Soils: 'Their Fornation, and Rela-

tions to Climate and Plant Growth ..... 400 net

Isaac P. Roberts' The Farmstead ........ 150 net

On Tillage, Crops, etc.

F. H. King's The Soil . . . . . . . . 150 net

Isaac P. Roberts' The Fertility of the Land . . . 150 net

Elwood Mead's Irrigation Institutions ...... 125 net

F. H. King's Irrigation and Drainage ...... 150 net

Wm. E. Smythe's 'The Conquest of Arid America . . 150 net

Edward B. Voorhees' Fertilizers . . . . . . . 125 net

Edward B. Voorhees' Forage Crops ....... 150 net

H. Snyder's Chemistry of Plant and Animal Life . . 125 net

H. Snyder's Soils and Fertilizers. 'Third edition . . 125 net

L. H. Bailey's Principles of Agrieulture . . . . $125 \mathrm{ne}^{+}$

W. C. Welborn's Elements of Agriculture, Southern and Western............ 75 net

J. F. Duggar's Agrieulture for Southern Sehools . . 75 net

On Plant Diseases, etc.

George Massee's Plant Diseases . . . . . . 160 net

J. G. Lipman's Bacteria in Relation to Country Life. 150 net

E. C. Lodeman's The Spraying of Plants . . . . 125 net

H. M. Ward's Disease in Plants (English) .... 160 net

A. S. Packard's A Text-book on Entomology . . . 450 net

On Production of New Plants

L. H. Bailey's Plant-Breeding . . . . . . . 125 net

L. H. Bailey's The Survival of the Unlike . . . . 200 net

L. H. Bailey's The Evolution of our Native Fruits . 200 net

W. S. Harwood's New Creations in Plant Life . . 175 net

\section{On Garden Making}

L. H. Bailey's Practical Garden-Book ...... 100 net

L. H Bailey's Garden-Making ........ 150 net

L. H. Bailey's Vegetable-Gardering ....... 150 net

L. H. Bailey's Hortieulturist's Rule Book ..... 75 net

L. H. Bailey's Foreing-Book ......... 125 net

A. French's Book of V'egetables ........ 175 net 


\section{BOOKS ON AGRICULTURE, continued}

On Fruit-growing, etc.

L. H. Bailey's Nursery-Book . . . . . . \$1 50 net

L. H. Bailey's Fruit-growing . . . . . . 150 net

L. H. Bailey's The Pruning-Book . . . . . . 150 net

F. W. Card's Bush Fruits.......... 150 net

On the Care of Live Stock

Nelson S. Mayo's The Diseases of Animals ... . 150 net

W. H. Jordan's The Feeding of Animals ..... 150 net

I. P. Roberts' The Horse . . . . . . . . 125 net

George C. Watson's Farm Poultry . . . . . . . 125 net

\section{On Dairy Work}

Henry H. Wing's Milk and Its Products ..... 150 net

C. M. Aikman's Milk . . . . . . . . . . 125 net

Harry Snyder's Dairy Chemistry ....... 100 net

W. D. Frost's Laboratory Guide in Elementary

Bacteriology .... ....... 160 net

I. P. Sheldon's The Farm and the Dairy..... 100 net

On Economics and Organization

L. H. Bailey's The State and the Farmer . . . . 125 net Henry C. Taylor's Agrieultural Economies . . . . . 125 net

I. P. Roberts' The Farmer's Business Handbook . . 125 net

George 'T. Fairchild's Rural Wealth and Welfare. . 125 net

S. E. Sparling's Business Organization . . . . . 125 net In the Citizen's Library. Includes a chapter on Farming.

Kate V. St. Maur's A Self-Supporting Home . . 175 net

Kate V. St. Maur's The Earth's Bounty . . . . . 175 net

On Everything Agricultural

L. H. Bailey's Cyclopedia of American Agriculture:

Vol. 1. Farms, Climates, and Soils.

Vol. II. Farm Crops.

Vol. III. Farm Animals.

Vol. IV. The Farm and the Community.

Price of sets: Cloth, $\$ 20$ net; half-moroceo, $\$ 32$ net.

For further information as to any of the above, address the publishers

\section{THE MACMILLAN COMPANY}




\section{BY HARRY SNYDER, B.S.}

Protesor of Agrlcultural Chemistry, Universliy of Mlnnesota, and Chemist of the Minnesota Agrlcultursl Experlment Ststion

\section{The Chemistry of Plant and Animal Life}

1llustrated. Cloth. 12mo. 406 pages. $\$ 1.25$; by mail, $\$ 1.35$.

"The langurge is, as it should be, plain and simple, free from all needless technicallty, and the story thus told is of absorbing interest to every one, man or woman, boy or girl, who takes an intelligent interest in farm life." - The New England Farmer.

"Although the book is highly technical, it is put in popular form and made comprebensible from the standpoint of the farmer; it deals largely wlth those questions which arise in his experlenee, and will prove an invaluable ald in countless directions."-The Farmer's Voice.

\section{Dairy Chemistry}

Illustrated. 190 pages. $\$ 1$ net; by mail, $\$ 1.10$.

"The book is a valuable one which any duiry farmer, or, indeed, any on bandling stock, may read with profit."-Rural New Yorker.

\section{Soils and Fertilizers}

Third Edition. Illustrated. $\$ 1.25$ net; by mail, $\$ 1.38$

A book wbich presents in a concise form the principles of soil fertility and discusses all of the topics relating to soils as outlined by the Committee on Methods of Teaching Agriculture. It contains 350 pages, with illustrations, and treats of a great variety of subjects, such as Physical Properties of Soils; Geological Formation, etc.; Nitrogen of the Soil and Air; Farm Manures; Commercial Fertilizers, several chapters; Rotation of Crops; Preparation of Soil for Crops, ete.

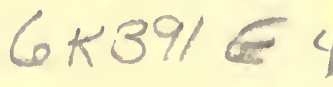

\section{THE MACMILLAN COMPANY}

64-66 Fifth Avenue

NEW YORK 
